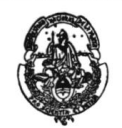

FACULTAD DE CIENCIAS NATURALES Y MUSEO

\section{PRODUCCIÓN LÍTICA, VARIABILIDAD Y CAMBIO EN ANTOFAGASTA DE LA SIERRA -ca.5500-1500 AP-}

\section{SALOMÓN HOCSMAN}

Tesis para optar al grado académico de Doctor en Ciencias Naturales

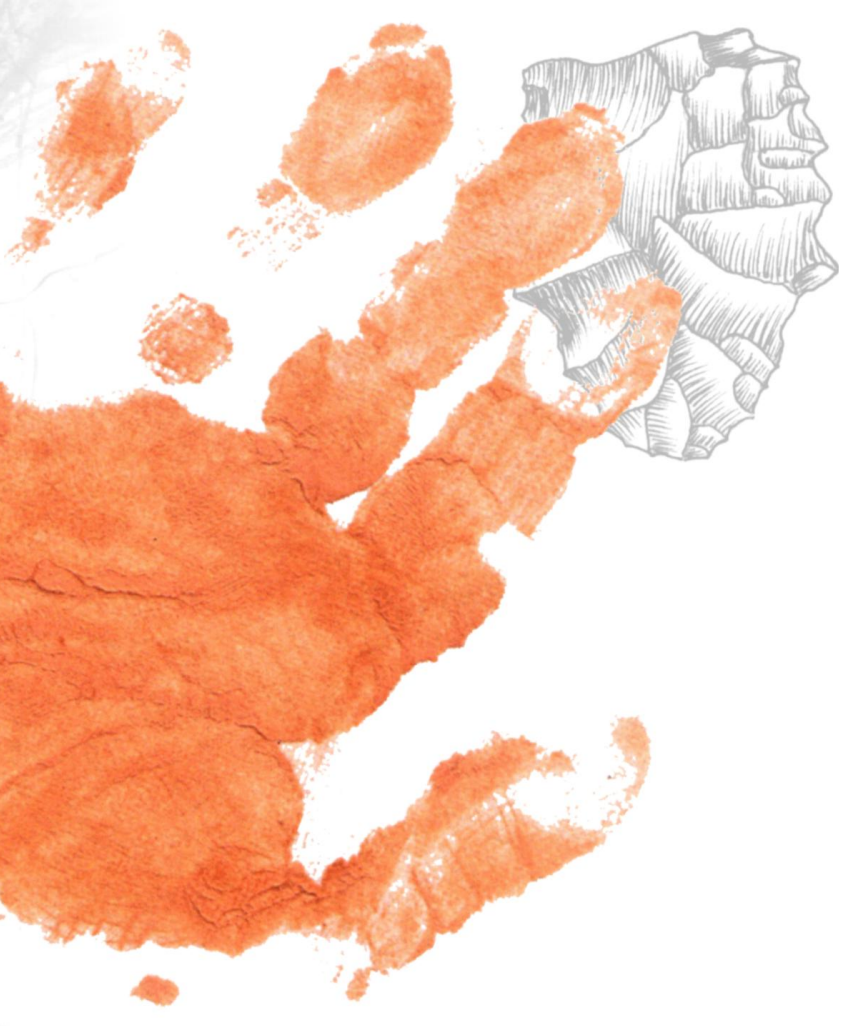

Director: Lic. Carlos A. Aschero Co-director: Dr. Gustavo Politis

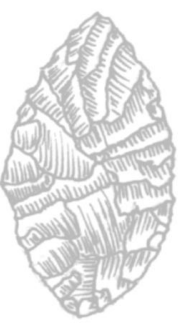




\section{AGRADECIMIENTOS}

Quisiera empezar agradeciendo a mis directores de Beca Doctoral de CONICET. Como agradecer poniendo distancia cuando todo está teñido por los afectos ... a Carlos Aschero le agradezco todo el apoyo y la confianza que me brindó en estos años, así como la posibilidad de trabajar en lo que me apasiona. Es posible que ese "Homo biface soñando cosas imposibles", de un ya remoto 1996, que está en la portada de la Tesis, fuera una suerte de premonición de lo que vendría después. Estos años de aprender y discutir su clasificación han sido fascinantes, pero más impresionante aún fue poder observarlo utilizando el "Ensayo..." como algo permeable y en cambio constante, como una herramienta y no como un fin. Hasta hoy día esa capacidad de mutar de la Tipología me deja perplejo y maravillado. También, por esas jugosas discusiones sobre procesos sociales y cambio, sobre cazadores, pastores ... y agricultores. Por dejarme ser y hacer, sin condicionamientos. Recuerdo lo que hablamos sobre maestros y discípulos en la cocina del puesto de Don Vicente Morales en Punta de la Peña, en un ya lejano 1998, mirando las estrellas y las llamas del fogón, espero que esta Tesis honre aquella charla. A Patricia Escola, le agradezco la posibilidad de trabajar con ella, su experiencia y rigurosidad en el análisis lítico han sido fundamentales para mi formación. También por considerarme un igual y por esa amplitud de criterio que me ha permitido crecer y desarrollar mi camino. Me ha apoyado en todo sentido y sus palabras de aliento en los momentos difíciles han sido invaluables. ¡Su nombre también debería aparecer en la portada de la Tesis!. Gracias por su tiempo generoso.

A Gustavo Politis, Co-Director de esta Tesis Doctoral. Quisiera agradecerle toda la ayuda brindada, desde su experiencia y su biblioteca. En todo momento tuvo un tiempo para el consejo, que me fue realmente útil para llegar a la estructura que tuvo finalmente el manuscrito. Ciertos aspectos de este trabajo se vieron motivados por algunos de sus desarrollos temáticos, le estoy sumamente agradecido por compartir sus impresiones sobre los mismos y por su interés en los resultados de esta investigación.

A Alfredo Calisaya, Aldo Gerónimo y Sebastián Mamaní Segura, quienes están recorriendo conmigo el fascinante camino de la arqueología de la transición en Antofagasta de la Sierra. También a Cecilia Haros y Lucía González Baroni. Su ayuda fue crucial para poder emplear hoy la información de buena parte de los desechos de talla de varios de los sitios considerados en este trabajo. No tengo dudas de que el aprendizaje fue y es mutuo. Prometo no agregarle ningún atributo más a la ficha.

A Sara María Luisa López Campeny, Elizabeth Pintar, María del Pilar Babot y Patricia Escola, quienes facilitaron parte de los materiales líticos analizados en esta investigación y suministraron toda la información necesaria, édita e inédita. 
A quienes participaron en las excavaciones con tanto interés y dedicación. En PCh1.3: Alfredo Calisaya, Aldo Gerónimo, Sebastián Mamaní Segura, Ceciclia Haros, María del Pilar Babot y Ezequiel “Cequi” Milena. También a Osvaldo Díaz. En PCh1.6: Sebastián Mamaní Segura, Alfredo Calisaya, Lucía González Baroni, Valeria Ucedo y Jorge Martínez. En PCh1.5: Carlos Aschero, Sara María Luisa López Campeny, Jorge Martínez y Andrés Romano.

Esta investigación fue posible gracias a una Beca Doctoral otorgada por el CONICET, al Instituto de Arqueología y Museo que facilitó su infraestructura y equipamiento y al apoyo de los siguientes proyectos de investigación dirigidos por Carlos Aschero: FONCYT/PICT No 09888 Arqueologías de la Diversidad. Casos de Análisis para el Centro-Oeste del NOA; PIP-CONICET No 3041 Arqueologías de Espacios Contrastados: Gente, Ambientes e Interacción Social; CIUNT Arqueología, Antropología e Historia de espacios contrastados. Articulación, interacción y cambio social y PIP-CONICET $\mathrm{N}^{\circ} 4975$ Subsistencia, Interacción y Movilidad Social en el pasado prehispánico e hispano-indígena. También al proyecto PEI-CONICET No 6272 Tras las Antiguas Rutas de Intercambio, Distribución y Circulación de Obsidianas en el NOA, dirigido por Patricia Escola.

Quisiera agradecer a Luis Borrero, quien siempre tuvo una palabra de aliento y un certero consejo. De mis discusiones con él con respecto a las escalas de trabajo surgió la alternativa de ir ampliando y disminuyendo la escala según el caso, lo cual ha sido extensamente empleado en este trabajo y ha servido de mucho para ordenar la información y obtener resultados. También a Hugo Yacobaccio, quien siempre se interesó por este trabajo y discutió generosamente saberes e ideas.

Asimismo, a Cristina Bayón, Cristina Bellelli, Teresa Civalero, Nora Flegenheimer, Nora Franco y Gabriela Guraieb (sólo en orden alfabético...), por todas sus muestras de apoyo, afecto y aliento. Todas colaboraron directa e indirectamente con diversos aspectos de este trabajo. No menos importante, este trabajo fue posible gracias a que ellas sentaron las bases.

A Jorge Martínez, por todas las discusiones enriquecedoras que tuvimos, muchas de las cuales se ven reflejadas en esta investigación, y porque siempre estuvo ahí cuando lo necesitaba, desde lo profesional y lo personal.

También, a Daniel Olivera, Norma Ratto, Cristina Scattolin, Paul Tchilinguirian, Fernanda Rodríguez, Mariana Mondini, Nurit Oliszewski, María del Carmen Reigadas y Gabriela Aguirre por colaborar de distintas formas y por brindar información de sumo interés. 
A Lautaro Núñez, por el acceso total a las fascinantes colecciones de los sitios Tulán 52 y 54 y por su interés en el trabajo desarrollado en el marco de esta Tesis. También por la visita a la Quebrada de Tulán, que fue sumamente valiosa y me hizo repensar muchas cosas. También a Patricio De Souza, por su ayuda durante mi estancia en San Pedro de Atacama.

A Elizabeth Pintar, Liliana Manzi, Patricia Escola, Andrea Toselli y Jorge Martínez, sus trabajos sobre tecnología lítica en Antofagasta de la Sierra fueron imprescindibles para que esta Tesis fuera posible.

A los miembros del equipo de Antofagasta de la Sierra filial Tucumán, por generar un ambiente agradable de discusión y de trabajo, tanto en el campo como en el laboratorio: Jorge Martínez, María del Pilar Babot, Álvaro Martel, Marisa López Campeny, Carolina Somonte, Lorena Cohen, Silvana Urquiza, Gabriela Aguirre, Andrés Romano, Ruy Zurita, Alejandra Schmitz, Jorge Funes, Cecilia Haros, Lucía González Baroni y Victoria Isasmendi. En especial, al equipo de la “transición”: Sebastián Mamaní Segura, Aldo Gerónimo y Alfredo Calisaya.

A Alexandre Chevallier, Robert Kelly, Betty Meggers, Lautaro Núñez, David Browman, Cristina Bayón, Nora Flegenheimer, Hugo Yacobaccio, Elizabeth Pintar, Fernanda Rodríguez, Mariano Bonomo, Luciano Prates, Carolina Rivet, Mariana Mondini, Hernán Muscio y Norma Ratto por facilitar bibliografía fundamental. A Carlos baied por las fotos que ilustran buena parte de la Tesis.

A Jorge Funes y Silvana Urquiza, quienes realizaron los dibujos de las piezas arqueológicas incluidos en este trabajo. Los mismos han sido claves para mostrar gráficamente ejemplos clarificadores ... y aligerar el tedio del texto.

A Luis Guillermo Babot (h) por el tratamiento digital de las imágenes y por el socorro constante en cuestiones informáticas, entre otros temas.

A Roxana Cattáneo, Andrés Izeta y Mercedes Izeta por hospedarme y por hacerme sentir “en casa” en las reiteradas ocasiones en que tuve que viajar a La Plata. También, por todas las atenciones que han tenido para conmigo, desde la gestión, lo profesional y lo personal.

A “Los Realescola”, Jorge, Julián y Patricia, por alojarme con tanto cariño (y paciencia) durante mis estancias en Catamarca.

A “Coty” Aschero, por hospedarme tan generosamente en su casa. 
A Luciano Prates, por su predisposición a colaborar en torno a cuestiones reglamentarias relativas a esta Tesis.

Al personal del Departamento de Postgrado de la Facultad de Ciencias Naturales y Museo por facilitar innumerables cuestiones administrativas.

A Luis y Pilar, Carmen y Mecha, Luisito, Sebastián y Jaime por toda la ayuda prestada.

A mis padres, Marcos y Stella, gracias a ellos hoy estoy aquí, al final de este camino. Siempre me apoyaron en todo lo que emprendí. Se que ha pesado demasiado la lejanía y las ausencias...

A Mariana y a Gabriel Hocsman, por enseñarme que los niños son parte del género homo y que los aprendices también somos los grandes. A Mariana, por su interés con sus dos años y medio en aprender la tipología de Aschero (por cierto, el primer grupo tipológico que aprendió a reconocer y nombrar es el de las puntas de proyectil, aunque con el mismo afán de cambio del padre, las llamó "puntas de piedra”) y por hacer suyas las frases: "Papá, tengo que trabajar” y "Papá, estoy ocupada”. A Gabriel, por sus risas y sonrisas, morisquetas y agos. Ya los recompensaré por mis ausencias...

A Pilar, mi compañera de sueños y realidades. No encuentro palabras adecuadas para agradecer todo lo que hiciste por mi. Congeniar la familia con la profesión no ha sido fácil para nosotros. Sólo los dos sabemos las presiones que nos han y nos hemos impuesto!. Tantas presiones!. Se que dejaste de lado muchas cosas para que yo termine esta Tesis, eso es impagable, pero lo es más el hecho de haber discutido tanto y de disfrutar, juntos, de lo que nos apasiona. Te prometo que tomaremos las vacaciones que nos merecemos, o aunque más no sea, unas vacaciones, alguna vez. 


\section{INDICE DE CONTENIDOS}

\section{TOMO I}

Pág.

INTRODUCCIÓN

CAPÍTULO 1. PROBLEMÁTICA DE LA INVESTIGACIÓN .......................................... 6

1.1. Problemática de la investigación .................................................................................... 6

1.1.1. La transición de cazadores-recolectores a sociedades agro-pastoriles en la Puna argentina y su borde desde la tecnología lítica ................................................................... 6

1.1.2. Variabilidad tecnológica y tipológica en artefactos líticos tallados ............................. 10

1.1.2.1. El problema de los bifaces ........................................................................... 11

1.1.2.2. La inversión del trabajo en la manufactura de artefactos líticos .............................. 14

1.1.2.3. Identificación de aprendices en el registro arqueológico ..................................... 15

1.1.2.4. Tecnología lítica y cazadores-recolectores complejos ........................................... 16

1.1.2.5. Incidencia de los cambios paleoambientales, el sedentarismo y las prácticas productoras sobre la tecnología lítica .................................................................................. 18

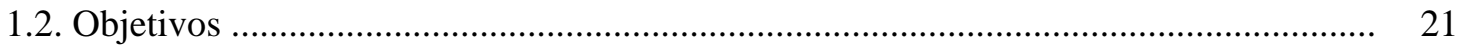

1.2.1. Objetivos generales ...................................................................................... 21

1.2.2. Objetivos particulares .................................................................................. 22

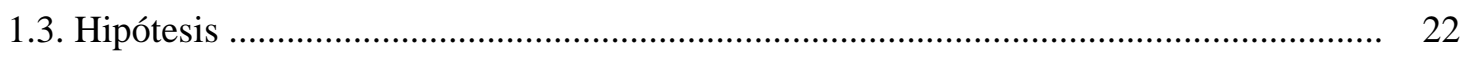

CAPÍTULO 2. CARACTERÍSTICAS AMBIENTALES DE LA MICRORREGIÓN DE

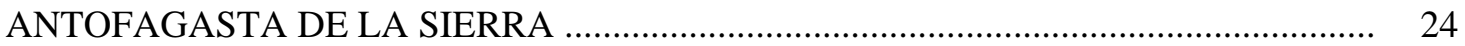


2.1. Antofagasta de la Sierra como parte de la Puna argentina ........................................... 24

2.2. La microrregión de Antofagasta de la Sierra …............................................................... 27

2.3. Humedales en el desierto ................................................................................ 31

2.4. La evolución paleoambiental local (5500-2000 AP) ................................................... 34

CAPÍTULO 3. APROXIMACIÓN TEÓRICA ……......................................................... 38

3.1. Cazadores-recolectores, agricultores y pastores ..................................................... 38

3.1.1. Caracterización general ........................................................................................ 38

3.1.2. Cuestiones relativas a situaciones de transición .......................................................... 40

3.1.3. Problemas inherentes a las nociones de Arcaico y Formativo .................................... 43

3.1.4. Complejidad en cazadores-recolectores ................................................................... 45

3.1.4.1. ¿Qué define a los cazadores-recolectores complejos? ............................................ 45

3.1.4.2. Indicadores arqueológicos de complejidad ..................................................... 47

3.2. Tecnología lítica ................................................................................................ 50

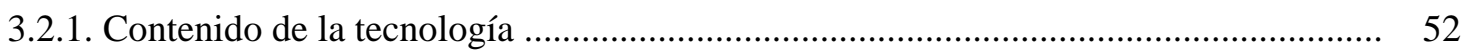

3.2.1.1. Conocimiento tecnológico ........................................................................... 53

3.2.1.1.1. Componentes del conocimiento tecnológico ........................................................ 53

3.2.1.1.2. Aproximación al conocimiento tecnológico ......................................................... 54

3.2.1.1.3. Abordaje tecno-tipológico del conocimiento tecnológico .................................... 57

3.2.2. Toma de decisiones ................................................................................................. 57

3.2.2.1. Aspectos generales de la toma de decisiones ........................................................ 58

3.2.2.2. Toma de decisiones, diseño y propiedades formales de artefactos líticos ............... 59

3.2.2.3. Inversión de trabajo en la producción de artefactos líticos ...................................... 60

3.2.3. Tecnología lítica y fuentes de cambio tecnológico ................................................... 61

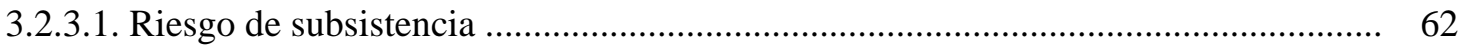

3.2.3.2. Movilidad y tecnología lítica ……........................................................................ 64

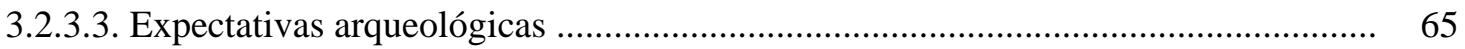

CAPÍTULO 4. METODOLOGÍA PARA EL ANÁLISIS TECNO-TIPOLÓGICO DE

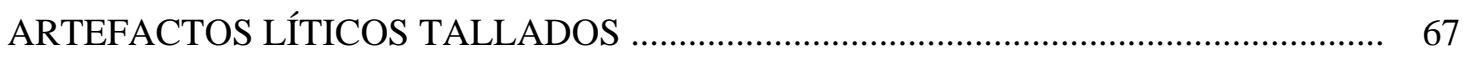

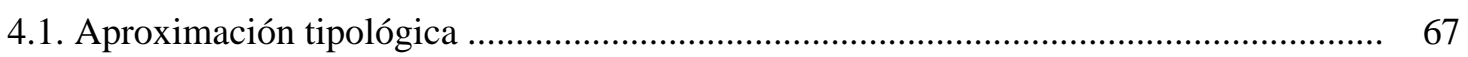

4.2. Consideraciones acerca del análisis morfológico-macroscópico en artefactos líticos tallados

4.2.1. Segmentación del conjunto y de cada una de las piezas ........................................... 69

4.2.2. Descripción técnico-morfológica y morfológico-funcional ........................................ 71 


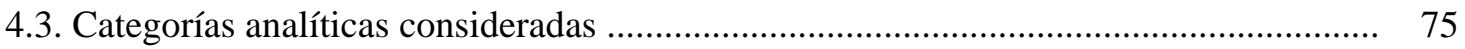

4.3.1. Conjunto lítico ...................................................................................................... 75

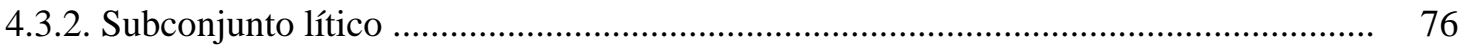

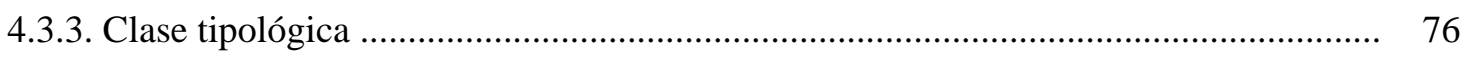

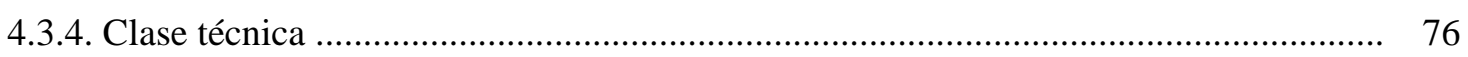

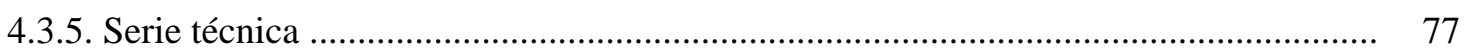

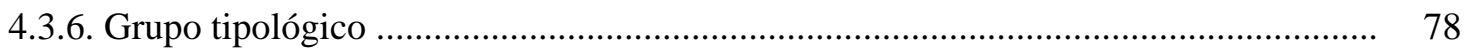

4.3.7. Subgrupo tipológico ........................................................................................ 80

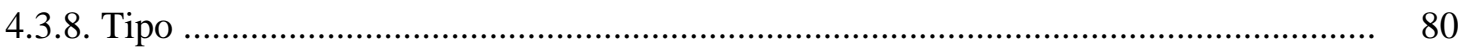

4.4. Caracterización de las clases técnicas .......................................................................... 82

4.4.1. Clases técnicas para artefactos formatizados ............................................................. 82

4.4.2. Propuesta de clasificación de clases técnicas ............................................................. 88

4.5. Especificaciones para el tratamiento de los grupos y subgrupos tipológicos ............... 92

4.5.1. Grupos tipológicos ……………………......................................................... 92

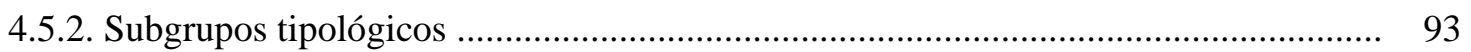

4.5.3. Descripción de grupos tipológicos de artefactos bifaciales ........................................ 93

4.5.3.1. Variables empleadas en la descripción ..................................................................... 93

4.5.3.2. Descripción de los grupos tipológicos considerados ............................................... 94

4.5.3.2.1. El grupo tipológico de los bifaces .......................................................................... 94

4.5.3.2.1.1. Subgrupo tipológico de los bifaces en sentido estricto ..................................... 95

4.5.3.2.1.2. Subgrupo tipológico de los bifaces parciales ................................................. 96

4.5.3.2.2. El grupo tipológico de las piezas foliáceas ...................................................... 97

4.5.3.2.3. El subgrupo tipológico de los esbozos de piezas bifaciales ................................. 98

4.5.3.2.4. El grupo tipológico de los filos bifaciales de arista sinuosa ............................... 99

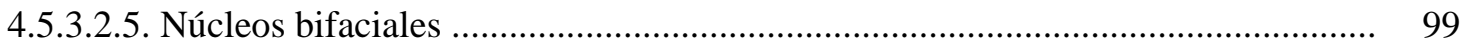

4.5.3.2.6. Comparación entre grupos tipológicos y subgrupos tipológicos de artefactos formatizados bifaciales y núcleos bifaciales ........................................................................... 101

4.5.4. Definición del grupo tipológico cincel ...................................................................... 103

4.5.5. Descripción del grupo tipológico puntas de proyectil .............................................. 104

4.5.5.1. Clasificación de subgrupos tipológicos .................................................................. 104

4.5.5.2. Tipo de inflexión de la base respecto de los bordes de pedúnculos o sectores

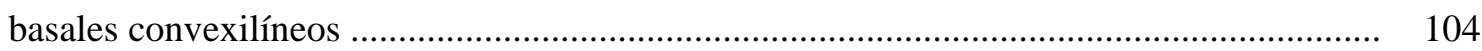

4.5.5.3. Características de la morfología “acuminada” en “Forma de la base...” ................. 104

4.5.5.4. Diferenciación de formas dentro de las bases "acuminadas" ................................... 104

4.5.5.5. Agregado de una variable en "Tratamiento técnico diferencial de bases, bordes o 
aletas”

4.5.6. Discriminación entre filo y fragmento no diferenciado de artefacto formatizado (idem para filo y artefacto con formatización sumaria)

4.5.7. Definición del grupo tipológico filo formatizado pasivo

4.5.8. Agregado de un subgrupo tipológico a los raspadores

4.5.9. Incorporación del subgrupo raedera de módulo grandísimo al grupo tipológico de las raederas

4.5.10. Incorporación de la extensión relativa del filo a la diferenciación en subgrupos del grupo tipológico cortante

4.5.11. Agregados en cuanto a extensión relativa del filo en los denticulados de bisel oblicuo/abrupto de sección asimétrica

4.6. Modificaciones e incorporaciones al análisis morfológico-descriptivo

4.6.1. Propuesta de modificación de la cuadrícula de localización

4.6.2. "Secuencia de formatización” en artefactos formatizados

4.6.3. "Secuencia tipológica" en artefactos formatizados

4.6.4. Consideraciones acerca del reciclaje y del mantenimiento

CAPITULO 5. LA SECUENCIA ARQUEOLÓGICA DE ANTOFAGASTA DE LA SIERRA EN EL LAPSO 5500-1500 AP

5.1. Breve caracterización de la secuencia ocupacional local entre los 10000 y los 5500 años AP

5.2. La ocupación humana en Antofagasta de la Sierra entre los 5500 y los 1500 años AP

5.3. Los sitios considerados en el análisis artefactual

5.3.1. Quebrada Seca 3 (QS3)

5.3.2. Punta de la Peña (PP4)

5.3.3. Peñas Chicas 1.3 (PCh1.3)

5.3.4. Peñas Chicas 1.1 (PCh1.1) .

5.3.5. Casa Chávez Montículos (CChM)

5.3.6. Punta de la Peña 9 (PP9)

5.3.7. Peñas Chicas 1.6 (PCh1.6)

5.3.8. Cueva Salamanca 1 (CS1)

5.3.9. Hallazgos aislados considerados 
DE LA SIERRA

6.1. Características del proceso transicional local desde distintas líneas de evidencia ...

6.2. Discusión de las evidencias del registro arqueológico de Antofagasta de la Sierra para el lapso 5500-1500 AP

6.2.1. Movilidad residencial reducida

6.2.2. Territorialidad

6.2.3. Subsistencia

6.2.4. Redes de interacción a larga distancia

6.2.5. Desigualdad social

6.2.6. Densidad poblacional

6.2.7. Ritual

CAPÍTULO 7. DISPONIBILIDAD DE MATERIAS PRIMAS LÍTICAS

7.1. Materias primas presentes en la microrregión

7.1.1. Acerca de las denominaciones de las materias primas

7.1.2. Distribución de las materias primas

\section{CAPÍTULO 8. APROXIMACIÓN GENERAL A LOS CAMBIOS EN LA} TECNOLOGÍA LÍTICA DURANTE LA TRANSICIÓN

8.1. Características generales de las muestras

8.2. Utilización de materias primas líticas

8.3. Aproximación diacrónica a los artefactos formatizados desde una perspectiva morfológico-funcional

8.4. Evidencias de cambio en la inversión de trabajo

8.4.1 Variaciones en inversión de trabajo en la manufactura de artefactos líticos tallados (5500-1500 AP)

8.4.1.1. Evidencias de cambio en la inversión de trabajo: Clases técnicas en artefactos formatizados

8.4.1.2. Evidencias de cambio en la inversión de trabajo. Otras líneas de evidencia: Utilización de índices diversos

8.4.2. Inversión de trabajo y complejidad en artefactos formatizados

8.4.3. Cambios en la inversión de trabajo en la porción meridional de los Andes CentroSur 


\section{TOMO II}

CAPÍTULO 9. TIPOS Y ESPECÍMENES MORFOLÓGICOS

9.1. Descripción de tipos morfológicos y especimenes morfológicos .................................. 236

9.1.1. Caracterización de tipos morfológicos ...................................................................... 238

9.1.2. Caracterización de especímenes morfológicos ....................................................... 265

9.1.3. Evidencias de reclamación de tipos morfológicos .................................................. 271

9.2. Distribución y dimensión temporal de tipos morfológicos y especimenes

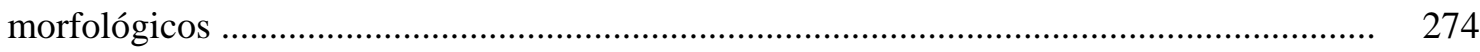

9.3. Análisis de la recurrencia de tipos y especimenes morfológicos .................................. 279

CAPÍTULO 10. VARIABILIDAD EN BIFACES ........................................................ 285

10.1. Aproximación a la variabilidad en bifaces .................................................................. 285

10.1.1. Categorías de abordaje de los bifaces .................................................................. 285

10.1.2. Producción lítica y aprendices ....................................................................... 287

10.1.3. Características del adelgazamiento bifacial .......................................................... 288

10.2. Variabilidad morfológica en bifaces e instrumentos sobre bifaces ............................. 291

10.2.1. Características de los bifaces del sitio QS3 ............................................................... 291

10.2.2. Características de los bifaces del sitio PCh1.3 ........................................................ 301

10.2.3. Características de los bifaces del sitio PCh1.1 .......................................................... 308

10.2.4. Características de los bifaces del sitio PP4 ............................................................. 318

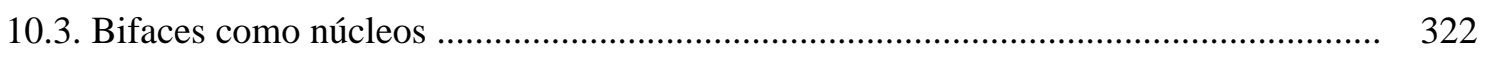

10.4. Bifaces como producto de la práctica de aprendices ................................................. 325

10.5. Niños y/o adolescentes como aprendices en los sitios considerados ......................... 334

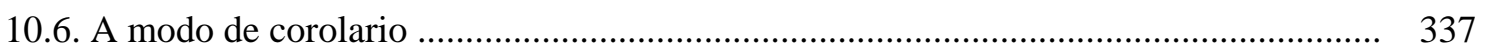

\section{CAPÍTULO 11. VARIABILIDAD TÉCNICO-MORFOLÓGICA Y MORFOLÓGICO-} FUNCIONAL EN PUNTAS DE PROYECTIL -GRUPOS CRONOLÓGICOS 2 Y 3- ..... 339

11.1. Análisis comparativo de puntas de proyectil .............................................................. 339

11.1.1. Pedúnculos, limbos y aletas ............................................................................... 342

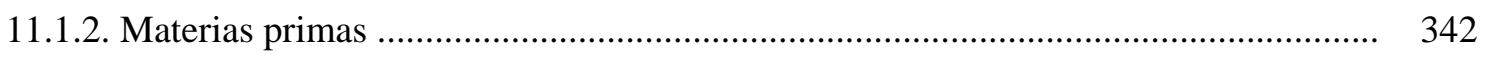

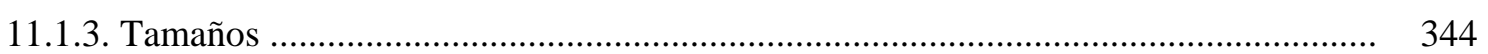

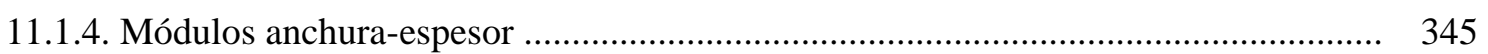

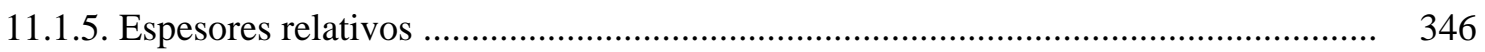


11.1.6. Pesos

11.1.7. Características de los pedúnculos y sectores basales en piezas apedunculadas

11.1.8. Mantenimiento y reciclaje

11.1.9. Formas-base

11.1.10. A modo de corolario

11.2. Las puntas de proyectil con pedúnculo destacado, aletas y/u hombros y limbo lanceolado como antecedente de las puntas con pedúnculo diferenciado, aletas y limbo triangular

CAPÍTULO 12. ANÁLISIS DE INSTRUMENTOS Y DESECHOS DE TALLA A PARTIR DE CASOS ESPECÍFICOS: APROXIMACIONES DESDE LA SEGMENTACIÓN DESCRIPTIVA .

12.1. Variabilidad de filos pasivos: El sitio PCh1.1 como caso de estudio

12.2. Variabilidad de casos de reciclaje en artefactos formatizados: Un ejemplo desde PCh1.1

12.3. Utilidad del análisis de la secuencia de formatización: El tratamiento de los limbos en puntas de proyectil del TM QS B.2

12.4. Identificación de desechos de talla de mantenimiento de raederas de módulo grandísimo

CAPÍTULO 13. DISCUSIÓN GENERAL Y CONCLUSIONES

13.1 La transición de cazadores-recolectores a pastores y agricultores en Antofagasta de la Sierra

13.1.1. Evaluación de las evidencias generales de la transición

13.1.2. Evidencias de complejidad socio-cultural en Antofagasta de la Sierra

13.1.2.1. Movilidad residencial

13.1.2.2. Territorialidad

13.1.2.3. Desigualdad social

13.1.2.4. Interacción a grandes distancias

13.1.2.5. Densidad poblacional

13.1.2.6. Intensificación en la explotación de recursos de subsistencia

13.1.2.7. Prácticas rituales

13.1.2.8. ¿Evidencias de especialización artefactual y artesanal en artefactos líticos tallados 
13.2. Tendencias diacrónicas y sincrónicas en la producción y uso de artefactos líticos tallados

13.3 Conclusiones

BIBLIOGRAFÍA CITADA

APENDICE I

I.1. Instructivo para la descripción técnico-morfológica y tipológica de artefactos formatizados 461

I.2. Instructivo para la descripción técnico-morfológica de desechos de talla 468

I.3. Instructivo para la descripción técnico-morfológica de núcleos

APENDICE II

II.1. Consideraciones sobre el armado de las listas tipológicas

II.2. Listas tipológicas de los sitios considerados en esta investigación

II.2.1. Lista tipológica del sitio Quebrada Seca III 481

II.2.2. Lista tipológica del sitio Punta de la Peña 4 -5(6)485

II.2.3. Lista tipológica del sitio Punta de la Peña 4 -4 a 5(5)486

II.2.4. Lista tipológica del sitio Peñas Chicas 1.3 489

II.2.5. Lista tipológica del sitio Peñas Chicas 1.1 492

II.2.6. Lista tipológica del sitio Punta de la Peña 9 497

II.2.7. Lista tipológica del sitio Casa Chávez Montículos 1

APENDICE III 501

III.1. Funcionalidad de las raederas de módulo grandísimo 501 


\section{INDICE DE FIGURAS}

Pág.

Figura 2.1. Ubicación de Antofagasta de la Sierra en el contexto del altiplano andino .............. 25

Figura 2.2. Antofagasta de la Sierra como parte de la Puna Salada ............................................. 26

Figura 2.3. El paisaje puneño. Vista de Punta de la Peña, Peñas Chicas, Peñas de las Trampas y Cerro Miriguaca desde Peñas Coloradas

Figura 2.4. Los volcanes Antofagasta y La Alumbrera, vistos desde el farallón de Peñas Chicas 28

Figura 2.5. Los volcanes Antofagasta y La Alumbrera 29

Figura 2.6. Mapa de Antofagasta de la Sierra 29

Figura 2.7. Vista de Confluencia y del río Los Colorados (al fondo) desde el Cerro Vía Crucis 30

Figura 2.8. Vista del río Las Pitas en Punta de la Peña 31

Figura 2.9. Vega de Quebrada Seca 32

Figura 2.10. Las coladas de Los Negros 32

Figura 2.11. Vista de las Lagunas de Antofagasta 33

Figura 2.12. La vega inmediata a las Lagunas de Antofagasta 33

Figura 2.13. Vista de la salina de Laguna Colorada 36

Figura 4.1. Categorías y niveles de clasificación 75

Figura 4.2. Artefacto formatizado con trabajo no invasivo unifacial - raedera + R.B.O. + muesca retocada + raspador en hocico - y bifacial - cortante - (QS3 - 2b4 - $\mathrm{N}^{\circ}$ inv. 639)

Figura 4.3. Artefacto con adelgazamiento bifacial. Biface de aristas regularizadas (QS3 - 2b11 - $\mathrm{N}^{\circ}$ inv. 819)

Figura 4.4. Artefacto con adelgazamiento unifacial. Uniface (Laguna Colorada de Yavi superficie -tomado de Aschero 1975)

Figura 4.5. Artefacto con reducción bifacial. Morfología afín a un núcleo bifacial (QS3 - 2b4 - $\mathrm{N}^{\mathrm{o}}$ inv. 316)

Figura 4.6. Artefacto con reducción bifacial. Punta de proyectil 86

Figura 4.7. Clases técnicas para artefactos bifaciales y unifaciales 89

Figura 4.8. Artefacto con adelgazamiento bifacial. Biface (QS3 - 2b5 - No inv. 509) 90 
Figura 4.9. Artefacto bifacial marginal. Cuchillo denticulado (QS3 - $2 \mathrm{~b} 5$ - $\mathrm{N}^{\mathrm{o}}$ inv. 642) ......

Figura 4.10. Artefacto con reducción unifacial. Cuchillo unifacial (filo oblicuo lateral izquierdo) + filo formatizado bifacial de arista sinuosa (filo oblicuo lateral derecho) (Confluencia - superficie)

Figura 4.11. Biface de pequeño tamaño (ICc4 - superficie - $\mathrm{N}^{\mathrm{o}}$ inv. 94) ................................... 95

Figura 4.12. Biface de pequeño tamaño (PCh 1.1 - $4^{\circ}$ ext. - $\mathrm{N}^{\mathrm{o}}$ inv. 54) ..................................... 95

Figura 4.13. Biface (QS3 - $2 \mathrm{~b} 5$ - No inv. 593) ..................................................................... 96

Figura 4.14. Biface parcial (AF1 - capa 11 base - tomado de Gradín et al. 1987) ...................... 96

Figura 4.15. Pieza foliácea fragmentada (QS3 - 2b4 - № inv. 514) ......................................... 97

Figura 4.16. Esbozo de pieza bifacial (PP4 - 5(2) - $\mathrm{N}^{\circ}$ inv. 238/12) …...................................... 98

Figura 4.17. Ejemplo de biface con características afines a un núcleo bifacial (QS3 - 2b3 - No inv. 302)

Figura 4.18. Izquierda: Base no inflexionada. Derecha: base inflexionada

Figura 4.19. Bases acuminadas. Izquierda: Puntiforme. Centro: Convexilínea restringida. Derecha: Rectilínea restringida

Figura 4.20. a) Cuadrícula de localización sensu Aschero (1983). b) Propuesta de modificación de la cuadrícula de localización

Figura 5.1. Secuencia arqueológica de Antofagasta de la Sierra, lapso 10000-5500 AP

Figura 5.2. Secuencia arqueológica de Antofagasta de la Sierra, lapso 5500-1500 AP

Figura 5.3. Localidades arqueológicas en Antofagasta de la Sierra

Figura 5.4. Ubicación de sitios arqueológicos en las localidades Punta de la Peña, Peñas Chicas y Peña de las Trampas

Figura 5.5. El sitio arqueológico Quebrada Seca 3

Figura 5.6. Excavaciones en Quebrada Seca 3. Principios de la década del '90

Figura 5.7. Planta del sitio Quebrada Seca 3

Figura 5.8. El sitio arqueológico Punta de la Peña 4

Figura 5.9. Vista del interior del alero

Figura 5.10. Planta del sitio Punta de la Peña 4

Figura 5.11. Perfil del sitio Punta de la Peña 4

Figura 5.12. Vista general del sitio Peñas Chicas 1.3

Figura 5.13. Plano del sitio Peñas Chicas 1.3

Figura 5.14. Estructuras de piedra formadas por lajas clavadas

Figura 5.15. Vista del taller y bloque. Nótese que en este último no se registra evidencia de oquedad alguna 
Figura 5.16. Excavación de una estructura de lajas clavadas

Figura 5.17. Vista parcial de la boca del alero bajo roca

Figura 5.18. El sitio Peñas Chicas 1.1

Figura 5.19. El sitio Casa Chávez Montículos 1

Figura 5.20. El sitio Punta de la Peña 9

Figura 5.21. Los sectores I y III del sitio PP9

Figura 5.22. Vista del sector I y de la estructura 3

Figura 5.23. El sitio Peñas Chicas 1.6

Figura 5.24. El sitio Cueva Salamanca 1

Figura 6.1. Estructura de piedra en PCh1.3

Figura 6.2. El Bebe de la Peña. Sitio PP11A

Figura 7.1. Distribución de fuentes de materias primas líticas en el sector centro-este de la microrregión de Antofagasta de la Sierra

Figura 7.2. Ubicación de Antofalla y Cueros de Purulla

Figura 7.3. Diagrama divariado de concentraciones de elementos - Dy/Mn

Figura 7.4. Diagrama divariado de concentraciones de elementos $-\mathrm{Na} / \mathrm{Mn}$

Figura 7.5. Diagrama divariado de concentraciones de elementos $-\mathrm{Th} / \mathrm{Fe}$

Figura 8.1. Tendencias temporales de clases técnicas en artefactos formatizados

Figura 9.1. Tipo morfológico QS B.2. Punta de proyectil (PP4. No inv 342) 238

Figura 9.2. Tipo morfológico QS B.2. Punta de proyectil (PP4. No inv 542) ... 238

Figura 9.3. Tipo morfológico QS E. Raspador (PP4. N inv 1330) 239

Figura 9.4. Tipo morfológico QS E. Raspador (PCh1.6. $\mathrm{N}^{\mathrm{o}}$ inv 70) 239

Figura 9.5. Tipo morfológico QS F. Punta de proyectil (QS3. No inv 508) 240

Figura 9.6. Tipo morfológico QS F. Punta de proyectil (QS3. Nº inv 283) 240

Figura 9.7. Tipo morfológico QS F.1. Punta de proyectil (QS3. $N^{0}$ inv 58)

Figura 9.8. Tipo morfológico QS F.1. Pedúnculo de punta de proyectil (QS3. No inv 506) ... 241

Figura 9.9. Tipo morfológico QS F.1. Punta de proyectil (QS3. Nº inv 292) .....

Figura 9.10. Tipo morfológico QS F.2. Fragmento limbo-pedúnculo de punta de proyectil (QS3. $\mathrm{N}^{\circ}$ inv 510)

Figura 9.11. Tipo morfológico QS F.2. Punta de proyectil (PCh1.3. $\mathrm{N}^{\mathrm{o}}$ inv 199) ...................... 242

Figura 9.12. Tipo morfológico QS G. Cortante (QS3. N $\mathrm{N}^{\mathrm{o}}$ inv 31) ............................................. 243

Figura 9.13. Tipo morfológico QS G. Cortante (QS3. No inv 604) ........................................... 243

Figura 9.14. Tipo morfológico PCh A. Punta de proyectil (PCh1.3. No inv 154) ....................... 244

Figura 9.15. Subtipo morfológico PCh A.1. Punta de proyectil (PCh1.6. № inv 187) ............... 245 
Figura 9.16. Subtipo morfológico PCh A.1. Punta de proyectil (PCh1.6. № inv 2) .................. 245

Figura 9.17. Subtipo morfológico PCh A.2. Punta de proyectil (PCh1.3. $\mathrm{N}^{\mathrm{o}}$ inv 155) .............. 246

Figura 9.18. Subtipo morfológico PCh A.2.a. Punta de proyectil (PCh1.3. $\mathrm{N}^{\circ}$ inv 162) ............ 246

Figura 9.19. Subtipo morfológico PCh A.2.b. Punta de proyectil (PCh1.3. № inv 161) ............ 246

Figura 9.20. Subtipo morfológico PCh A.3. Punta de proyectil (PCh1.3. $\mathrm{N}^{\mathrm{o}}$ inv 89) ................ 247

Figura 9.21. Subtipo morfológico PCh A.3.a. Punta de proyectil (PCh1.3. № inv 59) ............. 247

Figura 9.22. Subtipo morfológico PCh A.4. Punta de proyectil (PCh1.3. No inv 25) ................. 248

Figura 9.23. Subtipo morfológico PCh A.4.a. Punta de proyectil (PCh1.3. No inv 19) ............. 248

Figura 9.24. Subtipo morfológico PCh A.5.a. Punta de proyectil (PCh1.6. № inv T1-1) ........... 249

Figura 9.25. Subtipo morfológico PCh A.5.b. Punta de proyectil (PCh1.3. № inv 41) .............. 249

Figura 9.26. Subtipo morfológico PCh A.6.a. Punta de proyectil (PCh1.3. $\mathrm{N}^{\mathrm{o}}$ inv 156) ............ 250

Figura 9.27. Subtipo morfológico PCh A.6.b. Punta de proyectil (PCh1.3. $\mathrm{N}^{\mathrm{o}}$ inv 157) ............ 250

Figura 9.28. Tipo morfológico PCh B.a. Punta de proyectil (PCh1.6. $\mathrm{N}^{\mathrm{o}}$ inv 188) .................... 251

Figura 9.29. Tipo morfológico PCh B. Punta de proyectil (PCh1.6. № inv 27) ......................... 251

Figura 9.30. Tipo morfológico PCh B.b. Punta de proyectil (PP4. No inv 206) ......................... 251

Figura 9.31. Tipo morfológico PCh C.a. Punta de proyectil (PCh1.3. $\mathrm{N}^{\mathrm{o}}$ inv 203) ..................... 252

Figura 9.32. Tipo morfológico PCh C.b. Punta de proyectil (PP4. No inv 263) ......................... 252

Figura 9.33. Tipo morfológico PCh C.c. Punta de proyectil (QS3. № inv 596) ....................... 252

Figura 9.34. Tipo morfológico PCh D. Punta de proyectil (PCh1.6. $\mathrm{N}^{\mathrm{o}}$ inv 50) ........................ 253

Figura 9.35. Tipo morfológico PCh D. Preforma de punta de proyectil (PCh1.3. No inv 200) ... 253

Figura 9.36. Tipo morfológico PCh E. Punta de proyectil (PCh1.1. No inv 11) ......................... 254

Figura 9.37. Tipo morfológico PCh E. Punta de proyectil (PCh1.1. No inv 15) ......................... 254

Figura 9.38. Tipo morfológico PCh E. Punta de proyectil (PCh1.3. № inv 110) ....................... 254

Figura 9.39. Tipo morfológico PCh F. Punta de proyectil (PP4. No inv 239/1) .......................... 255

Figura 9.40. Tipo morfológico PCh F. Punta de proyectil (PCh1.3. № inv 168) ....................... 255

Figura 9. 41. Tipo morfológico PCz A. Punta de proyectil (QS3. N ${ }^{\circ}$ inv 16) ............................ 256

Figura 9.42. Tipo morfológico PCz A. Punta de proyectil (PCh1.1. No inv 7) ........................... 256

Figura 9.43. Tipo morfológico PCz A. Punta de proyectil (PCh1.1. № inv 209) ....................... 256

Figura 9.44. Tipo morfológico PCh G. Punta de proyectil (PCh1.3. № inv 201) ...................... 257

Figura 9.45. Tipo morfológico PCh G. Punta de proyectil (PCh1.3. $\mathrm{N}^{\mathrm{o}}$ inv 167) ....................... 257

Figura 9.46. Tipo morfológico PCh G. Punta de proyectil (PP4. № inv 243/28) ....................... 257

Figura 9.47. Tipo morfológico PP A.a. Punta de proyectil (PCh1.1. № inv 205) ...................... 258

Figura 9.48. Tipo morfológico PP A.a. Punta de proyectil (PP4. No inv 198/1) ....................... 258

Figura 9.49. Tipo morfológico PP A.b. Punta de proyectil (PP4. $\mathrm{N}^{\mathrm{o}}$ inv 663) ............................ 258 
Figura 9.50. Tipo morfológico PP A.b. Punta de proyectil (PP4. No inv 145) ........................... 258

Figura 9.51. Tipo morfológico PP B. Punta de proyectil (PP4. No inv 590) .............................. 259

Figura 9.52. Tipo morfológico PP B. Punta de proyectil (QS3. N inv 500) ............................... 259

Figura 9.53. Tipo morfológico PP B. Punta de proyectil (PP4. No inv 231) ……………........... 259

Figura 9.54. Tipo morfológico PP B. Punta de proyectil (PP4. № inv 245/15) ......................... 259

Figura 9.55. Tipo morfológico PP C. Punta de proyectil (PP9.I. Sup. s/n ${ }^{0}$ ) ................................ 260

Figura 9.56. Tipo morfológico PP C. Punta de proyectil (PP1. s/n ${ }^{\circ}$ ) .......................................... 260

Figura 9.57. Tipo morfológico PP C. Punta de proyectil (PH2-ES. s/n $\mathrm{n}^{\circ}$ ) ................................... 260

Figura 9.58. Subtipo morfológico CChM A.1.I-A.1.II. Punta de proyectil (CChM1) ................ 261

Figura 9.59. Subtipo morfológico CChM A.1.III. Punta de proyectil (CChM1) ........................ 261

Figura 9.60. Tipo morfológico CChM B. Punta de proyectil (CChM1) ..................................... 262

Figura 9.61. Tipo morfológico CChM C. Raedera de módulo grandísimo (CChM1) ................ 263

Figura 9.62. Tipo morfológico CCHM D. Pala y/o azada (CChM1) ………….......................... 264

Figura 9.63. Espécimen morfológico PCh 1.a. Punta de proyectil (PCh1.3. $\mathrm{N}^{\mathrm{o}}$ inv 82) ............. 265

Figura 9.64. Espécimen morfológico PCh 2.a. Punta de proyectil (PCh1.6. № inv 23) ............. 266

Figura 9.65. Espécimen morfológico PCh 3. Izq: Pedúnculo de punta de proyectil (PCh1.3. No inv 98). Der: Punta de proyectil Tu-54 ..................................................................................... 267

Figura 9.66. Espécimen morfológico PCh 4.a. Punta de proyectil (PCh1.3. № inv 204) ........... 268

Figura 9.67. Espécimen morfológico PCh 5.a. Punta de proyectil (PCh1.3. № inv 133) ........... 269

Figura 9.68. Ejemplos del espécimen morfológico CChM 1. Punta de proyectil ....................... 270

Figura 9.69. Punta de proyectil TM QS C (QS3. N ${ }^{\circ}$ inv 19) ...................................................... 272

Figura 9.70. Puntas de proyectil lanceoladas apedunculadas. PCh1.1 - excavación ................... 282

Figura 9.71. Preforma de punta de proyectil TM PCh A (PCh1.1. N $^{\circ}$ inv 58) ............................ 283

Figura 9.72. Fragmentos de limbos de puntas de proyectil pedunculadas. Arriba: PCh1.3. Abajo: PCh1.1.

Figura 10.1. Diferentes papeles de los bifaces

Figura 10.2. a) Percusión dura; b) Percusión blanda 289

Figura 10.3. A) Plano de equilibrio bifacial; B) Plano de equilibrio bilateral

Figura 10.4. Posiciones de la plataforma: a) debajo del plano de simetría; b) cercana al plano de simetría; c) por encima del plano de simetría

Figura 10.5. Bifaces como tales y reciclados de QS3. Arriba izquierda: № 509. Arriba derecha: $\mathrm{N}^{\mathrm{o}}$ 514. Abajo izquierda: $\mathrm{N}^{\mathrm{o}}$ 316. Abajo derecha: $\mathrm{N}^{\circ} 302$

Figura 10.6. Bifaces transformados en QS3. Arriba izquierda: No 525. Arriba derecha: $N^{\circ} 593$. Abajo izquierda: $\mathrm{N}^{\circ}$ 292. Abajo derecha: $\mathrm{N}^{\circ} 508$ 
Figura 10.7. Distribución de tamaños (L-A) en bifaces como tales, transformados y reciclados de QS3

Figura 10.8. Distribución de tamaños (A-E) en bifaces como tales, transformados y reciclados de QS3

Figura 10.9. Lascas de adelgazamiento bifacial de tamaño “muy grande” procedentes de QS3

Figura 10.10. Distribución de tamaños (L-A) en bifaces como tales, transformados y reciclados de PCh1.3

Figura 10.11. Distribución de tamaños (A-E) en bifaces como tales, transformados y reciclados de PCh1.3

Figura 10.12. Biface en proceso de manufactura (PCh1.1. $\mathrm{N}^{\circ}$ inv 34)

Figura 10.13. Distribución de tamaños (L-A) en bifaces como tales, transformados y reciclados de PCh1.1

Figura 10.14. Distribución de tamaños (A-E) en bifaces como tales y reciclados de PCh1.1 ....

Figura 10.15. Distribución de tamaños (A-E) en bifaces transformados de PCh1.1

Figura 10.16. Distribución de tamaños (L-A) en bifaces como tales, transformados y reciclados de PP4

Figura 10.17. Distribución de tamaños (A-E) en bifaces como tales, transformados y reciclados de PP4

Figura 10.18. Biface producto de aprendiz (PCh1.3. $\mathrm{N}^{0}$ inv 107)

Figura 10.19. Biface producto de aprendiz (PCh1.3. $\mathrm{N}^{\mathrm{o}}$ inv 26)

Figura 10.20. Biface producto de aprendiz (PCh1.1. $\mathrm{N}^{\mathrm{o}}$ inv 13)

Figura 11.1. Puntas de proyectil del sitio CChM1

Figura 11.2. Distribución de puntas de proyectil por materia prima. GC2 y GC3

Figura 11.3. Distribución de tamaños de puntas de proyectil. GC2 y GC3

Figura 11.4. Módulos A/E en puntas de proyectil. GC2 y GC3

Figura 11.5. Espesores en puntas de proyectil. GC2 y GC3

Figura 11.6. Distribución de tamaños de pedúnculos de puntas de proyectil. GC2-GC3

Figura 11.7. Ancho de la base del pedúnculo en puntas de proyectil. GC2-GC3

Figura 11.8. Formas-base de puntas de proyectil. GC2 y GC3

Figura 11.9. Punta de proyectil con pedúnculo destacado, aleta y hombro y limbo triangular de bordes convexos. PP9.I -superficie-

Figura 11.10. Punta de proyectil confeccionada por adelgazamiento bifacial. Recuperada en superficie entre Piedra Horadada 2 y El Sembrado (Punta de la Peña)

Figura 11.11. Contornos de puntas de proyectil recuperadas por pobladores locales en 
inmediaciones de la Laguna Colorada (¿LC2.1?). Museo del Hombre de Antofagasta de la Sierra

Figura 11.12. Fragmento limbo-pedúnculo de punta de proyectil (PP4. No inv 981/1) 358

Figura 11.13. Punta de proyectil con evidencias de reclamación (PP9. $\mathrm{N}^{\circ}$ inv 15) 359

Figura 11.14. Contornos de puntas de proyectil recuperadas en Tulán 54 360

Figura 11.15. Puntas de proyectil del subgrupo tipológico A.2.I. CChM1 361

Figura 11.16. Punta de proyectil (PCh1.6. $\mathrm{N}^{\mathrm{o}}$ inv 50) 363

Figura 11.17. Punta de proyectil lanceolada apedunculada (PCh1.3. $\mathrm{N}^{\mathrm{o}}$ inv 110)

Figura 12.1. Buril más filo bifacial de arista sinuosa sobre fragmento mesial de punta de proyectil reciclada (PCh1.1. $\mathrm{N}^{\mathrm{o}}$ inv $\mathrm{s} / \mathrm{n}^{\circ}$ )

Figura 12.2. Buril más tres filos formatizados pasivos sobre fragmento mesial de punta de proyectil reciclada (PCh1.1. $\mathrm{N}^{\mathrm{o}}$ inv 25)

Figura 12.3. Sierras más filo formatizado pasivo (PCh1.1. $\mathrm{N}^{\mathrm{o}}$ inv 40)

Figura 12.4. Cortante sobre punta de proyectil reciclada (PCh1.1. $\mathrm{N}^{\circ}$ inv 205). La flecha de color rojo señala la porción del limbo reciclada

Figura 12.5. Raspador sobre raspador reciclado sobre punta de proyectil reciclada (PCh1.1. N $^{\circ}$ inv 210). Las flechas de color rojo señalan las porciones del limbo recicladas

Figura 12.6. Izquierda: Perforador sobre fragmento limbo-apical de punta de proyectil reciclado (PCh1.1. $\mathrm{N}^{\circ}$ inv. 27). Derecha: Punta burilante sobre fragmento limbo-basal de punta de proyectil reciclado (PCh1.1. $\mathrm{N}^{\circ}$ inv. $\mathrm{s} / \mathrm{n}^{\circ}$ ). Las flechas rojas respectivas señalan el lugar del reciclaje

Figura 12.7. Puntas de proyectil TM QS B.2. Arriba: Diseño mantenido ( $\mathrm{N}^{\circ}$ inv 342). Abajo:

Diseño transformado ( $\mathrm{N}^{\circ}$ inv 542)

Figura 12.8. Raedera de módulo grandísimo. CChM1.

Figura 12.9. Desechos de talla de mantenimiento de raederas de módulo grandísimo. PP9- IE3

Figura 13.1. Fragmento de artefacto de arcilla secada al sol (PCh1.5, $\mathrm{N}^{\mathrm{o}}$ inv. 33)

Figura 13.2. Puntas de proyectil con pedúnculo con retoque/microrretoque alterno. Izquierda: TM QS B.2 (PP4. No inv. 342). Derecha: TM PCh A (PCh1.6. $\mathrm{N}^{\circ}$ inv. 187) ....

Figura 13.3. Tipos morfológicos predominantes en los sitios PCh1.3 (arriba), PP4 (medio) y PCh1.1 (abajo) 


\section{INDICE DE TABLAS}

Pág.

Tabla 3.1. Análisis de la variabilidad en el contenido de la tecnología lítica desde una aproximación tecno-tipológica

Tabla 3.2. Expectativas arqueológicas por clase tipológica

Tabla 4.1. Artefactos formatizados. Lista de variables agrupadas por su naturaleza 73

Tabla 4.2. Desechos de talla. Lista de variables agrupadas por su naturaleza 74

Tabla 4.3. Núcleos. Lista de variables agrupadas por su naturaleza ..... 74

Tabla 4.4. Comparación entre el grupo tipológico biface y sus subgrupos

Tabla 4.5. Comparación entre el grupo tipológico biface, el esbozo de pieza bifacial y el núcleo bifacial

Tabla 5.1. Sitios arqueológicos considerados (ca.5500-1500 AP) .

Tabla 5.2. Características de los grupos cronológicos 146

Tabla 5.3. Estadística sumaria 147

Tabla 5.4. Análisis de varianza (ANOVA) 147

Tabla 5.5. Test de Tukey 148

Tabla 6.1. Recursos vegetales comestibles como microfósiles en artefactos de molienda $-4700-3500$ AP162

Tabla 6.2. Distancia localidad arqueológica-ecozonas actuales (en km) 167

Tabla 6.3. Recursos bióticos alóctonos (5500-1500 años AP) 168

Tabla 6.4. Áreas de procedencia de recursos bióticos alóctonos 173

Tabla 7.1. Denominaciones de materias primas líticas en Antofagasta de la Sierra 180

Tabla 7.2. Distribución de fuentes de materias primas líticas 183

Tabla 7.3. Distancias entre abrigos rocosos y fuentes de materias primas líticas locales 184

Tabla 7.4. Concentraciones de elementos en partes por millón (ppm) - NAA 189

Tabla 7.5. Sitios arqueológicos y fuentes de procedencia (4500-3200 AP) 191

Tabla 8.1. Estado de fragmentación en desechos de talla. Sitio PP4 195

Tabla 8.2. Estado de fragmentación en desechos de talla. Sitio PCh1.3 195

Tabla 8.3. Estado de fragmentación en desechos de talla. Sitio PCh1.1 196

Tabla 8.4. Estado de fragmentación en desechos de talla. Sitio PP9 196 
Tabla 8.5. Clasificación de las rocas en función de las distancias a los sitios considerados 197

Tabla 8.6. Materias primas en artefactos formatizados por sitio arqueológico ... 198

Tabla 8.7. Materias primas en desechos de talla por sitio arqueológico 199

Tabla 8.8. Materias primas en artefactos formatizados y desechos de talla por grupo cronológico 200

Tabla 8.9. Materias primas en núcleos, por grupo cronológico 201

Tabla 8.10. Clasificación de rocas locales aplicada a artefactos formatizados, por grupo cronológico

Tabla 8.11. Clasificación de rocas locales aplicada a desechos de talla, por grupo cronológico

Tabla 8.12. Diferenciación del instrumental por inversión de trabajo y por su carácter de local-no local

Tabla 8.13. Presencia de reciclaje y de artefactos compuestos y no compuestos, por grupo cronológico

Tabla 8.14. Discriminación de grupos tipológicos por materia prima - GC1 210

Tabla 8.15. Discriminación de grupos tipológicos por materia prima - GC2 211

Tabla 8.16. Discriminación de grupos tipológicos por materia prima - GC3 212

Tabla 8.17. Presencia de grupos tipológicos por grupo cronológico

Tabla 8.18. Cantidad de subgrupos tipológicos por grupo tipológico para cada uno de los sitios considerados

Tabla 8.19. Complejidad del instrumental por grupo cronológico 221

Tabla 8.20. Clases técnicas en artefactos formatizados por sitio y grupo cronológico 222

Tabla 8.21. Indicadores de adelgazamiento y trabajo bifacial

Tabla 8.22. Cantidad de lascas de adelgazamiento bifacial y total de desechos de talla por nivel. QS3-2b2 a 2b5-

Tabla 8.23. Complejidad en puntas de proyectil, bifaces y resto del instrumental, por grupo cronológico

Tabla 9.1. Tipos y especímenes morfológicos por grupo tipológico

Tabla 9.2. Recurrencia de tipos y especímenes morfológicos por sitio arqueológico 280

Tabla 10.1. Bifaces como tales. QS3 292

Tabla 10.2. Bifaces reciclados. QS3 293

Tabla 10.3. Bifaces transformados. QS3 294

Tabla 10.3 (continuación). Bifaces transformados. QS3 295

Figura 10.5. Bifaces como tales y reciclados de QS3. Arriba izquierda: No 509. Arriba derecha: $\mathrm{N}^{0}$ 514. Abajo izquierda: $\mathrm{N}^{0}$ 316. Abajo derecha: $\mathrm{N}^{0} 302$ 296

Tabla 10.4. Bifaces como tales. PCh1.3 303

Tabla 10.5. Bifaces reciclados. PCh1.3 . 304

Tabla 10.6. Bifaces transformados. PCh1.3 305 
Tabla 10.7. Bifaces como tales. PCh1.1 309

Tabla 10.7 (continuación). Bifaces como tales. PCh1.1 310

Tabla 10.8. Bifaces reciclados. PCh1.1

Tabla 10.9. Bifaces transformados. PCh1.1

Tabla 10.9 (continuación). Bifaces transformados. PCh1.1

Tabla 10.10. Bifaces como tales. PP4 319

Tabla 10.11. Bifaces reciclados. PP4 319

Tabla 10.12. Bifaces transformados. PP4 320

Tabla 10.13. Bifaces como tales y reciclados de QS3. Atributos vinculados con destreza técnica

Tabla 10.14. Bifaces como tales y reciclados de PCh1.3. Atributos vinculados con destreza técnica

Tabla 10.15. Bifaces como tales y reciclados de PCh1.1. Atributos vinculados con destreza técnica

Tabla 10.15 (continuación). Bifaces como tales y reciclados de PCh1.1. Atributos vinculados con destreza técnica

Tabla 10.16. Bifaces como tales y reciclados de PP4. Atributos vinculados con destreza técnica

Tabla 11.1. Diferencias en las puntas de proyectil de los GC 2 y 3 354

Tabla 11.2. Comparación dimensional de las puntas de proyectil PP C, A.2.II y CChM A 361

Tabla 12.1. Artefactos formatizados con asociación de filos activos y pasivos formatizados (PCh1.1)

Tabla 12.2. Casos de reciclaje (PCh1.1) 370

Tabla II.1. Ejemplo de lista tipológica 475

Tabla II.2. Caso de instrumento simple en lista tipológica 475

Tabla II.3. Caso de instrumento compuesto en lista tipológica 476

Tabla II.4. Caso de biface transformado en lista tipológica 477

Tabla II.5. Caso de biface transformado en lista tipológica 478

Tabla II.6. Caso de transformación y reciclaje en lista tipológica 479

Tabla II.6. Caso de pieza reclamada en lista tipológica 480 


\section{RESUMEN}

Esta investigación es una contribución al conocimiento de la transición de cazadoresrecolectores a sociedades agro-pastoriles en Antofagasta de la Sierra (Puna Meridional Argentina), desde los artefactos líticos tallados. En cuanto al lapso abordado, si bien los límites impuestos fueron arbitrarios, se eligieron teniendo presente que el tratamiento de la transición requiere de conjuntos de datos que involucren periodos de tiempo lo suficientemente largos como para incluir los cambios postulados. De esta forma, se inicia ca.5500 años AP, ya que a partir de este momento se registran cambios importantes, por ejemplo, en la organización de los asentamientos, en el arte rupestre y en las evidencias de prácticas productivas. Finaliza ca.1500 AP, con ocupaciones agro-pastoriles plenas.

En este trabajo se pretendió, a partir de un aspecto concreto y particular como es la tecnología lítica, tratar con la variabilidad en el comportamiento humano. Específicamente, se encaró este problema a través del análisis de la variabilidad y el cambio en artefactos líticos tallados y en las técnicas que los produjeron.

Se plantearon los siguientes objetivos generales: 1) aportar conocimientos sobre el proceso que llevó al surgimiento de economías agro-pastoriles en Antofagasta de la Sierra, a partir del estudio de conjuntos líticos de nuevos sitios y de componentes ya procesados o aún sin procesar de sitios ya conocidos; 2) generar información sobre la variabilidad tecnológica y tipológica de los conjuntos líticos de los sitios, desde una perspectiva sincrónica y diacrónica; 3) evaluar la incidencia de las condiciones paleoambientales, del sedentarismo y de las prácticas agrícolas/pastoriles sobre las estrategias de aprovisionamiento, manufactura, uso y descarte de los conjuntos de artefactos líticos y 4) utilizar la información producida conjuntamente con otras líneas de evidencia en estudio por el equipo de investigación (recursos faunísticos, restos vegetales, etc.) para establecer las características generales del proceso de cambio, en base al estudio comparado de asociaciones contextuales intra-sitio y de contextos inter-sitio.

Con respecto a los postulados teóricos, el punto de partida fue entender a la tecnología como todo corpus de artefactos, comportamientos y conocimiento para crear y usar productos que es transmitido generacionalmente. Así, la tecnología no está constituida simplemente por los ítems físicos de la cultura material, sino que se deben considerar el comportamiento tecnológico y la acción humana. Por lo tanto, una aproximación a la tecnología lítica desde esta perspectiva implicaba 
emprender el estudio combinado de instrumentos y otros artefactos, materias primas, acciones físicas y destreza técnica. En este marco, la variabilidad de la tecnología se abordó a partir del análisis del contenido de la misma, considerando, específicamente, las técnicas empleadas, el saber, la destreza técnica, los diseños y los recursos utilizados.

La aproximación metodológica implicó un análisis de tipo macroscópico y morfológicodescriptivo, siguiendo los parámetros generales propuestos por Aschero (1975, 1983). El principio de la morfología descriptiva reside en una aproximación analítica que se basa en disociar los diversos componentes de la morfología de un objeto a fin de establecer sus particularidades. Por esto, se partió de la descripción de las “formas” de cada pieza, previa segmentación en partes y/o sectores diferentes, de acuerdo a atributos estandarizados. Se siguieron tres pasos: 1) segmentación del conjunto y de cada una de las piezas, 2) descripción técnico-morfológica y 3) descripción morfológico-funcional. Por otra parte, se destaca que se rescató y revalorizó la perspectiva tipológica que comprende la clasificación de Aschero (1975), mediante el reconocimiento de "tipos morfológicos” y “especimenes morfológicos”. Asimismo, tomando como encuadre general dicha clasificación se desarrollaron, en función del problema de la transición, una serie de herramientas instrumentales para el análisis artefactual, como las nociones de clase técnica, secuencia de formatización y secuencia tipológica.

En base a lo señalado, se exploró la utilización de materias primas líticas en el lapso abordado, resultando, por ejemplo, en un incremento en el uso de rocas locales inmediatas. Asimismo, se abordaron los artefactos formatizados desde un punto de vista morfológico-funcional con el objeto de establecer como fueron cambiando con el tiempo, trabajando desde los grupos tipológicos, los subgrupos tipológicos y la complejidad del instrumental. Al respecto, destacan la simplificación del instrumental al considerar el número de partes por pieza (complejidad); el mantenimiento de las clases y de la diversidad dentro de los artefactos formatizados vinculados a tareas de procesamiento/consumo, la desaparición de grupos tipológicos, como los bifaces, hacia los 3500 AP y la aparición de grupos nuevos, como las palas y las raederas de módulo grandísimo, en contextos agropastoriles plenos, vinculados a actividades agrícolas.

Por otra parte, se trató la inversión de trabajo en la confección de artefactos líticos tallados, a través de la diferenciación de clases técnicas en artefactos formatizados y de la utilización de índices diversos, pudiéndose establecer la disminución de la inversión de trabajo en la manufactura de artefactos líticos con el paso del tiempo, que incluyó la desaparición del adelgazamiento bifacial hacia los 2100 años AP.

Se analizó, asimismo, la distribución y dimensión temporal así como la recurrencia de tipos y especimenes morfológicos, destacando la diversidad de tipos morfológicos en el lapso 4100-3400 AP así como la representación intersitio diferencial de las puntas de proyectil en dicho momento. 
Con respecto a la consideración de artefactos específicos, se exploró la variabilidad morfológica de los bifaces, discriminando entre bifaces como tales, transformados y reciclados, por un lado, y entre bifaces en sí mismos y en proceso de manufactura, por el otro. Se destaca que se pudo identificar a parte de la variabilidad observada como producto del accionar de aprendices. En cuanto a las puntas de proyectil, se analizaron las diferencias y semejanzas de los diseños con cronología 41003400 AP y 2100-1500 AP, que permitieron establecer relaciones genéticas entre las puntas de proyectil del "nodo" del proceso transicional con aquellas características de las ocupaciones agropastoriles plenas.

Se consideró, por otra parte, la variabilidad en la toma de decisiones por parte de los artesanos, en base, entre otros aspectos, a las formas de tratamiento de los limbos de las puntas de proyectil.

Finalmente, se estableció un problema de equifinalidad al tratar los factores que pudieron haber condicionado la estructura de los conjuntos de artefactos líticos, como la movilidad residencial o los riesgos de subsistencia. 


\section{ABSTRACT}

The present research work contributes to a better understanding of the hunter-gatherer transition into agropastoralist societies in Antofagasta de la Sierra (Southern Argentine Puna) from the perspective of flaked stone tools. Although the limits set for the period studied were arbitrary, they were chosen keeping in mind that an adequate treatment of the transition requires sets of data that cover time lapses that $\mathrm{l}$ are long enough to include the changes postulated. It begins ca.5500 BP because important changes within settlement organization, rock-art and productive practices are recorded at this time. It finishes ca.1500 BP with agro-pastoralist settlements.

Human behavior is dealt with in this work through lithic technology, that is, by means of the analysis of variability and change in flaked stone tools and the techniques that produced them.

General objectives were: 1) add data concerning the process that brought agro-pastoralist economies into existence in Antofagasta de la Sierra through the study of lithic assemblages belonging to new sites and to processed or unprocessed components in known sites; 2) generate data on technological and typological variability of site lithic assemblages from diachronic and synchronic perspectives; 3) evaluate the importance of paleoenvironmental conditions, sedentarism and agropastoralist practices on procurement, manufacture, use and discard of lithic tools assemblages and 4) utilize the information gathered, together with other lines of evidence studied by the research team (faunal remains, microfossils, etc.), to establish the general characteristics of the process of change based on the comparative study of intra-site and inter-site contexts.

The theoretical starting point was to consider the technology as every generation by generation transmitted corpus of artefacts, behaviors, and knowledge developed to create and use products.

Thus, the technology does not only consist of physical items of material culture; human action and technological behavior must also be considered. An approach to lithic technology from this perspective meant a combined study of tools and other artefacts, raw materials, physical actions and technical skills. Hence, technological variability was undertaken through the analysis of its content, including techniques, wisdom, technical skill, designs and resources used. 
Methodologically, the general parameters of Aschero (1975, 1983) were followed in a macroscopical and morphological-descriptive analysis. The principle of descriptive morphology is based on the disassociation of the components of an object to ascertain its peculiarities. Thus, the starting point was the description of the "shapes" of each piece with a previous division in different parts and/or sectors according to standardized attributes. Three steps were followed: 1) segmentation of assemblage and of each piece, 2) technical-morphological description and 3) functionalmorphological description.

The acknowledgement of "morphological types" (tipos morfológicos) and "morphological specimens" (especímenes morfológicos) were some aspects of Aschero’s typological perspective (1975) recovered and enhanced. Also, in the general framework of his classification, a series of instrumental concepts, clase técnica, secuencia de formatización and secuencia tipológica, were developed for artefact analysis to solve questions related to the transition moment.

Based on the above-mentioned, the use of lithic raw material was studied in the time lapse established and an increment in the utilization of immediate local rocks was detected. From a morphologically-functionally perspective, tools were approached with the purpose of determining how they were changing with time, according to grupos tipológicos, subgrupos tipológicos and tool complexity. In this sense, the following items are remarkable: tool simplification when considering number of parts per specimen (complexity), class and diversity permanence of tools related to processing/consumption tasks, disappearance of certain grupos tipológicos like bifaces around 3500 $\mathrm{BP}$ and the emergence of new groups like palas and raederas de módulo grandísimo in agropastoralist contexts connected to farming activities.

Time and energy investment in flaked stone tool manufacturing was approached through the clases técnicas differentiation in tools and through the use of different indexes. A gradual reduction, which included the disappearance of bifacial thinning towards $2100 \mathrm{BP}$, was detected in the time and energy invested to produce stone tools.

Temporal dimension and distribution of tipos and especimenes morfológicos were analyzed as well as their recurrence. Diversity of tipos morfológicos and inter-site differential representation of projectile points in the 4100-3400 BP time lapse are remarkable.

Morphological variability was explored among bifaces diferentiating bifaces como tales, transformados and reciclados on one hand and bifaces en si mismos and en proceso de manufactura on the other. 
Part of the variability observed was identified as the work of apprentices. Design differences and similarities of projectile points of the periods 4100-3400 BP and 2100-1500 BP were analyzed and genetic relationships established between projectile points of the transitional process "node" and those characteristic of agro-pastoralist occupations.

Variability in craftsmen's decision making was considered concerning blade treatment in projectile points among other aspects.

Finally, was established that several factors may have conditioned the structure of flaked stone tool assemblages like residencial mobility or subsistence risk. 


\section{INTRODUCCIÓN}

Uno de los procesos más importantes en la larga historia de la humanidad por sus implicancias, para aquellos interesados en la diversidad humana y el cambio cultural, es el surgimiento de las prácticas productoras de alimentos. Dicho proceso implicó indudablemente grandes cambios, de largo plazo, en la estructura y organización de las sociedades que adoptaron el nuevo modo de vida, así como generó relaciones totalmente diferentes con el ambiente.

La porción meridional de los Andes Centro-Sur, en general, y el Noroeste Argentino, en particular, son áreas donde este proceso tuvo lugar. Al respecto, hay consenso en sostener que los cambios se produjeron en el seno de los grupos cazadores-recolectores y que no se debieron a estímulos transformadores desde “áreas nucleares” (Núñez 1992, 1994; Yacobaccio 1994b; Aschero 1994; Olivera 1998, entre otros). La información obtenida hasta el momento señala, asimismo, la ocurrencia de una importante variabilidad en las trayectorias locales dentro de la Puna argentina (Yacobaccio et al. 1997/98, Muscio 2001). En esta investigación, se aborda, justamente, un área específica del NOA y se analiza cómo se produjo el cambio, a partir del análisis de la variabilidad de los conjuntos de artefactos líticos recuperados en contextos arqueológicos de la microrregión de Antofagasta de la Sierra (Catamarca), ubicados por dataciones radiocarbónicas en un rango temporal que abarca desde los 5500 hasta los 1500 años AP. El lapso citado se relaciona, entonces, con este proceso de transición que llevó al cambio de economías cazadores-recolectoras a formas productivas agro-pastoriles con alto grado de sedentarismo.

La elección de Antofagasta de la Sierra como caso de estudio no es casual; ya en 1973, Raffino y Cigliano postularon a la microrregión como un lugar promisorio para tratar esta problemática. El hecho de contar, hoy en día, tras aproximadamente 20 años de trabajo ininterrumpido, con una de las secuencias más completas de la Puna argentina para el lapso clave en cuanto a número de sitios y cantidad de fechados radiocarbónicos; con evidencias de prácticas de domesticación y manejo de recursos animales y vegetales; con conjuntos de artefactos líticos numerosos y, más importante aún, recuperados en estratigrafía; y con información suministrada desde distintas líneas de evidencia, hacen que esta investigación sea posible.

En cuanto al lapso abordado, si bien los límites impuestos son arbitrarios, han sido elegidos teniendo en mente que el tratamiento de esta transición requiere de conjuntos de datos que involucren periodos de tiempo lo suficientemente largos como para producir los cambios postulados. De esta 
forma, se inicia ca.5500 años AP, ya que a partir de este momento se registran cambios importantes, por ejemplo, en la organización de los asentamientos (Aschero et al. 1993-94), en el arte rupestre (Aschero 1999a), a través de indicios de experimentación con animales (Reigadas 2000-2002) y en cuanto a presencia de cultígenos (Babot 2004a). Finaliza ca.1500 AP, con ocupaciones agro-pastoriles plenas, pero con un componente importante de caza (Olivera 1992, López Campeny 2001a, Babot et al. 2005).

En este trabajo se pretende, a partir de un aspecto concreto y particular como es la tecnología lítica, tratar con la variabilidad en el comportamiento humano. Específicamente, se encara este problema a través del análisis de la variabilidad y el cambio en artefactos líticos tallados y en las técnicas que los produjeron. En relación con esto, se propone dejar expuestas ciertas líneas de evidencias que permitan entender qué productos y estrategias tecnológicas son indicadores útiles en el desarrollo de la transición.

Asimismo, se explora la incidencia que pudieron tener las variaciones paleoclimáticas, el grado creciente de sedentarismo y la intensificación de las prácticas ganaderas y agrícolas en la variabilidad observada en los conjuntos líticos. Dentro de los conjuntos instrumentales, se hace especial énfasis en los bifaces, como artefactos en sí mismos, como núcleos o como preformas de puntas de proyectil lanceoladas o pedunculadas y/o cuchillos, ya que son artefactos particularmente sensibles a cambios en la subsistencia y la movilidad (Parry y Kelly 1987).

En la aproximación a los artefactos líticos tallados se parte de una visión de la tecnología conformada tanto por la cultura material como por el comportamiento tecnológico y la acción humana, de la cual es parte la destreza técnica (Ingold 1988, Lemmonier 1992). El análisis de la variabilidad en la tecnología se realiza, justamente, sobre estos aspectos.

Interesan, particularmente, las intenciones puestas en práctica en la actividad artesanal (Aschero 1975), pero no se enfatiza sólo en las estrategias económicas y en la relación con el ambiente, como es de tratamiento habitual en los estudios de organización tecnológica (Nelson 1991), sino también en cómo las condiciones sociales afectan la tecnología.

El punto de partida clasificatorio es la propuesta morfológico-macroscópica de Aschero (1975, 1983). De ella se rescata y revaloriza la perspectiva tipológica menuda que comprende el análisis morfológico-funcional de dicho Ensayo. Asimismo, tomando como encuadre general dicha clasificación se desarrollan, en función del problema de la transición, una serie de herramientas instrumentales para el análisis artefactual, como son, por ejemplo, las nociones de clase técnica, secuencia de formatización y secuencia tipológica, se reestructuran ciertos grupos tipológicos y se conforman otros nuevos. 
La Tesis propone trabajar simultáneamente a diferentes escalas. Una perspectiva de grano grueso es utilizada para realizar comparaciones diacrónicas en la cuenta larga, por ejemplo, mediante las clases técnicas propuestas. Al mismo tiempo, en una perspectiva de grano fino, se realizan diversos zooms que toman porciones más cortas de la secuencia o que se emplean para establecer comparaciones sincrónicas sobre aspectos específicos, como la presencia de diferencias en destreza técnica de los productores de artefactos en relación a los contextos arqueológicos estudiados.

A continuación se describe sucintamente el contenido de cada capítulo.

En el CAPÍTULO 1 se presenta la problemática de la investigación con sus ejes analíticos, objetivos e hipótesis.

Las características geográficas generales, el marco ambiental actual y paleoambiental del área de estudio, así como sus vinculaciones con información generada en otras áreas puneñas, se presentan en el CAPÍTULO 2.

El CAPÍTULO 3 está dedicado al planteo teórico, en el que se exploran, por un lado, la variabilidad existente dentro de las nociones de cazador-recolector y sociedad agro-pastoril y, por el otro lado, aproximaciones dinámicas a la tecnología lítica.

En el CAPÍTULO 4 se desarrollan las estrategias metodológicas implementadas para el estudio técnico-tipológico de los conjuntos de artefactos líticos analizados. En este sentido, se discuten conceptos instrumentales para el análisis técnico-morfológico y morfológico-funcional. Información de detalle sobre la ficha de descripción técnico-morfológica y morfológico-funcional de artefactos formatizados, desechos de talla y núcleos se ofrece en el APÉNDICE I.

En el CAPÍTULO 5 se realiza una breve caracterización de la ocupación humana anterior a los 5500 años AP, para posteriormente describir aspectos generales de la secuencia arqueológica del lapso abordado en esta investigación. Asimismo, se presentan los sitios arqueológicos considerados y se enuncia la procedencia de las muestras de artefactos líticos tallados analizadas. Finalmente, se detalla la segmentación de la secuencia de fechados radiocarbónicos en grupos cronológicos.

Por su parte, en el CAPÍTULO 6 se presenta la información obtenida, hasta el momento, en relación con la transición de una estrategia predominante de caza-recolección a otra agro-pastoril en Antofagasta de la Sierra, desde diferentes líneas de evidencia, permitiendo una caracterización del proceso. 
El CAPÍTULO 7 se dedica a la exposición de los resultados del análisis de disponibilidad e materias primas líticas empleadas en la talla. Dado que en este trabajo se emplea información de investigaciones previas en el área, se generan equivalencias entre las viejas denominaciones de las rocas, clasificadas en distintos momentos de diferente forma, y la propuesta en curso. Asimismo, se analiza la distribución de las materias primas locales y no locales y se presentan los resultados de los análisis de procedencia de muestras de obsidiana correspondientes al lapso 4000-3500 AP.

En el CAPÍTULO 8 se exponen las características generales de las muestras de artefactos líticos consideradas y se desarrollan los resultados alcanzados en cuanto a utilización de materias primas líticas en el lapso abordado. Asimismo, se abordan los artefactos formatizados desde un punto de vista morfológico-funcional con el objeto de establecer como fueron cambiando con el tiempo. Para ello, se trabaja desde los grupos tipológicos, los subgrupos tipológicos y la complejidad del instrumental. Por otra parte, se trata en este Capítulo la inversión de trabajo en la confección de artefactos líticos tallados, a través de la diferenciación de clases técnicas en artefactos formatizados y de la utilización de índices diversos. Finalmente, se analiza la relación entre inversión de trabajo y complejidad en artefactos formatizados. Las listas tipológicas que contienen la información referida a los grupos y subgrupos tipológicos por sitio arqueológico se encuentran en el APÉNDICE II. Asimismo, en este último se realizar una serie de consideraciones acerca del armado de las listas tipológicas

En el CAPÍTULO 9, por un lado, se describen los tipos y especimenes morfológicos presentes en Antofagasta de la Sierra entre el 5500 y el 1500 AP y, por el otro lado, se evalúan las evidencias de reclamación de tipos morfológicos, con particular referencia al tipo morfológico QS B.2. Asimismo, se trata la distribución y dimensión temporal así como la recurrencia de tipos y especimenes morfológicos.

En el CAPÍTULO 10 se aborda la variabilidad de los bifaces recuperados en excavación en los sitios QS3, PCh1.3, PCh1.1 y PP4. Para ello, se parte de la diferenciación entre bifaces como tales, transformados y reciclados, por un lado, y entre bifaces en sí mismos y en proceso de manufactura, por el otro. Asimismo, se tratan las vinculaciones entre producción lítica el aprendizaje, para luego abordar, particularmente, las características del adelgazamiento bifacial. Por otra parte, se evalúa el carácter de núcleos bifaciales de parte de la muestra de bifaces considerada. Finalmente se discute si tales bifaces son el resultado de la práctica de aprendices y si estos últimos eran niños y/o adolescentes.

Pasando al CAPÍTULO 11, en el mismo se analiza la variabilidad técnico-morfológica y morfológico-funcional de puntas de proyectil correspondientes a los lapsos 4100-3400 AP y 21001500 AP. Asimismo, se visualiza la ocurrencia de diferencias y semejanzas en las puntas de proyectil 
de los sitios PP4, PCh1.3 y PCh1.1, por un lado, y CChM1 y CChM4, por el otro, a partir de categorías tecnológicas y tipológicas generales. Por último, se plantea que las puntas de proyectil con pedúnculo destacado, aletas y/u hombros y limbo lanceolado son un antecedente de las puntas con pedúnculo diferenciado, aletas y limbo triangular

El CAPÍTULO 12 se emplea la segmentación descriptiva para tratar la variabilidad tecnológica y tipológica al nivel del artefacto. Específicamente, se aborda la variabilidad en la toma de decisiones por parte de los artesanos, en relación a la elección de partes pasivas y a la vinculación de las mismas con los activas, a las características que tomó el reciclaje y a las formas de tratamiento de los limbos de las puntas de proyectil. Por otra parte, se plantea la identificación de desechos de talla resultantes del mantenimiento de raederas de módulo grandísimo. Con respecto a esto último, se presenta en el APÉNDICE III el análisis de microfósiles realizado sobre estos instrumentos y sobre los desechos de talla referidos.

En el CAPÍTULO 13, finalmente, se realiza una discusión general de los resultados obtenidos para el área y el lapso implicados, para finalizar con las conclusiones de la investigación. 


\section{CAPÍTULO 1}

\section{PROBLEMÁTICA DE LA INVESTIGACIÓN}

\subsection{PROBLEMÁTICA DE LA INVESTIGACIÓN}

\subsubsection{LA TRANSICIÓN DE CAZADORES-RECOLECTORES A SOCIEDADES AGRO- PASTORILES EN LA PUNA ARGENTINA Y SU BORDE DESDE LA TECNOLOGÍA LÍTICA}

El problema de la transición de grupos cazadores-recolectores a sociedades agro-pastoriles ha constituido un tema central en la arqueología de la Puna argentina, en particular, en relación a la domesticación de camélidos (Olivera y Elkin 1994; Yacobaccio et al. 1994; Elkin 1996a, 1996b; Olivera 1998; Yacobaccio et al. 1997/1998; Yacobaccio 2001a, 2001b; Reigadas 1994, 2000-2002; entre otros) y, en menor medida, de especies vegetales (por ejemplo, Fernández Distel 1986, Fernández et al. 1992, Babot 2004a) o en cuanto al patrón de asentamiento (García 1998). Sin embargo, y por comparación, el componente artefactual lítico tallado asociado a dicha transición ha sido poco estudiado.

El inicio de los trabajos sistemáticos sobre artefactos líticos tallados en general se produce en la década del '60. En este momento y hasta principios de los '70, los análisis se centran casi exclusivamente en la descripción de materiales adscribibles a cazadores-recolectores recuperados en sitios arqueológicos superficiales de la Puna jujeña y su borde (Cigliano 1962; Fernández 1967, 1968b, 1971). El interés fundamental es la definición de "tipos" de artefactos formatizados en base a características morfológico-macroscópicas, con el objetivo de definir unidades culturales, tales como “culturas” e “industrias” (Cigliano 1962; Fernández 1968a, 1968b, 1968c, 1971, 1972). Si bien en los trabajos se abarcaban las diferentes clases de artefactos líticos, es decir, no sólo instrumentos sino también núcleos y desechos de talla, en mayor o menor profundidad, los mayores esfuerzos se centraban en la clasificación de los bifaces y las puntas de proyectil. Para ello, las propuestas de clasificación combinaban atributos técnicos y funcionales. Destaca la utilización por parte de Cigliano (1962) de la obra de Bordes (1961) para la descripción tipológica.

La intención manifiesta de establecer secuencias culturales, en base a la definición de "tipos guía”, que denotaban el paso de una industria a otra, tenía el gran problema de la ausencia de 
dataciones radiocarbónicas y de sitios estratificados. En general, los investigadores utilizaban las posibilidades de la geocronología para de esta forma correlacionar los materiales líticos con eventos paleoambientales, geomorfológicos o pedológicos. Un ejemplo de esto es la estimación que realiza Fernández (1968a) del momento de ocupación del sitio Morro Blanco (cuenca de Guayatayok, Jujuy), entre 2000 y 3000 años a.C., en base a la presencia del avance de un frente de médanos durante el Postglacial Medio -ver también Cigliano (1962) o Fernández (1968b, 1971)-. Por otra parte, partían de comparaciones tipológicas con sitios estratificados que contaban con fechados radiocarbónicos para asignar cronología a los materiales de superficie que estaban estudiando, por más que dichos sitios se encontraran a gran distancia -como el de la gruta de Intihuasi en San Luis (González 1952)-. Al respecto, ver, por ejemplo, Cigliano (1962).

En cuanto al problema de la transición de la caza-recolección a la vida agrícola-pastoril, no gozaba mayormente del interés por parte de los investigadores que trabajaban en el área, más preocupados por la antigüedad del hombre en la Puna (Fernández 1972) o el devenir de las industrias de cazadores-recolectores a nivel regional (Fernández 1967, 1971), aunque reconocían su importancia (Fernández 1971).

No se pretende aquí realizar disquisiciones sobre las deficiencias teórico-metodológicas de las aproximaciones de la época, sino más bien destacar algunos elementos que prácticamente dejan de estar presentes posteriormente y que se tratan de retomar en este trabajo: por un lado, el esfuerzo en usar a la tipología lítica como una herramienta para generar información sobre el pasado y, por el otro lado, la utilización de una perspectiva comparativa menuda intersitio a nivel regional.

El interés por el surgimiento de las sociedades agro-pastoriles, o más bien, del devenir de los cazadores-recolectores puneños en grupos productores se inició en la Puna jujeña a principios de la década de 1970, extendiéndose luego a la salteña y catamarqueña, hasta llegar a hoy en día con diversos proyectos trabajando directa o indirectamente sobre el tema, desde distintas perspectivas teórico-metodológicas y enfatizando en diferentes tipos de materiales arqueológicos. El caso específico de Antofagasta de la Sierra será tratado posteriormente.

A partir de los '70 adquiere fundamental importancia la excavación de sitios estratificados, tanto por sus posibilidades de conservación de asociaciones y restos orgánicos, como por poder contar con dataciones radiocarbónicas a partir de estos últimos. De esta manera se pudo obtener un cúmulo de dataciones que permitieron contextualizar temporalmente los materiales líticos recuperados.

Los sitios estratificados, con presencia de artefactos líticos tallados, en el lapso 5500-1500 AP se presentan como aleros y/o cuevas y sitios a cielo abierto. Entre los primeros destacan, en la Puna de 
Jujuy y su borde: Inca Cueva 7 (Aguerre et al. 1973), Cueva Huachichocana III (Fernández Distel 1986), Cueva de Cristóbal (Fernández 1988-89), Alero Unquillar (Yacobaccio et al. 2000), Inca Cueva alero 1 e Inca Cueva cueva 5 (García 1998), Tomayoc (Lavallée et al. 1997) y en la Puna de Catamarca: Cueva Salamanca (Delfino 1999). Entre los segundos se puede mencionar, en la Puna jujeña y su borde: Potrero de Caballo Muerto (Fernández 1996a), Torre (Fernández Distel 1998) y Estancia Grande (Palma y Olivera 1992-93); en la Puna salteña y su borde: Las Cuevas, Cerro El Dique y Potrero Grande (Raffino 1977), Cerro Colorado (Tarrago 1996), Ramadas 1 y Ramadas Estructura 1 (Muscio 2004) y en la Puna catamarqueña: Tebenquiche Chico (Haber 1999). Los sitios de superficie, por su parte, son escasamente considerados. Ejemplos son los trabajos de Fernández (1996b) en Munitayoc (Puna de Jujuy) y de Ratto (2003) en diversos sitios superficiales del área de Chaschuil (Puna de Catamarca).

El abordaje de los artefactos líticos se enmarca por lo general en la descripción de sitios, con grado de extensión variable (por ejemplo, Aguerre et al. 1973; Raffino 1977; Fernández Distel 1986, 1998; Fernández 1996a, 1996b, 1988-89; Delfino 1999; Tarragó 1996). Otros trabajos abordan el cambio tecnológico y tipológico, pero siempre en función de investigaciones más amplias, no siendo el material lítico la base de las mismas. Al respecto, se registra una amplia variedad de situaciones: tratamiento de un solo sitio con una serie de ocupaciones continuas abarcando el momento clave Tomayoc- (Lavallée et al. 1997), de conjuntos de sitios atribuibles a grupos agro-pastoriles comparados con sitios inmediatos contemporáneos o de momentos previos - por ejemplo, Inca Cueva alero 1 e Inca Cueva 7- (García 1998) o bien de sitios con la cronología en ciernes que son comparados con sitios mucho más antiguos -Alero Unquillar versus Hornillos- (Yacobaccio et al. 2000). Se destaca que un acercamiento adecuado del problema debería implicar conjuntos de sitios que cubran el momento clave. En este sentido, la perspectiva más cercana ha sido la de García (1998).

Las aproximaciones a los materiales líticos ha sido y son básicamente tecnológicas, integrando información de artefactos formatizados, desechos de talla y núcleos, sin priorizar una categoría sobre las demás. Interesan cuestiones relativas a: procedencia y calidades de materias primas (por ejemplo, Fernández 1988-89, Ratto 2003), inversión de trabajo y tiempo en la manufactura de artefactos líticos (Yacobaccio et al. 2000, Muscio 2004, entre otros), caracterización de sitios (García y Carrión 1992, García 1998, por ejemplo) y cómo factores como el riesgo, el sedentarismo y las prácticas productivas afectan la conformación de los conjuntos artefactuales (entre otros, García 1998, Yacobaccio et al. 2000).

Se destaca que la perspectiva tipológica también está presente, aunque básicamente en función de la comparación de diseños de puntas de proyectil específicos (Fernández 1988-89, 1996a, 1996b; García 1998, Ratto 2003). Casos a los que debe hacerse especial referencia son el tratamiento 
tipológico de los artefactos formatizados de Inca Cueva 7 (Aguerre et al. 1973) y la propuesta de discriminación de subgrupos tipológicos de puntas de proyectil de sitios agro-pastoriles de la Puna Septentrional y Meridional de Escola (1987). Cabe destacar la aproximación tipológica exhaustiva de Fernández Distel (1978), en la que analiza materiales líticos de diversos sitios de superficie del área de las Salinas Grandes, en la Puna de Jujuy, siendo posible observar una mezcla entre los intereses del momento previo señalado y las tendencias en vigencia al momento de redacción del artículo.

Ahora bien, en cuanto a las clasificaciones morfológico-macroscópicas empleadas, se ha utilizado fundamentalmente la propuesta de Aschero (1975, 1983) (Escola 1987, García y Carrión 1992, García 1998, Yacobaccio et al. 2000, Muscio 2004). Sin embargo, simultáneamente funcionan otros sistemas clasificatorios, como el de Fernández (1988-89, 1996a) o el de Haber (1999). Asimismo, se han generado aportes que se articulan al "Ensayo..." de Aschero, como el de Ratto (2003) en cuanto a clasificación de puntas de proyectil o de Muscio (2004) en relación a niveles de clasificación de los artefactos líticos.

En el caso específico de Antofagasta de la Sierra, las investigaciones se inician a principios de la década del '80. Se destaca que siempre hubo un marcado interés por el abordaje de la transición desde los artefactos líticos tallados. Esto está claramente evidenciado por la profusa bibliografía generada al respecto (Aschero et al. 1991; Aschero et al. 1993-94; Pintar 1990, 1995a, 1995b, 1996a, 1996b; Martínez 1997; Toselli 1998; Manzi 1999; Escola 1999, 2000; Hocsman 2001; entre otros) ${ }^{1}$, pero dichas aproximaciones adolecen de los mismos problemas que se ha manifestado para el resto de la Puna.

Así, una serie de trabajos abordan la secuencia holocénica de cazadores-recolectores. Pintar (1990) analiza los conjuntos líticos de los niveles 2b9 y 2 b3 de Quebrada Seca. Posteriormente, esta autora considera los materiales líticos de distintos niveles de Quebrada Seca 3 correspondientes al Holoceno Temprano, Medio y Tardío e incluye muestras de Punta de la Peña 4 y conjuntos de Peñas Chicas 1.1. A su vez, Manzi (1999) realiza un trabajo básicamente sobre desechos de talla de niveles correspondientes al Holoceno Temprano, Medio y Tardío de Quebrada Seca 3. Por su parte, Escola (1990-92, 1999, 2000) aborda conjuntos de artefactos líticos de los sitios agro-pastoriles plenos Casa Chávez Montículos 1 y Real Grande 1. De esto resulta que no se ha trabajado con secuencias lo suficientemente largas como para que incluyan los cambios involucrados en la transición, así como los momentos previos y posteriores (cf.Odell 1994). Esto se debe, en buena parte, a la "división" de la secuencia arqueológica local que se comenta en los párrafos siguientes.

\footnotetext{
${ }^{1}$ No se brindan mayores precisiones en cuanto a los resultados obtenidos ya que estos son incorporados y utilizados a lo largo de la Tesis
} 
En los trabajos de la microrregión, hasta el momento, preponderan los estudios vinculados a la organización de la tecnología en base a una serie de conceptos tales como sistema de producción lítica, cadenas operativas o secuencias de producción. En menor medida, se plantean abordajes tipológicos en profundidad, aunque siempre enmarcados en la organización de la tecnología y referidos a niveles arqueológicos específicos de sitios puntuales (Aschero et al. 1991, Aschero et al. 1993-94, Martínez 1997).

Como temas de análisis, destacan, por un lado, la relación de la tecnología lítica con la emergencia del pastoralismo, el papel jugado por el riesgo de subsistencia y la movilidad, vistos desde la perspectiva de los cazadores-recolectores (por ejemplo, Aschero et al. 1991, Pintar 1996a). Por otro lado, se plantea la integración de prácticas productivas y los efectos del riesgo y de la movilidad en el marco de sociedades agro-pastoriles plenas (Escola 1999, 2000).

La razón de estas dos perspectivas tiene que ver con la existencia de dos grupos de investigación: uno, dedicado a cazadores-recolectores (Aschero y colaboradores), y otro abocado a sociedades agro-pastoriles (Olivera y colaboradores). Esto llevó a que la secuencia arqueológica local fuera "particionada" en los dos lapsos temporales correspondientes a la secuencia holocénica de cazadores-recolectores y a las ocupaciones agro-pastoriles posteriores al 2000 AP, respectivamente. Esto se vio favorecido, además, por la ausencia de sitios residenciales con secuencias largas que tomen la transición.

Con esta investigación se pretende salvar esta “partición”, mediante un estudio sistemático de algunos temas que se consideran centrales para la problemática de la tecnología lítica de la transición, con énfasis en aspectos tipológicos. A esto se suma nueva información sobre sitios arqueológicos, recursos productivos (Babot 2004a) y la secuencia paleoambiental local (Olivera et al. 2002), con la que previamente no se contaba.

\subsubsection{VARIABILIDAD TECNOLÓGICA Y TIPOLÓGICA EN ARTEFACTOS LÍTICOS TALLADOS}

Una tendencia muy importante en la arqueología contemporánea y ya desde hace algún tiempo, es el abordaje de la variabilidad en el comportamiento humano (Jochim 1991, Borrero 1993, Kelly 1995).

La aproximación en curso a la variabilidad de los artefactos líticos tallados en la transición es de tipo multiescalar, ya que se parte de la utilización de tres niveles diferentes: 1) el de conjunto lítico 
(Capítulo 8); 2) el de artefacto (Capítulos 9, 10 y 11) y 3) el de atributos morfológicos específicos (Capítulo 12). Para ello, se toma como punto de partida la instrumentación de la segmentación descriptiva propuesta por Aschero (1975).

La perspectiva, a estas tres escalas, es básicamente comparativa, a partir de un tratamiento de los datos que puede ser diacrónico (Capítulo 11) o sincrónico (Capítulo 12), o bien una combinación de ambos (Capítulos 8, 9 y 10). Esto, asimismo, es sumamente útil para el tratamiento del cambio.

De esta forma, se trabaja simultáneamente con perspectivas que van de un grano grueso, pasando por un grano fino y llegando hasta uno muy fino. Esto permite abordar la variabilidad tanto en la manera en que se estructuran los conjuntos de artefactos como en las características particulares de artefactos puntuales. Destaca, en suma, la idea de complementariedad de las distintas escalas empleadas en función del tratamiento de la variación en el registro arqueológico. Se hace notar que en el Capítulo 12 se toma específicamente en cuenta el manejo de atributos para rescatar esa variabilidad en términos de prácticas de producción. Si bien produce un cierto desvío de la línea argumental central interesa para mostrar cómo esa variabilidad a escala de los comportamientos individuales de producción puede servir para avanzar en el análisis de la variación morfológica a nivel micro.

La variabilidad interesa, entonces, en su aplicación a la tecnología lítica y en relación a cinco temas-problema que permiten abordar distintos aspectos de esa variabilidad, así como los condicionantes que el marco paleoambiental, la disminución de la movilidad residencial y la emergencia de prácticas productivas pudieron haber impuesto a la estructura de los conjuntos de artefactos líticos.

\subsubsection{El problema de los bifaces}

La noción de "biface” interesa en cuanto a la variabilidad morfológica que el concepto abarca y por el especial interés que mantiene en la bibliografía especializada (Parry y Kelly 1987, Nami 1988, Hayden et al.1996, Odell 1998, Bamforth y Becker 2000, Soressi y Dibble 2003). Al realizar un análisis de las múltiples formas de presentación y usos de un biface, se reconoce inmediatamente que los intentos de generar una definición consistente del término se ven obstaculizados por su misma naturaleza y posibilidades como artefacto (Roe 2003), ya que esta noción puede referir tanto a un tipo morfológico, sea un instrumento o un núcleo, como a piezas en proceso de manufactura (Kelly 1988, Whittaker 1994, Andrefsky 1998, Aldenderfer 1998, Bamforth 2003, Roe 2003).

Estrictamente hablando, el concepto de biface es cualquier instrumento trabajado en ambas caras; de esta forma es considerado, por ejemplo, por Crabtree (1972), Gramly (1990) o Roe (2003). 
Aunque es cierto que esta noción tiene su fundamento en características técnicas (Nami 1993-94) además de su carácter bifacial, los lascados afectando ambas caras de la pieza-, hay otras variables, de carácter morfológico-funcional, que son esenciales para su clasificación como tales, como, por ejemplo, la conformación del borde y de la arista.

En un trabajo ya clásico, Kelly (1988) define tres roles potenciales para los bifaces: como núcleos, como artefactos de larga vida útil y como productos derivados (by-products) del proceso de manufactura.

En el primer caso, como fuentes de materia prima, los bifaces proveen de una variedad de formas y tamaños de lascas factibles de ser usadas. Asimismo, por la técnica de extracción empleada, se maximiza la materia prima ya que las lascas obtenidas son delgadas y porque poseen una alta razón borde-peso, permitiendo la producción de más borde cortante por unidad de masa (Parry y Kelly 1987, Kelly 1988, Nelson 1991). Por otro lado, al llevarse los potenciales utensilios en un solo biface sólido, se asegura que las lascas extraídas de él tengan filos aguzados y no dañados.

En el segundo caso, por poseer filos trabajados bifacialmente, al haber rotura o embotamiento de sus filos, los bifaces pueden ser reactivados fácilmente, continuando así siendo útiles. De acuerdo a Hayden (1989), la morfología delgada de los bifaces y la percusión blanda se relacionan con la búsqueda de conservación de bajos ángulos de bisel a la vez que con maximizar el número de reactivamientos y el uso de la materia prima, lo que implica un uso prolongado y un aumento de la longevidad (Hayden et al. 1996).

Por otra parte, su forma generalizada les permite ser modificados en otros instrumentos (Kelly 1988). Un ejemplo de esto pueden ser las raederas o cuchillos de retoque o retalla bifacial extendida o marginal, definidos de acuerdo a si la arista es regular, al ángulo de los biseles y a si los mismos guardan una relación de asimetría o simetría.

Es interesante el hecho de que los bifaces pueden ser tanto instrumentos flexibles como versátiles (sensu Nelson 1991), ya que pueden satisfacer demandas multifuncionales a partir de los cambios en su morfología a lo largo de su secuencia de reducción, o bien mantener una forma generalizada de filo adecuada para una amplia variedad de tareas, respectivamente. Esto último no ha impedido, sin embargo, que hayan sido caratulados como utensilios especializados en tareas de destazamiento (Hayden et al.1996).

Con respecto a la potencial flexibilidad de los bifaces, Andrefsky (1998) le otorga singular importancia al proceso de producción, ya que lo considera responsable de un amplio rango de 
variabilidad morfológica, que no sólo cambia la morfología del biface, sino que también puede cambiar la función del espécimen (por ejemplo, ver modelos de flujo en Nami 1986: 18 y Bousman 1993: 79, Figura 13). En suma, durante el transcurso de la secuencia de reducción de un biface se producen piezas con diferentes cualidades adecuadas para actividades variadas.

Es importante destacar que estas características de diseño se combinan con su condición de transportables (Kelly 1988, Nelson 1991), al satisfacer la demanda de utensilios utilizando un peso menor de materia prima (Parry y Kelly 1987).

En el tercer y último caso, para Kelly (1988), en esos by-products, la bifacialidad no es una intención explícita del artesano; por ejemplo, un proceso de manufactura que culmina en una punta de proyectil, donde el biface es un derivado. Al respecto, se considera que si bien esto puede presentarse en ciertos casos, hay muchos otros en que justamente hay una intencionalidad manifiesta de partir de una forma-base biface para confeccionar un utensilio determinado, justamente, en ciertos diseños de puntas de proyectil o cuchillos.

Es más, la inversión de tiempo, energía y esfuerzo en su producción hace que estos artefactos sean considerados confiables (Nelson 1991), en función de una manufactura y mantenimiento especializado y del énfasis en aspectos tales como el espesor y la robustez. Para Hayden et al. (1996) una excepción a esto serían las piezas muy delgadas, ya que por esa condición son muy frágiles y tienen una alta tasa de rotura, a pesar de poseer las características de elevada inversión de tiempo, energía y esfuerzo señaladas en el párrafo anterior.

El término biface, tal como es entendido aquí, refiere a la morfología del artefacto y no necesariamente implica una función. No obstante, es posible, a partir del análisis técnico-morfológico y morfológico-funcional, evaluar esta multiplicidad de papeles de los bifaces en los contextos arqueológicos (por ejemplo, si los bifaces fueron empleados como núcleos, si se utilizaron como formas-base de instrumentos o si fueron reciclados), aunque esto no es factible analizando sólo los bifaces e instrumentos confeccionados sobre los mismos, sino que deben estudiarse los instrumentos bifaciales con y sin adelgazamiento bifacial, las formas-base de los instrumentos bifaciales, las lascas de adelgazamiento bifacial desechadas y las empleadas como formas-base de instrumentos (Flegenheimer 1991).

El tratamiento de los bifaces en esta investigación parte de la elaboración de una definición operativa y consistente de dicho artefacto (Capítulo 4), en función de los parámetros propuestos por Aschero (1975) para la caracterización de los grupos tipológicos, a los que se les han incorporado otros. Por otro lado, se retoma la clasificación de Aschero (ibid.) de subgrupos tipológicos en bifaces; 
es decir, bifaces en sentido estricto y bifaces parciales (Capítulo 4). Asimismo, se explicita la diferenciación entre biface, esbozo de pieza bifacial y núcleo bifacial (Capítulo 4).

La variabilidad de roles de los bifaces en los casos considerados se analiza en base a la distinción entre bifaces como tales, reciclados y transformados, por un lado, y entre bifaces en si mismos y en proceso de manufactura, por el otro; combinados con la discriminación de núcleos bifaciales (Capítulo 10).

\subsubsection{La inversión del trabajo en la manufactura de artefactos líticos}

Un aspecto que ha sido recurrentemente considerado al abordar situaciones de cambio económico, de variaciones en la movilidad y el riesgo, entre otros factores, refiere a la inversión de trabajo en la confección de artefactos líticos (Parry y Kelly 1987, Koldehoff 1987, Torrence 1989, Teltser 1991, Jeske 1992, Hiscock 1994, Andrefsky 1998, Cowan 1999, Tomka 2001).

Una propuesta de clasificación, en este sentido, es la diferenciación entre instrumentos informales y formales de Andrefsky (1994a), donde los primeros refieren a artefactos con un bajo o nulo esfuerzo invertido en la producción y los segundos a instrumentos con mayor esfuerzo de manufactura.

Los instrumentos informales son artefactos simples, no estandarizados, de manufactura poco esforzada, sin un patrón formal en lo que respecta a diseño y confeccionados, usados y descartados en un lapso de tiempo relativamente corto (Andrefsky 1994b). Se destaca que las características opuestas caracterizarían a los artefactos formales.

Siguiendo a Tomka (2001), ejemplos de artefactos informales serían las lascas que no han sido alteradas previamente a su uso, o sea, lascas no retocadas (lascas con filos naturales con rastros complementarios en la terminología de Aschero 1975, 1983), mientras que, de artefactos formales, piezas con suficientes lascados como para cambiar significativamente el borde de la forma-base original, como un biface o una raedera unifacial. Andrefsky (1994a) incluye en esta última categoría a todos los instrumentos retocados sobre lasca.

Con respecto a estos últimos, Escola (2000) realiza una serie de observaciones realmente significativas, señalando que la inversión de trabajo en la manufactura de muchos artefactos confeccionados por retoque no es tan importante como para calificarlos de formales. Asimismo, desarrolla criterios para analizar la inversión de trabajo y diferenciar, de esta manera, entre instrumentos formales e informales. Dichos criterios implican el análisis de (ibid.). 
- las técnicas de reducción involucradas en la producción de determinadas formas-base,

- las evidencias de estandarización en los soportes, ya sea en lo atinente a tipo de lasca, tamaño o módulo,

- las técnicas de retoque implementadas en la formatización y regularización final de los instrumentos.

Es evidente que la propuesta de Escola representa un salto cualitativo en la discriminación en ciernes, pero la dicotomía formal-informal presenta problemas que exceden las dificultades clasificatorias, relacionados con la denominación de las categorías mismas.

Las nociones de formal-informal aluden a la ocurrencia de una morfología. Justamente, todo artefacto formatizado se caracteriza por una imposición de cierta forma (Aschero 1975, 1983, 1988a), sea que presente una baja o alta modificación ${ }^{2}$, de modo que el concepto de informal, referido a algo que no tiene forma, no es afortunado -lo mismo que la utilización recurrente del término amorfo (Parry y Kelly 1987, Torrence 1989)-.

El abordaje de las variaciones en el tiempo de la inversión de trabajo en la confección de materiales líticos tallados es un punto importante en la discusión del proceso transicional en Antofagasta de la Sierra. En este marco, es evidentemente necesario que para abordar a los artefactos líticos desde una perspectiva morfológica, se deben desarrollar nociones que no sean contradictorias con la clasificación tipológica marco. Al respecto, en el Capítulo 4 se proponen, como resultado de esta investigación, una serie de conceptos y propuestas metodológicas particularmente útiles para tratar la inversión de tiempo y energía en la manufactura de artefactos líticos, como son las nociones de clase técnica y de secuencia de formatización y de secuencia tipológica.

\subsubsection{Identificación de aprendices en el registro arqueológico}

Recientemente, ha surgido el interés por analizar la producción material de grupos de edad específicos, especialmente niños, y su contribución a la conformación del registro arqueológico (Lillehammer 1989, Sofaer Derevensky 1994, Politis 1999). En tal marco, interesa abordar la dinámica social a nivel de microescala que implica considerar la acción de los individuos y de grupos particulares en la cotidianeidad (Dobres y Hoffman 1994), y dentro de éstos, a los niños y jóvenes como productores y consumidores de cultura material (Lillehamer 1989, Politis 1999).

En este caso, interesa detectar la actividad infanto-juvenil no sólo por considerarlos actores sociales significativos sino, también, porque permiten analizar la variabilidad tecnológica generada por grupos de edad específicos.

\footnotetext{
${ }^{2}$ En el caso de que dicha modificación fuera nula, no se trataría de un artefacto formatizado, siguiendo a Aschero (1975).
} 
En relación con esto último, el aprendizaje de la talla de la piedra ocurre, generalmente, pero no sólo, durante la niñez y la adolescencia de los individuos (Pigeot 1990). Es aquí cuando los aprendices adquieren las destrezas necesarias para llevar a cabo las prácticas de talla satisfactoriamente -motoras y cognitivas, así como el conocimiento técnico-.

Dependiendo de la sofisticación y complejidad de la técnica, va a variar el tiempo requerido para el aprendizaje (Stout 2002), pero es durante este lapso cuando se debe registrar una progresión en cuanto a maestría operativa y conceptual (Pigeot 1990).

De acuerdo con Whittaker (1987), al identificar los productos de artesanos individuales se puede examinar la posición, habilidades y especialización de los individuos. Esto es posible mediante la identificación de atributos que varían en una forma particular entre artesanos diferentes.

En general, las aproximaciones arqueológicas al problema del reconocimiento de aprendices se han basado en análisis de remontaje de núcleos (Bodu et al. 1990, Fisher 1990, Bodu 1996). Otra posibilidad, sin embargo, es reconocer destreza técnica mediante el estudio de atributos morfológicos en artefactos formatizados (Whittaker 1994, Stout 2002). Se destaca que esta última línea de evidencia aunque muy promisoria, cuenta con escaso desarrollo metodológico. Al respecto, en esta investigación se generan una serie de criterios para discriminar niveles técnicos a partir de bifaces y, de esta forma, estimar la presencia de aprendices en el registro arqueológico local (Capítulo 10).

Si bien el abordaje de los aprendices es un tema general que no está necesariamente ligado a la problemática de la transición, su accionar genera variabilidad, la cual si es un aspecto clave en este trabajo, en función de un análisis de la variabilidad en la transición. Por otro lado, dado que los bifaces son instrumentos cruciales a la hora de estudiar la transición, tratar con los aprendices adquiere sentido.

\subsubsection{Tecnología lítica y cazadores-recolectores complejos}

El interés por la emergencia de complejidad está presente en la arqueología de los Andes Centro-Sur desde principios de la década del ochenta (Núñez 1981, 1992, 1994; Yacobaccio et al. 1997/98; Olivera 1998; Olivera et al. 2003). Una derivación actual de ese interés es considerar el comienzo de las prácticas domesticatorias de camélidos en relación a la existencia de cazadores complejos en la Puna y circumpuna argentina y chilena (Aschero y Yacobaccio 1998/99; Yacobaccio 2001a, 2004). 
La información utilizada hasta el momento para contrastar esta aseveración proviene de diversos sitios de la Puna Norte Argentina, su borde oriental y de la zona del Salar de Atacama, por lo que surge la pregunta de si la Puna Meridional Argentina cuenta con evidencias de cazadoresrecolectores complejos, formando parte del proceso regional.

Comprobar la existencia de un proceso local de emergencia de complejidad en Antofagasta de la Sierra es importante, además, ya que permitiría generar un marco de referencia para entender la serie de cambios socio-económicos que llevaron de las prácticas cazadoras-recolectoras a las agropastoriles en la microrregión.

Ahora bien, sería esperable que el proceso de complejización socio-cultural tuviese algún tipo de correlato en las características tecnológicas y tipológicas de los conjuntos de artefactos líticos, un aspecto que ha estado prácticamente ausente en los trabajos que tratan específicamente esta cuestión en la Puna argentina. Se destaca que sólo recientemente este tema está comenzando a ser abordado en otras partes del mundo (Odell 2001).

A nivel de tecnología, en general, se ha sugerido que la ocurrencia de estandarización y especialización artefactual (Núñez 1981, Price y Brown 1987, Yacobaccio 2001a) y el desarrollo de innovaciones ya sea en la tecnología o en las técnicas (Ames 1994) podrían estar correlacionados con el surgimiento de situaciones de complejidad (ver, también, Gero 1989).

En este mismo sentido, se han postulado la emergencia de cambios en la organización de la tecnología dados por la especialización artesanal (Johnson 1996) o bien por el accionar de grupos específicos (elites) que buscan controlar el acceso a los recursos, a través del control de la adquisición de materias primas líticas, de los lugares de trabajo y de la intensificación productiva (Nassaney 1996).

Una de las marcas más distintivas de una sociedad compleja sería, entonces, la especialización artesanal. Un punto crucial, por ende, es establecer qué constituye verdadera especialización artesanal y cómo se determina su ocurrencia en el registro arqueológico (Odell 2001). Una vía posible al respecto es analizar las características tecnológicas, dimensiones y la dificultad de confección de artefactos específicos que impliquen una producción por parte de expertos (Pigeot 1990, Bodu et al. 1990, Bodu 1996).

Una cuestión relacionada con la especialización artesanal, como ya se comentó, comprende el tipo de régimen bajo el cual se estructuraba la tarea artesanal, esto es, si la producción o distribución de materiales líticos estaba estrictamente controlada por un cuerpo político central o una clase social o 
si permanecían bajo la autoridad de unidades sociales más pequeñas, a nivel familiar o de parentesco; lo cual es factible de ser abordado a partir del estudio de los loci de producción y consumo.

Esta investigación pretende evaluar justamente la presencia de los elementos mencionados en base a las evidencias disponibles en el área de estudio (Capítulo 13).

1.1.2.5. Incidencia de los cambios paleoambientales, el sedentarismo y las prácticas productoras sobre la tecnología lítica

La información arqueológica señala para la Puna argentina (Aschero 1994, Olivera 1996, Yacobaccio 1997) y chilena (Núñez y Santoro 1988, Núñez 1994) que entre el 5500 y el 2000 AP se produjo una progresiva reducción de la movilidad que devino en un sedentarismo creciente.

Debido a que la movilidad tiene un impacto significativo en la forma en que estructura la tecnología, los grupos que presentan variaciones en la movilidad tenderán a organizar su tecnología diferencialmente. Un punto importante es tratar el efecto que tuvo el sedentarismo creciente (Parry y Kelly 1987, Odell 1998) en la conformación de los conjuntos artefactuales.

Este proceso de sedentarización coincide con el paso progresivo de condiciones climáticas marcadamente áridas a la constitución de un clima similar al moderno hacia el 3000 AP, según información paleoambiental de la Puna Salada (Núñez et al. 2001, Olivera et al. 2002). La situación de aridez del Holoceno Medio habría generado un incremento del riesgo (sensu Bamforth y Bleed 1997), que fue disminuyendo a medida que se establecían las condiciones “modernas” hacia el 3000 AP. Este stress ambiental habría propiciado el inicio de actividades productivas, como la domesticación de camélidos (Núñez 1992, Pintar 1995a).

Aunque la emergencia de prácticas pastoriles en Antofagasta de la Sierra no cuenta con evidencias definitivas (Elkin et al. 1992, Elkin 1996a), hay consenso en que el manejo de segmentos poblacionales de camélidos silvestres es un proceso regional que se desarrollaría en forma relativamente simultánea en la Puna argentina (Yacobaccio et al. 1997-1998).

En lo que respecta a la producción agrícola en Antofagasta de la Sierra, se ha sostenido que habría tenido escasa incidencia en los momentos iniciales de las ocupaciones agro-alfareras plenas, contrastando con la importancia del pastoralismo (Olivera 1996). Sin embargo, información reciente generada por Babot (2004a) para el área de estudio, permiten afirmar la existencia de cultígenos en fechas tan tempranas como 4700 años AP. Asimismo, la presencia de elementos asociados a prácticas 
agrícolas -palas, azadas, etc- (Olivera 1992) advierten sobre la necesidad de tenerlas en cuenta al considerar el cambio en los conjuntos líticos.

Otro punto relevante refiere a los conjuntos líticos relacionados con actividades de caza, las cuales nunca dejaron de ser importantes, aún en contextos agro-pastoriles (Olivera 1992, 1996, 1997; Yacobaccio et al. 1997-1998).

La implementación de estas nuevas formas de subsistencia tendría su correlato en cambios en la presencia y frecuencia de artefactos dentro de los conjuntos (por ejemplo, Núñez 1981, 1992; Jackson y Benavente 1994, 1995-1996; Pintar 1995b). Cabe destacar que no se pretende determinar la presencia de pastoralismo o agricultura a partir de los materiales líticos (punto reservado a los análisis osteométricos y de fibra y a los análisis botánicos, respectivamente, realizados en el proyecto de investigación marco), sino evaluar su posible incidencia sobre la producción de los artefactos líticos en los sitios considerados.

Parece plausible sostener, en consecuencia, que los cambios en la subsistencia y movilidad, asociados a las condiciones ambientales, debieron jugar un rol básico en la conformación de la conjuntos de artefactos líticos tallados de los grupos humanos de Antofagasta de la Sierra, durante el período considerado.

Interesa analizar, por ende, las respuestas ante el riesgo, a las que se puede acceder a través del estudio de las modificaciones en la diversidad y diseño de los conjuntos líticos; y analizando, entre otros, la selección de materias primas líticas y la movilidad. El estudio pormenorizado de los artefactos bifaciales constituiría otra vía de análisis para tratar con cambios de estrategias ante determinadas circunstancias.

Para Torrence (1989), la diversidad de los conjuntos líticos se relaciona directamente con el grado de riesgo involucrado. Así, se espera que las variaciones en los valores del riesgo generadas ante los cambios ambientales, de subsistencia, etc. ocurridos en la región bajo estudio desde el Holoceno Medio, produzcan variaciones en la diversidad de los materiales líticos. De tal forma que, a mayor riesgo, se estaría en presencia de una mayor especificidad de los artefactos que permitiría el aprovechamiento más eficiente de los productos explotados y la energía puesta en la tarea desarrollada. Vista en relación a distintos recursos explotados y a diferentes sitios esta especificidad llevaría a una mayor diversidad del conjunto artefactual (Franco y Borrero 1993).

Por su parte, todo diseño es el producto de la selección de una alternativa dentro de una serie de posibilidades, que provee una solución a un problema determinado (Bleed 1986). Si el problema 
cambia, se altera la efectividad y aplicabilidad de dicha estrategia, por lo que es esperable el empleo de un nuevo diseño afín a las nuevas condiciones. De esta forma, las fluctuaciones ambientales, cambios en la subsistencia, movilidad, etc. promueven a los grupos humanos a efectuar modificaciones en sus tácticas, alterando su tecnología, a fin de reducir el factor riesgo.

En este marco, se plantea que debería observarse un cambio en los tipos de diseños empleados en el lapso ca5500-2000 AP, al producirse nuevas condiciones climáticas, de subsistencia y movilidad. En este punto hay un aspecto interesante a investigar: si el proceso de cambio de un diseño a uno nuevo es inmediato o conlleva un cierto lapso donde conviven ambos diseños, para luego predominar uno de dos.

Surge como relevante, entonces, analizar las diferencias y semejanzas de los conjuntos de artefactos en relación a los procesos sincrónicos y a los procesos diacrónicos que culminaron, por ejemplo, en la utilización preponderante de puntas de proyectil con pedúnculo diferenciado y aletas entrantes o de limbo triangular, apedunculadas con base escotada (Escola 1987).

El enfoque propuesto implica tratar con la morfología de las piezas y la organización de los conjuntos, delimitando los constreñimientos (materiales acequibles, tecnología disponible, movilidad, etc.) y las consideraciones de diseño (peso y tamaño, ángulo y forma del borde, etc) para así definir las estrategias de producción resultantes (Hayden et al. 1996).

En la actualidad existe consenso al afirmar la complejidad de las relaciones entre movilidad y manufactura de instrumentos (Kelly 1992, Carr 1994), teniendo en cuenta que entran en juego un conjunto de variables relevantes, como el tipo y distribución de la materia prima, la estructura de los recursos vegetales y animales, el riesgo, la función de los instrumentos, etc. Es por esto que se plantea la aplicación de un enfoque flexible que tenga en cuenta dichos aspectos.

En lo que respecta a los bifaces, durante el lapso considerado, pudieron haber sido utilizados en Antofagasta de la Sierra como preformas de distintos diseños de puntas de proyectil lanceoladas pequeñas o muy grandes (dentadas o no), con pedúnculo, cuchillos, etc. También pudieron emplearse como artefactos en sí mismos o como núcleos (Kelly 1988), posibilidades que deben contrastarse.

Estudios preliminares han sugerido una disminución en el uso de bifaces a lo largo del Holoceno en Antofagasta de la Sierra (Pintar 1996a, Escola 2000). Por otra parte, estos artefactos han sido recurrentemente asociados a grupos móviles necesitados por esa condición de utensilios estandarizados, portátiles y multifuncionales que, al reducir su movilidad, ya no les resultaban prácticos (Parry y Kelly 1987, Hayden et al. 1996, Odell 1998). 
Por esto, el análisis tipológico de estos materiales arqueológicos tenderá a establecer relaciones entre formas-base, preformas y productos bifaciales terminados, utilizando, en lo posible, variables cuantitativas y no solamente cualitativas. Por tal motivo, se emplearán razones entre variables, por ejemplo, relación largo máximo-espesor, largo máximo-ancho máximo, etc. (Bordes 1961).

Una expectativa arqueológica interesante, resultante de esto refiere a que de establecerse estas tendencias en el registro arqueológico, sería esperable reconocer la existencia de ciertos productos finales ausentes a través de la identificación de productos intermedios en el proceso de manufactura.

\subsection{OBJETIVOS}

\subsubsection{OBJETIVOS GENERALES}

1) Aportar conocimientos sobre el proceso que llevó al surgimiento de economías agro-pastoriles en Antofagasta de la Sierra, a partir del estudio de conjuntos líticos de nuevos sitios y de componentes ya procesados o aún sin procesar de sitios ya conocidos.

2) Generar información sobre la variabilidad tecnológica y tipológica de los conjuntos líticos de los sitios, desde una perspectiva sincrónica y diacrónica.

3) Evaluar la incidencia de las condiciones paleoambientales, del sedentarismo y de las prácticas agrícolas/pastoriles sobre las estrategias de aprovisionamiento, manufactura, uso y descarte de los conjuntos de artefactos líticos.

4) Utilizar la información producida conjuntamente con otras líneas de evidencia en estudio por el equipo de investigación (recursos faunísticos, restos vegetales, etc.) para establecer las características generales del proceso de cambio, en base al estudio comparado de asociaciones contextuales intra-sitio y de contextos inter-sitio. 


\subsubsection{OBJETIVOS PARTICULARES}

1) Analizar la variabilidad técnico-morfológica y morfológico-funcional de conjuntos de artefactos líticos para lograr definir estrategias de producción y uso desde una perspectiva sincrónica y diacrónica, dentro del lapso citado.

2) Establecer la frecuencia y diversidad de artefactos con adelgazamiento bifacial en relación con la proporción y diversidad de las restantes clases de artefactos presentes a nivel intra e inter-sitio.

3) Analizar las tendencias en la inversión de trabajo en la manufactura de artefactos líticos tallados a lo largo del lapso propuesto.

4) Detectar posibles variaciones en la diversidad y en el diseño de los conjuntos de artefactos líticos en relación a probables aumentos o mermas en la disponibilidad de recursos como efecto de variaciones climáticas, al aumento del sedentarismo y a la integración de prácticas agrícolas/pastoriles.

5) Analizar la relación entre complejidad socio-cultural y características tecnológicas y tipológicas de los conjuntos artefactuales líticos.

6) Evaluar la presencia de aprendices en el registro arqueológico local, en base al análisis de artefactos bifaciales.

\subsection{HIPÓTESIS}

H1) La inversión de trabajo en la manufactura de artefactos líticos decrece con el paso del tiempo, en relación a modificaciones en las condiciones ambientales, en la subsistencia y la movilidad.

H2) El cambio en frecuencia de un diseño a otro es paulatino, para un mismo grupo/subgrupo tipológico o tipo/espécimen morfológico.

H3) La diversidad de los conjuntos líticos disminuye a medida que se avanza hacia el 1500AP, como respuesta a cambios en las condiciones ambientales, en la subsistencia y la movilidad.

H4) La distancia de las fuentes de materias primas líticas a los sitios considerados incide en el cambio de las estrategias de producción y uso de los artefactos líticos. 
H5) Es posible diferenciar, a partir de características técnico-morfológicas y morfológico-funcionales, bifaces como núcleos, como artefactos en sí mismos y como preformas de puntas de proyectil y otros diseños.

H6) En la confección de los distintos diseños de artefactos bifaciales se seleccionan variables cuantitativas y cualitativas que son reconocibles como tendencias en las características tecnológicas y tipológicas de las formas-base, preformas y del producto final.

H7) Entre el 5500 y el 1500 AP se produjeron cambios en las recetas para la acción y en la tecnociencia (Schiffer y Skibo 1987) involucrada en las mismas.

H8) La emergencia de complejidad socio-cultural propició mecanismos de estandarización y especialización en los conjuntos de artefactos líticos.

H9) Es posible reconocer aprendices en base a características morfológicas de piezas bifaciales.

Se destaca que en el capítulo correspondiente a la discusión (Capítulo 13) se retomarán las hipótesis para su evaluación en función de los resultados obtenidos. 


\section{CAPÍTULO 2}

\section{CARACTERÍSTICAS AMBIENTALES DE LA MICRORREGIÓN DE ANTOFAGASTA DE LA SIERRA}

\subsection{ANTOFAGASTA DE LA SIERRA COMO PARTE DE LA PUNA ARGENTINA}

La Puna argentina, continuación natural del altiplano peruano-boliviano, forma parte de la Puna de Atacama (Figura 2.1). Puede ser caracterizada desde diferentes perspectivas clasificatorias, considerando aspectos ambientales, fitogeográficos u otros.

Desde el punto de vista geográfico, es un bloque sobreelevado rodeado por altos sistemas montañosos. En Argentina, su límite occidental es la Cordillera de Domeyko, en territorio chileno, con alturas sobre los 6000 metros sobre el nivel del mar, mientras que el oriental está constituido por los cordones serranos de Santa Victoria, Zenta, Tilcara, Aguilar y los macizos de Chañi, Acay y Cachi, así alineados de norte a sur, que alcanzan en sus cumbres alturas semejantes. Entre ambos cordones marginales discurren una serie de montañas interiores, de disposición submeridiana y vertientes suaves, bolsones elevados y valles, con alturas medias comprendidas entre los 3500 y 4000 metros sobre el nivel del mar (Bruniard 1999). En tales cuencas centrípetas y valles pueden aparecer extensos salares en sus partes centrales (Turner y Mendez 1979). 


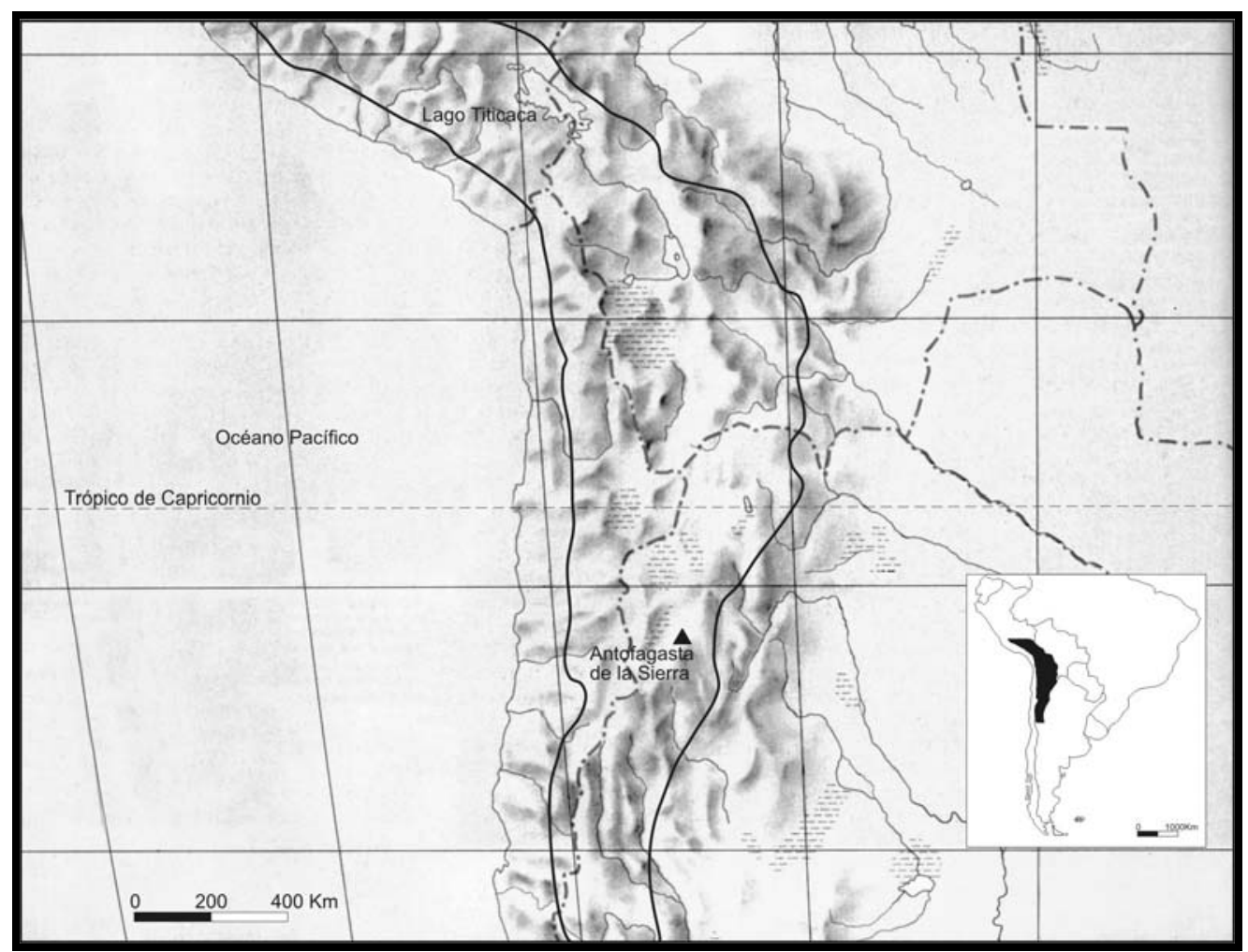

Figura 2.1. Ubicación de Antofagasta de la Sierra en el contexto del altiplano andino

Su extensión puede ubicarse entre los paralelos $22^{\circ}$ y $27^{\circ}$ de Latitud Sur y se corresponde con la provincia geológica Puna (sensu Turner 1972). Esta provincia comprende, a su vez, dos subprovincias geológicas con características estructurales y morfológicas distintivas: la Puna Septentrional y la Puna Austral o Meridional (por detalles ver Alonso et al. 1984). Antofagasta de la Sierra forma parte de la segunda.

Desde un punto de vista ambiental, la Puna es un bioma de desierto de altura, que se caracteriza por poseer un clima árido y frío, una intensa radiación solar debida a la altitud, gran amplitud térmica diurna/nocturna, marcada estacionalidad con precipitaciones estivales pobres y baja presión atmosférica. El promedio de precipitaciones va de los 18 a los 400 mm anuales en la porción más húmeda de la región, y la cantidad disminuye de noreste a suroeste. La vegetación es de tipo dispersa y compuesta principalmente por comunidades xerofíticas (Yacobaccio 1998).

Un punto importante es lo absolutamente impredecible del clima puneño en el corto y mediano plazo. Las lluvias de régimen estival, por ejemplo, pueden alternar períodos de algunos años de sequía extrema con otros donde son más abundantes, siendo casi impredecibles las condiciones de año a año (García et al. 2000). En general, estas lluvias son erráticas, cortas y de gran intensidad, situación usual en áreas áridas (Barker y Gilbertson 2000). 
La localización espacial de los recursos es predecible, aunque no su abundancia, dado el ambiente extremadamente variable en el corto plazo. La aparición de heladas, nevadas y vientos fuertes es impredecible. El régimen de lluvias es altamente inestable, como ya se mencionó, provocando sequías que afectan drásticamente la disponibilidad de los recursos (Yacobaccio et al. 1994).

Siguiendo a Troll (1958; en Nuñez y Santoro 1988), se pueden reconocer dentro de la Puna sectores con características ambientales diferentes. En el caso de la Puna argentina, dichos sectores son la Puna Seca y la Salada o Desértica. La primera se localiza en la porción noroeste y es la zona más húmeda, mientras que la segunda es más seca, conteniendo extensas áreas con salares y salinas, resultado de humedad reducida y altas tasas de evaporación (Yacobaccio 1998, Olivera 1998). Dentro del contexto general de la Puna, la microrregión de Antofagasta de la Sierra se incluye en la Puna Salada (Figura 2.2).

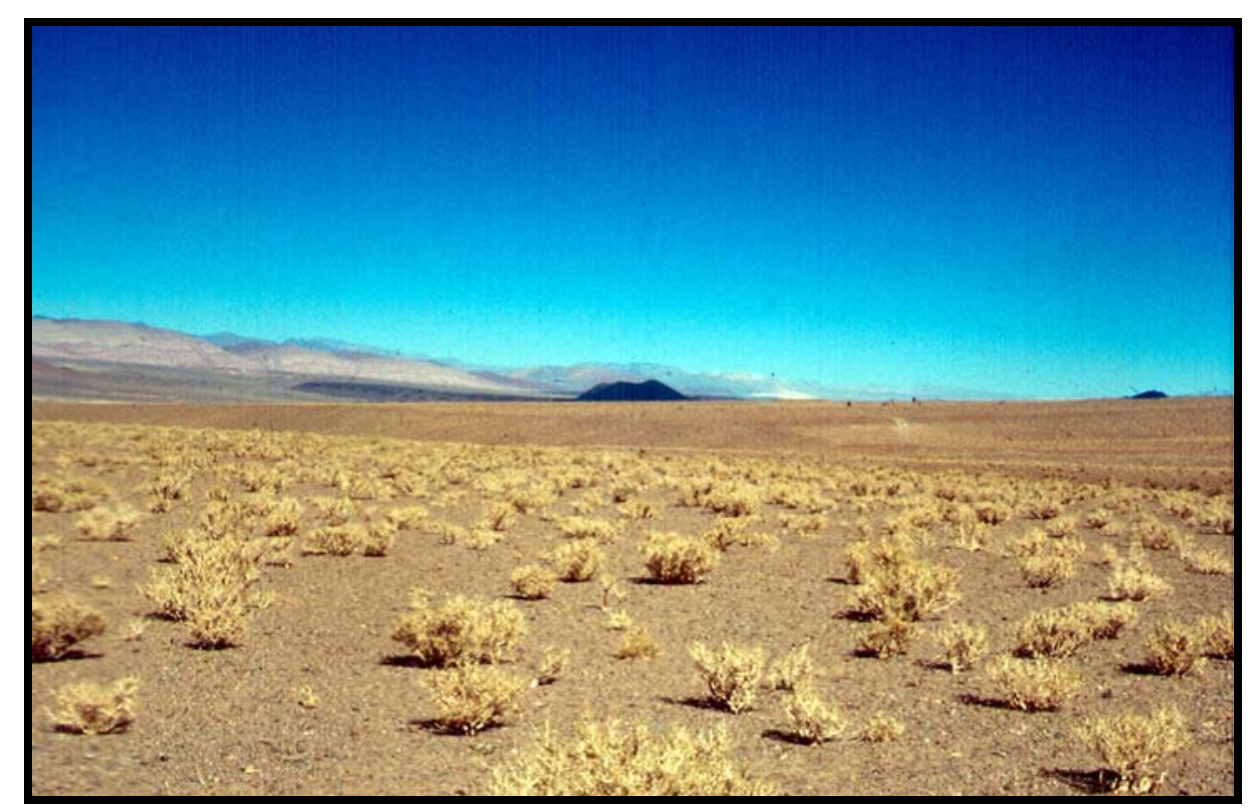

Figura 2.2. Antofagasta de la Sierra como parte de la Puna Salada

Asimismo, dentro de los sectores de Puna Salada y Seca, es posible distinguir entre “Quebradas y bolsones fértiles” y "Salares y estepas” (Olivera y de Aguirre 1995). Los primeros corresponden generalmente a cuencas endorreicas donde la provisión de recursos hidrológicos permite el desarrollo de cubiertas vegetales más o menos importantes y la existencia de fauna diversa. Es a lo largo de las fuentes de agua donde se desarrolla la vegetación de “vegas”. Los segundos corresponden a los sectores intermedios donde se localizan, por un lado, grandes extensiones de salinas y, por el otro lado, la altiplanicie esteparia desértica con escasa cubierta vegetal. La disponibilidad de recursos hídricos aquí es muy escasa. 
Entonces, en la Puna, definida por su extrema sequedad, sus áreas con vegetación sumamente restringidas, amplias extensiones de salares y recursos fijos -como agua y madera- extremadamente localizados (Yacobaccio 1997), las zonas de "Quebradas y bolsones fértiles” se convierten en verdaderos oasis (Yacobaccio 1998). En los puntos siguientes se evalúa el papel de Antofagasta de la Sierra en este sentido.

\subsection{LA MICRORREGIÓN DE ANTOFAGASTA DE LA SIERRA}

La microrregión (sensu Aschero 1988a) de Antofagasta de la Sierra se sitúa en el ángulo Noroeste de la provincia de Catamarca. Esta incluye una diversidad de geoformas y un mosaico de recursos y microambientes que permiten acotar un área de investigación representativa de lo que ofrece ambientalmente la Puna Salada. Sus límites geográficos corresponden a una figura rectangular de unos 90 km en dirección Norte-Sur y 50 km en dirección Este-Oeste, conformando un área de 4500 $\mathrm{km}^{2}$ aproximadamente (Aschero et al. 2002a). Específicamente, se encuentra limitada:

- al Norte por las tierras altas y serranías que separan la cuenca del Punilla de la del Salar del Hombre Muerto, hacia los $25^{\circ} 45^{\prime}$ de Latitud Sur.

- al Este, por las estribaciones occidentales del Volcán Galán (5912m), incluyendo la Laguna Diamante y otras cuencas lagunares, más pequeñas, ubicadas al Sur de ésta, sobre los $4000 \mathrm{msnm}$, siguiéndose en la dirección del meridiano de $67^{\circ}$ Longitud Oeste hacia el Oeste-Suroeste con la Sierra de Laguna Blanca. Este sector es el de mayor disponibilidad de agua y forrajes naturales (vegas) en los cursos altos e intermedios de varias quebradas importantes como la de Toconquis, Curuto, Cacao, Miriguaca, Las Pitas, Ilanco y Pirica.

- al Sur, por las estribaciones de la serranía de Pasto Ventura, incluyendo los sectores medanosos ubicados en las proximidades de la población de El Peñón, y la periferia Sur del Volcán Carachi Pampa, en el sector más bajo de la cuenca homónima, probablemente una de las más secas y desprovistas de vegetación de la Puna meridional (3200 msnm), hacia los 26³ 36 Latitud Sur.

- hacia el Oeste, las cumbres de la Sierra de Calalaste, que separan la cuenca de Antofagasta de la Sierra (o del Río Punilla) y de Carachi Pampa de la del Salar de Antofalla.

El paisaje de la microrregión se caracteriza por la presencia de planicies suavemente onduladas, interrumpidas por afloramientos de rocas ígneas y metamórficas así como cordones 
volcánicos y secuencias de rocas sedimentarias asociadas (García Salemi 1986, González 1992) (Figuras 2.3 y 2.4). En síntesis, un intenso vulcanismo durante el Terciario (principalmente Mioceno) y Cuaternario (Figura 2.5), junto a fenómenos neotectónicos importantes, otorgaron al paisaje sus rasgos particulares (García et al. 2000). Para mayor detalle ver Alonso et al. (1984), González (1992) o Escola (2000).

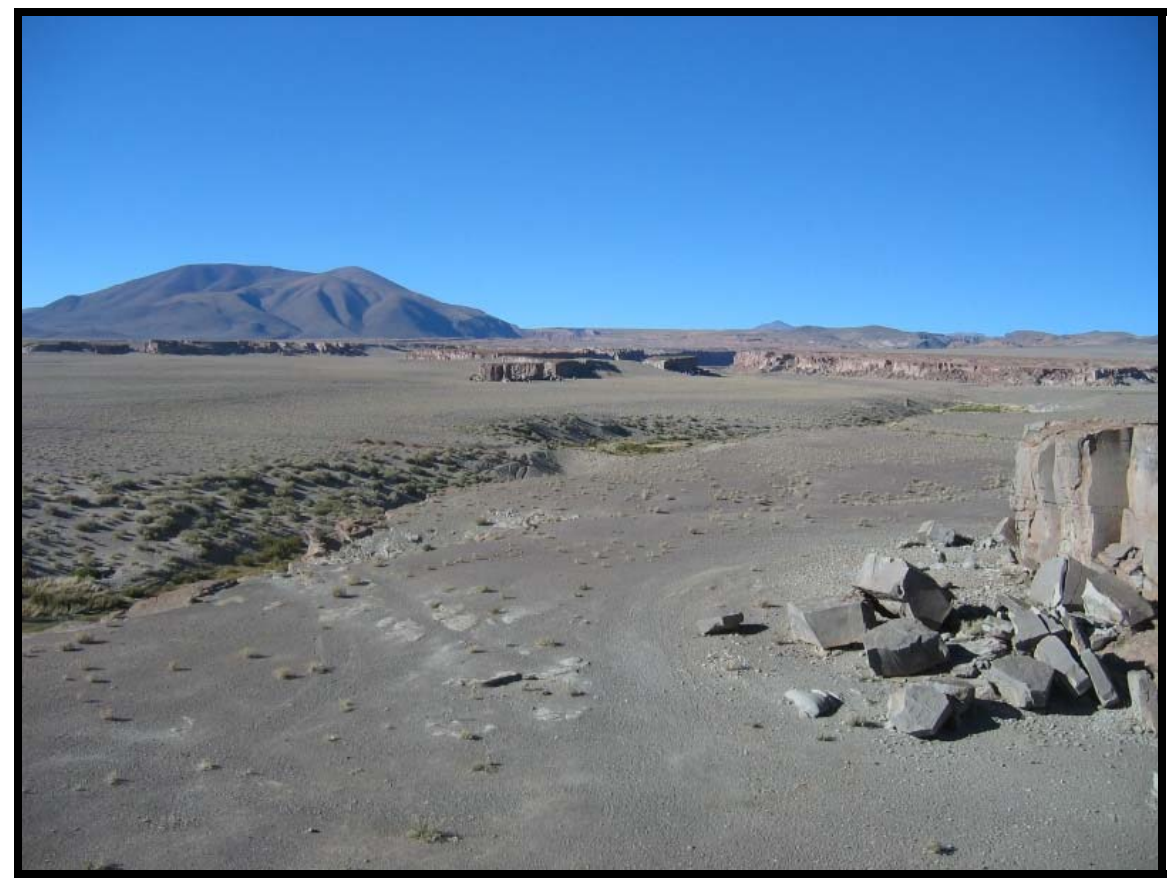

Figura 2.3. El paisaje puneño. Vista de Punta de la Peña, Peñas Chicas, Peñas de las Trampas y Cerro Miriguaca desde Peñas Coloradas (cortesía C. Baied)

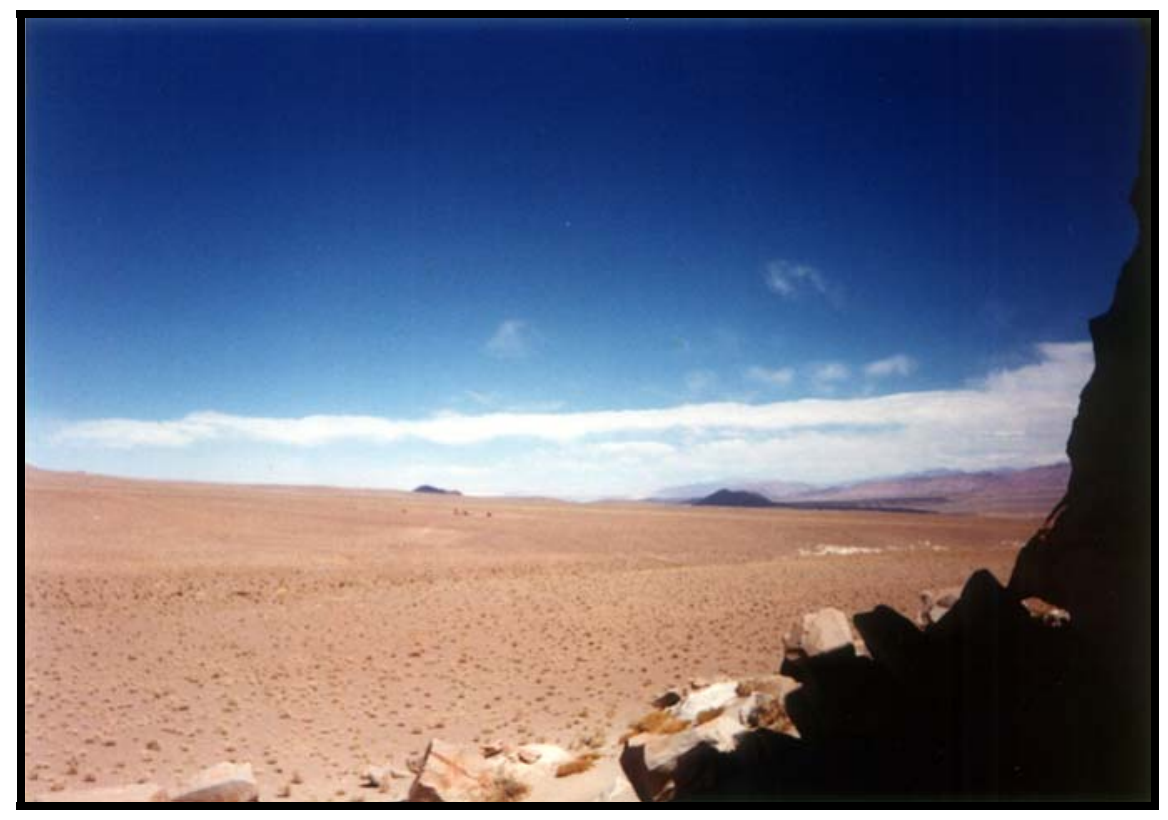

Figura 2.4. Los volcanes Antofagasta y La Alumbrera, vistos desde el farallón de Peñas Chicas 


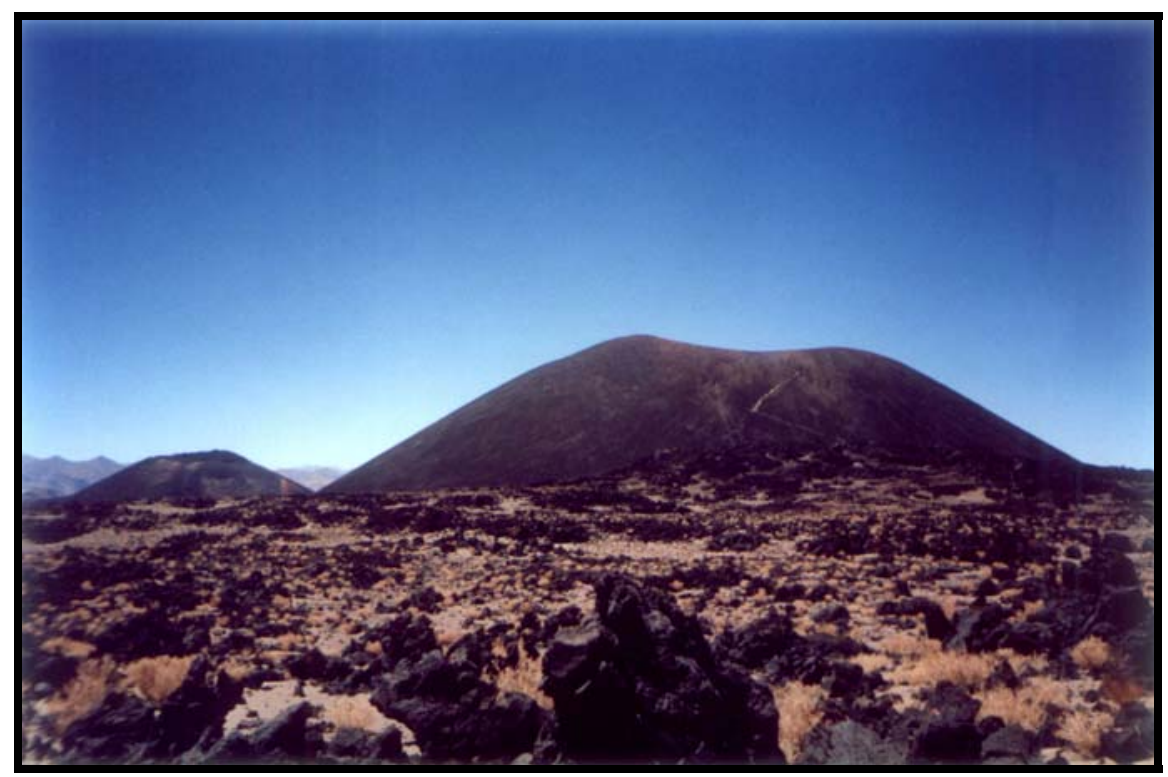

2.5. Los volcanes Antofagasta y La Alumbrera

Existen varios cursos de agua permanente cuya variación de caudal a lo largo del año no es significativa (Tchilinguirian y Olivera 2000). El curso colector es el río Punilla, el cual nace en la altura de la Sierra de Calalaste y desemboca en las Lagunas de Antofagasta. Entre los afluentes importantes de este colector destacan los ríos Miriguaca y Las Pitas por margen derecha y el Río Los Colorados por margen izquierda (Figura 2.6, Figura 2.7).

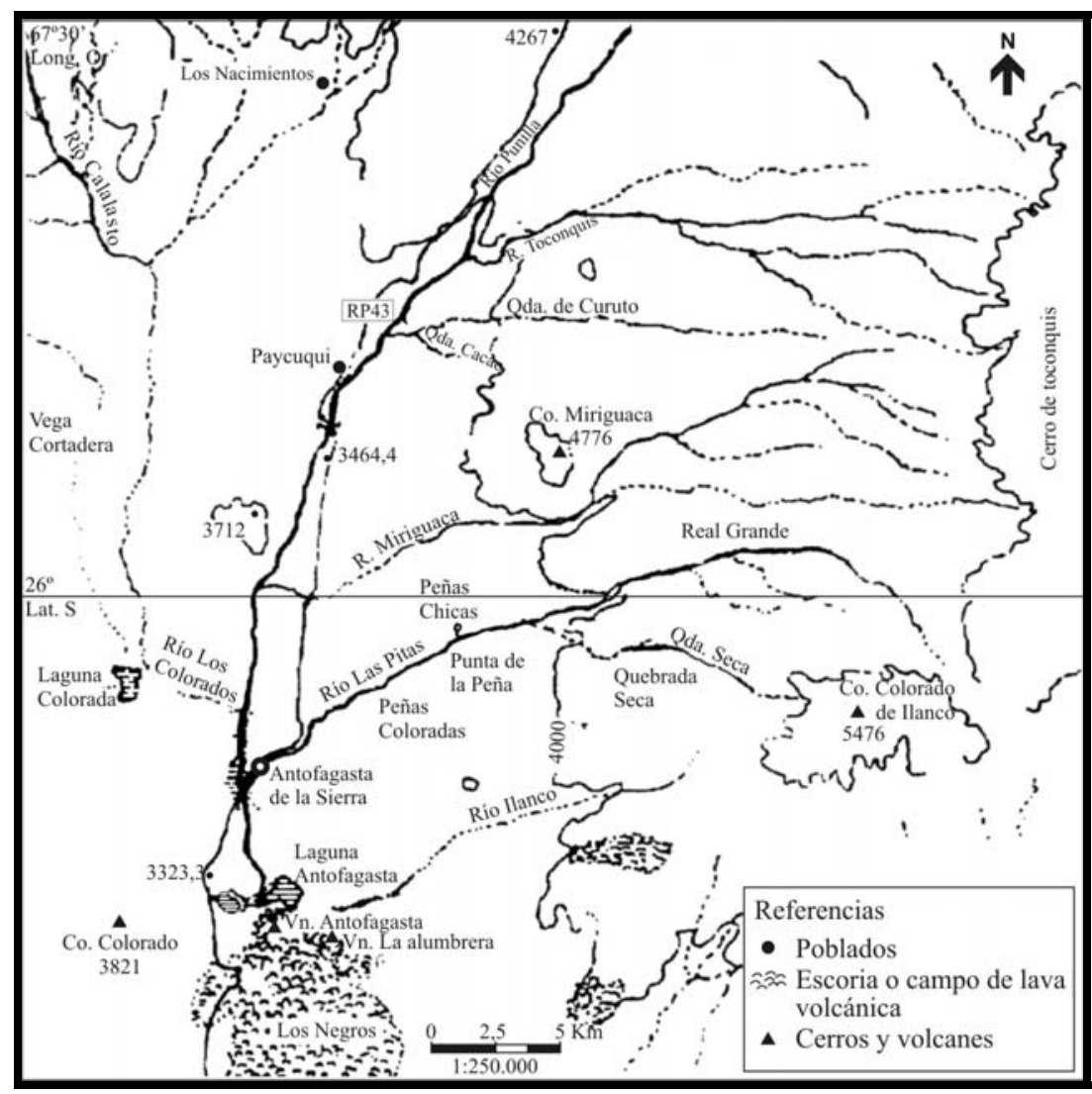

Figura 2.6. Mapa de Antofagasta de la Sierra 


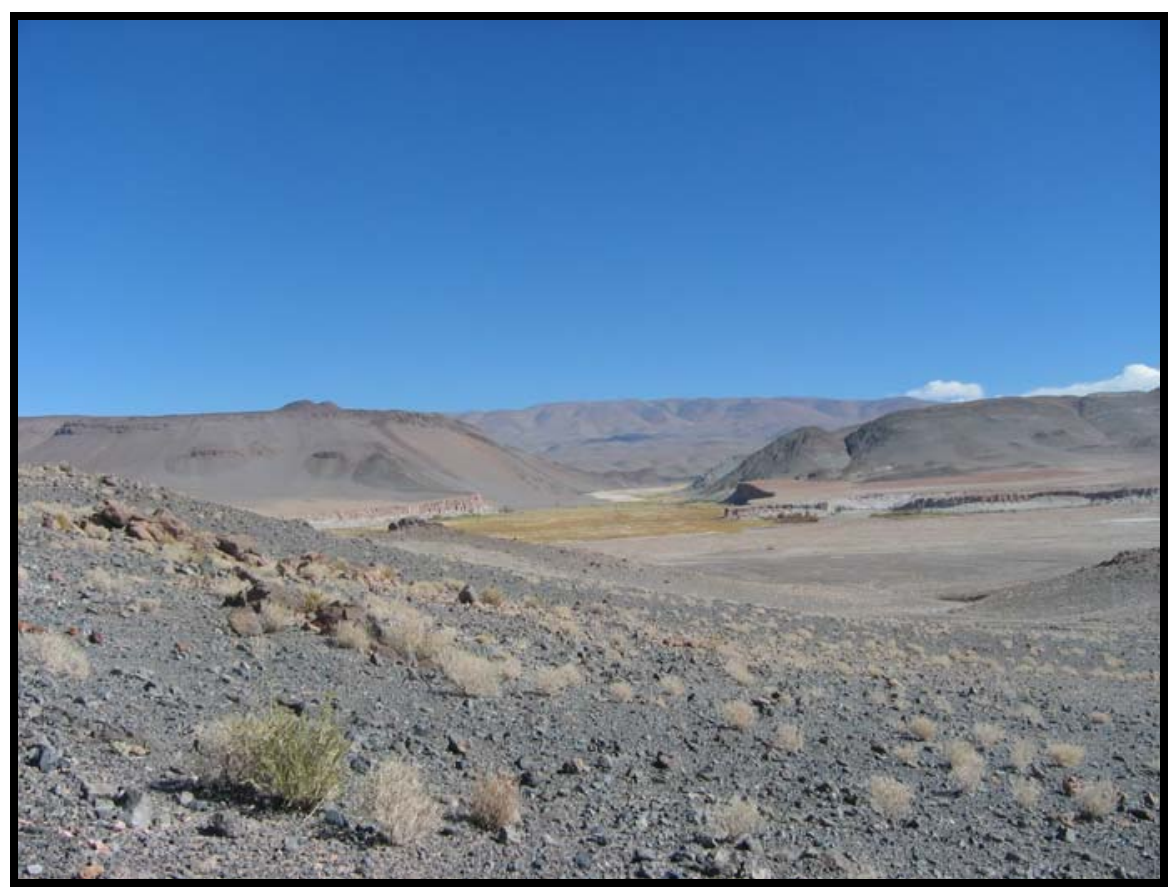

Figura 2.7. Vista de Confluencia y del río Los Colorados (al fondo) desde el Cerro Vía Crucis (cortesía C. Baied)

La mayoría del aporte de las aguas proviene de manantiales que son alimentados por un flujo diferido de agua subterránea proveniente de complejos subterráneos y rocosos. En el caso de los ríos Las Pitas y Miriguaca las surgencias se localizan al pie de la caldera del Cerro Galán y seguramente el acuífero es alimentado por los deshielos estacionales y la infiltración de las aguas de la Laguna Diamante ubicada a mayor cota y dentro de la caldera. En el caso del río Punilla, la alimentación subterránea también es esencial. Los deshielos, las vegas congeladas ubicadas en la Sierra de Calalaste (5200 m) y en las laderas occidentales del Cerro Galán son las principales fuentes (Tchilinguirian y Olivera 2000).

La microrregión cuenta y ha contado en el pasado con una serie de condiciones que la han hecho favorable a la ocupación humana. Tales elementos están dados, como se ha visto, por sectores con cauces fluviales acotados pero permanentes, asociados a una buena disponibilidad de pasturas y del recurso fauna. A ello se suma una excelente oferta local de materias primas líticas y otros recursos minerales esenciales como sales comestibles y alumbres. Debe destacarse, además, la abundancia de sectores de habitación con reparos naturales conformados por farallones de ignimbritas y sectores de desprendimientos asociados (Aschero et al. 2002a).

El caso de Antofagasta de la Sierra sería producto del contraste de un ambiente de parche, con múltiples zonas de concentración de nutrientes (Yacobaccio 1994a, Muscio 1998/99) relacionadas a la cuenca del Río Punilla, circundadas por un desierto extremo. 


\subsection{HUMEDALES EN EL DESIERTO}

Antofagasta de la Sierra se caracteriza por poseer un conjunto poco usual de humedales para lo que es el ambiente de Puna Meridional en general (Olivera y de Aguirre 1995, Tchilinguirian y Barandica 1995). Específicamente, los humedales refieren a todo terreno que: a) esté cubierto o saturado por agua al menos durante parte del año, b) contenga vegetación hidrofítica y/o c) posea suelos hídricos (Nicholas 1991). Estos ambientes son particularmente atractivos para el uso humano ya que poseen alta diversidad, productividad y confiabilidad de recursos (Nicholas 1998). Es evidente que la productividad en este caso no es comparable con la de humedales de regiones templadas o cálidas de menor altitud, pero es altamente significativa en este ambiente de desierto. Tal es así que Tchilinguirian y Olivera (2005) sostienen que los humedales puneños albergan la casi totalidad de la biomasa, los nutrientes y el agua.

En la Puna, los humedales se encuentran en lagos y lagunas, salares y vegas (Valqui et al. 2000, Sarmiento et al. 1998). En el caso particular de Antofagasta de la Sierra, los mismos se localizan en las lagunas de Antofagasta y en la Laguna Colorada, en el río Punilla y tributarios (Miriguaca, Las Pitas, Toconquis, entre otros) (Figura 2.8) y en ojos de agua diversos en las quebradas de altura (Figura 2.9).

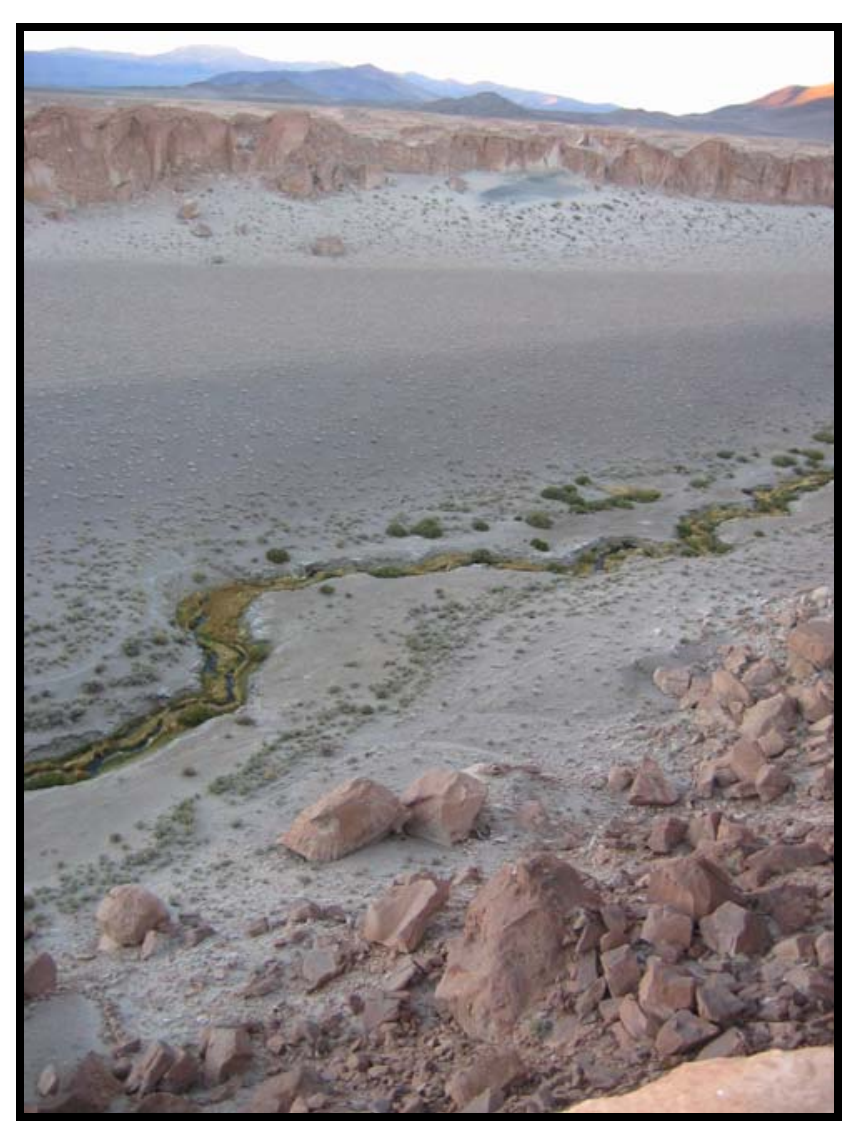

Figura 2.8. Vista del río Las Pitas en Punta de la Peña (cortesía C. Baied) 


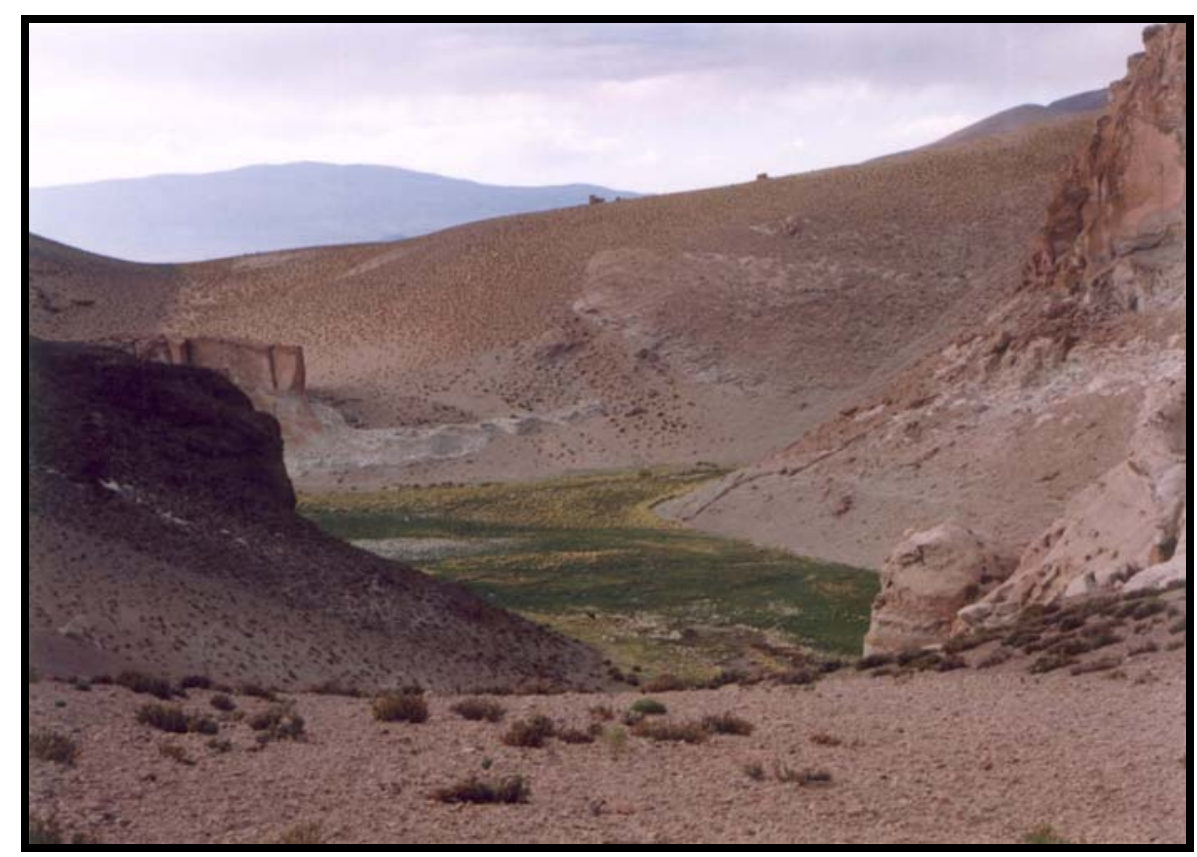

Figura 2.9. Vega de Quebrada Seca (cortesía S. López Campeny)

Es importante destacar que la microrregión sufrió una serie de acontecimientos geológicos que favorecieron la formación de un ambiente más apto para la generación de humedales, de acuerdo a información obtenida por Tchilinguirian y Barandica (1995). Así, según estos autores, el río Punilla sufrió un endicamiento en el Pleistoceno Superior, debido a la efusión de las coladas basálticas de Los Negros (Figura 2.10). Posteriormente, aguas arriba del endicamiento se formaron las Lagunas de Antofagasta (Figura 2.11) y comenzó a ensancharse la planicie de inundación del río Punilla debido a procesos de agradación sedimentaria. Como consecuencia de esto, la vega del río comenzó a ampliarse progresivamente aguas arriba y hacia los laterales del valle.

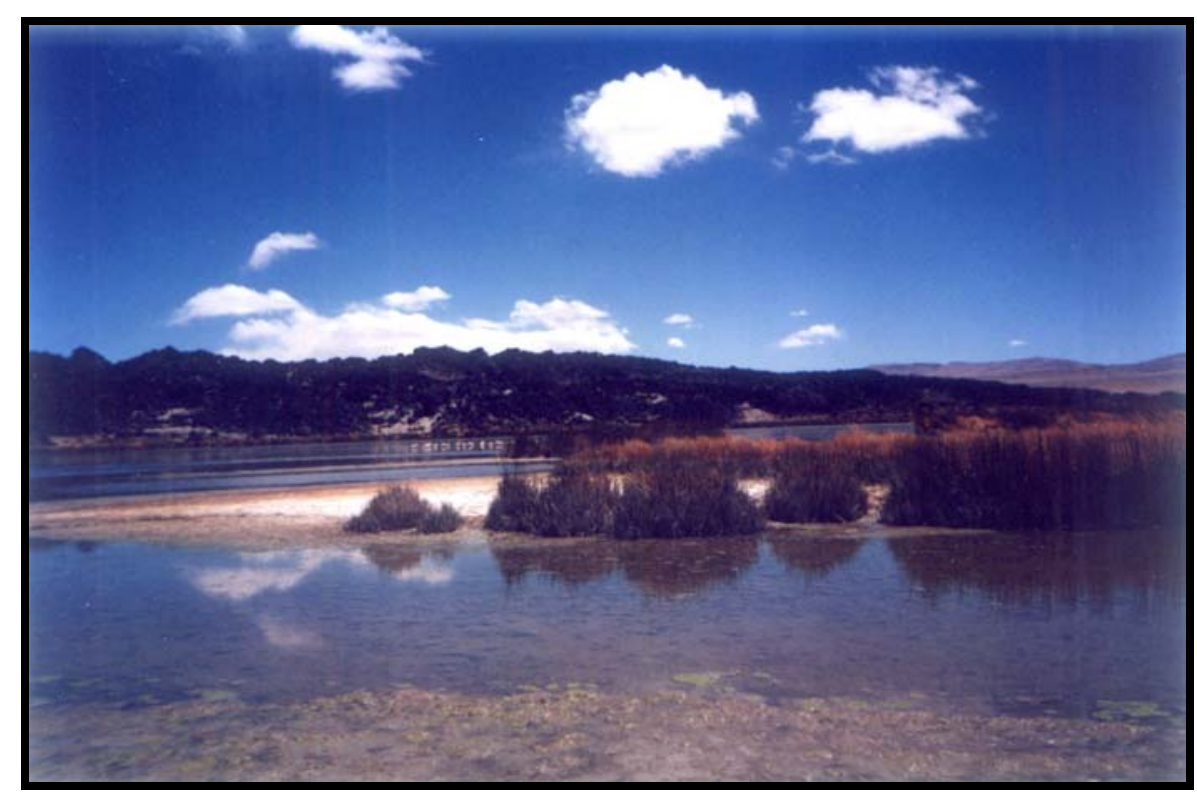

Figura 2.10. Las coladas de Los Negros 


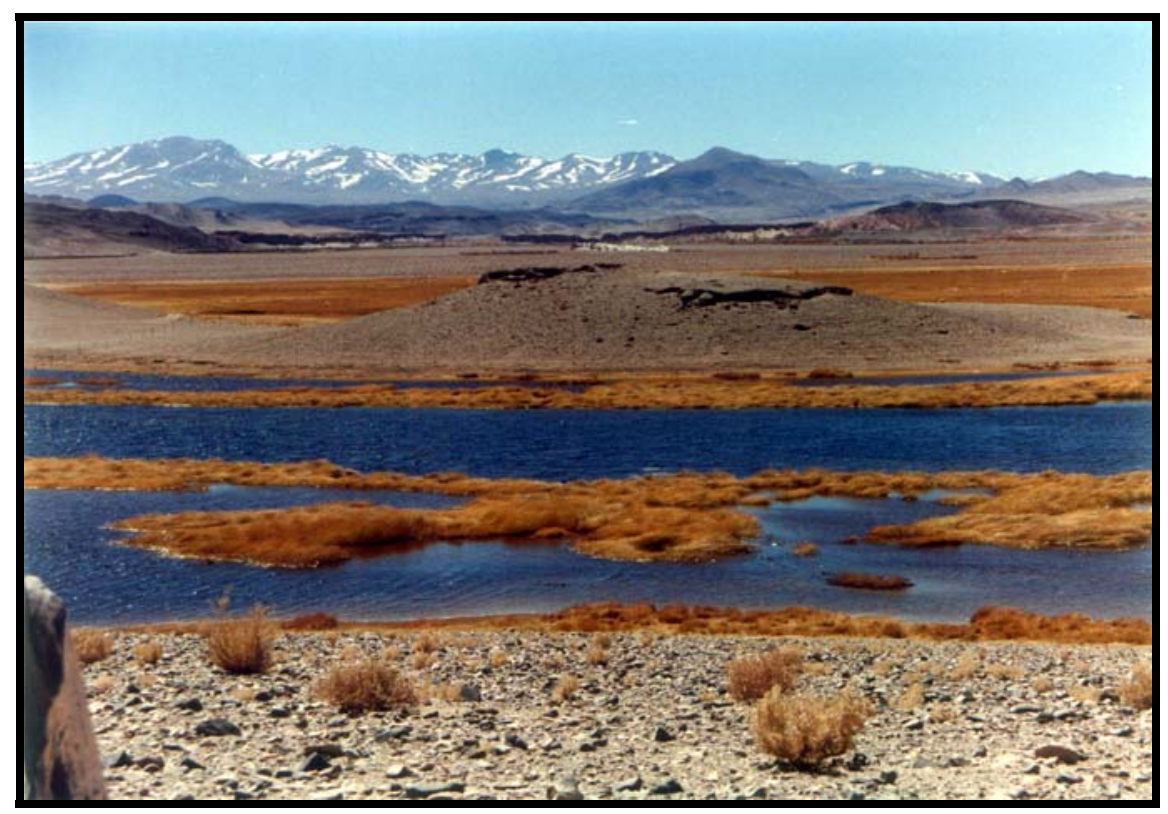

Figura 2.11. Vista de las Lagunas de Antofagasta

De esta manera, se originó una vega amplia con agua permanente, suelos orgánicos desarrollados sobre materiales finos que retienen la humedad y napas freáticas someras la mayor parte del año. Esta vega se extiende actualmente entre las localidades de Antofagasta de la Sierra y Paicuqui, distantes a $20 \mathrm{~km}$ entre sí aproximadamente, conformando unas 100.000 hectáreas (Figura 2.12).

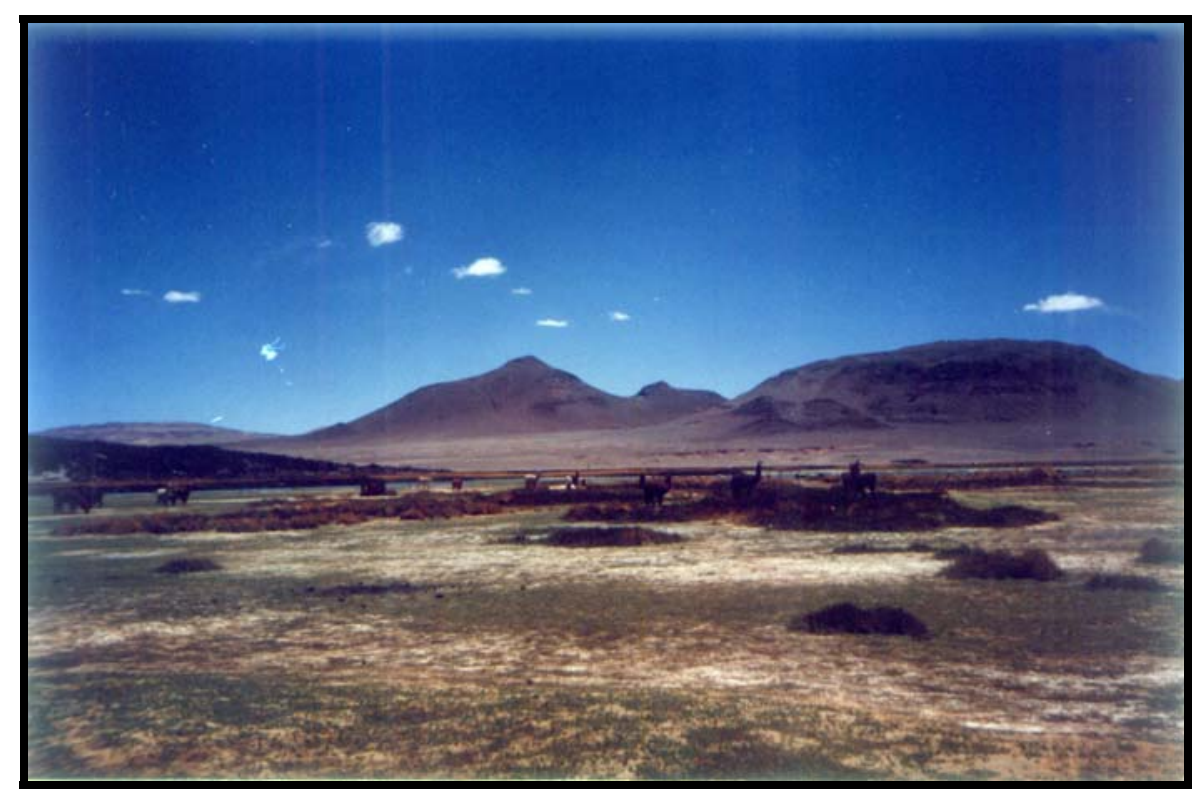

Figura 2.12. La vega inmediata a las Lagunas de Antofagasta

Fenómenos similares pero de menor magnitud y provocados por deslizamientos se presentan en los afluentes del río Punilla, como en la Quebrada de Miriguaca, que explica la presencia de una extensa vega. El mismo se originó por un descalce erosivo producto de la gran profundización del río 
en las litologías volcánicas. El endicamiento provocado por el movimiento originó la agradación aguas arriba del valle y el ascenso de la napa freática, hecho que generó una vega de 6 km por 100 a $200 \mathrm{~m}$ de ancho.

Estas condiciones, prácticamente únicas en la Puna meridional argentina, debieron tener particular incidencia sobre el proceso cultural prehispánico local (Olivera y de Aguirre 1995).

\subsection{LA EVOLUCIÓN PALEOAMBIENTAL LOCAL (5500-2000 AP)}

Recientemente, Olivera et al. (2002) han obtenido una secuencia paleoambiental local, generada en base a análisis sedimentológicos, geomorfológicos y pedológicos, así como a análisis isotópicos de ${ }^{18} \mathrm{O}$ y ${ }^{13} \mathrm{C}$, en lagunas, cursos de agua y vegas.

De acuerdo a los resultados alcanzados por estos autores (Olivera et al. 2002, Olivera et al. 2004, Tchilinguirian y Olivera 2005), el lapso abordado se vio sometido a una serie de cambios ambientales de magnitud. A partir de los 8500 años AP se produjo un proceso de aridización gradual, notablemente marcado desde los 6500/6000 AP, tornándose árido y cálido. Hacia los 3500-3000 años AP se registra un período de elevada humedad y de excedente de agua, que finaliza ca.1600 AP. Posteriormente a esta fecha se inicia un nuevo período de aridización que comienza a configurar el ambiente actual.

Puntualmente para el lapso 5500-3000 AP, la información geomorfológica y estratigráfica señala la ocurrencia de importantes procesos erosivos en los valles encajonados de ríos tributarios del Río Punilla, como las Quebradas de Miriguaca y Curuto y actual salina de Laguna Colorada, bajo la forma de sedimentos aluviales de alta energía relacionados con eventos de inundación y con materiales coluviales generados por acción pluvial (Olivera et al. 2002). Se destaca que esto podría indicar un paralelismo con las tormentas de corto tiempo y baja frecuencia con precipitaciones de gran intensidad registradas por L. Núñez y equipo en la cuenca del Salar de Atacama durante el Holoceno Medio (Núñez et al. 1999).

Mientras que la acción erosiva de los procesos aluviales sobre las quebradas habría afectado principalmente el cauce, la llanura de inundación y la porción inferior de sus bordes, la acción coluvial habría incidido sobre las paredes laterales de los cauces, generando un ambiente extremadamente cambiante en el corto y mediano plazo, impidiendo, posiblemente, su ocupación efectiva. Asimismo, 
las descargas aluvionales podrían haber disturbado posibles ocupaciones anteriores al Holoceno Medio.

La acción eólica, en cambio, habría incidido mayormente sobre los niveles de terrazas y de “pampas”, así como sobre las lagunas Antofagasta y Colorada con grandes extensiones convertidas en salinas, por medio de procesos erosivos -deflación- y de formación de médanos.

Aunque las evidencias denotan un clima más seco y más cálido en el Holoceno Medio, en ciertos sectores muy localizados se desarrollaron ambientes de mayor humedad, como el endicamiento aluvial del Río Las Pitas, que formó lagunas someras en el Río Punilla hacia el 4500 AP, en una extensión de 1500 m aproximadamente. Esto alerta acerca de la presencia de espacios que presentaban características favorables para la ocupación humana en el pasado y que actualmente carecen de ellas.

Como se vio previamente, hacia los 3500-3000 años AP comienza un período de alta humedad y excedente de agua, con su pico al final del mismo, en el 1600 AP aproximadamente. El registro muestra para ese momento (Olivera et al. 2002) ambientes mucho menos energéticos, en donde aparecen facies sedimentarias indicadoras de ambientes húmedos. Las vegas se expanden, así como los espejos de agua (aproximadamente un 30 \%). Por ejemplo, la Laguna Colorada tiene su máximo crecimiento hacia fines de este lapso, con un área cubierta dos veces más grande que la de la salina actual y con diez veces más agua que la que se encuentra actualmente en el medio de la salina. La Laguna de Antofagasta evidencia también su más grande expansión (+1,5 m). Bajo las nuevas condiciones húmedas, la inestabilidad morfológica de los ríos y lagunas de la microrregión se debe haber visto progresivamente reducida.

A partir del 1600 AP el clima nuevamente árido reactiva los procesos erosivos aluviales, coluviales y eólicos (ibid). La disminución del nivel de base en las lagunas lleva al desarrollo de terrazas por erosión en las quebradas tributarias al Punilla, como Miriguaca y las cuencas bajas de Ilanco y Las Pitas.

El cuerpo de agua de la laguna de Antofagasta se redujo en un 40\% con un posible incremento de la salinidad y la Laguna Colorada se convirtió en una salina (Figura 2.13). La reducción de las vegas fue muy importante tanto en el fondo de la cuenca (alrededor del 50\%) como en las quebradas tributarias al Punilla, aunque en las cuencas medias de dos de ellas, Curuto y Miriguaca, se habrían desarrollado mejor (reducción de un 20 a un 40\%). En otras, como en Ilanco, el agua desapareció y con ella la formación de vegas. En suma, las vegas se redujeron en los afluentes del río Punilla (Curuto, Las Pitas, Miriguaca e Ilanco); sin embargo, tuvieron un mejor desarrollo en las cuencas 
medias. Las cabeceras y afluentes de estos tributarios se secaron (por ejemplo, Ilanco) o tuvieron un escaso desarrollo de vegas (ejemplo, Curuto, Miriguaca y Las Pitas).

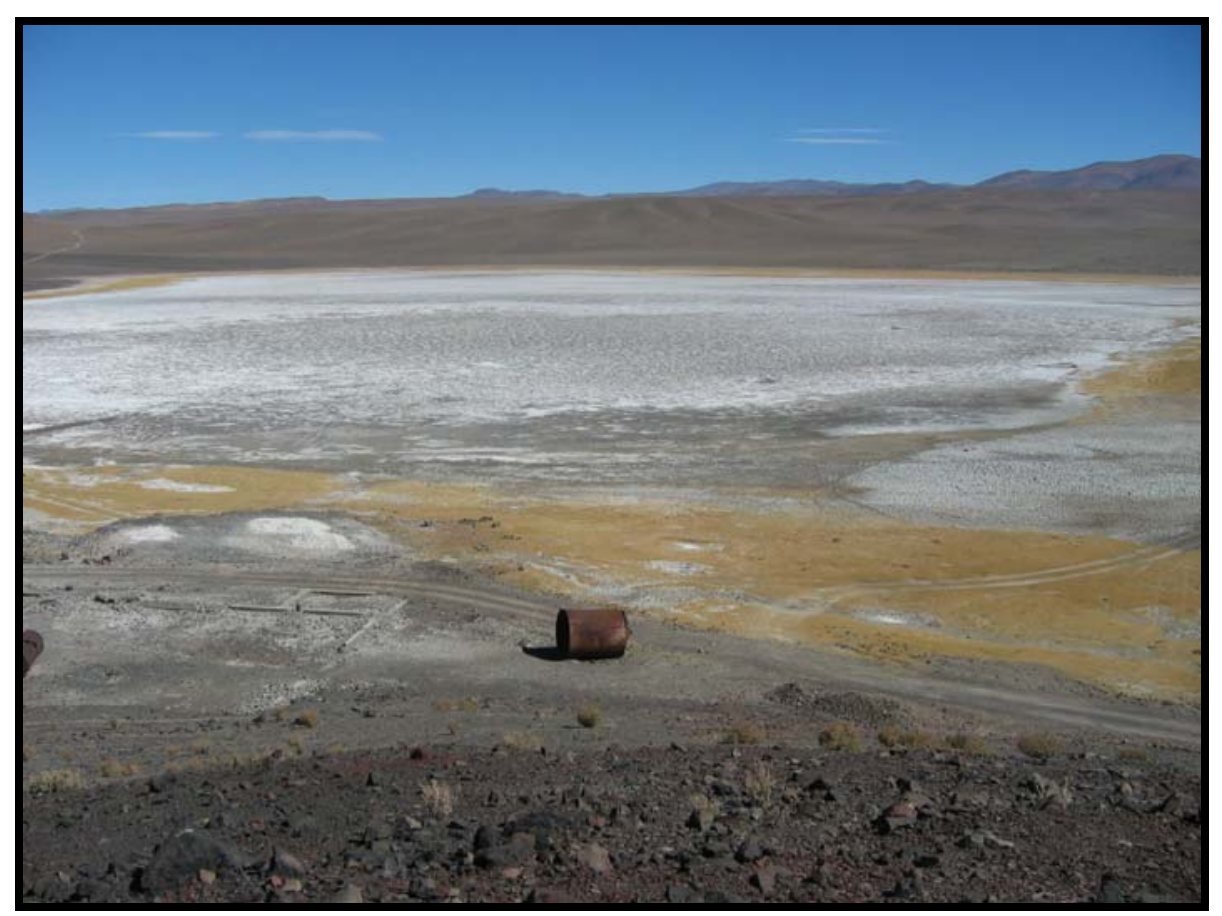

Figura 2.13. Vista de la salina de Laguna Colorada (cortesía C. Baied)

Olivera et al. (2002) encuentran una importante variabilidad ambiental sincrónica y diacrónica en distintos sectores de la microrregión, dentro del contexto paleoambiental señalado, con evidentes consecuencias para la ocupación y explotación de espacios inmediatos o próximos. Por ejemplo, hacia los 4500 años AP el abanico del río Las Pitas generó una obstrucción con materiales aluviales sobre el río Punilla, formándose un ambiente húmedo dentro de la fase árida local extendiéndose $1600 \mathrm{~m}$ aguas arriba desde la boca del río Las Pitas, que habría perdurado unos 500 años (ibid.).

Es factible sostener que los cambios ambientales, tanto climáticos como geomorfológicos, incidieron directamente sobre los humedales, materializándose en expansiones y retracciones y en apariciones-desapariciones. Sin embargo, de esta historia ambiental dinámica de Antofagasta de la Sierra, se desprende que dicha área siempre contó con importantes recursos hídricos y humedales aún en momentos de aridez extrema, con la consecuente flora y fauna asociadas. De acuerdo a Tchilinguirian y Barandica (1995), la microrregión habría sido mucho más vulnerable a los cambios climáticos si los acontecimientos geológicos favorables mencionados no se hubiesen producido.

Al considerar el contexto paleoambiental macrorregional, las variaciones registradas en Antofagasta de la Sierra tienen un fuerte correlato con los datos obtenidos en este sentido en otras áreas de la Puna, tanto en la vertiente argentina como chilena de los Andes. En la región de Chaschuil, en la misma Puna Meridional Argentina, a aproximadamente $160 \mathrm{~km}$ en línea recta al suroeste de 
Antofagasta de la Sierra, se ha documentado un período de mayor humedad relativa entre los ca.3000 y 1700 años AP, en base a análisis sedimentológicos e isotópicos en lagunas y salares (Valero-Garcés et al. 2000, Ratto 2003). Por otro lado, en la Puna Seca argentina y su borde oriental, los datos obtenidos mediante estudios polínicos señalan que el lapso árido del Holoceno Medio finaliza hacia el 4000-3700 AP (Markgraf 1985, Lupo 1998). De acuerdo a Schäbitz et al. (2000), el período húmedo se extiende de los 3700 a los 1500 años AP. Finalmente, en el Desierto del Norte de Chile, la información disponible en sedimentos lacustres, fluviales y clásticos sugiere un incremento de la humedad hacia los 3000 años AP (Núñez et al. 1999, Núñez et al. 2001, Núñez y Grosjean 2003).

Es importante denotar, sin embargo, que dentro de la homogeneidad mencionada, hay una cierta cuota de variabilidad, ya que el inicio del período húmedo va de los 4000 a los 3000 años AP según las distintas regiones. Así, podrían configurarse dos tendencias generales: una, que comprendería la Puna Seca argentina y su borde oriental, con fechados que oscilan en los 4000 años AP, y otra, que involucraría la Puna Salada argentina y el Desierto del Norte de Chile, con dataciones hacia los 3000 AP. Como dichas variaciones podrían tener connotaciones de importancia sobre los procesos culturales microrregionales, el hecho de contar con una secuencia paleoclimática local es significativo.

Finalmente, un punto importante a nivel macrorregional para la ocupación humana durante el Holoceno Medio es la concentración de recursos en áreas favorecidas, denominados "ecorrefugios” (Núñez et al. 2001). De esta forma, se han establecido ecorrefugios en la Quebrada de Puripica desierto del norte de Chile- (Núñez et al. 1999) y en la Quebrada de Lapao -Susques, Jujuy(Yacobaccio y Morales 2005). También se ha considerado a Antofagasta de la Sierra como un ecorrefugio (Núñez et al. 1999). Al respecto, es pertinente señalar ciertas diferencias que se cree son importantes para no considerar a la microrregión aquí abordada como un ecorrefugio. En primer lugar, la extensión espacial de esta última es muchísimo mayor que los sectores de las Quebradas de Puripica y Lapao involucrados, implicando un cambio sustancial de escala. En segundo lugar, y más importante aún, como se denotó previamente, Antofagasta de la Sierra siempre contó con recursos hídricos y bióticos mientras que los ecorrefugios propiamente dichos de Puripica y Lapao se caracterizan por una naturaleza episódica. 


\section{CAPÍTULO 3}

\section{APROXIMACIÓN TEÓRICA}

\subsection{CAZADORES-RECOLECTORES, AGRICULTORES Y PASTORES}

\subsubsection{CARACTERIZACIÓN GENERAL}

Al considerar las categorías de “cazador-recolector” y “grupo agro-pastoril”, la aproximación más frecuente es estimar que es lo que define y diferencia a estos modos de vida.

Por lo general, se señala como variable clave al tipo de subsistencia en ciernes. Por ejemplo, Ellen (1994) define a los cazadores-recolectores como aquellos que subsisten de la obtención de animales y plantas no domesticados.

El modo de subsistencia cazador-recolector se caracteriza, de acuerdo con esto, por la ausencia de control directo por parte del hombre sobre la reproducción de las especies explotadas, así como escaso o nulo control sobre otros aspectos de la ecología de las poblaciones como el comportamiento y distribución de los recursos comestibles. Esta ausencia de alteración deliberada del pool genético de los recursos explotados contrasta con la situación de una subsistencia basada en la agricultura y/o el pastoralismo.

En estrecha relación con las categorías mencionadas, ciertos autores diferencian entre modos de vida “extractivos” y "productores"; implicando los primeros la extracción de alimentos del ambiente sin esfuerzos sostenibles de regularlo, mientras que en los segundos el esfuerzo es invertido antes de la recolección de los recursos, por lo que presentan importantes mecanismos de regulación del ambiente (Ellen 1994). Estos últimos pueden implicar prácticas agrícolas o ganaderas exclusivas o bien una conjugación de las mismas. Al respecto, Price y Gebauer (1995) manifiestan que es conveniente distinguir entre domesticación, cultivo/cría de animales domésticos (husbandry) y agricultura [tal como es empleado, este término referiría a un "sistema agropecuario"]. 
La primera es un proceso biológico que implica cambios en los genotipos y en las características físicas de plantas y animales a medida que se hacen cada vez más dependientes de los humanos para tener éxito reproductivo. La domesticación es a menudo no intencional (en sus inicios), producto de la interacción continua entre el hombre y los ancestros silvestres de los recursos domesticados. En el caso de la domesticación animal comprende la captura, el amansamiento -o el entrenamiento de animales para vivir en proximidad con los humanos y para desarrollar ciertas tareasy el cautiverio (Yacobaccio 2001b, Yacobaccio et al. 1997/1998). El cultivo y la cría de animales domésticos, por otro lado, son ineludiblemente fenómenos culturales de carácter intencional. En el caso del primero involucra, entre otros, labranza, selección artificial, siembra, cosecha y almacenamiento (Ellen 1994), mientras que el segundo comprende, por ejemplo, el pastoreo -referido a la supervisión de los animales en el terreno- (ibid.). Finalmente, el sistema agropecuario, resultado de la relación con animales y plantas, involucra cambios en el uso de la tierra y en la estructura y organización de la sociedad.

Retomando la diferenciación entre “cazadores-recolectores” y "grupos agropecuarios”, para Panter-Brick et al. (2001) es útil la distinción puesto que permite una clara separación entre ambas categorías, al menos en términos económicos. Winterhalder (2001), por su parte, sostiene que no deben confundirse en las propiedades clave los rasgos primarios -de naturaleza ecológica: recursos animales y vegetales silvestres para el caso de los cazadores-recolectores- de aquellos rasgos secundarios tales como la organización social a nivel de banda y el igualitarismo.

Como alternativa a esta serie de posturas, otros investigadores han tratado de identificar conjuntos de características definitorias -económicas, ecológicas, sociales, ideológicas, etc.- (Isaac 1990, Barnard 2001)․ Así, Lee y DeVore (1968), por ejemplo, caracterizan el “estilo nomádico”, consistente de igualitarismo, baja densidad poblacional, ausencia de territorialidad, almacenamiento de comida mínimo y fluidez en la composición de la banda. Lee y Daly (1999), por su parte, sostienen que la subsistencia es sólo un punto de partida en la noción de cazador-recolector y postulan una definición multifacética, con tres grandes áreas de convergencia: subsistencia, organización social y cosmología.

Es importante remarcar que las evidencias contemporáneas señalan que los cazadores recolectores varían a lo largo de toda dimensión imaginable de comparación socioeconómica: en la diversidad y tipos de recursos consumidos, en el grado de movilidad residencial y logística, en las formas de tenencia de la tierra y de interacción intra e intergrupo, en tamaño y estructura de los grupos

\footnotetext{
${ }^{1}$ Para un tratamiento crítico del tema ver Kelly (1995), Panter-Brick et al. (2001).
} 
y en la organización social (por ejemplo, Price y Brown 1985, Kelly 1995, Endicott 1999, MacDonald y Hewlett 1999, Rowley-Conwy 2001).

Pero no sólo hay una considerable diversidad dentro y entre cazadores-recolectores, igual situación se presenta en las sociedades agro-pastoriles al tener en cuenta, por ejemplo, la incidencia variable en la dieta de la agricultura y la ganadería, el grado de movilidad, etc., aunque los esfuerzos no se han centrado en explorar la variabilidad de estos grupos, como en el caso de los cazadoresrecolectores.

Si a eso sumamos el hecho de evidencias de subsistencia mixta (productos extraídos y producidos) por parte de grupos cazadores-recolectores actuales y arqueológicos, ya sea por prácticas productivas por parte de estos mismos grupos y/o por obtención de recursos domesticados por interacción con grupos productores (Speth 1991, Shott 1992, Lee y Daly 1999, Panter-Brick et al. 2001) y de actividades de caza y recolección en grupos agro-pastoriles (Olivera 1998), resulta inadecuado considerar a estas categorías como compartimientos estancos, cuando de hecho no lo son.

Es indudable que las denominaciones mismas son un problema. Por ejemplo, Ellen (1994) afirma que el término cazador-recolector sugiere una uniformidad engañosa. Kelly (1995), por su parte, prefiere descartar esta denominación en favor de otra más genérica, como es la noción de forager, que tiene la ventaja de evitar privilegiar el lado cazador de la definición. Esto es extrapolable al caso agro-pastoril, cuando se emplean los términos de farmer y herder.

Una posibilidad es reemplazarlos o directamente no emplearlos. Sin embargo, no se considera apropiado prescindir de tales términos, dada la amplia utilización y difusión de los mismos y a que responden de mejor manera que otros de amplia difusión, como los de Arcaico y Formativo (ver punto 3.1.3. Problemas inherentes a las nociones de Arcaico y Formativo). Como se ha visto, es posible abordar cuestiones referidas a variabilidad a través de estos conceptos. Al respecto, si se considera la variabilidad reseñada dentro de los cazadores-recolectores y grupos agro-pastoriles, es esperable que la misma se vea potenciada en situaciones de cambio de un modo de vida a otro.

\subsubsection{CUESTIONES RELATIVAS A SITUACIONES DE TRANSICIÓN}

Por lo visto en el punto anterior, las nociones de caza-recolección y agricultura-pastoralismo son vistas aquí como los extremos de un continuum, entre las cuales hay numerosos estados posibles (ver Gil 1998/1999). De todos ellos, interesa particularmente uno: el de la transición de un modo de vida cazador-recolector a un modo de vida agro-pastoril. En esta destacan como supuestos dos 
aspectos, la idea de continuidad y de gradualidad en la trayectoria de cambio, los cuales están marcadamente contrapuestos a la perspectiva común (cf. Smith 2001) de ver a la transición como rápida y radical. El problema fundamental de esta última postura es que, al abordar el cambio entre dos estadios estáticos o soluciones adaptativas estables, sólo se capturan los puntos de inicio y final de los procesos de cambio, pero se falla al considerar qué sucede entre ambos (ibid.).

Tal como es empleado el término transición, no implica un proceso unidireccional, invariable e irreversible; el paso necesario de poblaciones que previamente se basaban en forma exclusiva de recursos silvestres a la adopción de la agricultura y el pastoralismo. Es más, puede haber soluciones económicas que combinan una dependencia de bajo nivel de especies domesticadas con un uso continuado de recursos silvestres, en forma estable y en el largo plazo.

Interesa introducir la noción de estrategia predominante, definida por Yacobaccio et al. (1997/1998: 391) como “... aquella que determina las esferas organizativas sobre las cuales se planifican y se llevan a cabo las diversas actividades económicas (obtención de recursos, procesamiento, consumo), producción de artefactos, pautas de asentamiento y movilidad, territorialidad e intercambio y relaciones sociales”.

A modo de ejemplo, se describe la siguiente secuencia de cambio, modificada de Yacobaccio et al. (ibid.):

Caza-recolección ........... Caza-recolección/domesticación Caza-recolección/pastoreo-agricultura Pastoreo-agricultura/caza-recolección

Se destaca que esta secuencia no es unilineal, ya que, por ejemplo, de una estrategia predominante de caza-recolección/domesticación animal no se debe pasar necesariamente a una estrategia de caza-recolección/pastoreo, o en cuanto a la importancia relativa de la agricultura y el pastoreo en las dos últimas situaciones. De acuerdo al caso, la secuencia se puede estructurar de manera diferente, denotando una variabilidad potencial muy importante.

Una propuesta alternativa pero al mismo tiempo complementaria es la de Smith (2001), que utiliza a la domesticación como un rasgo dominante y vinculante entre la caza-recolección y la actividad agropecuaria. En su sistema clasificatorio, las sociedades productoras de alimentos que dependen de especies domesticadas por menos del 30 al 50\% de su consumo calórico anual, se definen como "economías productivas de bajo nivel”2 (se considera que el momento transicional estaría

\footnotetext{
${ }^{2}$ En este caso, dado que no se cuenta con información precisa sobre dieta a lo largo de la secuencia estudiada, para estimar la incidencia sobre la misma de recursos domesticados, tanto vegetales como animales, se emplearán
} 
vinculado con la presencia de dicha modalidad). Por su parte, la simple ausencia o presencia de especies domesticadas, adjetivan dicha denominación. En el primer caso (sin domesticados), se está más cerca del límite con la caza-recolección exclusiva, mientras que en el segundo caso (con domesticados), ya las vinculaciones son más fuertes con la agricultura-pastoralismo.

Para un mejor entendimiento de lo que implica la producción de alimentos de bajo nivel sin domesticados, pueden mencionarse una serie de actividades esperables en ese contexto, tales como el cuidado de plantas silvestres por medio de la eliminación manual de especies competidoras, la labranza de la tierra para favorecer la aparición o germinación de especies silvestres, el transplantado de plantas y la siembra por dispersión de semillas silvestres. En el caso de los animales, se pueden dar en este marco situaciones de protección, así como la captura y amansamiento de animales jóvenes (ibid.).

Finalmente, considerar a un proceso como transicional implica sostener que los cazadoresrecolectores incorporaron prácticas agrícolas y/o ganaderas en su estrategia de vida y no la ocurrencia de un reemplazo de cazadores-recolectores por grupos productores. Al respecto, pueden señalarse distintas posibilidades:

$1^{0}$ ) inicio de prácticas domesticatorias en el seno de las sociedades cazadoras-recolectoras.

$2^{\circ}$ ) incorporación de prácticas agrícolas y/o ganaderas por contacto con grupos productores.

$3^{\circ}$ ) obtención de recursos comestibles domesticados por interacción con grupos productores.

Evidentemente, una situación de transición requeriría de la ocurrencia de por lo menos uno de los dos primeros casos. No obstante, debe resaltarse el papel del intercambio entre cazadoresrecolectores y grupos agrícolas y/o pastoriles.

En efecto, la información etnográfica, etnoaqueológica y arqueológica (Harris 1996, Lee y Daly 1999, Bodley 1999) señala que los grupos cazadores-recolectores han vivido con distinto grado de contacto e integración con sociedades productoras. En general, se parte de la idea de una interdependencia funcional (Spielmann y Eder 1994), dado que en ciertas situaciones los cazadoresrecolectores necesitan de esta interrelación para obtener carbohidratos, así como proteínas los agricultores. De esta forma, pueden conformarse extensas redes de intercambio con el objeto de obtener elementos vitales (Bodley 1999).

Se debe remarcar, entonces, que la presencia de cultígenos, por ejemplo, no es sinónimo de práctica agrícola (Gil 1997/1998), ya que pueden obtenerse por interacción. Esto tiene importantes

evidencias indirectas tales como presencia de tecnofacturas (por ejemplo, palas), campos de cultivo, corrales, recuperación de restos faunísticos y vegetales, etc. 
connotaciones en función de cómo se interpreta el registro arqueológico, por lo que es necesario dilucidar qué es lo que ocurre en cada caso.

\subsubsection{PROBLEMAS INHERENTES A LAS NOCIONES DE ARCAICO Y FORMATIVO}

$\mathrm{Al}$ abordar la transición de cazadores-recolectores a grupos agro-pastoriles como un proceso continuo y gradual se detecta la inadecuación de los términos de "Arcaico" y "Formativo" como unidades analíticas. Más aún, su utilización se contrapone al interés del análisis de la variabilidad del registro arqueológico aquí postulado (por una crítica pormenorizada de los conceptos de Arcaico y Formativo ver Muscio 2001, 2004).

Ambos conceptos presentan claras limitaciones de índole teórico-metodológico. Desde lo teórico, dichas categorías se plantearon como estadios de desarrollo sucesivos de cambio sociocultural, en una secuencia unilineal de evolución de lo más simple a lo más complejo (ver, por ejemplo, Willey y Phillips 1958), siguiendo una lógica de cambio esencialista que presupone una tendencia inherente al progreso (Muscio 2001).

Por otra parte, está implícita una concepción del cambio como transformación abrupta, donde estas subdivisiones dan una falsa idea de reemplazo (Borrero 1993).

Al considerar lo metodológico, dado que resultan de la identificación de "paquetes" de rasgos culturales característicos, de diversa índole (tipológicos, tecnológicos, económicos, etc.), parten de la búsqueda de recurrencias más que de diferencias. De esta forma, el cambio cultural implica conjuntos de rasgos que se transforman abruptamente. Evidentemente, se suprime toda posibilidad de tratar con la variación arqueológica (Muscio 2001).

Un ejemplo de lo expresado es la diferenciación propuesta por Aldenderfer y Barreto (2004) para el sitio Jiskairumoko, situado en la cuenca del río Ilave, al oeste de la porción sudoeste del Lago Titicaca, en la que discrimina entre un Arcaico Final (ca. 4500-3800 AP), un Arcaico Terminal (ca. 3800-3200 AP) y un Formativo (ca.3000 AP), en base a los tipos de puntas de proyectil y a la presencia de cerámica. Es evidente, en primer lugar, que la adscripción a cada etapa se basa en la presencia/ausencia de clases particulares de artefactos y, en segundo lugar, aunque es clara la continuidad del proceso, manifestada por la cronología de los fechados radiocarbónicos, la segmentación propuesta particiona arbitrariamente la secuencia. 
Se destaca que estas nociones registraron un cambio de contenido muy importante en la arqueología del Noroeste Argentino a partir de las propuestas de Olivera y Aschero de caracterización del Formativo y del Arcaico, respectivamente, con implicancias de interés. Así, Olivera (1992, 2001) considera al término Formativo no en referencia a un Estadio cultural sino en relación a un tipo de sistema de adaptación que implica estrategias puntuales de organización socio-económica basadas en prácticas productoras y básicamente sedentarias. Aschero (1994: 13), por su parte, presenta una posición similar, al considerar al Arcaico como formado por “... diversas estrategias socio-económicas postpleistocénicas organizadas en torno a ciertos recursos básicos de caza, pesca y/o recolección, con diversas alternativas de experimentación hacia la domesticación animal y vegetal...”.

Son remarcables las ventajas de estas definiciones, ya que incorporan la idea de variabilidad de situaciones y no implican partir de la conformación de paquetes de rasgos. Destacan, asimismo, las afinidades con la noción de estrategia predominante de Yacobaccio et al. (1997/1998). No obstante, no ofrecen una alternativa adecuada al problema del tratamiento del cambio, esencial para el momento de transición aquí abordado. De hecho, Aschero (1994) aboga por la continuidad en dicho proceso, pero está sujeto a las limitaciones de las unidades analíticas empleadas.

Es necesario, entonces, trabajar con categorías no tan problemáticas, como la propuesta en curso de emplear las nociones de cazador-recolector y grupo agro-pastoril.

En general, explícita o implícitamente se relaciona al Arcaico con los cazadores-recolectores y al Formativo con los grupos agro-pastoriles, pero si tales términos no son de por sí equiparables, lo son menos aún al tener en cuenta el tratamiento de la variabilidad. En efecto, al igual que los términos Arcaico y Formativo, las nociones de cazador-recolector y grupo agro-pastoril son constructos, es decir, construcciones ideacionales derivadas de cuerpos de ideas o teorías formalizadas (Ramenofsky y Steffen 1998), pero presentan tres diferencias fundamentales con los primeros: no refieren a estadios de desarrollo, no aluden a paquetes de rasgos y es posible tratarlas como un continuum.

En relación con esto último, es necesario disponer de unidades de segmentación temporal adecuadas para tratar la diversidad de cambios ocurridos en la emergencia de economías productoras (Muscio 2004). Es, en este marco, que el abordaje diacrónico de la transición de grupos cazadoresrecolectores a agro-pastoriles se realiza en base a una segmentación temporal que parte de la definición de unidades temporales a partir de criterios estrictamente cronológicos (Borrero 1993). Al respecto, se sigue la propuesta de Yacobaccio y Guráieb (1994) de conformación de patrones de agrupamiento de fechados radiocarbónicos (ver punto 5.3. Grupos cronológicos en el Capítulo 5). 


\subsubsection{COMPLEJIDAD EN CAZADORES-RECOLECTORES}

Dentro de la variabilidad que caracteriza a los cazadores-recolectores, un punto importante refiere a la presencia de complejidad (Lee y Daly 1999, Rowley-Conwy 2001).

De esta forma, se considera a las categorías de cazadores-recolectores simples y complejos como extremos de un continuum. Se está de acuerdo con Kelly (1995) que los términos simple y complejo no son afortunados, puesto que remiten a la idea que los primeros son menos “evolucionados” que los segundos. Sin embargo, emplearlos no implica postular una tendencia progresivista (Rowley-Conwy 2001).

\subsubsection{1. ¿Qué define a los cazadores-recolectores complejos?}

Para poder definir a los cazadores-recolectores complejos (en adelante CRC) es útil diferenciar a éstos de los cazadores-recolectores no complejos, llamados igualitarios o generalizados (CRG). Esto no significa que ambas categorías sean entendidas como contrapuestas, sino, por el contrario, como formas distintas de resolución de un mismo fenómeno. Asimismo, se debe tener en cuenta que la propia complejidad (sensu Hill et al. 1996) en cazadores-recolectores cuenta con manifestaciones tan variadas que resiste a una conceptualización única (Yacobaccio 2001a), por lo que se adopta un enfoque abierto a múltiples características definitorias, no necesariamente presentes en todos los casos y/o en forma simultánea.

Los CRC se caracterizan por una movilidad residencial reducida o bien por ser sedentarios (Price y Brown 1985; Arnold 1996). Al respecto, un factor que ha sido considerado clave para el surgimiento de la complejidad es la presencia de circunscripción social, que refiere a límites impuestos por condiciones naturales o sociales en la movilidad geográfica y social (Price y Brown 1985). Para Aschero y Yacobaccio (1998/99), la circunscripción implica movilidad residencial reducida y, además, el mantenimiento de los individuos dentro del grupo.

Asimismo, se definen por la presencia de comportamiento territorial, evidenciado por el abandono de los acuerdos formales y permisos para explotar recursos, llegándose, incluso, a la defensa perimetral por la fuerza (Yacobaccio 2001a). El comportamiento territorial más pronunciado se relacionaría con la disminución de la movilidad y una demarcación más estricta de los territorios (Price y Brown 1985, Aschero y Yacobaccio 1998/99).

Otro elemento que define a los CRC, relacionado con lo anterior, es su alta densidad poblacional y la presencia, en la mayoría de los casos, de grupos residentes grandes (Price y Brown 
1985). Al respecto, se ha sugerido que los líderes aparecen como respuesta a la necesidad de controlar grupos grandes y de disminuir el stress escalar (Kosse 1994).

Entre los CRC no todos los individuos tienen las mismas oportunidades de acceder a ciertos recursos, posición o bienes. La existencia de estas desigualdades entre las personas lleva a la constitución de jerarquías (Aldenderfer 1993). Para Arnold (1996), son complejas aquellas sociedades cazadoras-recolectoras que poseen relaciones sociales y laborales en las cuales los líderes tienen control sobre el trabajo de otras personas sin mediar relación de parentesco y donde la diferenciación social es hereditaria.

Se distinguen, además, por poseer economías de retorno diferido (Woodburn 1982) debido a que, en buena parte de sus actividades de subsistencia, no obtienen un beneficio directo e inmediato por su trabajo. En dichas economías dominan las estrategias de obtención de excedentes necesarios para poder sostener tareas con beneficios a largo plazo, y la presencia de almacenaje, para abastecerse durante el lapso existente entre la obtención de los recursos y su consumo posterior. Estos sistemas económicos requieren de líderes para coordinar las actividades y controlar y prorratear la distribución de lo obtenido en tiempos diferidos. La presencia de almacenaje y excedentes permitiría a estos líderes la adquisición y acumulación de propiedades en términos de bienes, rompiéndose el sistema de reparto (Woodburn 1982, Price y Brown 1985).

Por otro lado, más allá del almacenamiento, destacan por una explotación intensiva de recursos particulares y por presentar especialización ocupacional (Yacobaccio 2001a). Un punto clave a la hora de abordar la complejidad cultural es, entonces, el de la intensificación de la producción (Price y Brown 1985), que refiere a un incremento en el output productivo por unidad de tierra o trabajo o cualquier otra cantidad fija (Morrison 1994), por ejemplo, incrementando los inputs de tiempo o trabajo o a través de una tecnología más eficiente.

Finalmente, un elemento constante en los CRC es la importancia de las prácticas rituales, como formas de cohesión social y de reconfiguración de las dinámicas sociales, bajo condiciones de desigualdad y jerarquías (Aldenderfer 1993).

En cambio, los CRG presentan características muy diferentes. Entre los mismos tienden a surgir líderes sólo para el desempeño de tareas específicas; asimismo, la posición del líder no es hereditaria, sino temporaria, y únicamente presta su colaboración en el proceso de toma de decisiones del grupo, sin detentar poder (Barnard 2001). 
Los CRG están compuestos por grupos locales socialmente flexibles donde sus miembros pueden pasar fácilmente de un grupo a otro (Kelly 1995). Woodburn (1982) sostiene que este flujo de individuos o grupos es distintivo de sociedades caracterizadas por economías de retorno inmediato, esto es, sistemas económicos donde las personas reciben el beneficio por su trabajo de forma inmediata. Se definirían, entonces, por poseer estas formas económicas, ya que toman el alimento de la naturaleza y en general, lo consumen inmediatamente (Barnard 2001). Esto no significa que los CRG no almacenen, sino que esto no se realiza de manera intensiva y como parte de una planificación a largo plazo (Kelly 1995). Una de las principales características de los sistemas de retorno inmediato y, por ende, de estos grupos humanos, es su igualitarismo, que se manifiesta en la equidad material dado que el compartir tiene más valor que el acumular y los bienes se comparten en forma generalizada (Barnard 2001).

Los CRG se destacan por su mayor movilidad residencial y por una falta de territorialidad (Kelly 1995). Al respecto, la noción de "propiedad” de un territorio por parte de estos grupos humanos difiere en buena parte de la definiciones de propiedad de los sistemas legales occidentales, ya que, aunque grupos específicos retienen, por nacimiento, casamiento o residencia, derechos de acceso especial a territorios particulares, no pueden alienarlos; sólo pueden utilizar sus recursos, permitir a otros el uso de los mismos y, en algunos casos, negar o desalentar el acceso (Barnard 2001).

\subsubsection{Indicadores arqueológicos de complejidad}

Todos los elementos que definen a los CRC son factibles de manifestarse arqueológicamente, ya que implican comportamientos con consecuencias materiales de diversa índole y, por ende, visibles en el registro arqueológico.

Cabe recalcar que, en coincidencia con la idea de complejidad definida por múltiples variables no excluyentes, se considera que la presencia o ausencia de algunos indicadores arqueológicos específicos no es condición necesaria ni suficiente para sostener la existencia o no de CRC. Teniendo esto presente, se desarrollan a continuación los indicadores arqueológicos que serán considerados en este trabajo, en relación a los elementos definitorios enunciados:

- movilidad residencial reducida/sedentarismo: la disminución en la movilidad residencial implica principalmente cambios en el patrón de asentamiento, manifestados en, por ejemplo, su mayor tamaño, duración y diferenciación, tanto en organización interna como en el número y variedad de sitios. Aunque se ha considerado a los aglomerados residenciales como uno de los indicadores más consistentes de sedentarismo (Kelly 1992), contar con estructuras habitacionales no es garantía de que la ocupación haya sido sedentaria (Aldenderfer 1998). 
La presencia de sedentarismo puede inferirse también estudiando las variaciones a lo largo del tiempo de las áreas de proveniencia de recursos bióticos y abióticos locales y no locales, y las evidencias de estacionalidad que brindan los primeros.

El análisis del cambio en el tiempo de la frecuencia y aparición de ciertas clases de artefactos constituye otra vía posible de aproximación. Es el caso, por ejemplo, de los bifaces, relacionados consistentemente con una elevada movilidad residencial (Parry y Kelly 1987).

- territorialidad: de acuerdo a Price y Brown (1985), el comportamiento territorial está estrechamente vinculado a la demarcación de la identidad, cuya manifestación arqueológica sería la distribución de diseños, artefactos y materiales distintivos en un área dada (Aldenderfer 1998). Por otra parte, implicaría un aumento de las situaciones de conflicto externo, factibles de ser observadas, por ejemplo, en los restos humanos mismos (traumas causados por violencia) o en el arte rupestre (escenas de lucha).

- desigualdad social: la existencia de jerarquías, es decir, de desigualdades entre las personas, implicando el acceso diferencial a recursos, posición social, etc. (Aldenderfer 1993), está a menudo denotada por diferencias en los artefactos, ecofactos y estructuras en contextos arqueológicos específicos. Así, por ejemplo, se deberían registrar diferencias cuali y cuantitativas en patrones de enterramiento y ajuares en tumbas, o en características arquitectónicas y tipos de vestigios en lugares residenciales.

De particular relevancia en el abordaje de la desigualdad es la presencia de bienes de prestigio (Arnold 1996, 2000), ya que generalmente implican la apropiación individual de items producidos localmente o intercambiados, generando un reparto diferencial de recursos entre la población, a partir del control de su adquisición, producción, uso y/o distribución. Así, el hallazgo de elementos suntuarios provenientes de largas distancias significaría la operación de sistemas de intercambio para proporcionar a individuos de mayor status atributos materiales de su posición.

Por otro lado, siguiendo a Arnold (2000), la presencia de líderes de tiempo completo se podría observar a través de cambios en la organización del trabajo manifestados, por ejemplo, en actividades que requieren la participación comunitaria a gran escala, como son la construcción de edificaciones, estructuras ceremoniales o lugares de extracción de recursos.

- Redes de interacción a larga distancia: indicadores de la circulación de bienes extra-locales serían la presencia, por un lado, de recursos bióticos y/o abióticos con áreas de procedencia distantes, en forma 
de artefactos o ecofactos y, por el otro, de diseños de artefactos y representaciones de arte rupestre que se encuentren sincrónicamente a nivel macrorregional.

- Densidad poblacional: una forma tentativa de analizar esta variable es definir las variaciones en el tiempo del número de sitios presentes en un área, en conjunción con su tamaño relativo.

- Tecnología: en situaciones de complejidad, el instrumental relacionado con la subsistencia se diversifica en sus formas, debido a que se vuelve más especializado, y se estandariza (sería el caso, por ejemplo, de las puntas de proyectil). Asimismo, se producen innovaciones tecnológicas importantes (aparición de nuevos diseños de artefactos, uso de materiales no empleados anteriormente -por ejemplo, cerámica-, etc). La tecnología en general tiende a un mejoramiento de la performance de los artefactos. En artefactos de molienda para evaluar esto se analizan, por ejemplo, los cambios en el tamaño de las superficies activas de los artefactos y en el diseño de las piezas.

- Intensificación de la producción: esta variable involucra (Price y Brown 1985): a) cambios en la tecnología (ver arriba); b) presencia de especialización ocupacional, a través de la manufactura especializada de productos utilitarios y/o suntuarios o bien de la especialización en actividades económicas particulares, en general por parte de segmentos de la población; y c) cambios en las actividades de obtención y abastecimiento, involucrando la explotación intensiva de recursos particulares. La intensificación en la producción generalmente está acompañada por el almacenamiento a largo plazo, cuyo rasgo más definitorio es la presencia de estructuras destinadas a tal fin.

- Ritual: la actividad ritual se ve acrecentada en intensidad, lo que aumenta su visibilidad arqueológica. Asimismo, hay una mayor complejidad del simbolismo religioso. Aparecen elementos asociados con la esfera de lo ritual, como estructuras ceremoniales u ofrendas. 


\subsection{TECNOLOGÍA LÍTICA}

En esta investigación se plantea un estudio de cultura material, específicamente artefactos líticos tallados, en su contexto social y económico, de forma de abordar el comportamiento tecnológico como parte componente del comportamiento humano (Lemmonier 1986, Torrence 1989, Nelson 1991, Inizan et al. 1999). Dada la diversidad presente en este último, la aproximación en curso, asimismo, se centra en explorar la variabilidad tecnológica en materiales líticos tallados (Schiffer y Skibo 1987, Torrence 1989, Bleed 1997).

Se parte de la base de que la tecnología no implica sólo los objetos y medios usados por la sociedad para actuar sobre el ambiente físico (Bousman 1993, Bamforth y Bleed 1997, Bleed 1997), o que refiere solamente a los instrumentos en sí y a sus modos de uso (para una crítica a esta posición ver Ingold 1990), sino que involucra todos los aspectos posibles del proceso de acción sobre la materia (Lemmonier 1992).

Siguiendo esta línea de pensamiento, Sigaut (1994) sostiene que la tecnología está formada por actividades que definen acciones materiales, en el sentido que todas producen un cambio material en algo, y que, al mismo tiempo, son intencionales. Así, por tecnología se entiende a todo corpus de artefactos, comportamientos y conocimiento para crear y usar productos que es transmitido intergeneracionalmente (Schiffer y Skibo 1987).

Toda actividad de talla implica la existencia de un proyecto (relacionado con un producto que se desea obtener) más o menos elaborado, que incluye un esquema conceptual, de naturaleza intelectual, y que es implementado a través de series de operaciones denominadas esquemas operativos (Inizan et al. 1999). Tales “proyectos” son representaciones resultantes de representaciones mentales que son socialmente transmitidas y compartidas ${ }^{3}$ (Lemmonier 1992, Pelegrin 1995, Bradley y Giria 1996, Wynn 1998, Toth y Schick 1998). Esto no significa, empero, la no existencia de otros factores, como la intensidad de reducción o el mantenimiento, que generen cambios morfológicos y formas específicas (Dibble 1995, Hiscock y Attenbrow 2003, McPherron 2003).

Dado que la tecnología no está constituida simplemente por los ítems físicos de la cultura material, sino que, asimismo, se deben considerar el comportamiento tecnológico y la acción humana (Ingold 1988), una aproximación a la tecnología lítica desde esta perspectiva debe emprender el estudio combinado de instrumentos y otros artefactos, materias primas, acciones físicas y destreza técnica (Inizan et al. 1999). Estos elementos son desarrollados en el punto siguiente: Contenido de la

\footnotetext{
${ }^{3}$ Se está de acuerdo con Bleed (1997) cuando señala que no es necesario adoptar una posición mentalista para considerar que la producción y uso de artefactos se hace en un contexto de patrones intelectuales que influencian los resultados materiales.
} 
tecnología. Lo que importa destacar aquí, es que las decisiones tecnológicas que conectan a las acciones entre sí pueden ser tratadas como comportamientos concretos, observables tanto en los procesos de manufactura inferidos como en sus resultados materiales (Bleed 1997).

Es importante introducir, entonces, la noción de elección, o la posibilidad de optar entre dos o más alternativas técnicas en un momento dado (Lemmonier 1992). Se destaca que, tal como es empleada en esta investigación dicha noción, las distintas alternativas no sólo pueden referir a técnicas, sino también a instrumentos, tool kits, secuencias de producción, etc. Al respecto, Bleed (1997) discrimina entre operaciones tecnológicas que conforman actividades, cuando se hace algo, y puntos de elección, cuando se toman decisiones de qué hacer.

En su trabajo de 1992, Lemmonier señala que dichas elecciones pueden ser producto de necesidades físicas -es decir, que mejoren la calidad de vida o, más aún, que aseguren la supervivencia-, o bien ser resultantes de la práctica social; y que las segundas se pueden discernir a partir de la no ocurrencia de las primeras. Entonces, además de los constreñimientos físicos impuestos por el mundo material, las elecciones sociales también participan en la construcción y transformación de los sistemas tecnológicos.

Sin embargo, se considera aquí que ambos dominios no son contradictorios, ya que cualquier elección no puede ser separada de la influencia del contexto social (Dobres 2000). La tecnología se construye y está constreñida por su contexto social e histórico (Torrence 2001), de modo que el resultado tiene que ser necesariamente el producto de la conjunción de ambas esferas (Sigaut 1994, Ingold 1998a).

De acuerdo con Torrence (2001), la tecnología comprende las acciones físicas realizadas por actores instruidos quienes usan materiales cuidadosamente seleccionados para producir un resultado deseado. Dicho resultado surge de objetivos identificados por los individuos y los grupos y no implican necesariamente la maximización de alguna propiedad como la energía o el éxito reproductivo. Este resultado deseado, definido por los usuarios, es el factor más importante en la elección de instrumentos y acciones, si bien la tecnología debe ajustarse también a los objetivos y constreñimientos que compiten entre si planteados por el ambiente físico y social.

En suma, la producción de formas específicas implica una elección resultante de la combinación de lo que, en palabras de Bradley y Giria (1996), son las necesidades funcionales y tecnológicas, mediatizadas por el contexto social. 
Una manera posible de encarar el análisis de artefactos líticos tallados, y de amplia difusión, es a partir de la propuesta de la organización tecnológica o “... el estudio de la selección e integración de estrategias para hacer, usar, transportar y descartar instrumentos y los materiales necesarios para su manufactura y mantenimiento” (Nelson 1991: 57). Tales estrategias tecnológicas son vistas como respuesta a condiciones ambientales como así también a estrategias económicas y sociales. Sin embargo, los estudios de organización tecnológica han enfatizado en las estrategias económicas y en la relación con el ambiente, más que en las estrategias sociales (Carr 1994, Torrence 1994). En este trabajo, se pretende, justamente, explorar este punto al que se ha dado escasa atención, la relación entre organización tecnológica y condiciones sociales.

Finalmente, se destaca el papel del individuo en la tecnología. Sinclair (2000), en este sentido, sostiene que la tecnología es el conjunto de gestos técnicos y conocimiento que es aprendido y expresado por los individuos en el curso de prácticas sociales. Es indudable que la toma de decisiones de actos tecnológicos concretos se realiza a nivel individual (Pelegrin 1990, Pigeot 1990); el punto es, justamente, lidiar con un registro arqueológico que presenta, la mayor parte de las veces, conducta promediada. Borrero (1993) señala que la forma de relacionar las acciones de los individuos con el registro arqueológico es concentrarse básicamente en el estudio de la variación, propuesta que es tomada como eje de esta investigación y que se desarrolla en los puntos de este Capítulo que siguen a continuación.

\subsubsection{CONTENIDO DE LA TECNOLOGÍA}

Siguiendo a Bleed (1997), el contenido de la tecnología, o los comportamientos que la gente presenta cuando hacen y usan cultura material, está compuesto por una serie de variables, que son observables en acción y en los resultados materiales de una tecnología dada, a saber: 1) Conocimiento; 2) Aplicaciones y 3) Standards. A modo de caracterización general, podría decirse que el conocimiento refiere a qué y cómo se hacen las cosas, las aplicaciones a cómo se aplica el conocimiento y los standards a las normas y valores que guían el comportamiento tecnológico.

A partir del abordaje del contenido de la tecnología es posible considerar la variabilidad que existe dentro de la misma, puesto que es en el contenido comportamental de la tecnología donde existe la variación (Bleed 1997). En este caso se abordará la variabilidad tecnológica en base al análisis del primer punto exclusivamente. 


\subsubsection{Conocimiento tecnológico}

\subsection{Componentes del conocimiento tecnológico}

De acuerdo con Schiffer y Skibo (1987), el conocimiento tecnológico tiene 3 componentes esenciales: 1) recetas para la acción (recipes for action); 2) sistemas de enseñanza (teaching frameworks) y 3) tecno-ciencia (techno-science).

Las recetas para la acción son las reglas que subyacen el procesamiento de materias primas en productos terminados. En realidad, son modelos construidos por el investigador sobre la base del comportamiento visible en las evidencias arqueológicas (ver, por ejemplo, Pigeot 1990). Resultan de la conjunción de una serie de elementos y actividades: materias primas y utensilios e instalaciones (facilities) empleados, una descripción de la secuencia de acciones específicas llevadas a cabo en el proceso tecnológico y reglas de contingencia usadas para solucionar problemas que pueden aparecer. Casos de recetas para la acción lo constituirían, por ejemplo, los estadios de reducción de bifaces de Callahan (1979) y Nami (1988).

Por su parte, los sistemas de enseñanza, que permiten la transmisión intergeneracional del conocimiento, consisten en series de prácticas que pueden incluir imitación, instrucción verbal, demostración manual y aún autoaprendizaje por prueba y error. Como el sine qua non del aprendizaje de las recetas para la acción es practicar manipulando materiales, muchos sistemas de enseñanza hacen uso intensivo de la experiencia práctica (Wynn 1998). También se requiere de instrucción verbal, para proveer a los aspirantes con las indicaciones esenciales para llevar a cabo la acción exitosamente.

La transmisión de la tecnología generalmente demanda una práctica continua y maestros que, siguiendo la tradición, puedan conducir eficientemente el aprendizaje. Por este proceso los sistemas de enseñanza transmiten la parte más intangible del conocimiento, “el saber-cómo” -know how- (Pelegrin 1990, Inizan et al. 1999).

Las tecnologías “exitosas” incluyen sistemas de enseñanza que se transmiten, por medio de recetas para la acción, de generación en generación.

Finalmente, la tecno-ciencia, que involucra los principios que subyacen a las operaciones tecnológicas, explica por qué las recetas para la acción conducen al producto proyectado y por qué dicho producto, una vez terminado, puede desempeñar su/s función/es. Los principios que describen las operaciones tecnológicas son leyes de bajo nivel y teorías, pero se debe tener en cuenta que tales 
principios son construcciones del observador, derivados de la ciencia moderna. Los artífices de una actividad artesanal, en realidad, practican su especialidad en ignorancia de la tecno-ciencia subyacente.

Así, la tecno-ciencia, en la práctica de la talla, involucra una serie de principios físicos, relacionados, por ejemplo, con la mecánica de fracturas en materiales sólidos, los sistemas de ángulos y la administración de fuerzas (Cotterell y Kamminga 1990, Whittaker 1994).

En definitiva, durante el aprendizaje, se espera una progresión natural en destreza, un incremento del conocimiento y del saber-cómo y una adquisición sucesiva de competencias teóricas y prácticas (Pigeot 1990). De esta forma, durante el proceso de educación técnica, se van incorporando una serie de principios técnicos, de los más simples a los más complejos.

A modo de ejemplo (Pigeot 1990, Whittaker 1994):

- Seleccionar una pieza adecuada de materia prima.

- Selección del percutor adecuado

- Necesidad de operar con un ángulo igual o menor a $90^{\circ}$ durante la percusión dura

- Elección de las plataformas adecuadas para realizar las extracciones

- Control de la fuerza del golpe

Por otra parte, el tipo de técnica a emplear incide sobre la capacidad del aprendiz de llevarla a cabo; por ejemplo, al considerar la percusión dura en relación con la percusión blanda (Whittaker 1994). Esto lleva a sostener que a mayor complejidad de la técnica, se va a requerir que la duración de la enseñanza sea mayor.

\subsection{Aproximación al conocimiento tecnológico}

Una aproximación al conocimiento tecnológico implica, según Bleed (1997), tratar con las técnicas empleadas, el saber (wisdom), la destreza técnica (skill), los diseños y los recursos utilizados.

Técnicas

Para Mauss (1935; citado en Lemmonier 1992) una técnica es una acción que es efectiva y tradicional. Al desglosar esta definición en sus partes componentes, en base a lo postulado por Lemmonier (1992), surgen una serie de consideraciones de interés. Así, el término “acción” refiere a una intervención planeada. Si a esta noción se le incorpora el hecho de ser "tecnológica", es una acción que involucra al menos alguna intervención física que conduce a una transformación de la 
materia, en términos de leyes científicas del mundo físico. “Tradicional”, por su parte, significa que esos movimientos son heredados del pasado y aprendidos, de lo que se desprende que las técnicas son fenómenos sociales. En tanto que, al ser "efectiva” implica que el resultado material obtenido a través de la acción tecnológica es uno que se busca.

Para este autor (Lemmonier 1992), las técnicas se definen por la presencia de cinco elementos:

- Materia: el material, incluido el cuerpo humano, sobre el que actúa la técnica

- Energía: las fuerzas que mueven los objetos y que transforman la materia

- Objetos: son los artefactos usados para transformar la materia

- Gestos: mueven los objetos implicados en la acción tecnológica. Se organizan en secuencias, definidas en forma general como secuencias operativas.

- Conocimiento específico: es el resultado final de todas las posibilidades percibidas y de las elecciones, realizadas a nivel individual o societario, que han dado forma a una acción tecnológica.

Estos cinco elementos interactúan entre si y conforman, asimismo, la tecnología (Lemmonier ibid.), de ahí las notorias coincidencias con la propuesta de Bleed (1997), aquí empleada.

Es importante destacar que las técnicas, tal como son definidas, tienen un correlato inmediato con la propuesta en curso de "clases técnicas" (para su definición y caracterización ver punto 4.3. Categorías analíticas empleadas en Capítulo 4).

Saber (wisdom)

Esta formado por las recetas para la acción y la tecno-ciencia que organizan y racionalizan las acciones tecnológicas (Schiffer y Skibo 1987). Por una descripción de las mismas ver el punto 2.1.1.1.1. Componentes del conocimiento tecnológico en este Capítulo.

Destreza técnica (skill)

La destreza técnica es el resultado de destrezas motoras y capacidades cognitivas que operan en combinación con el conocimiento (Inizan et al. 1999). Para Pelegrin (1995), la destreza técnica es una aptitud nacida de la experiencia, en base a una práctica sostenida. Justamente, transformar el conocimiento en destrezas técnicas implica siempre un proceso de aprendizaje (Sigaut 1994).

Es importante introducir, entonces, la diferencia entre el conocimiento y el "saber-cómo" (Sigaut 1994), dos elementos de naturaleza neuropsicológica distinta. En base a lo señalado por 
Pelegrin (1990), como conocimiento pueden ser clasificadas las representaciones mentales de formas y materiales (conceptos) y el registro de modalidades de acción (secuencias de gestos asociadas con sus resultados prácticos). Es decir, refiere a las memorizaciones y representaciones mentales de objetos y de hechos. Con respecto al "saber-cómo", a su vez, se puede distinguir entre un "tiempo ideacional" (ideatory) y un "tiempo motor” (ibid.).

El primero implica la evaluación, reflexión y toma de decisiones en el marco de operaciones basadas en representaciones mentales. El artesano imagina (esto es, construye nuevas representaciones mentales de) el estado virtual del objeto de acuerdo a las acciones imaginadas, y considera sus respectivas ventajas y riesgos. Estas operaciones mentales no son sólo espaciales (en relación a formas), sino que también se organizan cronológica y secuencialmente, como cuando se deben ordenar series de extracciones de diferentes orientaciones. Evidentemente, sólo la experiencia práctica puede permitirle al artesano refinar estimaciones gradualmente y optimizar razonamientos, los cuales son esencialmente subconscientes.

El segundo involucra la programación y ejecución de gestos, implicando operaciones intuitivas que evalúan la adecuación de los parámetros de manufactura involucrados en la operación en curso. Así, se observan las características morfológicas del objeto a ser tallado por medio de la visión y el tacto. Posteriormente, se “calcula” la orientación y manejo del objeto por la mano no dominante, y la fuerza y trayectoria del gesto llevado a cabo por la mano dominante. Es crucial notar que estos gestos son rápidos, y que su curso no puede ser controlado apropiadamente por la visión. El ojo controla la posición y orientación del objeto antes de la percusión, pero el carácter del gesto de talla en sí mismo tiene que ser "programado" antes del movimiento. Esto significa que la adecuación y éxito de la ejecución muscular del gesto de talla se basa necesariamente en experiencia práctica previa.

Para finalizar, se sostiene que la destreza técnica en la ejecución de una técnica es una forma de variación tecnológica, puesto que implica capacidades personalizadas de sujetos particulares (Ingold 1998b) y, por ende, está distribuida diferencialmente entre y dentro de las sociedades (Bleed 1997).

Diseño

El diseño implica una imposición de forma a una materia prima (Aschero 1988a). Para Bleed (1997), los diseños de los instrumentos pueden ser considerados un tipo de conocimiento tecnológico, ya que los artesanos operan dentro de los constreñimientos de un conjunto dado de artefactos formatizados. Es decir, no son libres de crear un número ilimitado de instrumentos, sino que deben seleccionar de la disponibilidad que la tecnología les presenta. 
Siguiendo esta línea de pensamiento, Bradley y Giria (1996) afirman que hay formas y métodos de manufactura que podrían ser reconocidos como tradicionales, usuales o normales dentro de un grupo, conformando lo que denominan "normas culturales”.

Dichas posturas no tienen en cuenta un aspecto muy importante, el hecho de la capacidad de innovación del hombre. Los seres humanos no sólo tienen la habilidad de replicar un diseño establecido, sino también de conceptualizar nuevas formas en anticipación a su realización (Ingold 1998b).

Por esto, se deben considerar períodos de estabilidad, donde se siguen las recetas para la acción, pero también períodos de experimentación, momentos en que el artesano se interesa por acciones alternativas y sus consecuencias (Schiffer y Skibo 1987).

Recursos

Si bien los recursos, en este caso, materias primas líticas, están mediatizados por el ambiente, desde un punto de vista tecnológico reflejan el conocimiento de la gente en relación a su obtención y uso (Bleed 1997).

\subsection{Abordaje tecno-tipológico del conocimiento tecnológico}

En Tabla 3.1 pueden apreciarse los elementos a tener en cuenta (desarrollados en el Capítulo 4. Metodología para el análisis tecno-tipológico de artefactos líticos tallados) para el análisis de las variables que conforman el conocimiento tecnológico.

Tabla 3.1. Análisis de la variabilidad en el contenido de la tecnología lítica desde una aproximación tecno-tipológica

\begin{tabular}{|c|c|c|}
\hline \multicolumn{2}{|c|}{ Contenido de la tecnología } & Elementos a considerar \\
\hline \multirow{5}{*}{ CONOCIMIENTO } & Técnicas & $\begin{array}{l}\text { - Análisis de clases técnicas para artefactos formatizados, con el fin de } \\
\text { analizar las variaciones de las mismas a lo largo del tiempo }\end{array}$ \\
\hline & Saber & $\begin{array}{l}\text { - Análisis diacrónico de clases técnicas, grupos y subgrupos } \\
\text { tipológicos, tipos morfológicos, desechos de talla y núcleos, con el } \\
\text { objeto de inferir cambios en las recetas para la acción y en la tecno- } \\
\text { ciencia involucrada }\end{array}$ \\
\hline & Destreza técnica & - Análisis de bifaces con el objetivo de identificar aprendices \\
\hline & Diseños & $\begin{array}{l}\text { - Análisis de la variabilidad sincrónica y diacrónica en grupos y } \\
\text { subgrupos tipológicos y tipos morfológicos }\end{array}$ \\
\hline & Recursos & $\begin{array}{l}\text { - Análisis de la utilización sincrónica y diacrónica de materias primas } \\
\text { líticas }\end{array}$ \\
\hline
\end{tabular}

\subsubsection{TOMA DE DECISIONES}




\subsubsection{Aspectos generales de la toma de decisiones}

Todo proceso tecnológico implica una secuencia de comportamientos que resulta de elecciones técnicas específicas (Schiffer y Skibo 1987). Es importante destacar que se considera a esta toma de decisiones como desarrollándose simultáneamente a múltiples escalas, que van de la realización de gestos técnicos muy concretos, como, por ejemplo, la secuencia de extracciones a ejecutar durante la regularización de una punta de proyectil, o el hecho de seleccionar la dirección, el ángulo y la fuerza de un golpe para, de esta manera, eliminar un engrosamiento en un biface, hasta la estrategia tecnológica implementada en un determinado marco espacio-temporal.

Esto significa que el comportamiento tecnológico implica la solución de problemas, o la habilidad de ajustar el comportamiento tanto a la tarea específica que se está realizando (Wynn 1998) como a situaciones generadas por el ambiente físico y social (Nelson 1991).

Al respecto, los individuos racionalizan sus acciones y actúan estratégicamente dentro de contextos históricamente específicos y de condiciones cuyos límites están definidos culturalmente (Dobres y Hoffman 1994). Esta concepción de que los individuos piensan estratégicamente es considerada aquí una aproximación válida y razonable, alternativa a las posiciones del hombre “racional” y "optimizador" (por ejemplo, Smith y Winterhalder 1992), ya que extiende el rango de factores que se tienen en cuenta al tomar decisiones. Además de factores ambientales y biológicos, incluye percepciones y experiencias vividas, así como factores ideológicos y simbólicos (Dobres y Hoffman 1994). Por otro lado, toma en cuenta que los objetivos de los individuos y grupos dentro de una sociedad y las elecciones que ellos toman están culturalmente pautados, por lo que van a depender del contexto, invalidando generalizaciones tales como la optimización (ibid.)

Más aún, la noción de estratega es sumamente interesante. De acuerdo a Morin (1995), toda acción implica una serie de alternativas sobre las que se debe optar, por lo que involucra no sólo una decisión, sino también una apuesta, con sus connotaciones de riesgo e incertidumbre. De aquí surge la idea de estrategia. Esta permite, a partir de una decisión inicial, imaginar un cierto número de escenarios para la acción, que podrán ser modificados según las informaciones que lleguen en el curso de la acción y según los elementos aleatorios que sobrevendrán y perturbarán dicha acción (ibid.).

Como contrapuesto a la estrategia, se presenta el programa, o secuencia de acciones predeterminadas que debe funcionar en circunstancias que permiten el logro de los objetivos (ibid.).

Si las circunstancias no son favorables, el programa se detiene o falla; la estrategia, en cambio, elabora uno o varios escenarios alternativos. Sin embargo, el programa y la estrategia son 
complementarios: se deben utilizar múltiples fragmentos de acción programada para poder desarrollar estrategias adecuadas.

Dichas nociones de estrategia y programa son muy útiles, por ejemplo, al tratar los mecanismos de aprendizaje y la solución de problemas en situaciones de talla y para dinamizar el concepto de "organización tecnológica”.

Como ya fue mencionado en el primer punto de este Capítulo, las soluciones tecnológicas son las consecuencias particulares de decisiones que buscan resultados óptimos de objetivos identificados por los actores, y que dichos objetivos pueden no implicar necesariamente la maximización de alguna propiedad como la energía o el éxito reproductivo (Torrence 2001). Sin embargo, no se puede negar que, bajo ciertas condiciones, relacionadas básicamente a necesidades físicas, como la subsistencia, se prioricen aquellas estrategias que cumplan mejor los objetivos propuestos que otras existentes.

Finalmente, se debe destacar que toda elección técnica es desarrollada bajo ciertas condiciones sociales prevalecientes, y que el éxito de un proceso o producto -si es aceptado o no-, por más eficaz que sea, está condicionado por ese factor extra tecnológico (Schiffer y Skibo 1987, Lemmonier 1992).

\subsubsection{Toma de decisiones, diseño y propiedades formales de artefactos líticos}

Para Nelson y Lippmeier (1993), el aspecto de mayor influencia sobre el diseño de los utensilios es la tarea para la cual se espera que sean usados los mismos, debiendo ser mínimamente efectivos en la tarea para la que fueron producidos. De lo expresado se desprende el fuerte vínculo entre la performance y el diseño, ya que este último implica la selección de una alternativa entre una serie de opciones disponibles para solucionar un problema, siendo condición necesaria su efectividad por lo menos mínimamente- (Bleed 1986).

El desempeño está estrechamente vinculado con las propiedades formales de los artefactos (Schiffer 1995, Schiffer y Skibo 1997), ya que configuraciones específicas de atributos formales van a determinar que los artefactos cumplan mejor ciertas condiciones de uso (Tomka 2001). Ahora bien, la forma de los instrumentos es resultado tanto de necesidades funcionales como tecnológicas (Bradley y Giria 1996). Así, entre las variables morfológicas que van a determinar para qué tareas está mejor preparado el artefacto se puede mencionar, entre muchos otras, el tamaño y el peso del artefacto, la delineación de la arista, el ángulo del filo, su simetría y longitud, o el tipo de materia prima empleada. Estas características tienen incidencia sobre el desempeño del artefacto en cuestión, por ejemplo, en lo que refiere a durabilidad del filo, afilamiento, posibilidades de mantenimiento y de rotura, etc. (ver, por ejemplo, Bamforth 1992, Hayden et al. 1996, Beck 1998, Kelly 2000). 
Un punto clave es que, como las elecciones técnicas afectan las propiedades formales de los artefactos, influencian la performance de los mismos (Schiffer y Skibo 1997). Más aún, de acuerdo a Nelson y Lippmeier (1993), la aplicación exitosa de un instrumento para llevar a cabo determinadas tareas depende de la instancia de producción.

\subsubsection{Inversión de trabajo en la producción de artefactos líticos}

Siguiendo a Bousman (1993), el esfuerzo invertido en la manufactura de artefactos formatizados es un componente significativo en la organización de la tecnología. De esta forma, la tecnología puede tener un rol crítico en determinar las elecciones económicas de los grupos humanos, por lo que deben integrarse a los análisis los costos y beneficios que conlleva la utilización de variantes tecnológicas específicas.

Es así que la tecnología lítica puede vincularse a los análisis de optimización mediante la consideración de los costos de producción de distintas alternativas tecnológicas (cf. Bousman 1993, Tomka 2001), a partir de la estimación de la inversión de trabajo, en tiempo y energía, en la confección de artefactos líticos tallados. Las estrategias tecnológicas disponibles conforman, en este marco, un rango de opciones con costos y beneficios variables (Hayden et al. 1996, Andrefsky 1998, Cowan 1999, Tomka 2001) que definen tasas de retorno particulares.

En general, los conjuntos de artefactos líticos tallados presentan una importante variabilidad interna. De particular importancia dentro de esta última es, en base a lo expresado, el tratamiento tecnológico diferencial que se le da a los artefactos que constituyen dichos conjuntos. Así, una forma de abordar dicha variabilidad tecnológica es a través de la estimación de la inversión de trabajo implicada en la manufactura de las distintas clases de artefactos que constituyen las muestras arqueológicas.

Justamente, la discriminación de los artefactos formatizados, dentro de un mismo o entre distintos grupos tipológicos, en categorías basadas en la presencia de prácticas de adelgazamiento, reducción o trabajo no invasivo unifacial y bifacial y trabajo bipolar (ver puntos 4.3.4. Clase técnica y 4.4. Caracterización de clases técnicas en Capítulo 4) es una vía posible para este abordaje, ya que implican distintos costos de producción. También, porque requieren, durante el proceso de manufactura, un mayor conocimiento práctico -un “saber cómo”- más una experiencia en la talla y una destreza manual, habilidades técnicas particulares y variables de tallador en tallador.

De esta manera, hay un continuum en la morfología de los artefactos que pueden ser producidos con muy poco esfuerzo frente a la de otros que requieren de un mayor esfuerzo de 
producción. Pero de todas esas prácticas de rebaje son los artefactos con adelgazamiento bifacial los que fueron relacionados con la mayor inversión de trabajo en su manufactura (Hayden et al. 1996; Andrefsky 1998), difiriendo de aquellas piezas con una simple reducción unifacial marginal.

Este mayor tiempo de trabajo invertido y esas habilidades técnicas particulares que requiere el adelgazamiento bifacial puede tener distintos objetivos. Pueden ser funcionales como el reaseguro por falta de rocas aptas para la talla en travesías prolongadas, ofreciendo facilidades en el mantenimiento, reactivación o reformatización del artefacto. Aunque también puede ser que se trate de una "etapa" técnica insoslayable para producir un diseño que exija un cierto peso, longitud y condiciones de simetría estrictas para facilitar su enastilado y penetración por impacto a distancia, tal como es el caso de las largas puntas lanceoladas de sección biconvexa o subcircular gruesa, conocidas para el Holoceno temprano y medio de la Puna argentina (Aschero y Martínez 2001). Por fin, también, el adelgazamiento puede ser una práctica que juegue un papel importante en la competencia personal entre talladores expertos, cuando ese "plus” de trabajo es una forma de destacar al productor frente a otros de su grupo.

De esto se desprende que hay un "para qué” de esa variabilidad tecnológica que se ve reflejado en múltiples diseños y formas de instrumentos, lascas y núcleos, y beneficios que implican costos diferentes para los que los produjeron. Es necesario, entonces, generar criterios que permitan analizar la relación entre diseños de artefactos e inversión de trabajo; la alternativa metodológica aquí propuesta es un camino posible y práctico para lograr ese cometido.

\subsubsection{TECNOLOGÍA LÍTICA Y FUENTES DE CAMBIO TECNOLÓGICO}

La transición de cazadores-recolectores a sociedades agro-pastoriles implicó una serie de cambios socioeconómicos que fueron modificando el modo de vida de partida. Entre ellos, destacan la producción de alimentos y la disminución en la movilidad residencial, con consecuencias importantes para la organización de la tecnología lítica, siendo esperables marcados cambios tecnológicos.

Es plausible sostener, en consecuencia, que los cambios en la subsistencia y movilidad debieron jugar un rol básico en la conformación de los conjuntos de artefactos líticos tallados de los grupos humanos de Antofagasta de la Sierra, durante el período considerado. De esta forma, se plantea evaluar cómo el riesgo de subsistencia y las modificaciones en la movilidad afectaron la estructura de los conjuntos analizados. 


\subsubsection{Riesgo de subsistencia}

Bousman (1993: 64) define al riesgo como "variaciones ambientales (y económicas) impredecibles que influencian la obtención de suficiente comida como para sostener una población dada”, noción vinculada estrechamente con la probabilidad de caer por debajo de un nivel mínimo de subsistencia (Escola 1996).

La tecnología se transforma, en estos casos, en una estrategia para reducir el riesgo (Torrence 1989, Bousman 1993, Bamforth y Bleed 1997). Con respecto a esto, Wiessner (1982) identifica cuatro estrategias que los cazadores-recolectores emplean para amortiguar los efectos del riesgo, los cuales pueden extrapolarse perfectamente a sociedades agro-pastoriles, a saber: prevención de las pérdidas (prevention-of-loss), el compartir (sharing), el almacenamiento y la transferencia de la pérdida (transfer-of-loss). Es en la primera donde se incluye la tecnología (Torrence 2001).

Al clasificar a los grupos humanos por el patrón de subsistencia y tratándolo a este último como un continuum, en un extremo se presentan las economías cazadoras-recolectoras y en el otro las economías agrícolas y/o pastoriles; caracterizándose las primeras por responder a la distribución espacio-temporal natural de los recursos, mientras que las segundas mantienen un estricto control sobre la ocurrencia de los recursos a través del manejo de su reproducción.

Evidentemente, cada tipo de patrón de subsistencia puede controlar en grado muy diferente la variabilidad en la disponibilidad de recursos, que es lo que define la cantidad y calidad del riesgo (Torrence 1989), no registrándose control en el primer caso pero sí en el segundo. Esto significa que hay grandes diferencias en la forma y severidad del riesgo asociado con cada tipo de subsistencia, lo que debería afectar las características de la tecnología lítica puesta en marcha en cada una.

Cabe destacar que la diferencia planteada refiere al riesgo de corto plazo, relacionado con el retorno inmediato de los recursos, el cual define a las economías cazadoras-recolectores pero que se presenta diferido en las economías agro-pastoriles (Escola 2000).

Esto no significa que en las economías productoras no hay riesgos, sino que en las mismas prevalecen los de largo plazo, como los riesgos de producción (derivados de las fluctuaciones climáticas y ecológicas) y los de trabajo (referidos a los problemas de competencia entre actividades agrícolas y ganaderas), así como ciertos problemas generados por la programación del tiempo (Browman 1987a, 1987b; Escola 1996, 2000). 
Una postura aparentemente contraria a ésta es planteada por Tomka (2001), en base a un estudio etnoarqueológico de una comunidad agro-pastoril de la Puna del sur de Bolivia. Para este autor, las características del sistema de producción agro-pastoril (duración del ciclo de producción, programación de las tareas, distribución espacial de la fuerza de trabajo, etc.), en combinación con la incertidumbre ambiental (pequeña cantidad y distribución espacial impredecible de las precipitaciones, baja predecibilidad temporal de las heladas), crean un contexto en el que el fracaso de la producción tiene consecuencias desastrosas. En base a esto sostiene que el caso abordado es un ejemplo de que en los sistemas productivos también hay, como en los cazadores-recolectores, riesgo de subsistencia.

Se sostiene, en relación con esta aseveración, que es indiscutible la existencia de riesgo de subsistencia en comunidades agro-pastoriles; sin embargo, los riesgos involucrados en el caso de Tomka refieren a un largo plazo, tratándose tanto de riesgos de producción como de trabajo, diferenciándose de aquellos que afectan a los cazadores-recolectores.

Tanto de la definición de riesgo como de la consideración de los riesgos de producción se desprende que las variaciones en el riesgo no sólo están relacionadas con la puesta en práctica de actividades productivas, sino también con modificaciones en las condiciones ambientales, ya que puede presentarse como consecuencia de fluctuaciones en los recursos en momentos de cambio ambiental. En este marco, serían riesgosos los “momentos de balance energético negativo” (Lanata y Borrero 1994), como el lapso marcadamente árido del Holoceno medio en la Puna meridional argentina.

Por lo general, se asume que la evidencia paleoambiental refleja la estructura de los recursos, obteniéndose una estimación gruesa del riesgo (Bousman 1993). Así, por ejemplo, un mejoramiento de las condiciones climáticas aumentaría la disponibilidad de comida y, en consecuencia, reduciría el riesgo de la caza y recolección. Sin embargo, se debe tener en cuenta que la naturaleza estocástica del ambiente actúa a una escala de riesgo distinta que la del riesgo de obtener o no obtener alimento en el día a día; aunque, indudablemente, la tecnología lítica debe responder a ambas escalas (Barton 1999).

En general, al considerar los efectos del riesgo sobre la tecnología lítica, se parte del análisis de la estructuración de los conjuntos instrumentales, en base a la propuesta de Torrence $(1989,2001)$ que toma en cuenta:

- la composición del conjunto: la asociación particular de clases de instrumentos. 
- la diversidad ${ }^{4}$ : la cantidad de clases presentes, ya que es un mecanismo que reduce la posibilidad de fracasar en la obtención de un recurso.

- la complejidad: el número de partes por instrumento o bien la media del número de partes de los instrumentos en un conjunto. Se postula que la complejidad del instrumental se incrementará a medida que el riesgo sea más importante.

Tales partes son denominadas “tecno-unidades” (technounits), definidas como “... an integrated physically distinct, and unique structural configuration that contributes to the form of a finished artefact” (Oswalt 1976: 38). Estas tecno-unidades se correlacionan directamente con los filos y puntas resultantes de la segmentación en sus partes componentes de los artefactos formatizados de la propuesta de Aschero (1975, 1983).

Es indudable la utilidad de estas variables para tratar la relación riesgo-tecnología, siendo, de hecho, empleadas en esta investigación; sin embargo, se considera que el análisis de la incidencia de los riesgos de corto plazo sobre la tecnología lítica debe involucrar el abordaje de conjuntos líticos completos (Escola 2000).

Se destaca que una variable de análisis adecuada en estudios de este tipo es la inversión de trabajo en la tecnología, ya que estará condicionada por la severidad de la consecuencia de no contar con los recursos necesarios (Torrence 1989).

\subsubsection{Movilidad y tecnología lítica}

Hay consenso en sostener que la movilidad condiciona las estrategias tecnológicas; de esta forma, distintas estrategias de movilidad afectan diferencialmente los diseños y las opciones tecnológicas empleadas (Kelly 1988, Nelson 1991, Hayden et al. 1996, Cowan 1999). Sin embargo, no hay relaciones simples entre movilidad y manufactura (Kelly 1992), ya que intervienen muchas otras variables, como la función de los instrumentos (Andrefsky 1998, Tomka 2001), el tipo y distribución de materias primas (Bamforth 1992, Andrefsky 1994a) y el riesgo (ver punto inmediato anterior). Más allá de esto, son indiscutibles los constreñimientos que impone la movilidad a la tecnología.

Si bien la movilidad es una propiedad de los individuos, pudiéndose mover los mismos de diferentes formas: solos o en grupos, frecuente o infrecuentemente, sobre cortas o largas distancias,

\footnotetext{
${ }^{4}$ En este caso, la noción de diversidad es empleada en su sentido amplio -es decir, como número de clases- y no desde un punto de vista estadístico. Por esto, no se realizan análisis específicos con el fin de establecer las características particulares de los componentes de la diversidad, es decir, la riqueza y la homogeneidad (por aplicaciones en el país ver, por ejemplo, Lanata 1996, Guráieb 1999).
} 
moviéndose algunos más que otros -hombres versus mujeres, niños versus adultos, parientes versus no parientes, etc.- a diferentes escalas -diaria, estacional, anual- (Kelly 1992, 1995), interesa particularmente aquí aquella referida a la movilidad residencial, que implica el movimiento del grupo de un campamento a otro (Binford 1980).

Justamente, el decrecimiento de la movilidad residencial produce una serie de respuestas por parte de la tecnología lítica, por lo cual es básico analizar las consecuencias sobre la tecnología lítica de los procesos de sedentarización, es decir, la disminución de la movilidad residencial que culmina en ocupaciones de año completo (Rafferty 1985, Kelly 1992).

Así, Parry y Kelly (1987) sostienen que hay marcadas diferencias en la tecnología lítica empleada por grupos móviles y sedentarios. De esta forma, en los primeros, la movilidad impone la necesidad de artefactos formatizados estandarizados, portátiles, mantenibles y multifuncionales, con correlatos en núcleos y desechos de talla, que implican generalmente un esfuerzo extra de producción, mientras que los segundos se definen por un pequeño o nulo esfuerzo de manufactura, con escaso desarrollo de las características anteriormente mencionadas (ver, por ejemplo, Odell 1994, 1998; Andrefsky 1998; Cowan 1999).

\subsubsection{Expectativas arqueológicas}

Al considerar los efectos de la disminución del riesgo de subsistencia y de la movilidad residencial reducida sobre la tecnología lítica, surge que los resultados a nivel de conjunto artefactual son similares, por lo que la discriminación de la importancia relativa de una sobre la otra es imposible desde los artefactos líticos mismos; si es factible, no obstante, una valoración del papel de cada uno de estos factores a partir de las evidencias de otras líneas de evidencia.

En Tabla 3.2 se generan una serie de expectativas en relación a la configuración de conjuntos totales específicos. Se parte de un caso en donde los riesgos de corto plazo son mínimos y que está caracterizado por baja movilidad residencial; expectativas opuestas ocurrirían en situaciones con riesgos de corto plazo elevados y alta movilidad. 
Producción lítica, variabilidad y cambio en Antofagasta de la Sierra -ca.5500-1500 AP-, Salomón Hocsman

Tabla 3.2. Expectativas arqueológicas por clase tipológica

\begin{tabular}{|c|c|}
\hline Clase tipológica & $\begin{array}{c}\text { Expectativas arqueológicas } \\
\text { Riesgo mínimo en corto plazo - Baja movilidad }\end{array}$ \\
\hline ARTEFACTOS FORMATIZADOS & $\begin{array}{l}\text { - bajo grado de inversión de trabajo en la manufactura } \\
\text { - bajo grado de estandarización del instrumental } \\
\text { - bajo grado de “complejidad” en el instrumental } \\
\text { - bajo grado de diversidad instrumental } \\
\text { - escaso mantenimiento y reciclaje } \\
\text { - diseño de instrumentos de corta vida útil } \\
\text { - ausencia de artefactos multifuncionales } \\
\text { - elección de materias primas de calidad diversa }\end{array}$ \\
\hline DESECHOS DE TALLA & $\begin{array}{l}\text { - presencia de técnicas que implican inversión de tiempo y } \\
\text { esfuerzo de manufactura mínimos } \\
\text { - baja estandarización } \\
\text { - elección de materias primas de calidad diversa }\end{array}$ \\
\hline NÚCLEOS & $\begin{array}{l}\text { - predominio de núcleos multidireccionales } \\
\text { - baja estandarización } \\
\text { - bajo grado de aprovechamiento de la masa útil } \\
\text { - elección de materias primas de calidad diversa }\end{array}$ \\
\hline
\end{tabular}

Las expectativas arqueológicas así reseñadas son abordadas en el Capítulo 13, en tanto que la información de base para su tratamiento se desarrolla en los Capítulos 8 a 12. 


\section{CAPÍTULO 4}

\section{METODOLOGÍA PARA EL ANÁLISIS TECNO-TIPOLÓGICO DE ARTEFACTOS LÍTICOS TALLADOS}

\subsection{APROXIMACIÓN TIPOLÓGICA}

El análisis tecno-tipológico de esta investigación se desarrolla sobre la propuesta de Aschero (1975, 1983) “Ensayo para una clasificación morfológica de artefactos líticos aplicada a estudios tipológicos comparativos” y sus Apéndices A, B y C. A este trabajo base se suman derivaciones subsidiarias sobre aspectos específicos generadas por Aschero (1987, 1988a, 2004a, 2004b, 2004c), Aschero y Hocsman (2004), Hocsman y Martínez (2004), Martínez (2003), Martínez y Hocsman (2004), Escola (2000, 2004a) y Pérez (2004). Asimismo, se presentan en este capítulo modificaciones e incorporaciones a la clasificación base en función de los problemas abordados.

Puede resultar paradójico, a primera vista, que un estudio centrado en analizar la variabilidad en el comportamiento humano y en los artefactos líticos tallados tenga como base metodológica una aproximación tipológica que, por ende, está centrada en unidades que buscan organizar la variabilidad morfológica en elementos manejables para su comunicación (Brézillon 1983, Orquera y Piana 1986, Andrefsky 1998).

$\mathrm{Al}$ respecto, para ciertos autores, al tratar de documentar la variación en el comportamiento, se requiere de una aproximación a los artefactos que enfoque más en el comportamiento de atributos en el tiempo y en el espacio que en la construcción de tipos (por ejemplo, Kelly 1992, Ramenofsky y Steffen 1998).

Es cierto que, en general, las tipologías han sido empleadas meramente para facilitar la descripción y comparación formal de los conjuntos arqueológicos, privilegiando aquellos "tipos” que reflejaban especificidad temporal o espacial. Sin embargo, la tipología lítica hace tiempo que ha dejado de limitarse a “... reconocer, definir y clasificar las diferentes variedades de útiles...” (Bordes 1961), con el interés último de elaborar listas tipológicas, para buscar dilucidar modos humanos de conducta a partir de los artefactos y contextos en espacio y tiempo (Smith 1966, Vierra 1982, Eiroa et al. 1989, Demars y Laurent 1992). Es decir, de una visión estática de la tipología, donde ésta 
constituía un fin en sí mismo, se pasó a considerarla como un medio para adquirir información sobre el comportamiento humano.

Al considerar la propuesta de Aschero (1975), el “tipo” es una unidad de índole analítica que es la síntesis de un determinado número de atributos morfológicos, relevantes desde el punto de vista técnico y funcional. El tipo no es una construcción arbitraria del operador, sino que es más bien una construcción o abstracción realizada a partir de los atributos que el operador selecciona, por su repetición, de la totalidad de los descriptos para el conjunto, en el marco de un continuum morfológico al que hay que ordenar de acuerdo a las características que el propio material ofrece. Por ende, dicha clasificación no omite la existencia de un rango infinito de variabilidad morfológica, sino que simplemente la estructura de cierta forma. En este marco, puede resultar de interés, por ejemplo, analizar la variabilidad de grupos tipológicos en un sitio o de subgrupos tipológicos dentro de un grupo tipológico dado ${ }^{1}$, o bien abordar las variaciones de atributos específicos, como el largo y el ancho en una clase particular de artefacto.

En función del continuum morfológico señalado, se remarca que "El Ensayo...” no se basa en una visión esencialista de la variabilidad (Dunnell 1986), ya que no supone que la variabilidad ocurre en paquetes discretos y que aquella variabilidad no asignable a tales paquetes carece de significancia. Los tipos así definidos deben entenderse como aproximaciones arqueológicas a tipos empíricos, no a tipos como esencias (Shott 2003).

Desde esta perspectiva es posible, entonces, plantear un estudio de la variabilidad tipológica y tecnológica de conjuntos de artefactos líticos tallados.

Por otra parte, al observar las recurrencias morfológicas que se verifican en las herramientas simples conocidas actualmente y las “arqueológicas", que cuentan con atributos relativamente constantes que, por su propio carácter elemental, son recurrentes en tiempo y espacio, es viable considerar la existencia de una historia morfológica de las herramientas simples y las armas que se puede trazar en el tiempo (Aschero 1975, Leroi-Gourhan 1988, Pigeot 1991). Al abordar este tema desde un sistema de comparación basado en una nomenclatura sistematizada, orientado específicamente a la distinción de recurrencias y diferencias morfológicas, es factible la búsqueda de variación dentro de los artefactos líticos tallados, siempre que la sistematización esté guiada por principios teóricos apropiados (Vierra 1982).

En suma, el análisis de la variabilidad técnico-morfológica y morfológico-funcional de artefactos líticos puede transformarse en una herramienta viable para lograr conocimiento sobre la

\footnotetext{
${ }^{1}$ De hecho, Aschero (com pers.) instrumentó a los grupos y subgrupos tipológicos como una “apertura” hacia la variabilidad.
} 
variabilidad en el comportamiento de cazadores-recolectores en transición a un modo de vida agropastoril. El hecho de tratarse de una aproximación tipológica no es un impedimento para lograr tal objetivo.

\subsection{CONSIDERACIONES ACERCA DEL ANÁLISIS MORFOLÓGICO-MACROSCÓPICO EN ARTEFACTOS LÍTICOS TALLADOS}

El análisis emprendido es de tipo macroscópico y morfológico-descriptivo, ya que está basado en la observación a simple vista de las piezas líticas talladas y en la descripción de caracteres o relaciones de índole morfológico (Aschero 1975).

El principio de la morfología descriptiva reside en una aproximación analítica que se basa en disociar los diversos componentes de la morfología de un objeto a fin de establecer sus particularidades (Brézillon 1983). Como su nombre lo indica, se parte de la descripción de las “formas” de cada pieza, previa segmentación en partes y/o sectores diferentes, sean filos y/o puntas y/o superficies activas, de acuerdo a atributos estandarizados.

El análisis morfológico-descriptivo comprende 3 pasos (Aschero 1975):

1) segmentación del conjunto y de cada una de las piezas

2) descripción técnico-morfológica

3) descripción morfológico-funcional

\subsubsection{SEGMENTACIÓN DEL CONJUNTO Y DE CADA UNA DE LAS PIEZAS}

La segmentación del conjunto lítico implica la distinción en subconjuntos líticos y clases tipológicas (ver punto inmediato posterior 4.3. Categorías analíticas consideradas). Dentro de cada uno de estos agrupamientos, la descripción de cada pieza se realiza una vez que la misma haya sido orientada de acuerdo al eje de lascado o al morfológico, que se hayan distinguido caras, bordes, dorsos, filos, puntas o superficies activas y que se establezcan "sectores descriptivos" a través de la cuadrícula de segmentación (ver Apéndice 1), para dar cuenta de las partes descriptas.

De acuerdo a la propuesta de Aschero (1975, 1983), si bien los artefactos formatizados son segmentados en sus partes componentes, un gran peso del análisis recae sobre las piezas como un 
todo. En este caso, en cambio, se prioriza la consideración de los filos/puntas que los componen, trabajándose con listas tipológicas que implican el total de filos y/o puntas presentes en los artefactos formatizados estudiados. Se destaca que lo señalado precedentemente se aplica marcando las diferencias de lo que Demars y Laurent (1992) definen como piezas de morfología parcial y global. Las primeras son instrumentos (en este caso filos/puntas) que presentan formas relativamente variables, con una formatización que en general afecta sólo el borde de la pieza, así como parte del mismo (por ejemplo: raederas, raspadores, buriles). Por su parte, las segundas, tales como las puntas de proyectil, los bifaces y las palas y/o azadas, son consideradas en los conteos como una totalidad, a pesar de ser, de hecho, segmentadas en sus diferentes partes. Esto responde a la necesidad y conveniencia, dada su relevancia, de mantener el diseño del artefacto tal como fue concebido ${ }^{2}$.

Por otro lado, también se plantean ciertas diferencias en cuanto al registro de la parte segmentada (Aschero 1983). Así, para este autor, en la segmentación se distinguen partes activas básicas y complementarias (estas últimas pueden referir a otros grupos tipológicos o bien a dorsos o partes de prehensión, por lo que también pueden ser pasivas). Por ejemplo, cuando dos o más grupos tipológicos distintos están representados en una misma pieza, a uno de ellos se lo llamaba básico y al (a los) otro (s) complementario(s). Se propone que la designación de filos básicos sea dejada de lado para evitar que se pudiera entender un "peso" distinto de ciertos diseños de filos o puntas frente a otros presentes en una misma pieza (Aschero 2004c). Sin embargo, la distinción entre artefactos con o sin filos complementarios, esto es, “compuestos” y "no-compuestos” (aquellos con uno o más filos o puntas de un único grupo tipológico) es mantenida. Aschero (ibid.: 16) justamente retiene “... el uso del concepto "filo, punta o plataforma complementaria” para designar los casos en que hay más de un grupo tipológico representado en los filos, puntas o plataformas de una misma pieza. En la descripción de la pieza son "complementarios" aquellos que corresponden al segundo y subsecuentes registros de una descripción tipológica completa de la pieza”.

Esta noción de complementariedad tal como es definida por el autor implica un ingreso por medio de un filo o una punta de la pieza a la lista tipológica. Como se parte aquí de la concepción de que todos los filos y puntas presentes son igualmente importantes, se plantea la no utilización de este tipo de ingreso, empleándose listas tipológicas resultantes de la suma total de partes componentes.

Sí se considera importante, no obstante, mantener la diferencia entre partes activas y pasivas. En las primeras, la formatización está destinada a preparar un filo o punta para su uso posible sobre un objeto dado, mientras que en las segundas la formatización va a estar destinada a facilitar la prehensión o el enmangamiento (Demars y Laurent 1992). Cabe destacar que para Aschero (1975), un

\footnotetext{
${ }^{2}$ Tomando este criterio, al clasificar a los artefactos formatizados según “clases técnicas” (ver más adelante), las puntas de proyectil, los bifaces o las palas se toman como un todo. Igual situación es la de artefactos con filos convergentes, en los cuales se define la clase técnica en función del diseño global.
} 
filo es todo borde caracterizado por una arista "activa”, cualquiera sea el tipo de bisel que presente; en tanto que el dorso es un filo abrupto, mayor de $70^{\circ}$, que se opone a un filo (sensiblemente) menor de $70^{\circ}$. No obstante, pueden presentarse otras morfologías, que pueden calificarse como pasivas y que no son dorsos, resultantes de una formatización incluso sumaria que permite que la mano "se adapte” a la pieza para realizar el gesto técnico apropiadamente.

El papel evidente de las zonas activas hace que, por lo general, los esfuerzos tipológicos se concentren en ellas. Sin embargo, el examen de los medios de prehensión o de enmangamiento permite, por una parte, guiar la investigación de cómo trabajaron los filos y/o puntas y, por otra parte, completar la información de cómo fueron usados, en referencia a los gestos técnicos empleados (Brézillon 1983). Más aún, su consideración es imprescindible puesto que el instrumento se comporta como una suerte de intermediario ante la realización de un contacto con un objeto, posición que implica una doble adaptación: 1) contacto de la parte activa con el objeto aludido y 2) contacto del operador con el instrumento, el cual puede ser directo, con un sector de prehensión manual, o indirecto, por la interposición de un dispositivo de enmangamiento (ibid.).

\subsubsection{DESCRIPCIÓN TÉCNICO-MORFOLÓGICA Y MORFOLÓGICO-FUNCIONAL}

La descripción técnico-morfológica y morfológico-funcional se diferencian por el tipo de inferencias que se pueden extraer de cada una de ellas, ya que el análisis de las "formas" respecto de las normas frontal, lateral y basal de observación de la pieza, permite una determinada gama de inferencias dentro del campo de la técnica con que dicha pieza fue confeccionada o de la función que pudo desempeñar (Aschero 1975).

Se aclara que en la segunda se tratan de captar las variantes morfológicas que distinguen filos o puntas entre sí, teniendo en cuenta que ellos son el objetivo último o la "forma-producto" de una elección funcional. Tales caracteres son considerados "funcionales” puesto que se considera que todo cambio o variación que presente una de estas “formas” implica un modo de contacto o de penetración diferente entre el instrumentos y el objeto a modificar (ibid.).

En ambas descripciones se emplean formas, relaciones morfológicas, posiciones y dimensiones relativas o absolutas, a modo de parámetros descriptivos en cuyos atributos específicos se trata de captar los resultados de la actividad artesanal.

Las variables técnico-morfológicas y morfológico-funcionales empleadas, según el caso, en el análisis de artefactos formatizados (Tabla 4.1), desechos de talla (Tabla 4.2) y núcleos (Tabla 4.3) se 
encuentran descriptas en el Apéndice I, con excepción de las variables empleadas en la descripción de grupos tipológicos de artefactos bifaciales (ver punto 4.5.3. Descripción de grupos tipológicos de artefactos bifaciales de este Capítulo). 
Tabla 4.1. Artefactos formatizados. Lista de variables agrupadas por su naturaleza

\begin{tabular}{|c|c|c|}
\hline 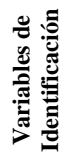 & $\begin{array}{l}\text { Operador/a y fecha } \\
\text { Número de hoja } \\
\text { 7. Número de bolsa } \\
\text { 8. Color de talonario }\end{array}$ & $\begin{array}{l}\text { 9. Número de pieza } \\
\text { 10. Código de Inventario } \\
\text { 11. Descripción }\end{array}$ \\
\hline 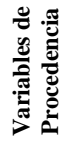 & $\begin{array}{l}\text { 1. Nombre del sitio } \\
\text { 2. Campaña mes / año } \\
\text { 3. Area / Sector }\end{array}$ & $\begin{array}{l}\text { 4. Cuadrícula / microsector } \\
\text { 5. Capa / Nivel } \\
\text { 6. Número de extracción }\end{array}$ \\
\hline 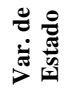 & $\begin{array}{l}\text { 12. Manufactura compuesta } \\
\text { 13. Sustancia adherida } \\
\text { 14. Pieza entera / fracturada }\end{array}$ & $\begin{array}{l}\text { 44. Alteraciones } \\
\text { 90. Sustancia adherida (segmentación) }\end{array}$ \\
\hline 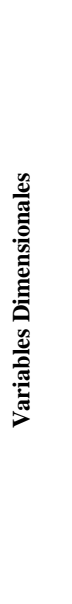 & $\begin{array}{l}\text { 25. Longitud máxima de la pieza } \\
\text { 26. Ancho máximo de la pieza } \\
\text { 27. Espesor máximo de la pieza } \\
\text { 28. Altura al Ancho máximo desde la base } \\
\text { 29. Altura al Espesor máximo desde la base } \\
\text { 30. Razón L/A } \\
\text { 31. Razón A/E } \\
\text { 32. Peso } \\
\text { 33. Tamaño } \\
\text { 34. Mod L-A } \\
\text { 35. Mod A-E } \\
\text { 36. Espesor relativo } \\
\text { 37. Longitud del pedúnculo / sector basal } \\
\text { 38. Ancho de la raíz del pedúnculo / sector basal } \\
\text { 39. Espesor de la raíz del pedúnculo / sector basal } \\
\text { 40. Ancho de la base del pedúnculo / sector basal } \\
\text { 58. Ancho del talón } \\
\text { 59. Espesor del talón } \\
\text { 60. Angulo medido del talón } \\
\text { 61. Angulo estimado del talón } \\
\text { 68. Longitud del filo o punta }\end{array}$ & $\begin{array}{l}\text { 69. Profundidad del bisel formatizado } \\
\text { 70. Profundidad de los últimos lascados de formatización } \\
\text { 71. Ancho de la boca de los últimos lascados de formatización } \\
\text { 82. Profundidad del bisel reactivado } \\
\text { 83. Profundidad de los últimos lascados de reactivación } \\
\text { 84. Ancho de la boca de los últimos lascados de reactivación } \\
\text { 85. Angulo medido } \\
\text { 86. Angulo estimado } \\
\text { 92. Angulo medido del ápice } \\
\text { 93. Angulo estimado del ápice } \\
\text { 94. Amplitud Aleta } \\
\text { 95. Angulo aleta } \\
\text { 97. Espesor de la fractura } \\
\text { 105. n (anchura a la mitad de la longitud, en bifaces) } \\
\text { 106. c (anchura a 3/4 de la longitud, en bifaces) } \\
\text { 107. Razón L/a (donde "a” es la altura al ancho máximo, desde la base) } \\
\text { 108. Razón n/A } \\
\text { 109. Razón L / A raíz (pedúnculo / sector basal) } \\
\text { 110. Razón L / A base (pedúnculo / sector basal) } \\
\text { 111. Razón A máximo / E máximo (pedúnculo / sector basal) }\end{array}$ \\
\hline 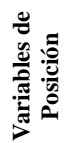 & $\begin{array}{l}\text { 64. Código y registro de parte segmentada } \\
\text { 66. Cara } \\
\text { 67. Posición del filo o punta } \\
\text { 81. Posición de la reactivación }\end{array}$ & $\begin{array}{l}\text { 89. Posición de los rastros complementarios } \\
\text { 91. Posición sustancia adherida } \\
\text { 96. Posición de la fractura }\end{array}$ \\
\hline 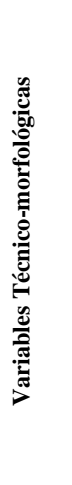 & $\begin{array}{l}\text { 21. Serie técnica } \\
\text { 24. Causa de descarte durante manufactura } \\
\text { 41. Materia prima } \\
\text { 42. Color } \\
\text { 43. Distribución del color } \\
\text { 45. Forma base (caracteres básicos) } \\
\text { 46. Forma base (caracteres complementarios) } \\
\text { - Cara ventral: } \\
\text { 47. Bulbo de percusión } \\
\text { 48. Cono de percusión } \\
\text { 49. Punto de percusión } \\
\text { 50. Ondas de percusión } \\
\text { 51. Estrías de percusión } \\
\text { 52. Labio } \\
\text { 53. Lascas adventicias } \\
\text { 54. Restos de cara ventral }\end{array}$ & $\begin{array}{l}\text { - Cara dorsal: } \\
\text { 55. Negativo/s de lascado original/es } \\
\text { 56. Corteza } \\
\text { - Talón / plataforma de percusión: } \\
\text { 57. Estado } \\
\text { 62. Forma de la superficie del talón } \\
\text { 63. Regularización del borde / frente de extracción } \\
\text { 72. Secuencia de formatización } \\
\text { 73. Profundidad de los lascados sobre el borde } \\
\text { 74. Situación de los lascados sobre las caras } \\
\text { 98. Forma geométrica de la fractura } \\
\text { 99. Sección de la fractura } \\
\text { 100. Forma de la superficie de fractura } \\
\text { 101. Defectos } \\
\text { 104. Clase técnica }\end{array}$ \\
\hline 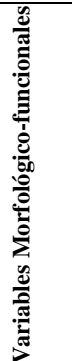 & $\begin{array}{l}\text { 15. Forma geométrica del contorno } \\
\text { 16. Forma geométrica del limbo } \\
\text { 17. Sección transversal de la pieza } \\
\text { 18. Sección longitudinal de la pieza } \\
\text { 19. Cantidad de filos o puntas del mismo grupo tipológico } \\
\text { 20. Presencia de filos o puntas complementarias, correspondientes a } \\
\text { otros grupos tipológicos } \\
\text { 22. Mantenimiento } \\
\text { 23. Reciclaje }\end{array}$ & $\begin{array}{l}\text { 65. Grupo tipológico - subgrupo tipológico } \\
\text { 75. Conformación del borde } \\
\text { 76. Regularidad del borde y la arista activa } \\
\text { 77. Forma de la base } \\
\text { 78. Tratamiento técnico diferencial } \\
\text { 79. Forma y dirección de los lascados de formatización } \\
\text { 80. Terminación de los lascados sobre las caras } \\
\text { 87. Estado del filo o ápice activo } \\
\text { 88. Rastros complementarios } \\
\text { 102. Sinuosidad } \\
\text { 103. Secuencia tipológica }\end{array}$ \\
\hline
\end{tabular}

Nota: los números identificatorios de las variables en esta tabla corresponden a los asignados para ellas en el procedimiento para la descripción de las piezas contenido en el Apéndice I. 
Producción lítica, variabilidad y cambio en Antofagasta de la Sierra -ca.5500-1500 AP-, Salomón Hocsman

Tabla 4.2. Desechos de talla. Lista de variables agrupadas por su naturaleza

\begin{tabular}{|c|c|c|}
\hline 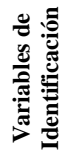 & $\begin{array}{l}\text { Operador/a y fecha } \\
\text { Número de hoja } \\
6 \text {. Número de bolsa }\end{array}$ & $\begin{array}{l}\text { 7. Color de talonario } \\
\text { 8. Número de planta } \\
\text { 9. Número de pieza }\end{array}$ \\
\hline 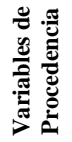 & $\begin{array}{l}\text { 1. Nombre del sitio } \\
\text { 2. Fecha de campaña } \\
\text { 3. Area / Sector }\end{array}$ & $\begin{array}{l}\text { 4. Cuadrícula / microsector } \\
\text { 5. Capa / nivel / extracción }\end{array}$ \\
\hline 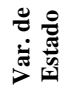 & 11. Cantidad de piezas por estado de fragmentación & 12. Número total de especímenes \\
\hline 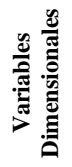 & $\begin{array}{l}\text { 17. Longitud máxima de la pieza } \\
\text { 18. Ancho máximo de la pieza } \\
\text { 19. Espesor máximo de la pieza } \\
\text { 20. Características litométricas } \\
\text { 21. Características litotécnicas }\end{array}$ & $\begin{array}{l}\text { 22. Ancho del talón } \\
\text { 23. Espesor del talón } \\
\text { 24. Angulo de cara ventral } \\
\text { 25. Angulo de cara dorsal }\end{array}$ \\
\hline 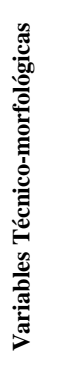 & $\begin{array}{l}\text { 10. Materia prima } \\
\text { 13. Tipo de lasca } \\
\text { - Cara dorsal: } \\
\text { 14. Posición del eje morfológico } \\
\text { 15. Número de negativos de lascado en cara dorsal } \\
\text { 16. Porcentaje de corteza en cara dorsal } \\
\text { - Talón: } \\
\text { 26. Forma del talón } \\
\text { 27. Tratamiento técnico diferencial } \\
\text { 28. Porcentaje de corteza en el talón } \\
\text { 29. Número de negativos de lascado en el talón }\end{array}$ & $\begin{array}{l}\text { - Cara ventral: } \\
\text { 30. Punto de percusión } \\
\text { 31. Labio } \\
\text { 32. Estrías de percusión } \\
\text { 33. Bulbo de percusión } \\
\text { 34. Lasca adventicia } \\
\text { 35. Ondas de percusión } \\
\text { 36. Terminación }\end{array}$ \\
\hline
\end{tabular}

Nota: los números identificatorios de las variables en esta tabla corresponden a los asignados para ellas en el procedimiento para la descripción de las piezas contenido en el Apéndice I.

Tabla 4.3. Núcleos. Lista de variables agrupadas por su naturaleza

\begin{tabular}{|c|c|c|}
\hline 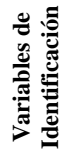 & $\begin{array}{l}\text { Operador/a y fecha } \\
\text { Número de hoja } \\
\text { 7. Número de bolsa } \\
\text { 8. Color de talonario }\end{array}$ & $\begin{array}{l}\text { 9. Número de pieza } \\
\text { 10. Designación morfológica del núcleo }\end{array}$ \\
\hline 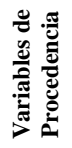 & $\begin{array}{l}\text { 1. Nombre del sitio } \\
\text { 2. Campaña mes / año } \\
\text { 3. Area / Sector }\end{array}$ & $\begin{array}{l}\text { 4. Cuadrícula / microsector } \\
\text { 5. Capa / Nivel } \\
\text { 6. Número de extracción }\end{array}$ \\
\hline 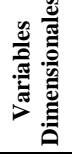 & $\begin{array}{l}\text { 13. Longitud máxima de la pieza } \\
\text { 14. Ancho máximo de la pieza } \\
\text { 15. Espesor máximo de la pieza }\end{array}$ & $\begin{array}{l}\text { 18. Anchura máxima de la plataforma de percusión } \\
\text { 19. Espesor máximo de la plataforma de percusión } \\
\text { 20. Angulo medido entre la plataforma y los negativos de lascado }\end{array}$ \\
\hline 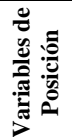 & 16. Código y registro de parte segmentada & \\
\hline 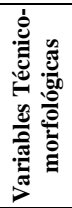 & $\begin{array}{l}\text { 11. Materia prima } \\
\text { 12. Forma base } \\
\text { 17. Estado de la plataforma de percusión }\end{array}$ & $\begin{array}{l}\text { 21. Forma de la superficie de la plataforma de percusión } \\
\text { 22. Regularización del borde de extracción } \\
\text { 23. Regularización del frente de extracción }\end{array}$ \\
\hline
\end{tabular}

Nota: los números identificatorios de las variables en esta tabla corresponden a los asignados para ellas en el procedimiento para la descripción de las piezas contenido en el Apéndice I. 


\subsection{CATEGORÍAS ANALÍTICAS CONSIDERADAS}

Se describen a continuación las categorías analíticas base de este trabajo (modificado de Aschero y Hocsman 2004), que funcionan a modo de niveles sucesivos de clasificación (Figura 4.1):

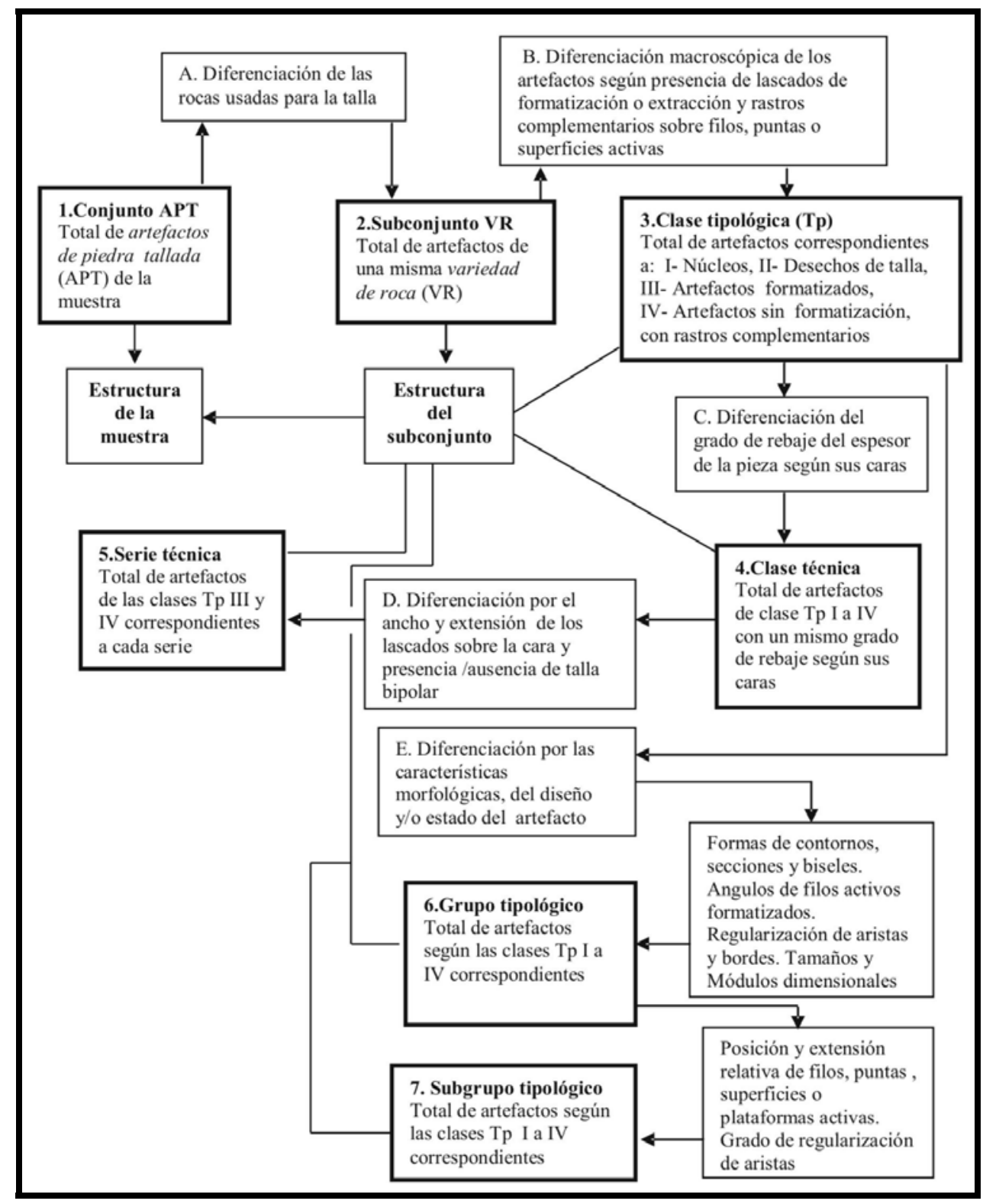

Figura 4.1. Categorías y niveles de clasificación

\subsubsection{CONJUNTO LÍTICO}

El conjunto lítico, que es el primer nivel de clasificación o categoría 1, está constituido por una muestra procedente de una excavación arqueológica, de una recolección de superficie o de un trabajo experimental, bajo ciertas condiciones de asociación. 


\subsubsection{SUBCONJUNTO LÍTICO}

El subconjunto lítico es la primera instancia de separación del conjunto lítico, según las variedades y/o calidades de las materias primas diferenciadas.

\subsubsection{CLASE TIPOLÓGICA}

La clase tipológica agrupa a aquellos artefactos cuyas características morfológicas permiten diferenciarlos en: I- Núcleos, II- Desechos de talla, III- Artefactos formatizados y IV- Artefactos (lascas u hojas) con filos, puntas o superficies con rastros complementarios.

Esta investigación se desarrolla sobre la base del análisis de las clases I a III. No se consideran los artefactos con rastros complementarios ya que no es posible discriminar macroscópicamente un origen producto del uso, de procesos post-depositacionales, por prehensión o bien por preparación de plataformas (Aschero 1983). Asimismo, la presencia de una importante cuota de ventifacción en ciertos contextos abordados y no en otros, implica que en algunos se ha eliminado todo vestigio al respecto, por lo que se generarían problemas de muestreo. Las únicas excepciones a esto son los cuchillos de filo natural con dorso formatizado y los cortantes de filo natural con dorso formatizado, en los que el filo con rastros complementarios, menor a $50^{\circ}$ y simétrico, está acompañado de un filo formatizado pasivo.

Esto implica que no se incluyen en los conteos piezas con filos naturales con rastros simples, dobles o triples, o estos filos cuando se combinan con filos formatizados (esto implica que a estos últimos se los trata como piezas simples). Si, empero, se tiene en cuenta la presencia y clase de rastros complementarios en aquellos artefactos formatizados que los posean o cuando no hay dudas que conforman dorsos asociados a filos y/o puntas de instrumentos.

\subsubsection{CLASE TÉCNICA}

La clase técnica distingue grados de trabajo invertido en la producción de artefactos de piedra tallada para las distintas clases antes mencionadas. Esta inversión de trabajo se mide, en los productos finales, a través de la superposición de lascados que cubren total o parcialmente la superficie de una u otra cara del artefacto, entrecruzándose o no en el eje medio de la pieza. Esos lascados son efectos resultantes de distintas operaciones técnicas -las diversas modalidades de la talla por percusión o por presión- implementadas para rebajar el espesor de la forma-base elegida. Esto es: para alcanzar un 
espesor requerido por el diseño final, en un útil o instrumento, o para obtener un determinado producto de talla de la parte interna de la masa lítica original, en un núcleo. Por lo tanto, estas operaciones de rebaje -con su plus de trabajo invertido- pueden obedecer a la búsqueda de productos finales diferentes, sea que se trate con artefactos formatizados o con núcleos. A su vez, los desechos de talla procedentes de estas tareas van a presentar características particulares que reflejan si se trata de una u otra de estas tareas de rebaje.

Este nivel opera como una tercera instancia en la separación de la muestra y tiene en cuenta, según las distintas clases tipológicas, la observación de características diferentes. Interesan:

- En desechos de talla: morfología del talón, morfología de la cara dorsal, morfología de la cara ventral y módulo dimensional.

- En artefactos formatizados: la cobertura total o parcial de los lascados, con o sin rebaje del espesor de la pieza, en cada una de sus caras. Complementariamente se observa el tipo de sección en norma sagital y lateral, el tamaño y el espesor relativo de las piezas dentro del conjunto.

En la propuesta original de Aschero (1975), se incluía a los núcleos y a los desechos de talla dentro de series técnicas específicas. Sin embargo, las diferencias en la inversión de trabajo durante el desbaste de núcleos a partir de distintos procedimientos técnicos -por ejemplo, al considerar núcleos poliédricos en relación a núcleos bifaciales o a núcleos de hojas y sus desechos resultantes- y el hecho de que las variables empleadas en la definición de las series técnicas (ver punto 4.3.5. Serie técnica) no cubren los aspectos mencionados para una adecuada caracterización de núcleos y desechos de talla, se consideran razones suficientes como para excluir a ambas categorías de las series técnicas e incorporarlas en esta propuesta como clases técnicas ${ }^{3}$.

\subsubsection{SERIE TÉCNICA}

La serie técnica establece las diferencias entre los distintos procedimientos técnicos utilizados para dar forma a cada artefacto formatizado o serie de instrumentos. Sólo se la emplea para artefactos formatizados y lascas u hojas con rastros complementarios, es decir, para las clases tipológicas III y IV. Estas últimas, a los fines de su representación en la estructura tipológica del conjunto, se reúnen en la serie "talla de extracción sin formatización".

\footnotetext{
${ }^{3}$ Por más que no son tratados aquí, los artefactos con rastros complementarios se deberían incluir en el análisis de las clases técnicas, al igual que los desechos de talla, para integrar la información del origen de la extracción de las formas-base, es decir, si proceden de tareas de extracción de lascas u hojas externas (con reserva de corteza) o internas (sin reserva de corteza).
} 
Para la caracterización de los artefactos formatizados se toma en cuenta: la secuencia de lascados de formatización, el tamaño de la boca de los lascados en el borde de la pieza, la diferencia en los anchos de los negativos de lascados en el sector central de las caras (en el caso de superposición de series de lascados) y la extensión más la profundidad relativa de los lascados en cada cara.

\subsubsection{GRUPO TIPOLÓGICO}

El grupo tipológico diferencia los artefactos según su diseño. Esta categoría opera como un vía analítica independiente de la clase y serie técnica (ver Figura 4.1) y, en algunos casos, requiere utilizar atributos empleados por aquellas para definir los diseños. Deben distinguirse, al respecto, tres niveles de aplicación del término diseño: el referido a la producción de ciertos tipos de artefactos, el referido a la concepción de la distintas partes (artefactos) que componen un instrumento compuesto (astil, intermediario y cabezal de un proyectil, por ejemplo) y el que se refiere a la concepción de equipo de artefactos transportables que constituyen el mínimo de útiles requeridos para ejecutar una serie de tareas previstas o concatenadas (equipo o set instrumental).

El primer nivel es el aplicado aquí y debe referirse a dos campos de observación: el contorno y caras del artefacto bajo tres normas de observación -frontal, lateral y sagital (la pieza vista desde su porción basal o distal)- y el tratamiento de cada uno de sus bordes para producir filos o puntas (aristas o ápices activos) o sectores pasivos de prehensión (dorsos).

En el caso de los artefactos formatizados y en particular de los bifaciales que se tratan luego, esta diferenciación resulta fundamental. Por ejemplo, dos artefactos pueden haberse producido mediante adelgazamiento bifacial y tener un 100\% de cobertura de las caras por lascados, tener los contornos simétricos y variar en el diseño de ambos bordes y/o su porción basal. Sería el caso de una punta de proyectil apedunculada de contorno subtriangular y de un cuchillo más raedera con la misma forma de contorno y dimensiones e igual rebaje de la porción basal.

La primera presentará un trabajo final de regularización semejante para ambos bordes del limbo y el ápice activo, definiendo las distintas partes que juegan un rol unitario en la función de punción y penetración a distancia y de sujeción al intermediario. En la otra pieza el diseño de cada filo ha previsto una función independiente para cada uno, la raedera y el cuchillo, diferenciándose por secciones de filos y ángulos diferentes. En este último caso ha de esperarse que en el diseño del artefacto estas funciones sean complementarias, esto es, que se articulen en la sucesión de tareas a cumplir por un mismo útil. El adelgazamiento bifacial opera en este último caso facilitando: a) el enmangue y/o b) el mantenimiento de ambos filos mediante un biselado profundo que facilita la 
reactivación o reavivamiento. Estas diferencias deben ser captadas y desplegadas por el estudio morfológico macroscópico, para facilitar, también, un posterior estudio microscópico de los rastros de uso.

Lo expuesto viene al caso de los "bifaces" propiamente dichos que deben ser caracterizados también no sólo por el tratamiento de las caras y el rebaje del espesor, sino también por la morfología de sus filos. Es decir, por una forma particular de filo diseñado para convertirse rápidamente en "otro". Son los llamados filos bifaciales de arista sinuosa (ver punto 4.5.3.2.4. El grupo tipológico de los filos bifaciales de arista sinuosa en este Capítulo) -una sinuosidad que puede ser regular o irregular-, combinando la observación del borde en norma frontal y de la arista en norma lateral. Si bien este carácter o atributo morfológico es el que caracteriza a los esbozos bifaciales, bifaces, piezas foliáceas y unifaces, también fue observado en filos complementarios (dorsos) de piezas formatizadas de retoque marginal, en la mayoría de los casos de raederas, raspadores o cuchillos. Esto lleva a proponerlos como un grupo tipológico independiente, una categoría que facilita la descripción segmental de los distintos diseños de filos que pueden ocurrir en una misma pieza.

Para la definición de grupos tipológicos se utilizan distintos caracteres morfológicos aplicados a la caracterización de:

- La forma general del contorno y caras del artefacto. Se incluye a) la extensión de los lascados sobre la cara, b) la simetría o asimetría en norma frontal, lateral y sagital y c) la forma de la sección transversal de la pieza.

El eje para determinar la simetría/asimetría en normas sagital y lateral es el plano virtual trazado entre las aristas de bordes opuestos.

- La conformación particular de los bordes en sectores pasivos, filos y puntas. Se incluye d) la situación de los lascados respecto a las caras de la pieza, aquí referidos a la conformación del bisel, arista y/o ápice activo; e) la profundidad de los lascados desde el borde o profundidad relativa del bisel; f) la delineación de la arista de filos en norma frontal (antes denominada "conformación del borde” (Aschero 1983); g) la regularidad de la arista combinando la observación en norma frontal y lateral; h) la simetría de la sección del bisel -en relación al plano virtual antes referido- combinada con la presencia de biseles simples o dobles; i) la forma geométrica del filo o de la sección transversal de la punta; y j) los ángulos del filo o del ápice activo, el real o medido y el original o estimado. 


\subsubsection{SUBGRUPO TIPOLÓGICO}

Los subgrupos tipológicos especifican los diseños de los grupos. Para artefactos de adelgazamiento bifacial o unifacial se utilizan los mismos caracteres morfológicos que se detallan en el acápite siguiente.

Para artefactos con formatización marginal se toman en cuenta los siguientes caracteres: a) extensión relativa del filo sobre el borde de la pieza; b) posición relativa del filo o punta respecto al eje longitudinal de la pieza; y c) relación de convergencia entre filos consecutivos o aristas laterales de una punta destacada (en el caso de perforadores o puntas entre muescas).

\subsubsection{TIPO}

Para Aschero (1975), un tipo es la síntesis de un determinado número de atributos morfológicos, relevantes desde el punto de vista técnico y funcional, que se repiten en dos o más piezas del conjunto en estudio. Se trata de unidades morfológicas que se repiten en espacio y tiempo, por lo que la definición de un tipo resulta de un análisis comparativo en coordenadas espaciotemporales.

Mientras que los grupos tipológicos son clases o agrupamientos mayores que presentan algunos caracteres comunes tras sus diferencias específicas, los tipos morfológicos resultan de la comparación y descripción segmental de especimenes individuales, implicando, a la vez, un cierto grado de síntesis dentro del total de variables morfológicas empleadas en la descripción. “... son la suma descriptiva de los atributos incluidos en la definición de una "serie”, un "grupo” y un "subgrupo", más todos aquellos otros atributos que se definen dentro de cada conjunto, conformando su individualidad...” (Aschero 1975: 5). Asimismo, se diferencian de los grupos tipológicos por ser definidos en relación a un marco espacio-temporal.

Se propone una modificación a la clasificación de Aschero (1975) de los tipos morfológicos. Así, se plantea diferenciar entre tipos standard y tipos recurrentes escasos. Los primeros implican un tipo morfológico que está representado por un alto porcentaje o número de piezas a diferencia de los restantes tipos y que, llevado a nivel comparativo, mantiene esa relación en otros conjuntos. Los segundos, por su parte, son tipos que están representados con una baja frecuencia de piezas en el conjunto analizado pero que, en el curso del análisis comparativo, muestran una distribución amplia en distintos conjuntos regionales, aunque siempre con una frecuencia baja. Asimismo, estos últimos pueden presentarse en un solo sitio, siendo registrados reiteradamente en un momento determinado. 
Ambas clases de tipos se definen por la recurrencia de ciertos atributos morfológicos, pero puede haber casos en que esta recurrencia no se presenta, por lo que dichas series de atributos configuran diseños únicos que difieren de los diseños encontrados en forma más o menos ubicua regionalmente. Para estos diseños se propone el calificativo de especimenes morfológicos. Se destaca que éstos no constituyen tipos, dada su aparición en un sólo sitio como un único ejemplar. Estas piezas pueden convertirse en tipo mediante el análisis de otros conjuntos regionales, es decir, son tipos "en potencia”.

Cabe introducir aquí la distinción entre tipos morfológicos "básicos” y "transformados" (Aschero 1988a). Los primeros refieren a piezas que no han sufrido cambios en su morfología por mantenimiento o reactivación de limbos o bases, mientras que los segundos sí han pasado por mantenimiento intensivo resultando en una transformación sustancial de la morfología original. A esto se suma una categoría intermedia propuesta por Martínez (2003), denominada tipo morfológico "mantenido", que define a las piezas que no se corresponden directamente con los tipos transformados ya que los atributos técnicos y tipológicos mantienen proporcionalmente sus diferencias dimensionales y formales. Este término responde al hecho de que las modificaciones a un tipo morfológico básico por mantenimiento no siempre genera una pieza tan diferenciada como para considerarla transformada.

Es importante señalar que los tipos morfológicos “standard” y los “recurrentes escasos" se definen en base a los tipos morfológicos básicos y mantenidos exclusivamente. En cuanto a los “especimenes morfológicos” pueden corresponder a diseños básicos, mantenidos o transformados (cuando no es posible correlacionar una morfología con modificación severa con los tipos definidos).

Para la definición de los tipos morfológicos se emplea el nombre de la localidad arqueológica en la cual el diseño es preponderante o bien, al presentar frecuencias bajas, donde fue recuperado por primera vez, seguida de una letra en mayúscula (por ejemplo, Peñas Chicas A). De esta forma, se sigue parcialmente la propuesta de Martínez (2003), basada en el “sitio tipo” y no en la localidad. La razón de esta variación es simple, el citado autor trabajó con sitios puntuales de localidades distintas, mientras que en este caso, hay ciertas localidades que cuentan con más de un sitio, y cada sitio cuenta con tipos propios, por lo que, para no incorporarles el número de sitio, se prefiere trabajar a nivel de localidad. Cuando se realice una diferenciación en subtipos de un tipo morfológico dado, a cada uno de los mismos se los denomina incorporando a la letra mayúscula un número arábigo, separados por un punto (por ejemplo, Peñas Chicas A.1). En aquellos casos de ejemplares mantenidos o transformados, que pueden correlacionarse a un tipo o subtipo, se suma una letra minúscula (por ejemplo, Peñas Chicas A.a o Peñas Chicas A.1.a, según se trate del primer o del segundo caso). 
En cuanto a los especimenes morfológicos, a la localidad se le incorpora un número arábigo (por ejemplo, Punta de la Peña 1). Esto se hace así para diferenciarlos de los tipos morfológicos. Cuando las evidencias permiten definir un tipo morfológico a partir de un espécimen morfológico, por multiplicación de evidencias, simplemente se cambia el número por una letra. En los casos en que los especimenes morfológicos se definen en base a diseños mantenidos o transformados, se emplea una letra minúscula, de la misma forma que para los tipos.

\subsection{CARACTERIZACIÓN DE LAS CLASES TECNICAS}

\subsubsection{CLASES TÉCNICAS PARA ARTEFACTOS FORMATIZADOS}

La clasificación de clases técnicas de artefactos formatizados se basa, por un lado, en la presencia de adelgazamiento, reducción, trabajo no invasivo -ex marginal ${ }^{4}$ (Aschero y Hocsman 2004)- y trabajo bipolar -categoría nueva aquí introducida- y, por el otro, si se trata de formatización bifacial, alternante o unifacial en las tres primeras categorías.

Diferenciar el trabajo no invasivo, sea unifacial, alternante o bifacial, en relación al de adelgazamiento y al de reducción, no presenta mayores problemas, puesto que los lascados de formatización afectan sólo los bordes de la pieza, con escasa o nula modificación del centro de la(s) cara(s) (Figura 4.2).

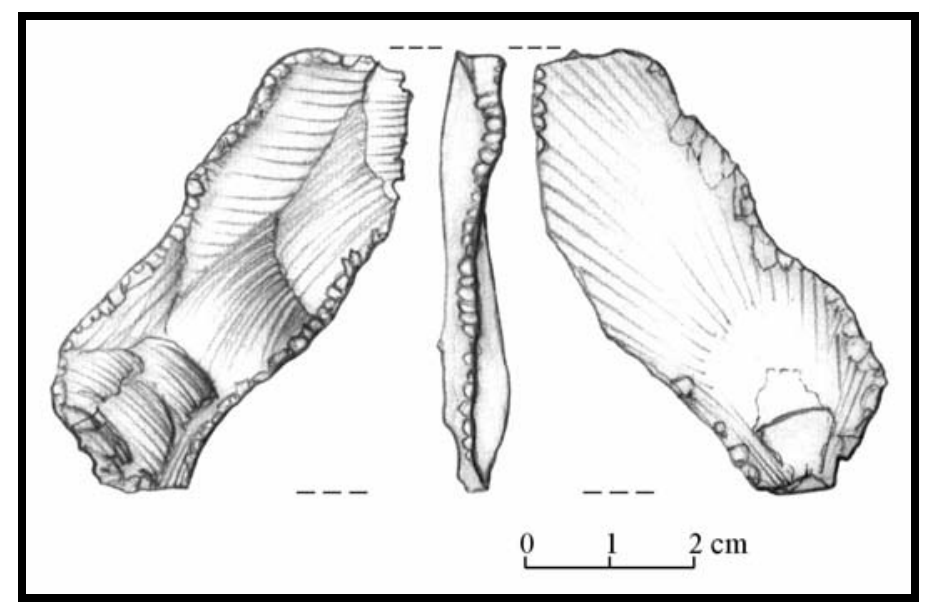

Figura 4.2. Artefacto formatizado con trabajo no invasivo unifacial - raedera + R.B.O. + muesca retocada + raspador en hocico - y bifacial - cortante - (QS3 - $2 \mathrm{~b} 4$ - No inv. 639)

\footnotetext{
${ }^{4}$ Se opta por el calificativo de trabajo no invasivo, en vez de marginal, para no generar inconvenientes con la noción de marginal empleada tanto en la extensión de los lascados sobre las caras de la pieza como en la profundidad de los lascados desde el borde.
} 
Este trabajo refleja una intención puesta en la búsqueda de una morfología de filo o punta particular con un determinado requerimiento de bisel, ángulo y forma de su sección, delineación y forma geométrica del filo, afectando uno o más bordes o el contorno completo de la pieza. Implica, entonces, lascados que afectan los bordes de la pieza sin alcanzar las zonas centrales, siendo marginales al cubrir menos de un 50\% de la cara, de acuerdo a lo especificado por Aschero (1975) en cuanto a extensión de los lascados sobre las caras de la pieza. Este tipo de práctica se caracteriza, además, por profundidades de los lascados desde el borde (Aschero 1983) menores que 1/3 de la menor de las dimensiones correspondientes a la longitud o al ancho máximos de la pieza.

El trabajo bipolar, por su parte, por sus características morfológicas particulares (Flegenheimer et al. 1995), es fácilmente discernible del resto de las categorías propuestas: presencia de lascados bidireccionales planos, con plataformas astilladas.

Por otro lado, discriminar los efectos de actividades de adelgazamiento de las de reducción, tanto en piezas bifaciales como unifaciales, puede resultar, en ciertos casos, bastante problemático. No obstante, hay elementos que pueden utilizarse para distinguir una de la otra.

En el adelgazamiento hay una doble intención: reducir el espesor de un artefacto y mantener con la menor afectación posible el ancho, o dimensión transversal de la pieza en relación al frente de trabajo. Sus efectos son una sección regular, de forma geométrica determinable obtenida por medio de lascados bifaciales o unifaciales que afectan proporcionalmente más las caras que los bordes (Figuras 4.3 y 4.4$)$.

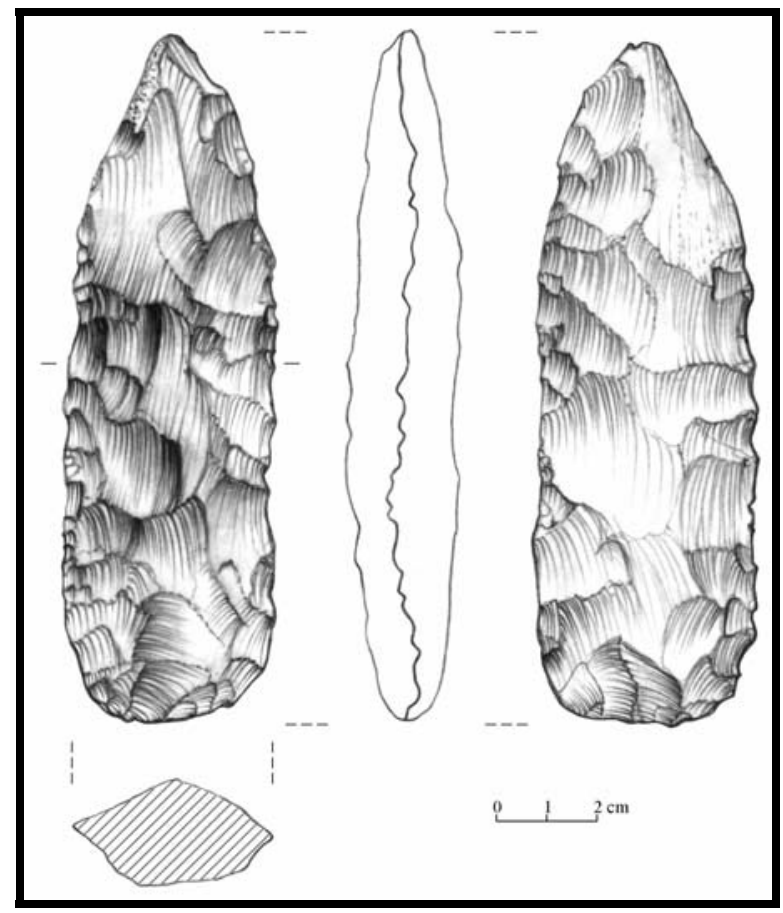

Figura 4.3. Artefacto con adelgazamiento bifacial. Biface de aristas regularizadas (QS3 - 2b11 - No inv. 819) 


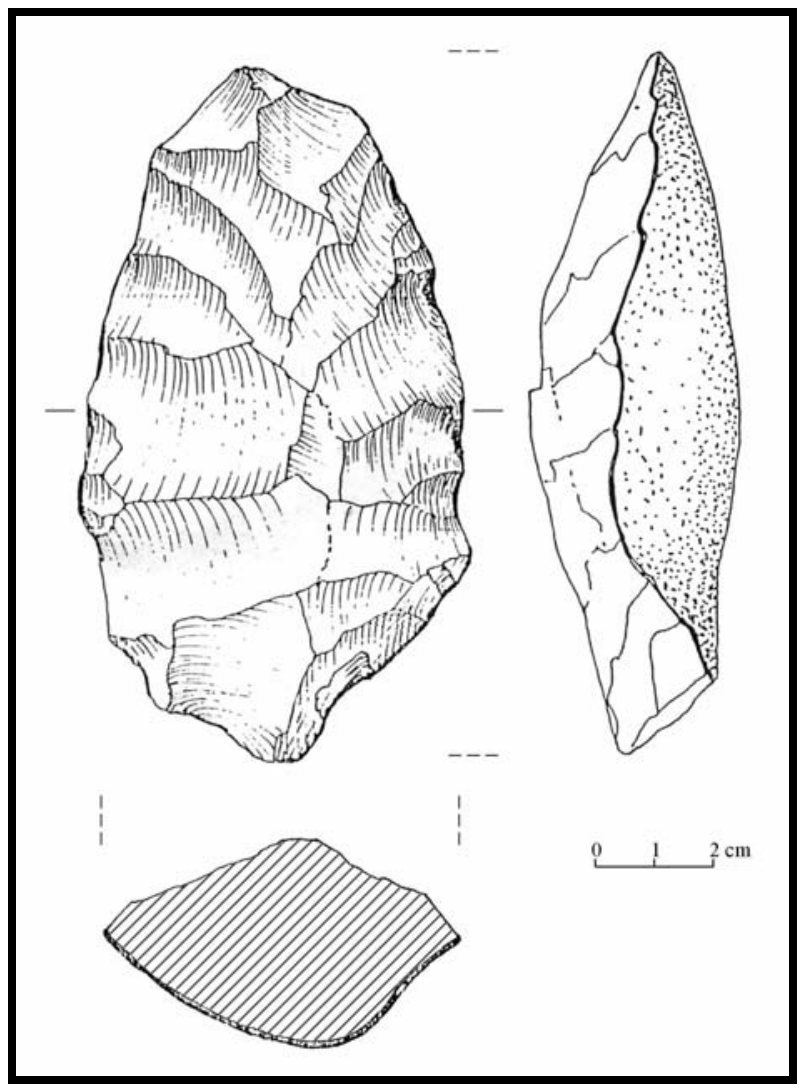

Figura 4.4. Artefacto con adelgazamiento unifacial. Uniface (Laguna Colorada de Yavi -superficie- tomado de Aschero 1975)

En lo que se denomina reducción, en cambio, el objetivo del trabajo sería distinto según se aplique a artefactos formatizados o a núcleos bifaciales u otros que impliquen preparación de plataformas y extracciones que afecten dos o más caras. Para los primeros apunta a imponer una cierta forma geométrica -simétrica o asimétrica- al artefacto, visto en norma frontal, lateral y/o sagital. En los núcleos tiene que ver con el aprovechamiento de la masa interna, reduciéndola, para extraer lascas u hojas de determinadas formas o dimensiones. En ambos casos, aunque los lascados bifaciales también afectan más las caras que los bordes, hay una disminución en el tamaño general de la pieza, que puede estar acompañada, o no, de una reducción de su espesor como resultado no intencional.

La posición de la plataforma es un aspecto que debe ser tenido en cuenta, ya que el adelgazamiento requiere de una plataforma centrada con el plano de simetría longitudinal. Con ésta es más fácil generar una lasca larga y relativamente espesa -removiendo, por ende, más material- que sobrepase el centro de la cara y corte cualquier arista central. Esto produce una sección transversal más aplanada, razón por la cual es éste el mejor tipo de plataforma para adelgazar una pieza. En el caso de la reducción, y particularmente para los núcleos bifaciales, no es necesario enderezar y centrar el borde, por lo que la presencia de plataformas centradas no es una condición necesaria.

De acuerdo a lo expuesto se espera que las piezas con adelgazamiento presenten: a) lascados que se extiendan desde el borde hasta un poco más allá del centro del artefacto, b) que éstos contacten 
o se superpongan con negativos provenientes del margen opuesto. Para los artefactos con reducción, donde el espesor no es un factor clave, si bien los negativos pueden llegar al centro de la cara, la tendencia es: a) que no alcancen a cubrir el centro de la cara, o, en el caso de alcanzarlo, b) que no se superpongan con los lascados procedentes del otro borde.

Abundando sobre lo expresado se introduce este concepto de reducción bifacial o unifacial para incluir aquellos artefactos cuyos diseños:

1) no requieren de la búsqueda de simetrías ni secciones específicas, y donde la tendencia es que los lascados no afecten el centro mismo de la pieza. Un ejemplo de esto serían los núcleos bifaciales, definidos por la extracción de lascas relativamente invasivas y donde no son relevantes ni la simetría ni el tipo de sección (Figura 4.5).

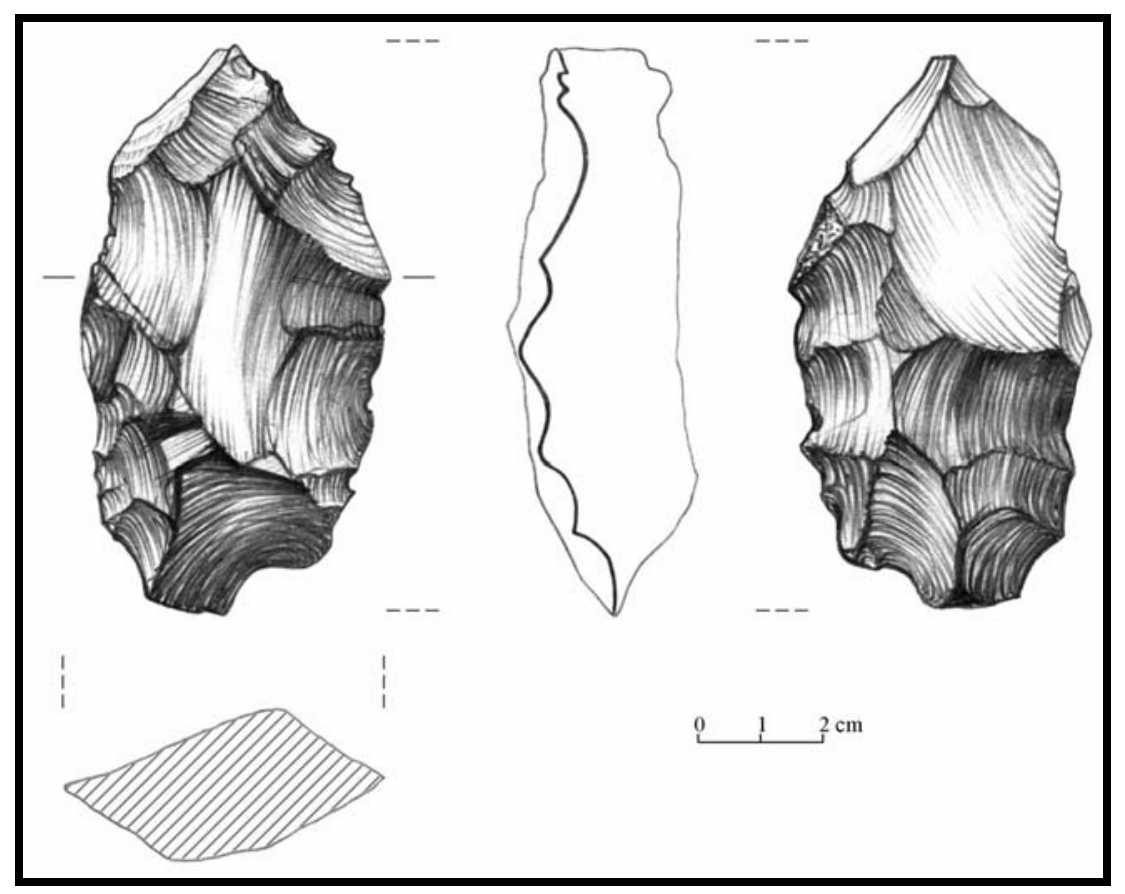

Figura 4.5. Artefacto con reducción bifacial. Morfología afín a un núcleo bifacial (QS3 - 2b4 - No inv. 316)

2) requieren de contornos y/o secciones determinadas -sin afectar el espesor de la pieza que estaría dado por el de la forma-base original-, cubriéndose por medio de lascados hasta, o cerca, del centro de la pieza. Se destaca que en este tipo de reducción el énfasis está puesto en la búsqueda de conformaciones específicas de contornos. Ejemplo de esto pueden ser las puntas de proyectil de limbo triangular de tipo isósceles, con pedúnculo diferenciado y aletas entrantes, típicas de las ocupaciones agro-pastoriles del NOA, en las que, por su pequeño tamaño, los ángulos del limbo y la materia prima (obsidiana), el retoque a presión incide sobre las caras de las piezas a través de lascados parcialmente extendidos o extendidos (Escola 1991, 2000), en función de la generación de un limbo triangular y una sección biconvexa (Figura 4.6). 


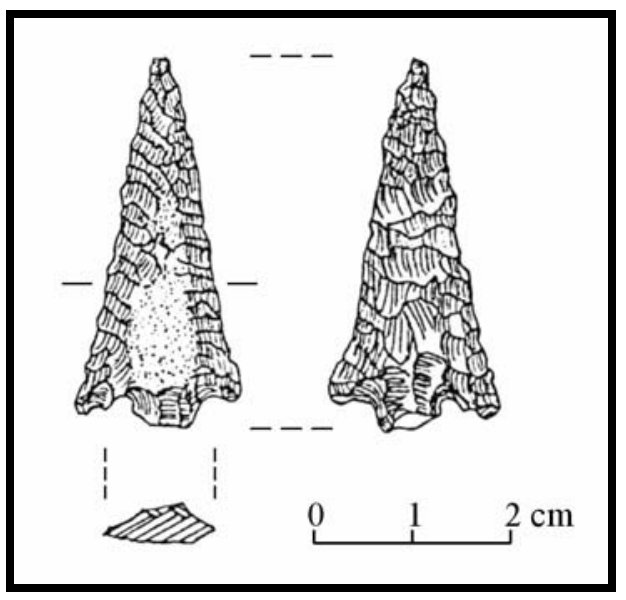

Figura 4.6. Artefacto con reducción bifacial. Punta de proyectil (tomada de Escola 1991)

Pero el ejemplo de estas puntas de proyectil es demostrativo, también, de un problema vigente en numerosos conjuntos de artefactos líticos. Escola (2000) encuentra que el 57,9\% de las piezas de Casa Chávez Montículos 1 presenta un trabajo de retoque extendido que no permite distinguir la forma-base original y que el 42,1\% restante cuenta con una formatización parcialmente extendida o marginal que permite establecer que se empleaban lascas como soporte inicial, a partir de la preservación de remanentes de las caras de las mismas.

Ahora bien, es inobjetable la presencia de reducción en las puntas de proyectil con lascados parcialmente extendidos o aún extendidos que cubran menos del 100\% de las caras, pero, remitiendo a consideraciones estrictamente morfológicas, ¿cómo no aducir la posibilidad de presencia de adelgazamiento en aquellas piezas con lascados que se contactan o superponen en el centro de la cara?.

Se destaca que este hecho de un mismo diseño que esté siendo confeccionado simultáneamente por ambos procedimientos técnicos no es algo infrecuente; en el territorio argentino se presenta en distintas regiones. Por ejemplo, en las puntas de proyectil "colas de pescado" procedentes de colecciones patagónicas (Nami 2000) o pampeanas (Flegenheimer 2001), o bien en las puntas de proyectil con pedúnculo destacado, bordes del pedúnculo confeccionados por formatización alterna y limbo triangular presentes en contextos arqueológicos de Antofagasta de la Sierra -Catamarca- (Hocsman 2001).

La decisión de emplear un procedimiento u otro parecería estar supeditada, entre otros factores, al tamaño y espesor inicial de los artefactos o nódulos empleados como soportes. De esta forma, cuando la forma-base con la que se inicia la secuencia de producción tiene un espesor relativamente cercano al previsto para la pieza terminada, ya no sería necesario adelgazar. En estos casos, donde se eligen formas-base que tienen ya el espesor requerido, se contaría con reducción. 
Con respecto al tamaño, Nami (1984) divide a los artefactos bifaciales en dos categorías, según el proceso de manufactura aplicado. Una, denominada A, que implica adelgazamiento bifacial y que se presenta en piezas de tamaño mediano-grande y grande (sensu Aschero 1975), y otra, calificada como B, que no involucra la elaboración de "bifaces" previos, sobre artefactos de tamaño muy pequeño y pequeño.

Otros criterios para la identificación del adelgazamiento y la reducción son la observación del tipo y extensión de los negativos de lascado que subyacen a la regularización de las piezas (Nami 1986) o bien de los desechos de talla que se presentan en los subconjuntos de artefactos líticos analizados.

Así, este último autor diferencia, dentro de las puntas de proyectil, piezas “...que tienen evidencia clara de haber sido confeccionadas con previa etapa de adelgazamiento bifacial. Este se observa por la existencia de negativos de lascados característicos de este procedimiento que subyacen a los retoques que dan forma final a la pieza" (Nami 1984: 87), de aquellas confeccionadas sobre una lasca, “...cuya cara ventral y dorsal subyacen a los negativos de lascado que dan forma final a la punta” (ibid).

De particular importancia, por ende, es la presencia en el registro arqueológico de las denominadas lascas de adelgazamiento (Crabtree 1972), dentro de la clasificación de desechos de talla, producto del adelgazamiento de artefactos por percusión o presión.

Partiendo de la base de que las características de las lascas de adelgazamiento bifacial ${ }^{5}$ pueden hacerse extensivas a las lascas de adelgazamiento en general, estas últimas se definen por ser relativamente delgadas y planas, con una tendencia a expandirse en ancho desde la plataforma; su bulbo de percusión es plano o "difuso" y la plataforma es frecuentemente muy pequeña, con presencia de labio en su interior; generalmente presentan una marcada concavidad de la cara de lascado, así como preparación de la plataforma (Aschero 1983, Nami 1991, Whittaker 1994, Andrefsky 1998). Ya en los instrumentos, éstas se presentan como negativos de lascado amplios y chatos, con aristas muy poco pronunciadas, y generando una importante convexidad en la/s cara/s.

Aunque las lascas de reducción comparten numerosas características con las de adelgazamiento, especialmente en el caso 2 (ver más arriba), se pueden señalar ciertas diferencias. Por ejemplo, la presencia en las primeras de lascados no tan largos y anchos, una menos frecuente

\footnotetext{
${ }^{5}$ En su momento, Aschero (1983) definió como sinónimos a las lascas de adelgazamiento bifacial y a las de reducción bifacial; se considera aquí que dichas categorías no son equivalentes.
} 
expansión desde el borde y una menor curvatura. A esto se suma, en el caso 1, lascas o negativos de lascado con talones más grandes o bocas más pronunciadas, respectivamente.

Por otra parte, las lascas de adelgazamiento bifacial, especialmente en casos de adelgazamiento extremo (Callahan 1979), tienden a generar terminaciones en charnela (hinged). Estas ayudan a eliminar la parte central de la cara cuando los lascados originados en el borde opuesto se encuentran. En las lascas de reducción, aunque este tipo de terminación se puede presentar, generalmente las charnelas no son tan amplias ni profundas como en las lascas de adelgazamiento.

Los rasgos que presentan las lascas de adelgazamiento son considerados propios del trabajo por percusión blanda (Whittaker 1994, Andrefsky 1998). En éste, el tipo de golpe involucrado produce una lasca larga, impulsando la fuerza dentro del material de tal manera que la lasca se desprende a lo largo de la cara (Whittaker 1994), por lo que el percutor blando (madera, hueso o asta) es particularmente útil para adelgazar, achatar y dar forma a los artefactos líticos, y es también la manera más fácil de hacerlo (Callahan 1979).

Pero esto no significa que no pueda haber adelgazamiento por presión. Un punto importante es que este último no tiene la misma capacidad de rebaje que el adelgazamiento por percusión (Callahan 1979). No obstante, es posible generar piezas delgadas, dependiendo, entre otros factores, de la materia prima, del tamaño y espesor de la forma base inicial y de la morfología de las caras de la pieza (Whittaker 1994; Callahan 1979; Nami 1986).

\subsubsection{PROPUESTA DE CLASIFICACIÓN DE CLASES TÉCNICAS}

Se definen las siguientes clases técnicas para artefactos formatizados, en función de una inversión de trabajo decreciente, a saber: artefactos con adelgazamiento bifacial, artefactos con reducción bifacial, artefactos con adelgazamiento unifacial, artefactos con reducción unifacial, artefactos con trabajo no invasivo bifacial, artefactos con trabajo no invasivo unifacial y artefactos con trabajo no invasivo alternante (Figura 4.7). A éstas se suman, siguiendo el orden decreciente, los artefactos

con trabajo bipolar. 


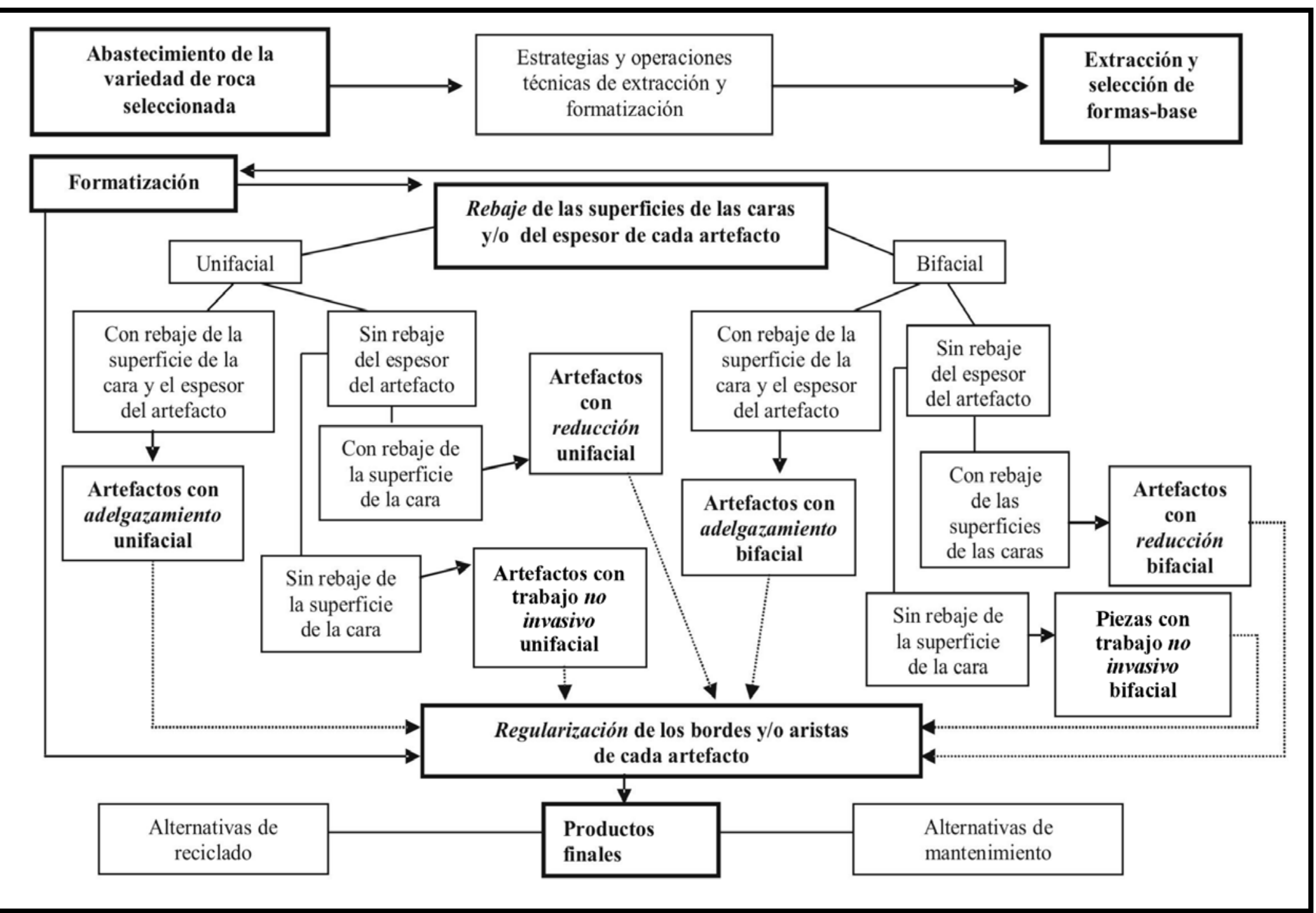

Figura 4.7. Clases técnicas para artefactos bifaciales y unifaciales 
Así, los instrumentos bifaciales ${ }^{6}$ se dividen en:

- artefactos con adelgazamiento bifacial: piezas en las que hay una intencionalidad en rebajar el espesor de un artefacto y generar una sección determinada, generalmente biconvexa, por medio de lascados bifaciales que afectan proporcionalmente más las caras que los bordes (Figuras 4.3 y 4.8).

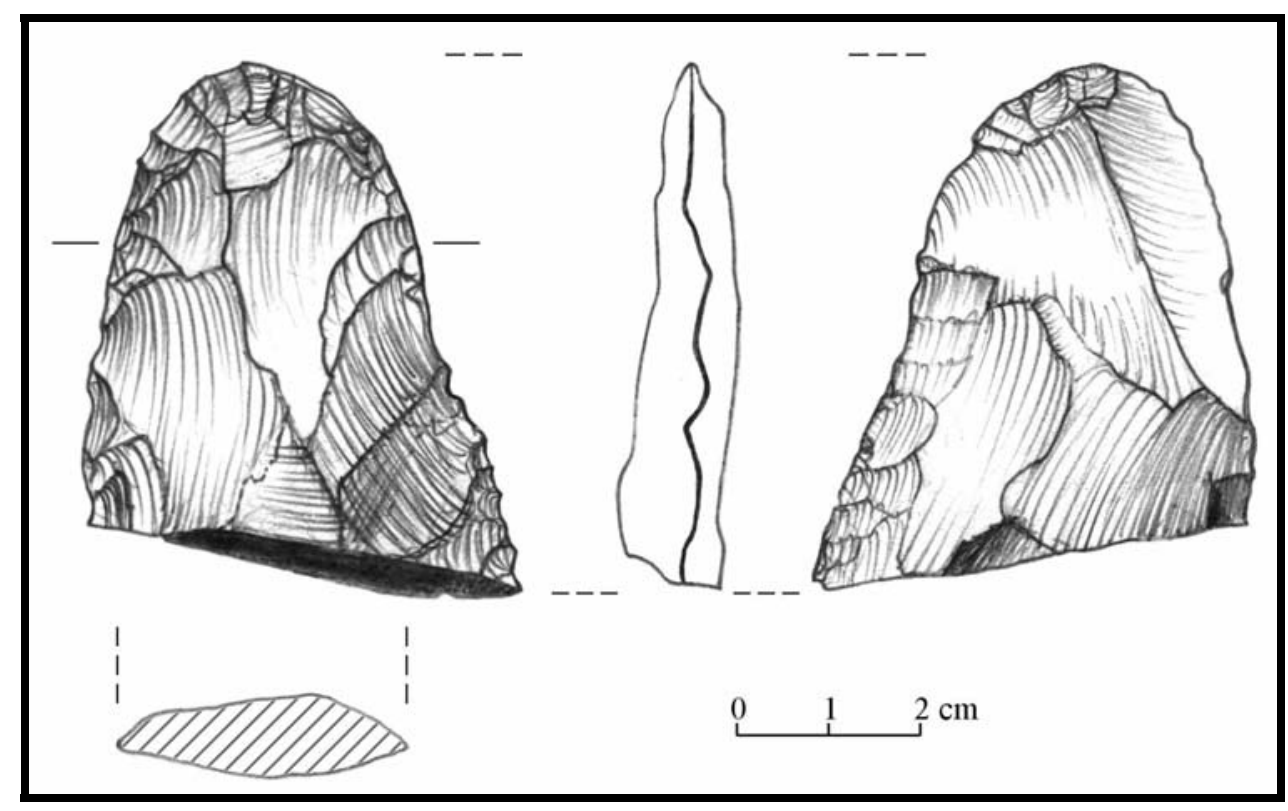

Figura 4.8. Artefacto con adelgazamiento bifacial. Biface (QS3 - 2b5 - No inv. 509)

- artefactos con reducción bifacial: artefactos confeccionados por lascados bifaciales que afectan proporcionalmente más las caras que los bordes, pudiendo presentar una reducción de su espesor como resultado no intencional. En las piezas de esta clase técnica puede haber una búsqueda de secciones y contornos determinados -ejemplo de esto pueden ser ciertos diseños de puntas de proyectil- (Figura 4.6), o bien una ausencia de los mismos -por ejemplo, los núcleos bifaciales- (Figura 4.5).

- artefactos con trabajo no invasivo bifacial: instrumentos donde el énfasis está puesto en la búsqueda de una morfología de filo particular basada en la extracción de lascas en ambas caras que afectan más los bordes que las caras de la pieza, en función de requerimientos en cuanto a bisel y/o a contorno (Figura 4.9).

\footnotetext{
${ }^{6}$ Se adopta la noción de artefacto bifacial como categoría más general e inclusiva, considerándose como tal a todo artefacto trabajado por técnicas de talla en ambas caras (Primera Convención Nacional de Antropología 1966). Esta característica fundamental remite a caracteres técnico-morfológicos que son considerados al tratar la formatización de un artefacto, es decir, el hecho de presentar lascados que afectan las dos caras de una pieza, yuxtaponiéndose a lo largo de una arista (situación de los lascados respecto a las caras de la pieza, sensu Aschero 1975).
} 


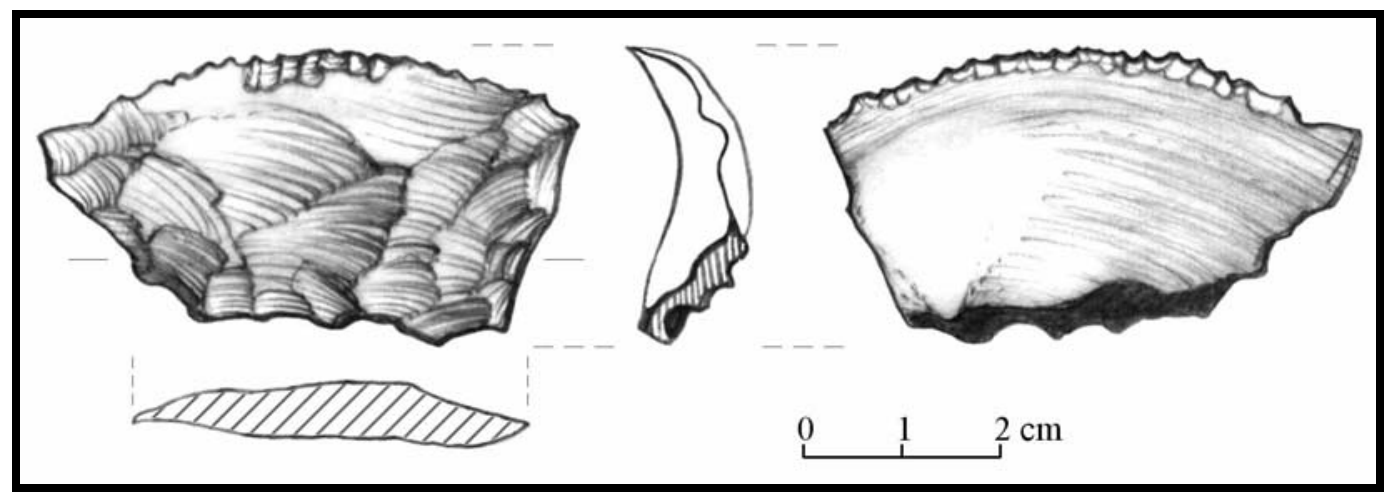

Figura 4.9. Artefacto bifacial marginal. Cuchillo denticulado (QS3 - $2 \mathrm{b5}$ - $\mathrm{N}^{\circ}$ inv. 642)

Por otro lado, los artefactos formatizados unifaciales ${ }^{7}$ se discriminan en:

- artefactos con adelgazamiento unifacial: instrumentos que ven reducido su espesor por lascados que cubren una sola de sus caras. En esta clase de artefactos hay una búsqueda de espesores y secciones específicos, pero en el marco de un trabajo unifacial (Figura 4.4). El adelgazamiento unifacial puede ocurrir, por ejemplo, en situaciones donde una cara se presenta abultada respecto de la otra, siendo esta ultima más plana.

- artefactos con reducción unifacial: en las piezas de esta categoría la formatización unifacial afecta proporcionalmente más la cara que el borde. Responden a la búsqueda de contornos y secciones específicas (Figura 4.10).

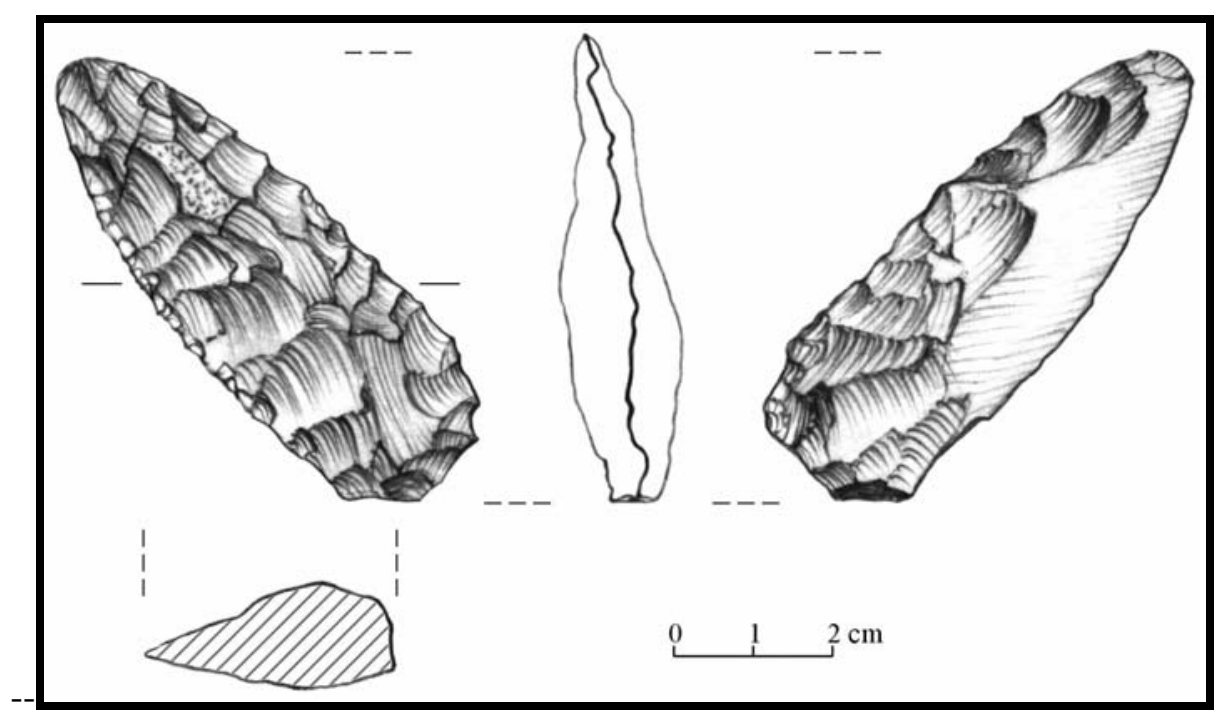

Figura 4.10. Artefacto con reducción unifacial. Cuchillo unifacial (filo oblicuo lateral izquierdo) + filo formatizado bifacial de arista sinuosa (filo oblicuo lateral derecho) (Confluencia - superficie)

\footnotetext{
${ }^{7}$ Los artefactos unifaciales son aquellos trabajados en una sola cara por técnicas de talla (Primera Convención Nacional de Antropología 1966).
} 
- artefactos con trabajo no invasivo unifacial: instrumentos donde el énfasis está puesto en la búsqueda de una morfología de filo particular a partir de lascados en una sola de las caras que afectan más el borde que la cara de la pieza (Figura 4.2).

En cuanto a los artefactos con trabajo no invasivo alternante, interesa obtener un determinado tipo de filo sin afectar las caras de la pieza, por medio de series de lascados que se alternan en una y otra cara sobre un mismo borde.

Finalmente, en el caso de los artefactos con trabajo bipolar, la intención es producir filos. Se destaca el escaso control sobre los productos en el marco de una bajísima inversión de tiempo y esfuerzo de manufactura (Flegenheimer et al. 1995).

\subsection{ESPECIFICACIONES PARA EL TRATAMIENTO DE LOS GRUPOS Y SUBGRUPOS TIPOLÓGICOS}

\subsubsection{GRUPOS TIPOLÓGICOS}

La lista tipológica aquí empleada corresponde al Código para Inventario de Muestreos desarrollado por Aschero (1987). Al mismo tiempo, se adoptan con modificaciones las propuestas de reestructuración de los grupos tipológicos puntas de proyectil de Martínez (2003) y de bifaces y otros instrumentos bifaciales de Aschero y Hocsman (2004), así como se incorporan nuevos grupos, como las gubias y escoplos por Aschero (2004a) y las palas y/o azadas manufacturadas por lascado por parte de Pérez (2004), y subgrupos, tales como las "grandes lascas con retoque” o raederas de módulo grandísimo (Escola 2000, Babot et al. 2004) dentro del grupo de las raederas. Asimismo, se presentan nuevos grupos tipológicos, como el de cincel.

Un somero análisis de la nomenclatura tipológica utilizada en esta clasificación morfológica evidencia que algunos términos son puramente descriptivos (por ejemplo, biface, muesca, denticulado) y otros hacen presumir una forma de uso (raedera, raspador, perforador, entre otros).

En particular, estas denominaciones aparentemente funcionales no deben ser tomadas en su sentido literal: no prejuzgan sobre la función cumplida efectivamente por ese utensilio. Así, una raedera pudo haber servido para raer, pero también para cortar o raspar. Su caracterización como raedera depende de sus características morfológicas, no de que haya servido para raer o se presuma de 
ello (Orquera y Piana 1986). Dichos términos se continúan empleando por la sencilla razón de que han sido consagrados por el uso (Bordes 1961).

\subsubsection{SUBGRUPOS TIPOLÓGICOS}

En aquellos subgrupos tipológicos que requieran de la definición de la extensión relativa del filo sobre el borde de la pieza (restringido, corto, largo, etc.) y de la posición relativa del filo o punta respecto al eje longitudinal de la pieza (frontal, lateral, etc.) se sigue justamente este orden de clasificación; a diferencia de la propuesta de Aschero (1987), donde se disponen al revés. Este cambio tiene su fundamento en que, desde un punto de vista tipológico, se considera que la primer variable debe tener un mayor peso para abordar variabilidad de grupos tipológicos específicos.

Por otra parte, en la posición relativa del filo se incluye la medición de la inclinación del filo (Aschero 1975), diferenciándose entre filos frontales transversales u oblicuos y filos laterales inclinados o paralelos-subparalelos.

\subsubsection{DESCRIPCIÓN DE GRUPOS TIPOLÓGICOS DE ARTEFACTOS BIFACIALES}

Se presenta aquí la descripción técnico-morfológica y morfológico-funcional de una serie de grupos tipológicos de artefactos bifaciales que modifican o se agregan a la lista tipológica en uso por distintos investigadores (Aschero 1975 y 1983), incluyendo piezas que no habían sido adecuadamente definidas.

\subsubsection{Variables empleadas en la descripción}

Para la definición de los grupos y subgrupos tipológicos considerados se emplean las siguientes variables, numeradas entre paréntesis (se desarrollan únicamente aquellas que han sufrido modificaciones respecto de la propuesta original de Aschero o bien que no estaban presentes en la misma):

Características técnico-morfológicas:

(1) Situación de los lascados respecto de las caras de la pieza (Aschero 1983)

(2) Profundidad de los lascados desde el borde (Aschero 1983)

(3) Extensión de los lascados sobre las caras de la pieza (Aschero 1975) 
Características morfológico-funcionales:

(4) Delineación de la arista (antes denominada conformación del borde en Aschero -1983-)

(5) Regularidad del borde y de la arista activa (Aschero 1983)

(6) Extensión relativa del filo respecto de los bordes de la pieza (Aschero 1975):

- Filos restringidos: se extienden en un borde, extremo o en el sector extremo de un borde

- Filos cortos: se extienden en un borde menor de la pieza con referencia a otros de mayor longitud

- Filos largos: se extienden en los bordes de mayor longitud

- Filos extendidos: filos no convergentes, de retoque continuo que ocupan la mayor parte del perímetro de la pieza (filos que abarcan por lo menos 2/3 de la misma)

- Filos perimetrales: ocupan la totalidad o casi totalidad del perímetro de la pieza (filos que abarcan prácticamente 3/3)

(7) Sección transversal de la pieza (Aschero 1983):

- Biconvexa

- Plano-convexa

- Triangular

- Romboidal

- Irregular

(8) Simetría en norma sagital:

- Simetría transversal

- Asimetría transversal

(9) Simetría en norma lateral:

- Simetría longitudinal

- Asimetría longitudinal

(10) Simetría en norma frontal:

- Simetría frontal

- Asimetría frontal

\subsubsection{Descripción de los grupos tipológicos considerados}

\subsection{El grupo tipológico de los bifaces}

Descripción: Instrumentos (1) bifaciales (2) con lascados profundos y (3) extendidos o parcialmente extendidos; (4) de filo normal con (5) borde regular y/o irregular y arista sinuosa regular y/o irregular en normas frontal y lateral, respectivamente; (6) filo perimetral; (7) sección transversal biconvexa o plano-convexa; y secciones simétricas o asimétricas en norma sagital (8), lateral (9) y frontal (10) (Figura 4.3). 
Observaciones: aunque se ha asociado recurrentemente a los bifaces con piezas de tamaño considerable (Primera Convención Nacional de Antropología 1966; Whittaker 1994; Hayden et al. 1996), son tomados aquí como un grupo de artefactos que presentan, independientemente del tamaño y peso, características morfológicas recurrentes (comentario de C. Aschero, Primeras Jornadas de Tecnología y Tipología Líticas 1980) (Figuras 4.11 y 4.12).

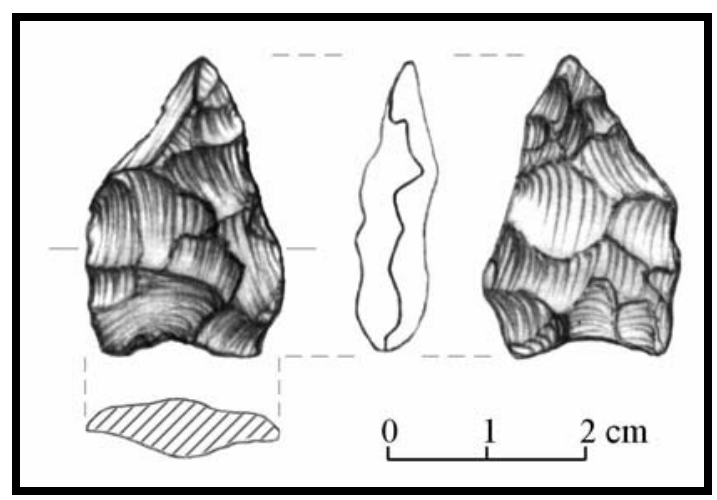

Figura 4.11. Biface de pequeño tamaño (ICc4 - superficie - $\mathrm{N}^{\circ}$ inv. 94)

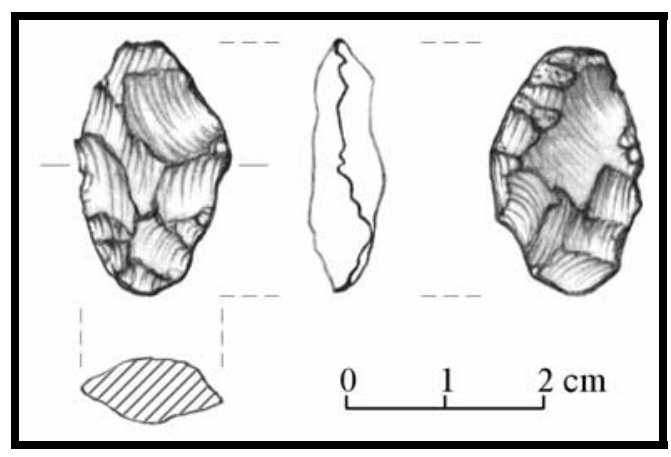

Figura 4.12. Biface de pequeño tamaño (PCh 1.1 - $4^{\circ}$ ext. - No inv. 54)

Si bien se ha sostenido que los bifaces para ser calificados como tales deben haber sido trabajados, total o parcialmente, por percusión (Primera Convención Nacional de Antropología 1966; Kelly 1988; Whittaker 1994), no se debe desconocer la posibilidad de confeccionar este tipo de instrumentos por medio de técnicas de presión (ver, por ejemplo, Callahan 1979), especialmente en piezas de pequeño tamaño y/o con espesores convenientes.

A continuación se desarrollan las particularidades técnico-morfológicas y morfológicofuncionales que definen a los subgrupos que integran el grupo tipológico bifaces:

\subsection{Subgrupo tipológico de los bifaces en sentido estricto}

Descripción: Piezas (2) con lascados profundos y (3) extendidos o parcialmente extendidos; (6) filo perimetral; (7) sección transversal biconvexa o plano-convexa (Figura 4.13). 


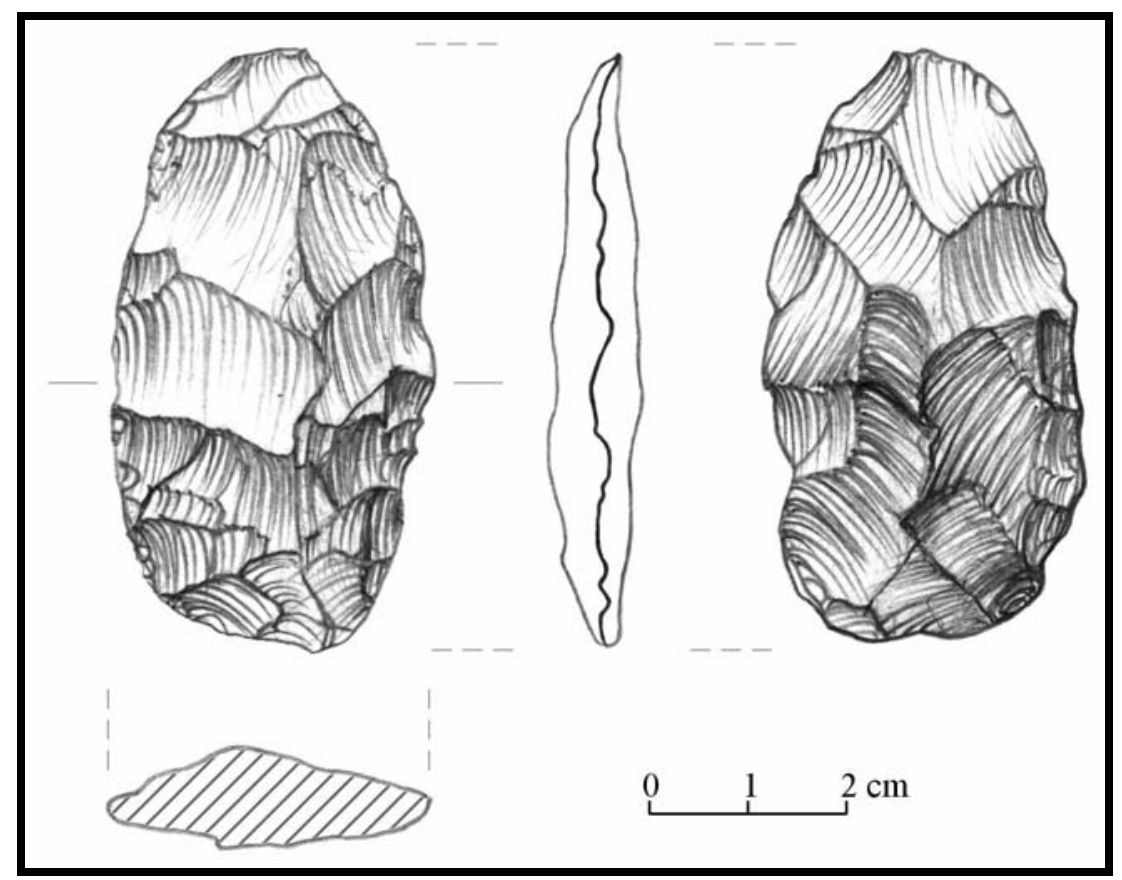

Figura 4.13. Biface (QS3 - 2b5 - Nº inv. 593)

Observaciones: Sus características se corresponderían con los tipos “clásicos” o bifaces propiamente dichos de la tipología de Bordes (1961) o, en la terminología de Aschero (1975), con el subgrupo de los bifaces de talla extendida.

\subsection{Subgrupo tipológico de los bifaces parciales}

Descripción: Piezas (2) con lascados marginales y (3) parcialmente extendidos o marginales; (6) filo perimetral, extendido o largo; (7) sección transversal biconvexa o plano-convexa (Figura 4.14).

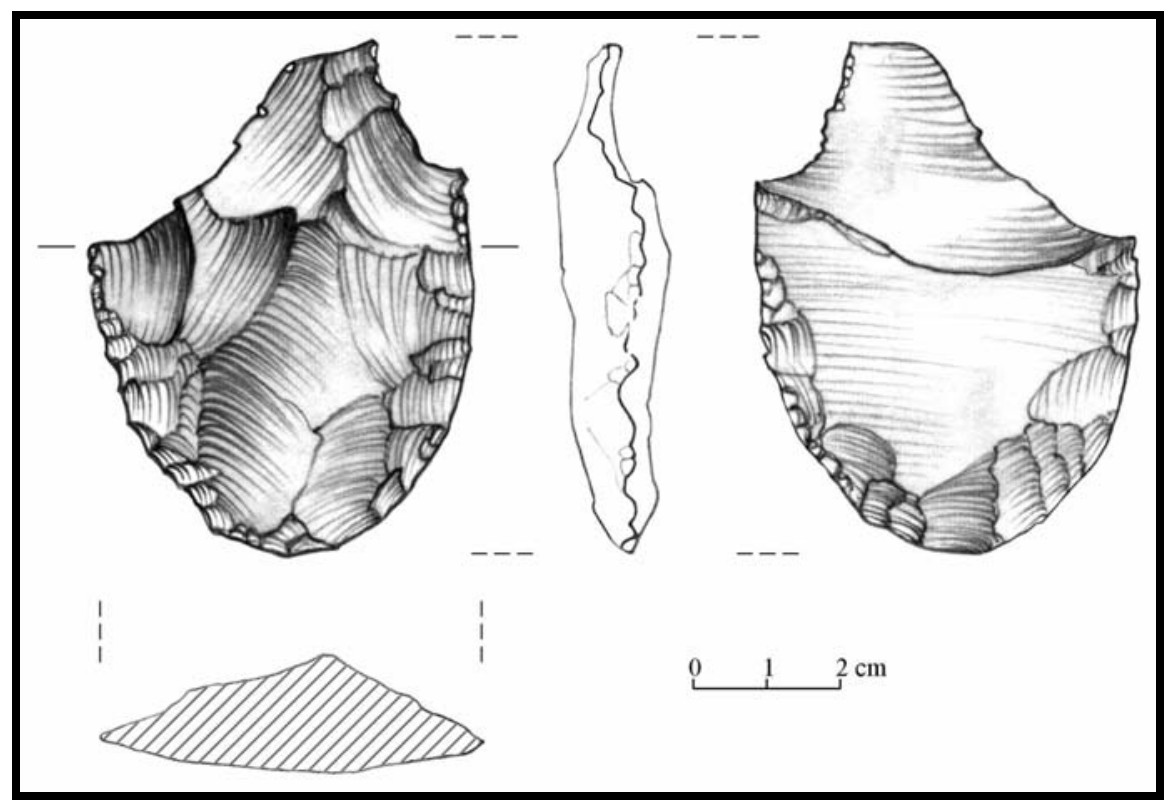

Figura 4.14. Biface parcial (AF1 - capa 11 base - tomado de Gradín et al. 1987) 
Observaciones: Estas piezas hacen referencia al subgrupo de los bifaces parciales de la tipología de Aschero (1975).

Para Bordes (1961), los bifaces parciales son artefactos trabajados en sus dos caras que tienen extensas áreas no formatizadas, por lo menos, en una de ellas. Esto lleva, al considerar la profundidad de los lascados desde el borde y la extensión de los lascados sobre las caras (Aschero 1975), a que se observe una formatización por lascados marginales y parcialmente extendidos, respectivamente, o bien a una combinación de sectores con lascados profundos y extendidos producto del adelgazamiento con porciones con lascados marginales y parcialmente extendidos o, aún, sin formatización.

En realidad, estos artefactos pueden formar parte de los primeros momentos de la secuencia de producción de los bifaces en sentido estricto o bien tratarse de núcleos bifaciales. También pueden presentarse como consecuencia de las características particulares de la forma-base. Así, por ejemplo, en piezas donde una de las caras es muy convexa y la otra es casi plana, habría adelgazamiento en la primera y formatización sumaria en la segunda.

\subsection{El grupo tipológico de las piezas foliáceas}

Descripción: Instrumentos (1) bifaciales (2) con lascados profundos y (3) extendidos o parcialmente extendidos; (4) de filo normal con (5) borde regular y/o irregular y arista sinuosa regular y/o irregular; (6) filo perimetral; (7) sección transversal biconvexa; sección simétrica en norma sagital (7) y lateral (8) y sección simétrica o asimétrica en norma frontal (9). A estas variables debe agregarse el módulo anchura-espesor (ver Observaciones) (Figura 4.15).

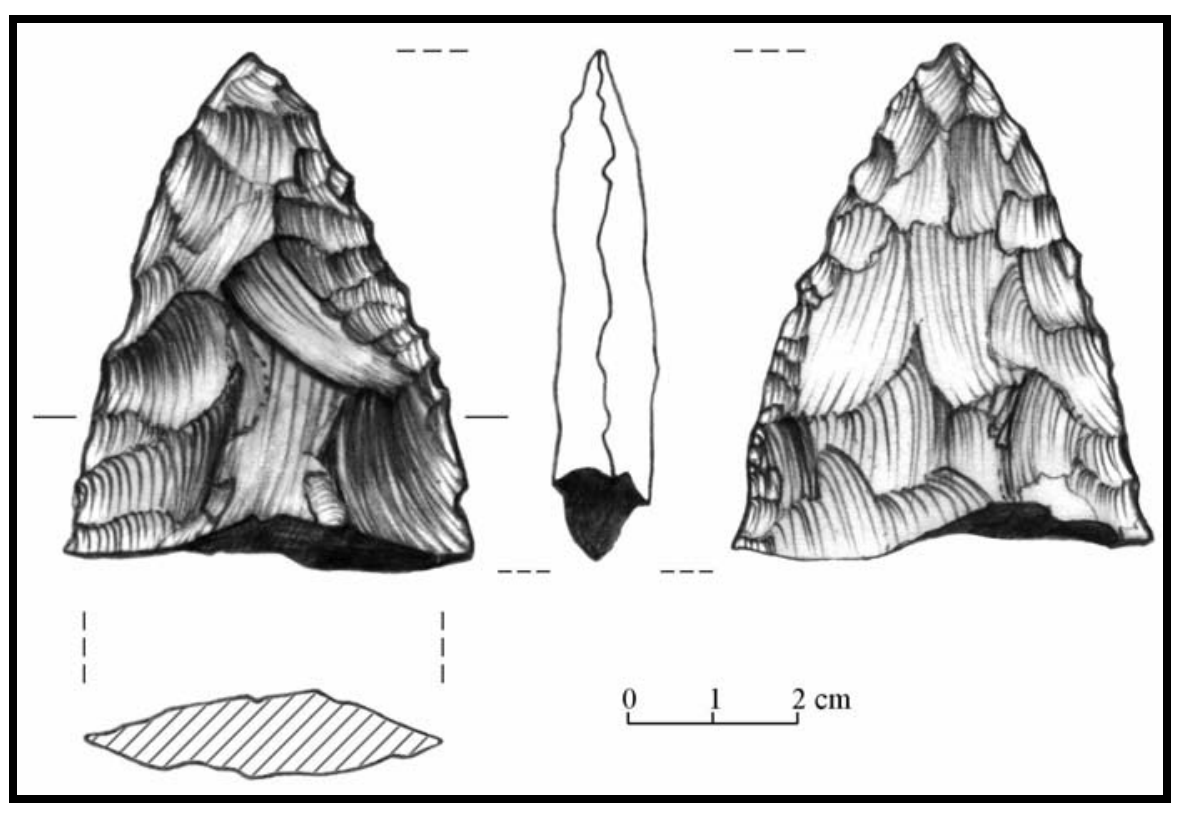

Figura 4.15. Pieza foliácea fragmentada (QS3 - 2b4 - No inv. 514) 
Observaciones: Las piezas foliáceas difieren de los bifaces, básicamente, por la relación entre la anchura máxima y el espesor máximo de la pieza (índice anchura-espesor): si el cociente es igual o mayor que 5 se clasifica como foliácea, si es menor, como biface (comentario de C. Aschero, Primeras Jornadas de Tecnología y Tipología Líticas 1980).

Las piezas foliáceas se caracterizan, por otro lado, por poseer aristas sinuosas regulares, mientras que las irregulares son más frecuentes en los bifaces, en razón de su mayor espesor, cuando hay escaso grado de formatización (ibid).

\subsection{El subgrupo tipológico de los esbozos de piezas bifaciales}

Descripción: Piezas (1) bifaciales (2) con lascados profundos y/o marginales y (3) extendidos y/o parcialmente extendidos; (4) de filo normal con (5) borde irregular y arista sinuosa irregular; (6) filos extendidos; (7) sección transversal irregular y secciones asimétricas en norma sagital (8), lateral (9) y frontal (10) (Figura 4.16).

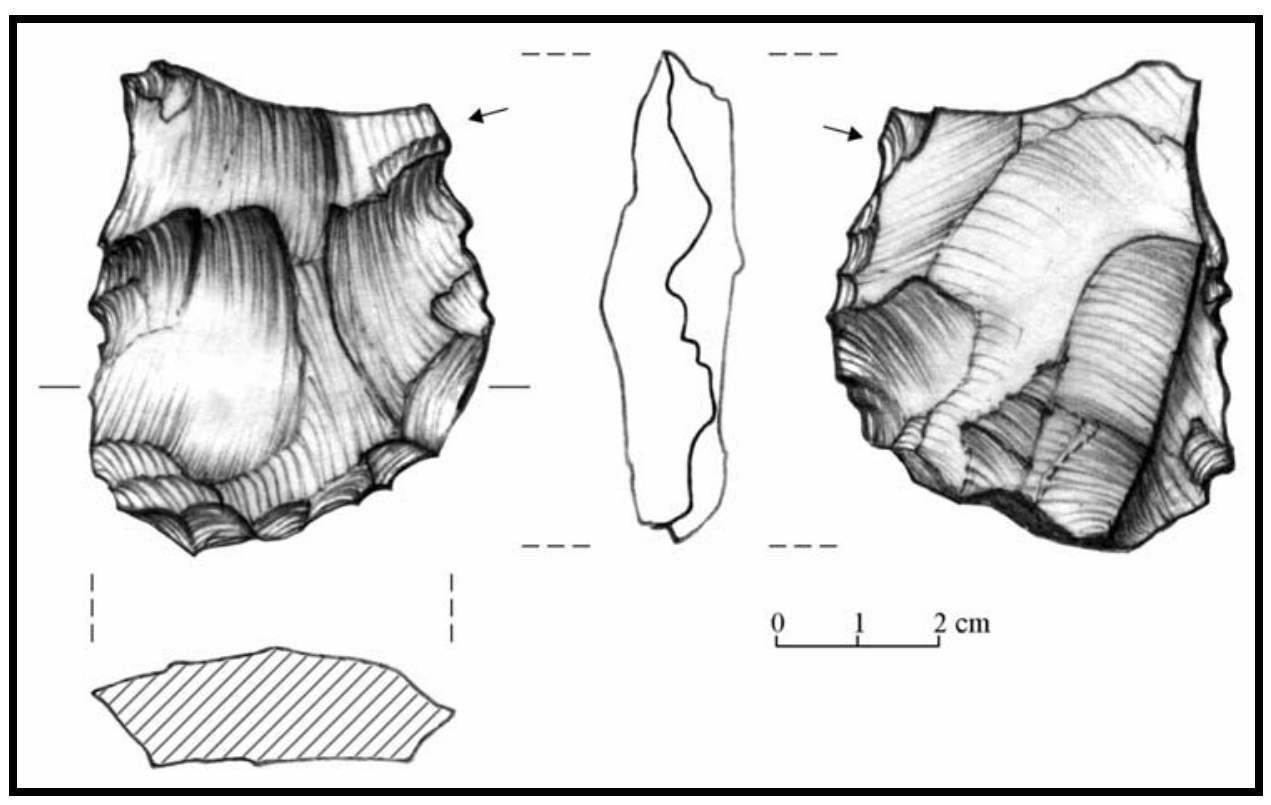

Figura 4.16. Esbozo de pieza bifacial (PP4 - 5(2) - No inv. 238/12)

Observaciones: este subgrupo tipológico se caracteriza por presentar lascados aislados y/o grupos de lascados aislados en ambas caras, por lo que se observan importantes porciones de la forma-base, ya sean facetas naturales con corteza o bien las caras ventral y/o dorsal de lascas. Se define, asimismo, por un contorno irregular.

Los esbozos de piezas bifaciales se incluyen en la propuesta de Aschero (1987) como un subgrupo dentro del grupo de los Artefactos con formatización sumaria. 
4.5.3.2.4. El grupo tipológico de los filos bifaciales de arista sinuosa

Descripción: Filos (1) bifaciales con (2) con lascados profundos y/o marginales y (3) extendidos, parcialmente extendidos o marginales; (4) de filo normal con (5) borde regular y/o irregular y arista sinuosa regular y/o irregular; (6) filo largo, corto o restringido; (7) no pertinente; (8) sección simétrica o asimétrica en norma lateral, (9) no pertinente, (10) no pertinente (Figura 4.10).

Observaciones: este término se corresponde a los filos formatizados bifaciales de arista sinuosa definidos por Aschero y Hocsman (2004).

La categoría de filo bifacial de arista sinuosa se aplica a aquellas piezas con filos simples o bien en artefactos compuestos que posean filos bifaciales, aún bifaces y bifaces parciales al ser segmentados en sus filos componentes, cuya extensión no involucre todo el perímetro y que no puedan ser adscriptos a ningún otro grupo tipológico de la propuesta de Aschero (1983).

Estos filos pueden presentarse tanto en artefactos con adelgazamiento bifacial o reducción bifacial como en artefactos bifaciales marginales.

Una parte de estos filos podría haber funcionado, por ejemplo, como dorsos, o bien en situaciones de enmangue.

\subsection{Núcleos bifaciales}

Nota aclaratoria: si bien los núcleos bifaciales no se incluyen como grupo tipológico dentro de los artefactos formatizados bifaciales, ya que se trata de núcleos, las dificultades de diferenciación de los mismos con las distintas variantes de instrumentos bifaciales hace pertinente su definición en este acápite.

Descripción: Piezas (1) bifaciales (2) con lascados profundos y (3) extendidos o parcialmente extendidos; (4) de filo normal con (5) borde regular y/o irregular y arista sinuosa irregular; (6) filo perimetral o extendido; (7) sección transversal biconvexa, plano-convexa, triangular o romboidal; y sección simétrica o asimétrica en norma sagital (8), lateral (9) y frontal (10) (Figuras 4.5 y 4.17). 


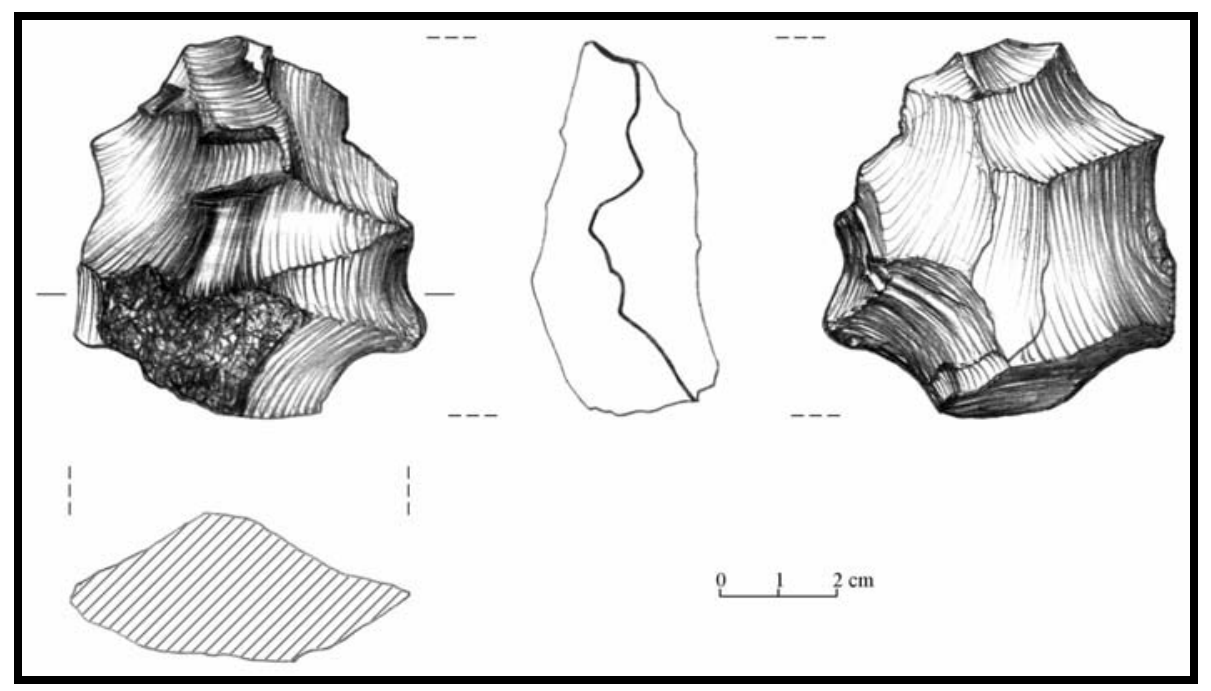

Figura 4.17. Ejemplo de biface con características afines a un núcleo bifacial (QS3 - 2b3 - No inv. 302)

Observaciones: los núcleos bifaciales se caracterizan por una marcada amplitud del sinusoide (offset, en el sentido otorgado por Callahan 1979) en sus aristas, así como por la tendencia a que su plataforma no esté en un plano de simetría longitudinal.

Son pertinentes las observaciones que hacen Karlin et al. (1995) acerca de los núcleos del abrigo rocoso Telarmachay, que pueden hacerse extensivos a la problemática de los núcleos bifaciales. Estas autoras diferencian dos tipos: a) los que están destinados a ser transformados en piezas bifaciales específicas (puntas de proyectil, cuchillos, etc.), siendo los residuos de su preparación descartados o recuperados de acuerdo a si sus tamaños y formas los vuelven aptos, y b) los que quedarán, en todos los momentos del proceso de talla, como bloques de materia prima de las cuales se extraerán lascas, donde parte de las mismas será descartada, pero el resto poseerá formas y dimensiones calibradas de manera de satisfacer las necesidades de los usuarios. Así, en el primer caso, la extracción de lascas tiende hacia la transformación del núcleo en un objeto de morfología predeterminada, mientras que, en el segundo caso, son las lascas las predeterminadas (Karlin et al. 1995: 242).

Dichas autoras sostienen que el volumen es un criterio relativamente fiable para diferenciar entre núcleos bifaciales y bifaces strictu sensu, siendo las piezas más voluminosas casi con certeza núcleos. Se aclara que esta aseveración sería aplicable sólo al segundo tipo de núcleos bifaciales, ya que en el primer caso, como se busca en definitiva culminar en una pieza de sección dada, se tendería a una reducción cuidadosa del espesor, por lo que no habría diferencias morfológicas con la formatización de un biface en sentido estricto. Esto permitiría afirmar que, en realidad, en el tipo a) no hay tareas de “adelgazamiento” sino de “reducción”.

Otro punto importante refiere a la idea de que los núcleos bifaciales son piezas grandes (Kelly 1988; Gramly 1990), pero esta afirmación debe ser necesariamente contrastada a través del análisis de 
los tamaños de las lascas de adelgazamiento bifacial utilizadas como formas base de instrumentos en los conjuntos analizados y de los bifaces presentes caratulados como tales.

Para Orquera y Piana (1986) los núcleos bifaciales se diferencian del resto de los bifaces por el tamaño medio de los lascados y por la irregularidad de las caras.

4.5.3.2.6. Comparación entre grupos tipológicos y subgrupos tipológicos de artefactos formatizados bifaciales y núcleos bifaciales

Se introduce aquí, por un lado, la comparación del grupo tipológico biface con sus subgrupos: bifaces sensu strictu y bifaces parciales (Tabla 4.4) y, por el otro lado, del grupo tipológico biface con el esbozo de pieza bifacial y el núcleo bifacial (Tabla 4.5).

Los atributos en negrita señalan diferencias entre los grupos o subgrupos. 
Producción lítica, variabilidad y cambio en Antofagasta de la Sierra -ca.5500-1500 AP-, Salomón Hocsman

Tabla 4.4. Comparación entre el grupo tipológico biface y sus subgrupos

\begin{tabular}{|c|c|c|c|}
\hline \multirow[t]{2}{*}{ Variables } & Grupo tipológico & \multicolumn{2}{|c|}{ Subgrupos tipológicos } \\
\hline & BIFACE & BIFACE STRICTU SENSU & BIFACE PARCIAL \\
\hline Sit lasc caras & Bifacial & $\overline{\text { Bifacial }}$ & Bifacial \\
\hline Prof lasc borde & Profundos & Profundos & Profundos / Marginales \\
\hline Ext lasc caras & $\begin{array}{c}\text { Extendidos o parcialmente } \\
\text { extendidos }\end{array}$ & $\begin{array}{c}\text { Extendidos o parcialmente } \\
\text { extendidos }\end{array}$ & $\begin{array}{c}\text { Parcialmente extendidos / } \\
\text { Marginales }\end{array}$ \\
\hline $\begin{array}{l}\text { Conformación del } \\
\text { borde }\end{array}$ & Normal & Normal & Normal \\
\hline & IIIITIS $: 1$, & $\begin{array}{ll}0 & 1 \\
\end{array}$ & \\
\hline Reg borde y arista & $\begin{array}{c}\text { Borde regular y/o irregular } \\
\text { y arista sinuosa regular y/o } \\
\text { irregular }\end{array}$ & $\begin{array}{c}\text { Borde regular y/o irregular y } \\
\text { arista sinuosa regular y/o } \\
\text { irregular }\end{array}$ & $\begin{array}{c}\text { Borde regular y/o irregular } \\
\text { y arista sinuosa regular y/o } \\
\text { irregular }\end{array}$ \\
\hline Ext relat filo & Perimetral & Perimetral & $\begin{array}{c}\text { Perimetral, extendido o } \\
\text { largo }\end{array}$ \\
\hline Sección transversal & Biconvexa o plano convexa & Biconvexa o plano convexa & Biconvexa o plano convexa \\
\hline
\end{tabular}


Tabla 4.5. Comparación entre el grupo tipológico biface, el esbozo de pieza bifacial y el núcleo bifacial

\begin{tabular}{|c|c|c|c|}
\hline Variables & Artefacto formatizado & Núcleos & $\begin{array}{c}\text { Artefactos con } \\
\text { formatización sumaria }\end{array}$ \\
\hline & $\overline{\text { BIFACE }}$ & NÚCLEO BIFACIAL & $\begin{array}{c}\text { ESBOZO DE PIEZA } \\
\text { BIFACIAL }\end{array}$ \\
\hline Sit lasc caras & Bifacial & Bifacial & Bifacial \\
\hline Prof lasc borde & Profundos & Profundos & Profundos y/o marginales \\
\hline Ext lasc caras & $\begin{array}{c}\text { Extendidos o } \\
\text { parcialmente extendidos }\end{array}$ & $\begin{array}{c}\text { Extendidos o parcialmente } \\
\text { extendidos }\end{array}$ & $\begin{array}{c}\text { Extendidos y/o parcialmente } \\
\text { extendidos }\end{array}$ \\
\hline $\begin{array}{l}\text { Conformación del } \\
\text { borde }\end{array}$ & Normal & Normal & Normal \\
\hline Reg borde y arista & $\begin{array}{l}\text { Borde regular } y / 0 \\
\text { irregular } y \text { arista sinuosa } \\
\text { regular } y / 0 \text { irregular }\end{array}$ & $\begin{array}{l}\text { Borde regular y/o irregular } \\
\text { y arista sinuosa irregular }\end{array}$ & $\begin{array}{l}\text { Borde irregular y arista } \\
\text { sinuosa irregular }\end{array}$ \\
\hline Ext relat filo & Perimetral & Perimetral o extendido & $\begin{array}{c}\text { Lascados aislados y/o } \\
\text { grupos lascados aislados }\end{array}$ \\
\hline Sección transversal & $\begin{array}{c}\text { Biconvexa o plano } \\
\text { convexa }\end{array}$ & $\begin{array}{l}\text { Biconvexa, plano convexa, } \\
\text { triangular o romboidal }\end{array}$ & Irregular \\
\hline
\end{tabular}

\subsubsection{DEFINICIÓN DEL GRUPO TIPOLÓGICO CINCEL}

Se propone la conformación de un nuevo grupo tipológico denominado cincel. El mismo se define por (Aschero 2005, com pers.):

- un filo corto o restringido, frontal (transversal al eje longitudinal)

- un bisel simétrico unifacial o bifacial

- una delineación rectilínea de la arista, vista en norma sagital

- un filo recto, o cóncavo o convexo muy atenuados. 


\subsubsection{DESCRIPCIÓN DEL GRUPO TIPOLÓGICO PUNTAS DE PROYECTIL}

\subsubsection{Clasificación de subgrupos tipológicos}

La propuesta de clasificación de subgrupos tipológicos de puntas de proyectil empleada corresponde al desarrollo de Martínez (2003). Además, se considera necesario incluir las características generales del pedúnculo o sector basal, a saber: Forma de los bordes del pedúnculo (Aschero 1975), Forma de la base del limbo o pedúnculo en puntas de proyectil u otras piezas de base formatizada (Aschero 1983; más agregados de Escola 2004a y Martínez y Hocsman 2004) y Tipo de inflexión de la base respecto de los bordes de pedúnculos o sectores basales convexilíneos. Este último atributo es una incorporación resultado de este trabajo (ver a continuación).

4.5.5.2. Tipo de inflexión de la base respecto de los bordes de pedúnculos o sectores basales convexilíneos

Este atributo describe en pedúnculos y sectores basales con morfología general convexilínea, el tipo de inflexión observada entre la base y los bordes. Así, diferencia entre bases no inflexionadas e inflexionadas (Figura 4.18), en función de la presencia de un punto de quiebre o inflexión entre la base y los bordes del pedúnculo.

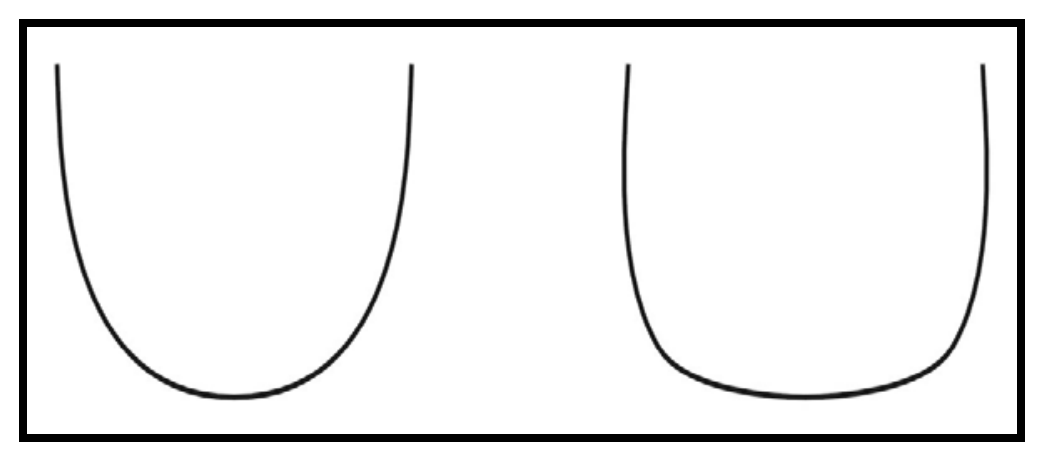

Figura 4.18. Izquierda: Base no inflexionada. Derecha: base inflexionada

4.5.5.3. Características de la morfología “acuminada” en "Forma de la base..."

Se definen como "acuminadas" aquellas bases cuyo ancho es menor o igual a $1 / 4$ del ancho de la raíz del pedúnculo o sector basal.

4.5.5.4. Diferenciación de formas dentro de las bases “acuminadas”

Se plantea la discriminación de las bases acuminadas en (Figura 4.19): 
- Acuminadas puntiformes

- Acuminadas convexilíneas restringidas.

- Acuminadas rectilíneas restringidas.

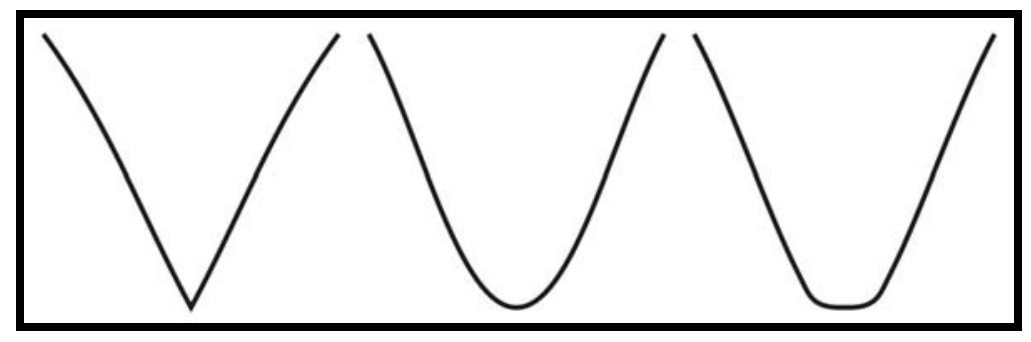

Figura 4.19. Bases acuminadas. Izquierda: Puntiforme. Centro: Convexilínea restringida. Derecha: Rectilínea restringida

\subsubsection{Agregado de una variable en "Tratamiento técnico diferencial de bases, bordes o aletas"}

Se propone la incorporación en el punto "Base: adelgazamiento" dentro de "Tratamiento técnico diferencial...” de la variable Formatizada por lascados provenientes de los bordes del pedúnculo.

\subsubsection{DISCRIMINACIÓN ENTRE FILO $\quad \mathrm{Y}$ FRAGMENTO NO DIFERENCIADO DE}

\section{ARTEFACTO FORMATIZADO (IDEM PARA FILO Y ARTEFACTO CON FORMATIZACIÓN SUMARIA)}

Se plantea la diferenciación entre filo no diferenciado de artefacto formatizado y fragmento no diferenciado de artefacto formatizado. El primero se emplea cuando en un artefacto compuesto uno más de los filos que conforman la pieza se presenta fracturado y no es posible establecer por esta causa su filiación tipológica. En el segundo, por su parte, la pieza presenta una o más fracturas que imposibilitan discernir de que instrumento se trataba, sean filos simples o piezas cuya formatización sea total. En este último caso, puede tratarse, por ejemplo, de un remanente de un artefacto bifacial no diferenciado producto de múltiples fracturas, en el que no es factible establecer su naturaleza.

Por otra parte, se propone distinguir entre artefacto con formatización sumaria y filo con formatización sumaria. En el primer caso, se trata de piezas con filos simples que presentan formatización sumaria, mientras que en el segundo caso, se refiere a filos específicos dentro de una serie de filos en artefactos compuestos, dobles o triples. 
Se destaca que el calificativo de filo o fragmento con fragmento con formatización sumaria suplanta al subgrupo tipológico “... con retoque o microrretoque sumario” del Código de Inventario de Muestreos de Aschero (1983), adicionándose la posibilidad de la retalla.

\subsubsection{DEFINICIÓN DEL GRUPO TIPOLÓGICO FILO FORMATIZADO PASIVO}

Describe aquellas morfologías que funcionarían como dorsos o para prehensión y que no responden a los grupos tipológicos definidos por Aschero (1975, 1983, 1987) y Aschero y Hocsman (2004), con excepción de los filos con formatización sumaria.

Dichos filos pasivos, sean unifaciales, bifaciales o alternantes, pueden contar con ángulos mayores o menores de $70^{\circ}$ (denominándose dorso o sistema de prehensión, respectivamente), con la salvedad de que el ángulo no debe ser producto del mantenimiento o del uso sino de la manufactura. Además, deben estar asociados a un filo activo. En el caso de tratarse de una formatización sumaria, la presencia de los elementos mencionados define al filo como pasivo.

Los filos formatizados pasivos cuentan con una arista regular, por lo que se diferencian de los filos bifaciales de arista sinuosa (aunque éstos últimos pueden conformar dorsos, como ya se mencionó).

\subsubsection{AGREGADO DE UN SUBGRUPO TIPOLÓGICO A LOS RASPADORES}

Se propone la inclusión del subgrupo tipológico raspador de filo extendido dentro del grupo tipológico de los raspadores.

\subsubsection{INCORPORACIÓN DEL SUBGRUPO RAEDERA DE MÓDULO GRANDISIMO AL GRUPO TIPOLÓGICO DE LAS RAEDERAS}

Se propone la inclusión del subgrupo tipológico raedera de módulo grandísimo al grupo de las raederas, ya que cuenta con los requerimientos morfológico-funcionales para ser definido como una raedera (Aschero 1975), siendo clave en la caracterización del subgrupo el módulo (características litométricas -Aschero 1983-). 
A la denominación propuesta se le debe sumar extensión relativa y posición del o los filos, como en los subgrupos restantes.

Estas piezas fueron denominadas “grandes lascas con retoque” por Escola (2000).

\subsubsection{INCORPORACIÓN DE LA EXTENSIÓN RELATIVA DEL FILO A LA DIFERENCIACIÓN EN SUBGRUPOS DEL GRUPO TIPOLÓGICO CORTANTE}

Se considera pertinente sumar a la diferenciación en vigencia de los cortantes la extensión relativa del filo, a saber: filos cortos y restringidos.

\subsubsection{AGREGADOS EN CUANTO A EXTENSIÓN RELATIVA DEL FILO EN LOS DENTICULADOS DE BISEL OBLICUO/ABRUPTO DE SECCIÓN ASIMÉTRICA}

Se propone incorporar a los filos cortos y restringidos, a los ya establecidos filos largos, para distinguir subgrupos dentro de los denticulados de bisel oblicuo/abrupto de sección asimétrica.

\subsection{MODIFICACIONES E INCORPORACIONES AL ANÁLISIS MORFOLÓGICO- DESCRIPTIVO}

\subsubsection{PROPUESTA DE MODIFICACIÓN DE LA CUADRÍCULA DE LOCALIZACIÓN}

De acuerdo a Aschero (1983), la cuadrícula de localización se utiliza para determinar la posición de la parte descripta del artefacto formatizado -cada una de las partes segmentadas- en relación a la cara y sector del borde que ocupa. Así, por medio de una serie de designaciones codificadas se indica la localización en cuadrícula de la parte descripta.

Se propone modificar las designaciones de los sectores frontales distal y proximal, ante la existencia en conjuntos líticos analizados de la Puna argentina de artefactos con filos frontales transversales u oblicuos que por su longitud y características requieren una mayor precisión en la ubicación de la formatización, considerando inclusive las porciones U, V y W. 
Así, el sector frontal distal, denominado 7, se divide en dos sectores iguales: 7, o sector frontal distal izquierdo, y 9, o sector frontal distal derecho. Por su parte, el sector frontal proximal, señalado como 8, se discrimina en dos sectores iguales: 8, o sector frontal proximal izquierdo, y 0 , o sector frontal proximal derecho. Cada uno de los sectores así conformados puede ser dividido, a su vez, en las porciones U, V y W (Figura 4.20).

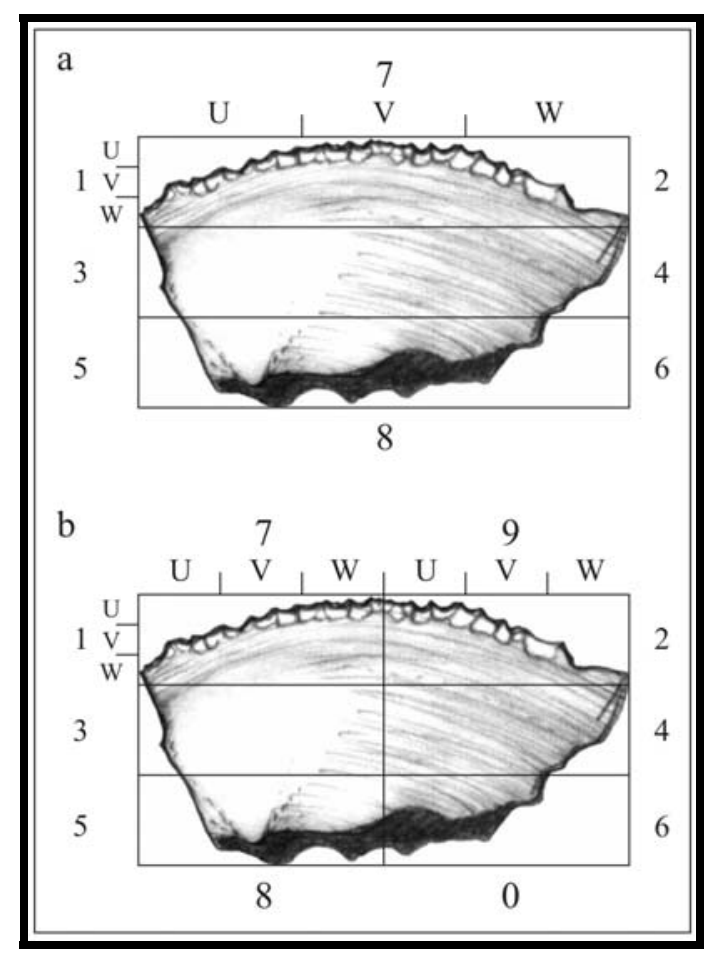

Figura 4.20. a) Cuadrícula de localización sensu Aschero (1983).

b) Propuesta de modificación de la cuadrícula de localización.

En casos de convergencia, la notación para el sector frontal distal se propone como (79), mientras que para el sector frontal proximal sería (80).

\subsection{2. “SECUENCIA DE FORMATIZACIÓN” EN ARTEFACTOS FORMATIZADOS}

Se propone la inclusión de una nueva variable para el análisis de artefactos formatizados tallados, denominada “secuencia de formatización” (modificada de Hocsman y Martínez 2004), que se basa en el análisis del o los filos o puntas que componen un instrumento dado, por borde y por cara.

Este concepto surge, justamente, ante la necesidad de describir por borde y por cara los filos y/o puntas presentes y de definir secuencias relativas de manufactura de filos. Su utilización permite un análisis detallado de la formatización de un instrumento, al dividirlo en sus partes componentes, pudiéndose registrar, por ejemplo, gestos técnicos del o los artesanos. 
Específicamente, esta variable resulta de la consideración de la anchura de los lascados sobre el borde más la profundidad de los lascados desde el borde (Aschero 1975, 1983), por cada borde y cara formatizados.

El procedimiento de análisis implica que, una vez definidos los filos y/o puntas que conforman una pieza por borde y por cara, se procede a describir cada uno de ellos por medio de "subsecuencias de formatización", conformando las "secuencias" en sí a partir de la sumatoria de dichas “subsecuencias”. Esta suma se hace sobre la base de las evidencias de superposición de filos sobre otros, siguiendo el orden en que tuvo lugar la formatización, es decir, se establece la sucesión ordenada de pasos por los que pasó el artefacto.

La superposición se indica con dos barras paralelas inclinadas “//”. La inclinación señala cual filo se superpone al otro. En el caso de filos bifaciales por extracciones alternadas se emplea el signo igual (“=”). En el caso de dos o más series de lascados, se subraya la serie de lascados que es la que en definitiva está superpuesta.

La secuencia de formatización se explicita mediante las posiciones de los filos (entre paréntesis) y las características técnico-morfológicas definidas. Los corchetes se emplean para definir subsecuencias o bien para discriminar conjuntos de filos relacionados de otros que no están asociados por superposiciones.

Ejemplos:

$1^{\circ}$ ) Secuencia de formatización de artefacto con 3 filos:

$(\mathrm{A} 31)+(\mathrm{A} 24) \mathrm{E} 1 / /(\mathrm{A} 79) \mathrm{D} 2$

Descripción: los dos filos E1 se superponen al filo D2. Esto significa que el filo D2 se confeccionó primero que los 2 filos E1.

$2^{\circ}$ ) Secuencia de formatización de artefacto con 3 filos:

[(A31) E1 // (A79) D2] + (A24) E1

Descripción: un solo filo E1 (A31) se superpone al filo D2, mientras que el otro filo E1 (A24) no se superpone. Esto significa que el filo D2 es anterior al filo E1 (A31) y puede ser anterior, contemporáneo o posterior (no se puede aseverar ninguna alternativa), al filo E1 (A24). 
$3^{\circ}$ ) Secuencia de formatización de limbo de punta de proyectil:

$[(\mathrm{A} 24) \mathrm{D} 2+\underline{\mathrm{E} 1} / /(\mathrm{B} 31) \mathrm{D} 2]+[(\mathrm{B} 24) \mathrm{D} 2+\underline{\mathrm{E} 1} / /(\mathrm{A} 31) \mathrm{D} 2]$

Descripción: se describen 4 subsecuencias, correspondientes a dos caras y dos bordes, conjugadas en esta secuencia de formatización general. Cada par de corchetes representa un borde; así, el primer par de corchetes describe el borde izquierdo y el segundo par el borde derecho. Se evidencia que la pieza termina regularizada por microrretoque alterno.

$4^{\circ}$ ) Secuencia de formatización de filo reciclado sobre limbo de punta de proyectil:

(A79) D2

Descripción: en el caso de filos o puntas reciclados, se definen, por un lado, los eventos de formatización directamente relacionados con la confección del nuevo filo o punta, es decir, sin sumar la formatización del filo o punta reciclado y, por el otro lado, los de este último. Igual consideración se realiza para los bifaces.

Resta diferenciar la secuencia de formatización de la serie técnica. Si bien serían comparables en escala, pues ambas se dan a nivel de pieza (con excepción de las puntas de proyectil), son conceptos totalmente diferentes. Así, la serie técnica siempre es un total producto de una sumatoria; en cambio, la secuencia puede ser dividida en subsecuencias. Más importante aún, la serie técnica no puede emplearse para describir filos específicos: en su definición (Aschero 1983) implica conjugar la anchura de los lascados desde el borde más la extensión de los lascados sobre la cara. El problema radica en esta última variable, ya que considera indefectiblemente la cara completa, y no los bordes. Una aproximación a las piezas desde bordes específicos debería prescindir, entonces, de la noción de serie técnica.

\subsection{3. “SECUENCIA TIPOLÓGICA” EN ARTEFACTOS FORMATIZADOS}

La secuencia tipológica busca describir en una sucesión ordenada la serie de grupos-subgrupos tipológicos que definen a un artefacto formatizado particular. Refleja la secuencia sistemática de acciones (formatización de filos y/o puntas) realizadas en una pieza, relativamente sincrónicas o diacrónicas. 
Esto implica tratar con parte de la "historia morfológica"8 de dicho artefacto, que comprende, específicamente, las distintas formatizaciones acaecidas durante los diferentes eventos de manufactura, para el caso de los artefactos compuestos, incluyendo los reciclajes.

Su definición se basa en el análisis de superposiciones y de utilización de fracturas. Así, la confección de un filo que se superpone a otro puede:

- implicar la eliminación total o parcial del filo o punta confeccionado previamente, inutilizándolo (reciclaje).

- afectar sólo una parte del filo, por lo que es factible que este último continúe siendo utilizado.

Es importante destacar que las superposiciones indican claramente una diacronía que refleja un "punto" de cambio en el tiempo, si bien la confección de los filos y puntas puede ser relativamente sincrónica. Por eso, tanto éstas como las fracturas funcionan como una suerte de puntos de inflexión, que permiten caracterizar la secuencia de confección de las piezas analizadas.

Para la descripción de la secuencia tipológica se emplean los paréntesis y corchetes para establecer asociaciones entre filos, en tanto que el uso de las barras paralelas inclinadas está restringido a aquellas superposiciones que no implican la eliminación del filo o punta. Asimismo, se emplea una flecha para indicar el reciclaje. Cuando el reciclaje se produce en función de una fractura, se coloca "fr" en la flecha.

Ejemplos:

$1^{\circ}$ ) Secuencia tipológica de pieza compuesta

[cuchillo // raedera] + cortante

Descripción: hay dos grupos tipológicos relacionados por una superposición, donde el cuchillo es posterior a la raedera pero ésta continúa funcionando. El cortante no presenta asociación con ninguno de los grupos mencionados, por lo que no es posible definir su posición relativa en la secuencia.

\section{$2^{\circ}$ ) Secuencia tipológica de pieza reciclada}

Punta de proyectil $\longrightarrow$ perforador

\footnotetext{
${ }^{8}$ Dicha historia morfológica, más allá de las estrechas vinculaciones, es distinta de la "historia de vida” (Schiffer 1987), puesto que la primera incluye sólo la manufactura, el mantenimiento y el reciclaje.
} 
$3^{\circ}$ ) Secuencia tipológica de pieza compuesta y reciclada

raspador + [cuchillo doble $\stackrel{\mathrm{fr}}{\longrightarrow}$ buril]

Es necesario puntualizar en el tratamiento de los filos bifaciales de arista sinuosa (FBAS). Cuando forman parte de bifaces, al estar los mismos necesariamente formados por dos o más filos de este tipo, se coloca "Bf” entre paréntesis a cada uno de los FBAS al momento de la segmentación. Cuando los FBAS no conforman filos en bifaces esto no se realiza.

\subsubsection{CONSIDERACIONES ACERCA DEL RECICLAJE Y DEL MANTENIMIENTO}

El reciclaje es el retorno de un artefacto a un proceso de manufactura, después de un cierto período de uso, sin pasar por descarte (Schiffer 1987).

Para Darnay y Franklin (1972; citado en Schiffer 1987), el reciclaje es una actividad por la cual un "material secundario" es introducido como materia prima en un proceso de manufactura, por el cual es transformado en un nuevo producto de tal manera que su identidad original se pierde. Para estos autores, "materiales secundarios" son aquellos que: 1) han cumplido su función útil y que no pueden ser más usados en su forma o composición presente y 2) se producen como desecho de la manufactura o conversión de productos. Esta segunda posibilidad presenta una serie de problemas clasificatorios ya que, por ejemplo, una lasca de adelgazamiento bifacial resultante de la confección de un producto "biface” se consideraría un material secundario. Por esto, se reserva aquí la ocurrencia de reciclaje sólo para aquellos casos donde hay un cambio de forma y de función en el artefacto formatizado, perdiendo su identidad original.

Una excepción a lo dicho precedentemente lo constituyen los bifaces, puesto que, al poseer filos generalizados (Hayden et al. 1996), están pensados para ser transformados fácilmente y no hay cambio de función anterior. Es decir, hay cambio de morfología, pero no de función, porque están destinados desde un comienzo a ser otras cosas. Por esto, se emplea el calificativo de biface transformado cuando hay una modificación de la arista sinuosa, generalmente en arista regular, no mediando reciclaje. Se destaca que esta noción de biface transformado no tiene correspondencia alguna con la de tipo morfológico transformado desarrollada previamente.

En general, una pieza es reciclada cuando no puede continuar con su vida útil, ya sea por fractura, por embotamiento del filo o bien por cambios en la morfología por mantenimiento, que impiden que continúe con su función original (Schiffer 1987, Andrefsky 1998). Es decir, se presenta 
tanto en artefactos enteros como en aquellos que han sufrido una fractura. Asimismo, puede afectar no sólo piezas completas (por ejemplo, un perforador sobre punta de proyectil reciclada) sino también filos específicos en una pieza compuesta (ejemplo, cortante sobre cuchillo reciclado) o armarse en función de una fractura (como un buril sobre fractura) ${ }^{9}$.

En cuanto a la identificación del reciclaje por medio de atributos morfológicos, debido a que implica un proceso de manufactura, generalmente deja trazas reconocibles en los artefactos (Schiffer 1987). Al respecto, se remarca que la presencia de pátinas o ventifacción diferencial en una pieza no es un indicador válido de reciclaje, ya que dichas alteraciones implican, necesariamente, la ocurrencia de descarte y del transcurso de un lapso x de tiempo que supera con creces los lapsos implicados en el contexto sistémico, y el reciclaje transcurre por definición en dicho contexto.

Justamente, el proceso donde un artefacto retorna desde un contexto arqueológico a uno sistémico es conocido como reclamación (ibid.). El proceso de reclamar artefactos, a nivel intrasitio, puede dividirse en:

- salvage, que implica materiales recuperados de ocupaciones de grupos anteriores, sin relación con los actuales ocupantes del sitio.

- scavenging, en el cual las acumulaciones de artefactos previamente depositadas en un sitio son explotadas por los habitantes del asentamiento. Este puede incluir el gleaning o reclamación de ítems descartados.

Ya a nivel intersitio, los procesos de reclamación incluyen el collecting y el pothunting, que implican la perturbación, remoción y transporte de materiales superficiales y subsuperficiales, respectivamente.

Se destaca que puede resultar muy difícil diferenciar entre reciclaje y scavenging, es decir, discriminar si piezas particulares continuaron en el registro sistémico o reingresaron al mismo por acciones puntuales de un mismo grupo humano. La no ocurrencia de alteraciones físico-químicas imposibilita esta tarea. Una forma de lograr algún tipo de resultado en este sentido podría ser evaluar la disponibilidad de ítems factibles de ser empleados como formas-base y analizar si hay alguna tendencia en la utilización de las mismas. Por ejemplo, sería esperable una variabilidad muy alta en un contexto de scavenging (pensando en una selección de piezas dentro del amplio espectro de posibilidades que brinda una concentración de artefactos líticos de un sitio habitacional, como los aquí abordados) y una direccionalidad muy marcada para el caso de las piezas recicladas (en función de un

\footnotetext{
${ }^{9}$ En casos de piezas formatizadas que sean recicladas, si las evidencias señalan que se buscó específicamente ese módulo de tamaño y/o morfología, por ejemplo, al armarse los filos o puntas sobre la fractura misma, la pieza es considerada como entera y las dimensiones se colocan sin corchete.
} 
conocimiento muy preciso de con qué piezas se cuenta, cuánto tiempo se ha invertido en su manufactura, etc., que lleva a una selección más orientada).

Los procesos de mantenimiento, por su parte, pueden conducir a cambios en la forma del artefacto, al igual que el reciclaje, pero se diferencian claramente de este último puesto que los cambios en el mantenimiento tienden a ser relativamente menores -aunque pueden comprender grandes cambios en la morfología general- y el artefacto reanuda su primer función (Schiffer 1987).

El mantenimiento es generalmente visible por cambios en la morfología y por presentarse un patrón escamoso escalonado (Aschero 1983). El patrón escamoso irregular en ciertas ocasiones puede ser diagnóstico, por ejemplo, cuando hay marcadas diferencias de patrón en un mismo filo. 


\section{CAPITULO 5}

\section{LA SECUENCIA ARQUEOLÓGICA DE ANTOFAGASTA DE LA SIERRA EN EL LAPSO 5500-1500 AP}

\subsection{BREVE CARACTERIZACIÓN DE LA SECUENCIA OCUPACIONAL LOCAL ENTRE LOS 10000 Y LOS 5500 AÑOS AP}

Antofagasta de la Sierra cuenta para el lapso 10000-5500 años AP con una secuencia arqueológica prácticamente continua (Figura 5.1), señalando una relativa estabilidad ocupacional., con sólo pequeños vacíos de información ${ }^{1}$ que no duran más de 500 años durante el Holoceno Medio. Se recuerda que la información paleoambiental local señala para este momento un desmejoramiento ambiental pero no una desaparición de los recursos hídricos y bióticos como en otras áreas Puneñas, tal lo ocurrido en el Salar de Atacama (Chile), donde se postuló un "silencio arqueológico" que implicó el abandono de ciertas áreas y el desplazamiento a sectores denominados "ecorrefugios" (Núñez et al. 1999).

\footnotetext{
${ }^{1}$ Estos no se consideran hiatos ya que las investigaciones día a día robustecen las evidencias de una secuencia ininterrumpida.
} 


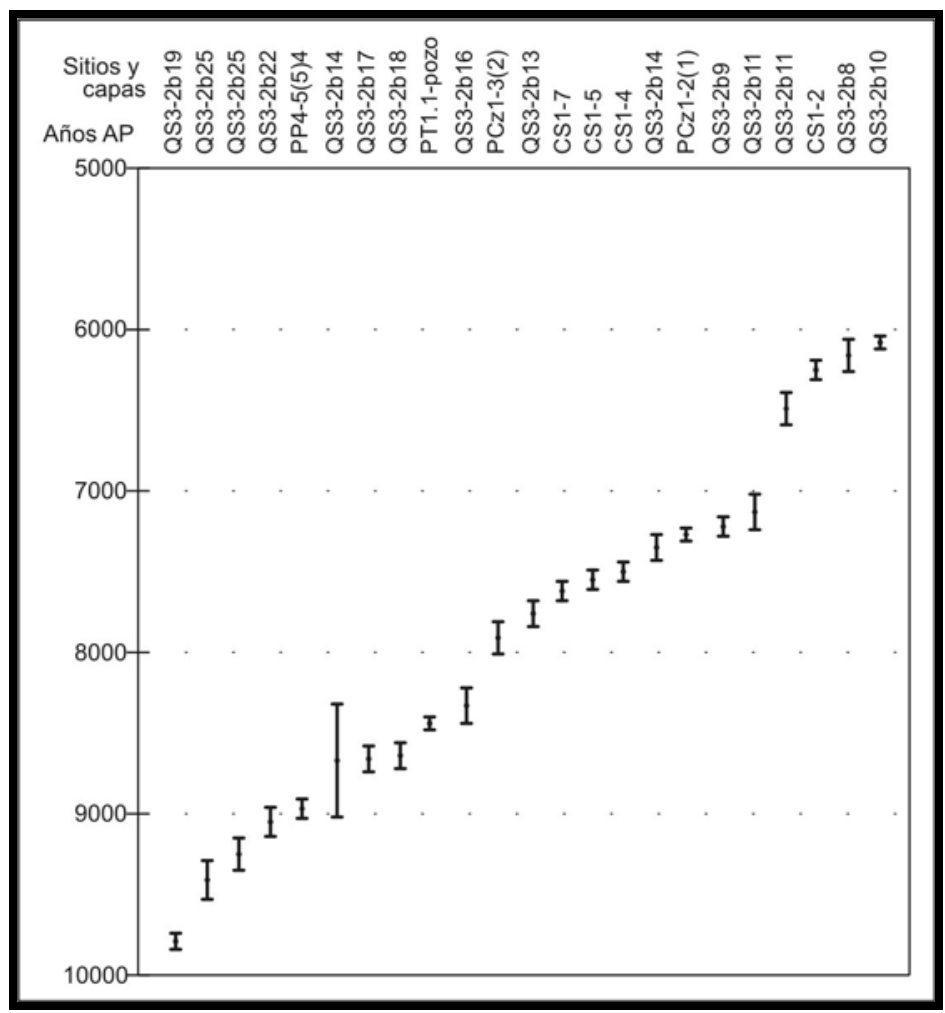

Figura 5.1. Secuencia arqueológica de Antofagasta de la Sierra, lapso 10000-5500 AP

Específicamente, la ocupación humana se inicia en la microrregión hacia los 9790 años AP con el sitio QS3. Recién ca.8500-8000 años AP se agregan los sitios Peñas de la Trampas 1.1 (PT1.1) (Martínez 2003), Peñas de la Cruz 1 (PCz1) (Martínez 2005) y Cueva Salamanca 1 (CS1) (Pintar 2004a).

QS3 y PCz1 son bases residenciales que pueden definirse como campamentos temporarios con énfasis en actividades de caza, mientras que CS1 sería una base residencial de las mismas características que las anteriores pero más duradera (Pintar 2004a). Por su parte, PT1.1 requiere de una mayor apertura para poder realizar alguna aseveración al respecto, contando por el momento con evidencias funerarias (Martínez 2003, Martínez et al. 2004)

Otro sitio es Punta de la Peña 4, que cuenta con un fechado de 8970 AP, pero por el momento no se puede establecer con certeza el tipo de ocupación (ver punto 5.3 Los sitios considerados en el análisis artefactual en este Capítulo).

A los yacimientos mencionados deben sumarse sitios con arte rupestre, como Quebrada Seca 1 o Punta de la Peña 5 (Aschero 1999a y 1999b) y sitios a cielo abierto con artefactos líticos y/o estructuras de piedra, como Quebrada Seca 7 y Quebrada Seca 5, respectivamente (Aschero y Martínez 2001). 
Hasta el momento, los sitios adscribibles a esta cronología, sean datados en forma absoluta o relativa, se localizan exclusivamente en cotas superiores a los 3600 m.s.n.m.

Por información sobre las características de la secuencia en este lapso, desde diversas líneas de evidencia, se remite a bibliografía édita e inédita, entre otros: Aschero (1999a), Pintar (1995a, 1996a, 2004a, 2004b), Elkin (1996a, 1996b), Martínez (2003) Aschero y Martínez (2001), Rodríguez (1999a, 1999b, 2003), Mondini (2004), Rodríguez y Martínez (2001), Hocsman et al. (2004), Babot (2004a), Martínez et al. (2004).

\subsection{LA OCUPACIÓN HUMANA EN ANTOFAGASTA DE LA SIERRA ENTRE LOS 5500 Y LOS 1500 AÑOS AP}

De acuerdo a Yacobaccio (1998), desde los 5000 años AP, aproximadamente, se incrementan notablemente las evidencias de ocupación humana en la Puna Argentina. La microrregión de Antofagasta de la Sierra presenta una situación coincidente, ya que se registra una mayor cantidad de sitios que en el lapso anterior, particularmente desde los 4000 años AP aproximadamente, si se considera exclusivamente a los sitios con cronología absoluta. Pero no sólo es mayor la cantidad de sitios en este último momento, sino que también aumenta el número de los mismos con ocupaciones relativamente sincrónicas (Hocsman 2002) (Figura 5.2).

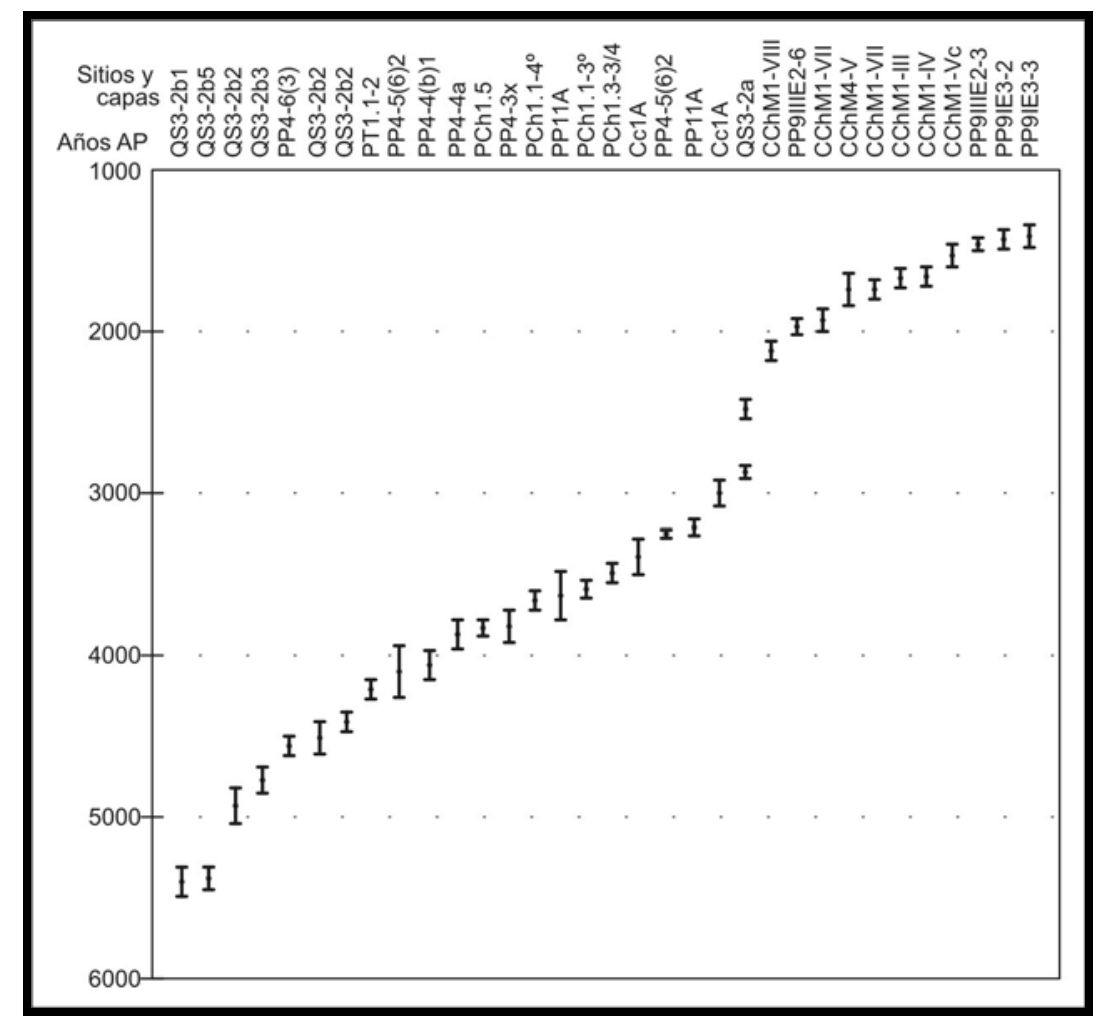

Figura 5.2. Secuencia arqueológica de Antofagasta de la Sierra, lapso 5500-1500 AP 
Ahora bien, los sitios y fechados radiocarbónicos disponibles señalan un vacío de información, hasta el momento, en lo que respecta a ocupaciones domésticas o “sitios de habitación”, entre los 3200 y los 2100 años AP . Esto, se remarca, no significa un hiatus de ocupación en Antofagasta de la Sierra, ya que se cuenta con dataciones de $2480 \pm 60$ años AP en QS3 (Pintar 1996a) y $3000 \pm 80$ y $2870 \pm 40$ AP en Cueva Cacao 1A (Olivera et al. 2003), aunque se trata de contextos funerarios y/o rituales que no cuentan con los materiales líticos necesarios para el tipo de análisis aquí desarrollado.

Asimismo, se dispone de toda una serie de evidencias que apuntan a la idea de una continuidad ocupacional. Entre ellos, se puede mencionar que la técnica empleada en la manufactura de cestas es la misma entre los 5500 y los 2000 AP, como puede observarse en los especimenes recuperados de QS3 (2b5), QS3 (lente 1x) y PP11A (Pérez de Micou y Ancibor 1994, Aschero et al.1999b).

Por otro lado, la utilización de las materias primas líticas, tanto para artefactos líticos tallados, que se verá en este trabajo, como para artefactos de molienda (Babot 2004a), revela una continuidad en cuanto a la información disponible sobre distribución de rocas.

El hallazgo en superficie y en estratigrafía en diversos sitios de la microrregión de puntas de proyectil con pedúnculo destacado y limbo lanceolado, de pequeño tamaño, recuperadas en contextos agro-pastoriles tempranos (3200-2500 AP) del desierto del norte de Chile, como Tulán 54 (Núñez 1994), y de la Puna Norte Argentina y su borde, como el sitio Cueva Huachichocana III (Fernández Distel 1986) o Las Cuevas (Raffino 1976), se constituye en otra línea de evidencia posible.

Finalmente, Aschero (1999a) define la modalidad de arte rupestre "Río Punilla”, datándola relativamente, por medio de análisis de superposiciones y de pátina, entre los 3500 y los 2500 años AP.

Todas estas evidencias se contraponen a lo postulado por Olivera (1992, 2001) y Tchilinguirian y Olivera (2000), respecto a una suerte de reemplazo poblacional ante la llegada a la microrregión de grupos “portadores” de alfarería entre el 3000 y el 1500 AP. Aschero (1994) plantea a nivel macroareal, la posibilidad de una agregación de nuevas poblaciones a otras preexistentes en el proceso de cambio de cazadores-recolectores a grupos agro-pastoriles. Vista la información disponible ${ }^{2}$, esta segunda opción parecería ser más factible, o bien, sin duda, la incorporación de ciertos elementos como la cerámica por parte de grupos locales (esto será tratado en el Capítulo 13) .

\footnotetext{
${ }^{2}$ No sería esperable en grupos recién llegados a un área, por ejemplo, el conocimiento menudo de las fuentes de aprovisionamiento de rocas locales, como se presenta en los asentamientos agro-pastoriles de Antofagasta de la Sierra.
} 
En cuanto a la ubicación de los sitios identificados para el lapso 5500-1500 AP, se encuentran no sólo en las quebradas y vegas con altitudes superiores a los 3600 m (Localidades arqueológicas de Quebrada Seca, Real Grande, Punta de la Peña, Quebrada Salamanca-El Sembrado, Peñas Chicas, Peñas Coloradas y Cacao-Curuto), sino que se extienden también a los sectores más bajos de la microrregión, hacia los 3500 m.s.n.m., a saber: Laguna Antofagasta-Río Punilla (Localidades arqueológicas de La Torre y Confluencia) y Laguna Colorada (Localidad arqueológica del mismo nombre) (Figura 5.3, Figura 5.4, Tabla 5.1).

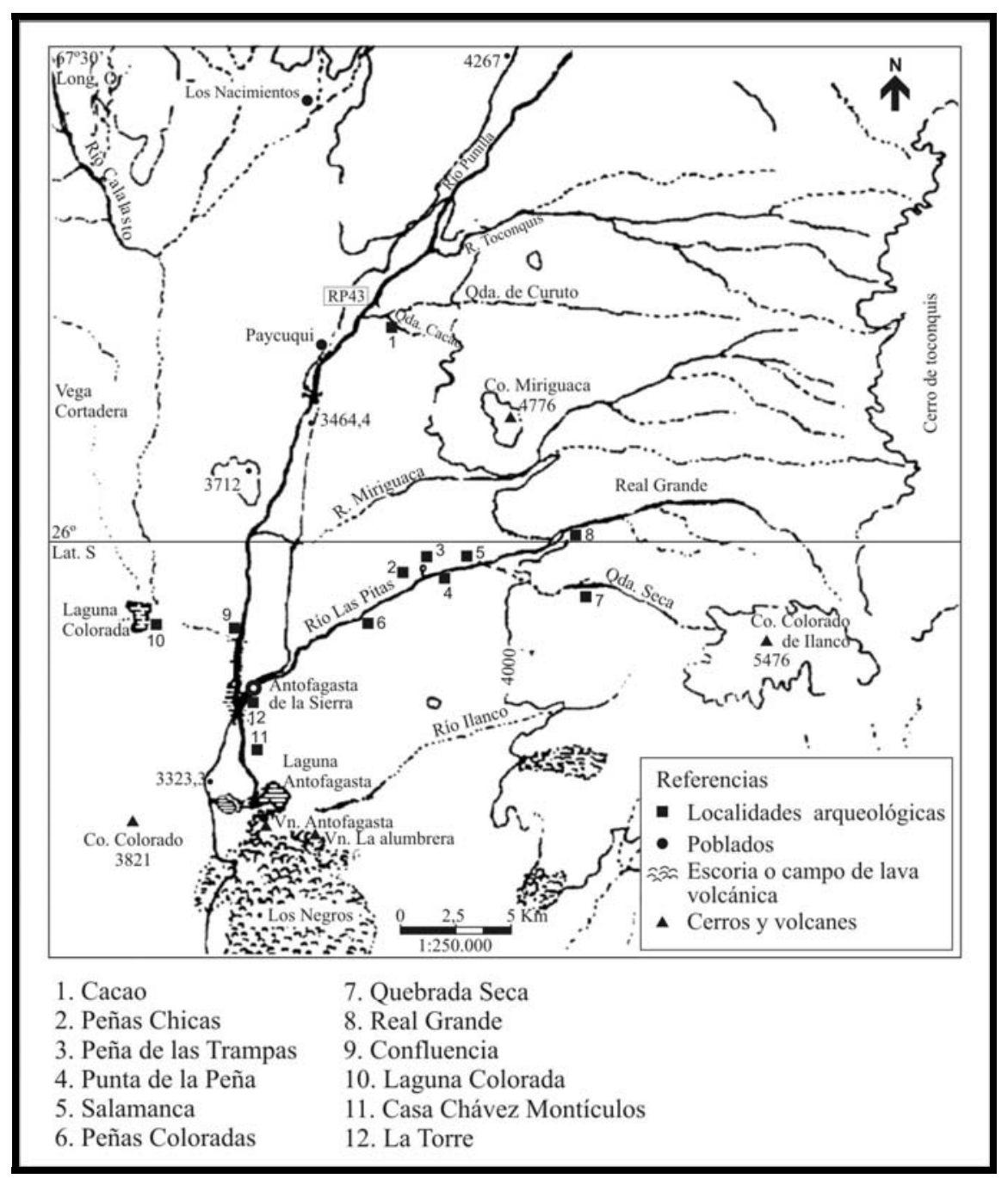

Figura 5.3. Localidades arqueológicas en Antofagasta de la Sierra 


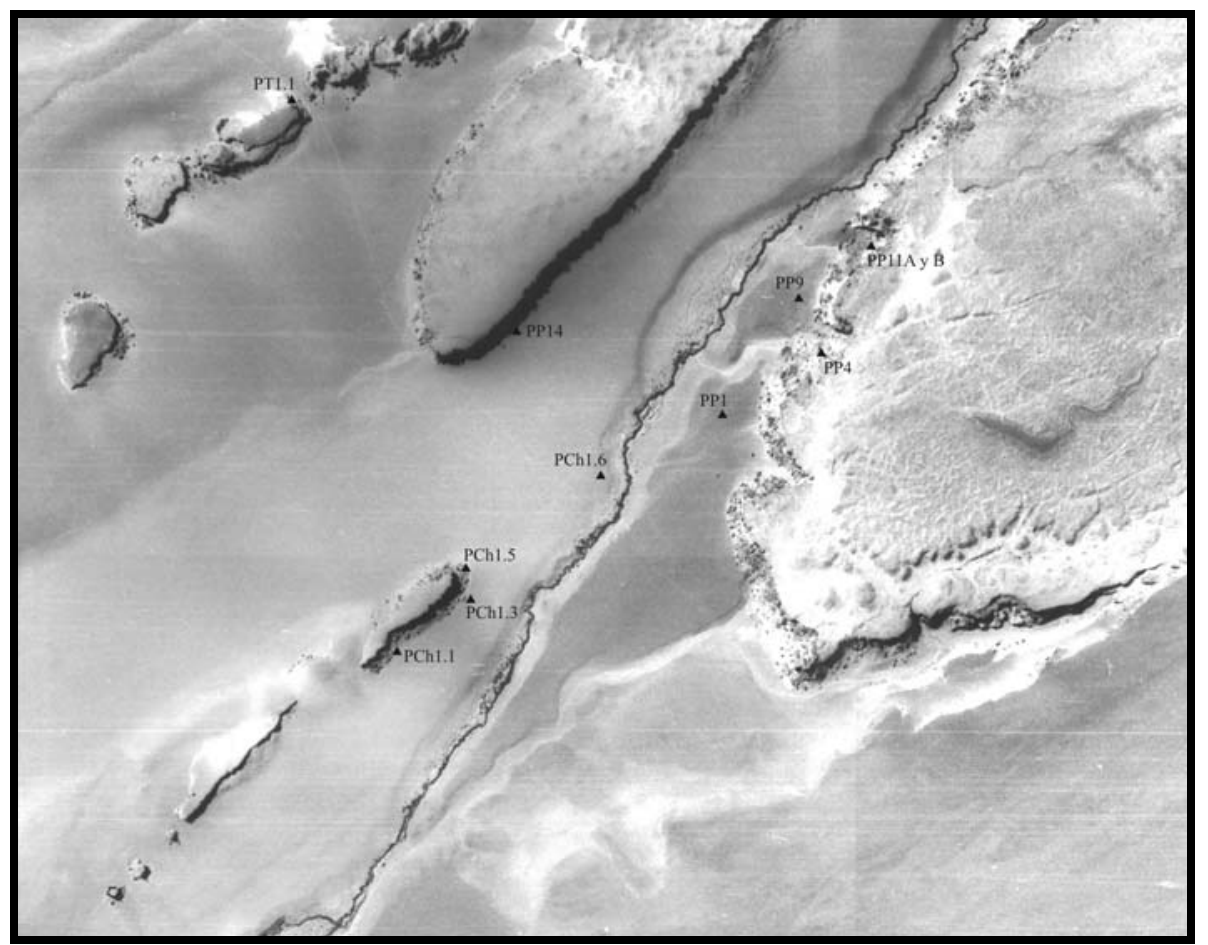

Referencias: PCh1.1: Peñas Chicas 1.1; PCh1.3: Peñas Chicas 1.3; PCh1.5: Peñas Chicas 1.5; PCh1.6: Peñas Chicas 1.6; PP1: Punta de la Peña 1; PP4: Punta de la Peña 4; PP9: Punta de la Peña 9; PP11 A y B: Punta de la Peña 11 A y B; PP14: Punta de la Peña 14; PT1.1: Peñas de las Trampas 1.1

Figura 5.4. Ubicación de sitios arqueológicos en las localidades Punta de la Peña, Peñas Chicas y Peña de las Trampas

Aunque en términos generales están representados los mismos tipos de sitios que en el momento anterior, destacan una serie de sitios que no tienen correlato previo. Dentro de éstos se encuentran: a) los campamentos temporarios con espacios acondicionados y equipamiento, como QS3, PP4, y PCh1.3; b) los campamentos temporarios con énfasis en actividades de caza y equipamiento, el caso de PCh1.1; c) los depósitos intencionales de objetos, sean tumbas u ofrendas, como PP11A,

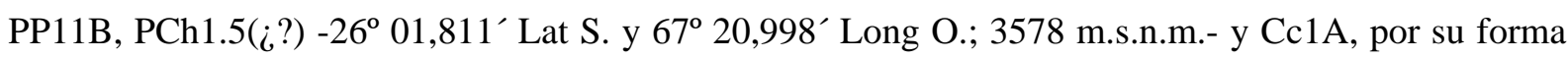
de presentación y contenido y d) las bases residenciales de actividades múltiples de ocupación anual, como Casa Chávez Montículos 1.

En relación con los campamentos temporarios (categorías 1 y 2), a partir de los 5500 años AP se registran cambios en la organización del espacio. Así, por ejemplo, en los niveles 2b5 a 2b2 de QS3 se observa un emplazamiento diferente de los fogones y de las dispersiones de tecnofacturas y ecofactos, a lo que se suman posibles estructuras de cavado en $2 \mathrm{~b} 3$, ya sea que se trate de relictos de pozos de almacenamiento o lugares preparados para asiento (Aschero et al. 1993/94). Tales espacios acondicionados se encuentran también en PP4 y PCh1.3 (alero bajo roca) en forma de estructuras de piedra, con cronologías absolutas entre 4500 y 3500 años AP (Hocsman 2002). Situación similar posiblemente se presente en CS1 (Pintar 2004a). 
Tabla 5.1. Sitios arqueológicos considerados (ca.5500-1500 AP)

\begin{tabular}{|c|c|c|c|c|c|c|}
\hline Localidad & Sitio & Caracterización & \begin{tabular}{|c|} 
Datación \\
radiocarbónica \\
/ estimada (AP) \\
\end{tabular} & $\begin{array}{c}\text { Capa / } \\
\text { nivel }\end{array}$ & $\begin{array}{c}\text { Material / } \\
\text { Indicador } \\
\text { cronológico }\end{array}$ & Fuente \\
\hline \multirow[t]{9}{*}{$\begin{array}{l}\text { Quebrada } \\
\text { Seca }\end{array}$} & $\begin{array}{l}\text { Quebrada Seca } \\
1 \\
\text { (QS1) }\end{array}$ & $\begin{array}{l}\text { Cueva } \\
\text { Arte rupestre sin } \\
\text { ocupación }\end{array}$ & ¿5500-4500? & - & Representaciones & $\begin{array}{l}\text { Aschero } \\
\text { 1999a }\end{array}$ \\
\hline & $\begin{array}{l}\text { Quebrada Seca } \\
2 \\
\text { (QS2) }\end{array}$ & $\begin{array}{l}\text { Cueva } \\
\text { Arte rupestre sin } \\
\text { ocupación }\end{array}$ & ¿5500-4500? & - & Representaciones & $\begin{array}{l}\text { Aschero } \\
\text { 1999a }\end{array}$ \\
\hline & \multirow{7}{*}{$\begin{array}{l}\text { Quebrada Seca } \\
3 \\
\text { (QS3) }\end{array}$} & \multirow{7}{*}{$\begin{array}{l}\text { Alero y cueva } \\
\text { Campamento } \\
\text { temporario con } \\
\text { espacios } \\
\text { acondicionados y } \\
\text { equipamiento, } \\
\text { con evidencia } \\
\text { funeraria (2b2) }\end{array}$} & $\begin{array}{l}2480 \pm 60 \\
\text { (LP 278) }\end{array}$ & $\begin{array}{l}2 \text { a (lente } \\
1 \mathrm{x})\end{array}$ & $\begin{array}{l}\text { Tallos de Senecio } \\
\text { santelicis }\end{array}$ & $\begin{array}{l}\text { Pintar } \\
\text { 1996a } \\
\end{array}$ \\
\hline & & & $\begin{array}{l}5400 \pm 90 \\
(\mathrm{LP} 270)\end{array}$ & 2b1 & Carbón & $\begin{array}{l}\text { Pintar } \\
1996 a\end{array}$ \\
\hline & & & $\begin{array}{l}4410 \pm 60 \\
\text { (UGA 8357) }\end{array}$ & $2 \mathrm{~b} 2$ & Hueso humano & $\begin{array}{l}\text { Aschero } \\
\text { com pers. }\end{array}$ \\
\hline & & & $\begin{array}{l}4510 \pm 100 \\
\text { (Beta 27801) }\end{array}$ & $2 \mathrm{~b} 2$ & Gramíneas & $\begin{array}{l}\text { Aschero et } \\
\text { al. } 1991\end{array}$ \\
\hline & & & $\begin{array}{l}4930 \pm 110 \\
(A C 1115)\end{array}$ & $2 \mathrm{~b} 2$ & Carbón & $\begin{array}{l}\text { Aschero et } \\
\text { al. } 1991\end{array}$ \\
\hline & & & $\begin{array}{l}4770 \pm 80 \\
\text { (Beta 27802) }\end{array}$ & $2 \mathrm{~b} 3$ & Carbón & $\begin{array}{l}\text { Aschero et } \\
\text { al. } 1991\end{array}$ \\
\hline & & & $\begin{array}{l}5380 \pm 70 \\
\text { (Beta 59927) }\end{array}$ & $2 \mathrm{~b} 5$ & Carbón & $\begin{array}{l}\text { Aschero et } \\
\text { al. 1993/94 }\end{array}$ \\
\hline \multirow[t]{2}{*}{ Real Grande } & $\begin{array}{l}\text { Real Grande } 3 \\
\text { (RG3) }\end{array}$ & $\begin{array}{l}\text { Alero } \\
\text { Arte rupestre sin } \\
\text { ocupación }\end{array}$ & ¿6000-3000? & - & Representaciones & $\begin{array}{l}\text { Aschero } \\
\text { 1999a }\end{array}$ \\
\hline & $\begin{array}{l}\text { Real Grande } \\
11 \text { (RG11) }\end{array}$ & $\begin{array}{l}\text { Parapetos de piedra } \\
\text { Estación de caza } \\
\text { por intercepción }\end{array}$ & ¿6000-3000? & - & $\begin{array}{l}\text { Tipología de puntas } \\
\text { de proyectil }\end{array}$ & $\begin{array}{l}\text { Aschero y } \\
\text { Martínez } \\
2001 \\
\end{array}$ \\
\hline \multirow[t]{14}{*}{$\begin{array}{l}\text { Punta de la } \\
\text { Peña }\end{array}$} & $\begin{array}{l}\text { Punta de la } \\
\text { Peña } 1 \text { (PP1) }\end{array}$ & $\begin{array}{l}\text { A cielo abierto } \\
\text { Campamento- taller }\end{array}$ & ¿6000-3000? & - & $\begin{array}{l}\text { Tipología de } \\
\text { artefactos líticos } \\
\text { tallados }\end{array}$ & $\begin{array}{l}\text { Aschero } \\
\text { com pers. }\end{array}$ \\
\hline & \multirow[t]{6}{*}{$\begin{array}{l}\text { Punta de la } \\
\text { Peña } 4 \text { (PP4) }\end{array}$} & \multirow{6}{*}{$\begin{array}{l}\text { Alero } \\
\text { Campamento } \\
\text { temporario con } \\
\text { espacios } \\
\text { acondicionados y } \\
\text { equipamiento. Arte } \\
\text { rupestre }\end{array}$} & $\begin{array}{l}3820 \pm 100 \\
\text { (UGA 9254) }\end{array}$ & $3 \mathrm{x}$ & Carbón & $\begin{array}{l}\text { Aschero } \\
\text { com pers. }\end{array}$ \\
\hline & & & $\begin{array}{l}3870 \pm 90 \\
\text { (Beta 77748) }\end{array}$ & $4 \mathrm{a}$ & Madera & $\begin{array}{l}\text { Pintar } \\
\text { 1996a }\end{array}$ \\
\hline & & & $\begin{array}{l}4060 \pm 90 \\
\text { (Beta } 77749)\end{array}$ & $4 \mathrm{~b}(1)$ & Madera & $\begin{array}{l}\text { Pintar } \\
\text { 1996a }\end{array}$ \\
\hline & & & $\begin{array}{l}3250 \pm 50 \\
\text { (UGA 8354) }\end{array}$ & $5(6) 2$ & $\begin{array}{l}\text { Hueso de camélido } \\
\text { (AMS) Fechado } \\
\text { observado }\end{array}$ & $\begin{array}{l}\text { Aschero } \\
\text { com pers. }\end{array}$ \\
\hline & & & $\begin{array}{l}4100 \pm 160 \\
\text { (UGA 7976) }\end{array}$ & $5(6) 2$ & $\begin{array}{l}\text { Carbón y madera } \\
\text { carbonizada }\end{array}$ & $\begin{array}{l}\text { Aschero } \\
\text { com pers. }\end{array}$ \\
\hline & & & $\begin{array}{l}4560 \pm 60 \\
\text { (UGA 15094) }\end{array}$ & $6(3)$ & Hueso de camélido & $\begin{array}{l}\text { Aschero } \\
\text { com pers. }\end{array}$ \\
\hline & \multirow{4}{*}{$\begin{array}{l}\text { Punta de la } \\
\text { Peña 9 } \\
\text { (PP9) }\end{array}$} & \multirow{2}{*}{$\begin{array}{l}\text { Sector I E3 } \\
\text { A cielo abierto } \\
\text { Base residencial de } \\
\text { actividades } \\
\text { temporarias }\end{array}$} & $\begin{array}{l}1430 \pm 60 \\
(\text { LP 1430) }\end{array}$ & 2 & $\begin{array}{l}\text { Excremento de } \\
\text { camélido }\end{array}$ & $\begin{array}{l}\text { Babot et al. } \\
2004\end{array}$ \\
\hline & & & $\begin{array}{l}1410 \pm 70 \\
(\text { LP 1473) }\end{array}$ & 3 & Carbón & $\begin{array}{l}\text { Babot et al. } \\
2004\end{array}$ \\
\hline & & \multirow{2}{*}{$\begin{array}{l}\text { Sector III E2 } \\
\text { A cielo abierto } \\
\text { Base residencial de } \\
\text { actividades } \\
\text { temporarias }\end{array}$} & $\begin{array}{l}1460 \pm 40 \\
\text { (UGA 9069) }\end{array}$ & 3 (pasillo) & Semillas & $\begin{array}{l}\text { López } \\
\text { Campeny } \\
2001 \\
\end{array}$ \\
\hline & & & $\begin{array}{l}1970 \pm 50 \\
\text { (UGA 9076) }\end{array}$ & $\begin{array}{l}\text { Bajo bloque } \\
\text { con } \\
\text { grabados } \\
\text { (relación } \\
\text { con nivel 6) } \\
\end{array}$ & $\begin{array}{l}\text { Excremento de } \\
\text { camélido }\end{array}$ & $\begin{array}{l}\text { López } \\
\text { Campeny } \\
2001\end{array}$ \\
\hline & \multirow{2}{*}{$\begin{array}{l}\text { Punta de la } \\
\text { Peña 11A } \\
\text { (PP11A) }\end{array}$} & \multirow[t]{2}{*}{$\begin{array}{l}\text { Oquedad rocosa } \\
\text { Enterratorio }\end{array}$} & $\begin{array}{l}3630 \pm 150 \\
\text { (UGA 7977) }\end{array}$ & - & Gramíneas & $\begin{array}{l}\text { Aschero et } \\
\text { al. 1999b }\end{array}$ \\
\hline & & & $\begin{array}{l}3210 \pm 50 \\
\text { (UGA 8355) }\end{array}$ & - & Hueso humano & $\begin{array}{l}\text { Aranibar et } \\
\text { al. } 2001\end{array}$ \\
\hline & $\begin{array}{l}\text { Punta de la } \\
\text { Peña 11B } \\
\text { (PP11B) } \\
\end{array}$ & $\begin{array}{l}\text { Oquedad rocosa } \\
\text { Camada de paja }\end{array}$ & ¿4000-3000? & - & $\begin{array}{l}\text { Evidencias } \\
\text { contextuales }\end{array}$ & $\begin{array}{l}\text { Rodríguez } \\
\text { et al. } 2003\end{array}$ \\
\hline
\end{tabular}


Producción lítica, variabilidad y cambio en Antofagasta de la Sierra -ca.5500-1500 AP-, Salomón Hocsman

\begin{tabular}{|c|c|c|c|c|c|c|}
\hline & $\begin{array}{l}\text { Punta de la } \\
\text { Peña 14 } \\
\text { (PP14) }\end{array}$ & $\begin{array}{l}\text { Superficie } \\
\text { Hallazgos aislados } \\
\text { de material lítico }\end{array}$ & ¿4000-3000? & - & $\begin{array}{l}\text { Tipología de puntas } \\
\text { de proyectil }\end{array}$ & Este trabajo \\
\hline $\begin{array}{l}\text { Peñas de las } \\
\text { Trampas }\end{array}$ & $\begin{array}{l}\text { Peña de las } \\
\text { Trampas 1.1. } \\
\text { (PT1.1) }\end{array}$ & $\begin{array}{l}\text { Alero } \\
\text { Camada de paja con } \\
\text { artefactos asociados }\end{array}$ & $\begin{array}{l}4210 \pm 60 \\
(L P 1588)\end{array}$ & 2 & Gramíneas & $\begin{array}{l}\text { Martínez } \\
\text { 2003, } \\
\text { com pers. }\end{array}$ \\
\hline \multirow[t]{6}{*}{$\begin{array}{l}\text { Peñas } \\
\text { Chicas }\end{array}$} & \multirow[t]{2}{*}{$\begin{array}{l}\text { Peñas Chicas } \\
1.1 \text { (PCh1.1) }\end{array}$} & \multirow{2}{*}{$\begin{array}{l}\text { Alero } \\
\text { Campamento } \\
\text { temporario con } \\
\text { énfasis en } \\
\text { actividades de caza } \\
\text { y equipamiento }\end{array}$} & $\begin{array}{l}3590 \pm 55 \\
(\mathrm{LP} 263)\end{array}$ & $3^{\circ}$ ext & Carbón & Pintar 1996 \\
\hline & & & $\begin{array}{l}3660 \pm 60 \\
(\mathrm{LP} 261)\end{array}$ & $4^{\circ}$ ext & Carbón & $\begin{array}{l}\text { Pintar } \\
\text { 1996a }\end{array}$ \\
\hline & \multirow[t]{2}{*}{$\begin{array}{l}\text { Peñas Chicas } \\
1.3 \text { (PCh1.3) }\end{array}$} & \multirow{2}{*}{$\begin{array}{l}\text { Alero bajo roca } \\
\text { Campamento } \\
\text { temporario con } \\
\text { espacios } \\
\text { acondicionados y } \\
\text { equipamiento } \\
\end{array}$} & $\begin{array}{l}3490 \pm 60 \\
\text { (LP 1421) }\end{array}$ & $3 / 4$ & Carbón & Este trabajo \\
\hline & & & $\begin{array}{l}3680 \pm 50 \\
\text { (UGA 15092) }\end{array}$ & 7 & Carbón & Este trabajo \\
\hline & $\begin{array}{l}\text { Peñas Chicas } \\
1.5 \text { (PCh1.5) }\end{array}$ & $\begin{array}{l}\text { Alero bajo roca } \\
\text { Depósito } \\
\text { intencional de } \\
\text { objetos ( } \dot{\mathcal{L}} ?)\end{array}$ & $\begin{array}{l}3830 \pm 50 \\
\text { (UGA 15097) }\end{array}$ & - & Hueso de camélido & Este trabajo \\
\hline & $\begin{array}{l}\text { Peñas Chicas } \\
1.6 \text { (PCh1.6) }\end{array}$ & $\begin{array}{l}\text { A cielo abierto } \\
\text { Campamento-taller }\end{array}$ & ¿4500-3000? & - & $\begin{array}{l}\text { Tipología de puntas } \\
\text { de proyectil }\end{array}$ & Este trabajo \\
\hline $\begin{array}{l}\text { Quebrada } \\
\text { Salamanca- } \\
\text { El } \\
\text { Sembrado } \\
\end{array}$ & $\begin{array}{l}\text { Cueva } \\
\text { Salamanca } 1 \\
\text { (CS1) }\end{array}$ & $\begin{array}{l}\text { Cueva } \\
\text { Campamento } \\
\text { temporario }(\dot{\mathcal{c}} ?)\end{array}$ & ¿4500-3000? & - & $\begin{array}{l}\text { Tipología de puntas } \\
\text { de proyectil }\end{array}$ & $\begin{array}{l}\text { Pintar } \\
\text { 2004a }\end{array}$ \\
\hline \multirow[t]{4}{*}{$\begin{array}{l}\text { Cacao/ } \\
\text { Curuto }\end{array}$} & \multirow[t]{3}{*}{$\begin{array}{l}\text { Cueva Cacao } 1 \\
\text { A (Cc1 A) }\end{array}$} & $\begin{array}{l}\text { Cueva } \\
\text { Depósito } \\
\text { intencional de } \\
\text { objetos }\end{array}$ & $\begin{array}{l}2870 \pm 40 \\
\text { (UGA 9066) }\end{array}$ & - & $\begin{array}{l}\text { Tira de sandalia de } \\
\text { cuero }\end{array}$ & $\begin{array}{l}\text { Olivera et } \\
\text { al. } 2003\end{array}$ \\
\hline & & $\begin{array}{l}\text { Cueva } \\
\text { Depósito } \\
\text { intencional de } \\
\text { objetos } \\
\end{array}$ & $\begin{array}{l}3000 \pm 80 \\
\text { (UGA 8627) }\end{array}$ & - & $\begin{array}{l}\text { Trenza de pelo } \\
\text { humano }\end{array}$ & $\begin{array}{l}\text { Olivera et } \\
\text { al. } 2003\end{array}$ \\
\hline & & $\begin{array}{l}\text { Cueva } \\
\text { Campamento } \\
\text { temporario (i?). } \\
\text { Arte rupestre } \\
\end{array}$ & $\begin{array}{l}3390 \pm 110 \\
(\text { LP 507) }\end{array}$ & 5 & Carbón & $\begin{array}{l}\text { Olivera et } \\
\text { al. } 2003\end{array}$ \\
\hline & $\begin{array}{l}\text { Curuto } 5 \\
(\mathrm{Cu} 5)\end{array}$ & $\begin{array}{l}\text { Farallón } \\
\text { Arte rupestre sin } \\
\text { ocupación }\end{array}$ & $\dot{¿}^{5500-4500 ?}$ & - & Representaciones & $\begin{array}{l}\text { Aschero et } \\
\text { al. } 2003\end{array}$ \\
\hline $\begin{array}{l}\text { Peñas } \\
\text { Coloradas }\end{array}$ & $\begin{array}{l}\text { Peñas } \\
\text { Coloradas } 1 \\
\text { (PC1) } \\
\end{array}$ & $\begin{array}{l}\text { Farallón } \\
\text { Arte rupestre sin } \\
\text { ocupación }\end{array}$ & ¿3500-2500? & - & Representaciones & $\begin{array}{l}\text { Aschero } \\
1999 \text { a }\end{array}$ \\
\hline Confluencia & $\begin{array}{l}\text { Confluencia } \\
1(\mathrm{C} 1)\end{array}$ & $\begin{array}{l}\text { Farallón } \\
\text { Arte rupestre sin } \\
\text { ocupación }\end{array}$ & $\dot{\iota}^{3500-2500 ?}$ & - & Representaciones & $\begin{array}{l}\text { Aschero } \\
1999 \text { a }\end{array}$ \\
\hline \multirow{7}{*}{$\begin{array}{l}\text { Casa } \\
\text { Chávez } \\
\text { Montículos }\end{array}$} & \multirow{6}{*}{$\begin{array}{l}\text { Casa Chávez } \\
\text { Montículos } 1 \\
\text { (CChM1) }\end{array}$} & \multirow{6}{*}{$\begin{array}{l}\text { A cielo abierto } \\
\text { Base residencial de } \\
\text { actividades } \\
\text { múltiples }\end{array}$} & $\begin{array}{l}1670 \pm 60 \\
\text { (Beta 27199) }\end{array}$ & III & Carbón & $\begin{array}{l}\text { Olivera } \\
1992 \\
\end{array}$ \\
\hline & & & $\begin{array}{l}1660 \pm 60 \\
(\text { LP 251) }\end{array}$ & IV & Carbón & $\begin{array}{l}\text { Olivera } \\
1992 \\
\end{array}$ \\
\hline & & & $\begin{array}{l}1530 \pm 70 \\
\text { (Beta 27201) } \\
\end{array}$ & Vc & Carbón & $\begin{array}{l}\text { Olivera } \\
1992 \\
\end{array}$ \\
\hline & & & $\begin{array}{l}1740 \pm 60 \\
(\text { Beta 27202) }\end{array}$ & VII & Carbón & $\begin{array}{l}\text { Olivera } \\
1992 \\
\end{array}$ \\
\hline & & & $\begin{array}{l}1930 \pm 70 \\
\text { (Beta 27200) }\end{array}$ & VII & Carbón & $\begin{array}{l}\text { Olivera } \\
1992 \\
\end{array}$ \\
\hline & & & $\begin{array}{l}2120 \pm 60 \\
\text { (LP 299) }\end{array}$ & VIII & Hueso & $\begin{array}{l}\text { Olivera } \\
1992 \\
\end{array}$ \\
\hline & $\begin{array}{l}\text { Casa Chávez } \\
\text { Montículos } 4 \\
\text { (CChM4) }\end{array}$ & $\begin{array}{l}\text { A cielo abierto } \\
\text { Base residencial de } \\
\text { actividades } \\
\text { múltiples }\end{array}$ & $\begin{array}{l}1740 \pm 100 \\
\text { (Beta 27198) }\end{array}$ & $\mathrm{V}$ & Carbón & $\begin{array}{l}\text { Olivera } \\
1992\end{array}$ \\
\hline $\begin{array}{l}\text { Laguna } \\
\text { Colorada } \\
\end{array}$ & $\begin{array}{l}\text { Laguna } \\
\text { Colorada } 1 \\
\end{array}$ & $\begin{array}{l}\text { Cueva } \\
\text { Arte rupestre sin }\end{array}$ & ¿5500-3000? & - & Representaciones & $\begin{array}{l}\text { Aschero } \\
\text { com pers. }\end{array}$ \\
\hline
\end{tabular}


Producción lítica, variabilidad y cambio en Antofagasta de la Sierra -ca.5500-1500 AP-, Salomón Hocsman

\begin{tabular}{|c|c|c|c|c|c|c|}
\hline & (LC1) & ocupación & & & & \\
\hline & $\begin{array}{l}\text { Laguna } \\
\text { Colorada } 3 \\
\text { (LC3) }\end{array}$ & $\begin{array}{l}\text { A cielo abierto } \\
\text { Parapetos de piedra. } \\
\text { Estación de caza } \\
\text { por intercepción. } \\
\text { Arte rupestre }\end{array}$ & ¿5000-4000? & - & $\begin{array}{l}\text { Tipología de puntas } \\
\text { de proyectil y } \\
\text { representaciones }\end{array}$ & $\begin{array}{l}\text { Aschero } \\
\text { 1999b }\end{array}$ \\
\hline & $\begin{array}{l}\text { Laguna } \\
\text { Colorada } 7 \\
\text { (LC7) }\end{array}$ & $\begin{array}{l}\text { A cielo abierto } \\
\text { Parapetos de piedra. } \\
\text { Estación de caza } \\
\text { por intercepción }\end{array}$ & ¿5000-4000? & - & $\begin{array}{l}\text { Tipología de puntas } \\
\text { de proyectil }\end{array}$ & $\begin{array}{l}\text { Aschero } \\
\text { com pers. }\end{array}$ \\
\hline & $\begin{array}{l}\text { Laguna } \\
\text { Colorada } 2.1 \\
(\mathrm{LC} 2.1) \\
\end{array}$ & $\begin{array}{l}\text { Distribución de } \\
\text { materiales en } \\
\text { superficie }\end{array}$ & ¿4500-3000? & - & $\begin{array}{l}\text { Tipología de puntas } \\
\text { de proyectil }\end{array}$ & $\begin{array}{l}\text { Tchilinguiri } \\
\text { an y Olivera } \\
2005 \\
\end{array}$ \\
\hline & $\begin{array}{l}\text { Laguna } \\
\text { Colorada } \\
\text { (no ubicado) }\end{array}$ & $\begin{array}{l}\text { Recolección } \\
\text { superficial de } \\
\text { pobladores } \\
\text { (procedencia } \\
\text { desconocida) }\end{array}$ & ¿4000-3000? & - & $\begin{array}{l}\text { Tipología de puntas } \\
\text { de proyectil }\end{array}$ & $\begin{array}{l}\text { Este trabajo } \\
\text { (este sitio } \\
\text { puede } \\
\text { coincidir } \\
\text { con LC2.1) } \\
\end{array}$ \\
\hline La Torre & $\begin{array}{l}\text { La Torre } 1 \\
\text { (LT1) }\end{array}$ & $\begin{array}{l}\text { Bloques con arte } \\
\text { rupestre. } \\
\text { Hallazgos aislados } \\
\text { en superficie }\end{array}$ & ¿5500-3000? & - & Representaciones & $\begin{array}{l}\text { Aschero } \\
\text { com pers. }\end{array}$ \\
\hline
\end{tabular}

Nota: a este listado de sitios deberían sumarse los sitios agro-pastoriles descriptos por Olivera y Podestá (1993), aunque con los recaudos necesarios ya que no cuentan con datación absoluta, por lo que podrían ser posteriores al 1500 AP

\subsection{LOS SITIOS CONSIDERADOS EN EL ANÁLISIS ARTEFACTUAL}

Se consideraron para el análisis las siguientes bases residenciales, en base a su situación cronológica (Tabla 5.1) y a la presencia de materiales líticos factibles de ser analizados:

\subsubsection{QUEBRADA SECA $3(\mathrm{QS3})$}

Quebrada Seca 3 es un abrigo rocoso ubicado al pie del farallón de ignimbritas que conforma la margen sur de la vega de Quebrada Seca, en las quebradas de altura ${ }^{3}$. Se encuentra a una altitud de 4100 m.s.n.m. (Aschero 1988b) (Figura 5.5, Figura 5.6).

\footnotetext{
${ }^{3}$ Se emplea la diferenciación ambiental de Olivera (1992) entre fondo de cuenca, sectores intermedios y quebradas de altura.
} 


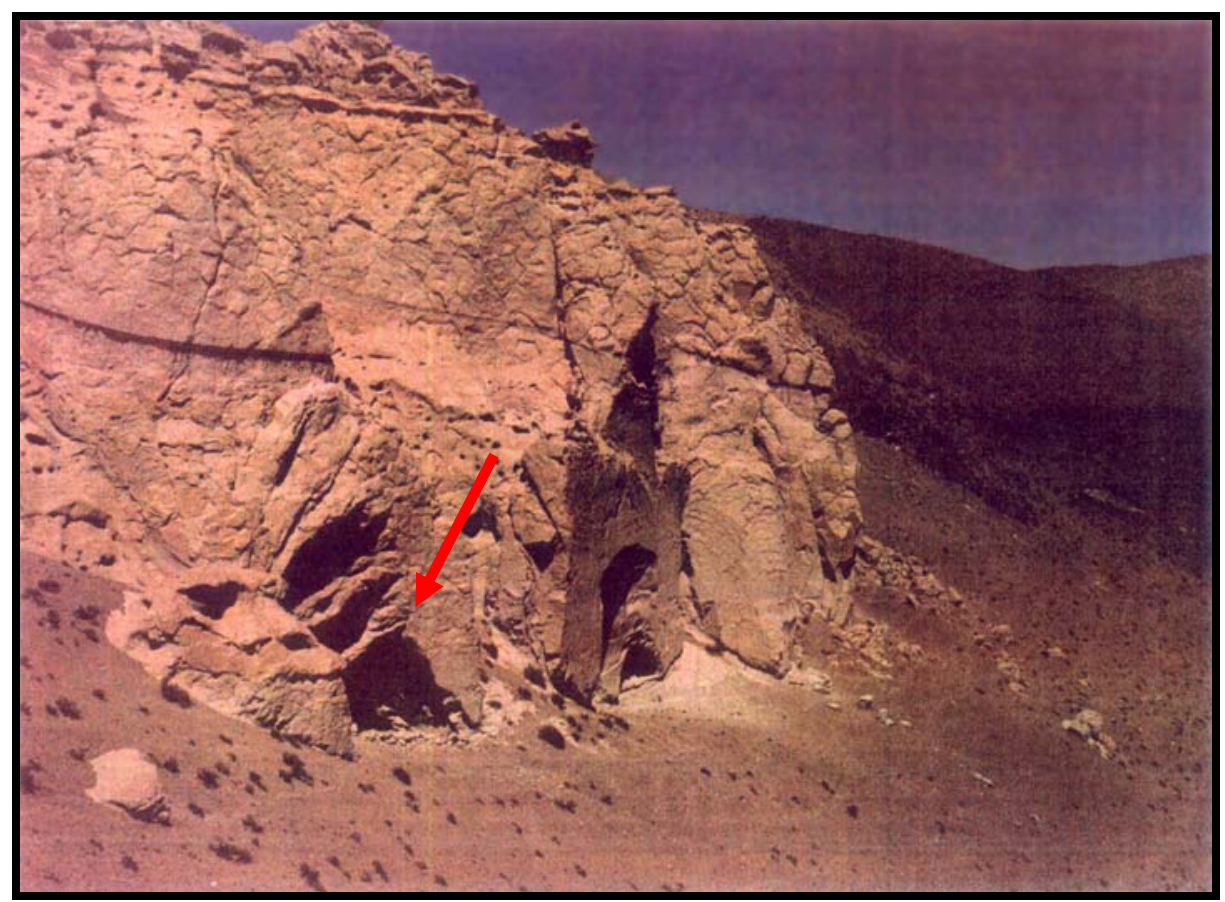

Figura 5.5. El sitio arqueológico Quebrada Seca 3 (cortesía C. Aschero)

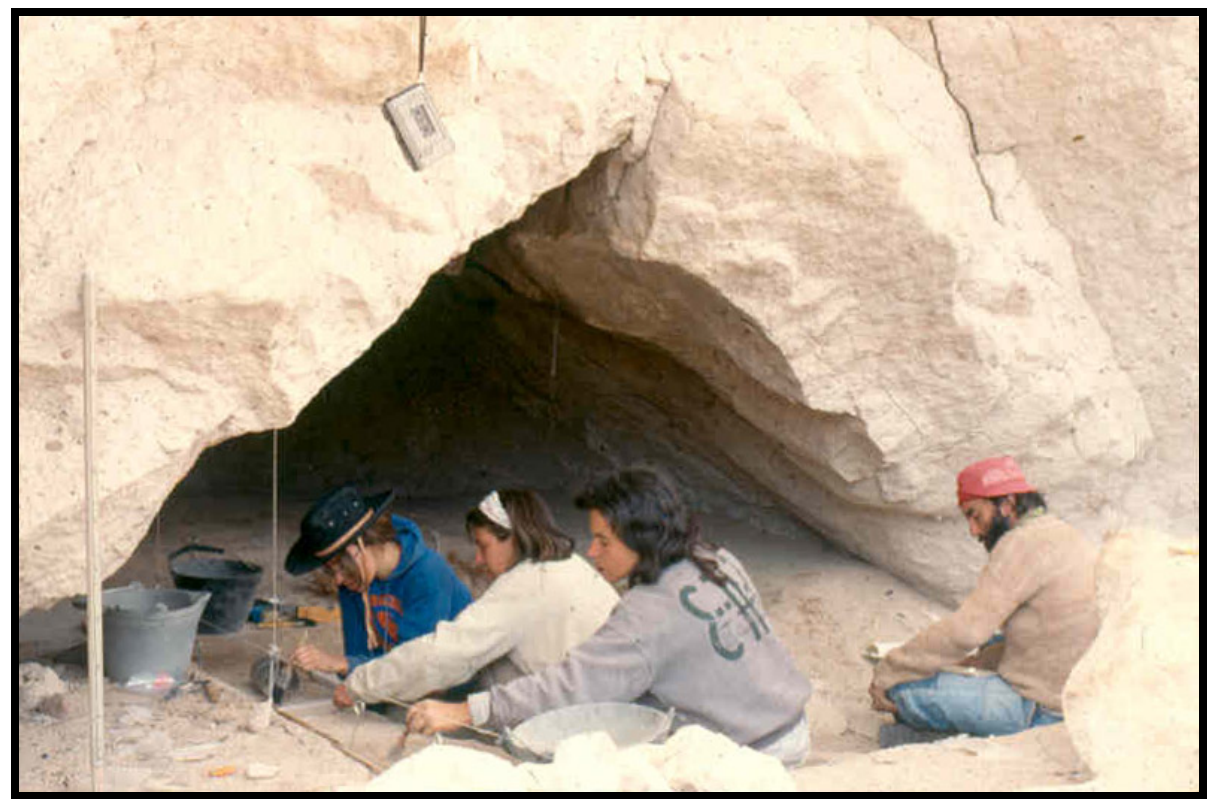

Figura 5.6. Excavaciones en Quebrada Seca 3. Principios de la década del ’90 (cortesía C. Aschero)

La boca del abrigo está orientada hacia el Noreste y presenta un área de reparo cuyas dimensiones lineales, en ancho y profundidad desde el área de goteo hasta la pared del fondo, son de 9 x $5 \mathrm{~m}$, con una superficie promedio de $24 \mathrm{~m}^{2}$. Dicha área fue dividida en un espacio exterior y uno interior, designados alero y cueva respectivamente, por la existencia de una visera rocosa interna que restringe el espacio útil de habitación (Aschero et al. 1991) (Figura 5.7). 


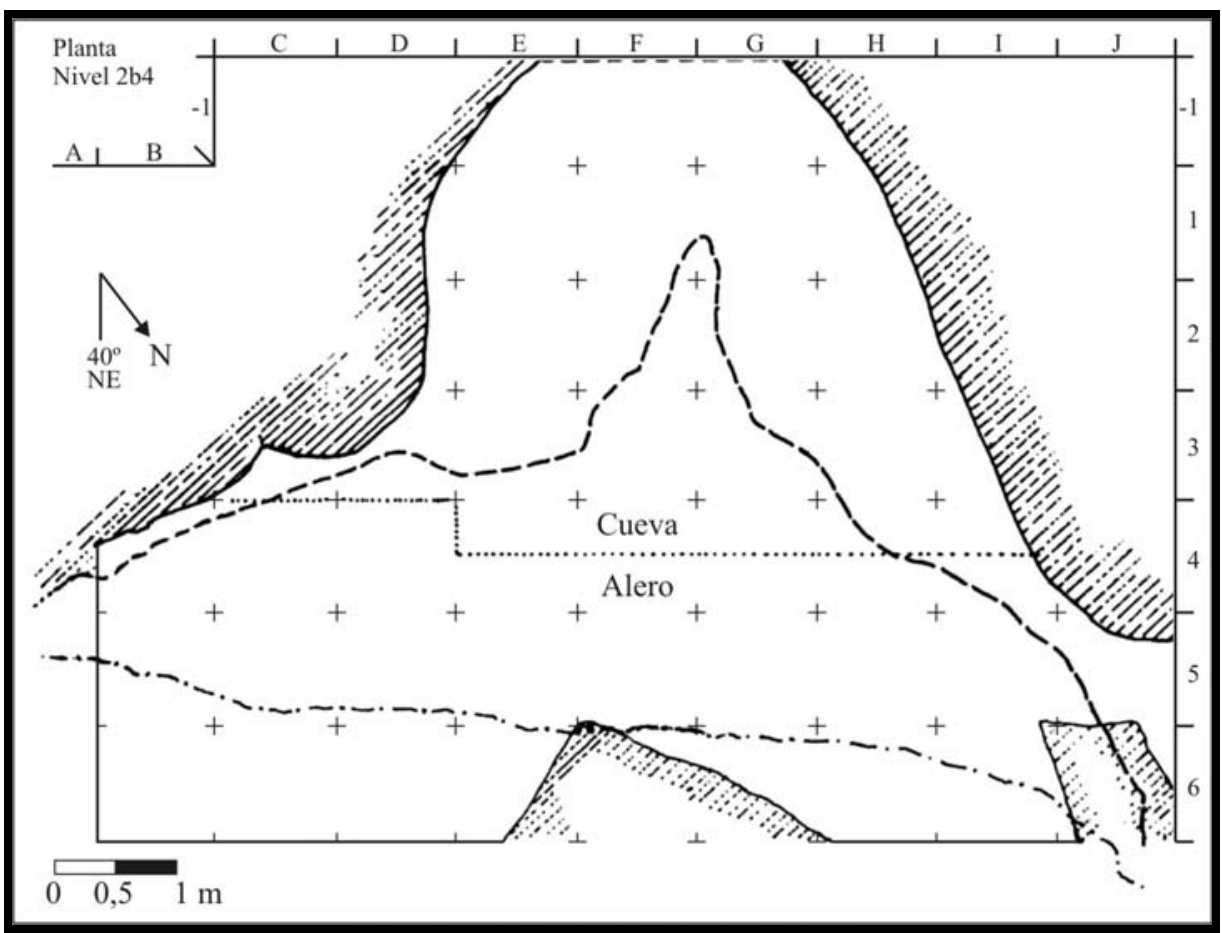

Figura 5.7. Planta del sitio Quebrada Seca 3 (modificado de Aschero et al. 1993-94)

En el transcurso de las excavaciones el área correspondiente a la cueva se ha ido ampliando, mostrándose como un espacio útil de habitación en posición sentada, a partir y entre los niveles $2 \mathrm{~b} 2$ a 2 b13 y en posición parada para los niveles por debajo de 2b14. Consecuentemente, para las ocupaciones primero citadas, esa visera interior ha debido ser un elemento condicionante en la utilización del espacio (Aschero et al. 1993-94).

En relación con la estratigrafía, se diferenciaron cuatro unidades estratigráficas (Aschero 1988b, Aschero et al. 1991):

- Capa 0: capa superficial limo-arenosa suelta y guano. Contiene intercalaciones de restos vegetales, faunísticos y sedimentos carbonosos; estos últimos de aparente origen antropogénico (lente 1x: episodio de depositación restringido).

- Capa 1: sedimento compacto limo-arenoso arqueológicamente estéril.

- Capa 2a: sedimento arenoso no compactado que presenta en su cumbre una coloración gris a castaño claro con escasos restos antropogénicos.

- Capa 2b: sedimento arenoso a areno-limoso castaño claro con importantes aportes antropógenos. Dentro de esta capa se diferenciaron 25 niveles, conformando la secuencia de cazadores-recolectores más completa del Noroeste Argentino.

A los fines de esta investigación, interesan el fechado radiocarbónico de la capa 2a y los materiales líticos de los niveles 2b1 a 2b5 de la capa 2b (Tabla 5.1). 
De acuerdo a Aschero et al. (1993-94), en base a evidencias de organización del espacio, de actividades y de descarte/abandono de artefactos líticos, QS3 puede definirse en estos niveles como un sitio de uso redundante y estacional por parte de unidades sociales reducidas.

El análisis de los materiales líticos tallados implica la consideración de los cinco niveles en conjunto (2b1 a 2b5), de forma de obtener una visión integral. Al respecto, si bien desde los inicios de los trabajos en la microrregión se han destacado las semejanzas entre estos niveles (Aschero et al. 1993-94), los diversos análisis realizados hasta el momento han abordado sólo niveles específicos o bien series de niveles, pero nunca el total.

Así, Aschero et al. (1991) estudian artefactos formatizados y desechos de talla del nivel 2b2; Aschero et al. (1993-94) abordan artefactos formatizados, desechos de talla y núcleos del nivel 2b4; Pintar (1990) analiza artefactos formatizados, desechos de talla y núcleos del nivel 2b3; posteriormente, esta autora (Pintar 1996a) considera los conjuntos líticos de los niveles 2b2 y 2 b3. Martínez (1997), por su parte, realiza un análisis tipológico de puntas de proyectil de los niveles 2b4 y 2b5. Finalmente, Manzi (1999), trabaja básicamente con desechos de talla de los niveles 2b2, 2b4 y $2 b 5$.

En general, puede afirmarse que los temas seleccionados han estado relacionados con problemas de organización tecnológica (por ejemplo, Aschero et al. 1991, Pintar 1996a), con menor relevancia de los abordajes tipológicos de artefactos formatizados, aunque siempre presentes en algún grado -con excepción del trabajo de Martínez (1997) referido específicamente a eso, para un tipo particular de instrumento-. Por otra parte, el interés por la arqueología distribucional se ve reflejada en la propuesta de Manzi (1999).

Con respecto a las muestras utilizadas en esta investigación, se han empleado todas las piezas recuperadas hasta el momento, desde el inicio de las excavaciones (año 1984) hasta el cierre del sitio (año 1996). Esto implica que en este trabajo se consideran muestras de artefactos formatizados y de núcleos ya analizadas por otros investigadores del equipo. Se destaca, al respecto, que el análisis de las piezas se planteó en función de nuevas preguntas que implicaron un estudio tipológico menudo profundizar en el conocimiento de grupos y subgrupos tipológicos- y la consideración de superposiciones de filo y/o puntas y de casos de reciclaje y reclamación. Asimismo, se analizaron muestras de artefactos formatizados no publicadas hasta el momento, procedentes de los niveles $2 \mathrm{~b} 1 \mathrm{y}$ 2b5 -en este último, se exceptúan las puntas de proyectil, como se señaló en los dos párrafos anteriores-, incorporándose además piezas de distintos niveles recuperadas en la última excavación que no habían sido descriptas con anterioridad. 
En cuanto a los datos sobre desechos de talla, se utiliza la profusa información generada al respecto, en forma édita e inédita (Aschero et al. 1991; Aschero et al. 1993-94; Pintar 1990, 1996a; Manzi 1999).

\subsubsection{PUNTA DE LA PEÑA 4 (PP4)}

El sitio PP4 es un alero rocoso de 15 x 7 m orientado hacia el Nor-noreste que se presenta "colgado" en la porción superior de un farallón de ignimbritas. Se encuentra en los sectores intermedios y, dentro de éstos, en el curso medio-inferior del Río Las Pitas, a una altura de 3650 m.s.n.m. (Toselli 1998) (Figura 5.8, Figura 5.9, Figura 5.10)

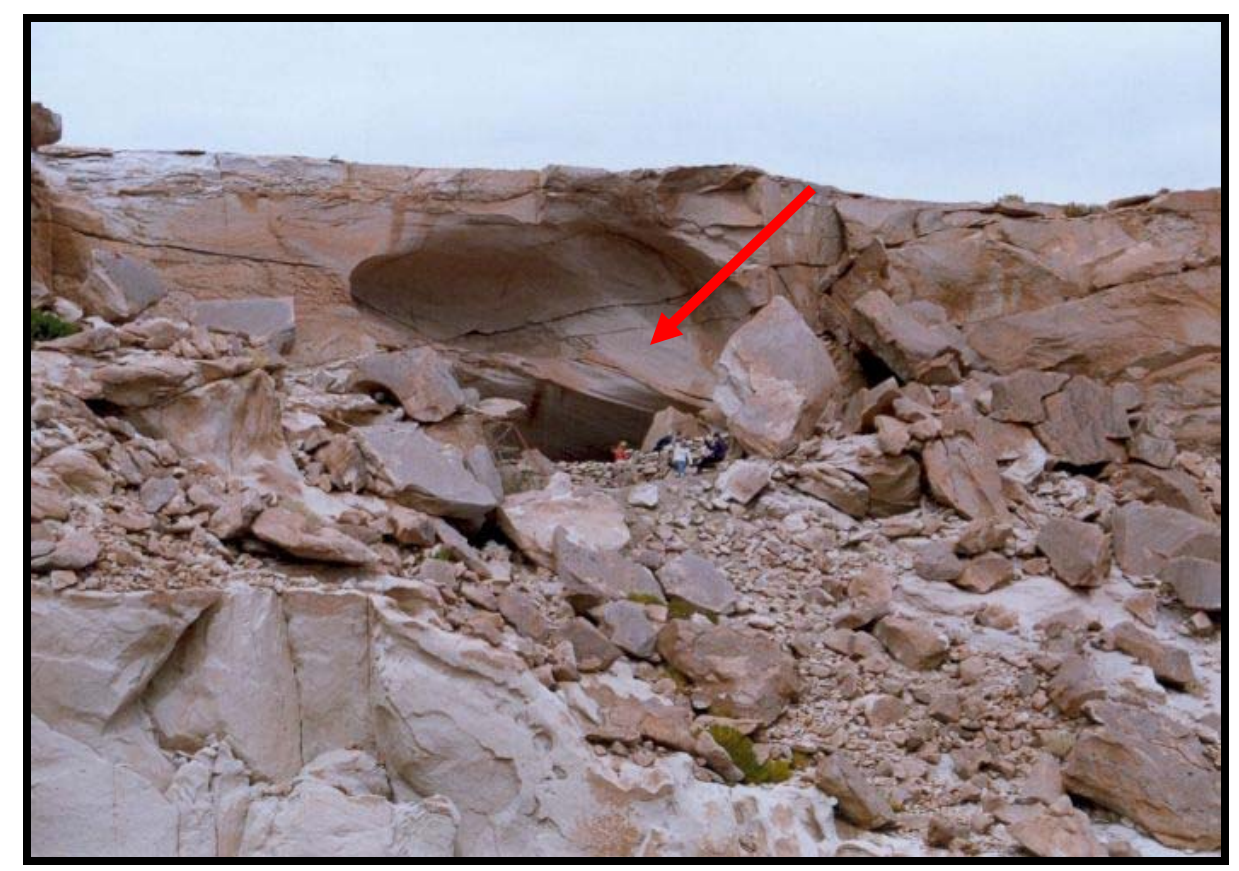

Figura 5.8. El sitio arqueológico Punta de la Peña 4 (cortesía C. Baied) 


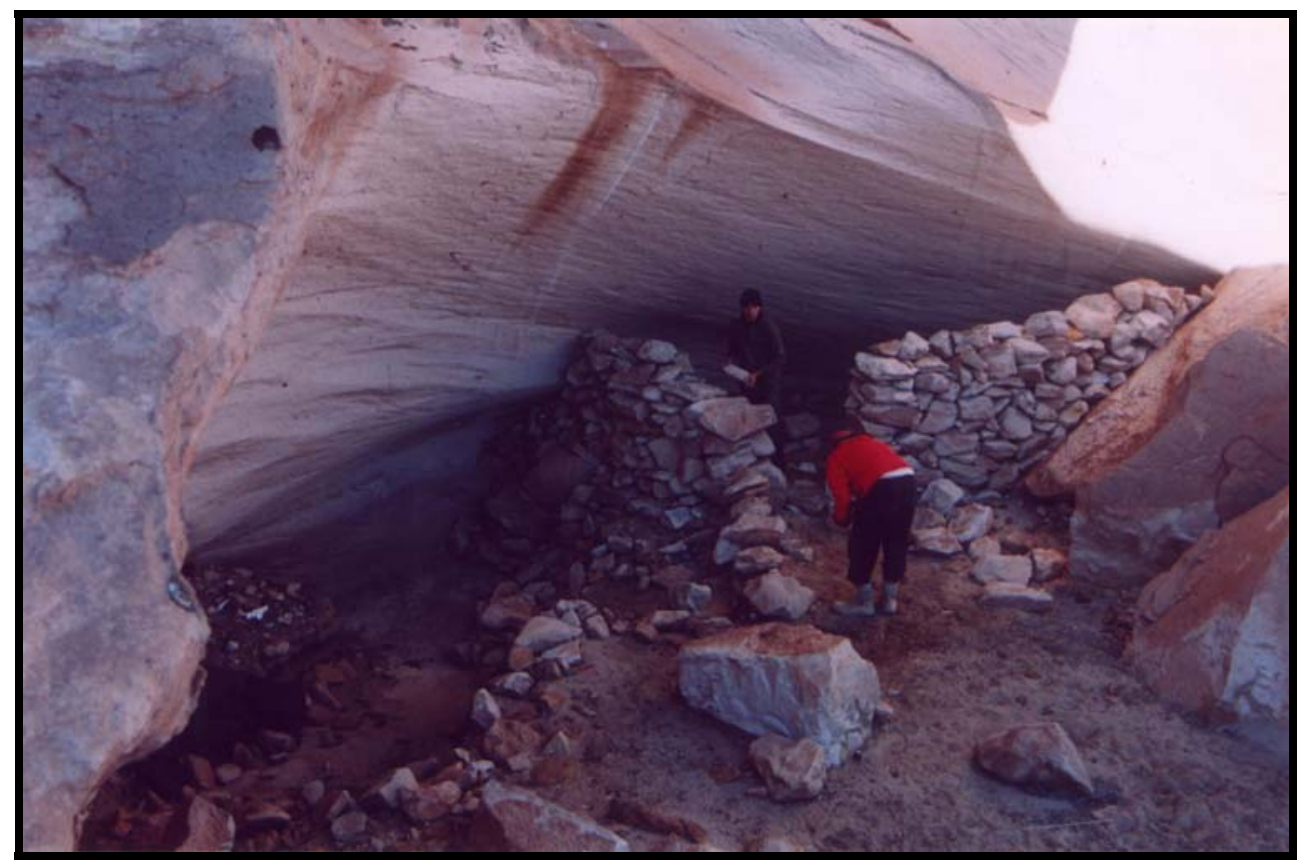

Figura 5.9. Vista del interior del alero (cortesía C. Aschero)

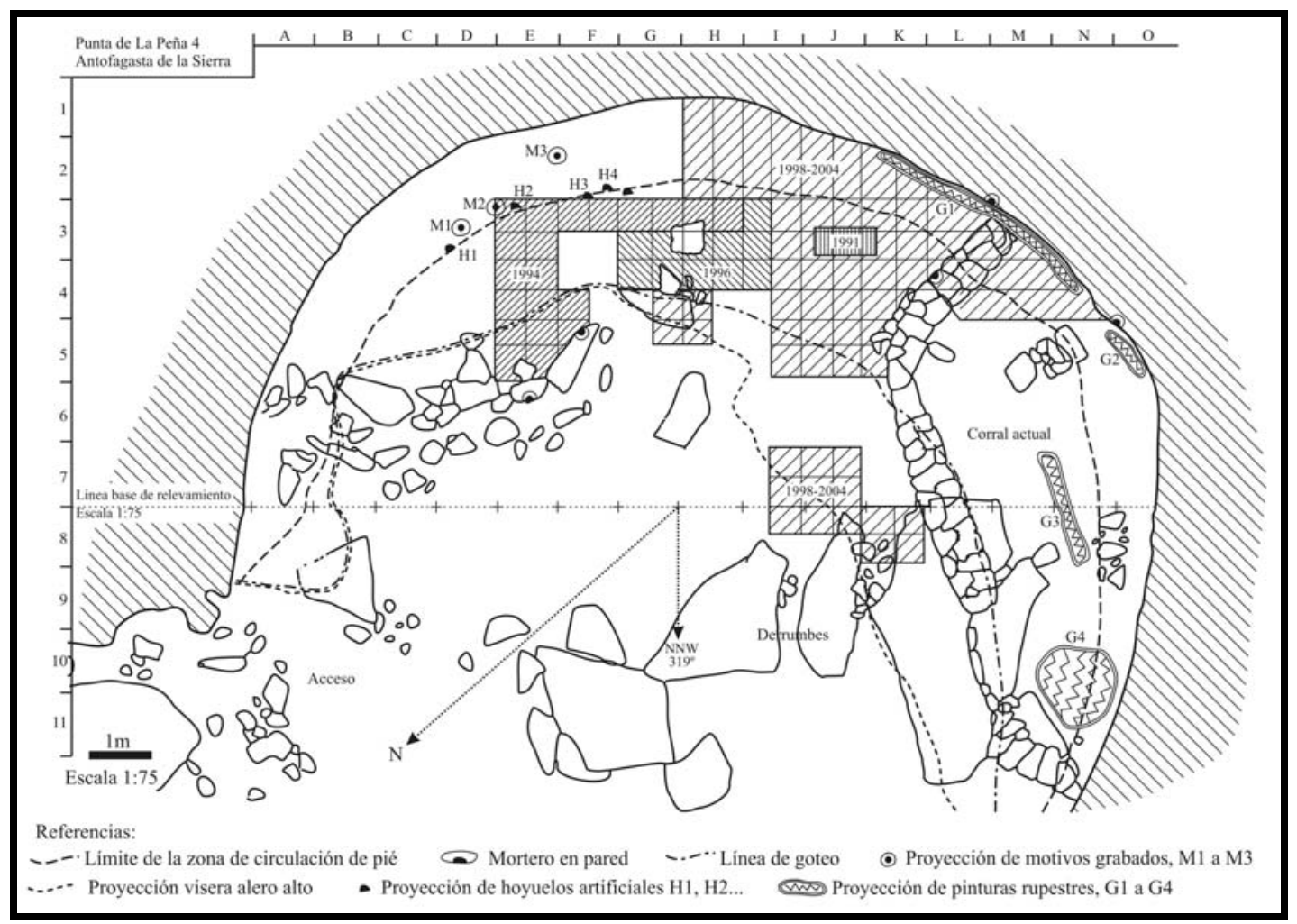

Figura 5.10. Planta del sitio Punta de la Peña 4 (modificada de Rodríguez et al. 2005)

Las excavaciones en este sitio se iniciaron en el año 1994 (Pintar 1996a) y continúan hasta hoy en día. 
Siguiendo a Aschero (2005a) y Aschero et al. (2005), se diferenciaron 7 unidades estratigráficas, incluyendo un potente depósito de excrementos de ovinos y camélidos (capa 0) con diversos episodios de compactación que incluyen material cultural. Las subsiguientes capas 1 a 3 y 4 a 6 se diferencian claramente por una matriz limo-arenosa marrón clara con abundantes restos vegetales para las primeras y por una matriz areno-limosa rojiza a gris-rojiza para las segundas, con escasa conservación de restos vegetales. La diferenciación entre uno y otro paquete de capas es claro y distinto en los perfiles expuestos. Entre las capas 3 y 4, sin embargo, se distinguieron tres lentes, denominadas 3x, 3y y 3z, cuya cronología está en discusión (Figura 5.11).

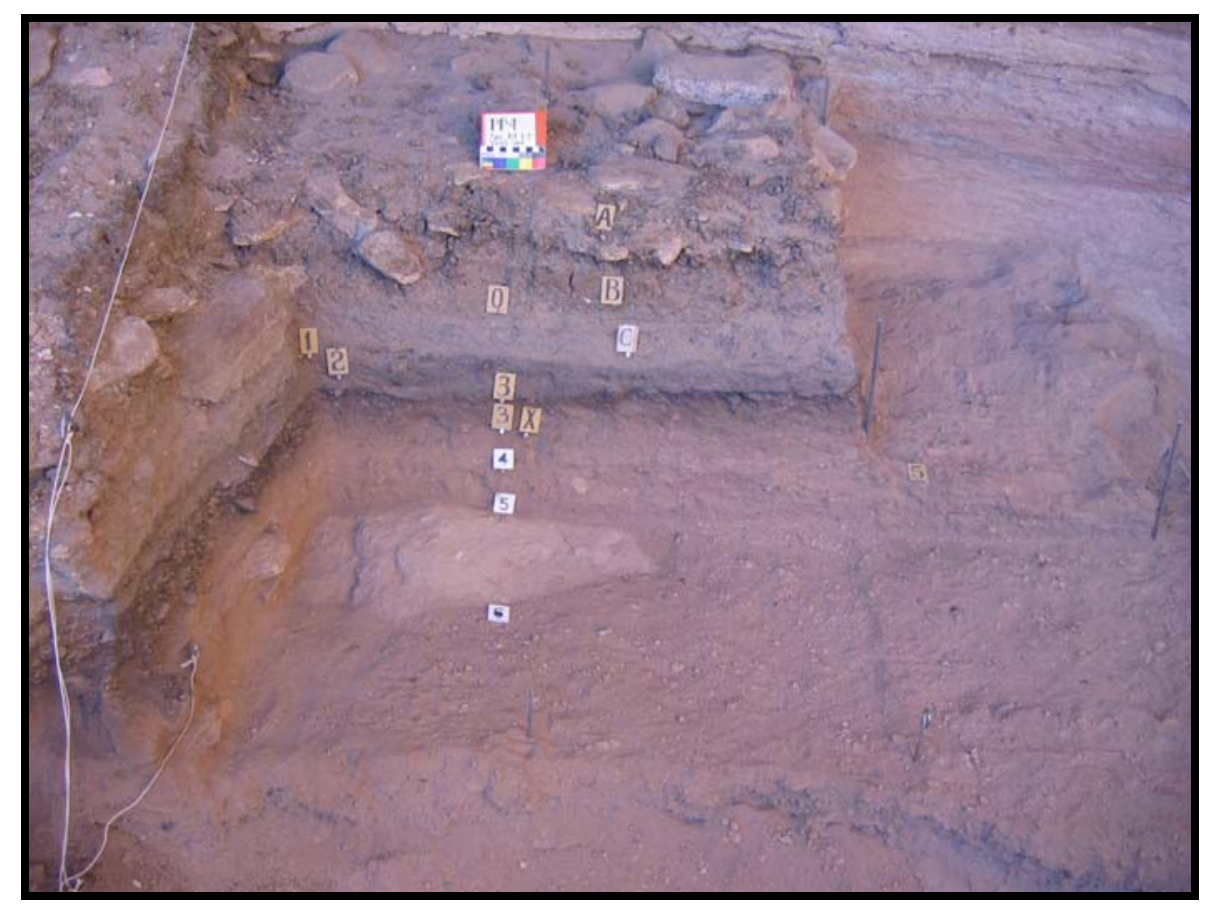

Figura 5.11. Perfil del sitio Punta de la Peña 4 (cortesía C. Baied)

Las dataciones radiocarbónicas y la evidencia estratigráfica señalan la siguiente secuencia de ocupación del sitio PP4 (Aschero 2005, Aschero et al. 2005):

I) Un componente inicial aún no claramente calibrado en su conformación y cronología, pero asociado

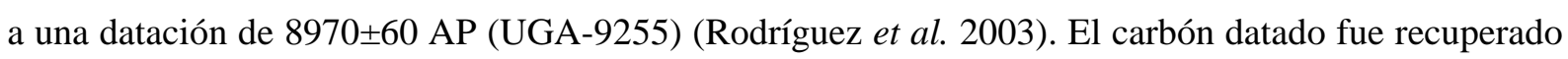
de un área de combustión sobre el piso de roca, situada en la base de la capa 6 o 5(6) -según la nomenclatura de cada campaña-. En la campaña 2003 se observó que esta área de combustión estaba recortada por una estructura de cavado posterior a esa datación, posiblemente como parte de una excavación mayor que habría preparado un área de habitación bajo nivel del terreno expuesto en aquél entonces, que se abría extendido entre los sectores G a M y 4 a 1 (Figura 5.9). La extensión de este componente inicial y sus asociaciones es, consecuentemente, un problema pendiente de resolver en el sitio. 
En este momento se habrían realizado pinturas sobre la pared del alero. La ocupación se habría producido con un piso de roca desnuda expuesta.

II) El segundo componente corresponde a una serie de ocupaciones sucesivas registradas en la capa 6 / 5(6) por la superposición de planos de apoyo horizontal de artefactos líticos, astillas óseas y lentes carbonosas. Se registran por lo menos tres posibles eventos de ocupación dentro del sedimento arenoso suelto (no compactado) que rellena la depresión intencionalmente excavada y que apoya directamente sobre el piso de roca. Sobre éste, un fogón playo muy circunscrito brindó una datación de 4100£160 AP (UGA 7976) sobre carbón y madera parcialmente quemada. Se considera que esta fecha es problemática, ya que si bien se trataba en ambos casos de materia vegetal, se combinó restos completamente carbonizados con otros que lo estaban parcialmente. Una astilla de hueso de camélido

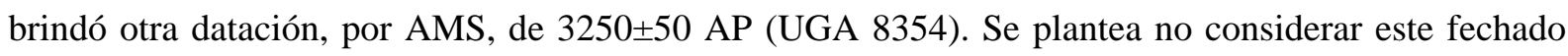
debido a que el hueso se encontraba muy deteriorado, y posiblemente poseía poco colágeno. Otra datación sobre hueso de camélido, resultó en 4560_60 (UGA 15094) (Tabla 5.1).

Se desconoce aún qué ocurre en la periferia exterior a la depresión modelada, donde es posible que se haya llevado a cabo un set distinto de actividades.

A partir del segundo y tercer plano de apoyo de artefactos y ecofactos (extracciones) se recuperaron diversos fragmentos de roca exfoliada de las paredes con pinturas rojas. Ello indica que los procesos de degradación del soporte con pinturas rupestres ya estaba avanzado en momentos de estas ocupaciones y que dichas pinturas podrían asociarse con el componente inicial.

En oportunidad de estas excavaciones se amplió significativamente la muestra artefactual, en particular del primer evento de ocupación de la capa 6 / 5(6) que, hacia el fondo de la pared del alero, mostró una importante cantidad de raspadores, raederas, cuchillos y puntas de proyectil, entre otras clases que sugieren una alta variabilidad de actividades a las que fueron aplicados. Un probable peso de propulsor, diversas muestras de pigmentos minerales (rojos y ocres) y una pieza textil en técnica de malla, en lana de camélido, también se asocian a este contexto.

Los artefactos líticos recuperados muestran relaciones tipológicas con componentes más antiguos, como son las capas 18 a 14 de Quebrada Seca 3. Esto sugiere una continuidad de los diseños en el tiempo que, unida al conjunto de dataciones disponibles para la microrregión, también indicaría la continuidad de las poblaciones originales y las prácticas tecnológicas.

Este momento corresponde a la ejecución de una serie de grabados que se superponen a las pinturas rupestre. 
III) Un tercer componente se refiere a las ocupaciones de las capas 5(1) a 5(5) y 4. Las dataciones disponibles fechan la porción superior de dicha porción del paquete estratigráfico, con dataciones de

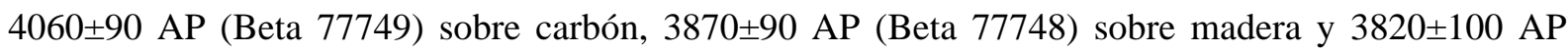
(UGA 9254) sobre carbón (Tabla 5.1).

Tanto la capa 5 como la 4 presentan abundancia de artefactos líticos (formatizados y desechos de talla), siendo las densidades más altas junto con la capa 6, de las conocidas en sitios del área.

Este componente mostró, por vez primera en la región, la presencia de estructuras de piedra de planta subcircular, con diámetros de $1.50 \mathrm{~m}$ hasta tamaños de $3 \times 1.80 \mathrm{~m}$, en número de 4 . La construcción de éstas tiene una baja selección de rocas que no superan dos hiladas mantenidas. No presentan, en primera instancia, diferencia de contenidos interior-exterior.

Estos sedimentos y parte de las estructuras tapan grabados rupestres ejecutados sobre la pared de fondo del alero, superpuestos a las antedichas pinturas. Consecuentemente su ejecución correspondería a las ocupaciones de Capa 6, es decir aquellas previas a la instalación de las estructuras de piedra.

IV) Este componente corresponde a ocupaciones de sociedades agro-alfareras entre los 900 y los 500 años AP, con acumulaciones de basura, estructuras de piedra y acumulaciones de paja y fogones bordeados de piedras.

V) Ultimo componente asociado a ocupaciones del período colonial y post-Colonial vinculado con la instalación de corrales para animales domésticos de origen indígena (llamas) o europeo (ovejas y cabras). El pisoteo de estos animales hizo que en esta capa de guano (capa 0) se incorporaran artefactos y ecofactos de capa 1 que aparecen aquí mezclados con elementos de momentos posteriores.

Son objeto de análisis en esta investigación los conjuntos de artefactos líticos tallados recuperados en los componentes II y III. Es importante mencionar que la porción del paquete estratigráfico bajo consideración está fechado en su base y en su techo, entre los 4500 y los 3800 años AP. No se cuenta, hasta el momento, con fechados intermedios, sin embargo, es posible sostener una continuidad de la ocupación en el lapso señalado, al tener en cuenta la conformación de la estratigrafía y la densidad de materiales arqueológicos.

Como antecedentes se deben citar los trabajos de Pintar (1996a) en base a materiales de la campaña del año 1994 y de Toselli $(1998,1999)$ sobre artefactos obtenidos en la campaña del año 1996. Ambos trabajos estaban orientados a discutir problemas vinculados con organización tecnológica. 
Para este estudio se abordaron tecno-tipológicamente los artefactos formatizados recuperados durante la campaña del año 1999. Al realizar la clasificación de los instrumentos por clase técnica, se sumaron las piezas correspondientes al año 1996. Asimismo, se analizaron desde el punto de vista técnico y tipológico las puntas de proyectil de las campañas 1996 y Mayo de 1998 con el objeto de generar una clasificación tipológica de detalle.

En relación con los desechos de talla, se parte de la muestra procedente de la campaña del año 1999; utilizándose, además, complementariamente, información generada por Toselli (1998, 1999).

\subsubsection{PEÑAS CHICAS 1.3 (PCh1.3)}

Los trabajos de campo desarrollados en esta investigación permitieron la detección de una serie de nuevos sitios arqueológicos, entre los que se destaca Peñas Chicas 1.3, el cual cuenta con información sustantiva acerca de la transición en estudio.

El sitio en cuestión se encuentra en la terraza alta del río Las Pitas (curso medio-inferior), en la localidad arqueológica Peñas Chicas, a 3574 m.s.n.m. Sus coordenadas geográficas son 260150,9”

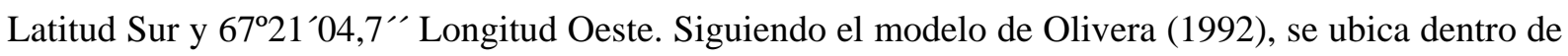
los sectores intermedios (Figura 5.12, Figura 5.13).

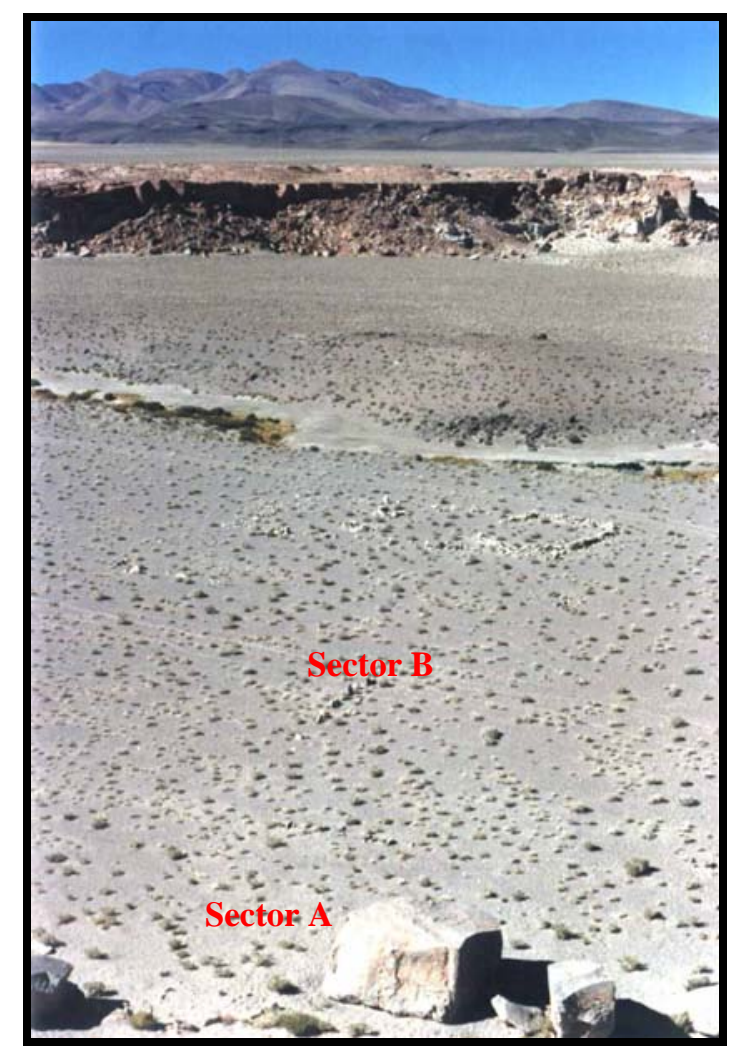

Figura 5.12. Vista general del sitio Peñas Chicas 1.3 


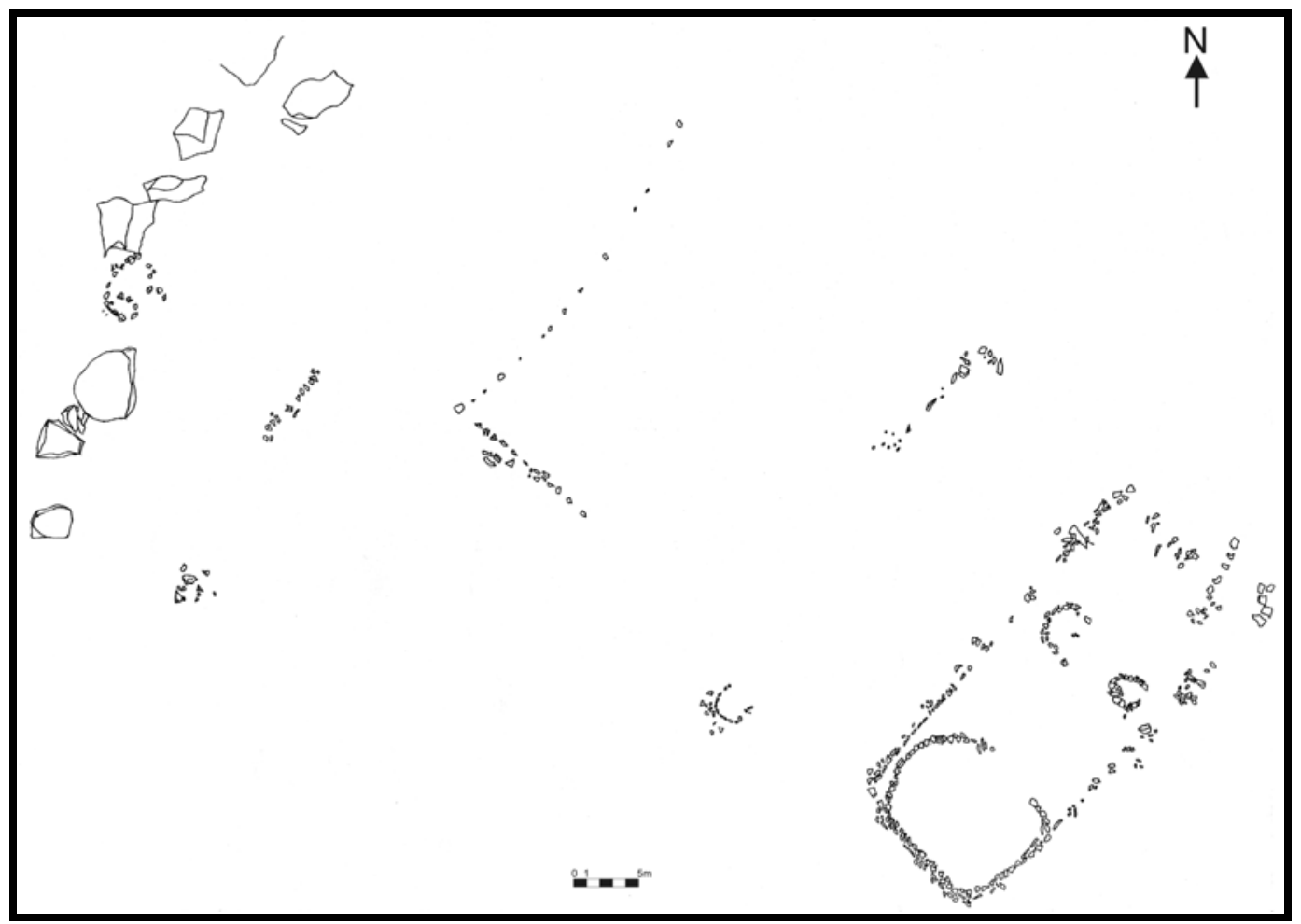

Figura 5.13. Plano del sitio Peñas Chicas 1.3

Desde el punto de vista sedimentario, PCh1.3 refleja claramente su presencia en un desierto, ya que son dominantes los procesos geomorfológicos de erosión y depositación eólicas. Así, se observa un importante médano adosado al farallón de ignimbritas de Peñas Chicas, mientras que la planicie inmediata está formada por un sedimento clástico compuesto por fragmentos rocosos gravosos con tamaños entre 64 y $2 \mathrm{~mm}$, y por una matriz arenosa cuyo tamaño de partículas va de los 2 a los 0,0625 mm. Se destaca que en superficie se ha formado un "pavimento del desierto”, con una preponderancia de clastos tamaño grava, producto de la deflación eólica.

El sitio fue dividido por Aschero (1983, libreta de campo) en dos sectores (Figura 5.12):

"Sector A: taller en faldeo con basalto y obsidiana. Preformas de puntas de proyectil de pedúnculo destacado. No hay cerámica. Estructuras con bloques de roca local en forma de paredes sin cerramiento. Bloques acumulados entre bloques mayores. Frente con taller 50 x 15 pasos”

"Sector B: Estructuras ... recinto perimetral (rectangular) ... y otras estructuras interiores. Afuera alineaciones de piedra y una estructura circular pequeña (posiblemente huaqueada)”

Básicamente, el sitio consiste en: a) estructuras de piedra compuestas por lajas clavadas, situadas a cielo abierto (Figura 5.14); b) un alero bajo roca totalmente cubierto por sedimentos y que fue descubierto al realizar un sondeo contra un gran bloque en un área a reparo del viento, en el año 2002 (Figura 5.15); y c) un taller a cielo abierto de artefactos líticos tallados (Figura 5.15). 


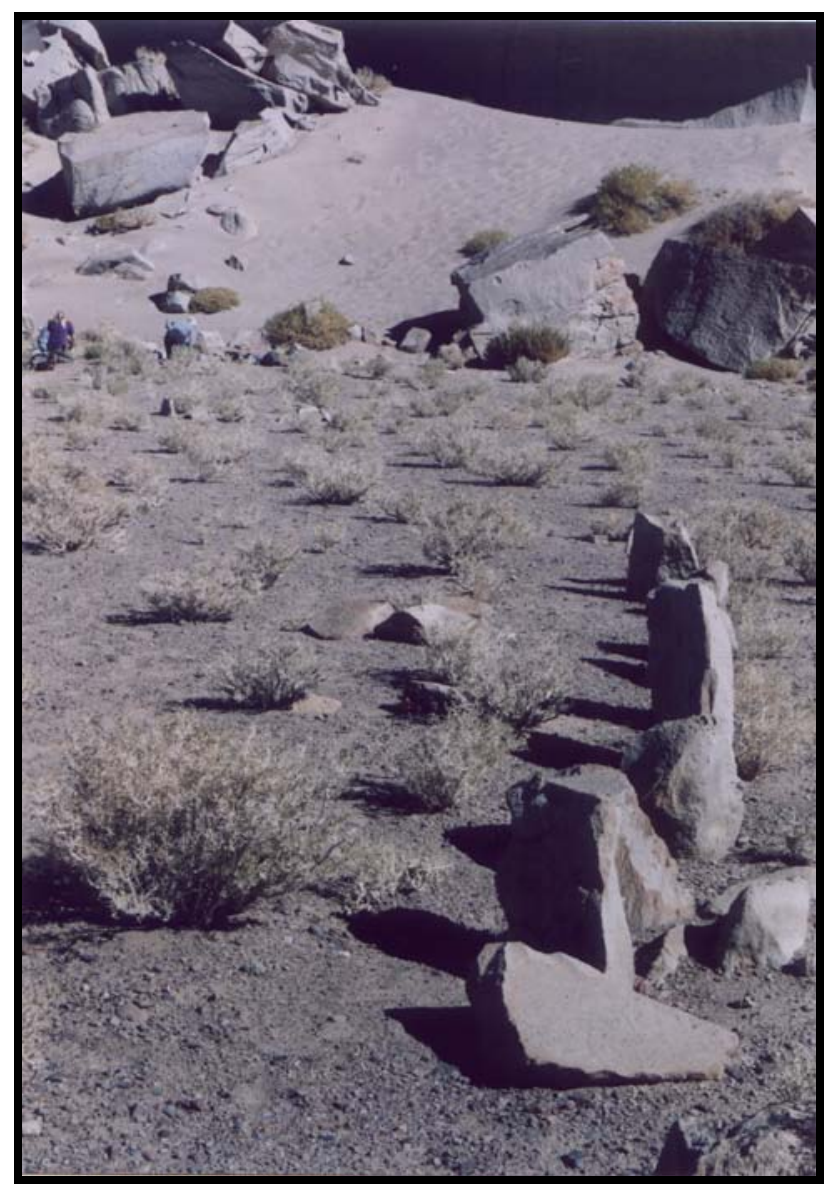

Figura 5.14. Estructuras de piedra formadas por lajas clavadas

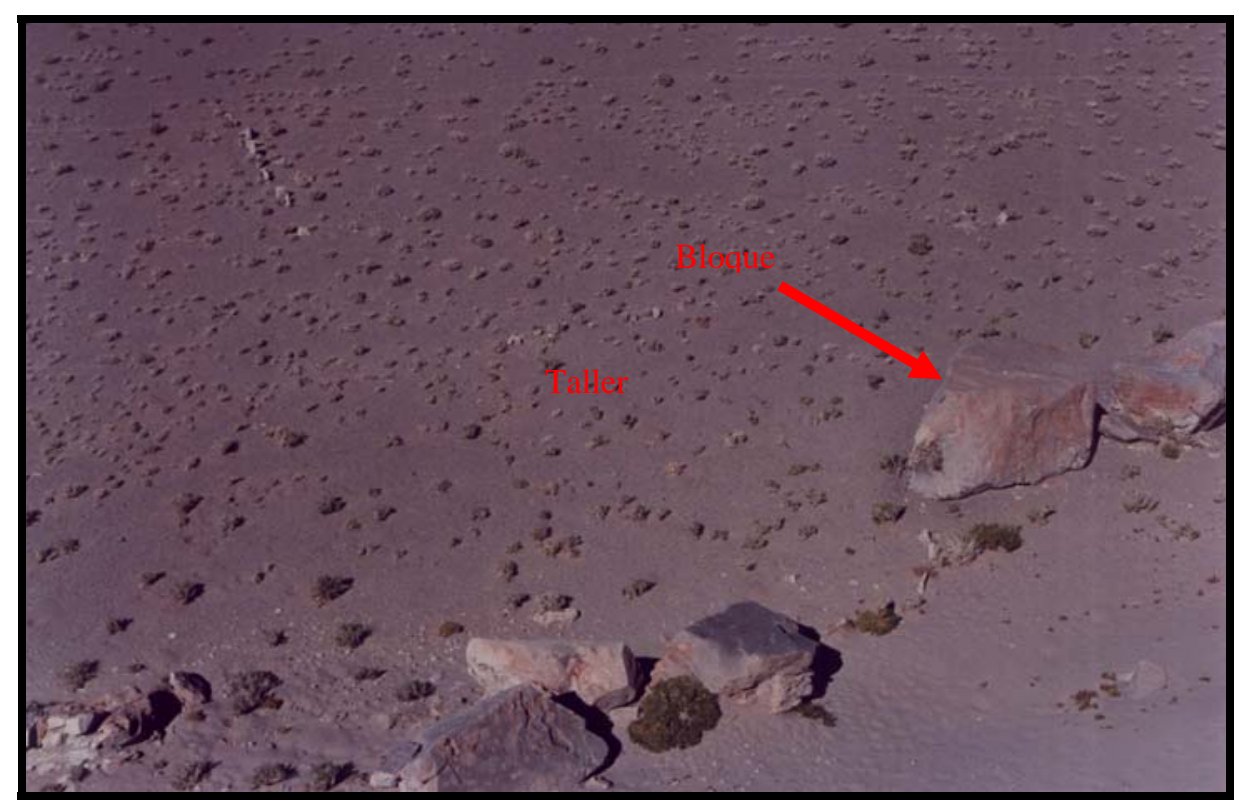

Figura 5.15. Vista del taller y bloque. Nótese que en este último no se registra evidencia de oquedad alguna

Al considerar la diferenciación de Aschero, actualmente, el Sector A comprende las estructuras, el alero bajo roca y el taller que se encuentran más cerca de la pared de ignimbritas y del 
médano de arena; en tanto que el Sector B, compuesto por estructuras de piedra, se encuentra en la parte más próxima a la terraza del Río Las Pitas. En este último sector el material lítico es muy escaso.

Las estructuras de piedra consisten en líneas o bien en círculos o rectángulos de tamaño variable, formadas por lajas clavadas y calzadas entre sí con pequeñas piedras. Es importante destacar que parte de las estructuras fueron parcialmente desarmadas o reutilizadas para la construcción de un círculo y dos pequeñas estructuras semicirculares, siendo evidente por el cambio en la técnica arquitectónica, ya que las lajas se dispusieron horizontalmente.

La excavación de una de las estructuras compuestas por lajas clavadas resultó en una ocupación doméstica, definida por artefactos líticos, fragmentos cerámicos toscos con hollín, restos óseos y una mano de molino asociados a una estructura de combustión. Una datación radiocarbónica procedente de dicho fogón permitió fechar la ocupación en $415 \pm 40$ años AP (LP-1469) (Figura 5.16). Esto permitiría datar relativamente la reutilización de las estructuras como posterior al 450 AP.

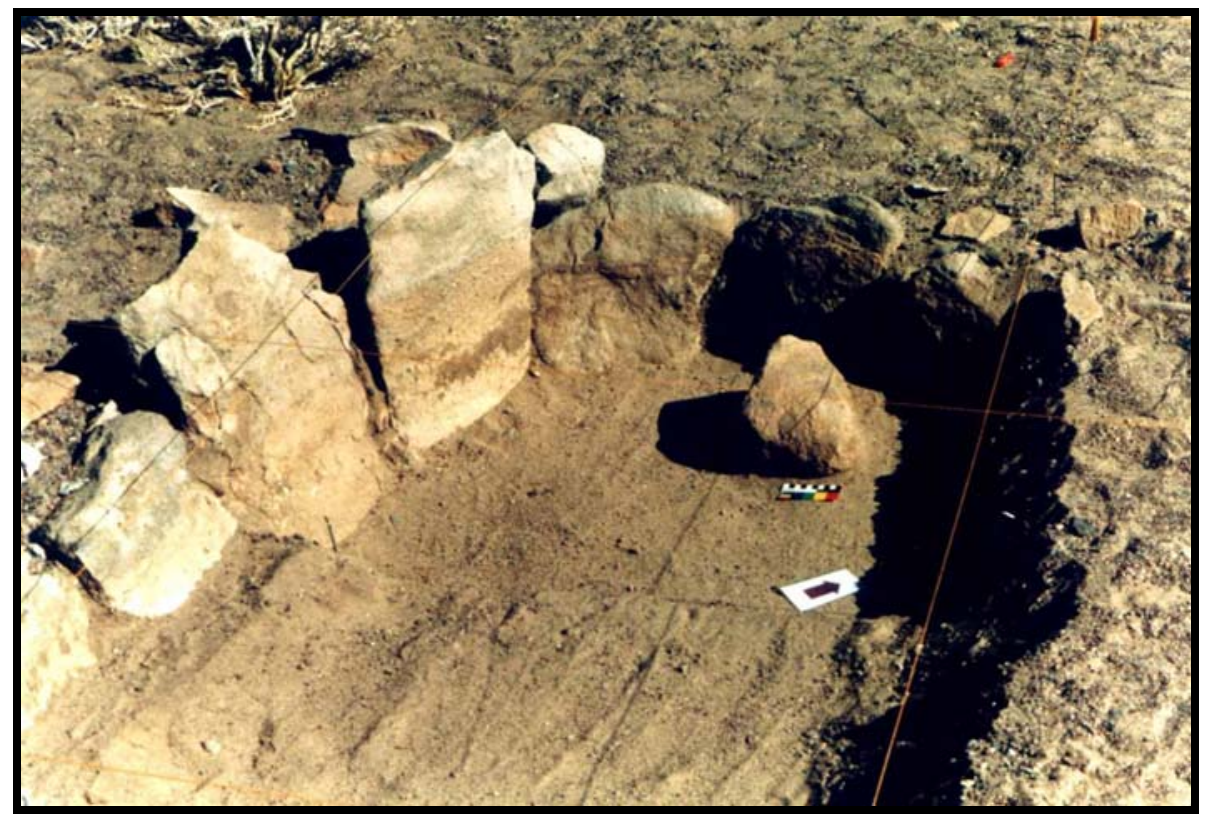

Figura 5.16. Excavación de una estructura de lajas clavadas

A los fines de este trabajo interesan las evidencias del alero bajo roca y del taller a cielo abierto, inmediatos uno del otro.

El alero se presenta bajo un gran bloque de ignimbritas desprendido del farallón cercano. Hasta el momento, las dimensiones de la oquedad son de 2,80 m para la boca, con una profundidad de 1,90 m, sin haberse encontrado todavía las paredes laterales pero sí el fondo, que continúa 
profundizándose. La superficie excavada ${ }^{4}$ es de $5 \mathrm{~m}^{2}$. La potencia alcanzada en la boca del alero es de 0,80 m, mientras que en el interior la altura máxima alcanzada es de 0,50 m (Figura 5.17).

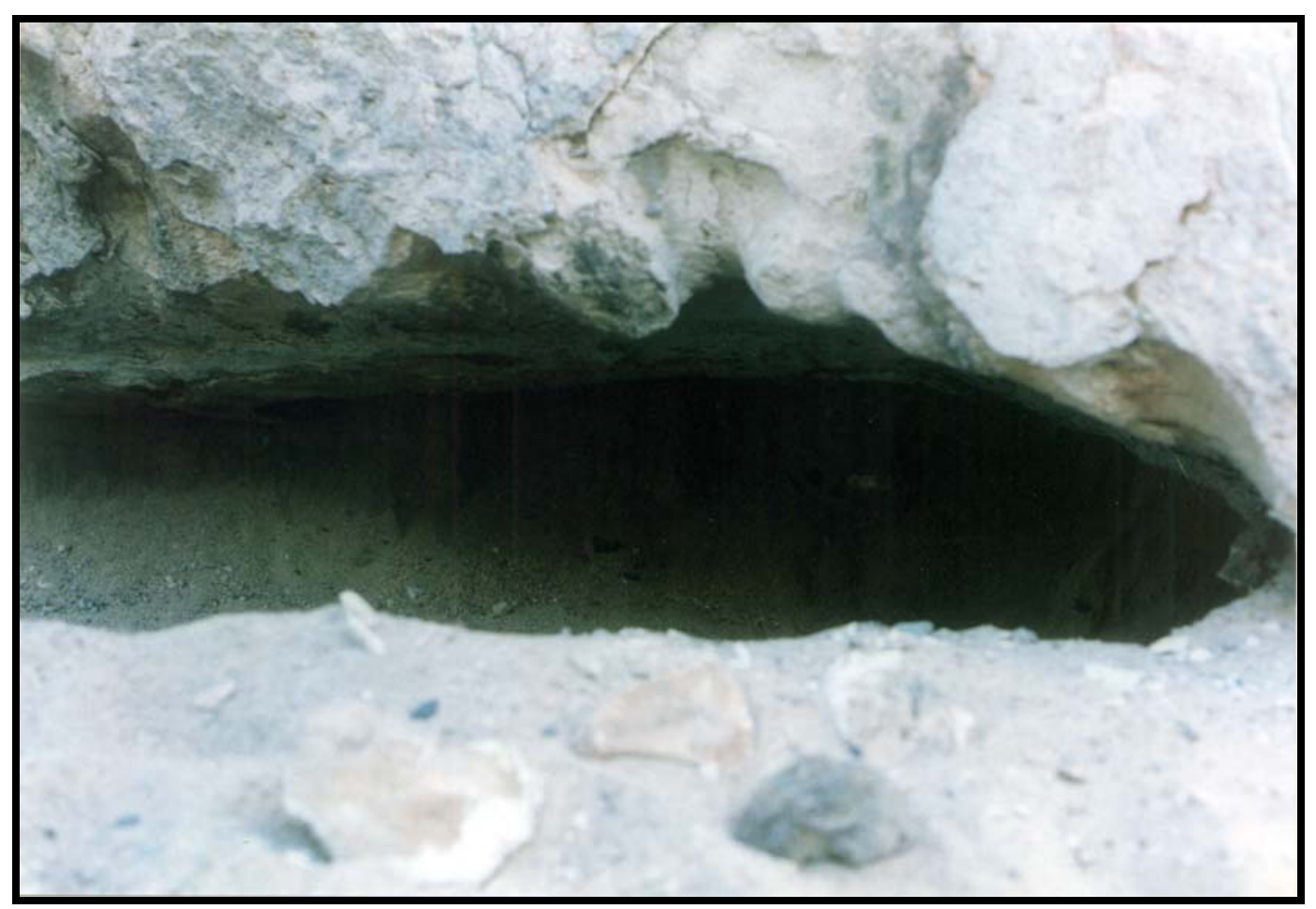

Figura 5.17. Vista parcial de la boca del alero bajo roca

\footnotetext{
${ }^{4}$ La excavación de los sitios arqueológicos de Antofagasta de la Sierra se encuentra relativamente estandarizada a partir de las consideraciones generales definidas por C. Aschero y seguidas por los miembros del equipo de investigación, a los fines comparativos intra e intersitio.

Así, las unidades de excavación, sean cuadrículas, trincheras, etc., se plantean a partir de una cuadriculación con denominación alfa-numérica en base a cuadros de 1x1m, subdivididos en cuatro microsectores de 0,50x0,50m que son las unidades mínimas de recuperación, mapeo y embolsado (Aschero 1988b). Dentro de cada una de estas unidades se mantiene separado el material in situ, denominado "de planta", documentando en plantas de escala 1:10, del recogido en zaranda -malla de 1mm- (Aschero et al.1993-94), colocándose la bolsa con materiales de zaranda dentro de la de planta correspondiente.

Con el fin de generar inventarios de los elementos recuperados, se emplea un talonario de números correlativos como rótulos para bolsas de planta, con un color determinado, y otro talonario de distinto color para artefactos formatizados, estructuras y muestras diversas (sedimento, carbón, etc.)

A los vestigios arqueológicos, sean artefactos o ecofactos registrados en planta se les otorga una ubicación espacial bidimensional y en las mismas plantas se consignan las profundidades de inicio y finalización de cada decapado o extracción para los extremos de cada microsector, en tanto que a los artefactos formatizados, estructuras de combustión, cavado y/o acumulación u otros vestigios diagnósticos se los registra tridimensionalmente (ver, por ejemplo, Rathje y Schiffer 1982, Roskams 2001). Para el mapeo en planta de artefactos, ecofactos y estructuras se cuenta con una simbología standard desarrollada por C. Aschero.

Preferentemente, las excavaciones se realizan decapando siguiendo niveles naturales. Sin embargo, cuando los mismos no están presentes no queda otra alternativa que plantear niveles arbitrarios.

Para realizar las mediciones de diferencias de altura en función del posicionamiento tridimensional de objetos y de niveles de unidades de recuperaciones se utiliza nivel taquimétrico y mira graduada, pero en aquellos casos de sitios con visera, como aleros y cuevas, que no permiten la utilización de mira, se emplea nivel de burbuja. En todos los casos se define un punto de referencia fijo de altura conocida (datum point).

En cuanto a los materiales de excavación se recurre generalmente a pinceles y estecas, y en ocasiones excepcionales a cucharín, dado las características friables de los sedimentos.
} 
El depósito está formado, además de los materiales antropogénicos, por sedimentos resultantes de dos procesos distintos: por un lado, sedimentos consistentes de materiales de fuera del abrigo que ingresaron al mismo, es decir, acumulación de arena por acción del viento, con el alero funcionando como "trampa" y posiblemente por la acción del pisoteo/pateo de los grupos humanos que lo ocuparon y, por el otro, materiales detríticos que se formaron dentro del alero, por desprendimientos del techo y paredes, y depositados allí. El depósito arqueológico en sí no presenta diferenciación estratigráfica, por lo que fue excavado por niveles artificiales, pero sí se discrimina de un nivel suprayacente formado por arena eólica que terminó de colmatar el alero.

Las tareas de excavación se vieron dificultadas por las características de la matriz sedimentaria, de tipo arenosa ${ }^{5}$, que implicó la caída constante de sedimento y de materiales arqueológicos de los perfiles.

Es importante señalar las diferencias existentes entre el interior del alero y el área por fuera de él, inmediatamente después de la línea de goteo, en cuando a presencia de humedad en subsuperficie, ya que la misma aparece sólo en el exterior, a cielo abierto. Esto es importante, ya que explicaría la conservación de restos tales como flores, carbones, semillas, huesos de camélido con tegumento, cartílago, etc. dentro del alero, y la no ocurrencia de restos vegetales, así como la mala conservación de los huesos fuera de él.

En cuanto a las evidencias arqueológicas recuperadas, éstas son de gran interés, puesto que se comprobó la asociación de puntas de proyectil con pedúnculo destacado convexilíneo de base inflexionada y no inflexionada, aletas y limbo lanceolado con los diseños de puntas de proyectil lanceolados pequeños típicos de principios del Holoceno Tardío de la Puna argentina, como Inca Cueva 7 (Aguerre et al. 1973), con fechas absolutas de 3490+/-60 AP (LP-1421) -nivel 3/4- y 3680 \pm 50 (UGA 15092) -nivel 7- (Tabla 5.1).

Se recuperó, además, una estructura de piedra parcialmente desarmada que se constituye en un antecedente de la arquitectura agro-pastoril posterior, siguiendo aproximadamente la línea de goteo de la oquedad.

Por otra parte, la presencia en artefactos de molienda de microrrestos de recursos comestibles silvestres y domesticados (Babot 2004a), señala el papel de la recolección de vegetales silvestres y,

\footnotetext{
${ }^{5}$ En el caso considerado, el hecho de contar con arena como elemento detrítico dominante en la matriz sedimentaria implica que se está tratando con materiales no consolidados, con un componente importante de espacios vacíos, que pueden estar ocupados con aire y/o agua (Pettijohn et al 1987). Esto lleva a que la arena sea muy poco compacta o coherente, es decir, las partículas no están unidas unas a otras, o lo están mínimamente (Porta Casanellas et al 1994), lo que potencia la acción de la gravedad como factor de erosión y, por ende, la presencia de materiales coluviales (Derruau 1978).
} 
más importante aún, la posibilidad de prácticas de cultivo destinadas al consumo humano o, por lo menos, la presencia de cultígenos obtenidos por acceso directo o indirecto en fechas tan tempranas como 3500 AP. Se destaca que se han recuperado, además, macrorrestos (Aguirre 2005) que corroboran los hallazgos del registro microscópico.

Destaca la ausencia de cerámica en el alero, lo que pone de manifiesto la variabilidad de situaciones previsible en contextos transicionales, como el aquí considerado

El taller a cielo abierto, por su parte, consiste en artefactos líticos tallados, incluyendo desechos de talla, núcleos y artefactos formatizados que se corresponden tecnológica y tipológicamente con los del alero bajo roca, dispersos en un área de 40 x 15 m aproximadamente, tanto en superficie como en subsuperficie, tal como lo atestiguan un sondeo de 0,70 x 0,70 m realizado por Elizabeth Pintar en el año 1994 contra una estructura cercana al alero bajo roca y una cuadrícula de 1,50 x 1,50 m planteada prácticamente contigua a dicho sondeo. Los sedimentos están constituidos por materiales gravosos y arenosos.

Se analizan, específicamente, los artefactos formatizados y los núcleos recuperados en el alero bajo roca en las dos campañas realizadas hasta el momento (Septiembre de 2002 y Abril de 2003). En cuanto a los desechos de talla, la muestra considerada corresponde a la campaña del año 2002. Asimismo, se han incluido una serie de puntas de proyectil recolectadas asistemáticamente en superficie en distintos sectores del sitio en diferentes oportunidades (1983, 1996, 2001 y 2003), que por su morfología son interesantes al abordar la variabilidad tipológica.

\subsubsection{PEÑAS CHICAS 1.1 (PCh1.1)}

PCh1.1 es un alero rocoso que se encuentra al pie del mismo farallón de ignimbritas que PCh1.3, pero en el extremo Suroeste, a aproximadamente $200 \mathrm{~m}$ de este último, y a ca.3580 m.s.n.m. Está constituido por dos aleros contiguos -designados A y B- y una concentración de material lítico al pie del talud del alero B. Ambos aleros presentan restos de una pared de piedra frontal (Aschero 1986) (Figura 5.18). 


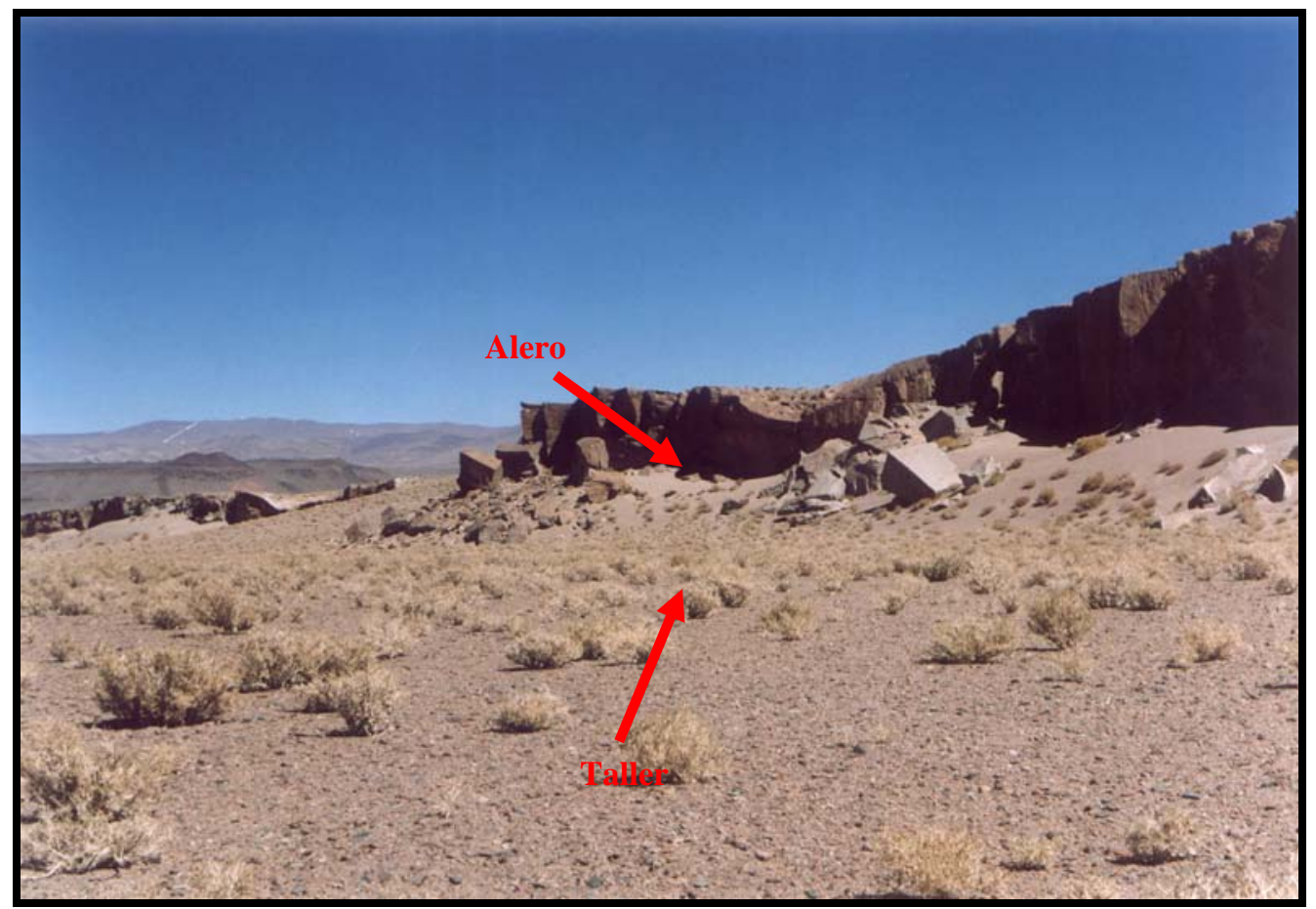

Figura 5.18. El sitio Peñas Chicas 1.1

Interesa particularmente el alero $\mathrm{B}$, dados los materiales líticos recuperados en las excavaciones y la cronología obtenida. Específicamente, el sitio se extiende a lo largo de la pared rocosa sobre una explanada delimitada por una línea de piedras en el comienzo del talud de arena. Esta orientado hacia el Sureste, presentando un área de reparo de 15 x 3 m (Pintar 1996a). Cuenta con dos estructuras circulares de piedra adosadas a la pared, delimitando espacios reducidos de 1,80 y 1,90 m de diámetro (Aschero 1986), realizadas con grandes piedras verticales unidas con argamasa rica en arcilla y con un piso del mismo material de clara factura artificial (Olivera y Elkin 1994).

La excavación de una de estas estructuras circulares resultó en el hallazgo de materiales arqueológicos por encima y por debajo del piso de arcilla. Así, una muestra de carbón supra piso de

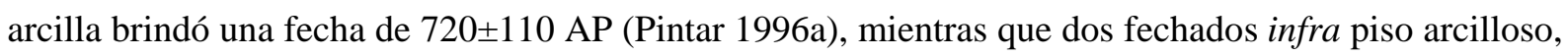
permitieron datar las ocupaciones en ca.3600 años AP (Tabla 5.1).

La matriz sedimentaria del sitio es de tipo arenosa. Pintar (1996a) manifiesta la no ocurrencia de cambios visibles en la estratigrafía, por lo que se procedió a excavar por niveles artificiales de 0,05 m. De esta forma, se descubrieron 14 niveles, alcanzándose la roca madre a una profundidad de 1,5 m.

En cuanto a los materiales considerados en esta investigación, se clasifican tipológicamente los artefactos formatizados de las campañas arqueológicas Enero y Mayo/Junio de 1991 y Enero 1994. Se destaca que este instrumental cuenta con una primera aproximación por parte de Pintar (ibid.). En cuanto a los desechos de talla, se utiliza información suministrada por esta autora en el trabajo 
señalado y se analizan, además, artefactos no procesados hasta el momento correspondientes a la campaña de Enero de 1994.

\subsubsection{CASA CHÁVEZ MONTÍCULOS (CChM)}

El sitio, a cielo abierto, está ubicado a 1,7-2 km al sur de la población de Antofagasta de la Sierra, sobre la margen izquierda del río Punilla, en el fondo de cuenca, a 3450 m.s.n.m. (Olivera 1989) (Figura 5.19).

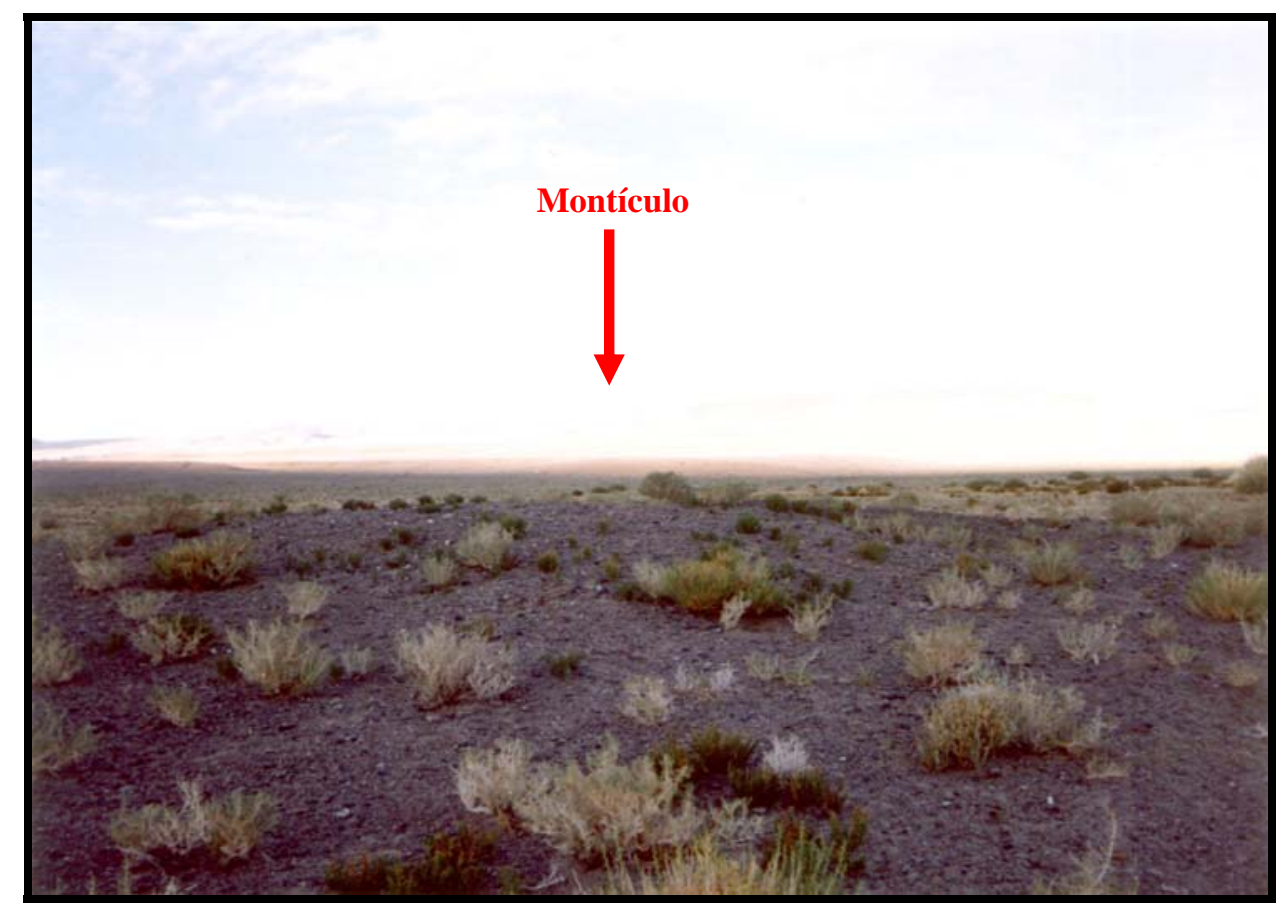

Figura 5.19. El sitio Casa Chávez Montículos 1

Se trata de un conjunto de diez estructuras monticulares, de factura artificial y dimensiones variables, dispuestas en dos grupos alrededor de un espacio deprimido central, en una superficie de alrededor de 300 x 300 m (Olivera 1992).

Los materiales arqueológicos superficiales se presentan sobre las estructuras y en los espacios intermonticulares, siendo prácticamente inexistentes en el sector deprimido. El registro estratigráfico, por su parte, parece limitarse a los montículos.

Los artefactos líticos considerados provienen del Montículo 1. El mismo se excavó por capas artificiales de 0,10 m debido a la homogeneidad relativa de la matriz sedimentaria (básicamente arenosa); sin embargo, se respetó la configuración natural en la medida en que la presencia de diferencias en la misma o en la existencia de restos de estructuras así lo requirieron (ibid.). 
Las excavaciones permitieron detectar estructuras de basural, de combustión y de cavado, sectores de talla lítica, evidencias de fabricación y uso de cerámica, indicadores de actividades agrícolas, y vestigios de procesamiento y consumo de camélidos. En base a estas evidencias el sitio fue definido como una Base residencial de actividades múltiples con una ocupación casi ininterrumpida durante lapsos prolongados, por parte de grupos agro-pastoriles "plenos” (Olivera 1996).

Para el análisis en curso se tuvieron en cuenta todas las capas, en número de diez, datadas entre 2100 y 1500 AP (Tabla 5.1).

El análisis de los artefactos formatizados, núcleos y desechos de talla del Montículo 1 fue realizado por la Dra. Patricia. Escola, por lo que se empleó en esta investigación información édita (Escola 1991, 1999, 2004b, 2004c) e inédita (Escola 1987, 2000). Asimismo, esta investigadora suministró las fichas de análisis originales de las puntas de proyectil.

Complementariamente, se utilizó información inédita de Escola (fichas de análisis), referida exclusivamente a puntas de proyectil, de CChM4 (Olivera 1992).

\subsubsection{PUNTA DE LA PEÑA 9 (PP9)}

PP9 es un sitio a cielo abierto que se encuentra emplazado en la localidad arqueológica de Punta de la Peña, en la cuenca media del río Las Pitas, a una altitud de 3590 m.s.n.m. Corresponde a una ocupación agro-pastoril plena (Figura 5.20).

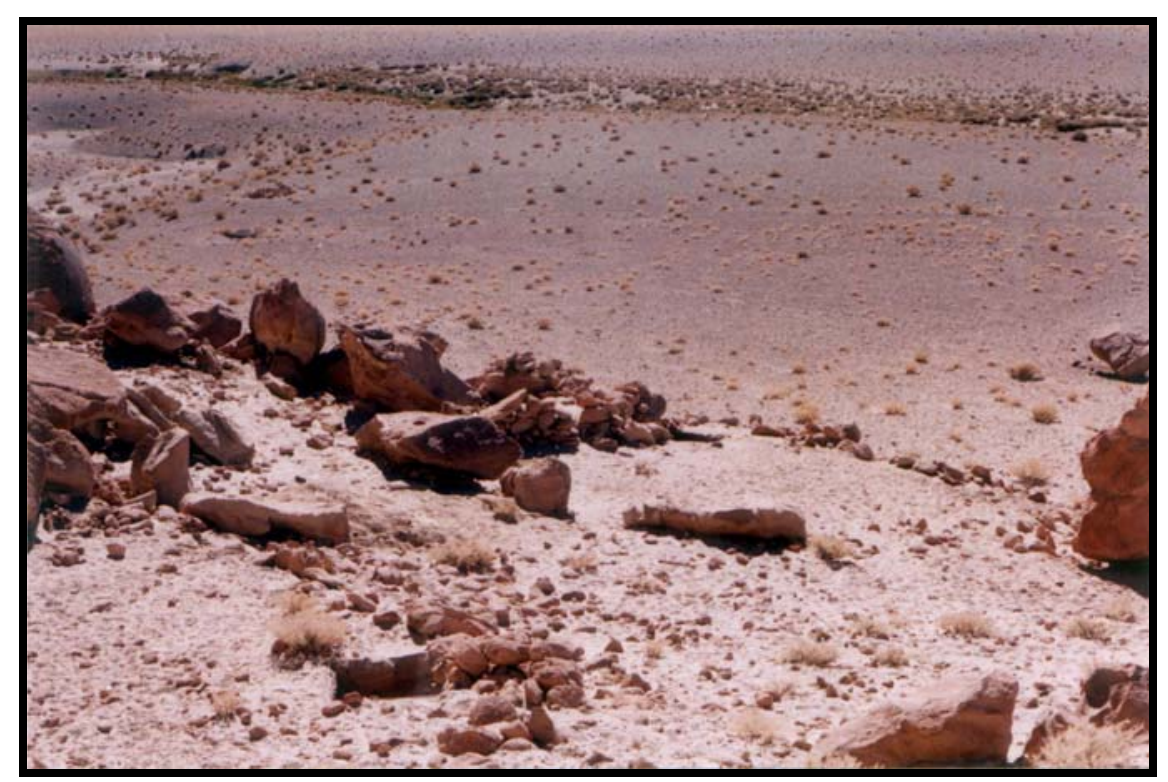

Figura 5.20. El sitio Punta de la Peña 9 (cortesía S. López Campeny) 
Interesan en este caso dos sectores: el Sector I (PP9 I), compuesto por unidades subcirculares y elípticas simples dispersas en la terraza alta del río Las Pitas, (Babot et al. 2004) y el Sector III (PP9 III), correspondiente a un conjunto de cinco estructuras arquitectónicas simples y compuestas ubicadas próximas a un gran farallón de ignimbritas (López Campeny 2001a, 2001b). Las estructuras arquitectónicas visibles en superficie presentan forma predominantemente circular (Figura 5.21, Figura 5.22).

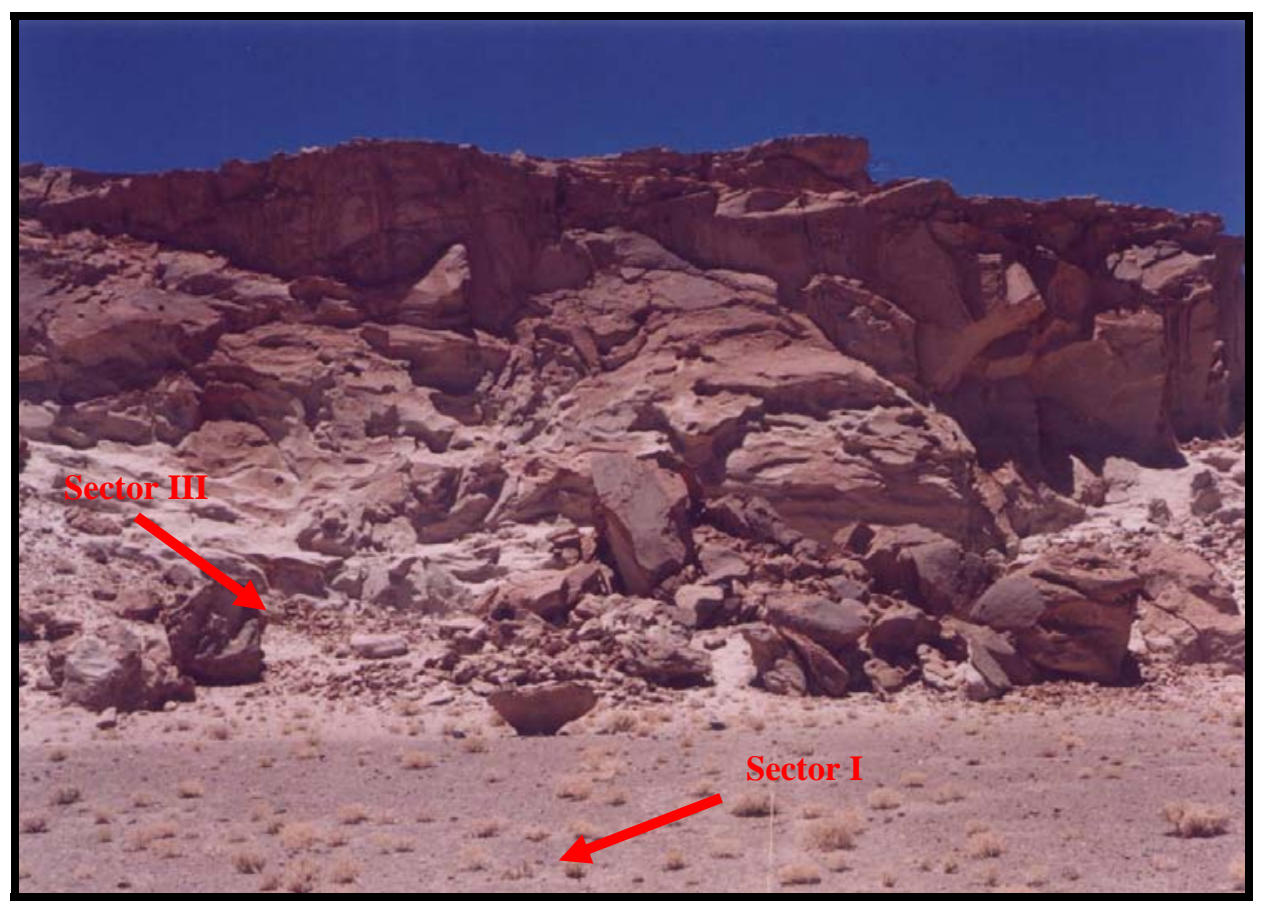

Figura 5.21. Los sectores I y III del sitio PP9 (cortesía S. López Campeny)

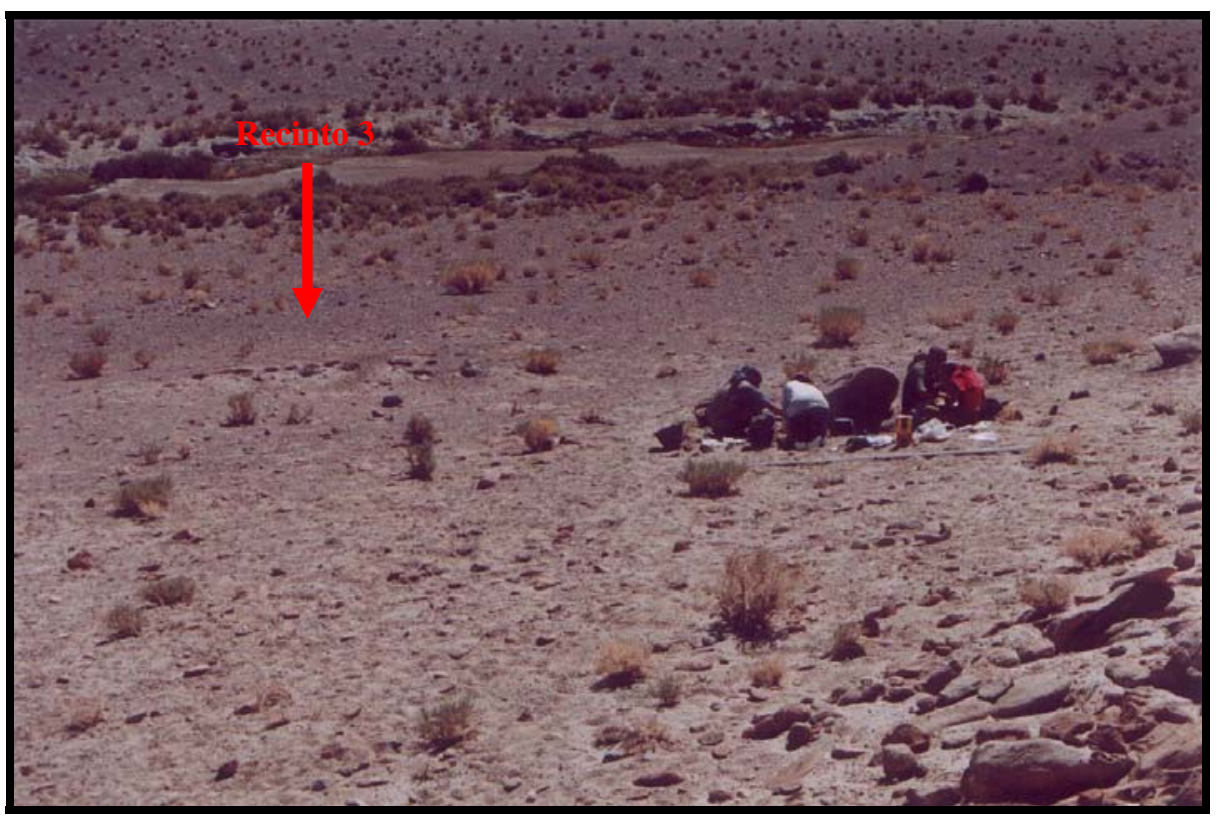

Figura 5.22. Vista del sector I y de la estructura 3 (cortesía M.P. Babot) 
El recinto 3 del Sector I posee dos dataciones cercanas a 1450 años AP y corresponde a una habitación con registro de actividades múltiples de tipo doméstico evidenciadas, entre otros aspectos, por presencia de estructuras de combustión, cocción y/o almacenamiento de sustancias y posible uso de mordientes en la tinción de lanas, regularización y reactivación de artefactos líticos (Babot et al. 2004, Babot 2004). Evidencia al menos tres episodios de ocupación intramuro diferenciados. Los mismos se encuentran estratificados en un perfil de 0,70 $\mathrm{m}$ de potencia promedio (Babot et al. 2004).

Para este trabajo se consideraron los materiales líticos procedentes de todas las excavaciones realizadas hasta el momento en el recinto 3 (Diciembre de 1999 y Abril de 2003). Asimismo, se ha incluido una punta de proyectil recuperada en superficie como hallazgo aislado en el sector I, localizada por M.P. Babot.

Por su parte, la estructura 2 del Sector III presenta una serie de dataciones que documentan una serie de ocupaciones recurrentes entre ca.2000 y 500 años AP. Con respecto a las características de la estratigrafía arqueológica del recinto, López Campeny (2001a) ha identificado un total de tres capas y de seis niveles ocupacionales en el espacio circunscrito por los bloques y el muro pircado, y tres niveles de ocupación para un sector de pasillo de circulación y/o de acceso al recinto.

Se destaca que, en este último caso, los conjuntos líticos analizados provienen de un espacio doméstico de habitación fechado entre 1500 y 1100 años AP (niveles 4 y 5) y de un nivel de corral datado hacia los 2000 AP (nivel 6). Dichos materiales corresponden a las campañas de los años 1998, 1999 y 2000 realizadas por López Campeny.

Además de estos sitios, se utiliza información complementaria de:

\subsubsection{PEÑAS CHICAS 1.6 (PCh1.6)}

Se trata de un sitio que ha sido localizado recientemente (año 2003), en el marco de esta investigación. El mismo se encuentra en un codo del río las Pitas a 3586 m.s.n.m., en la porción media-alta de la terraza alta de dicho río, a media distancia entre los farallones de Puna de la Peña y

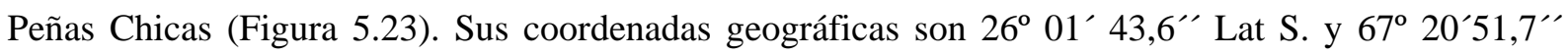
Long. O. 


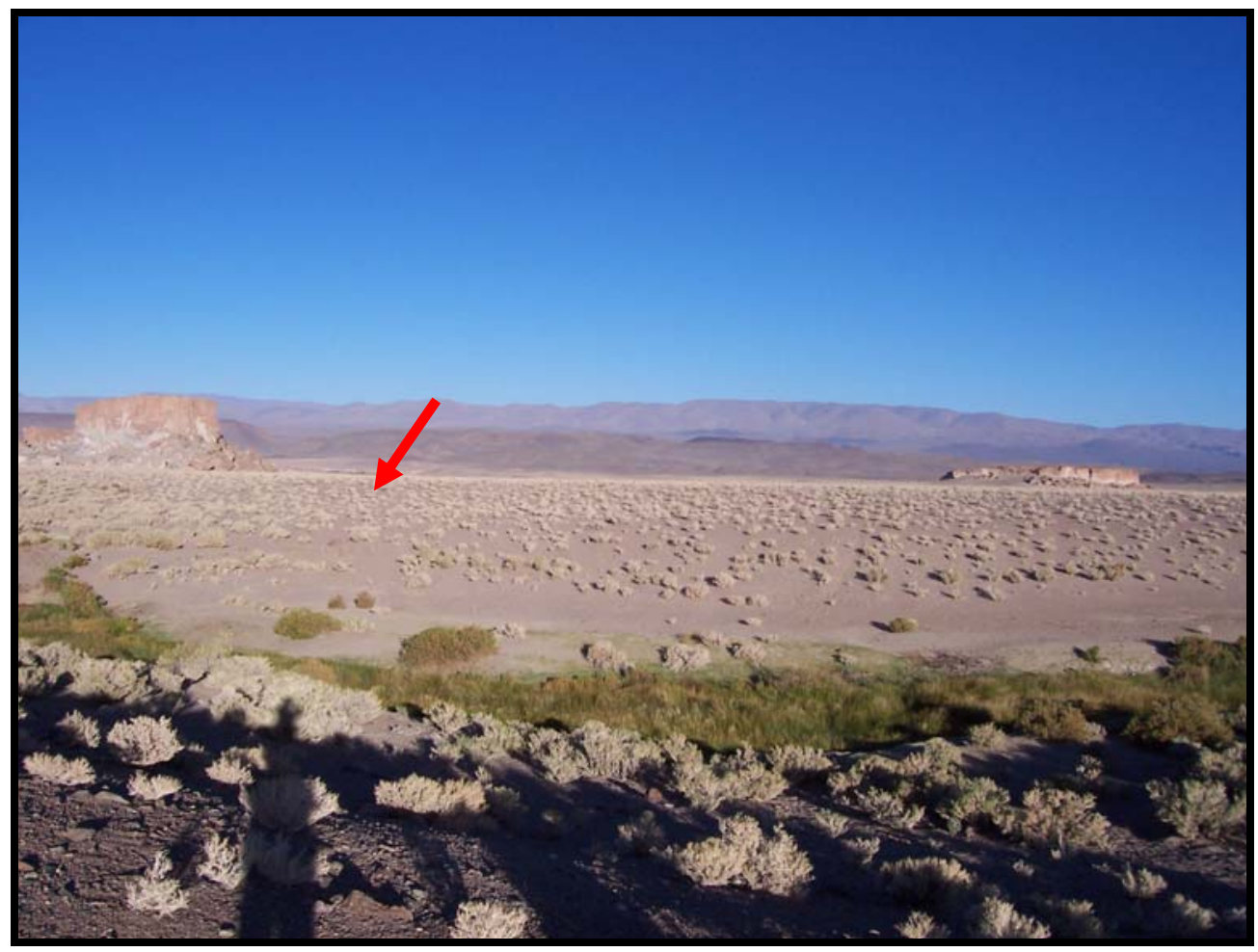

Figura 5.23. El sitio Peñas Chicas 1.6

Hasta el momento, se realizó una recolección superficial sistemática a lo largo de una transecta en Mayo de 2004 y se excavó una serie de pozos de sondeo en un muestreo sistemático en Septiembre de 2005.

Se destaca que los instrumentos, desde un punto de vista tipológico, se relacionan estrechamente con los recuperados en los sitios próximos Peñas Chicas 1.3 y Peñas Chicas 1.1.

Se trataría de un campamento a cielo abierto, con abundantes artefactos líticos en superficie, registrándose materiales también en subsuperficie. En principio, podría señalarse la presencia de estructuras de piedra, dado el registro de ciertos alineamientos de rocas en subsuperficie; sin embargo, este es un punto que requiere de una mayor apertura de las excavaciones para su confirmación. Más allá de contar o no con estructuras de piedra, el sitio es de por sí interesante, puesto que la información sobre sitios residenciales anteriores al 3000 AP provenía hasta el momento de cuevas y aleros.

Se consideran en este trabajo una serie de puntas de proyectil recuperadas en superficie y en excavación durante la realización de sondeos. 


\subsubsection{CUEVA SALAMANCA 1 (CS1)}

Siguiendo a Pintar (2004a), CS1 es una cueva situada en la margen izquierda del Río Las Pitas, a una latitud de 3560 m.s.n.m. Sus dimensiones son: $11 \mathrm{~m}$ de ancho, $8 \mathrm{~m}$ de profundidad y $7 \mathrm{~m}$ de alto El área de reparo, entre la línea de goteo y la pared del fondo, es de aproximadamente $77 \mathrm{~m}^{2}$ (Figura 5.24).

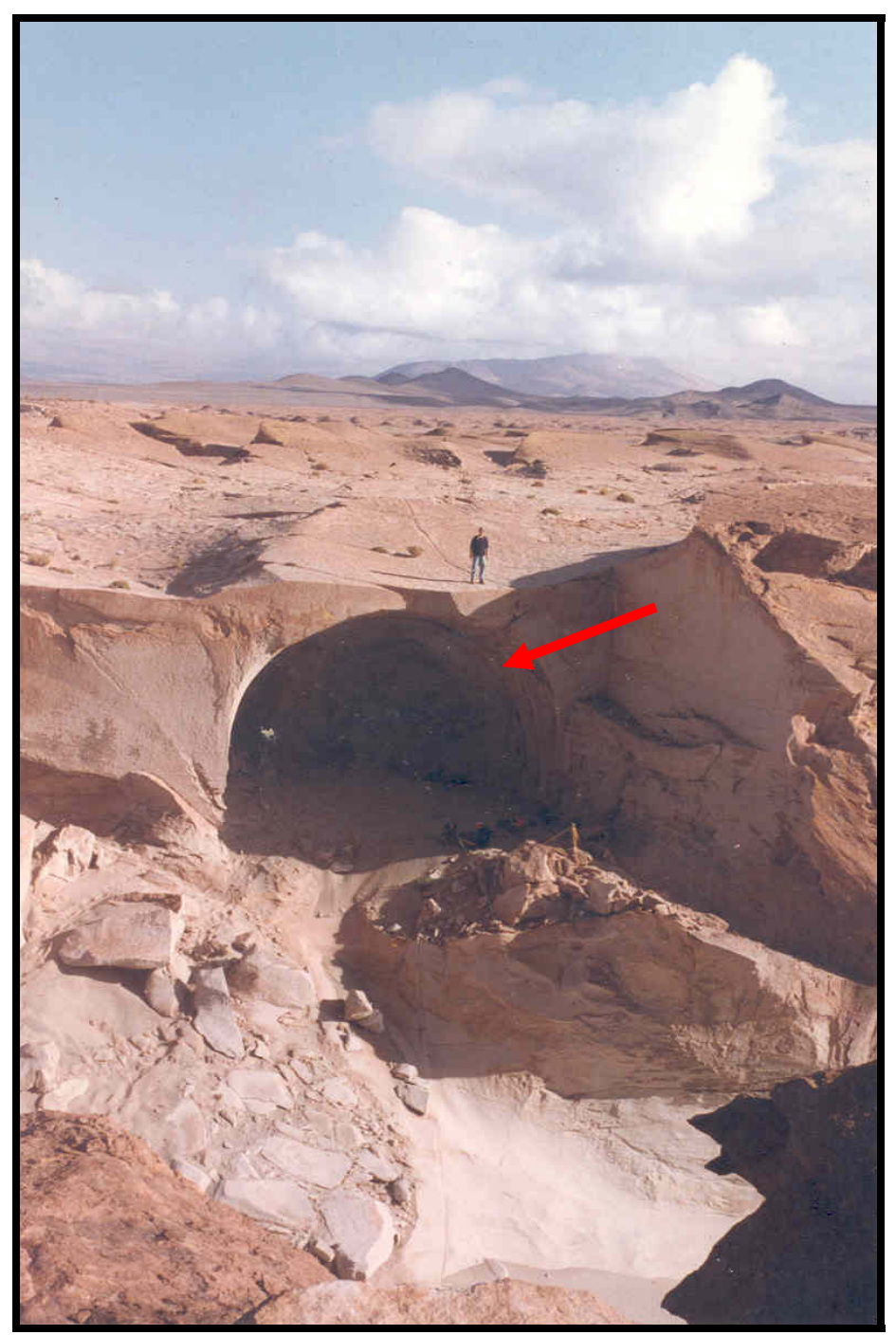

Figura 5.24. El sitio Cueva Salamanca 1 (cortesía C. Aschero)

De la estratigrafía de dicho sitio, es relevante el nivel 1. Si bien no se cuenta con dataciones absolutas en dicho nivel (Pintar com pers.), la presencia de puntas lanceoladas de pequeño tamaño sugiere una utilización ca. 3500 AP (Pintar 2004a, 2004b)

La Dra. Pintar cedió para su análisis una serie de puntas de proyectil de los niveles 1 y 2, de interés para la problemática aquí abordada. 


\subsubsection{HALLAZGOS AISLADOS CONSIDERADOS}

Se incluyen, además, una serie de puntas de proyectil recuperadas en superficie, como hallazgos aislados, provenientes de distintos sectores de Punta de la Peña y de Laguna Colorada.

En relación con esta última área, las piezas, en número de 3, forman parte de las colecciones del Museo del Hombre (Municipalidad de Antofagasta de la Sierra). Fueron recolectadas por pobladores locales por lo que no se cuenta con su ubicación exacta, pudiendo proceder de un sólo sitio o bien de distintos sitios. Una posibilidad es el sitio Laguna Colorada 2.1, identificado recientemente por Olivera y equipo (Tchilinguirian y Olivera 2005).

\subsection{GRUPOS CRONOLÓGICOS}

Se propone el análisis de los conjuntos de artefactos líticos tallados de los contextos arqueológicos considerados en base a la conformación de patrones de agrupamiento de fechados radiocarbónicos, siguiendo la perspectiva de Yacobaccio y Guráieb (1994). De esta forma, se establecieron grupos cronológicos (GC) cuyo criterio de definición se basa en conjuntos de fechas que superponen sus rangos en un sigma (Tabla 5.2, Figura 5.2). Como criterio complementario se utiliza la posición relativa de las fechas disponibles y de los niveles estratigráficos. Se destaca que para la conformación de dichos grupos se utilizaron exclusivamente los fechados de los sitios que contribuyeron con muestras de artefactos líticos.

Tabla 5.2. Características de los grupos cronológicos

\begin{tabular}{|c|c|c|c|c|}
\hline Grupos & Media (A.P.) & $\mathbf{N}^{1}$ & Rango $^{2}$ & Sitios \\
\hline 1 & 4851 & 7 & $5490-4350$ & QS3 - PP4 [5(6) / 6] \\
\hline 2 & 3739 & 7 & $4150-3430$ & $\begin{array}{c}\text { PP4 [4 y 5(1) a 5(5)] } \\
- \text { PCh1.1 - PCh1.3 }\end{array}$ \\
\hline 3 & 1692 & 10 & $2180-1340$ & CChM1 - PP9 \\
\hline
\end{tabular}

Notas: ${ }^{1}$ Cantidad de fechados radiocarbónicos; ${ }^{2} 1$ sigma

Se definieron de esta manera tres grupos cronológicos (Tabla 5.2) ${ }^{6}$. El primero está conformado por los niveles 2b1 a 2b5 del sitio Quebrada Seca 3 más la capa 5(6) o 6 (denominada de

\footnotetext{
${ }^{6}$ Es importante destacar que Manzi (1999), desde una aproximación similar, diferencia grupos cronológicos tomando la secuencia holocénica del sitio QS3 exclusivamente. De esta forma, el grupo cronológico 6 de esta autora equivale, en términos generales, al grupo cronológico 1 aquí propuesto. Las diferencias radican en que, en este caso, a la muestra de QS3 se le suman niveles de PP4 y, en el otro caso, a los niveles $2 \mathrm{~b} 5$ a $2 \mathrm{~b} 1$ se les adiciona la capa 2a (ca. $2420 \mathrm{AP})$.
} 
ambas formas según la campaña) del sitio PP4. El segundo se compone de las capas 4 y 5(1) a 5(5) de PP4 y el total de niveles de PCh1.3 y PCh1.1. El tercero y último está formado por la secuencia completa de CChM1, los niveles 4 a 6 de PP9 (III. E2) y toda la secuencia de PP9 (I. E3).

La diferencia cronológica es notoria entre el GC2 y el GC3, y menor entre el GC1 y el GC2. Cabe destacar que en el GC1, a pesar de no haber superposición entre las fechas anteriores al 5300 AP y posteriores al 4900 AP (Figura 5.2), el hecho de contar con un nivel no directamente datado (2b4) pero que ha sido situado estratigráfica y cronológicamente entre las dataciones correspondientes a los niveles 2b3 y 2 b5 por Aschero et al. (1993-94), estaría señalando una secuencia ininterrumpida. En relación con este grupo, asimismo, se incluye al nivel $2 \mathrm{~b} 1$ en el mismo aunque no se cuenta con una datación radiocarbónica, dadas las similitudes estratigráficas y la proximidad con los niveles subyacentes inmediatos. Al considerar el GC3, si bien los fechados más tempranos no presentan superposición con las dataciones restantes, por cercanía relativa se incluye a los mismos dentro de este grupo.

Con el objeto de establecer la validez de la discriminación en tales grupos cronológicos, se aplicó el análisis de varianza (ANOVA) para controlar la existencia de diferencias significativas entre las medias de cada grupo (Tabla 5.3, Tabla 5.4). Para ello, se empleó el programa informático Origin 7.0220 SRO. Copyright 1991-2002 Origin Lab Corporation.

Tabla 5.3. Estadística sumaria

\begin{tabular}{|c|c|c|c|c|}
\hline $\begin{array}{c}\text { Grupo } \\
\text { cronológico }\end{array}$ & N & Media & $\begin{array}{c}\text { Desviación } \\
\text { standard }\end{array}$ & $\begin{array}{c}\text { Error } \\
\text { standard }\end{array}$ \\
\hline 1 & 7 & 4851.42857 & 406.0964 & 153.49001 \\
\hline 2 & 7 & 3738.57143 & 191.78361 & 72.48739 \\
\hline 3 & 10 & 1692 & 247.01777 & 78.11388 \\
\hline
\end{tabular}

Tabla 5.4. Análisis de varianza (ANOVA)

\begin{tabular}{|c|c|c|c|c|c|}
\hline Fuente & $\begin{array}{c}\text { Grados de } \\
\text { libertad }\end{array}$ & $\begin{array}{c}\text { Suma de } \\
\text { cuadrados }\end{array}$ & $\begin{array}{c}\text { Media al } \\
\text { cuadrado }\end{array}$ & Valor F & Valor P \\
\hline Modelo & 2 & 43858964.4 & 21929482.2 & 261.75803 & $1.44329 \mathrm{E}-15$ \\
\hline Error & 21 & 1759331.43 & 83777.6871 & & \\
\hline
\end{tabular}


A partir de dicha técnica (ANOVA: $F=261.75803$; $p<0,05$ ) es posible sostener que hay variaciones significativas entre las medias de los conjuntos de fechados de los grupos cronológicos definidos.

Por otra parte, se aplicó el Test de Tukey por medio del programa informático mencionado para definir entre qué grupos había diferencias, resultando en la presencia de diferencias significativas entre los tres (Tabla 5.5).

Tabla 5.5. Test de Tukey

\begin{tabular}{|c|c|c|c|c|c|}
\hline \multirow{2}{*}{$\begin{array}{c}\text { Grupo } \\
\text { cronológico }\end{array}$} & \multirow[t]{2}{*}{ Media } & \multirow{2}{*}{$\begin{array}{c}\text { Diferencia } \\
\text { entre } \\
\text { medias }\end{array}$} & \multicolumn{2}{|c|}{ Intervalos de confidencia } & \multirow{2}{*}{$\begin{array}{l}\text { Significancia } \\
\text { al } 0,05\end{array}$} \\
\hline & & & Límite inferior & Límite superior & \\
\hline 1 & 4851.42857 & & & & \\
\hline 2 & 3738.57143 & 1112.85714 & 722.88921 & 1502.82508 & $\mathrm{Si}$ \\
\hline 3 & 1692 & 3159.42857 & 2799.8959 & 3518.96124 & $\overline{\mathrm{Si}}$ \\
\hline 2 & 3738.57143 & & & & \\
\hline 3 & 1692 & 2046.57143 & 1687.03876 & 2406.1041 & $\mathrm{Si}$ \\
\hline
\end{tabular}




\section{CAPITULO 6}

\section{ASPECTOS GENERALES DE LA TRANSICIÓN EN ANTOFAGASTA DE LA SIERRA}

\subsection{CARACTERÍSTICAS DEL PROCESO TRANSICIONAL LOCAL DESDE DISTINTAS LINEAS DE EVIDENCIA}

Para comprender cómo cambió la tecnología lítica tallada en la transición de un modo de vida cazador-recolector a otro agro-pastoril es imprescindible definir el contexto socio-económico en que dicho cambio tuvo lugar. Es por esto que en este Capítulo se analizan las características de la trayectoria microrregional en el lapso 5500-1500 AP.

Para ello, se consideran las siguientes variables: movilidad residencial, territorialidad, subsistencia, redes de interacción a larga distancia, desigualdad social, densidad poblacional y ritual. El análisis del conjunto de variables estudiadas permitirá abordar, posteriormente (Capítulo 13), las evidencias disponibles hasta el momento de un proceso de emergencia de complejidad socio-cultural.

De particular importancia para entender el proceso transicional local son los puntos de movilidad residencial, subsistencia e interacción a nivel macrorregional. El primero, en función de las evidencias de movilidad reducida desde distintas líneas de evidencia; el segundo, en relación con los datos disponibles sobre recursos alimenticios silvestres y, fundamentalmente, domesticados; y, finalmente, el tercero, al considerar tanto la obtención de elementos provenientes de áreas alejadas, sean comestibles o no, como la recepción de información en cuanto a diseños de puntas de proyectil, tecnología cerámica, etc.

Cabe destacar que si bien el interés se centra en el proceso desarrollado puntualmente en Antofagasta de la Sierra, se realizan comparaciones con evidencias específicas de otras áreas de la Puna argentina y del desierto del Norte de Chile, con el fin de identificar y caracterizar las particularidades del registro arqueológico local. 


\subsection{DISCUSION DE LAS EVIDENCIAS DEL REGISTRO ARQUEOLÓGICO DE ANTOFAGASTA DE LA SIERRA PARA EL LAPSO 5500-1500 AP}

\subsubsection{MOVILIDAD RESIDENCIAL REDUCIDA}

Antes de analizar los diferentes indicadores disponibles en cuanto a una reducción en la movilidad residencial, es pertinente señalar que las particulares características ambientales existentes a partir del Holoceno Medio en la Puna argentina, definidas por un ambiente en mosaico, podrían haber generado un terreno propicio para la circunscripción social. Este podría haber sido el caso de Antofagasta de la Sierra, ya que la microrregión contaba, de acuerdo a lo expuesto en el Capítulo 2, con recursos hídricos y vegetales importantes en relación a las condiciones generales imperantes en el resto de la Puna Salada durante el lapso mencionado.

La situación de circunscripción social en este caso estaría definida por barreras ambientales, producto del contraste de este ambiente en mosaico, con distintas zonas de concentración de nutrientes relacionadas a la cuenca del Río Punilla y éstas, a su vez, circundadas por un desierto extremo. La circunscripción estaría generada, por la competencia social entre estos territorios con muy baja productividad primaria, que llevaría a una demarcación más estricta de los mismos (ver más adelante la discusión sobre Territorialidad).

Un punto importante a la hora de abordar la movilidad en cazadores-recolectores es aceptar un uso tripartito del espacio por parte de los mismos, el cual está conformado por: 1) un espacio más pequeño, donde la movilidad individual y grupal está relacionada principalmente con la obtención de recursos básicos para la subsistencia, como especies animales y vegetales, agua y leña (micromovilidad); 2) otro adyacente, más extenso, en el que se viajan distancias más grandes, que es compartido con grupos vecinos (mesomovilidad); y 3) otro mucho más amplio, que no implica necesariamente el viaje del grupo en cuestión o de parte de él, sino que puede ser accesible a través de redes de intercambio, de reciprocidad o matrimoniales (macromovilidad) (Aschero y Yacobaccio 1998/1999, MacDonald y Hewlett 1999, Barnard 2001).

Diversas clases de vestigios arqueológicos han brindado evidencias de una reducción de la movilidad a medida que avanzaba el Holoceno en Antofagasta de la Sierra. En este sentido, Rodríguez (1999a), a partir del análisis de restos arqueobotánicos del sitio QS3, señala que a fines del Holoceno Medio, hacia el $4000 \mathrm{AP}$, los vegetales no locales ${ }^{1}$ eran menos frecuentes que en momentos anteriores,

\footnotetext{
${ }^{1}$ Rodríguez (1999a) entiende por vegetales locales a especies que crecen en un radio de aproximadamente 20 $\mathrm{km}$ a partir de QS3, siendo no locales las que se encuentran a distancias mayores.
} 
infiriendo una menor movilidad. Asimismo, Pintar (1996a), mediante el abordaje de las tasas de mantenimiento, reemplazo y descarte de las materias primas líticas no locales ${ }^{2}$ utilizadas en la confección de artefactos tallados de los sitios QS3, CS1, PP4 y PCh1.1, concluye que hay una paulatina reducción en la movilidad residencial a lo largo del Holoceno, aunque se mantiene la movilidad logística a áreas no locales.

Debe tenerse en cuenta, ante la ocurrencia simultánea de distintas esferas de movilidad a diferentes escalas, que el hecho de un grado creciente de fijación de los grupos humanos al paisaje a escala micro no debe llevar obligatoriamente a que la circulación regional (macromovilidad) disminuya o deje de funcionar. La información disponible parecería sustentar, justamente, una micromovilidad reducida y una macromovilidad en pleno funcionamiento (ver punto 6.2.4. Redes de interacción a largas distancias) a fines del Holoceno Medio y durante el Holoceno Tardío ${ }^{3}$.

Entre los elementos que sostendrían la posición de una micromovilidad reducida pueden considerarse aquellos referidos a distancias de búsqueda de los recursos explotados. Así, Rodríguez (1999b), para el sitio QS3 y en los momentos considerados, sostiene que se recorrieron distancias muy cortas, de aproximadamente 0 a $3 \mathrm{~km}$, para recolectar las especies utilizadas como leña; las que se incrementarían al tratarse de especies seleccionadas por alguna característica particular, como ser Deyeuxia eminens, una gramínea utilizada en el acondicionamiento de los pisos de ocupación, con un radio de 0 a $20 \mathrm{~km}$, o materiales empleados para cestería, como Cortaderia sp., con un rango de 4 a 17 km. Distancias muy parecidas a éstas se registran en sitios de la localidad Punta de la Peña (Rodríguez 2003).

Otro sitio que cuenta con información al respecto es PCh1.3, en el cual se señala una estrecha interacción con el entorno vegetal cercano al sitio, más específicamente el Tolar, en relación con la recolección de especies leñosas y herbáceas (Aguirre 2005a).

El abordaje de las materias primas líticas brinda, asimismo, evidencias en este sentido, ya que de las 17 variedades de rocas/minerales utilizadas, 11 de ellas fueron obtenidas en fuentes distribuidas en un radio no mayor a 15 km, tomando como centro la localidad de Punta de la Peña sobre el Río Las Pitas, por lo que la prueba y selección de las variedades de rocas se realizó básicamente en espacios próximos a los asentamientos, significando una movilidad restringida entre espacios de recursos líticos conocidos (Aschero et al. 2002).

\footnotetext{
${ }^{2}$ La autora define como recursos locales a aquellos que se encuentran en un radio de $20 \mathrm{~km}$, y los no locales a distancias mayores que esta (Pintar 1996a).

${ }^{3}$ Se recuerda que el Holoceno Tardío comenzaría hacia el 3000 AP en Antofagasta de la Sierra, de acuerdo a datos paleoambientales generados en la microrregión (Olivera et al. 2002).
} 
El indicador arqueológico más comúnmente usado en la determinación de movilidad reducida/sedentarismo es la presencia de recintos habitacionales (Kelly 1992). En la Puna argentina no se tienen aún datos sobre asentamientos complejos, con espacios residenciales estructurados de uso redundante, adscribibles a momentos anteriores al 2500 AP, como sí ocurre en el Desierto de Atacama (Chile) con los sitios Tulán 52, Puripica 1 y Tulán 54 (Núñez 1992, 1994). La existencia de tales espacios residenciales están datados recién hacia el comienzo de la era en Antofagasta de la Sierra, con el sitio CChM1, asociado a grupos agro-pastoriles plenos (Olivera 1992).

Sin embargo, un fenómeno que goza de una destacada recurrencia en Antofagasta de la Sierra es la presencia de estructuras de piedra en abrigos rocosos. Un ejemplo de esto es el sitio PP4 con, por lo menos, 4 estructuras circulares parcialmente desarmadas construidas contra la pared del alero, que no pueden adscribirse a corrales (Aschero 2005a, Aschero et al. 2005). Los bloques que conforman la base de las mismas apoyan inmediatamente bajo el nivel 5(2) e incluyen el nivel 5(1) suprayacente. Las dataciones de los niveles involucrados se sitúan hacia los 3800 años AP. Otro sitio que responde a estas características es PCh1.3, ya que el alero bajo roca cuenta con una estructura de piedra desarmada con sectores remanentes que sigue aproximadamente la línea de goteo del abrigo. La cronología de las ocupaciones van de los 3700 a los 3500 años AP aproximadamente (Figura 6.1).

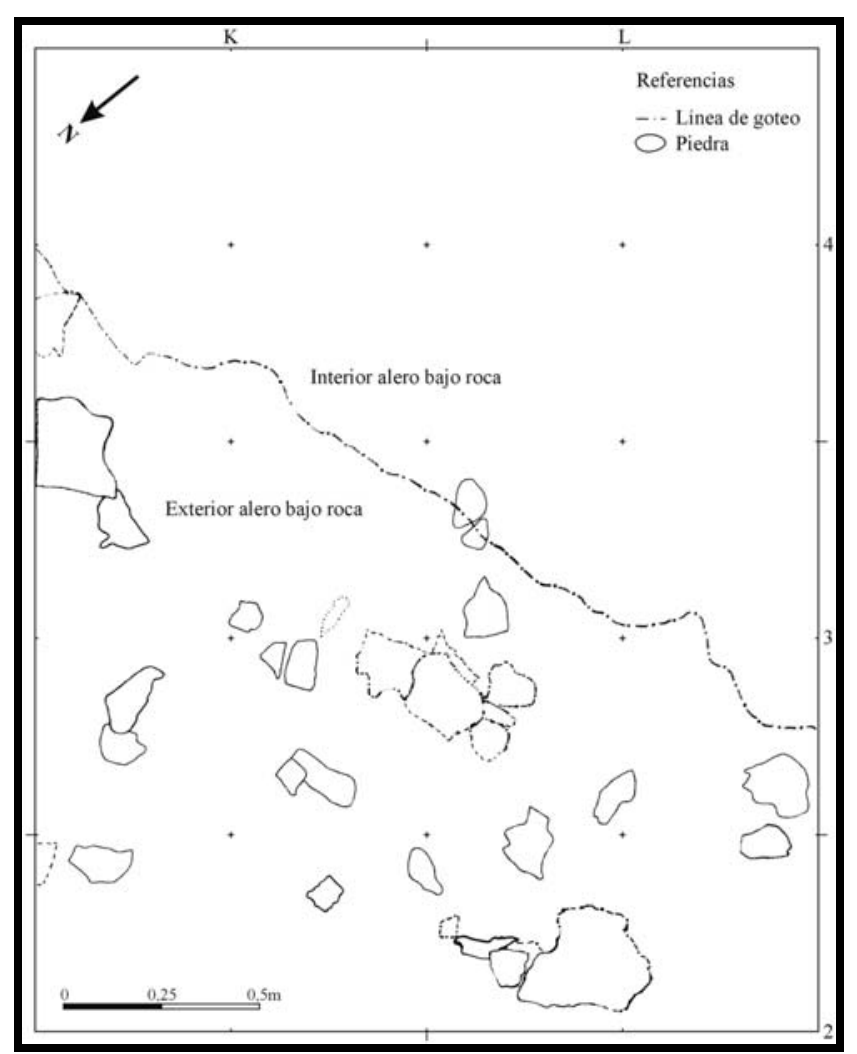

Figura 6.1. Estructura de piedra en PCh1.3

Otros sitios podrían constituirse en casos en este sentido. Cueva Salamanca 1 posee tres estructuras pircadas, de las cuales dos han sido parcialmente excavadas. Aunque todavía no están 
fechadas, el hallazgo de una punta lanceolada pequeña en una de las estructuras sugeriría su uso ca. 3500 AP de acuerdo a Pintar (2004a, 2004b). Por su parte, Peñas Chicas 1.6 parecería contener estructuras de piedra de algún tipo.

Una reducción en la movilidad implicaría, también, cambios en el número y variedad de sitios, incluida la aparición de sitios de características distintas, y modificaciones en la organización interna y duración de las ocupaciones. Efectivamente, los datos disponibles sustentarían diferencias en estos aspectos al agrupar los sitios localizados hasta el momento en dos lapsos: previo al 5500 AP y entre el 5500 y el 1500 AP. En este último no sólo se incrementa el número de sitios, sino que aparecen otros que no tenían correlato anteriormente, ya que a las bases residenciales y a los sitios con arte rupestre del primer momento se agregan eventos discretos de depositación de materiales arqueológicos en oquedades. Asimismo, al tomar en consideración las bases residenciales, se evidencia una diversificación en las mismas ya que a los campamentos temporarios con énfasis en actividades de caza se les suman espacios acondicionados y/o equipamiento de sitio. Se debe considerar, también, la aparición de bases residenciales de actividades múltiples de ocupación anual.

Merecen especial atención, en este sentido, los niveles 2b5 a $2 \mathrm{~b} 2$ del sitio QS3, con cronologías absolutas entre 5500 y 4400 años AP, ya que la organización del espacio, a través de un emplazamiento diferente de fogones y de dispersiones de tecnofacturas y ecofactos, sumándose a esto posibles estructuras de cavado en $2 \mathrm{b3}$ y la alternativa de descarte de y/o abandono de instrumentos con posibilidades de uso, contrastan con las evidencias de los niveles inferiores, siendo interpretados los primeros como ocupaciones de uso redundante, correspondientes a un puesto (Aschero et al. 1993/94, Pintar 1995b).

La presencia de artefactos de molienda descartados como residuos de facto en este sitio, así como en PP4, PCh1.1 y PCh1.3, más las características morfológicas de los mismos, señalan también la posibilidad de ocupaciones redundantes, recurrentes y anticipadas en los mismos (Babot 2004a). Para un tratamiento específico y en profundidad sobre el tema ver Babot (2006).

Otro caso de cambios en la organización interna es el de las estructuras de piedra anteriormente mencionadas, por constituir una configuración del espacio no registrada en momentos previos.

En cuanto a la duración de las ocupaciones, QS3 habría sido ocupado durante los meses de primavera-verano y comienzos del otoño, de acuerdo a la presencia de camélidos recién nacidos en el registro arqueofaunístico y de frutos y flores. Sin embargo, no es posible descartar una ocupación durante el invierno debido a la permanente disponibilidad de vicuñas y recursos vegetales en la vega y 
en la pampa cercanas al sitio. Por lo tanto, QS3 pudo haber sido habitado temporariamente en distintos momentos del año, siendo las ocupaciones más prolongadas durante los meses más cálidos (Rodríguez y Rúgolo de Agrasar 1996). PCh1.3, por su parte, de acuerdo a lo que indican exclusivamente los órganos reproductivos de las gramíneas recuperadas, habría sido ocupado durante la primavera y/o el verano (Aguirre 2005b).

Sin embargo, información reciente daría cuenta de ocupaciones más prolongadas, tanto en este sitio como en otros (QS3, PCh1.1 y PP4). En los mismos se ha recuperado una serie de cultígenos en forma de microrrestos vegetales en artefactos de molienda (Babot 2004a, 2005), así como probablemente de macrorrestos (Aguirre 2005b), que implicarían la ocurrencia local de actividades de siembra y cosecha de especies microtérmicas, es decir, típicamente puneñas y, tal vez, de especies mesotérmicas (ver punto 6.2.3. Subsistencia).

Un punto clave, para corroborar esto, es contar con datos que impliquen que dichos recursos no fueron "introducidos” a la microrregión vía interacción. Efectivamente, tales recursos pudieron provenir también de otras áreas de la Puna, o bien de la Prepuna ${ }^{4}$, obtenidos por intercambio o reciprocidad mediante acceso directo o indirecto. Al respecto, si se acepta la presencia de cultígenos en otras áreas de la Puna con la cronología señalada y que los mismos fueron producidos allí, no debería ser un problema considerar que ciertas especies domesticadas fueron cultivadas en Antofagasta de la Sierra, como parte integrante de la Puna.

Dentro de los recursos identificados, se encuentran una quenopodiacea (Chenopodium sp aff. C. quinoa), papa (Solanum tuberosum) y maíz (Zea mays). Siguiendo información de Muscio (2004) referida a San Antonio de los Cobres (Puna de Salta) -distante a aproximadamente $300 \mathrm{~km}$ en línea recta de Antofagasta de la Sierra- para estas tres especies, la época de siembra es Septiembre-Octubre y la de cosecha Marzo-Abril. Si se extrapolan dichos datos al caso considerado, esto implica que había estadías de seis meses, como mínimo, entre la siembra y la cosecha, vinculada al cuidado de los cultivos, ya sea de parte del grupo o del grupo completo.

Aschero et al. (1993/94) y Aschero (1999a) señalan, para el lapso 5500-3500 AP, la existencia en la microrregión de una movilidad muy pautada, con retorno a lugares previstos, en el marco de un sistema de asentamiento semi-sedentario o bien de recorridos/circuitos estacionales bien demarcados. La información aquí presentada está en tono con esto, aunque también va un poco más allá, ya que el

\footnotetext{
${ }^{4}$ Son significativas las evidencias de recursos comestibles silvestres y de cultígenos provenientes de grandes distancias, lo que es perfectamente plausible, dado el contexto de fuerte interacción entre pisos ecológicos diferentes que abarcaba prácticamente todo el NOA (ver punto siguiente 6.2.4. Redes de interacción a larga distancia).
} 
hecho de que parte del grupo, por lo menos, permanece en ciertos lugares prácticamente durante todo el año, denota una situación de relativo sedentarismo (Rafferty 1985).

Un alto grado de sedentarismo, con asentamientos con ocupación de año redondo, se presentaría recién hacia el 2000 AP, con la aparición de bases residenciales de actividades múltiples asociadas a grupos agro-pastoriles plenos (Olivera 1992). En éstos, los elementos del registro involucran evidencias de ocupaciones recurrentes en el tiempo y variabilidad en el uso del espacio intrasitio -estructuras de combustión, áreas concentradas de arrojado de basura, sectores de recintos, pisos consolidados artificiales, etc-.

Finalmente, se destaca que todavía no es posible, en base a las evidencias generadas hasta el momento, retrotraer en unos 1500 años, como mínimo, el hecho de un sedentarismo pleno en Antofagasta de la Sierra, aunque es factible que con las investigaciones futuras pueda dirimirse esta cuestión.

\subsubsection{TERRITORIALIDAD}

Para Price y Brown (1985), el comportamiento territorial es identificado por una acrecentada señalización de identidad. En esta dirección puede entenderse el planteo de Aschero (1999a) acerca de la existencia de modalidades estilísticas regionales bien diferenciadas en el arte rupestre del lapso 5500-3500 años AP, tanto dentro del mismo ámbito puneño argentino como entre éste y el atacameño.

Las diferencias son marcadas, entre la Puna Meridional-Septentrional argentina y el Salar de Atacama-alto Río Loa, en Chile, a partir de la importancia que adquieren las representaciones de camélidos en los conjuntos rupestres, siendo escasos y no repetitivos en las primeras y dominantes y repetitivos en los segundos. A su vez, los camélidos en la Puna argentina son representados en actitudes estáticas, mientras que en el Norte de Chile se busca la captación figurativo-analítica de las formas y actitudes, respectivamente (Aschero 1998).

Al considerar exclusivamente la Puna argentina, el arte rupestre de los cazadores-recolectores se caracterizó, desde principios del Holoceno, por motivos geométrico abstracto simples (Aschero y Podestá 1986; Podestá 1986/87). Sin embargo, hacia los 5500 años AP, además de los motivos geométricos simples, se agregan en Antofagasta de la Sierra figuras de circunferencias o circunferencias concéntricas con apéndices inferiores, junto con representaciones de figuras humanas, camélidos, felinos y aves, aunque estos últimos en proporciones mínimas (Aschero 1999a). Tanto es 
así que la “... asociación camélido/felino/ave constituiría un tema particular presente desde el Arcaico Tardío en la Puna Meridional Argentina...” (Aschero 1998: 185).

Un punto importante es la ocurrencia de variaciones microrregionales en las representaciones de camélidos entre la Quebrada de Cacao, la de Quebrada Seca y la zona conocida como La Torre (esta última en el fondo de cuenca), que ha sido vinculada con una situación de territorialidad por Aschero (2005a).

Por otro lado, de acuerdo a Aschero (1999b), el arte rupestre en Antofagasta de la Sierra se asocia a espacios domésticos y a espacios vinculados con buenos recursos de caza y recolección, por lo que una función posible de las representaciones se relacionaría con la denotación de espacios de retorno previsto. Es interesante, también, que todos los sitios con arte rupestre coinciden con vegas o fuentes de agua permanente y con territorios aptos para la caza y/o recolección (sitios QS1, QS2, RG3, Cc1A, PP4, LC3 y Cu5), siendo factible, entonces, que el arte rupestre esté funcionando como una marca territorial.

Con este sentido funcionarían, a partir del 2000 AP aproximadamente, las representaciones de la figura humana en forma de máscaras y/o figuras de cuerpo elongado para las sociedades agropastoriles de la Puna Sur, que se relacionarían con los ancestros y, por ende, con la legitimización de los derechos territoriales (Aschero 1998). Se debe destacar que la presencia de la figuración humana en momentos previos se limita en Antofagasta de la Sierra a las dos figuras humanas del sitio QS2 que se asociarían a los niveles de ocupación de QS3 datados entre 5400 y 4500 años AP-, a la registrada en RG3 -con ubicación temporal similar-, al rostro humano presente en el sitio PC1 -con una posición cronológica estimada entre 3500 y 2500 años AP- (Aschero 1999a, com pers.) y a las dos figuras humanas del sitio Cu5 (Aschero et al.2003). Si bien son muy escasos a nivel intrasitio, esta cierta recurrencia intersitio permitiría plantear que constituyen antecedentes del desarrollo posterior.

Otro elemento interesante es que las inhumaciones (QS3 -nivel 2b2- y PP11A) y las depositaciones intencionales de conjuntos de objetos, definidas como posibles ofrendas por Olivera et al. (2003) (QS3 -capa 0/lente 1x-, Cc1A y RG3), así como el hallazgo de PCh1.5, coinciden, como el arte rupestre, con las zonas con concentración de nutrientes; por lo que es probable que esta asociación de los muertos y las ofrendas con sectores particulares del paisaje haya servido también para denotar el derecho territorial. Cabe señalar que en este sentido se han tomado las inhumaciones de cabezas removidas de sus cuerpos de la Puna Norte y Andes Centrales, relacionándolas con un culto a los ancestros o como recordatorio de relaciones intergeneracionales, que reafirman y legitiman los derechos familiares sobre el paisaje (Yacobaccio 2001a). 
Por otra parte, hasta el momento no se han recuperado indicios de defensa perimetral del territorio por la fuerza en Antofagasta de la Sierra, uno de los indicadores más extremos de existencia de territorialidad.

La territorialidad también se expresa en forma de diseños de artefactos distintivos (Price y Brown 1985). Aunque esta línea de investigación aún no ha sido abordada de manera sistemática, para Aschero (1988) hay una variabilidad regional importante, con comportamientos estilísticos diferentes. Para el caso de Antofagasta de la Sierra, este punto es tratado en el Capítulo 10.

En definitiva, a partir de las evidencias del arte rupestre, de los enterratorios y las ofrendas, entre otros, se podría argumentar un incremento en la presencia de marcas territoriales hacia el 35003000 AP en Antofagasta de la Sierra, producto de un proceso de regionalización asociado al surgimiento de territorios fijos, que adquiere sentido al tener en cuenta la información existente sobre movilidad reducida. Aschero (2005a) plantea que localmente se trataría de territorios no muy extensos, sujetos al control por parte de un grupo familiar o linaje, que coincidirían aproximadamente con quebradas con agua permanente.

\subsubsection{SUBSISTENCIA}

Hay consenso en que a partir de los 5000 años AP aproximadamente se intensificó la explotación de los camélidos, un recurso básico para la subsistencia en los Andes Centro-Sur (Olivera 1998), lo que devino en una caza especializada y en un proceso domesticatorio (Núñez 1981; Yacobaccio et al. 1997/98; Olivera 1998, Yacobaccio 2001b).

Al respecto, Yacobaccio (com pers.) sostiene que el proceso de especialización no habría tenido lugar en Antofagasta de la Sierra, ya que las frecuencias de camélidos se mantuvieron relativamente constantes a lo largo del Holoceno. Más allá de que se haya producido o no un proceso local de intensificación en relación a los camélidos, es factible postular una explotación intensiva de los mismos en Antofagasta de la Sierra, en el lapso abordado, al considerar el predominio absoluto de las proporciones de restos óseos de camélidos sobre otros taxones, con altísimos valores de NISP, en QS3 y PCh 1.1 (Aschero et al. 1991; Olivera y Elkin 1994; Elkin 1996a, 1996b).

En cuanto a la cuestión de un proceso de domesticación local, hasta el momento no hay evidencias osteométricas seguras de cambio en el tamaño de los camélidos. Si bien en los niveles correspondientes al lapso 5500-4500 AP de QS3, se identificaron dos grupos de tamaño de camélidos a partir de análisis osteométricos, uno comparable a la vicuña (Lama vicugna) actual y otro al guanaco 
(Lama guanicoe), predominando las formas pequeñas (Elkin 1996b), lo único que podría apoyar la presencia de camélidos domesticados es la existencia de falanges robustas y de huesos de tamaño coincidente con llama (Lama glama) actual, pero la evidencia es débil (Elkin 1996a).

La presencia de vicuña y guanaco está constatada, además, por el hallazgo de fibras y de incisivos inferiores, aunque el panorama no es tan claro para los incisivos asignados a guanaco, ya que son similares a los de llama (Olivera y Elkin 1994). A esto se suma, por un lado, la dificultad de distinguir entre guanacos y llamas en base a restos óseos y, por otro lado, la presencia de una fibra que es análoga a la de un tipo de llama actual, denominada llama intermedia, de uso generalizado, desde momentos tempranos y que continúa durante el resto del Holoceno (Reigadas 1994, Olivera 1998, Yacobaccio 2001b).

Para PCh1.1, la ausencia de incisivos completos o restos de fibras, sumado el hecho de que el material óseo se presenta, en general, en un muy mal estado de conservación y altamente fragmentado, condicionó el reconocimiento de taxones a criterios osteométricos sobre unos pocos especimenes, con resultados coincidentes con los estándares actuales de vicuña (Olivera y Elkin 1994).

En base a la información generada, entonces, se puede plantear la existencia de dos poblaciones de tamaño diferente y la ausencia de evidencia osteológica segura que permita discernir un evento local de domesticación. Yacobaccio (2001b) señala, en este sentido, que es significativo que la secuencia de QS3 termina hacia el 4500 AP, unos 500 años antes de las primeras evidencias de cambios en el tamaño de los camélidos detectables en los huesos en otras áreas puneñas.

Es paradójico que sólo se haya encontrado una especie silvestre en PCh1.1, cuando por la cronología de la ocupación debería haber quedado evidenciado un cambio en el tamaño de los huesos, aunque esto puede ser producto del tamaño reducido de la muestra o de la funcionalidad del sitio, entre otros factores.

Desafortunadamente, los sitios con cronologías que se encuadran en el lapso clave para identificar prácticas domesticatorias o bien presentan materiales arqueofaunísticos en el mismo estado que los de PCh1.1, como en PP4, o cuentan con muestras que están siendo procesadas, como PCh1.3 y PCh1.5.

Coincidiendo con los resultados obtenidos por Yacobaccio (2001b) en cuanto a que un animal de igual tamaño que la llama actual estaba presente con seguridad desde los 2000 AP, los primeros datos seguros de llama en Antofagasta de la Sierra aparecen hacia esta fecha, en los sitios CChM1 y PP9. En el primero, se han identificado especies silvestres (vicuña) y domesticadas (llama) utilizando 
criterios osteométricos, de dentición y fibra (Olivera y Elkin 1994, Olivera 1998), en tanto que, en el segundo, se encontró una lente de guano que fue interpretada como el remanente de un corral de una ocupación agro-pastoril datada en 1970ะ50 AP (López Campeny 2001A), constituyendo la primera evidencia de cautiverio en la microrregión. Asimismo, en este sitio se definió presencia de llama en base a osteometría (López Campeny et al. 2005).

Lo cierto es que la ambigüedad de los resultados no permite que se descarte la posibilidad de un proceso domesticatorio local. Al respecto, Reigadas (2000-2002) postula una instancia de experimentación en Antofagasta de la Sierra, con características de control intencional en los niveles fechados entre 4700 y 4500 AP de QS3.

Yacobaccio (2001b), por su parte, establece que es posible que se haya dado en la microrregión una situación de protección (protective herding), en la que el hombre modifica la relación predador-presa a favor de una especie o población en particular, brindándole cierto grado de resguardo de otros predadores y facilitándole un acceso más seguro a mejores fuentes de alimentación, sin intervenir sobre la reproducción (Yacobaccio 2001a, Yacobaccio y Vilá 2002). Esto es importante, ya que dicho manejo no significa necesariamente un control o selección dirigida al cambio de tamaño de los animales, aunque puede incluir prácticas de amansamiento y confinamiento y, por ende, algún tipo de control (Yacobaccio 2001b, Yacobaccio y Vilá 2002).

De particular relevancia es que estas prácticas tienen lugar, por ende, en un contexto cazadorrecolector, en el que se establece un nuevo tipo de relación ecológica con los camélidos (Yacobaccio 2001b). Reigadas (2000-2002) califica a esta situación como transicional.

Cabe remarcar que la aparición de animales domésticos no es sinónimo de presencia de pastoralismo (ver, por ejemplo, Yacobaccio y Vilá 2002). Evidentemente ambos sucesos se encuentran ligados aunque no necesariamente tienen que darse en el mismo lugar (Yacobaccio et al. 1997-98). Siguiendo a estos últimos autores, el pastoreo surge a partir de la intensificación de la explotación de animales domesticados en un contexto cazador-recolector. Es decir, los contextos pastoriles aparecen con la domesticación efectiva, es decir, cuando hay un sistema productivo en pleno funcionamiento (Reigadas 2000-2002), el cual implica una dependencia de los animales de rebaño que no necesariamente va a encontrarse durante los momentos de captura, amansamiento y cautiverio (Yacobaccio et al. 1997-98).

Es así que, para Yacobaccio y Vilá (2002), la implementación de estrategias económicas pastoriles se habría producido en la Puna Argentina recién hacia los 2600 años AP, mientras que para Olivera (1997, 1998), grupos pastoriles plenos ya estarían presentes ca.3000 años AP en dicha área. 
En Antofagasta de la Sierra, por su parte, ocurriría ca.2100 años AP, en concordancia con la aparición de bases residenciales agro-pastoriles a cielo abierto (Olivera 1992, Olivera y Elkin 1994).

La identificación de pastoralismo en el registro arqueológico es crucial, ya que implica una disminución sustancial en los riesgos de subsistencia de corto plazo (Escola 2002) y el comienzo de una economía de retorno diferido al implicar un almacenamiento de "carne en pie" (Pintar 1995b). Cabe destacar que una situación de protección tendría también cierto impacto sobre los riesgos de corto plazo, de acuerdo a lo manifestado por Yacobaccio (2001a).

Sin embargo, esto no impidió que la caza de camélidos silvestres tuviera una incidencia muy importante en la economía de los grupos humanos posteriores al 2000 AP (Olivera 1992, 1997, 1998; Olivera y Elkin 1994). Al respecto, Escola (2000, 2002) plantea que la caza se transforma en una opción para mitigar los riesgos de producción de mediano y largo plazo.

Al considerar la subsistencia en Antofagasta de la Sierra hacia el 2000 AP, se ha señalado un sistema mixto agro-pastoril, con predominio del componente pastoril en sus primeros momentos (Olivera 1992, 1998). Sin embargo, información generada recientemente sobre presencia de cultígenos desde ca.4500 años AP llevaría a rever estas afirmaciones o, por lo menos, a considerar a los recursos vegetales comestibles como significativos en este ámbito puneño, a lo largo de la secuencia considerada.

Esto adquiere sentido desde el punto de vista de los requerimientos nutricionales de los seres humanos, ya que los aportes de proteínas y grasas derivados del consumo de recursos animales deben complementarse necesariamente con carbohidratos de origen vegetal (Speth 1993, Spielmann y Eder 1994).

En relación con estos últimos, estudios sobre microfósiles en artefactos de molienda provenientes de sitios de la microrregión datados entre los 4700 y los 3400 años AP, llevados a cabo por Babot (2004a, 2005), resultaron en el hallazgo de una importante variedad de recursos vegetales comestibles. Se debe remarcar que los artefactos analizados fueron recuperados de cuatro sitios arqueológicos, tres de los cuales son relativamente sincrónicos, mientras que el restante está conectado temporalmente; por otra parte, todas las piezas provienen de estratigrafía.

De acuerdo a Babot (2004b), la implementación de la práctica de la molienda en el lapso citado no sería ocasional, sino más bien regular, y planificada o programada, aunque a una escala reducida. Asimismo, para esta autora, los recursos de molienda se habrían consumido con cierta 
regularidad y en relativa cantidad, lo que sugeriría que tuvieron un papel importante en la subsistencia (Babot 2006).

Previamente a estos datos, las únicas evidencias procedían de macrorrestos de QS3 y referían a algunas especies vegetales potencialmente comestibles, no pudiéndose confirmar su ingesta. Así, en los niveles 2b5, 2b4 y 2b2 se recuperaron frutos de Hoffmannseggia eremophila, cuyas tuberosidades son comestibles (Rodríguez 1999b), y en 2b5 se encontraron partes leñosas de Adesmia horrida, que cuenta con raíces comestibles (Rodríguez y Deginani 1994-95). Finalmente, en este último nivel, se identificó un fragmento de vaina de Arachis sp, que por su morfología correspondería a una especie silvestre aff. a A. Montícola "maní” (Rodríguez 1999c).

La información procedente de los microfósiles recuperados en los artefactos de molienda da cuenta, por su parte, de una gama importante de recursos vegetales que, evidentemente, fueron procesados y, muy posiblemente, consumidos, tanto silvestres como domesticados (Tabla 6.1) Dentro de los primeros, se han hallado evidencias de items procedentes de grandes distancias, como Opuntia sp "penca”, Juglans australis “nuez”, Prosopis sp “algarrobo” y Canna edulis “achira”, así como locales, tal el caso de Ciperaceae. Para los segundos, se cuenta con vegetales no locales, tales como: Cucurbita sp, Lagenaria siceraria “mate”, Amaranthus caudatus / mantegazzianus “amaranto" y locales, como Chenopodium sp aff. C. quinoa, Oxalis tuberosa "oca”, Solanum tuberosum "papa blanca", Ullucus tuberosus "ulluco" y Zea mays "maíz”. Asimismo, se han identificado tubérculos/raíces no diferenciados, aunque no es posible establecer si se trata de recursos locales o no, o si son silvestres o cultivados (Babot 2004a).

\footnotetext{
${ }^{5}$ De hecho, los residuos representados proceden de las partes útiles de las plantas, que son justamente las que se consumen.
} 
Tabla 6.1. Recursos vegetales comestibles como microfósiles en artefactos de molienda -4700-3500 AP- (Babot 2004a, 2005)

\begin{tabular}{|c|c|c|}
\hline Sitio & Capa & Material \\
\hline \multirow[t]{9}{*}{ QS3 } & \multirow[t]{5}{*}{$2 \mathrm{~b} 2$} & Microfósiles en mano de molino: granos de almidón de semillas de maíz (Zea mays) \\
\hline & & Microfósiles en mano de molino: posibles silicofitolitos de Cucurbita sp \\
\hline & & $\begin{array}{l}\text { Microfósiles en mano de molino: granos de almidón y oxalatos de calcio de semilla de } \\
\text { Chenopodium sp aff. C. quinoa }\end{array}$ \\
\hline & & Microfósiles en mano de molino: silicofitolitos de fruto de Opuntia sp \\
\hline & & Microfósiles en mano de molino: granos de almidón de tubérculos/raíces no diferenciados \\
\hline & \multirow[t]{4}{*}{$2 \mathrm{~b} 3$} & $\begin{array}{l}\text { Microfósiles en artefacto de molienda: granos de almidón y oxalatos de calcio de semilla de } \\
\text { Chenopodium sp aff. C. quinoa }\end{array}$ \\
\hline & & Microfósiles en artefacto de molienda: posibles silicofitolitos de Cucurbita sp \\
\hline & & Microfósiles en artefacto de molienda: silicofitolitos de fruto de Opuntia sp \\
\hline & & Microfósiles en artefacto de molienda: granos de almidón de tubérculos/raíces no diferenciados \\
\hline \multirow[t]{12}{*}{ PP4 } & \multirow[t]{3}{*}{$5\left(4^{\circ}\right)$} & Microfósiles en molino: granos de almidón y silicofitolitos de fruto de maíz (Zea mays) \\
\hline & & Microfósiles en molino: silicofitolitos de fruto de Opuntia sp \\
\hline & & Microfósiles en molino: posibles silicofitolitos de fruto de nuez (Juglans australis) \\
\hline & \multirow[t]{9}{*}{$5\left(5^{\circ}\right)$} & $\begin{array}{l}\text { Microfósiles en mano de moler: granos de almidón y fitolitos de calcio del tubérculo de oca } \\
\text { (Oxalis tuberosa) }\end{array}$ \\
\hline & & Microfósiles en mano de moler: granos de almidón de tubérculo de papa (Solanum tuberosum) \\
\hline & & Microfósiles en mano de moler: granos de almidón de corteza de mate (Lagenaria siceraria) \\
\hline & & Microfósiles en mano de moler: silicofitolitos de fruto de maíz (Zea mays) \\
\hline & & $\begin{array}{l}\text { Microfósiles en mano de moler: silicofitolitos y fitolitos de calcio de pulpa de la vaina de } \\
\text { algarrobo (Prosopis sp) }\end{array}$ \\
\hline & & Microfósiles en mano de moler: posibles silicofitolitos de Cucurbita sp \\
\hline & & Microfósiles en mano de moler: silicofitolitos de fruto de Opuntia sp \\
\hline & & Microfósiles en mano de moler: silicofitolitos de tubérculo de Ciperaceae \\
\hline & & Microfósiles en mano de moler: granos de almidón de tubérculos/raíces no diferenciados \\
\hline \multirow[t]{4}{*}{ PCh1.1 } & \multirow[t]{4}{*}{4} & $\begin{array}{l}\text { Microfósiles en artefactos de molienda: granos de almidón y fitolitos de calcio de semillas de } \\
\text { Amaranthus caudatus/ mantegazzianus }\end{array}$ \\
\hline & & $\begin{array}{l}\text { Microfósiles en artefactos de molienda: granos de almidón y fitolitos de calcio de semillas de } \\
\text { Chenopodium sp aff. C. quinoa }\end{array}$ \\
\hline & & $\begin{array}{l}\text { Microfósiles en artefactos de molienda: posibles granos de almidón y silicofitolitos de achira } \\
\text { (Canna edulis) }\end{array}$ \\
\hline & & Microfósiles en artefactos de molienda: tubérculos/raíces no diferenciados \\
\hline \multirow[t]{5}{*}{ PCh1.3 } & 4 & $\begin{array}{l}\text { Microfósiles en artefacto de molienda: posibles granos de almidón y silicofitolitos de achira } \\
\text { (Canna edulis) }\end{array}$ \\
\hline & \multirow[t]{4}{*}{7} & $\begin{array}{l}\text { Microfósiles en artefacto de molienda: granos de almidón y fitolitos de calcio de tubérculo de } \\
\text { oca (Oxalis tuberosa) }\end{array}$ \\
\hline & & Microfósiles en artefacto de molienda: silicofitolitos de ulluco (Ullucus tuberosus) \\
\hline & & $\begin{array}{l}\text { Microfósiles en artefacto de molienda: silicofitolitos y fitolitos de calcio de algarrobo } \\
\text { (Prosopis sp) }\end{array}$ \\
\hline & & Microfósiles en artefacto de molienda: posibles silicofitolitos de Cucurbita sp \\
\hline
\end{tabular}


Cabe destacar que el registro microbotánico está comenzando a ser acompañado por evidencias macrobotánicas. Así, en el alero bajo roca de PCh1.3, se recuperó un endocarpo de Prosopis sp (Oliszewsky com pers.) y un tallo carbonizado de Chenopodium quinoa (Aguirre 2005a, $2005 b)^{6}$-aunque no es posible establecer fehacientemente si se trata de una especie doméstica o no, pese a la estrecha similitud del mismo con un tallo de una variedad doméstica de quinoa (Rodríguez com pers.)-. Se destaca que en un artefacto de molienda de dicho alero se identificaron silicofitolitos y fitolitos de calcio de Prosopis sp. Asimismo, Babot (2005) identificó granos de almidón y fitolitos de calcio de Chenopodium sp en los sitios relativamente sincrónicos PCh1.1 y PP4.

Este hallazgo de un tallo de quinoa tiene importantes consecuencias, ya que implicaría que localmente se realizaban cosechas de este pseudocereal. En base a información etnográfica (Tagle y Planella 2002, Muscio 2004, Aguirre 2005b), su cosecha implica una siega cortando la planta en el tallo a unos $20 \mathrm{~cm}$. desde la superficie del terreno; posteriormente los cortes se recogen en fardos para su posterior trilla y aventado. Esto implicaría que los fardos con quínoa ingresaron a PCh1.3 para su tratamiento postcosecha. En caso de tratarse de un cultígeno, desde algún campo de cultivo todavía no localizado. Al respecto, una posibilidad es la terraza del río Las Pitas, que es el lugar más factible para una actividad productiva de muy baja escala.

Se podría postular también la ocurrencia de siembra de otros cultígenos microtérmicos (típicos del ambiente puneño), recuperados en artefactos de molienda, como la oca, el ulluco o la papa (Babot 2004a). En cuanto al maíz, si bien por ser mesotérmico merece mayores reparos, no debe olvidarse que actualmente se cultiva en zonas de la Puna Salteña, como Matancillas, o de la Puna Jujeña, como Rachaite, a unos 3700 m.s.n.m. (Muscio 2004) y en la misma Antofagasta de la Sierra, en Peñas Coloradas, a unos 3600 m.s.n.m. (Aschero com pers.).

Cabe destacar que el 75\% de los sitios con evidencias de microfósiles en la microrregión se encuentran a una altitud de 3600 metros sobre el nivel del mar, aproximadamente. Es pertinente denotar, además, la cercanía de los mismos con la terraza aluvial del río Las Pitas, el lugar más apropiado dadas las características del paisaje local. Así, PCh1.3 se encuentra en la terraza superior y muy cercano, a unos 100 metros; Pch1.1 y PP4, por su parte, a distancias menores a $250 \mathrm{~m}$. Un sitio que merece especial atención es PCh1.6, inmediato a la terraza aluvial aludida.

La identificación de plantas domesticadas que, por tratarse de especies microtérmicas, plantean por si mismas la posibilidad de su cultivo local, lleva inmediatamente a postular la ocurrencia de una producción a pequeña escala en la microrregión hacia el 3600 AP, dada la confluencia de

\footnotetext{
${ }^{6}$ Se considera que la cantidad de ejemplares de tallo de quinoa recuperados responde a la metodología instrumentada, que implicó la selección de sólo 2 a 3 individuos por cada nivel de excavación (Aguirre 2005b). Es indudable que, si se aumenta la muestra, se incrementará la cantidad de especimenes de este pseudocereal.
} 
indicadores micro y macro. Un punto pendiente que por el estado de la cuestión no es posible dilucidar en este momento es si tales tareas productivas, en caso de haberse presentado, refieren a procesos de experimentación y domesticación de recursos vegetales o bien a una práctica consolidada.

Aunque no se han identificado, hasta ahora, situaciones similares de datos concretos sobre actividades agrícolas con igual cronología en el resto de la Puna argentino-chilena y sus bordes, si se cuenta con evidencias de cultígenos relativamente sincrónicos en tales áreas. Así, en Inca Cueva 7 (borde de Puna jujeña), con fechados de ca.4000 años AP, se recuperaron restos de Lagenaria sicerarea (Aguerre et al. 1973, Aschero y Yacobaccio 1997/98); en Cueva Huachicocana III (borde de Puna jujeña), en la capa E2 -ca.3500 AP- se identificaron Lagenaria sicerarea, Zea mays y Arachis hipogaea (¿ं?) (Fernández Distel 1986); en Tulán 54 y 85, por su parte, hacia los 3200 años AP, se identificó ají (Capsicum sp) posiblemente doméstico, quínoa de una variedad doméstica (Chenopodium sp), calabaza (Cucurbita sp) y maíz (Zea mays) (Núñez 1994, 2000); otro sitio que contaría con evidencias de tubérculos domesticados, posiblemente oca (Oxalis tuberosa) o ulluco (Ullucus tubeosus), sería Cueva de Cristóbal, datado hacia los 2900 años AP (Fernández et al. 2002). Al extender el área de comparación, puede mencionarse el sitio Alero Las Morrenas 1, en el Centro de Chile, con presencia de Quenopodium quinoa con cronología de ca.3000 AP (Panella y Tagle 2004, Planella et al. 2005). Asimismo, diversos sitios de la cuenca del Lago Titicaca (Perú-Bolivia), como Chiripa, Quelcatani y Jiskairumoko, registran, con fechados coincidentes -4000-3500 AP-, quínoa (Quenopodium quinoa) y papa (Solanum tuberosum) (Hastdorf 1999, Aldenderfer 2002, Aldenderfer y Barreto 2004). Otro sitio, del sur del Perú, denominado Waynuna, brindó evidencias de fitolitos de maíz (Zea mays) con una cronología de 3800 a 3400 años AP (Perry et al. 2006).

Otro aspecto relevante es que, más allá de la presencia o no de una actividad de producción de alimentos local, la práctica del almacenamiento habría estado instalada, denotando también una economía de retorno diferido. Esto puede afirmarse dado que los tubérculos, la quínoa y el maíz mencionados requieren ser deshidratados y almacenados para su posterior machacado y molido (Babot 1999, 2004a). De esta forma, tales recursos funcionarían como un "reaseguro", destinados a prevenir o minimizar los riesgos de subsistencia de corto plazo, ya que la implementación de la molienda ocurriría durante buena parte del año (Babot 2004a). Al respecto, se ha señalado como posible pozo de almacenamiento una estructura de cavado en el nivel 2b3 de QS3 (Pintar 1995b), donde, se destaca, procede uno de los artefactos de molienda considerados.

Para el lapso 2100-1500 AP, por su parte, se cuenta con una serie de evidencias que revelan una continuidad en el empleo de recursos vegetales comestibles, tanto domesticados como silvestres. $\mathrm{Al}$ igual que en el momento anterior, se verifica la obtención a distancia de tales recursos básicos en 
zonas ambientales de diferente altitud (ver punto siguiente 6.2.4. Redes de interacción a larga distancia).

Así, Olivera (1992) señala el hallazgo de semillas, un fragmento de vaina y parte de un marlo de maíz, así como semillas de Prosopis flexuosa y Prosopis alba o chilensis en el componente superior de CChM1.

Por otra parte, al analizar "raederas de módulo grandísimo" de CChM1 y desechos de talla resultantes del mantenimiento de dichos instrumentos, de la estructura 3 de PP9.I, Babot et al. (2005) identificaron granos de almidón asignables a tubérculos/raíces y, en un caso, compatibles con granos compuestos de quínoa (Chenopodium quinoa). Tales artefactos formatizados han sido definidos como instrumental de labranza (ibid.). A éstos se deben sumar las palas y/o azadas, ubícuas en sitios agropastoriles posteriores al 2000 AP (Escola 2000).

Asimismo, en la estructura 3 mencionada anteriormente la preparación y/o consumo de especies vegetales está representada por endocarpos de chañar (Geoffroea decorticans) y corteza de mate (Lagenaria siceraria) (Babot et al. 2004).

Por su parte, los microfósiles recuperados en residuos de piedras de moler del Sector I del sitio PP9 señalan el procesamiento para uso o consumo de: a) semillas de Zea mays, Amaranthus caudatus/mantegazzianus, Chenopodium quinoa y Phaseolus vulgaris, b) tubérculos, raíces tuberosas y rizomas de Solanum tuberosum, Oxalis tuberosa, Ullucus tuberosus, Canna edulis, Hypseocharis pimpinellifolia y otros no diferenciados, c) frutos de Opuntia sp y Prosopis sp, d) corteza del fruto de Lagenaria siceraria y Cucurbita sp (Babot 2004a). Si bien los artefactos de molienda proceden de superficie, se los ha correlacionado con las unidades residenciales de ca.1400 AP situadas en el Sector señalado (Babot et al. 2004).

Otra estructura del sitio PP9 presenta también información sobre recursos vegetales comestibles. Se trata de la estructura 2 del Sector III (López Campeny 2001a), con evidencias de granos de Zea mays, semillas de Phaseolus vulgaris, endocarpos de Prosopis sp, carozos de Geoffroea decorticans “chañar” y fragmentos de Lagenaria siceraria.

Se considera, a modo de corolario, para este momento cercano y posterior al 2000 AP, que recursos microtérmicos tales como Solanum tuberosum, Oxalis tuberosa, Ullucus tuberosus o Chenopodium quinoa e incluso mesotérmicos como el Zea mays, muy posiblemente fueron cultivados localmente (ver, al respecto, Olivera 1992, López Campeny 2001a, Babot 2004a). 
Es indudable, por otro lado, la obtención de recursos comestibles de áreas distantes, tanto cultivados (Lagenaria siceraria, Phaseolus vulgaris) como silvestres (Prosopis sp, Opuntia sp, Canna edulis, Geoffroea decorticans). Destaca, asimismo, la presencia de Hypseocharis pimpinellifolia “soldaque”, un tubérculo silvestre típicamente puneño.

\subsubsection{REDES DE INTERACCIÓN A LARGA DISTANCIA}

La obtención de recursos bióticos y abióticos, así como información sobre prácticas de subsistencia, diseños de tecnofacturas y de arte rupestre, en espacios situados a grandes distancias (macromovilidad), sea por medio de intercambio, viajes de propósito especial, redes de parentesco o matrimoniales, está bien representada en el registro arqueológico de la Puna Norte argentina, su borde y la región circumpuneña chilena entre el 5500 y el 1500 AP (Aschero y Yacobaccio 1998/1999, Yacobaccio 2001a), y cuenta con evidencias significativas en Antofagasta de la Sierra.

Aquí, los elementos alóctonos fueron utilizados como materia prima para la confección de artefactos asociados a actividades de subsistencia -como obsidiana para la elaboración de instrumentos o astiles y/o intermediarios sobre Chusquea lorentziana-, para la alimentación -taxones silvestres y domesticados diversos-, y formaron parte de una tecnología de prestigio, posiblemente relacionada con el ritual -como sería el caso de artefactos sobre valva, calabaza y cordeles de palmera-.

Las grandes distancias involucradas en la interacción, con un mínimo de 130 km y un máximo de 350 km en línea recta (Tabla 6.2), hablarían en favor de la adquisición de estos recursos a través de la participación en una red de circulación regional de recursos, información y conocimientos (Núñez 1994, Aschero 1998, Yacobaccio et al. 2000). Se destaca que estas distancias mínimas en dirección general Este-Oeste no implican direcciones de circulación. De hecho, se evidencia también la circulación Norte-Sur de materias primas o artefactos, por el efecto de la latitud en la distribución de ciertas especies. Ejemplo de esto es el hallazgo en Antofagasta de la Sierra de fibras de palmera (Acrocomia chunta) (Rodríguez y Aschero 2005) típica del sector norte de Yungas (Boelcke 1986, Brown et al 2001) -hasta la latitud de Orán (Salta), a más de 450 km lineales- y que fueron usadas en la confección de cordeles. 
Tabla 6.2. Distancia localidad arqueológica-ecozonas actuales (en km)

\begin{tabular}{|c|c|c|c|c|}
\hline Puna & $\begin{array}{c}\text { Valles y } \\
\text { quebradas }\end{array}$ & Yungas & $\begin{array}{c}\text { Llanura } \\
\text { chaqueña }\end{array}$ & $\begin{array}{c}\text { Costa del } \\
\text { Océano } \\
\text { Pacífico }\end{array}$ \\
\hline Antofagasta de la Sierra & 128 & 173 & 191 & 340 \\
\hline
\end{tabular}

Se destaca que las evidencias de obtención de recursos bióticos alóctonos son tan antiguas como las primeras señales de ocupación humana en la microrregión (ca.9700 AP), y se mantienen en forma constante a lo largo de toda la secuencia, con acceso a bienes provenientes de los Valles y quebradas, Yungas y Llanura chaqueña (Hocsman et al.2004). El rango de acción se amplía recién en el momento considerado por esta investigación, más precisamente, a fines del Holoceno Medio, con la incorporación de elementos de la costa del Océano Pacífico.

Con respecto a los vegetales comestibles (ver el punto anterior 6.2.3. Subsistencia), se plantea un tratamiento como alóctonos a recursos microtérmicos como Chenopodium sp aff. C. quinoa o mesotérmicos, específicamente, Zea mays recuperados entre los 4700 y los 4400 años AP en QS3 (Tabla 6.3). Esta caracterización, evidentemente hipotética, tiene su fundamento en que no hay evidencia alguna de que hayan sido producidos localmente. A esto se suma la cronología temprana de tales hallazgos y la falta de recurrencia de tales elementos a nivel intersitio -lo cual es producto, muy posiblemente, del hecho de que QS3 es el único sitio con esa cronología, por el momento-. Con posterioridad a esta fecha, entre 4000 y 3500 años AP, se considera que pueden ser locales no sólo a éstos sino también a otros, como Solanum tuberosum u Oxalis tuberosa, dada la conjunción de evidencias a nivel de micro y macrorrestos y a la aparición de ciertos elementos que son clave (por ejemplo, tallos de quínoa). Una situación similar presentan los sitios fechados hacia el 2000 AP, en los que se considera como indiscutible una producción local, más aún cuando se cuenta con evidencias de cultígenos en filos de artefactos de labranza, como las raederas de módulo grandísimo (Babot et al. 2005), por lo que tales recursos no se incluyen en la Tabla citada. Un caso especial es el de los tubérculos/raíces no diferenciados, en los cuales no puede diferenciarse si son locales o alóctonos ni domésticos o silvestres. 
Tabla 6.3. Recursos bióticos alóctonos (5500-1500 años AP)

\begin{tabular}{|c|c|c|c|c|c|c|}
\hline Sitio & $\begin{array}{c}\text { Capa/ } \\
\text { nivel }\end{array}$ & $\begin{array}{l}\text { Cronología } \\
\text { en años AP }\end{array}$ & Material & Procedencia & $\begin{array}{c}\text { Funcionalidad } \\
\text { del item* }\end{array}$ & Contexto** $^{* *}$ \\
\hline \multirow[t]{14}{*}{$\begin{array}{l}\text { Quebrada Seca } \\
3 \text { (QS3) }\end{array}$} & $\begin{array}{l}2^{\mathrm{a}} \\
\text { Lente } \\
1 \mathrm{x}\end{array}$ & $2480 \pm 60$ & $\begin{array}{l}\text { Rama de Salix } \\
\text { humboldtiana con un } \\
\text { extremo quemado }\end{array}$ & Valles y quebradas & $\mathrm{D}$ & $\mathrm{C}$ \\
\hline & \multirow[t]{6}{*}{$2 \mathrm{~b} 2$} & \multirow[t]{6}{*}{$\begin{array}{l}4410 \pm 60 \\
4510 \pm 100 \\
4930 \pm 110\end{array}$} & $\begin{array}{l}\text { Microfósiles en mano de } \\
\text { molino: granos de } \\
\text { almidón de semillas de } \\
\text { Zea mays }\end{array}$ & $\begin{array}{l}\text { Puna/Valles y } \\
\text { quebradas }\end{array}$ & A1 & \multirow[t]{6}{*}{$\mathrm{A}$} \\
\hline & & & $\begin{array}{l}\text { Microfósiles en mano de } \\
\text { molino: silicofitolitos de } \\
\text { Acrocomia sp }\end{array}$ & $\begin{array}{l}\text { Yungas (Selva } \\
\text { pedemontana) de Salta } \\
\text { y Jujuy }\end{array}$ & B3 & \\
\hline & & & $\begin{array}{l}\text { Microfósiles en mano de } \\
\text { molino: posibles } \\
\text { silicofitolitos de } \\
\text { Cucurbita sp }\end{array}$ & Valles y quebradas & A1 & \\
\hline & & & $\begin{array}{l}\text { Microfósiles en mano de } \\
\text { molino: granos de } \\
\text { almidón y oxalatos de } \\
\text { calcio de semilla de } \\
\text { Chenopodium sp aff. C. } \\
\text { quinoa }\end{array}$ & $\begin{array}{l}\text { Puna } \\
¿ \text { ¿No local? }\end{array}$ & A1 & \\
\hline & & & $\begin{array}{l}\text { Microfósiles en mano de } \\
\text { molino: silicofitolitos de } \\
\text { fruto de Opuntia sp }\end{array}$ & Valles y quebradas & A1 & \\
\hline & & & $\begin{array}{l}\text { Microfósiles en mano de } \\
\text { molino: granos de } \\
\text { almidón de } \\
\text { tubérculos/raíces no } \\
\text { diferenciados }\end{array}$ & $\begin{array}{l}\text { Puna/Valles y } \\
\text { quebradas } \\
\text { ¿No local? }\end{array}$ & A1 & \\
\hline & \multirow[t]{5}{*}{$2 \mathrm{b3}$} & \multirow[t]{5}{*}{$4770 \pm 80$} & $\begin{array}{l}\text { Fragmento de astil de } \\
\text { caña maciza Chusquea } \\
\text { lorentziana }\end{array}$ & $\begin{array}{l}\text { Yungas (Selva } \\
\text { montana) }\end{array}$ & B2 & \multirow[t]{5}{*}{$\mathrm{A}$} \\
\hline & & & $\begin{array}{l}\text { Microfósiles en artefacto } \\
\text { de molienda: granos de } \\
\text { almidón y oxalatos de } \\
\text { calcio de semilla de } \\
\text { Chenopodium sp aff. C. } \\
\text { quinoa }\end{array}$ & $\begin{array}{l}\text { Puna } \\
¿ \text { ¿No local? }\end{array}$ & A1 & \\
\hline & & & $\begin{array}{l}\text { Microfósiles en artefacto } \\
\text { de molienda: posibles } \\
\text { silicofitolitos de } \\
\text { Cucurbita sp }\end{array}$ & Valles y quebradas & A1 & \\
\hline & & & $\begin{array}{l}\text { Microfósiles en artefacto } \\
\text { de molienda: } \\
\text { silicofitolitos de fruto de } \\
\text { Opuntia sp }\end{array}$ & Valles y quebradas & A1 & \\
\hline & & & $\begin{array}{l}\text { Microfósiles en artefacto } \\
\text { de molienda: granos de } \\
\text { almidón de } \\
\text { tubérculos/raíces no } \\
\text { diferenciados }\end{array}$ & $\begin{array}{l}\text { Puna/Valles y } \\
\text { quebradas } \\
\text { ¿No local? }\end{array}$ & A1 & \\
\hline & $2 \mathrm{~b} 4$ & - & $\begin{array}{l}\text { Dos fragmentos de astil } \\
\text { de caña maciza Chusquea } \\
\text { lorentziana }\end{array}$ & $\begin{array}{l}\text { Yungas (Selva } \\
\text { montana) }\end{array}$ & B2 & $\mathrm{A}$ \\
\hline & 2b5 & $5380 \pm 70$ & $\begin{array}{l}\text { Vaina partida de Arachis } \\
\text { sp; por sus características } \\
\text { morfológicas puede } \\
\text { tratarse de una especie } \\
\text { silvestre aff. a A. } \\
\text { Montícola "mani" }\end{array}$ & Yungas & A1 & A \\
\hline $\begin{array}{l}\text { Punta de la } \\
\text { Peña 11A } \\
\text { (PP11A) }\end{array}$ & - & $\begin{array}{l}3630 \pm 150 \\
3210 \pm 50\end{array}$ & $\begin{array}{l}\text { Valva de Anodontites } \\
\text { trapezialis }\end{array}$ & $\begin{array}{l}\text { Llanura chaqueña } \\
\text { (Ríos de llanura de } \\
\text { Jujuy, Salta y Tucumán) }\end{array}$ & $\mathrm{C} 2$ & B \\
\hline
\end{tabular}




\begin{tabular}{|c|c|c|c|c|c|c|}
\hline & & & $\begin{array}{l}\text { Cordeles de palmera } \\
\text { Acrocomia chunta }\end{array}$ & $\begin{array}{l}\text { Yungas (Selva } \\
\text { pedemontana) de Salta } \\
\text { y Jujuy }\end{array}$ & B2 & \\
\hline \multirow[t]{2}{*}{$\begin{array}{l}\text { Cueva Cacao } \\
1 \mathrm{~A}(\mathrm{Cc} 1 \mathrm{~A})\end{array}$} & \multirow[t]{2}{*}{-} & \multirow[t]{2}{*}{$\begin{array}{l}3000 \pm 80 \\
2870 \pm 40\end{array}$} & $\begin{array}{l}\text { Sonajero de Lagenaria sp. } \\
\text { “mate”, con decoración } \\
\text { pirograbada }\end{array}$ & Yungas & $\mathrm{C} 1$ & \multirow[t]{2}{*}{$\mathrm{C}$} \\
\hline & & & $\begin{array}{l}\text { Valva de pelecípodo } \\
\text { marino (parte del } \\
\text { sonajero) }\end{array}$ & $\begin{array}{l}\text { Costa del Océano } \\
\text { Pacífico }\end{array}$ & $\mathrm{C} 2$ & \\
\hline \multirow[t]{9}{*}{$\begin{array}{l}\text { Punta de la } \\
\text { Peña } 4 \text { (PP4) }\end{array}$} & \multirow[t]{6}{*}{$5\left(5^{\circ}\right)$} & \multirow[t]{6}{*}{$\begin{array}{l}3820 \pm 100 \\
3870 \pm 90 \\
4060 \pm 90\end{array}$} & $\begin{array}{l}\text { Microfósiles en mano de } \\
\text { moler: granos de almidón } \\
\text { de corteza de Lagenaria } \\
\text { siceraria }\end{array}$ & Yungas & & \multirow[t]{6}{*}{$\mathrm{A}$} \\
\hline & & & $\begin{array}{l}\text { Microfósiles en mano de } \\
\text { moler: silicofitolitos de } \\
\text { fruto de Zea mays }\end{array}$ & $\begin{array}{l}\text { Puna/Valles y } \\
\text { quebradas } \\
\text { ¿No local? }\end{array}$ & A1 & \\
\hline & & & $\begin{array}{l}\text { Microfósiles en mano de } \\
\text { moler: silicofitolitos y } \\
\text { fitolitos de calcio de } \\
\text { pulpa de la vaina de } \\
\text { Prosopis sp }\end{array}$ & Valles y quebradas & A1 & \\
\hline & & & $\begin{array}{l}\text { Microfósiles en mano de } \\
\text { moler: posibles } \\
\text { silicofitolitos de } \\
\text { Cucurbita sp }\end{array}$ & Valles y quebradas & A1 & \\
\hline & & & $\begin{array}{l}\text { Microfósiles en mano de } \\
\text { moler: silicofitolitos de } \\
\text { fruto de Opuntia sp }\end{array}$ & Valles y quebradas & A1 & \\
\hline & & & $\begin{array}{l}\text { Microfósiles en mano de } \\
\text { moler: granos de almidón } \\
\text { de tubérculos/raíces no } \\
\text { diferenciados }\end{array}$ & $\begin{array}{l}\text { Puna/Valles y } \\
\text { quebradas } \\
\text { ¿No local? }\end{array}$ & A1 & \\
\hline & \multirow[t]{3}{*}{$5\left(4^{\circ}\right)$} & \multirow[t]{3}{*}{$\begin{array}{l}3820 \pm 100 \\
3870 \pm 90 \\
4060 \pm 90\end{array}$} & $\begin{array}{l}\text { Microfósiles en molino: } \\
\text { granos de almidón y } \\
\text { silicofitolitos de fruto de } \\
\text { Zea mays }\end{array}$ & $\begin{array}{l}\text { Puna/Valles y } \\
\text { quebradas } \\
\text { ¿No local? }\end{array}$ & A1 & \multirow[t]{3}{*}{$\mathrm{A}$} \\
\hline & & & $\begin{array}{l}\text { Microfósiles en molino: } \\
\text { silicofitolitos de fruto de } \\
\text { Opuntia sp }\end{array}$ & Valles y quebradas & A1 & \\
\hline & & & $\begin{array}{l}\text { Microfósiles en molino: } \\
\text { posibles silicofitolitos de } \\
\text { fruto de Juglans australis }\end{array}$ & Yungas & A1 & \\
\hline \multirow[t]{3}{*}{$\begin{array}{l}\text { Peñas Chicas } \\
1.1 \text { (PCh1.1) }\end{array}$} & \multirow[t]{3}{*}{4} & \multirow[t]{3}{*}{$\begin{array}{l}3590 \pm 55 \\
3660 \pm 60\end{array}$} & $\begin{array}{l}\text { Microfósiles en artefactos } \\
\text { de molienda: granos de } \\
\text { almidón y fitolitos de } \\
\text { calcio de semillas de } \\
\text { Amaranthus caudatus/ } \\
\text { mantegazzianus }\end{array}$ & Valles y quebradas & A1 & \multirow[t]{3}{*}{$\mathrm{A}$} \\
\hline & & & $\begin{array}{l}\text { Microfósiles en artefactos } \\
\text { de molienda: posibles } \\
\text { granos de almidón y } \\
\text { silicofitolitos de Canna } \\
\text { edulis }\end{array}$ & Yungas & A1 & \\
\hline & & & $\begin{array}{l}\text { Microfósiles en artefactos } \\
\text { de molienda: } \\
\text { tubérculos/raíces no } \\
\text { diferenciados }\end{array}$ & $\begin{array}{l}\text { Puna/Valles y } \\
\text { quebradas } \\
\text { ¿No local? }\end{array}$ & A1 & \\
\hline \multirow[t]{2}{*}{$\begin{array}{l}\text { Peñas Chicas } \\
1.3 \text { (PCh1.3) }\end{array}$} & 4 & $3490 \pm 60$ & $\begin{array}{l}\text { Microfósiles en artefacto } \\
\text { de molienda: posibles } \\
\text { granos de almidón y } \\
\text { silicofitolitos de Canna } \\
\text { edulis }\end{array}$ & Yungas & A1 & $\mathrm{A}$ \\
\hline & 7 & $3680 \pm 50$ & $\begin{array}{l}\text { Microfósiles en artefacto } \\
\text { de molienda: } \\
\text { silicofitolitos y fitolitos } \\
\text { de calcio de pulpa de la } \\
\text { vaina de Prosopis sp }\end{array}$ & Valles y quebradas & A1 & A \\
\hline
\end{tabular}




\begin{tabular}{|c|c|c|c|c|c|c|}
\hline & & & $\begin{array}{l}\text { Microfósiles en artefacto } \\
\text { de molienda: posibles } \\
\text { silicofitolitos de } \\
\text { Cucurbita sp }\end{array}$ & Valles y quebradas & A1 & \\
\hline \multirow[t]{2}{*}{$\begin{array}{l}\text { Casa Chávez } \\
\text { Montículos } 1 \\
\text { (CChM1) }\end{array}$} & III a Vc & $\begin{array}{l}1670 \pm 60 \\
1660 \pm 60 \\
1530 \pm 70\end{array}$ & $\begin{array}{l}\text { Semillas de Prosopis } \\
\text { flexuosa y Prosopis alba } \\
\text { o chilensis }\end{array}$ & Valles y quebradas & A1 & A \\
\hline & I a VII & \begin{tabular}{|l|}
$1670 \pm 60$ \\
$1930 \pm 70$ \\
\end{tabular} & $\begin{array}{l}\text { Cuentas fabricadas con } \\
\text { caracoles de Olivia sp }\end{array}$ & \begin{tabular}{|l|} 
Costa del Océano \\
Pacífico \\
\end{tabular} & $\mathrm{C} 2$ & A \\
\hline \multirow{10}{*}{$\begin{array}{l}\text { Punta de la } \\
\text { Peña 9, Sector } \\
\text { III, Estructura } \\
2 \\
\text { (PP9.III.E2) }\end{array}$} & \multirow[t]{6}{*}{3} & \multirow[t]{6}{*}{$1460 \pm 40$} & $\begin{array}{l}\text { Recipiente confeccionado } \\
\text { sobre medio mate de } \\
\text { Lagenaria sicerarea }\end{array}$ & Yungas & B1 & \multirow[t]{6}{*}{ B } \\
\hline & & & $\begin{array}{l}\text { Cuerda de fibra de } \\
\text { Acrocomia sp combinada } \\
\text { con pelo de camélido }\end{array}$ & \begin{tabular}{|l|} 
Yungas (Selva \\
pedemontana) de Salta \\
y Jujuy
\end{tabular} & $\mathrm{C} 2$ & \\
\hline & & & $\begin{array}{l}\text { Semillas de Phaseolus sp } \\
\text { "poroto" }\end{array}$ & Yungas & A1 & \\
\hline & & & $\begin{array}{l}\text { Endocarpos de Prosopis } \\
\text { sp }\end{array}$ & Valles y quebradas & A1 & \\
\hline & & & $\begin{array}{l}\text { Endocarpos de Geoffroea } \\
\text { decorticans }\end{array}$ & Valles y quebradas & A1 & \\
\hline & & & $\begin{array}{l}\text { Fragmentos de Lagenaria } \\
\text { sicerarea }\end{array}$ & Yungas & A1 & \\
\hline & \multirow[t]{4}{*}{3 a 6} & \multirow[t]{4}{*}{$\begin{array}{l}1460 \pm 40- \\
1970 \pm 50\end{array}$} & $\begin{array}{l}\text { Endocarpos de Prosopis } \\
\text { sp }\end{array}$ & Valles y quebradas & A1 & \multirow[t]{4}{*}{ A } \\
\hline & & & $\begin{array}{l}\text { Endocarpos de Geoffroea } \\
\text { decorticans }\end{array}$ & Valles y quebradas & A1 & \\
\hline & & & $\begin{array}{l}\text { Fragmentos de Lagenaria } \\
\text { sicerarea }\end{array}$ & Valles y quebradas & A1 & \\
\hline & & & $\begin{array}{l}\text { Semilla aff. a Schinopsis } \\
\text { sp “quebracho Colorado" }\end{array}$ & Llanura chaqueña & $\mathrm{D}$ & \\
\hline \multirow[t]{7}{*}{$\begin{array}{l}\text { Punta de la } \\
\text { Peña 9, Sector } \\
\text { I (PP9.I) }\end{array}$} & \multirow[t]{7}{*}{-} & \multirow[t]{7}{*}{ ca.1400 AP } & $\begin{array}{l}\text { Microfósiles en artefactos } \\
\text { de molienda: } \\
\text { Amaranthus } \\
\text { caudatus/mantegazzianus } \\
\text { "amaranto" }\end{array}$ & Valles y quebradas & A1 & \multirow[t]{7}{*}{ A } \\
\hline & & & $\begin{array}{l}\text { Microfósiles en artefactos } \\
\text { de molienda: } \\
\text { Phaseolus vulgaris } \\
\end{array}$ & Yungas & A1 & \\
\hline & & & $\begin{array}{l}\text { Microfósiles en artefactos } \\
\text { de molienda: } \\
\text { Canna edulis }\end{array}$ & Yungas & A1 & \\
\hline & & & $\begin{array}{l}\text { Microfósiles en artefactos } \\
\text { de molienda: } \\
\text { Opuntia sp }\end{array}$ & Valles y quebradas & A1 & \\
\hline & & & $\begin{array}{l}\text { Microfósiles en artefactos } \\
\text { de molienda: } \\
\text { Prosopis sp }\end{array}$ & Valles y quebradas & A1 & \\
\hline & & & $\begin{array}{l}\text { Microfósiles en artefactos } \\
\text { de molienda: } \\
\text { Lagenaria siceraria }\end{array}$ & Yungas & A1 & \\
\hline & & & $\begin{array}{l}\text { Microfósiles en artefactos } \\
\text { de molienda: } \\
\text { Cucurbita sp }\end{array}$ & Valles y quebradas & A1 & \\
\hline \multirow{2}{*}{$\begin{array}{l}\text { Punta de la } \\
\text { Peña 9, Sector } \\
\text { I, Estructura } 3 \\
\text { (PP9.I.E3) } \\
\end{array}$} & \multirow[t]{2}{*}{$2-3$} & \multirow[t]{2}{*}{$\begin{array}{l}1430 \pm 60 \\
1410 \pm 70\end{array}$} & $\begin{array}{l}\text { Endocarpos de Geoffroea } \\
\text { Decorticans }\end{array}$ & Valles y quebradas & A1 & \multirow[t]{2}{*}{ A } \\
\hline & & & $\begin{array}{l}\text { Corteza de Lagenaria } \\
\text { sicerarea }\end{array}$ & Yungas & A1 & \\
\hline
\end{tabular}

Referencias: QS3: Aschero et al. 1991; Rodríguez 1999a, 1999b, 1999c, 2003; Rodríguez y Martínez 2001; Babot 2004a, 2005. PP4: Babot 2004a, 2005. PCh1.1: Babot 2004a, 2005. PCh1.3: Babot 2004a, 2005; Aguirre 2005a, 2005b. PP11A: Aschero et al. 2002. Cc1A: Olivera et al. 2003. CChM1: Olivera 1992. PP9IIIE2: López Campeny 2001a. PP9.I: Babot 2004a. PP9IE3: Babot et al. 2004. 
* Categorías de análisis (modificado de Hocsman et al. 2004):

A. Ecofactos: semillas, frutos u otros items de recursos naturales originales, no modificados, empleados para el consumo directo. Son diferenciados en:

A1. Especimenes de subsistencia: vinculados con la dieta o con materias primas directamente vinculadas con su uso en técnicas de subsistencia.

A2. Especimenes empleados en prácticas simbólicas o alucinatorias.

B. Artefactos vinculados a prácticas o técnicas de subsistencia (caza, transporte, vestimenta u otras). Se diferencian según la presencia o no de "decoración", entendida como la ejecución de representaciones, por medio de técnicas de incisión, grabado, pirograbado o pintura, sobre soportes de formas preestablecidas.

B1. Con decoración

B2. Sin decoración

B3. Presencia de decoración no diferenciada

C. Artefactos suntuarios y de prestigio: su función se vincula al adorno personal o bien al status social o al ceremonial (Albeck 1994). Vuelven a diferenciarse según los criterios anteriores:

C1. Con decoración

C2. Sin decoración

C3. Presencia de decoración no diferenciada

D. Función no conocida

La variante "decoración" no implica sólo una adición, sino un agregado cualitativamente importante para reforzar connotaciones simbólicas o de identidad grupal o individual mas allá de las funciones utilitarias que la forma o diseño particular de un artefacto pudieran haber tenido. En el primer sentido indicado estas connotaciones pueden adquirir particular relevancia en el intercambio de objetos bajo situaciones de reciprocidad (ver por ejemplo Nash 1998). Esta variable se analiza en relación con el contexto de uso.

** Se diferencian los siguientes contextos arqueológicos en base a su función (Hocsman et al. 2004):

A. Residencial o doméstico

B. Funerario

C. Depósito intencional de objetos

De la consideración de las categorías de elementos alóctonos surgen ciertas tendencias de interés. Así, es notoria la preponderancia de ecofactos en forma de recursos de subsistencia, con un $79,20 \%$, mientras que los artefactos vinculados con prácticas de subsistencia constituyen el 11,32\%, los bienes suntuarios o de prestigio el 5,66\% y los artefactos con funcionalidad indiferenciada el $3,77 \%$.

Dado que no se cumple la expectativa usual en este tipo de casos de que los elementos suntuarios o de prestigio son los que predominan sobre las materias primas alóctonas, se plantea una situación muy interesante, que puede ser comprendida al tener en cuenta la bajísima productividad primaria de la Puna (Muscio 1998-99), siendo necesario recurrir a otras áreas ecológicas por recursos bióticos.

La totalidad de los recursos comestibles alóctonos es de origen vegetal, a su vez, dentro de estos últimos, el 80\% corresponde a ítems comestibles. Esto posiblemente se deba a que en la Puna existen recursos de alto rendimiento cárneo como son los camélidos silvestres (vicuña y guanaco) y domesticados (llama), los cuales fueron explotados integralmente (carne, cuero, fibra, hueso, etc.).

Por otra parte, los elementos foráneos empleados en la manufactura de bienes utilitarios no tienen análogo en cuanto a performance con las puneñas correspondientes, o directamente no existen. 
Por ejemplo, Chusquea lorentziana. En cuanto a los recursos animales, se trata de valvas de molusco no disponibles en el área puneña.

Volviendo a los recursos vegetales alóctonos, del total de géneros/especies identificados (N: 20), el $30 \%$ son cultígenos, el $50 \%$ silvestres y el $20 \%$ restante, al no poder distinguir si se trata de recursos silvestres o domesticados, se los define como no diferenciados. Es interesante notar que la proporción de cultígenos procedentes de otras áreas del NOA es muy importante; más aún, si se considera el porcentaje de recursos no diferenciados, de los que por lo menos una parte podría llegar a ser cultivado. Por otro lado, la presencia de tales cultígenos está señalando vinculaciones con (así como la existencia de) grupos productores en pisos ecológicos más bajos, sincrónicos a las ocupaciones en Antofagasta de la Sierra ya desde fines del Holoceno medio, en los Valles y quebradas (por ejemplo, Amaranthus caudatus/mantegazzianus) y las Yungas (Canna edulis o Lagenaria sicerarea).

El "área de captación” en relación a la proveniencia de estos insumos es realmente amplio y significativo, ya que incluye, además de distintos sectores de la misma Puna Meridional argentina, zonas de menor altitud del Noroeste Argentino, como los Valles y quebradas mesotermales, las selvas montanas del oriente (Yungas) y la Llanura chaqueña. Se debe incluir, además, la costa del Océano Pacífico (Tabla 6.4). Se destaca que en esta Tabla no se han incluido los recursos vinculados a las ocupaciones de ca.4500 años AP -Chenopodium sp aff. C. quinoa, Zea mays “maíz” y tubérculos / raíces no diferenciados-, que provendrían de otras áreas de la Puna. 
Tabla 6.4. Áreas de procedencia de recursos bióticos alóctonos

\begin{tabular}{|c|c|c|c|c|c|}
\hline Lapso & Recurso & $\begin{array}{c}\text { Valles y } \\
\text { quebradas }\end{array}$ & Yungas & $\begin{array}{c}\text { Llanura } \\
\text { chaqueña }\end{array}$ & $\begin{array}{c}\text { Costa del } \\
\text { Océano } \\
\text { Pacífico }\end{array}$ \\
\hline \multirow[t]{2}{*}{$\begin{array}{l}4700-3000 \\
\text { AP }\end{array}$} & Vegetal & $\begin{array}{l}\text { - Cucurbita sp } \\
\text { - Opuntia sp } \\
\text { - Prosopis sp } \\
\text { - Amarantus caudatus/ } \\
\text { mantegazzianus } \\
\text { "amaranto" }\end{array}$ & $\begin{array}{l}\text { - Chusquea lorentziana } \\
\text { - vaina de Arachis sp. } \\
\text { "maní” } \\
\text { - palmera Acrocomia sp. } \\
\text { - palmera Acrocomia } \\
\text { chunta } \\
\text { - Lagenaria siceraria } \\
\text { "mate” } \\
\text { - Lagenaria sp } \\
\text { - Juglans australis } \\
\text { "nuez” } \\
\text { - Canna edulis “achira” }\end{array}$ & - & - \\
\hline & Fauna & - & - & $\begin{array}{l}\text { - Anodontites } \\
\text { trapezialis }\end{array}$ & $\begin{array}{l}\text { - pelecípodo } \\
\text { marino }\end{array}$ \\
\hline \multirow[t]{2}{*}{$\begin{array}{l}2100-1500 \\
\text { AP }\end{array}$} & Vegetal & $\begin{array}{l}\text { - Prosopis flexuosa } \\
\text { "algarrobo" } \\
\text { - Prosopis alba o chilensis } \\
\text { "algarrobo blanco" } \\
\text { - Prosopis sp “algarrobo" } \\
\text { - Geofroea decorticans } \\
\text { "chañar” } \\
\text { - Opuntia sp } \\
\text { - Amaranthus } \\
\text { caudatus/mantegazzianus } \\
\text { "amaranto" }\end{array}$ & $\begin{array}{l}\text { - Lagenaria siceraria } \\
\text { "mate” } \\
\text { - Acrocomia sp } \\
\text { - Phaseolus sp “poroto” } \\
\text { - Phaseolus vulgaris } \\
\text { "poroto común” } \\
\text { - Canna edulis “achira” }\end{array}$ & - & - \\
\hline & Fauna & - & - & - & - Olivia sp \\
\hline
\end{tabular}

Nota: En casos de recursos que puedan encontrarse en distintos pisos ecológicos, se toma como referente al más cercano a la microrregión.

De la observación de la Tabla 6.4 surge, por otro lado, la destacada continuidad en el aprovisionamiento de recursos vegetales de los Valles y quebradas y de las Yungas, a lo largo de la secuencia considerada.

En cuanto a los contextos de donde se recuperaron los recursos bióticos alóctonos, son de diversa índole, aunque priman los residenciales. En éstos, como es esperable, dominan los elementos comestibles, siguiéndoles en orden de importancia los artefactos vinculados con actividades de subsistencia (por ejemplo, Chusquea lorentziana). Ya en los contextos funerarios o en el conjunto intencional de objetos considerado, adquieren un papel significativo los bienes suntuarios o de prestigio (sonajero sobre Lagenaria sp., por ejemplo).

Se destaca que los recursos bióticos no son los únicos que brindan información sobre situaciones de interacción, otros elementos a considerar son la obtención de rocas distantes y las evidencias de circulación de información. Con respecto a las primeras, refiere al aprovisionamiento de una materia prima en particular, la obsidiana, cuya presencia en el registro arqueológico local es abordada en el Capítulo 8. En cuanto a las segundas, son de diverso tipo. Entre otros aspectos, 
involucra la incorporación de la tecnología cerámica y de artefactos de labranza como las palas y/o azadas o las raederas de módulo grandísimo (Olivera 1992, Escola 2000), así como la circulación de motivos en el arte rupestre y en la cerámica a nivel macrorregional (Aschero y Podestá 1986; Olivera 1992; Podestá y Manzi 1995; Aschero 1998, 1999a). Un claro ejemplo de esto es la presencia de arte rupestre afín a los estilos Kalina-Puripica y Taira-Tulán del desierto del norte de Chile en el sitio de Confluencia (Aschero 1999a, 2005a). Desde los artefactos líticos tallados, especialmente diseños de puntas de proyectil, también se pueden establecer vinculaciones con otras áreas del NOA, lo cual es desarrollado en el Capítulo 9.

A modo de corolario, las evidencias arqueológicas procedentes de los diversos sitios analizados, y la evaluación de sus contextos y cronologías, brindan una clara idea de que el uso de recursos, conocimientos e información de zonas distintas y distantes estaba firmemente establecido en las prácticas económicas y sociales a lo largo del proceso transicional local.

\subsubsection{DESIGUALDAD SOCIAL}

De acuerdo a Aschero (1998, 1999a), en el arte rupestre de la Puna argentina es posible observar diferencias de tamaño y tratamiento -como tocados cefálicos, armas, cabezas-trofeo, adornos pectorales, etc. (cf. Podesta 1986/87)- en los grupos de figuras humanas representados en sitios adscribibles a sociedades agro-pastoriles, que sugieren un orden de importancia o jerarquía. Sin embargo, hay evidencias en la Puna Norte argentina que parecerían indicar la aparición de desigualdad social en momentos más tempranos. Estas se refieren a la presencia de enterratorios con ajuares y a conjuntos de artefactos que incluyen tecnología de prestigio y bienes de riqueza confeccionados tanto sobre insumos locales como provenientes de grandes distancias, de los cuales se infiere un trato no igualitario (Aschero y Yacobaccio 1998/1999, Yacobaccio 2001a).

En Antofagasta de la Sierra, los indicios de inhumaciones son aún escasos y se dista de llegar a conclusiones definitivas. Sin embargo, hay ciertos indicios de interés, vinculados a la presencia de dos enterratorios. El primero, datado en 4510 \pm 100 AP, fue recuperado en el nivel 2b2 del sitio QS3, fechado, a su vez, en 4930 $110 \mathrm{AP}$, y consiste en un fardo funerario conformado por un envoltorio de cuero de camélido atado con un cordel de lana que contiene los restos óseos de un feto humano (Aschero et al. 1991). El segundo, localizado en una oquedad natural (sitio PP11A), con una

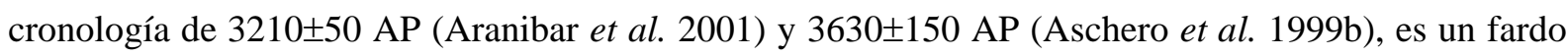
funerario compuesto por una envoltura doble de cuero que contiene un párvulo momificado naturalmente, de hasta 4 meses de vida, acompañado por cuatro cestas; dos externas al fardo, una de ellas con decoración geométrica, y dos internas tapando la cabeza. Se asocian otros elementos tales 
como cordeles de fibras de palmera y un pectoral de valva de Anodontites trapezialis (Aschero et al. 1999a, Rodríguez 2003) (Figura 6.2).

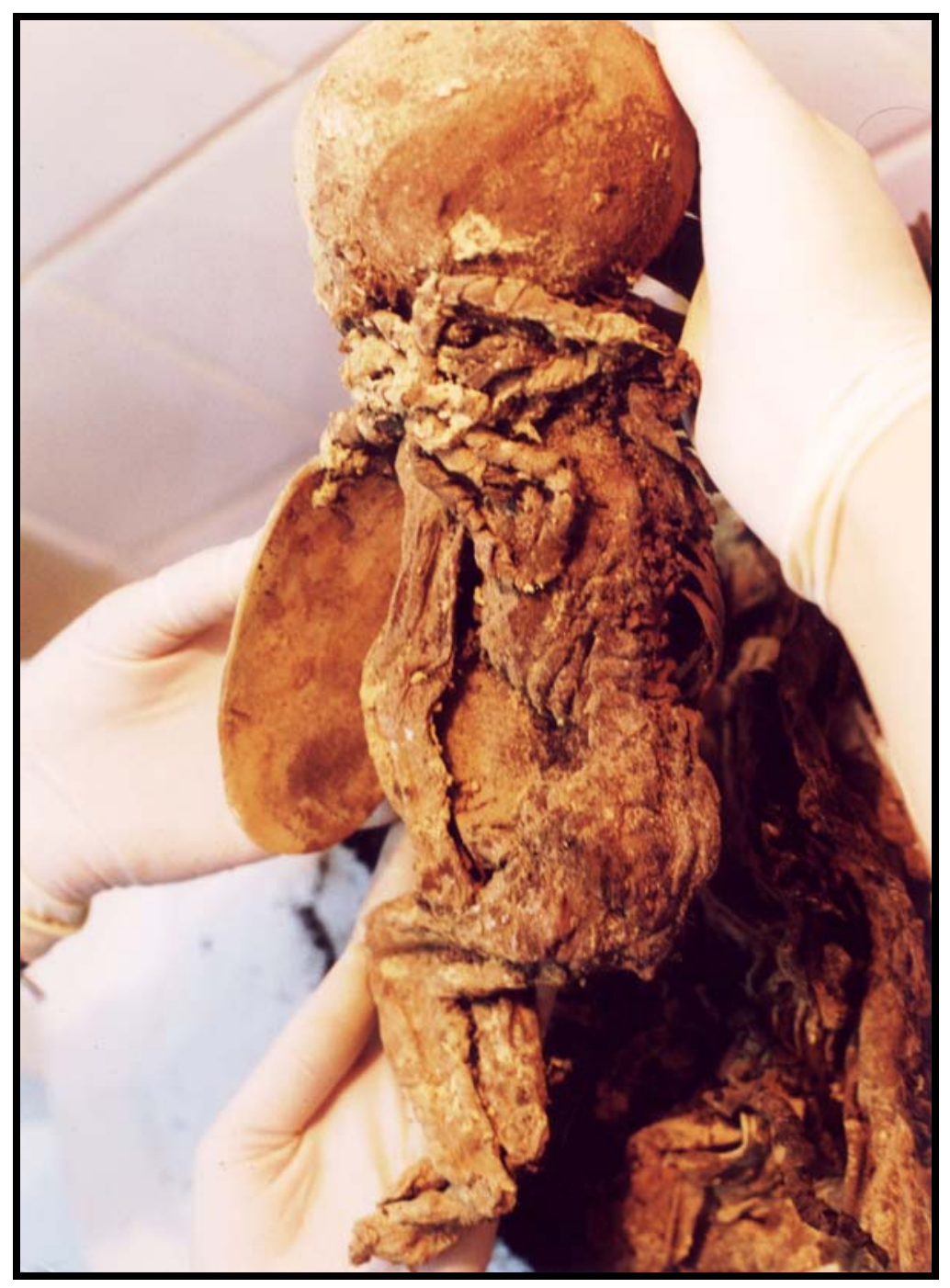

Figura 6.2. El Bebe de la Peña. Sitio PP11A. Nótese la valva de molusco y el cordel de palmera en el cuello (cortesía C. Aschero)

Las características del segundo fardo son relevantes ya que señalarían la posibilidad de presencia de desigualdad. Al tratarse de un párvulo con un ajuar diversificado y con artefactos confeccionados sobre materias primas provenientes de grandes distancias, es probable que dicho individuo (o su familia) poseyera cierto status, aunque no se puede aseverar que su posición social se basara en el linaje.

Ahora bien, al considerar las diferencias cronológicas entre la inhumación de QS3, sin ajuar significativo, y la de PP11A, con las características señaladas, se podría argumentar que en el lapso 5000-3000 AP pudo haberse producido un cambio relacionado con la composición de los ajuares y la presencia de desigualdad que coincide con el proceso observado en otras áreas de los Andes CentroSur. Las evidencias disponibles al respecto en Antofagasta de la Sierra son, por el momento, 
demasiado acotadas como para ser concluyentes, pero su ocurrencia no parecería ser casual, a la luz de los indicadores macrorregionales.

Por otro lado, hasta el momento, no se cuenta con evidencias de obras de construcción a nivel comunitario que pudieran requerir líderes de tiempo completo, y tampoco se han registrado diferencias en las características de los sitios residenciales que puedan ser correlacionadas con diferencias de status. Sin embargo, la técnica de caza colectiva por acecho y uso de parapetos (Aschero y Martínez 2001) vigente para estos momentos podría haber implicado el surgimiento de liderazgos temporarios.

\subsubsection{DENSIDAD POBLACIONAL}

De acuerdo a Yacobaccio (1998), desde los 5000 años AP aproximadamente se incrementan notablemente las evidencias de ocupación humana en la Puna argentina. En Antofagasta de la Sierra esta tendencias se verifica al analizar las cantidades de sitios datados en base a cronologías absolutas y relativas. Al respecto, se observa que la proporción de sitios entre el 9500 y el 5500 AP es considerablemente menor en relación al momento 5500-2000 AP. Pero no sólo es mayor la cantidad de sitios en este último sino que también aumenta el número de sitios con ocupaciones relativamente sincrónicas, lo que podría ser tomado como un indicio indirecto de una mayor densidad poblacional en la microrregión para el lapso abordado. Esta tendencia creciente continúa a partir del 2000 AP, con las ocupaciones agro-pastoriles, de acuerdo a la información recuperada en el fondo de cuenca, sectores intermedios y quebradas de altura, por el equipo de D. Olivera (Olivera 1992, Olivera y Podestá 1993) y en la cuenca media del río Las Pitas, por el equipo de C. Aschero (López Campeny 2001a, López Campeny et al. 2005, Babot 2004a, Babot et al. 2004, Cohen 2005).

Es importante señalar que esta mayor densidad poblacional no significa necesariamente un incremento poblacional, sino que puede ser resultado de la redistribución de la población en un contexto de movilidad reducida en un ambiente de mosaico, definido por la utilización de oasis. Asimismo, la ausencia de asentamientos residenciales grandes en Antofagasta de la Sierra anteriores al 2000 AP, no es un impedimento para considerar una densidad de población relativamente alta, ya que puede responder a un patrón de distribución disperso a nivel microrregional.

Un indicio indirecto de mayor densidad poblacional podría ser la ocurrencia de episodios de caza colectiva, aunque hayan sido discontinuos en el tiempo y en el espacio (Aschero y Martínez 2001). Así, la técnica de caza colectiva por acecho y uso de parapetos, que está registrada en Antofagasta de la Sierra a partir del 7000 AP, implica el uso simultáneo de gran cantidad de parapetos y un número importante de personas integrando las partidas de caza -cazadores y azuzadores-. Esto 
conlleva la obtención de un mayor número de presas, que podría relacionarse con una situación de mayor demanda por parte de grupos sociales más grandes. Debe destacarse, sin embargo, que la puesta en práctica de caza comunal no necesariamente es resultado de tal situación, puesto que es producto de la conjunción de múltiples variables estratégicas, como la eficacia en el sistema técnico, la etología de las piezas y las características del terreno (Ratto 2003).

Para el lapso considerado se cuenta con evidencias de parapetos de piedra asociados a puntas lanceoladas afines a las recuperadas en PCh1.1 en el sitio LC3 (Aschero com pers.). Por otro lado, es probable que los sitios con parapetos QS5 y RG11 (Aschero y Martínez 2001) hayan sido utilizados en este momento, así como otras técnicas de caza individual o colectiva con otros requerimientos topográficos y organizativos.

\subsubsection{RITUAL}

En Antofagasta de la Sierra hay una serie importante de contextos arqueológicos que habrían tenido una función en la esfera de lo simbólico-ritual, tal vez a manera de “ofrendas” (Olivera et al. 2003).

Uno de éstos es el conjunto de Cc1A, datado en $2870 \pm 40$ AP; compuesto por un par de sandalias de cuero de camélido, un sonajero y dos trenzas de pelo humano cortadas intencionalmente. El sonajero se confeccionó empleando diversos materiales. El cuerpo del instrumento está formado por una calabaza (Lagenaria sp) decorada con figuras pirograbadas; la misma está perforada en sus dos extremos para la introducción de los elementos idiófonos en su interior (semillas) y la sujeción del mango (un eje de cuero recubierto de vellón de lana de camélido terminado con capas de trenzas de cabello humano). Para cerrar el orificio superior se empleó una valva de pelecípodo marino, proveniente de la costa del Océano Pacífico (ibid.).

Otro hallazgo es el de la capa 0 (lente $1 \mathrm{x}$ ) de QS3, una cesta decorada que presenta una porción quemada circunscripta a un sector de la parte externa, sin otras asociaciones artefactuales más que un palito de Sálix humboldtiana con un extremo quemado, y vinculada con una depositación de sedimento carbonoso (Rodríguez 1999a). Un fechado de una lente de la capa 2a situada

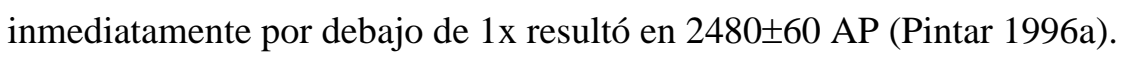

Olivera et al. (2003) incluyen el sitio RG9 como un hallazgo de tipo "ofrenda”. El mismo consta de un fragmento de cesta apoyado en arena suelta con abundantes restos vegetales y faunísticos, alrededor del cual se hallaron plumas de falcónido dispuestas sobre la arena. El conjunto estaba 
parcialmente tapado por una piedra de regular tamaño (Olivera y Podestá 1993). No se cuenta con una cronología absoluta del contexto, por lo que no es segura su correspondencia con el momento abordado.

Un tema sugestivo relacionado con lo ritual es la asociación de distintos géneros de gramíneas, básicamente del género Deyeuxia, con las prácticas funerarias (Rodríguez et al. 2001). Esto se evidencia en los fardos funerarios de la capa 2b2 de QS3 (Aschero et al. 1991, Rodríguez y Rúgolo de Agrasar 1999) y del sitio PP11A (Aschero et al. 1999b, Rodríguez et al. 2003), que yacían sobre camadas de gramíneas que, asimismo, los envolvían y cubrían, respectivamente. Estas camadas se encuentran también en pequeñas oquedades, sin enterratorios, como en el caso del sitio PP11B, asociadas con cordeles (Rodríguez et al. 2003), o en las cercanías de PCh1.3.

Todos los hallazgos, sean "ofrendas” o enterratorios, se caracterizan por ser eventos discretos de depositación y por presentarse en abrigos rocosos u oquedades, en asociación con fuentes de agua y vegetación abundante (Olivera et al. 2003). Un nuevo caso de esto podría ser PCh1.5, un alero bajo roca con abundantes restos de cordelería, restos faunísticos y una serie de rocas anudadas entre si, entre otros materiales arqueológicos. En segundo lugar, implican, en general, la utilización de artefactos con una cierta inversión de trabajo, algunos de los cuales proceden de grandes distancias, o la selección de determinadas especies animales y vegetales con fines específicos, por ejemplo, las gramíneas. En tercer y último lugar, están apareciendo recurrentemente en momentos posteriores al 3500 AP, señalando posiblemente para entonces un incremento de las prácticas rituales.

En consonancia con esto, Aschero (2005b) propone, para el lapso 3500-2500 AP, una estrategia de control social a través de un culto a la fertilidad de los camélidos silvestres y domésticos, en base a la aparición de íconos, a su emplazamiento particular y a lo discreto de su localización espacial. De esta forma, le asigna al sitio Confluencia 1 un papel simbólico ritual, vinculado a la reproducción de las tropas de camélidos (Aschero 2005a). 


\section{CAPÍTULO 7}

\section{DISPONIBILIDAD DE MATERIAS PRIMAS LÍTICAS}

\subsection{MATERIAS PRIMAS PRESENTES EN LA MICRORREGIÓN}

Las fuentes de aprovisionamiento de rocas empleadas para la talla en Antofagasta de la Sierra se caracterizan por su ubicuidad espacial y su destacada disponibilidad, lo cual conformó un conjunto de opciones particulares para la selección y utilización de recursos líticos por los grupos humanos del pasado. Asimismo, en los sitios arqueológicos se encuentran diversas rocas procedentes de fuentes no locales, así como de fuentes no identificadas hasta el momento.

A lo largo del desarrollo de las investigaciones arqueológicas en el área se emplearon una serie de denominaciones basadas en criterios macroscópicos y microscópicos, de tipo petrográfico / mineralógico y químico. Dado que en este trabajo se emplea información de materiales que fueron clasificados en distintos momentos de diferente forma, es necesario generar equivalencias entre las viejas denominaciones y la propuesta en vigencia de Aschero et al.(2002).

Asimismo, se presenta información sumaria sobre la distribución de las fuentes de materias primas líticas conocidas para la microrregión y áreas colindantes del Salar de Antofalla y del Volcán Cueros de Purulla, en base a una compulsa de la bibliografía arqueológica y geológica generada hasta el momento (para un tratamiento exhaustivo ver Aschero et al. 2002). Además, se añaden datos inéditos sobre fuentes y se introducen modificaciones en las denominaciones de las materias primas.

\subsubsection{ACERCA DE LAS DENOMINACIONES DE LAS MATERIAS PRIMAS}

Las denominaciones de las rocas empleadas en la confección de artefactos tallados en Antofagasta de la Sierra (Catamarca) siguieron, en términos generales, dos grandes trayectorias paralelas, coincidiendo con los dos grupos de investigación que trabajaban en distintos sectores de la microrregión, a saber, el grupo de Aschero y colaboradores y el equipo de D. Olivera (Tabla 7.1). 
Tabla 7.1. Denominaciones de materias primas líticas en Antofagasta de la Sierra (tomado de Aschero et al. 2002)

\begin{tabular}{|c|c|c|c|c|c|c|c|c|c|}
\hline $\begin{array}{c}\text { Aschero et } \\
\text { al } 1991\end{array}$ & $\begin{array}{l}\text { Aschero et } \\
\text { al 1993-94 }\end{array}$ & $\begin{array}{c}\text { Pintar } \\
1996\end{array}$ & $\begin{array}{c}\text { Martínez } \\
1997\end{array}$ & $\begin{array}{c}\text { Toselli } \\
1998\end{array}$ & $\begin{array}{c}\text { Manzi } \\
1999\end{array}$ & $\begin{array}{c}\text { Escola } \\
1991\end{array}$ & $\begin{array}{c}\text { Escola } \\
1990- \\
1992 \\
\end{array}$ & $\begin{array}{c}\text { Escola } \\
2000\end{array}$ & $\begin{array}{l}\text { Aschero } \\
\text { et al. } 2002\end{array}$ \\
\hline Basalto 1 & DV 1 & D. 1 & Da 1 & $\mathrm{Db} 1$ & Dv 1 & & $\begin{array}{c}\text { Basalto } \\
\text { var } 1\end{array}$ & $\begin{array}{c}\text { Basalto } \\
\text { var } 1\end{array}$ & Vc 1 \\
\hline Basalto 2 & DV 2 & D. 2 & Da 2 & $\mathrm{Db} 2$ & Dv 2 & $\begin{array}{c}\text { Basalto } \\
\text { var.C }\end{array}$ & $\begin{array}{c}\text { Basalto } \\
\text { var C }\end{array}$ & $\begin{array}{c}\text { Basalto var } \\
\text { C }\end{array}$ & Vc 2 \\
\hline Basalto 3 & DV 3 & D. 3 & Da 3 & $\mathrm{Db} 3$ & Dv 3 & $\begin{array}{c}\text { Sin } \\
\text { homólogo }\end{array}$ & $\begin{array}{c}\text { Sin } \\
\text { homólogo }\end{array}$ & $\begin{array}{c}\text { Sin } \\
\text { homólogo }\end{array}$ & Vc 3 \\
\hline Basalto 4 & DV 4 & D. 4 & Da 4 & $\mathrm{Db} 4$ & Dv 4 & $\begin{array}{c}\text { Basalto } \\
\text { var. A }\end{array}$ & $\begin{array}{c}\text { Basalto } \\
\text { var. A }\end{array}$ & $\begin{array}{c}\text { Basalto var } \\
\text { A }\end{array}$ & Vc 4 \\
\hline Basalto 5 & DV 5 & D. 5 & Da 5 & Db 5 & Dv 5 & & \begin{tabular}{|c|} 
Vidrio \\
Vv. var. 2 \\
\end{tabular} & $\begin{array}{c}\text { Vidrio Vv. } \\
\text { var..2 } \\
\end{array}$ & Vc 5 \\
\hline Basalto 6 & DV 6 & D. 6 & Da 6 & $\mathrm{Db} 6$ & Dv 6 & $\begin{array}{c}\text { Basalto } \\
\text { var. E }\end{array}$ & $\begin{array}{c}\text { Vidrio } \\
\text { Vv. var. } 1 \\
\end{array}$ & $\begin{array}{c}\text { Vidrio Vv. } \\
\text { var. } 1 \\
\end{array}$ & Vc 6 \\
\hline Basalto 7 & DV 7 & D. 7 & Da 7 & Db7 & Dv 7 & $\begin{array}{c}\text { Sin } \\
\text { homólogo }\end{array}$ & $\begin{array}{c}\text { Sin } \\
\text { homólogo } \\
\end{array}$ & $\begin{array}{c}\text { Sin } \\
\text { homólogo }\end{array}$ & Vv 1 \\
\hline \multirow[t]{3}{*}{ Basalto 8} & DV 8 & D. 8 & & Db 8 & Dv 8 & $\begin{array}{c}\text { Basalto } \\
\text { var. B y D }\end{array}$ & $\begin{array}{c}\text { Basalto } \\
\text { var. B }\end{array}$ & $\begin{array}{c}\text { Basalto var. } \\
\text { B }\end{array}$ & Vc 7 \\
\hline & & & & Db 9 & & & & $\begin{array}{c}\text { Vidrio Vv. } \\
\text { var. } 3 *\end{array}$ & Vv 2 \\
\hline & & & & & & $\begin{array}{c}\text { Pórfiro } \\
\text { andesítico }\end{array}$ & $\begin{array}{c}\text { Basalto } \\
\text { var. X }\end{array}$ & $\begin{array}{c}\text { Basalto var. } \\
\text { X }\end{array}$ & Vc 8 \\
\hline \multirow[t]{8}{*}{ Obsidiana } & Obsidiana & Obsidiana & Obsidiana & Obsidiana & Obsidiana & Obsidiana & Obsidiana & Obsidiana & Ob 1 \\
\hline & & & & & & & & $\begin{array}{c}\text { Vidrio Vv. } \\
\text { no dif. }\end{array}$ & $\begin{array}{c}\text { Ob 2a y } \\
2 b\end{array}$ \\
\hline & & & & & & & & $\begin{array}{c}\text { Vidrio Vv. } \\
\text { no dif. + } \\
\end{array}$ & Ob 3 \\
\hline & & Cuarcita & & Cuarcita & Cuarcita & Cuarcita & Cuarcita & Cuarcita & $\overline{C c}$ \\
\hline & & Cuarzo & & Cuarzo & Cuarzo & & & Cuarzo & $\mathbf{Q z}$ \\
\hline & & Opalo & & Sílice & Opalo & Opalo & Opalo & Opalo & \multirow{4}{*}{ Si } \\
\hline & & \multirow[t]{3}{*}{ Chert } & & $\begin{array}{c}\text { Chert } \\
\text { (cal. } \\
\text { silicif.) }\end{array}$ & & & & & \\
\hline & & & & & & & & Calcedonia & \\
\hline & & & & & & & & Sílice & \\
\hline
\end{tabular}

Referencias : DV y Dv : Dacita variedad; D. y Da. : Dacita ; Db : Dacita-Basalto ; Basalto var. : Basalto variedad ; Vidrio Vv. var. Vidrio Volcánico variedad ; Vidrio Vv. no dif. : Vidrio Volcánico No Diferenciado ; Ca. Silicif. : Calcedonia Silicificada.

Nota:

* Se aclara que la discriminación del vidrio volcánico var. 3 es posterior al trabajo de Escola (2000)

+ (Escola dato inédito 2001). Se dispuso en dicha columna por razones de espacio.

$\mathrm{Al}$ analizar las distintas propuestas de determinaciones petrográficas de las rocas volcánicas en el contexto del primer grupo, se observa que las mismas fueron identificadas inicialmente como basaltos (Pintar y Aschero 1988, Aschero et al. 1991). Posteriormente, un análisis de componentes realizado por E. Pintar en los EEUU indicó que las muestras de rocas correspondían a dacitas con altos valores de Potasio (Aschero et al. 1993-94) y no a basaltos como previamente se había determinado. Por este motivo, trabajos posteriores utilizaron el término dacita para referirse a las rocas ígneas de la cuenca del Río Las Pitas y zonas adyacentes (Pintar 1996a, Martínez 1997, Manzi 1999).

En 1998, Toselli realizó nuevos análisis de muestras de Antofagasta de la Sierra, debido a que las determinaciones de rocas volcánicas logradas un tiempo antes por Pintar en los EEUU, ya 
mencionadas, y por N. Ratto en Buenos Aires, arrojaron distintas denominaciones para las mismas rocas (Ratto y Nestiero 1994). Es así que la descripción textural le permitió establecer que se trataba de andesitas, en su mayor parte. Sin embargo, siguió considerando la nomenclatura de las materias primas vigente hasta ese momento, definiéndolas como dacitas/basaltos y abreviándolas $D b$. Es necesario aclarar que al emplear estos términos no fue su intención referirse a rocas intermedias, desde el punto de vista composicional, entre dacitas y basaltos, sino simplemente continuar empleando las disímiles denominaciones anteriores, para no generar confusiones (Toselli op cit.).

Pasando ya al equipo de D. Olivera, Escola señala en un trabajo de 1991 la presencia de cinco variedades de basalto y un pórfiro andesítico, identificadas a partir de caracteres macroscópicos en muestras de mano por el Dr. Killmurray, de la Facultad de Ciencias Naturales y Museo (UNLP). Posteriormente, Escola (1990-92) modificó su clasificación anterior, diferenciando variedades de basalto y de vidrio volcánico. Trabajos ulteriores de la autora continuaron empleando dicho esquema (Escola 1999, 2000), aunque debe agregarse al mismo una variedad más de vidrio volcánico, no considerada en los trabajos citados (Escola dato inédito 2001).

De lo dicho anteriormente, se desprende que se han definido a las materias primas ígneas de Antofagasta de la Sierra con nombres diversos, con los consecuentes problemas a la hora de realizar comparaciones intra e inter autores. Por ejemplo, las mismas rocas fueron caratuladas con diferentes nombres, a saber, basalto, dacita, andesita y, en algunas muestras, vidrio volcánico [aquellos interesados en la descripción petrográfica de cortes delgados de muestras de rocas de la región pueden recurrir a Toselli (1998) y Escola (2000, 2003)].

Esta falta de consenso llevó a la necesidad de desarrollar una clasificación de materias primas que superara los problemas citados y que fuera operativa desde una perspectiva arqueológica. En función de esto, Aschero et al. (2002) proponen diferenciar a las rocas ígneas presentes en la microrregión de Antofagasta de la Sierra, así como aquellas procedentes de fuera de la misma, en base a la proporción de vidrio presente en las muestras, generándose dos grandes grupos: el primero, formado por rocas con un porcentaje de vidrio mayor al $80 \% \mathrm{y}$, el segundo, con porcentajes menores a dicha cifra (tomado de Teruggi $1980^{1}$ ). Esto tendría su correlato en calidades diferenciales de las rocas para la talla (con respecto a este tema ver, por ejemplo, Nami 1992, Aragón y Franco 1997).

Asimismo, esta distinción es relevante arqueológicamente, ya que permite separar los vidrios volcánicos, que tienen una gran circulación regional -en especial la obsidiana- (Yacobaccio et al.

\footnotetext{
${ }^{1}$ En esta propuesta se han agrupado las categorías de Teruggi (1980) correspondientes a valores de vidrio menores a $80 \%$ y mantenido la categoría correspondiente a valores de vidrio mayores a $80 \%$.
} 
2004), del resto de las rocas volcánicas que son empleadas más localmente, en un contexto microrregional. Se destaca que el análisis textural sobre cortes delgados que permitió medir la proporción de vidrio en las muestras, fue realizado por el geólogo Pedro Larrahona de la Facultad de Ciencias Naturales e Instituto Miguel Lillo, de la Universidad Nacional de Tucumán (Larrahona 2001).

De esta forma, se discriminan los vidrios volcánicos con nombres específicos (como el caso de los vidrios volcánicos ácidos como la obsidiana -Ob-) junto con los vidrios volcánicos no diferenciados - Vv- (aquellos con más del 80\% de vidrio pero donde no es posible establecer si son ácidos o básicos), de las rocas volcánicas con proporciones de vidrio menores al 80\%. Debido a que no hay ningún termino adecuado en el campo de la geología que denomine a esta última categoría, se decidió optar por la noción de vulcanita -Vc- para denotar a este conjunto de rocas, si bien es cierto que, en su sentido estrictamente geológico, el término refiere al conjunto total de rocas ígneas volcánicas (Bates y Jackson 1980), es decir, incluyen a las obsidianas y otros vidrios volcánicos que son aquí discriminados.

Ahora bien. al abordar las rocas silíceas ${ }^{2}$ se observan los mismos problemas que para las rocas ígneas. Así, por ejemplo, se utilizaron distintos términos para referir a la misma roca, como es el caso de los términos chert (Pintar 1996a), sílice (Elkin 1992, Toselli 1998) y ópalo (Escola 1990-1992, 1991, 2000; Manzi 1999); o bien se definieron rocas silíceas distintas, como plantea Pintar (1996a) al discriminar ópalo de chert, Toselli (1998) al separar sílice de chert (o calcedonia silicificada) o Escola (2000) al discriminar ópalo, calcedonia y sílice. Esta carencia de consenso lleva a postular la categoría sílice -Si- como vocablo a usar, ya que es un término general que permite incluir todas las variedades de rocas sedimentarias silíceas de grano fino (para una discusión sobre el tema ver Luedtke 1992). Se destaca que es necesario profundizar en las identificaciones de muestras de estas rocas, de forma de lograr un panorama más fidedigno.

Otras materias primas como la cuarcita -Cc- o el cuarzo -Qz- no presentan problemas nomenclaturales al analizar la literatura arqueológica local.

\subsubsection{DISTRIBUCIÓN DE LAS MATERIAS PRIMAS}

Al analizar la distribución espacial de las 19 materias primas líticas identificadas por Aschero et al. (2002), empleadas en la confección de artefactos tallados, puede observarse que la microrregión

\footnotetext{
${ }^{2}$ Cabe aclarar que se desconoce el origen geológico de las rocas silíceas (pe. sedimentario, metasedimentario o producto de precipitación de soluciones silíceas) dado que no hay estudios al respecto y al momento no es relevante para la problemática arqueológica.
} 
cuenta con una oferta destacada, ya que las fuentes son ubicuas, variadas y las rocas y minerales presentes abundantes (Tabla 7.2).

Tabla 7.2. Distribución de fuentes de materias primas líticas (tomado de Aschero et al. 2002)

\begin{tabular}{|c|c|c|c|}
\hline Sector & Microambiente & Fuente & Materias primas presentes \\
\hline \multirow{18}{*}{$\begin{array}{c}\text { Sector centro-este de la } \\
\text { microrregión de Antofagasta de la } \\
\text { Sierra }\end{array}$} & \multirow[t]{5}{*}{$\begin{array}{l}\text { Quebradas de } \\
\text { Altura }\end{array}$} & Pampa Oeste & $\begin{array}{l}\text { Vc } 1 \text { (dominante), Vc 2, Vc 3, Vc } \\
4 \text {, Vc 5, Vc 7, Vv1 } \\
\end{array}$ \\
\hline & & Pampa Este & $\begin{array}{l}\text { Vc } 1 \text { (dominante), Vc 2, Vc 3, Vc } \\
4, \text { Vc 5, Vc } 6\end{array}$ \\
\hline & & Pampa Norte & Vc 1 \\
\hline & & $\begin{array}{l}\text { Vega de Quebrada } \\
\text { Seca }\end{array}$ & Vc 1 \\
\hline & & Las Trancas & $\mathrm{Si}$ \\
\hline & \multirow[t]{6}{*}{$\begin{array}{c}\text { Sectores } \\
\text { Intermedios }\end{array}$} & PPZAC & Vc 1 (dominante), Vc 5, Vc 7 \\
\hline & & Farallón Salamanca & Vc 1 \\
\hline & & $\begin{array}{c}\text { Terraza de Punta de } \\
\text { la Peña }\end{array}$ & Cc, Si \\
\hline & & $\begin{array}{l}\text { Rinconada de las } \\
\text { Trampas }\end{array}$ & Cc \\
\hline & & Cantera Inca de Onix & Vc 2 \\
\hline & & PCzZAC & Vc 2 \\
\hline & \multirow[t]{7}{*}{$\begin{array}{l}\text { Fondo de } \\
\text { Cuenca }\end{array}$} & $\begin{array}{c}\text { La Torre / Punta del } \\
\text { Pueblo } \\
\end{array}$ & Cc \\
\hline & & Confluencia & Cc \\
\hline & & Pista Vieja & $\mathrm{Qz}$ \\
\hline & & Campo Farfán & Cc, Qz \\
\hline & & Bajo del Coypar II & Cc \\
\hline & & $\begin{array}{c}\text { Los Negros Sector } \\
\text { Norte } \\
\end{array}$ & Vc 4, Vc 8 \\
\hline & & $\begin{array}{l}\text { Los Negros Sector } \\
\text { Sur }\end{array}$ & Vc 4, Cc \\
\hline \multirow{2}{*}{$\begin{array}{l}\text { Sector norte de la microrregión de } \\
\text { Antofagasta de la Sierra }\end{array}$} & & Drenaje Río Punilla & Vc 1 \\
\hline & & Quebrada Miriguaca & Vv 2 \\
\hline $\begin{array}{l}\text { Sector oeste de la microrregión de } \\
\text { Antofagasta de la Sierra }\end{array}$ & & Río Calalaste & Vc 1 \\
\hline Salar de Antofalla & & Ona-Las Cuevas & Ob 1 \\
\hline Volcán Cueros de Purulla & & Cueros de Purulla & Ob 2 a y b \\
\hline Desconocida & & Desconocida & Ob 3 \\
\hline Desconocida & & Desconocida & Vv 1 \\
\hline Desconocida & & Desconocida & Vv 2 \\
\hline
\end{tabular}

Aquellos interesados en una caracterización de la distribución de cada una de las materias primas ver el análisis pormenorizado realizado por Aschero et al. (2002). 
El área de estudio presenta ocho variedades de vulcanita, cuarzo, cuarcita y sílice, que se califican como locales, con distancias mínimas menores al kilómetro y máximas no mayores a los 25 kilómetros (Tabla 7.3). En términos generales, estas materias primas pueden ser obtenidas en fuentes distribuidas en un radio no mayor a 15 km, tomando como centro a la localidad de Punta de la Peña sobre el Río Las Pitas, a unos 8 km al Este de la población actual de Antofagasta de la Sierra.

Tabla 7.3. Distancias entre abrigos rocosos y fuentes de materias primas líticas locales (modificado de Martínez y Hocsman 2001)

\begin{tabular}{|c|c|c|c|c|c|c|c|c|c|c|}
\hline \multirow{2}{*}{\multicolumn{2}{|c|}{\begin{tabular}{|c|} 
Distancias \\
expresadas en \\
kilómetros
\end{tabular}}} & \multicolumn{9}{|c|}{ CANTERAS } \\
\hline & & \multirow{2}{*}{$\begin{array}{c}\text { QS } \\
\text { ZAC } \\
1,30\end{array}$} & \multirow{2}{*}{$\begin{array}{l}\text { PO } \\
5,00\end{array}$} & \multirow{2}{*}{$\begin{array}{c}\mathbf{P E} \\
1,40\end{array}$} & \multirow{2}{*}{$\begin{array}{c}\mathbf{P N} \\
1,10\end{array}$} & \multirow{2}{*}{$\begin{array}{c}\text { PP } \\
\text { ZAC } \\
6,90\end{array}$} & \multirow{2}{*}{$\begin{array}{c}\text { PCz1 } \\
\text { ZAC } \\
9,10\end{array}$} & \multirow{2}{*}{$\begin{array}{l}\text { Onix } \\
13,85\end{array}$} & \multirow{2}{*}{$\begin{array}{c}\begin{array}{c}\text { Los } \\
\text { Negros }\end{array} \\
21,45\end{array}$} & \multirow{2}{*}{$\begin{array}{c}\mathbf{C c} \\
14,75\end{array}$} \\
\hline SITIOS & QS3 & & & & & & & & & \\
\hline & PP4-PP9 & 4,75 & 2,80 & 8,85 & 8,25 & 0,60 & 7,45 & 14,50 & 16,10 & 7,75 \\
\hline & $\begin{array}{l}\text { PCh1.1- } \\
\text { PCh1.3 }\end{array}$ & 5,30 & 3,30 & 9,35 & 8,70 & 1,10 & 7,70 & 14,75 & 15,90 & 7,30 \\
\hline \multirow{9}{*}{$\begin{array}{l}\mathbf{C} \\
\mathbf{A} \\
\mathbf{N} \\
\mathbf{T} \\
\mathbf{E} \\
\mathbf{R} \\
\mathbf{A} \\
\mathbf{S}\end{array}$} & $\begin{array}{c}\text { QS } \\
\text { ZAC }\end{array}$ & & 2,90 & 2,45 & 2,00 & 4,30 & 6,90 & 11,30 & 16,60 & 10,90 \\
\hline & $\begin{array}{l}\text { QS } \\
\text { PO }\end{array}$ & & & 6,40 & 6,00 & 2,20 & 6,10 & 12,70 & 17,00 & 9,70 \\
\hline & $\begin{array}{l}\text { QS } \\
\text { PE }\end{array}$ & & & & 1,10 & 8,30 & 10,00 & 14,10 & 22,50 & 16,10 \\
\hline & $\begin{array}{l}\text { QS } \\
\text { PN }\end{array}$ & & & & & 7,20 & 10,20 & 14,80 & 22,50 & 15,70 \\
\hline & $\begin{array}{c}\text { PP } \\
\text { ZAC }\end{array}$ & & & & & & 7,10 & 14,10 & 16,30 & 8,10 \\
\hline & $\begin{array}{l}\text { PCz1 } \\
\text { ZAC }\end{array}$ & & & & & & & 7,10 & 12,90 & 7,90 \\
\hline & Onix & & & & & & & & 14,60 & 12,70 \\
\hline & $\begin{array}{c}\text { Los } \\
\text { Negros }\end{array}$ & & & & & & & & & 7,10 \\
\hline & Cc & & & & & & & & & \\
\hline
\end{tabular}

Referencias:

- Abrigos rocosos con vestigios arqueológicos estratificados: QS3: Quebrada Seca 3; PP4: Punta de la Peña 4; PP9: Punta de la Peña 9; PCh1.1: Peñas Chicas 1.1; PCh1.3: Peñas Chicas 1.3.

- Canteras de materias primas locales: QS ZAC: Zona de Aprovisionamiento y Cantera de Quebrada Seca, PO: Pampa Oeste, PE: Pampa Este, PN: Pampa Norte; PP ZAC: Zona de Aprovisionamiento y Cantera de Punta de la Peña; PCz1 ZAC: Zona de Aprovisionamiento y Cantera de Peñas de la Cruz 1; Onix: Sector de Cantera de Onix.

Las fuentes reconocidas en la microrregión (N: 21) cubren las probables procedencias de las 11 variedades de rocas/minerales locales utilizadas. De estas 21 fuentes 10 que son potenciales (45,8 \%) y 11 son canteras efectivas (52,38\%) (Figura 7.1). 


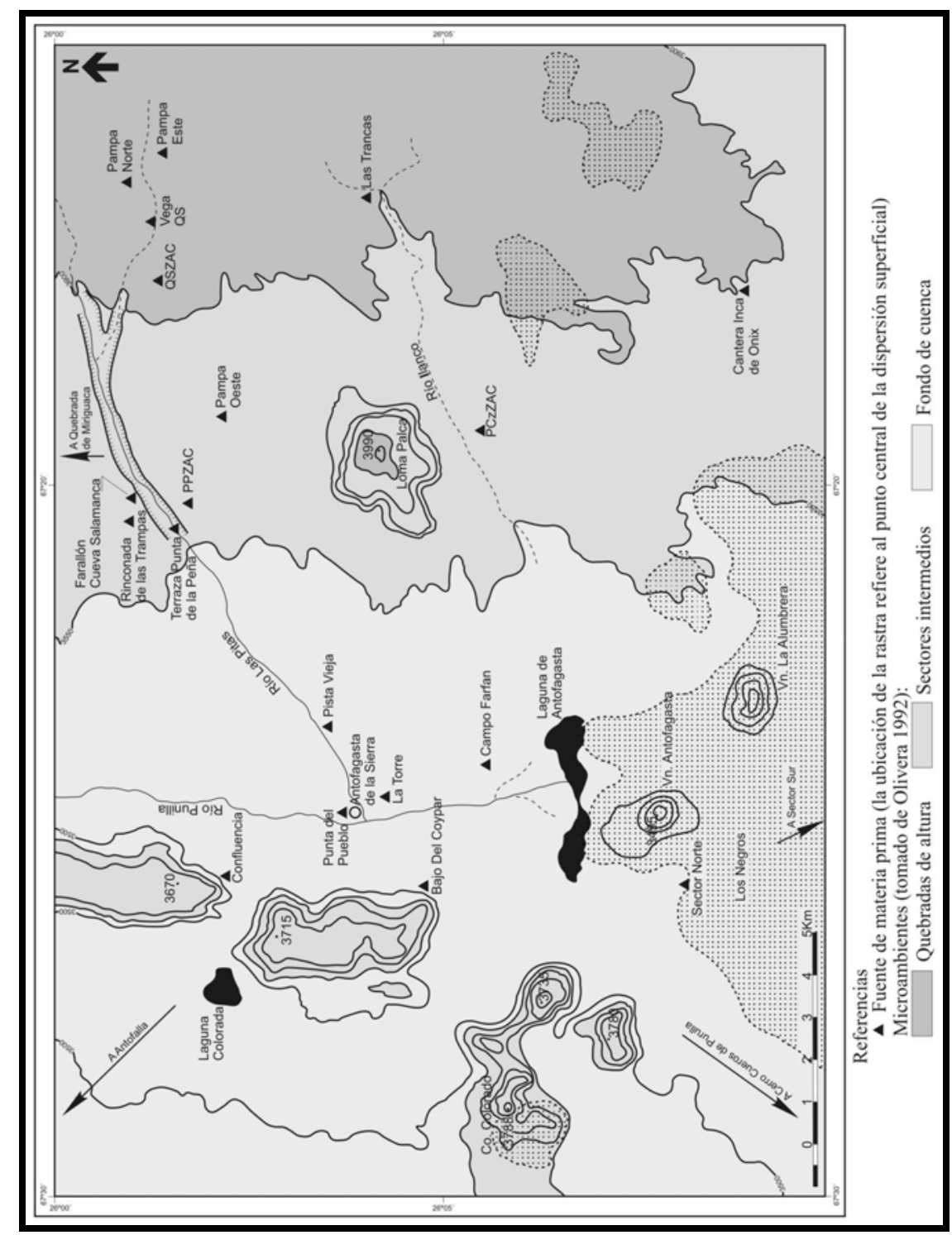

Figura 7.1. Distribución de fuentes de materias primas líticas en el sector centro-este de la microrregión de Antofagasta de la Sierra (tomado de Aschero et al. 2002: Mapa 2) 
Las transectas y recorridas realizadas a lo largo de las vías más conocidas de circulación, recurren en mostrar que la variedad 1 de las vulcanitas (Vc1) es la de más amplia distribución en la microrregión, como hallazgos aislados o agrupamiento de nódulos en las "pampas" que median entre el cauce del Río Ilanco, Las Pitas y el Miriguaca, en el curso alto del Punilla, aguas arriba de Paicuqui, y en el curso alto del Río Calalaste, entre Cueva Colorada y Cueva Blanca, en el paso más utilizado hacia el Salar de Antofalla. De todas formas, en el estado actual de las prospecciones del área de estudio, es claro que la más alta concentración de sitios se ubica a lo largo de los Río Las Pitas y Miriguaca y del curso inferior del Punilla (ver Capítulo 5). Coinciden en esta distribución con los dos cauces que mantienen su curso de agua a lo largo del año y con el sector del fondo de cuenca del Río Punilla, entre la confluencia del Calalaste y la Laguna de Antofagasta.

Al parecer, es esta conjunción de recursos líticos de buena calidad para la talla con la disponibilidad de cursos de agua permanente, de la presencia de pasturas naturales de vegas en distintas altitudes o de otras fuentes alternativas de aprovisionamiento de agua para las especies de camélidos silvestres o domésticos, como manantiales y lagunas -ubicadas en un perfil de unos $30 \mathrm{~km}$, transversal al eje del Río Punilla- los que han jugado un papel discriminante para la mayor concentración de poblaciones en este sector de $15 \mathrm{~km}$ de radio, tomando en cuenta las características desérticas que presentan y habrían presentado los ambientes periféricos.

Dos materias primas, por su parte, los vidrios volcánicos 1 y 2, no registran hasta el momento fuente de procedencia; sin embargo, sería factible sostener que son no locales, dado que no se las ha identificado durante las prospecciones intensivas realizadas en la microrregión. Análisis realizados en el marco de esta investigación han permitido definir al vidrio volcánico 1 como una obsidiana, por lo que esta materia prima es tratada aquí como tal (ver punto siguiente 7.1.3. Análisis de procedencia de obsidiana).

En cuanto a las obsidianas, en la Puna Meridional Argentina se han identificado cuatro fuentes de aprovisionamiento, a saber Ona-Las Cuevas, Cueros de Purulla, Chascón y Valle Ancho (Escola 2000, Yacobaccio et al. 2002, Yacobaccio et al. 2004). Se destaca que las tres primeras se encuentran ubicadas en el Departamento de Antofagasta de la Sierra. A los fines de esta investigación, interesan particularmente las fuentes de Ona-Las Cuevas y Cueros de Purulla, de mayor relevancia en la región.

La primera de estas se encuentra localizada unos $80 \mathrm{~km}$ al noroeste de la microrregión, mientras que la segunda está situada unos $70 \mathrm{~km}$ al sureste de la misma (por una caracterización de las mismas ver: Escola 2000, 2004b). Las distancias involucradas lleva a considerarlas materias primas no locales (Figura 7.2). 


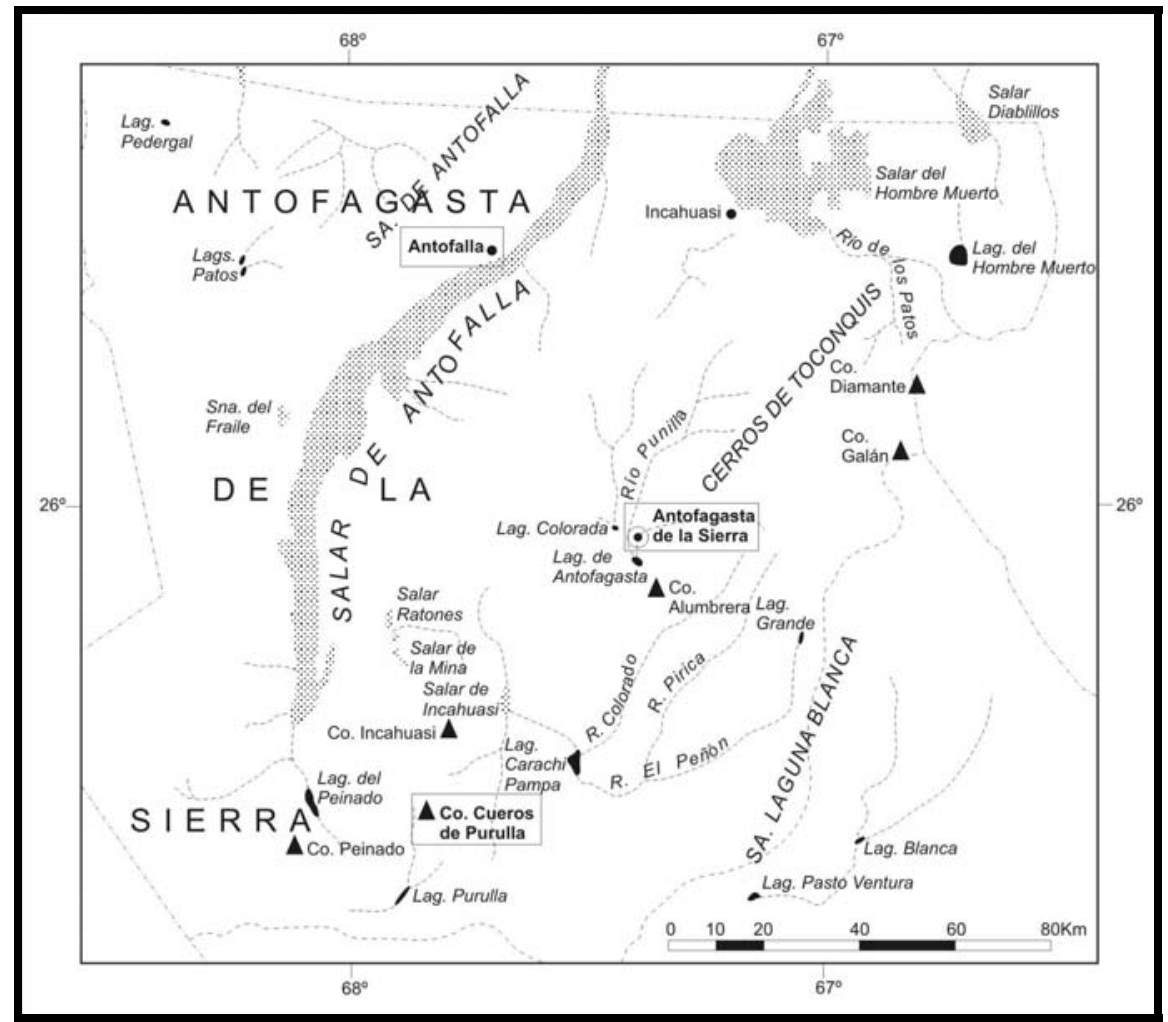

Figura 7.2. Ubicación de Antofalla y Cueros de Purulla (modificado de Aschero et al. 2002: Mapa 1)

Asimismo, es importante mencionar que análisis de procedencia de obsidiana en muestras arqueológicas, han identificado ocho posibles fuentes adicionales de las cuales se desconoce aún su ubicación geográfica, denominadas Fuentes desconocidas A, B, C, E, F, G, H, K y M (Escola 2004b). El hecho de que las muestras provienen de sitios de la provincia de Catamarca llevaría a considerar que las fuentes se encuentran en algún lugar del sector puneño de dicha provincia (ibid.). Pese a que no se han encontrado aún dichas fuentes, dadas las prospecciones intensivas en función de la identificación de fuentes de aprovisionamiento de materias primas líticas en Antofagasta de la Sierra, sería factible postular que se trata de fuentes no locales al considerar la microrregión.

Con respecto a la Ob3 definida por Aschero et al. (2002), hasta el momento no se ha ubicado la fuente, debiéndose establecer si se corresponde con alguna de las fuentes desconocidas ya denominadas o si se trata de una nueva. Se destaca que macroscópicamente se diferencian claramente de las obsidianas amarillas de Alto Tocomar y Quirón, localizadas en la Puna salteña (Yacobaccio et al. 2002, Yacobaccio et al. 2004).

Finalmente, hay una serie de rocas que se encuentran representados en los conjuntos en muy baja proporción, de diversa índole, como areniscas o vulcanitas no diferenciadas. A dichas materias primas se las engloba bajo el rótulo de "Otros". Se postula un origen local, dada la geología microrregional. 


\subsubsection{ANÁLISIS DE PROCEDENCIA DE OBSIDIANAS}

La obsidiana presenta una serie de elementos minoritarios con concentraciones menores al 1\%, denominados comúnmente "elementos traza”. Cada formación geológica o parte de la misma se define por concentraciones específicas de tales elementos traza. De esta forma, esta huella química permite una caracterización geoquímica de las fuentes de obsidiana, a partir de la cual se puede identificar el afloramiento de origen de los artefactos confeccionados sobre esta roca (Escola 2000).

En este marco, se analizaron una serie de artefactos de obsidiana $(\mathrm{N}: 13)$ recuperados en estratigrafía en sitios de la microrregión con cronología absoluta entre los 4500 y los 3500 años AP. Estos son: PP4 (N: 4), Peñas Chicas 1.1 (N: 5) y Peñas Chicas 1.3 (N: 4). La selección de las muestras se realizó sobre la base de variaciones en atributos macroscópicos, a saber: color, bandeamiento, presencia/ausencia de inclusiones, etc.

Se destaca que los estudios de proveniencia de obsidiana en Antofagasta de la Sierra se habían centrado en el lapso 2100-700 AP, a partir de los trabajos pioneros de Escola (Vázquez y Escola 1995; Escola 2000, 2004b; Yacobaccio et al. 2004), por lo que los datos aquí suministrados arrojan luz sobre la utilización de la obsidiana hacia fines del Holoceno Medio, momento que, hasta ahora, no había sido abordado sistemáticamente ${ }^{3}$.

Específicamente, se realizaron análisis de activación neutrónica (NAA) en el Laboratorio de Arqueometría del Missouri University Research Reactor (MURR). Por información de detalle sobre los procedimientos respectivos ver Cobean et al. (1991) y Glascock et al. (1988). Se emplearon dos procedimientos analíticos para medir las concentraciones de elementos. Todas las muestras fueron sometidas al primer procedimiento, el cual utiliza una irradiación y un decaimiento cortos de forma de medir 7 elementos de vida corta ( $\mathrm{Al}, \mathrm{Ba}, \mathrm{Cl}$, Dy, K, Mn y Na). Luego de examinar los datos generados por este proceso para identificar posibles grupos químicos, se seleccionó una serie de muestras para ser sometidas a irradiación larga, mediante 22 elementos (Ba, La, Lu, Nd, Sm, U, Yb, Ce, Co, Cs, Eu, Fe, Hf, Rb, Sb, Sc, Sr, Ta, Tb, Th, Zn y Zr). Dicha elección se realizó en base a si los especimenes respondían a grupos desconocidos o bien si los resultados de la irradiación corta eran inseguros. En la Tabla 7.4 se presentan las concentraciones de elementos obtenidas en las 13 muestras de artefactos de obsidiana.

\footnotetext{
${ }^{3}$ Como antecedente puede señalarse el análisis de procedencia de dos instrumentos de obsidiana del Holoceno Medio de QS3 realizado por Pintar (1996a). Se destaca que el Holoceno Medio para esta autora comprendía el lapso 7500-4500 AP.
} 
Tabla 7.4. Concentraciones de elementos en partes por millón (ppm) - NAA

\begin{tabular}{|c|c|c|c|c|c|c|c|c|c|c|c|c|c|c|}
\hline $\begin{array}{c}\mathbf{N}^{\mathbf{o}} \\
\text { muestra }\end{array}$ & $\mathbf{B A}$ & $\mathbf{L A}$ & $\mathbf{L U}$ & $\mathbf{N D}$ & $\mathbf{S M}$ & $\mathbf{U}$ & $\mathbf{Y B}$ & $\mathbf{C E}$ & $\mathbf{C O}$ & $\mathbf{C S}$ & $\mathbf{E U}$ & $\mathbf{F E}$ & HF & $\mathbf{R B}$ \\
\hline 81 & 560,8 & 23,2999 & 0,3935 & 15,9958 & 3,7058 & 10,8315 & 1,1422 & 45,9416 & 0,2348 & 11,3499 & 0,5396 & 4809,5 & 3,0547 & 219,77 \\
\hline 82 & 509,5 & 0,0000 & 0,0000 & 0,0000 & 0,0000 & 0,0000 & 0,0000 & 0,0000 & 0,0000 & 0,0000 & 0,0000 & 0,0 & 0,0000 & 0,00 \\
\hline 83 & 574,4 & 0,0000 & 0,0000 & 0,0000 & 0,0000 & 0,0000 & 0,0000 & 0,0000 & 0,0000 & 0,0000 & 0,0000 & 0,0 & 0,0000 & 0,00 \\
\hline 84 & 625,0 & 56,1116 & 0,4799 & 37,6764 & 6,5846 & 6,5835 & 2,2987 & 104,8218 & 0,7330 & 7,3340 & 1,1703 & 9573,5 & 4,8084 & 171,89 \\
\hline 85 & 589,4 & 0,0000 & 0,0000 & 0,0000 & 0,0000 & 0,0000 & 0,0000 & 0,0000 & 0,0000 & 0,0000 & 0,0000 & 0,0 & 0,0000 & 0,00 \\
\hline 86 & 106,5 & 16,7519 & 0,8341 & 28,3559 & 10,0220 & 30,8921 & 1,6464 & 54,8706 & 0,0000 & 92,3049 & 0,0000 & 2967,3 & 4,7619 & 1100,46 \\
\hline 87 & 240,3 & 19,9708 & 0,3137 & 20,5867 & 5,9315 & 53,7010 & 1,9151 & 47,6837 & 0,0877 & 94,4297 & 0,1231 & 3239,3 & 4,8224 & 645,97 \\
\hline 88 & 481,0 & 0,0000 & 0,0000 & 0,0000 & 0,0000 & 0,0000 & 0,0000 & 0,0000 & 0,0000 & 0,0000 & 0,0000 & 0,0 & 0,0000 & 0,00 \\
\hline 89 & 570,3 & 0,0000 & 0,0000 & 0,0000 & 0,0000 & 0,0000 & 0,0000 & 0,0000 & 0,0000 & 0,0000 & 0,0000 & 0,0 & 0,0000 & 0,00 \\
\hline 90 & 121,4 & 16,4674 & 0,9210 & 28,1547 & 10,2897 & 33,0012 & 2,0350 & 54,0152 & 0,0000 & 90,2616 & 0,0000 & 2905,3 & 5,1330 & 1077,38 \\
\hline 91 & 612,6 & 42,2639 & 0,2677 & 31,2990 & 5,4311 & 6,9974 & 0,9001 & 81,4952 & 5,7475 & 12,5332 & 0,9186 & 19436,5 & 5,2263 & 221,54 \\
\hline 92 & 93,8 & 16,7379 & 0,8141 & 27,9009 & 9,9743 & 31,2331 & 1,7050 & 55,5535 & 0,0000 & 91,9047 & 0,0000 & 2891,9 & 4,5338 & 1095,46 \\
\hline 93 & 86,3 & 10,6466 & 0,9070 & 15,3488 & 6,8473 & 18,1909 & 3,5692 & 29,2337 & 0,1074 & 38,7279 & 0,1433 & 4024,5 & 3,3604 & 480,23 \\
\hline
\end{tabular}

\begin{tabular}{|c|c|c|c|c|c|c|c|c|c|c|c|c|c|c|}
\hline $\begin{array}{c}\mathbf{N}^{\circ} \\
\text { muestra }\end{array}$ & SB & SC & SR & TA & TB & TH & ZN & ZR & AL & CL & DY & $\mathbf{K}$ & MN & NA \\
\hline 81 & 0,1811 & 1,8283 & 147,09 & 2,0319 & 0,3392 & 21,4680 & 34,03 & 159,08 & 70378,1 & 687,4 & 1,7685 & 39266,9 & 391,45 & 25767,9 \\
\hline 82 & 0,0000 & 0,0000 & 0,00 & 0,0000 & 0,0000 & 0,0000 & 0,00 & 0,00 & 67884,8 & 663,0 & 2,1710 & 40121,0 & 391,32 & 25834,3 \\
\hline 83 & 0,0000 & 0,0000 & 0,00 & 0,0000 & 0,0000 & 0,0000 & 0,00 & 0,00 & 73169,4 & 455,8 & 2,1433 & 40300,3 & 402,23 & 26172,3 \\
\hline 84 & 0,3517 & 3,1521 & 330,36 & 2,3851 & 0,6943 & 19,5504 & 52,70 & 186,43 & 74262,1 & 271,7 & 4,9642 & 38092,0 & 606,29 & 28033,6 \\
\hline 85 & 0,0000 & 0,0000 & 0,00 & 0,0000 & 0,0000 & 0,0000 & 0,00 & 0,00 & 72677,6 & 579,2 & 1,9277 & 38914,4 & 401,86 & 26624,5 \\
\hline 86 & 1,6335 & 13,3170 & 0,00 & 16,1151 & 1,1686 & 9,3723 & 107,56 & 218,19 & 72506,5 & 145,6 & 6,0404 & 33361,6 & 1845,84 & 33820,0 \\
\hline 87 & 3,8298 & 5,2630 & 0,00 & 6,3209 & 0,2072 & 22,5875 & 42,79 & 520,53 & 67853,5 & 53,0 & 1,0501 & 35117,3 & 860,02 & 31746,3 \\
\hline 88 & 0,0000 & 0,0000 & 0,00 & 0,0000 & 0,0000 & 0,0000 & 0,00 & 0,00 & 68706,2 & 566,3 & 2,6668 & 38310,7 & 407,29 & 26923,2 \\
\hline 89 & 0,0000 & 0,0000 & 0,00 & 0,0000 & 0,0000 & 0,0000 & 0,00 & 0,00 & 69315,2 & 517,7 & 1,8777 & 41639,4 & 408,63 & 27685,2 \\
\hline 90 & 1,5661 & 13,1686 & 0,00 & 15,9413 & 1,2272 & 9,5898 & 104,39 & 230,77 & 70053,7 & 53,8 & 5,6794 & 28255,5 & 1832,70 & 33534,2 \\
\hline 91 & 0,3023 & 5,8271 & 322,38 & 1,0008 & 0,3692 & 24,9678 & 72,77 & 232,14 & 78038,5 & 691,4 & 2,1446 & 36155,4 & 305,57 & 27631,8 \\
\hline 92 & 1,6410 & 13,2676 & 0,00 & 16,0451 & 1,1742 & 9,3867 & 112,10 & 236,27 & 72116,7 & 84,6 & 4,9821 & 33589,0 & 1904,32 & 33414,6 \\
\hline 93 & 0,7196 & 8,1255 & 0,00 & 3,9490 & 1,2199 & 16,9783 & 48,14 & 196,97 & 72806,7 & 118,7 & 8,0732 & 36488,2 & 830,93 & 32189,5 \\
\hline
\end{tabular}


La evaluación estadística de los datos se efectuó en MURR por medio de diagramas de dispersión bivariados. Este tipo de análisis es una vía clave para lograr asignaciones no ambiguas de artefactos con la fuente en regiones con escasas fuentes potenciales (Glascock et al. 1998).

A continuación se presentan tres diagramas de dispersión bidimensionales con el objeto de visualizar distinciones de fuentes en los artefactos (Figura 7.3, Figura 7.4 y Figura 7.5).

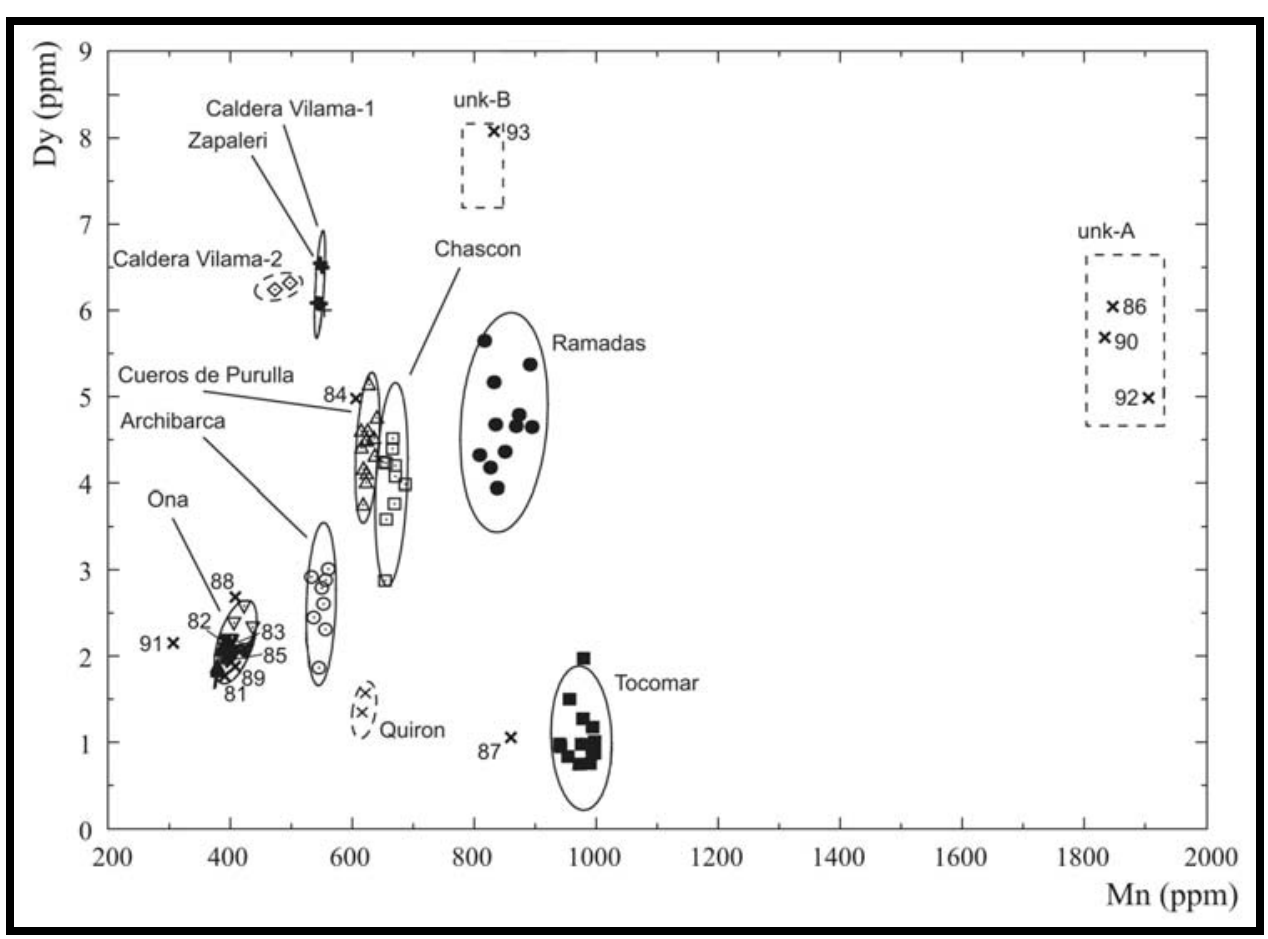

Figura 7.3. Diagrama divariado de concentraciones de elementos - Dy/Mn

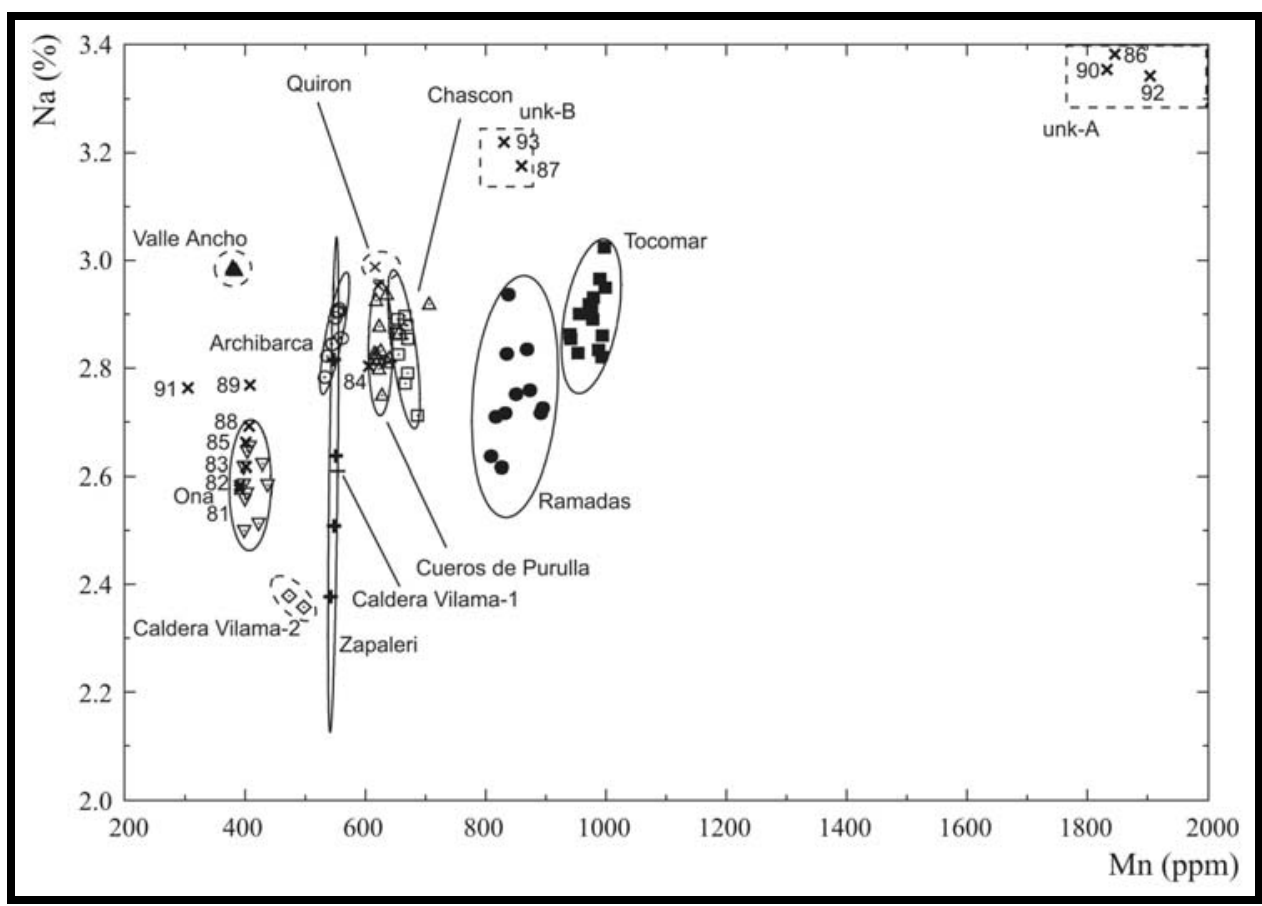

Figura 7.4. Diagrama divariado de concentraciones de elementos - Na/Mn 


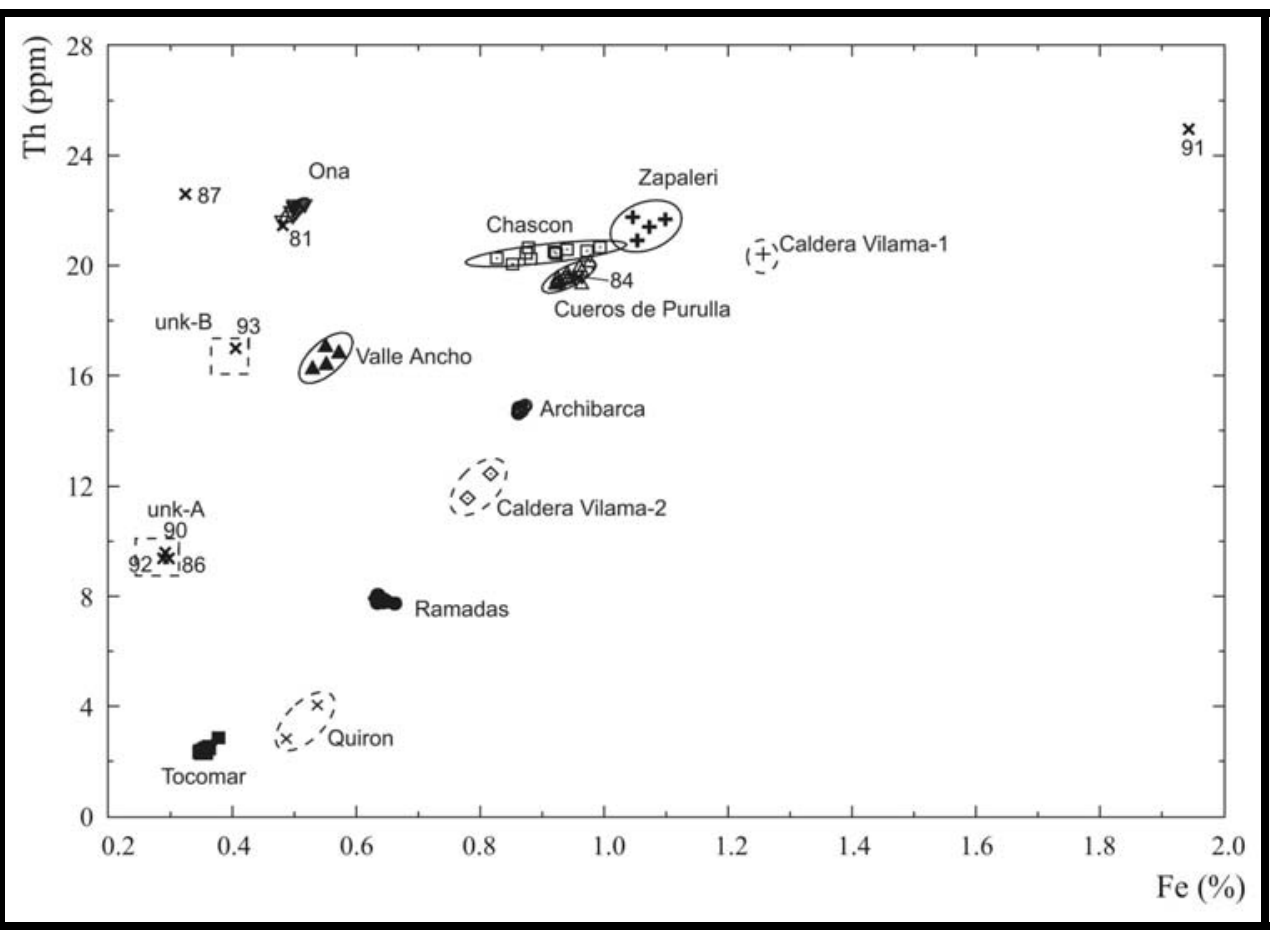

Figura 7.5. Diagrama divariado de concentraciones de elementos - Th/Fe

A partir de los gráficos precedentes es posible advertir que además de estar representadas las fuentes de Ona y Cueros de Purulla, hay una serie de grupos composicionales que implican la utilización de fuentes desconocidas diversas, a saber: Fuentes desconocidas A, B, C y G (Tabla 7.5).

Tabla 7.5. Sitios arqueológicos y fuentes de procedencia (4500-3200 AP)

\begin{tabular}{|l|l|l|l|}
\hline \multicolumn{1}{|c|}{$\begin{array}{c}\text { No de } \\
\text { muestra }\end{array}$} & \multicolumn{1}{|c|}{ Sitio } & Nombre de la fuente & Código de la fuente \\
\hline 81 & Punta de la Peña 4 & Ona & ONA \\
\hline 82 & Punta de la Peña 4 & Ona & ONA \\
\hline 83 & Punta de la Peña 4 & Ona & ONA \\
\hline 84 & Punta de la Peña 4 & Cueros de Purulla & CPA \\
\hline 85 & Peñas Chicas 1.3 & Ona & ONA \\
\hline 86 & Peñas Chicas 1.3 & Fuente desconocida A & unk-A \\
\hline 87 & Peñas Chicas 1.3 & Fuente desconocida C & unk-C \\
\hline 88 & Peñas Chicas 1.3 & Ona & ONA \\
\hline 89 & Peñas Chicas 1.1 & Ona & ONA \\
\hline 90 & Peñas Chicas 1.1 & Fuente desconocida A & unk-A \\
\hline 91 & Peñas Chicas 1.1 & Fuente desconocida G & unk-G \\
\hline 92 & Peñas Chicas 1.1 & Fuente desconocida A & unk-A \\
\hline 93 & Peñas Chicas 1.1 & Fuente desconocida B & unk-B \\
\hline
\end{tabular}


Como puede apreciarse en la Tabla 7.4, el 46,15\% de los artefactos de los sitios arqueológicos muestreados provienen de la fuente de Ona, el 7,69\% a Cueros de Purulla y el 46,15\% restante a las fuentes desconocidas citadas. Dado el importante porcentaje de fuentes desconocidas en la muestra, estos resultados tienen una serie de implicaciones que deben ser tenidas en cuenta durante el tratamiento de los datos en las determinaciones macroscópicas de tipo de materia prima lítica. Esto se debe a que hay mayor variabilidad en las fuentes de obsidiana reconocidas por análisis de proveniencia que las fuentes de obsidiana definidas en Aschero et al. (2002).

Los análisis realizados, por otra parte, permitieron identificar al Vidrio volcánico 1 (muestra $\mathrm{N}^{\circ} 93$ correspondiente al sitio PCh1.1) como proveniente de la fuente desconocida B. A partir de esta información se considera a esta materia prima como una obsidiana. Cabe destacar que con esto es posible correlacionar macroscópicamente una fuente desconocida con una materia prima particular.

Cabe destacar que hay una serie de obsidianas grises oscuras a negras, recuperadas mayormente en artefactos formatizados, que microscópicamente son claramente distintas a las restantes, tanto conocidas como desconocidas. Si bien no se han enviado todavía muestras de forma de identificar su procedencia, es indudable su carácter de obsidiana “desconocida”, pudiendo proceder de más de una fuente, dada la variabilidad existente.

Al considerar la diferenciación de las obsidianas en muestras de mano y su correlato por NAA, es evidente que artefactos de fuente desconocida pueden subsumirse dentro de la fuente de Ona (Ob1 sensu Aschero et al. 2002). A su vez, no hay forma confiable de distinguir macroscópicamente a la Ob3 de otras obsidianas; al mismo tiempo, no se ha realizado análisis de proveniencia sobre la misma (lo cual se instrumentará en el corto plazo), por lo que no es posible vincularla con ningún grupo composicional conocido. Por otra parte, la obsidiana de Cueros de Purulla no presenta problemas en su determinación macroscópica. Esto lleva, por consiguiente, a la necesidad de modificar la clasificación de obsidianas vigente. A continuación se realiza una propuesta que será empleada en esta investigación ${ }^{4}$ :

ObA: comprende la obsidiana de Ona-Las Cuevas (Ob1), más aquellas obsidianas que, siendo de fuente desconocida (A, C y G), no pueden diferenciarse macroscópicamente de la primera, y la Ob3. Evidentemente, esta categoría adolece del problema de la inclusión de un número importante de fuentes distintas en un único conjunto (aunque de acuerdo a los análisis realizados la obsidiana de Ona-Las Cuevas sería la mayoritaria en cuanto a su representación). Lamentablemente no se vislumbra mejor solución por el momento.

\footnotetext{
${ }^{4}$ Se espera sea mejorada a la brevedad, de forma de poder correlacionar adecuadamente artefactos en muestra de mano con fuentes identificadas.
} 
ObB: define a las obsidianas de Cueros de Purulla, tal como lo especifican Aschero et al. (2002) y Escola (2004b).

ObC: corresponde macroscópicamente al Vidrio volcánico 1, definido como obsidiana desconocida B por los análisis de procedencia.

ObD: incluye obsidianas grises oscuras a negras, muy vidriosas, que no poseen identificación por huella química.

En cuanto a la identificación como locales o no locales de dichas obsidianas, las cuatro categorías se consideran no locales. En el caso de la ObB esto no es problemático, pero si en la ObA, la ObC y la ObD, ya que las tres incluyen una serie de fuentes que aún no han sido identificadas. Al respecto, se considera que, dadas las prospecciones realizadas, es muy posible que las mismas se encuentren fuera del radio de $25 \mathrm{~km}$ señalado. 


\section{CAPÍTULO 8}

\section{APROXIMACIÓN GENERAL A LOS CAMBIOS EN LA TECNOLOGÍA LÍTICA DURANTE LA TRANSICIÓN}

\subsection{CARACTERÍSTICAS GENERALES DE LAS MUESTRAS}

El conjunto lítico de QS3, correspondiente a los niveles 2b1 a 2b5, está formado por 111 piezas formatizadas, en las cuales se han definido 261 filos y puntas (morfología parcial) y piezas de morfología global (ver en Apéndice II punto II.2.1. Lista tipológica del sitio Quebrada Seca 3) ${ }^{1}$. La muestra de núcleos, por su parte, consiste en 6 piezas. En cuanto a los desechos de talla, se emplea información édita e inédita procedente de distintos autores para los distintos niveles considerados. Así, el nivel 2 cuenta con 612 lascas, con un Número Mínimo de Desechos² -NMD-, de 316 individuos (Manzi 1999). El nivel 3 consta de un NMD de 838 lascas (Pintar 1996a). A su vez, el nivel 4 está formado por 5273 desechos, con un NMD de 3210 piezas (Aschero et al. 1993-94). Finalmente, la muestra del nivel 2b5 está constituida por un NMD de 1556 artefactos en función de 2714 piezas totales (Manzi 1999). Cabe notar que no se cuenta con información referida al nivel 1.

En cuanto al sitio PP4, se utiliza en este capítulo información correspondiente a materiales recuperados en la campaña realizada en el año 1999. Se debe discriminar entre la capa 5(6), por un lado, y las capas 4 a 5(5), por el otro. De esta forma, la capa 5(6) consta de 2 artefactos formatizados, uno con un filo (de morfología parcial) y una pieza de morfología global (ver en Apéndice II punto II.2. Lista tipológica del sitio Punta de la Peña 4 -5(6)-. No se registran núcleos. No se dispone información de desechos de talla para esta capa. Por otra parte, en las capas restantes, tomadas en conjunto, se han analizado 76 piezas que definen 121 filos y puntas y piezas de morfología global (ver en Apéndice II punto II.3. Lista tipológica del sitio Punta de la Peña 4 -4 a 5(5)-), un núcleo (se emplea, asimismo, la muestra de núcleos recuperada en el año 1996, formada por 11 piezas) y un NMD de 1186 lascas (Tabla 8.1).

\footnotetext{
${ }^{1}$ Para una descripción del armado y funcionamiento de las listas tipológicas ver en el Apéndice II.

${ }^{2}$ El total mínimo real de desechos constituidos por la sumatoria de lascas enteras y fracturadas con talón (Aschero et al. 1993-94).
} 
Tabla 8.1. Estado de fragmentación en desechos de talla. Sitio PP4

\begin{tabular}{|c|c|}
\hline $\begin{array}{c}\text { ESTADO DE } \\
\text { FRAGMENTACIÓN }^{*}\end{array}$ & $\mathbf{N}$ \\
\hline LENT & 320 \\
\hline LFCT & 866 \\
\hline LFST & 2136 \\
\hline INDI & 161 \\
\hline TOTAL & 3483 \\
\hline
\end{tabular}

* En base a la propuesta de clasificación de Bellelli (1991)

En lo que respecta al sitio PCh1.3, los artefactos formatizados y los núcleos analizados proceden de las dos campañas realizadas hasta el momento, contándose con 141 piezas formatizadas que constituyen 233 filos, puntas y piezas de morfología global (ver en Apéndice II punto II.2.4. Lista tipológica del sitio Peñas Chicas 1.3) y 3 núcleos. La muestra de desechos de talla corresponde a la campaña de Septiembre de 2002 y está formada por 2096 lascas, con un NMD de 760 (Tabla 8.2).

Tabla 8.2. Estado de fragmentación en desechos de talla. Sitio PCh1.3

\begin{tabular}{|c|c|}
\hline $\begin{array}{c}\text { ESTADO DE } \\
\text { FRAGMENTACIÓN }^{*}\end{array}$ & N \\
\hline LENT & 255 \\
\hline LFCT & 505 \\
\hline LFST & 1294 \\
\hline INDI & 42 \\
\hline TOTAL & 2096 \\
\hline
\end{tabular}

* En base a la propuesta de clasificación de Bellelli (1991)

El sitio PCh1.1, por su parte, consta de 160 artefactos formatizados, que comprenden 292 filos, puntas o piezas de morfología global (ver en Apéndice II punto II.2.5. Lista tipológica del sitio Peñas Chicas 1.1). Se cuenta, por otra parte, con 12 núcleos y con 608 desechos de talla; su NMD es de 323 (Tabla 8.3) Asimismo, se emplea información tecnológica sobre desechos de este sitio (NMD: 1179 piezas) generada por Pintar (1996a: 231-232). 
Tabla 8.3. Estado de fragmentación en desechos de talla. Sitio PCh1.1

\begin{tabular}{|c|c|}
\hline $\begin{array}{c}\text { ESTADO DE } \\
\text { FRAGMENTACIÓN }^{*}\end{array}$ & N \\
\hline LENT & 124 \\
\hline LFCT & 199 \\
\hline LFST & 238 \\
\hline INDI & 47 \\
\hline TOTAL & 608 \\
\hline
\end{tabular}

* En base a la propuesta de clasificación de Bellelli (1991)

Por su parte, la muestra del sitio PP9, que incluye la estructura 3 del Sector I y la estructura 2 del Sector III en sus capas 4 a 6, está formada por 19 artefactos formatizados, que definen 43 filos, puntas y piezas de morfología global (ver en Apéndice II punto II.2.6. Lista tipológica del sitio Punta de la Peña 9), y 241 desechos de talla, con un NMD de 133 individuos (Tabla 8.4). No se han recuperado núcleos.

Tabla 8.4. Estado de fragmentación en desechos de talla. Sitio PP9

\begin{tabular}{|c|c|}
\hline $\begin{array}{c}\text { ESTADO DE } \\
\text { FRAGMENTACIÓN }^{*}\end{array}$ & N \\
\hline LENT & 51 \\
\hline LFCT & 82 \\
\hline LFST & 98 \\
\hline INDI & 10 \\
\hline TOTAL & 241 \\
\hline
\end{tabular}

* En base a la propuesta de clasificación de Bellelli (1991)

Finalmente, para el sitio CChM1 se ha utilizado información édita en inédita generada por P. Escola. Así, la muestra de artefactos formatizados es de 197 piezas (ver en Apéndice II punto II.2.7. Lista tipológica del sitio Casa Chávez Montículos 1), la de núcleos 18 y la de desechos de talla 1230, con un NMD de 674 (Escola 2000). Asimismo, se emplean datos sobre instrumentos y desechos de obsidiana publicados por Escola (2004b).

\subsection{UTILIZACIÓN DE MATERIAS PRIMAS LÍTICAS}

Al abordar la disponibilidad de materias primas líticas en la microrregión de Antofagasta de la Sierra (Capítulo 7), se pudo observar que la misma está caracterizada por una oferta destacada de materias primas líticas de muy buena calidad para la talla. Este hecho imprimió una serie de 
características peculiares a la secuencia arqueológica local en lo que respecta a la utilización de rocas para la confección de artefactos líticos.

Para abordar esto se propone una clasificación de las materias primas líticas en función de las distancias de obtención de las mismas:

A. Materias primas locales: refieren a aquellas rocas situadas entre 0 y $25 \mathrm{~km}$ de los sitios considerados.

Dentro de las mismas se discrimina entre:

A.1. Inmediatas: rocas que se encuentran a una distancia menor o igual a $2 \mathrm{~km}$.

A.2. Mediatas: materias primas disponibles a más de $2 \mathrm{~km}$ y a menos de $25 \mathrm{~km}$. A su vez, dichas rocas se dividen en:

A.2.1. Mediatas cercanas: localizadas entre 2 y $10 \mathrm{~km}$.

A.2.2. Mediatas lejanas: situadas a más de $10 \mathrm{~km}$ y a menos de $25 \mathrm{~km}$.

A.3. No diferenciadas: rocas en las que se puede establecer su carácter local pero en las que no es posible discernir si se trata de materias primas inmediatas o mediatas.

B. Materias primas no locales: rocas disponibles a más de $25 \mathrm{~km}$ de los sitios abordados.

La calificación de cada roca como inmediata o mediata para cada uno de los sitios va a variar según el caso. De esta forma, los sitios considerados cuentan con la siguiente disponibilidad de rocas (Tabla 8.5):

Tabla 8.5. Clasificación de las rocas en función de las distancias a los sitios considerados

\begin{tabular}{|c|c|c|c|c|}
\hline \multicolumn{2}{|c|}{ MATERIA PRIMA } & QS3 & $\begin{array}{c}\text { PP4, PCh1.3, PCh1.1, } \\
\text { PP9 }\end{array}$ & CChM1 \\
\hline LOCAL & INMEDIATA & $\begin{array}{c}\text { Vc1, Vc3, Vc5, Vc6, } \\
\text { Vc7 }\end{array}$ & Vc1, Vc5, Vc7, Cc & Cc \\
\cline { 2 - 5 } & $\begin{array}{c}\text { MEDIATA } \\
\text { CERCANA }\end{array}$ & Vc2, Cc & Vc2, Vc3, Vc6 & Vc2, Vc4, Vc8 \\
\cline { 2 - 6 } & $\begin{array}{c}\text { MEDIATA } \\
\text { LEJANA }\end{array}$ & Vc4, Vc8 & Vc4, Vc8 & $\begin{array}{c}\text { Vc1, Vc3, Vc5, } \\
\text { Vc6, Vc7 }\end{array}$ \\
\cline { 2 - 6 } & $\begin{array}{c}\text { NO } \\
\text { DIFERENCIADA }\end{array}$ & Si, Otras & Si, Otras & Si, Otras \\
\hline NO LOCAL & $\begin{array}{c}\text { ObA, ObB, ObC, } \\
\text { ObD, Vv2 }\end{array}$ & $\begin{array}{c}\text { ObA, ObB, ObC, } \\
\text { ObD, Vv2 }\end{array}$ & $\begin{array}{c}\text { ObA, ObB, ObC, } \\
\text { ObD, Vv2 }\end{array}$ \\
\hline
\end{tabular}

Como es esperable en una situación de ubicuidad relativa de materias primas, los grupos humanos que ocuparon el área de estudio en el lapso abordado utilizaron en forma sistemática la amplia gama de rocas locales, lo cual se evidencia al tener en cuenta las materias primas en artefactos formatizados (Tabla 8.6) y desechos de talla (Tabla 8.7). Por ejemplo, en el GC1 sólo la Vc1 y la Vc2 
tienen una representación del 41,28\% y 33,94\%, respectivamente, en el instrumental y del 50,75\% y $33,81 \%$ en los desechos de talla. Tal tendencia se ve reafirmada al considerar los restantes grupos cronológicos.

Tabla 8.6. Materias primas en artefactos formatizados por sitio arqueológico

\begin{tabular}{|c|c|c|c|c|c|c|}
\hline \multirow{2}{*}{$\begin{array}{l}\text { MATERIA } \\
\text { PRIMA }\end{array}$} & \multirow{2}{*}{$\begin{array}{l}\text { GC1 } \\
\text { QS3 }\end{array}$} & \multicolumn{3}{|c|}{ GC2 } & \multicolumn{2}{|c|}{ GC3 } \\
\hline & & PP4 & PCh1.3 & PCh1.1 & PP9 & CChM1 \\
\hline Vc1 & 45 & 31 & 74 & 102 & 17 & - \\
\hline Vc2 & 37 & 11 & 18 & 23 & - & 8 \\
\hline Vc3 & 2 & 4 & 1 & 2 & 1 & - \\
\hline Vc4 & 8 & - & 2 & 4 & 1 & 86 \\
\hline Vc5 & 7 & - & 3 & 5 & - & - \\
\hline Vc6 & - & - & - & - & - & 3 \\
\hline Vc7 & 3 & 3 & 4 & 4 & - & 29 \\
\hline Vc8 & - & - & - & - & 3 & $*$ \\
\hline Vv2 & - & - & - & - & - & - \\
\hline ObA & - & 20 & 12 & 11 & 7 & 58 \\
\hline ObB & 1 & 1 & 5 & - & - & \\
\hline $\mathrm{ObC}$ & 2 & 2 & 6 & 6 & - & - \\
\hline ObD & - & 1 & 1 & - & - & - \\
\hline Cc & - & 1 & - & 2 & - & 3 \\
\hline $\mathrm{Si}$ & - & 2 & 2 & 1 & - & 6 \\
\hline Otros & 4 & - & 3 & - & - & 4 \\
\hline Total & 109 & 76 & 131 & 160 & 29 & 197 \\
\hline
\end{tabular}

Nota: GC1: formado por el sitio QS3 exclusivamente. QS3: no se incluyeron dos puntas de proyectil reclamadas ya que no se eligieron por la materia prima sino por el diseño. CChM1: Los datos de cantidad de instrumentos por materia prima provienen de Escola (2000). Se incluyeron calcedonias, ópalos y sílices diferenciados por Escola (2000) bajo la denominación global de sílice. * Se destaca la presencia de 150 fragmentos y una pieza entera de palas y/o azadas en CCHM1, pero el altísimo grado de fragmentación de la muestra hace que la muestra no sea considerada representativa 
Tabla 8.7. Materias primas en desechos de talla por sitio arqueológico

\begin{tabular}{|c|c|c|c|c|c|c|}
\hline \multirow{2}{*}{$\begin{array}{l}\text { MATERIA } \\
\text { PRIMA }\end{array}$} & \multirow{2}{*}{$\begin{array}{c}\text { GC1 } \\
\text { QS3 }\end{array}$} & \multicolumn{3}{|c|}{ GC2 } & \multicolumn{2}{|c|}{ GC3 } \\
\hline & & PP4 & PCh1.3 & PCh1.1 & PP9 & CChM1 \\
\hline Vc1 & 3857 & 341 & 373 & 193 & 70 & 2 \\
\hline Vc2 & 2390 & 156 & 71 & 87 & 2 & 20 \\
\hline Vc3 & 405 & 69 & 40 & 4 & 4 & - \\
\hline Vc4 & 27 & 26 & 7 & 4 & 48 & 227 \\
\hline Vc5 & 230 & 1 & 90 & 5 & 1 & 6 \\
\hline Vc6 & 64 & - & 14 & - & - & 2 \\
\hline Vc7 & - & 173 & 84 & 24 & - & 75 \\
\hline Vc8 & - & - & - & - & 4 & 177 \\
\hline Vv2 & - & 16 & 2 & - & - & - \\
\hline ObA & 79 & 328 & 43 & - & 4 & 132 \\
\hline ObB & - & 4 & 14 & 2 & - & \\
\hline $\mathrm{ObC}$ & 15 & 28 & 11 & 2 & - & - \\
\hline ObD & - & 1 & - & - & - & - \\
\hline Cc & - & 39 & 1 & 2 & - & 15 \\
\hline $\mathrm{Si}$ & - & 4 & 10 & - & - & 11 \\
\hline Otros & 11 & - & - & - & - & 7 \\
\hline Total & 7078 & 1186 & 760 & 323 & 133 & 674 \\
\hline
\end{tabular}

Nota: GC1: formado exclusivamente por el sitio QS3. QS3: 2b2: Manzi (1999, Apéndice: Tabla 6); 2b3: Pintar (1996a: 224; Appendix A, Table A); 2b4: Aschero et al. (1993-94: 196; Cuadro 1); 2b5: Manzi (1999, Apéndice: Tabla 6). PCh1.1: los conteos por materia prima se ha armado en función de resultados de Pintar (1996a: 231-232; Appendix A, Table N, O, P y Q) y de datos propios. CChM1: Los datos provienen de Escola (2000). Dicha autora no contaba en ese momento con una diferenciación macroscópica en los artefactos entre las obsidianas de ONA y de Cueros de Purulla, por lo que aquí se engloban en uno sólo los casilleros correspondientes. Por otra parte, la categoría "Otros" aquí utilizada incluye el Basalto Var. 2 (sin correlato en la clasificación de rocas empleada), cuarzo y materias primas diversas dentro del rótulo de "Otros" definido por Escola en el trabajo citado. Finalmente, bajo la denominación global de sílice se incluyeron calcedonias, ópalos y sílices diferenciados por Escola. 
Es factible, además, reconocer una continuidad en el lapso abordado en lo que respecta a la información disponible sobre distribución de rocas a nivel microrregional, ya que, al realizar la comparación, conjugando artefactos formatizados (Tabla 8.6) y desechos de talla (Tabla 8.7), del GC1 con el GC2, se puede observar que ambos grupos cronológicos comparten 8 de 11 rocas locales, mientras que el GC2 y el GC3 coinciden en 10 materias primas. Esto se contrapondría con la hipótesis de que grupos agro-pastoriles plenos (GC3) se habrían instalado en Antofagasta de la Sierra provenientes de otras áreas hacia los 2100 AP (Olivera 1992), debido a que, si hubiera sido así, debería haber claras evidencias de una falta de conocimiento de la disponibilidad de recursos. De hecho, se manifiesta una situación completamente distinta a la en ciernes, que implica un conocimiento acabado en el GC3 de las fuentes y materias primas locales. Esto se ve reforzado por el hecho de que éstas últimas son ampliamente mayoritarias en los 3 grupos cronológicos diferenciados al considerar los artefactos formatizados, con el 97,30\% en el GC1, el 82,29\% en el GC2 y el 71,24\% en el GC3 (Tabla 8.8). Esta tendencia general se ve corroborada al analizar los porcentajes de desechos de talla confeccionados sobre rocas locales. Así, el GC1 presenta un 98,67\% de los mismos, el GC2 un $80,12 \%$ y el GC3 un 83,15\%.

Tabla 8.8. Materias primas en artefactos formatizados y desechos de talla por grupo cronológico

\begin{tabular}{|c|c|c|c|c|c|c|}
\hline \multirow{2}{*}{ MATERIA PRIMA } & \multicolumn{2}{|c|}{ GC1 } & \multicolumn{2}{c|}{ GC2 } & \multicolumn{2}{c|}{ GC3 } \\
\cline { 2 - 7 } & INST & DT & INST & DT & INST & DT \\
\hline LOCAL & 106 & 6984 & 302 & 1818 & 161 & 671 \\
\hline NO LOCAL & 3 & 94 & 65 & 451 & 65 & 136 \\
\hline TOTAL & 109 & 7078 & 367 & 2269 & 226 & 807 \\
\hline
\end{tabular}

Nota: El GC1 está formado en este caso por QS3, el GC2 por PP4 -4 a 5(5)-, PCh1.1 y PCh1.3 t el GC3 por PP9 y CCHM1

Al tratar las rocas no locales, es factible reconocer un incremento en el tiempo de las mismas, aunque en un contexto de frecuencias relativamente bajas. En el instrumental, los porcentajes son del 2,75\% en el GC1, del 17,71\% en el GC2 y del 28,76\% en el GC3, mientras que en los desechos de talla es del 1,33\% en el GC1, 19,88\% en el GC2 y 16,85\% en el GC3 (Tabla 8.8).

De la consideración de la materia prima de los núcleos se afianzan las tendencias señaladas previamente. Pese a que no se cree conveniente diferenciar dentro de las rocas locales entre inmediatas, mediatas y no diferenciadas, dado el tamaño de las muestras, sí es posible realizar un análisis en base a la dicotomía local-no local, que resulta nuevamente en una preponderancia de las primeras -75\% en el GC1, 93,75\% en el GC2 y 66,67\% en el GC3- (Tabla 8.9). Por otra parte, más 
allá de la escasa cantidad de piezas ${ }^{3}$, destaca el bajo número de rocas representadas, básicamente en los GC1 y 2, en contraposición a la diversidad presente en artefactos formatizados (Tabla 8.6) y desechos de talla (Tabla 8.7). Finalmente, la información disponible no permite entrever una tendencia en la utilización de las obsidianas. Sin embargo, de la consideración de los resultados obtenidos por Escola (2004b), quien analiza 16 núcleos de obsidiana que surgen del total de artefactos formatizados y núcleos recuperados en CChM1 (N: 531), se puede establecer una direccionalidad en el uso de la obsidiana de Ona en el GC3, ya que el 93,75\% se presentan en esta materia prima, mientras que el 6,25\% restante a Cueros de Purulla. Esto es corroborado más adelante al considerar tanto artefactos formatizados como desechos de talla.

Tabla 8.9. Materias primas en núcleos, por grupo cronológico

\begin{tabular}{|c|c|c|c|c|}
\hline \multicolumn{2}{|c|}{$\begin{array}{l}\text { MATERIA } \\
\text { PRIMA }\end{array}$} & \multirow{2}{*}{$\begin{array}{c}\text { GC1 } \\
4\end{array}$} & \multirow{2}{*}{$\begin{array}{c}\text { GC2 } \\
17\end{array}$} & \multirow{2}{*}{$\begin{array}{c}\text { GC3 } \\
-\end{array}$} \\
\hline Local & Vc1 & & & \\
\hline & Vc2 & 1 & 4 & 2 \\
\hline & Vc5 & - & 1 & - \\
\hline & Vc4 & - & - & 2 \\
\hline & Vc5 & - & 1 & - \\
\hline & Vc6 & - & - & 1 \\
\hline & Vc7 & - & - & 1 \\
\hline & Cc & - & - & 4 \\
\hline & Si & - & - & 2 \\
\hline \multirow[t]{3}{*}{ No local } & ObA & - & 3 & 6 \\
\hline & ObB & 1 & - & - \\
\hline & ObD & - & 1 & - \\
\hline
\end{tabular}

Nota: los GC1 y Gc3 están formados sólo por los sitios QS3 y CChM1, respectivamente, ya que tanto PP4-5(6)- como PP9 no disponen de núcleos. Los datos sobre núcleos de CChM1 se basan en Escola (2000). La muestra de PP4 -4 a 5(5)- en el GC2 está compuesta por los núcleos de las campañas 1996 y 1999. A esta se suman artefactos de PCh1.1 y PCh1.3.

Diversos trabajos en el área de estudio han vinculado la fluctuación en la utilización de fuentes locales versus no locales con cambios en los patrones de movilidad de los cazadores-recolectores holocénicos (Aschero et al. 1993-94, Pintar 1996a, Manzi 1999). Así, por ejemplo, Pintar (1996a) plantea que el decrecimiento en la proporción de las materias primas no locales puede relacionarse con un incremento del sedentarismo y un decrecimiento en el tamaño del territorio explotado. Si fuera

\footnotetext{
${ }^{3}$ La bajísima representación de núcleos en los conjuntos ha sido recurrentemente asociada a la ocurrencia de sistemas de producción lítica de tipo secuencial formados por bases residenciales y canteras. Dada la cercanía de estas últimas, se ha planteado (y comprobado) el transporte a los sitios domésticos de formas-base lasca de tamaños adecuados (Aschero et al. 1991, Aschero et al. 1993-94, Pintar 1996a, Toselli 1998).
} 
así, en vista de los resultados obtenidos en este caso, podría argumentarse un aumento de la movilidad en el lapso abordado. Sin embargo, se plantea una postura alternativa que parecería responder mejor a la luz de los resultados obtenidos.

En el Capítulo 6 (punto 6.2.1. Movilidad residencial reducida) se desarrollaron las evidencias disponibles acerca de una disminución de la movilidad residencial entre los 5500 y los 1500 años AP, planteándose que la creciente fijación de los grupos humanos al paisaje a escala micro no debía llevar necesariamente a que la circulación regional (macromovilidad) disminuyera o deje de funcionar. De hecho, la información disponible para este momento sustenta la idea de una micromovilidad reducida y una macromovilidad en pleno funcionamiento ${ }^{4}$ (punto 6.2.4. Redes de interacción a larga distancia en el Capítulo 6). De esta forma, las materias primas no locales no tendrían injerencia alguna sobre la movilidad a nivel micro, siendo, en cambio, las rocas locales, las que sí son significativas a la hora de tratar variaciones en la movilidad residencial a nivel microrregional.

Para el abordaje de las variaciones en el tiempo de la representatividad de las rocas locales se utiliza la diferenciación de las mismas en inmediatas, mediatas cercanas, mediatas lejanas y no diferenciadas, desarrollada al inicio de este punto. En las Tablas 8.10 y 8.11 se expresan los conteos de artefactos formatizados y desechos de talla, respectivamente, en función de dicho ordenamiento, por grupo cronológico. Se recuerda que en la Tabla 8.5 se presentan las materias primas clasificadas en función de la distancia de obtención desde los sitios estudiados.

Tabla 8.10. Clasificación de rocas locales aplicada a artefactos formatizados, por grupo cronológico

\begin{tabular}{|c|c|c|c|c|c|}
\hline \multicolumn{2}{|r|}{ MATERIA PRIMA } & \multirow{3}{*}{$\begin{array}{c}\text { GC1 } \\
57\end{array}$} & \multirow{3}{*}{$\begin{array}{c}\text { GC2 } \\
229\end{array}$} & \multicolumn{2}{|c|}{ GC3 } \\
\hline & & & & PP9 & CChM1 \\
\hline \multirow[t]{4}{*}{ LOCAL } & INMEDIATA & & & 17 & 3 \\
\hline & $\begin{array}{l}\text { MEDIATA } \\
\text { CERCANA }\end{array}$ & 37 & 59 & 1 & 94 \\
\hline & $\begin{array}{l}\text { MEDIATA } \\
\text { LEJANA }\end{array}$ & 8 & 6 & 4 & 32 \\
\hline & $\begin{array}{c}\text { NO } \\
\text { DIFERENCIADA }\end{array}$ & - & 8 & - & 10 \\
\hline & TOTAL & 102 & 302 & 22 & 139 \\
\hline
\end{tabular}

Nota: En el GC1 se consideró solamente al sitio QS3. El GC2 está formado por PP4 -4 a 5(5)-, PCh1.3 y PCh1.1. En el GC3 se debió diferenciar a PP9 de CChM1 debido a que presentan variaciones en las rocas que se incluyen en cada categoría.

\footnotetext{
${ }^{4}$ La obtención de la obsidiana en sus distintas variantes podría haberse dado, entonces, por medio de acceso directo -en forma de partidas logísticas- o bien por acceso indirecto, a través de la interacción vía intercambio, reciprocidad, etc.
} 
Tabla 8.11. Clasificación de rocas locales aplicada a desechos de talla, por grupo cronológico

\begin{tabular}{|c|c|c|c|c|c|}
\hline \multirow{2}{*}{\multicolumn{2}{|c|}{ MATERIA PRIMA }} & \multirow{3}{*}{$\begin{array}{l}\text { GC1 } \\
4556\end{array}$} & \multirow{3}{*}{$\begin{array}{c}\text { GC2 } \\
1326\end{array}$} & \multicolumn{2}{|c|}{ GC3 } \\
\hline & & & & \multirow{2}{*}{$\begin{array}{c}\text { PP9 } \\
71\end{array}$} & \multirow{2}{*}{$\begin{array}{c}\text { CChM1 } \\
15\end{array}$} \\
\hline LOCAL & INMEDIATA & & & & \\
\hline & $\begin{array}{l}\text { MEDIATA } \\
\text { CERCANA }\end{array}$ & 2390 & 441 & 6 & 424 \\
\hline & $\begin{array}{l}\text { MEDIATA } \\
\text { LEJANA }\end{array}$ & 27 & 37 & 52 & 85 \\
\hline & $\begin{array}{c}\text { NO } \\
\text { DIFERENCIADA }\end{array}$ & 11 & 14 & - & 18 \\
\hline \multicolumn{2}{|r|}{ TOTAL } & 6984 & 1818 & 129 & 542 \\
\hline
\end{tabular}

Nota: En el GC1 se consideró solamente al sitio QS3. El GC2 está formado por PP4 -4 a 5(5)-, PCh1.3 y PCh1.1. En el GC3 se debió diferenciar a PP9 de CChM1 debido a que presentan variaciones en las rocas que se incluyen en cada categoría.

El análisis de las frecuencias de las distintas clases de materias primas locales revela un marcado incremento en el uso de las rocas inmediatas al pasar del GC1 al GC2, tanto en artefactos formatizados -de 53,77\% a 75,83\%- como en desechos de talla -65,23 \% a 72,94\%- y, como correlato, una disminución del papel de las rocas mediatas, tomadas en conjunto, de $42,46 \%$ a $21,53 \%$ en artefactos formatizados y de $34,61 \%$ a $27,06 \%$ en desechos de talla. Asimismo, disminuyen los dos tipos de rocas mediatas al pasar de un grupo cronológico a otro, aunque las rocas mediatas lejanas tiene la particularidad de que se reducen a una mínima expresión en el GC2, siendo del 1,99\% en artefactos formatizados y del 2,04\% en lascas. A partir de esto puede postularse una progresiva restricción en la movilidad residencial (y también logística), al haber una cada vez menor representación de rocas de más de $2 \mathrm{~km}$ y menos de $25 \mathrm{Km}$ y, al mismo tiempo, un recorte en las distancias involucradas en el aprovisionamiento.

Cabe destacar que tanto en el GC1 como en el GC2 la única roca mediata lejana es la Vc4, ya que no hay uso en estos momentos de la Vc8, que es empleada posteriormente. Al respecto, si se tiene en cuenta la distribución de las materias primas, siguiendo la propuesta de Olivera (1992) de diferenciación ambiental, la Vc4 se presenta en el fondo de cuenca, en la cantera de Los Negros, a unos $21 \mathrm{~km}$ de QS3 y a unos $16 \mathrm{~km}$ de PP4, PCh1.3 y PCh1.1. Tales distancias pueden estar involucradas perfectamente en actividades diarias de subsistencia, en un contexto de micromovilidad (ver Capítulo 6), por lo que es interesante tal comportamiento en la utilización de la materia prima. Resulta sugerente, en este marco, que Aschero (2005a, 2005b) encuentra diferencias en el arte rupestre, a modo de representaciones de diferentes “estilos” dentro de la modalidad Río Punilla, hacia el 3500 AP, entre el fondo de cuenca, los sectores intermedios y diferentes quebradas de altura, que vincula a la presencia de territorialidad. Tal vez, la baja representación de la Vc4 en el GC1 y mínima en el GC2 -este último con cronología coincidente al momento definido por Aschero-, dadas las 
distancias involucradas, sea el producto de una restricción progresiva en el acceso a dicho recurso lítico debido a la ocurrencia de ámbitos de control territorial ${ }^{5}$.

Ya en el GC3, se presentan 2 situaciones marcadamente distintas. Por un lado, el sitio PP9 revela un predominio de las rocas locales inmediatas, con un $77,27 \%$ en las piezas formatizadas y un 55,04\% en desechos de talla, lo que está en consonancia con las tendencias señaladas precedentemente de utilización intensiva de rocas muy próximas. Le siguen en orden de importancia las rocas mediatas lejanas, con un 18,18\% en instrumentos y 40,31\% en desechos de talla. Finalmente, se presentan las rocas mediatas cercanas, con un 4,55\% y un 4,65\% en instrumentos y lascas, respectivamente. Esto es sumamente interesante, puesto que se están priorizando rocas disponibles a mayor distancia sobre otras más cercanas. En realidad, la razón es simple, los grupos humanos que ocupaban PP9 requerían de las materias primas mediatas lejanas para la confección de artefactos muy específicos, como son las palas y/o azadas (Vc8) y las raederas de módulo grandísimo (Vc4). Tales proporciones, además, indican estrechas vinculaciones con CChM1, en función de la utilización de las materias primas en dicho sitio (Escola 2000, 2004c).

CChM1, por otro lado, se diferencia de los casos desarrollados previamente, ya que se registra una preponderancia de las rocas mediatas cercanas $-67,63 \%$ en el instrumental y $78,23 \%$ en los desechos de talla-. Las mediatas lejanas les siguen en orden de importancia, con el 23,02\% en los artefactos formatizados y el 15,68\% en los desechos. Notoriamente, las rocas inmediatas alcanzan sólo un $2,16 \%$ en los artefactos formatizados y un 2,77\% en los desechos de talla. Esto podría estar relacionado con la búsqueda de rocas de mejor calidad para la talla (Escola 2000), ya que como roca inmediata se presenta la cuarcita, el aprovisionamiento se habría orientado a mejores rocas, estando las más próximas en el radio de las mediatas cercanas -por ejemplo, la Vc4-. Otra posibilidad es que el componente pastoril, con su consiguiente movilidad, esté incidiendo sobre la representación de materias primas mediatas y lejanas (Escola et al. 2005). En relación con la restricción a ciertas fuentes, planteado para el GC1 pero principalmente para el GC2, en el GC3 no continuaría funcionando, dado el manejo señalado de rocas procedentes del fondo de cuenca, sectores intermedios y quebradas de altura al conjugar CChM1 y PP9.

En suma, son rotundas las evidencias de un uso primordial de las rocas locales sobre las no locales, patrón que es característico de casos con buena disponibilidad de materias primas de alta calidad (Andrefsky 1994b). Asimismo, otro elemento importante que es esperable en estos contextos

\footnotetext{
${ }^{5}$ De Souza (2004a) plantea, a nivel hipotético, dos áreas de movilidad independiente en la cuenca superior del Río Loa (desierto del norte de Chile) durante el Holoceno medio, a modo de territorios, en base a la presencia de diseños de puntas de proyectil característicos y a la utilización de variedades de materias primas distintas. El caso de Antofagasta de la Sierra sería diferente, ya que comprendería una única área con sectores de uso exclusivo, restringidos a otros grupos y otros de uso común -por ejemplo, el sitio Confluencia (Aschero 2005b).
} 
es que se manufacturen sobre las rocas locales tanto instrumentos con gran inversión de trabajo como con baja inversión de tiempo y energía (Andrefsky 1994a, 1998). Para abordar ésto, se ha diferenciado a los artefactos formatizados en dos categorías (Tabla 8.12): por un lado, las puntas de proyectil y los bifaces, los instrumentos con mayor inversión de trabajo en su confección del conjunto y, por el otro lado, el instrumental con menor inversión de trabajo, constituido por los filos y puntas de morfología parcial y ciertas piezas de morfología global, como los artefactos bipolares. Estos últimos reciben el calificativo de "Resto del instrumental". Los conteos por materia prima para los grupos tipológicos presentes en cada grupo cronológico, en base a los cuales se plasmó la Tabla 8.12, se pueden visualizar en las Tablas 8.14, 8.15 y 8.16 .

Tabla 8.12. Diferenciación del instrumental por inversión de trabajo y por su carácter de local-no local

\begin{tabular}{|l|c|c|c|c|c|c|}
\hline \multirow{2}{*}{ INSTRUMENTO } & \multicolumn{2}{|c|}{ GC1 } & \multicolumn{2}{c|}{ GC2 } & \multicolumn{2}{c|}{ GC3 } \\
\cline { 2 - 7 } & LOCAL & NO LOCAL & LOCAL & NO LOCAL & LOCAL & NO LOCAL \\
\hline $\begin{array}{l}\text { Puntas de } \\
\text { proyectil y } \\
\text { bifaces }\end{array}$ & 71 & 3 & 80 & 33 & 3 & 21 \\
\hline $\begin{array}{l}\text { Resto del } \\
\text { instrumental }\end{array}$ & 175 & 8 & 416 & 54 & 234 & 46 \\
\hline Total & 246 & 11 & 496 & 87 & 237 & 67 \\
\hline
\end{tabular}

Nota: En este caso, el GC1 esta formado por QS3, el GC2 por PP4 -4 a 5(5)-, PCh1.1 y PCh1.3 y el GC3 por CCHM1 y PP9.

Así, en los GC1 y GC2 se observa que las rocas locales son dominantes, tanto en las puntas de proyectil y bifaces como en el resto del instrumental -95, 95\% y 95,63\%, respectivamente, en el GC1 y 70,80\% y 88,51\% en el GC2. Esta tendencia se ve matizada, sin embargo, en el GC3, por una situación particular. Sólo un 12,66\% de las puntas de proyectil y bifaces en este grupo cronológico está confeccionado sobre rocas locales, mientras que el instrumental restante sí está manufacturado básicamente sobre las mismas, con un 98,73\%. Al respecto, Escola (2000, 2004b) ha señalado la utilización selectiva de la obsidiana para la confección de puntas de proyectil en CChM1, que es extensible al sitio PP9. Esta direccionalidad tan rotunda, el 87,50\% de las puntas de proyectil están manufacturadas sobre obsidiana, en realidad, parecería ser la conclusión de un proceso de estandarización de la materia prima de las puntas de proyectil, que se iniciaría ca.3600 AP. En este sentido puede entenderse el hecho de que el 41,54\% de las puntas de proyectil en el GC2 están confeccionadas sobre obsidianas de distinto tipo. En suma, se estaría en presencia de una tendencia en el tiempo de un uso cada vez mayor de la obsidiana para la confección de puntas de proyectil, estando sus comienzos en los grupos humanos de la transición.

Otros aspectos que han sido estrechamente vinculados con la disponibilidad de materia prima son el mantenimiento y el reciclaje, con la ocurrencia destacada de ambos ante una escasez de recursos líticos (Bamforth 1986). De acuerdo con Odell (1996), tales situaciones de carestía implicarían, 
asimismo, la confección de una mayor cantidad de implementos en función de los recursos disponibles. Por ejemplo, por unidad de roca. Una posibilidad al respecto es elaborar artefactos compuestos $^{6}$-que como se dejó asentado en el Capítulo 4, combinan diferentes filos y/o puntas- y no compuestos, en forma de filos y/o puntas dobles, múltiples, etc.

De esto se desprende que en casos como éste con cantidad de rocas localmente disponibles, las tasas de reactivación y reciclaje deberían reducirse a su mínima expresión y, por ende, la tendencia sería artefactos formatizados con vidas útiles relativamente cortas. Por otra parte, los artefactos compuestos deberían estar escasamente representados. En suma, no sería esperable un comportamiento de tipo “maximizador” como el expresado en el párrafo anterior.

En este caso se plantea que no es posible una estimación adecuada de la tasa de mantenimiento, dado que no es posible reconocer satisfactoriamente la presencia de reactivación en todos los grupos tipológicos, estando, en realidad, limitada a un reducido espectro de clases, básicamente, cuchillos de filo retocado, raederas, raspadores, cortantes y puntas de proyectil.

$\mathrm{Si}$, en cambio, es factible abordar el papel del reciclaje y cómo éste cambia en el tiempo. Para ello, se considera la cantidad de casos de reciclaje en función del total de filos, puntas y piezas de morfología global, por grupo cronológico, exceptuándose los fragmentos no diferenciados de artefactos formatizados. En primer lugar, se puede apreciar que el reciclaje cuenta con valores bajos a lo largo del lapso abordado -en el GC1 representa el 11,90\%, 13,02\% en el GC2 y 5,45\% en el GC3(Tabla 8.13), siendo esto concordante con la tendencia esperada. En segundo lugar, es importante denotar el marcado descenso de la frecuencia en el último grupo cronológico. Fuera del efecto de la disponibilidad de materias primas sobre la presencia de reciclaje, la inversión de trabajo en la manufactura del instrumental tendría también un papel a tener en cuenta, ya que el mismo varía diferencialmente entre categorías artefactuales, lo cual es tratado posteriormente en el punto 8.5 Evidencias de cambio en la inversión de trabajo.

\footnotetext{
${ }^{6}$ Más allá de la consabida conjugación de filos funcionalmente complementarios para la realización de actividades específicas o series de tareas.
} 
Tabla 8.13. Presencia de reciclaje y de artefactos compuestos y no compuestos, por grupo cronológico

\begin{tabular}{|c|c|c|c|}
\hline $\begin{array}{c}\text { ARTEFACTOS } \\
\text { FORMATIZADOS }\end{array}$ & GC1 & GC2 & GC3 \\
\hline Reciclaje & 30 & 78 & 9 \\
\hline $\begin{array}{c}\text { Artefactos } \\
\text { compuestos }\end{array}$ & 39 & 79 & 13 \\
\hline $\begin{array}{c}\text { Artefactos no } \\
\text { compuestos }\end{array}$ & 56 & 240 & 152 \\
\hline
\end{tabular}

Nota: el GC1 está constituido sólo por QS3. Para los conteos de filos y/o puntas complementarios no se consideraron los fragmentos no diferenciados de artefacto formatizado.

En cuanto a la presencia de artefactos compuestos, en contra de lo esperado, se registra una frecuencia importante en el GC1, con el 41,05\%, reduciéndose drásticamente en los grupos cronológicos subsiguientes, ya que en el GC2 es del 24,76\% y en el GC3 es de sólo el 7,88\%. Se plantea que la ubicuidad de materias primas no estaría afectando la complementariedad de filos y/o puntas, sino, más bien, aspectos vinculados con los riesgos de corto plazo, en un contexto de movilidad reducida. Así, la disminución de los mismos por la consolidación progresiva de las prácticas productivas habría llevado a una importancia cada vez mayor de los artefactos no compuestos, y dentro de éstos, a los filos y puntas simples (ver punto siguiente 8.3. Aproximación diacrónica a aspectos morfológico-funcionales de artefactos formatizados).

Pasando ya al tema de la relación entre grupos tipológicos y materias primas específicas, no se registra en general una asociación estrecha entre ambos, notándose un uso indiscriminado de las rocas en la confección de las diferentes clases de artefactos formatizados. La preponderancia de la Vc1 y la Vc2 en el GC1 (Tabla 8.11) y el GC2 (Tabla 8.12) y de la Vc4 en el GC3 (Tabla 8.13) en la mayor parte de los grupos tipológicos se vincularía sencillamente, por lo expresado anteriormente, a una cuestión de acceso a los recursos y de calidad de las rocas -para una discusión sobre esto en función del sitio PP4 ver Toselli (1998,1999)-.

Como ya se mencionó, las puntas de proyectil típicas de los contextos agro-pastoriles plenos del GC3 se confeccionaban prácticamente en un cien por ciento sobre obsidiana; asimismo, una fracción importante de las piezas del GC2 también. Pero hay otro aspecto que merece atención que surge de la comparación, que es el tipo de obsidiana utilizado, encontrándose importantes diferencias. Así, en el GC2 las puntas de proyectil se manufacturaron sobre las cuatro obsidianas definidas (Tabla 8.12), aunque con frecuencias variables, donde 51,85\% corresponde a la ObA, 7,41\% a la ObB, 37, 04\% a la ObC y 3,70\% a la ObD. Por otro lado, en el GC3 se restringe drásticamente el número de fuentes de obsidiana involucradas. 
Al respecto, en su Tesis doctoral, Escola (2000) utiliza en el análisis artefactual una única categoría de materia prima obsidiana que incluía a las obsidianas de Ona y a otras fuentes que estaban recién empezando a ser estudiadas en ese momento (Cueros de Purulla), aunque manifiesta como factible la posibilidad de una preponderancia de Ona. Posteriormente, esta misma autora (Escola 2004b) realiza un análisis pormenorizado de los materiales sobre obsidiana de Casa Chávez Montículos 1, de forma de establecer el papel desempeñado por las distintas fuentes. Para esto, toma la muestra completa de instrumentos de obsidiana ( $\mathrm{N}$ : 113) del total de artefactos recuperados en el sitio (N: 531). En relación a las puntas de proyectil (N: 39) encuentra que el 97,44\% fue confeccionada con la obsidiana de Ona y el 2,56\% restante con la de Cueros de Purulla. Esto implica una utilización preferencial de lo que aquí se define como ObA (en este caso, formada exclusivamente por obsidiana de Ona) en el GC3 y en mínima proporción de ObB. Dada las características macroscópicas de la materia prima de las puntas de proyectil de PP9, es muy posible que también sean de Ona.

La pregunta que surge de esto, desde una perspectiva diacrónica, es por qué se produjo tal selección. Más allá de los consabidos factores de distancia relativa de las fuentes y calidad diferencial de las rocas, una posibilidad, entre varias, es que se hayan producido restricciones en el acceso a fuentes especificas -dadas las evidencias de territorialidad en Antofagasta de la Sierra, podría argumentarse su ocurrencia en el resto de la Puna Meridional argentina-, limitando así el número de canteras al que se tenía acceso, independientemente de si éste era directo o indirecto. Por su parte, Escola (2004b) ha manifestado que la intensidad de consumo de la obsidiana de Ona en CChM1 pudo haberse vinculado a aspectos de índole social, lo cual es perfectamente extrapolable a la cuenta larga aquí abordada. Tales alternativas deben explorarse en el futuro.

En el GC3 se presentan otros dos artefactos formatizados que están vinculados estrechamente con una materia prima en particular. Son las palas y/o azadas y las raederas de módulo grandísimo. Las primeras están confeccionadas sobre la Vc8, que se encuentra disponible en el fondo de cuenca, en las inmediaciones de la localidad de Los Negros. Tal exclusividad se relacionaría con el tamaño y morfología de las formas-base de esta materia prima, que las convierte en la opción más viable para la confección de dichos instrumentos, dada la oferta de materias primas líticas microrregional (Escola com pers.). No obstante, de acuerdo a Escola (2000), debe haber habido una adecuada selección de las formas-base, especialmente en cuanto a espesor. Las evidencias sustentan un transporte de las formasbase desde la fuente hacia CChM1 y PP9, dado los desechos de talla de formatización recuperados en ambos sitios.

Las segundas, por su parte, se manufacturaban en CChM1 sobre Vc4, cuya fuente se localiza también en Los Negros, en el fondo de cuenca. Si bien las muestras analizadas de PP9 no incluyen estas raederas, sí se han identificado lascas del mantenimiento de las mismas (ver punto 12.4 
Identificación de desechos de talla de mantenimiento de raederas de módulo grandísimo en el Capítulo 12), así como de su formatización. Esto implicaría que hubo un transporte desde el fondo de cuenca hasta los sectores intermedios tanto de piezas terminadas como de sus formas-base -lascas grandísimas-. El hecho de haber identificado en PP9 una lasca resultante de la formatización de tales instrumentos en Vc1 abre la posibilidad de que se hayan explotado fuentes alternativas a la de Los Negros. 
Tabla 8.14. Discriminación de grupos tipológicos por materia prima - GC1

\begin{tabular}{|c|c|c|c|c|c|c|c|c|c|c|c|c|c|c|c|c|c|}
\hline & Vc1 & Vc2 & Vc3 & Vc4 & Vc5 & Vc6 & Vc7 & Vc8 & Vv2 & ObA & ObB & ObC & ObD & Cc & Si & Otros & Tot \\
\hline Uf & 1 & - & - & - & 1 & - & - & - & - & - & - & - & - & - & - & - & 2 \\
\hline Bf & 22 & 16 & - & 7 & 4 & - & - & - & - & - & - & 2 & - & - & - & - & 51 \\
\hline Fbas & - & 1 & - & - & 1 & - & 1 & - & - & - & 1 & - & - & - & - & 1 & 5 \\
\hline Rp & 4 & 2 & - & - & - & - & - & - & - & - & 1 & 1 & - & - & - & - & 8 \\
\hline Rc & 7 & 4 & - & 1 & - & - & 2 & - & - & - & - & 1 & - & - & - & 2 & 17 \\
\hline Rd & 4 & 1 & - & - & - & - & - & - & - & - & - & 1 & - & - & - & - & 6 \\
\hline Cfr & 7 & 3 & - & 2 & 1 & - & 1 & - & - & - & 1 & - & - & - & - & 1 & 16 \\
\hline Cfn & - & 1 & - & - & - & - & - & - & - & - & - & - & - & - & - & - & 1 \\
\hline $\mathrm{Ct}$ & 10 & 9 & - & 3 & 1 & - & 2 & - & - & - & - & 1 & - & - & - & - & 26 \\
\hline Mu & 5 & 1 & - & - & 2 & - & 1 & - & - & - & - & - & - & - & - & - & 9 \\
\hline Dt & 3 & 1 & - & - & - & - & - & - & - & - & - & - & - & - & - & - & 4 \\
\hline CDt & - & 4 & - & - & 1 & - & - & - & - & - & - & - & - & - & - & - & 5 \\
\hline PcA & - & - & - & - & - & - & - & - & - & - & - & - & - & - & - & 1 & 1 \\
\hline PEM & 4 & 2 & - & - & - & - & - & - & - & - & - & - & - & - & - & - & 6 \\
\hline AB & 14 & 12 & 1 & - & 2 & - & 1 & - & & - & 1 & - & - & - & - & - & 31 \\
\hline Per & 1 & - & - & - & - & - & - & - & - & - & - & - & - & - & - & - & 1 \\
\hline Gu & - & 1 & - & - & - & - & - & - & - & - & - & - & - & - & - & - & 1 \\
\hline PP & 4 & 11 & - & 6 & 1 & - & - & - & - & - & - & 1 & - & - & - & - & 23 \\
\hline FFP & 2 & 3 & - & 1 & - & - & 1 & - & - & - & - & - & - & - & - & 1 & 8 \\
\hline AFS & 6 & 5 & 2 & - & - & - & 1 & - & - & - & - & - & - & - & - & - & 14 \\
\hline $\mathbf{A B p}$ & 2 & 3 & - & - & - & - & - & - & - & - & - & - & - & - & - & - & 5 \\
\hline F/fnd & 10 & 3 & - & 2 & - & - & - & - & - & - & - & - & - & - & - & 2 & 17 \\
\hline Tot & 106 & 83 & 3 & 22 & 14 & 0 & 10 & 0 & 0 & 0 & 4 & 7 & 0 & 0 & 0 & 8 & 257 \\
\hline
\end{tabular}

Referencias: Uf: Uniface. Bf: Biface. Fbas: Filo bifacial de arista sinuosa. Rp: Raspador. Rc: Raclette. Rd: Raedera. Cfr: Cuchillo de filo retocado. Cfn: Cuchillo de filo natural con dorso formatizado. Ct: Cortante. Mu: Muesca retocada y de lascado simple. Dt: Denticulado bisel oblicuo/abrupto sección asimétrica. CDt: Sierra o cuchillo denticulado. PcA: Percutor de arista formatizada. PEM: Punta entre muescas. AB: Artefacto burilante. Per: Perforador. Gu: Gubia. PP: Punta de proyectil. FFP: Filo formatizado pasivo. AFS: Artefacto de Formatización Sumaria. ABp: Artefacto bipolar. F/fnd: Fragmento/filo no diferenciado de artefacto formatizado. Nota: La información del GC1 refiere exclusivamente a QS3. 
Tabla 8.15. Discriminación de grupos tipológicos por materia prima - GC2

\begin{tabular}{|c|c|c|c|c|c|c|c|c|c|c|c|c|c|c|c|c|c|}
\hline & Vc1 & Vc2 & Vc3 & Vc4 & Vc5 & Vc6 & Vc7 & Vc8 & Vv2 & ObA & ObB & ObC & ObD & Cc & Si & Otros & Tot \\
\hline Uf & 1 & - & - & 1 & - & - & - & - & - & - & - & - & - & - & - & - & 2 \\
\hline Bf & 33 & 4 & 2 & 1 & 1 & - & 1 & - & - & 3 & - & 3 & - & - & - & - & 48 \\
\hline Fbas & 9 & 3 & - & 1 & 1 & - & 1 & - & - & - & - & - & - & 1 & - & - & 16 \\
\hline Cp & - & - & - & - & - & - & - & - & - & - & - & - & - & 1 & - & - & 1 \\
\hline $\mathbf{R p}$ & 13 & 3 & - & 1 & 1 & - & - & - & - & - & 1 & - & - & 2 & 2 & - & 23 \\
\hline Rc & 22 & 5 & - & - & - & - & 2 & - & - & 3 & - & - & - & - & - & - & 32 \\
\hline Rd & 19 & 3 & - & - & 1 & - & - & - & - & - & - & - & - & 1 & - & - & 24 \\
\hline LR & 1 & - & - & - & - & - & - & - & - & - & - & - & - & - & - & - & 1 \\
\hline RBO & 1 & - & - & - & - & - & - & - & - & - & - & - & - & - & 1 & - & 2 \\
\hline Cfr & 15 & 3 & - & 1 & - & - & 2 & - & - & - & 1 & - & - & - & 1 & - & 23 \\
\hline Cfn & - & - & - & - & 1 & - & - & - & - & - & - & - & - & - & - & - & 1 \\
\hline $\mathrm{Ct}$ & 12 & 1 & 1 & 2 & - & - & 6 & - & - & 3 & - & 1 & - & - & 1 & - & 27 \\
\hline Mu & 31 & 7 & 5 & - & 1 & - & 4 & - & - & 8 & - & - & - & - & 1 & - & 57 \\
\hline Dt & 24 & 7 & - & 1 & - & - & 1 & - & - & 1 & 1 & - & - & - & - & - & 35 \\
\hline CDt & 3 & - & - & - & - & - & 2 & - & - & - & - & - & - & - & - & 2 & 7 \\
\hline PcA & 4 & - & - & - & - & - & - & - & - & - & - & - & - & - & - & 1 & 5 \\
\hline PEM & - & - & - & - & - & - & 1 & - & - & 1 & - & - & - & - & - & - & 2 \\
\hline AB & 29 & 6 & 3 & 1 & 4 & - & 2 & - & - & 6 & - & 1 & - & - & - & - & 52 \\
\hline Per & 2 & - & - & - & - & - & - & - & - & 3 & - & - & - & - & - & - & 5 \\
\hline Gu & 2 & 1 & - & - & - & - & - & - & - & - & - & - & - & - & - & - & 3 \\
\hline Es & 2 & - & - & - & - & - & - & - & - & - & - & - & - & - & - & - & 2 \\
\hline $\mathbf{C i}$ & - & 2 & - & - & - & - & - & - & - & - & - & - & - & - & - & - & 2 \\
\hline PP & 22 & 10 & - & 3 & & - & 2 & - & - & 14 & 2 & 10 & 1 & - & 1 & - & 65 \\
\hline FFP & 11 & 4 & - & 1 & 1 & - & 2 & - & - & 1 & - & - & - & - & - & - & 20 \\
\hline AFS & 12 & 7 & - & - & 1 & - & 3 & - & - & 4 & - & - & - & 1 & 2 & - & 30 \\
\hline ABp & 6 & 2 & - & - & - & - & & - & - & 1 & - & - & - & - & - & - & 9 \\
\hline F/fnd & 48 & 18 & - & 1 & 2 & - & 2 & - & - & 14 & 2 & 1 & 1 & - & - & - & 89 \\
\hline Tot & 322 & 86 & 11 & 14 & 14 & 0 & 31 & 0 & 0 & 62 & 7 & 16 & 2 & 6 & 9 & 3 & 583 \\
\hline
\end{tabular}

Referencias: Uf: Uniface. Bf: Biface. Fbas: Filo bifacial de arista sinuosa. Cp: Cepillo. Rp: Raspador. Rc: Raclette. Rd: Raedera. LR: Lámina retocada. RBO: Artefacto mediano pequeño/muy pequeño RBO sección asimétrica. Cfr: Cuchillo de filo retocado. Cfn: Cuchillo de filo natural con dorso formatizado. Ct: Cortante. Mu: Muesca retocada y de lascado simple. Dt: Denticulado bisel oblicuo/abrupto sección asimétrica. CDt: Sierra o cuchillo denticulado. PcA: Percutor de arista formatizada. PEM: Punta entre muescas. AB: Artefacto burilante. Per: Perforador. Gu: Gubia. Es: Escoplo. Ci: Cincel. PP: Punta de proyectil. FFP: Filo formatizado pasivo. AFS: Artefacto de formatización sumaria. ABp: Artefacto bipolar. F/fnd: Fragmento/filo no diferenciado de artefacto formatizado. Nota: GC2: PP4 -4 a 5(5)-, PCh1.1 y PCh1.3. 
Tabla 8.16. Discriminación de grupos tipológicos por materia prima - GC3

\begin{tabular}{|c|c|c|c|c|c|c|c|c|c|c|c|c|c|c|c|c|c|}
\hline & Vc1 & Vc2 & Vc3 & Vc4 & Vc5 & Vc6 & Vc7 & Vc8 & Vv2 & ObA & ObB & ObC & ObD & Cc & Si & Otros & Tot \\
\hline Ch & - & - & - & 1 & - & - & - & - & - & . & - & - & - & 1 & - & - & 2 \\
\hline Bf & - & - & - & 1 & - & - & - & - & - & . & - & - & - & - & - & - & 1 \\
\hline Fuas & 1 & - & - & - & - & - & - & - & - & . & - & - & - & - & - & - & 1 \\
\hline Fbas & 1 & - & - & - & - & - & - & - & - & 1 & 1 & - & - & - & - & - & 2 \\
\hline Rp & - & 1 & - & 3 & - & - & 2 & - & - & 4 & 4 & - & - & - & - & - & 10 \\
\hline Rc & 3 & - & - & 1 & - & - & - & - & - & 5 & 5 & - & - & - & - & - & 9 \\
\hline Rd & 4 & 1 & - & 19 & - & - & 5 & - & - & 1 & 1 & - & - & - & - & - & 30 \\
\hline RBO & - & - & - & 2 & - & - & 1 & - & - & 1 & 0 & - & - & - & 1 & - & 14 \\
\hline Cfr & 1 & - & - & 2 & - & - & - & - & - & . & - & - & - & - & - & - & 3 \\
\hline $\mathbf{C t}$ & 1 & - & - & 3 & - & - & - & - & - & 2 & 2 & - & - & - & - & - & 6 \\
\hline Mu & 6 & - & - & 8 & - & 1 & 3 & - & - & 3 & 3 & - & - & - & 1 & 1 & 23 \\
\hline Dt & 1 & 1 & - & 7 & - & - & - & - & - & 1 & 1 & - & - & - & - & - & 10 \\
\hline PEM & 1 & - & - & 1 & - & 1 & - & - & - & . & - & - & - & - & - & - & 3 \\
\hline AB & 1 & - & - & 2 & - & - & - & - & - & 2 & 4 & - & - & - & - & - & 7 \\
\hline Per & - & - & - & - & - & - & - & - & - & 1 & 1 & - & - & - & 2 & - & 3 \\
\hline Es & - & - & - & - & - & - & - & - & - & 1 & 1 & - & - & - & & - & 1 \\
\hline PP & - & 1 & - & - & - & 1 & - & - & - & 2 & 1 & - & - & - & - & - & 23 \\
\hline FFP & 1 & - & - & - & - & - & - & - & - & - & - & - & - & - & - & - & 1 \\
\hline AFS & 2 & 3 & 1 & 9 & - & - & - & - & - & 1 & 1 & - & - & 2 & 1 & 2 & 21 \\
\hline $\mathbf{P} / \mathbf{A}$ & - & - & - & - & - & - & - & 65 & - & . & - & - & - & - & - & - & 65 \\
\hline F/fnd & 7 & 1 & - & 29 & - & - & 18 & - & - & 1 & 2 & - & - & - & 1 & 1 & 69 \\
\hline Tot & 30 & 8 & 1 & 88 & 0 & 3 & 29 & 65 & 0 & 6 & 7 & 0 & 0 & 3 & 6 & 4 & 304 \\
\hline
\end{tabular}

Referencias: Ch: Chopper. Bf: Biface. Fuas: Filo unifacial de arista sinuosa. Fbas: Filo bifacial de arista sinuosa. Rp: Raspador. Rc: Raclette. Rd: Raedera. RBO: Artefacto mediano pequeño/muy pequeño RBO sección asimétrica. Cfr: Cuchillo de filo retocado. Ct: Cortante. Mu: Muesca retocada y de lascado simple. Dt: Denticulado bisel oblicuo/abrupto sección asimétrica. PEM: Punta entre muescas. AB: Artefacto burilante. Per: Perforador. Es: Escoplo. Ci: Cincel. PP: Punta de proyectil. FFP: Filo formatizado pasivo. AFS: Artefacto de formatización sumaria. P/A: Pala y/o azada. F/fnd: Fragmento/filo no diferenciado de artefacto formatizado. Nota: El GC3 está formado por CChM1 y PP9. Los datos de CChM1 proceden de Escola (2000) y Escola et al. 2005). 


\subsection{APROXIMACIÓN DIACRÓNICA A LOS ARTEFACTOS FORMATIZADOS DESDE UNA PERSPECTIVA MORFOLÓGICO-FUNCIONAL}

$\mathrm{Si}$, tal como fue planteado en el Capítulo 4 al considerar los elementos constituyentes del conocimiento tecnológico, los productores y usuarios de los artefactos líticos tallados operan con un número limitado de clases instrumentales, la continuidad en el tiempo de ciertos grupos y subgrupos tipológicos implicaría una continuidad en el saber y, por ende, una historia morfológica común.

En este marco, una forma de abordar la recurrencia de los grupos tipológicos en el tiempo es establecer la presencia-ausencia de las diferentes clases artefactuales, sin entrar en consideraciones sobre variaciones en frecuencia de las mismas. Los resultados obtenidos son sugerentes: los tres grupos cronológicos comparten 15 grupos tipológicos de un total de 29 -no se han considerado los fragmentos y filos no diferenciados de artefactos formatizados- (Tabla 8.17, Apéndice II). Si bien esta cifra equivale a sólo un 51,72\%, deben tenerse en cuenta una serie de consideraciones que se exponen a continuación que afianzan la tendencia descripta.

En primer lugar, como ciertos grupos tipológicos han sido definidos recientemente (ver Capítulo 4), no pudieron ser tenidos en cuenta por Escola. Esto afecta de dos formas al GC3 (y, de esta forma, a la comparación en curso). Por un lado, ciertas categorías nuevas están presentes sólo en PP9 (como casos se señala al escoplo, al filo formatizado pasivo, al filo unifacial de arista sinuosa y al filo bifacial de arista sinuosa) y, por el otro lado, más importante aún, hay una serie de clases que directamente no están representadas, por lo que su ausencia puede ser el producto de este hecho (por ejemplo, la gubia y el cincel).

En segundo lugar, ciertos grupos tipológicos se vinculan exclusivamente con grupos cronológicos determinados. Un ejemplo de esto es el uniface en los GC1 y 2. Como típicos de dichos grupos cronológicos podrían definirse también los bifaces, ya que, pese a contarse con un ejemplar en el GC3, involucra una forma de tratar las caras de la pieza que es típica de los contextos previos al 3500 AP y que desaparece posteriormente. Desafortunadamente, no hay evidencias macroscópicas que lleven a pensar que dicha pieza es producto de una reclamación (Escola com pers.). Ciertos artefactos bipolares, asimismo, son característicos de los GC 1 y 2. Provisionalmente, se plantea que los mismos serían artefactos formatizados, por poseer características morfológico-macroscópicas afines a las cuñas (pieces esquillées) ${ }^{7}$, más que a núcleos -hay un sólo caso de núcleo bipolar en QS3 (Pintar 1990) para el lapso abordado-. Siguiendo los criterios definidos por Hayden (1980), entre otras serían: tamaños

\footnotetext{
${ }^{7}$ Tipológicamente, se los definió a nivel de subgrupo tipológico como artefactos bipolares no diferenciados (Apéndice II), de manera de obviar una denominación que puede ser incorrecta.
} 
Tabla 8.17. Presencia de grupos tipológicos por grupo cronológico

\begin{tabular}{|c|c|c|c|}
\hline GRUPOS TIPOLÓGICOS & GC1 & GC2 & GC3 \\
\hline CHOPPER & - & - & 2 \\
\hline UNIFACE & 2 & 3 & - \\
\hline BIFACE & 51 & 112 & 1 \\
\hline FILO UNIFACIAL DE ARISTA SINUOSA & - & - & 1 \\
\hline FILO BIFACIAL DE ARISTA SINUOSA & 5 & 15 & 2 \\
\hline CEPILLO & - & 1 & - \\
\hline RASPADOR & 8 & 23 & 10 \\
\hline RACLETTE & 17 & 32 & 9 \\
\hline RAEDERA & 6 & 24 & 30 \\
\hline LÁMINA RETOCADA & - & 1 & - \\
\hline ARTEF. MEDIANO PEQ./MUY PEQ. R.B.O. SECCIÓN ASIM & - & 2 & 14 \\
\hline CUCHILLO DE FILO RETOCADO & 16 & 23 & 3 \\
\hline CUCHILLO DE FILO NATURAL CON DORSO FORMATIZADO & 1 & 1 & - \\
\hline CORTANTE & 27 & 28 & 6 \\
\hline MUESCA RETOCADA Y DE LASCADO SIMPLE & 9 & 57 & 23 \\
\hline DENTICULADO BISEL OBLICUO / ABRUPTO SECCIÓN ASIM & 5 & 36 & 10 \\
\hline CUCHILLO DENTICULADO & 5 & 7 & - \\
\hline PERCUTOR DE ARISTA FORMATIZADA & 1 & 5 & - \\
\hline PUNTA ENTRE MUESCAS & 6 & 2 & 3 \\
\hline ARTEFACTO BURILANTE & 31 & 53 & 7 \\
\hline PERFORADOR & 1 & 6 & 3 \\
\hline GUBIA & 1 & 3 & - \\
\hline CINCEL & - & 2 & - \\
\hline ESCOPLO & - & 2 & 1 \\
\hline PUNTA DE PROYECTIL & 25 & 66 & 23 \\
\hline FILO FORMATIZADO PASIVO & 8 & 21 & 1 \\
\hline ARTEFACTO DE FORMATIZACIÓN SUMARIA & 13 & 30 & 21 \\
\hline ARTEFACTO BIPOLAR & 5 & 9 & - \\
\hline PALA Y/O AZADA & - & - & 65 \\
\hline $\begin{array}{l}\text { FRAGMENTO/FILO NO DIFERENCIADO DE ARTEFACTO } \\
\text { FORMATIZADO }\end{array}$ & 18 & 89 & 69 \\
\hline
\end{tabular}


de extracciones que normalmente no serían utilizables, aún para la confección de microlitos ${ }^{8}$ y negativos de lascado que no cubren la totalidad de las caras de la forma-base original, quedando, por lo tanto, remanentes de la misma. No obstante, se desea dejar en claro que tal asignación no es definitiva, y más aún cuando todavía no está cerrada la discusión sobre la diferenciación entre productos y subproductos del trabajo bipolar (Leaf 1979; Shott 1989b, 1999; Flegenheimer et al. 1995). Son necesarios análisis macroscópicos tecnológicos y tipológicos específicos y en profundidad, así como estudios funcionales de diversa índole sobre tales artefactos. Los mismos se realizarán en el futuro.

Ya en el GC3, dichos artefactos bipolares desaparecen (Tabla 8.17), pero no el trabajo bipolar, que se presenta bajo la forma de núcleos bipolares (Escola 2000), en función de la obtención de lascas, básicamente sobre obsidiana, con el fin de extremar la utilización de un recurso no local (Escola 2004b). Otra diferencia importante se relaciona justamente con la materia prima, puesto que todos los instrumentos bipolares de los GC1 y 2 se confeccionaron sobre rocas locales (ver Tablas 8.14 y 8.15).

En tercer y último lugar, las nuevas necesidades producto de la intensificación de las prácticas productivas llevaron a la generación de nuevos grupos tipológicos, sin correlato previo, que dan cuenta de la capacidad inventiva y de innovación ante requerimientos sin existencia previa, más allá de la utilización de diseños tradicionalmente utilizados. Es el caso de las palas y/o azadas en el GC3, que si bien pueden emplearse para diversas actividades no vinculadas con la subsistencia (por ejemplo, en la preparación de mezcla o mortero para la construcción), es indiscutible su participación en las labores agrícolas. A nivel de subgrupo tipológico, puede señalarse a las raederas de módulo grandísimo que, como se pudo comprobar aquí (ver punto 12.4. Identificación de desechos de talla de mantenimiento de raederas de módulo grandísimo en el Capítulo 12 y el Apéndice III), han sido empleadas también en tareas de producción agrícola.

Retomando el punto de la continuidad de los grupos tipológicos en los grupos cronológicos definidos, se señala que la misma no es casual. Se plantea que más allá de la variación en el tiempo de la preponderancia de las prácticas extractivas y productivas, las actividades de procesamiento y consumo implicaron un cierto número de "funciones primarias" (sensu Aschero 1975) que se mantuvieron relativamente constantes, dado su carácter básico. Esto adquiere sentido al tener en cuenta que todos los sitios tratados son bases residenciales, en los cuales se esperaría la ocurrencia de

\footnotetext{
${ }^{8}$ Se destaca que de los análisis tecnológicos realizados del instrumental de QS3, PCh1.3 y PCh1.1, no hay casos de lascas bipolares como formas-base. Por otra parte, entre los desechos de talla, hasta el momento, no se han identificado este tipo de lascas, tanto en QS3 (Aschero et al. 1993-94, Pintar 1996a, Manzi 1999), como en PCh1.3 y PCh1.1, de acuerdo a datos propios.

${ }^{9}$ Se tiene en claro que la información respecto de para qué fueron utilizados los instrumentos se logra sólo a través del análisis funcional; sin embargo, la morfología de los artefactos formatizados brinda herramientas para definir cuál sería "potencialmente” el mejor uso posible, en el marco de una gama acotada de acciones.
} 
múltiples actividades vinculadas con la utilización de artefactos líticos tallados, no limitados necesariamente a la subsistencia, como la vestimenta y la ornamentación, entre muchos otros.

En relación a cómo se emplea el instrumental, surge otro aspecto de sumo interés. Las funciones primarias implican tipos de acciones y modos de accionar que conllevan gestos técnicos específicos, involucrando operaciones de prensión digito-palmar e interdigital que son tan importantes como el instrumento mismo para la realización adecuada de la tarea, ya que es el gesto técnico el que lo hace técnicamente eficaz (Leroi-Gourhan 1971). De esta forma, la continuidad temporal de los grupos tipológicos señalada debería haber estado acompañada por la persistencia de gestos técnicos particulares. Al respecto, Leroi-Gourhan (ibid.) señala que las series de acciones que relacionan al instrumento y al gesto definen programas de comportamiento inscriptos en la memoria. Se plantea que tales programas estuvieron sujetos a transmisión cultural. Es interesante pensarlo, parafraseando a este autor, como una suerte de "memoria virtual”, cuyo contenido pertenece a la sociedad.

Diversos autores han manifestado la ocurrencia de un "empobrecimiento tecnológico" en situaciones donde la producción de alimentos es la actividad predominante, estando asociada a una baja movilidad residencial (Parry y Kelly 1987, Torrence 1989). En tales casos, generalmente se describe a los artefactos formatizados como amorfos y sin estandarización (ver, por ejemplo, Koldehoff, 1987, Torrence 1989, Jeske 1992, Cowan 1999). Se considera que esto responde, en parte, a la forma de clasificar al instrumental en las tipologías empleadas en tales trabajos ( $c f$.Andrefsky 1998, Odell 2001). Cabe preguntarse si en el caso que aquí compete se podría estar en presencia de un “empobrecimiento tipológico”, más allá de lo ocurrido con los aspectos tecnológicos. Así, la continuidad en el tiempo de los grupos tipológicos se contrapondría a esta idea.

A modo de ejercicio, más allá de los problemas resultantes de emplear el calificativo de “amorfo”en una tipología expresamente morfológica como la aquí usada ${ }^{10}$, se analiza la proporción del único grupo tipológico de la clasificación de Aschero $(1975,1983)$ que se correspondería con las características de lo que en la bibliografía se considera un instrumento "amorfo", el artefacto de formatización sumaria y, dentro de éste, específicamente, a los subgrupos tipológicos artefacto con formatización sumaria y filo con formatización sumaria (no entraría aquí el esbozo de pieza bifacial). Así, en el GC1 los artefactos y filos con formatización sumaria constituyen el 5,35\%, en el GC2 el 4,96\% y en el GC3 el 8,09\% (en los conteos no se han incluido los filos y fragmentos no diferenciados de artefacto formatizado), De esto resulta, en primer lugar, la baja frecuencia de la categoría en cuestión a lo largo de la secuencia abordada. En segundo lugar, aún con el leve aumento en el GC3 se

${ }^{10}$ Ver los comentarios vertidos en este trabajo acerca de la condición de "informales" y "amorfos" de los artefactos formatizados en el punto 1.1.2.2. La inversión del trabajo en la manufactura de artefactos líticos del Capítulo 1. 
está lejos de la tendencia que sería esperable de acuerdo a la bibliografía citada, o sea, de mayor incidencia del instrumental amorfo a medida que pase el tiempo, para culminar siendo preponderante.

Una forma más operativa de abordar si hubo un empobrecimiento tipológico o no, en función de la perspectiva tipológica en ciernes, es a través de la consideración de las variaciones en el tiempo de la cantidad de subgrupos tipológicos, ya que, como se ha visto, la diferencia no estaría a nivel de grupo tipológico, dados los requerimientos múltiples en cuanto a funciones primarias de las bases residenciales. Un empobrecimiento, entonces, debería implicar una disminución en el número de subgrupos presentes.

Para tal estimación se parte de la obtención de la media del número de subgrupos tipológicos por grupo cronológico. En función de esto, en la Tabla 8.18 se expone la cantidad de subgrupos tipológicos para cada uno de los grupos tipológicos que conforman los grupos cronológicos (los conteos se realizaron sobre la base de los listados presentados en el Apéndice II). Es pertinente a continuación realizar algunos comentarios sobre la forma de tratar las muestras. En primer lugar, para la diferenciación de los subgrupos tipológicos se partió de la extensión relativa del filo y de la posición relativa del filo, pero sin considerar en esta última las medidas de inclinación (Aschero 1975), ya que la discriminación en subgrupos realizada por Escola (2005) para CChM1 no contaba con ese nivel de clasificación, por lo que era necesario homogeneizar las variables. En segundo lugar, es pertinente abordar la forma de contar. En el caso de grupos tipológicos que tengan a nivel de subgrupo una única categoría que sea no diferenciada (por ejemplo, un raspador no diferenciado), se la toma como un sólo caso de subgrupo; no siendo así cuando se presentan combinadas con subgrupos diferenciados, ya que en tales situaciones no son considerados. Esto se debe a que un subgrupo no diferenciado podría corresponder al o a algún subgrupo diferenciado. Finalmente, se aclara que en los conteos no se han incluido los filos y fragmentos no diferenciados de artefacto formatizado.

Los resultados alcanzados señalan una media de 2,76 en el GC1, de 3,27 en el GC2 y de 2,15 en el GC3. Los datos reseñados muestran, efectivamente, un decrecimiento en el GC3; sin embargo, se considera que este detrimento no es producto de una restricción en las opciones tipológicas con posterioridad al $2100 \mathrm{AP}$, sino, sencillamente, un reflejo de necesidades específicas que llevaron a la confección de ciertos artefactos y no de otros. De la misma forma pueden entenderse los valores obtenidos en los GC1 y 2. Esto lleva a plantear que los grupos humanos que ocuparon Antofagasta de la Sierra entre el 5500 y el 1500 AP disponían del conocimiento de toda una gama de alternativas morfológico-funcionales (aunque no infinita), que equivaldrían a lo que en el Capítulo 3 se definió como proyectos, y dentro de éstos, a los esquemas conceptuales (Pelegrin 1995) -que, se recuerda, son socialmente transmitidos y compartidos-, seleccionando ciertas variantes del total de diseños posibles en función de los requerimientos concretos de las situaciones que se les presentaban. Así puede 
Tabla 8.18. Cantidad de subgrupos tipológicos por grupo tipológico para cada uno de los sitios considerados

\begin{tabular}{|c|c|c|c|}
\hline GRUPOS TIPOLÓGICOS & GC1 & GC2 & GC3 \\
\hline CHOPPER & - & - & 1 \\
\hline UNIFACE & 1 & 1 & - \\
\hline BIFACE & 2 & 2 & 1 \\
\hline FILO UNIFACIAL DE ARISTA SINUOSA & - & - & 1 \\
\hline FILO BIFACIAL DE ARISTA SINUOSA & 1 & 1 & 1 \\
\hline CEPILLO & - & 1 & - \\
\hline RASPADOR & 5 & 11 & 4 \\
\hline RACLETTE & 6 & 8 & 4 \\
\hline RAEDERA & 2 & 2 & 4 \\
\hline LÁMINA RETOCADA & - & 1 & - \\
\hline $\begin{array}{l}\text { ARTEF. MEDIANO PEQ./MUY PEQ. R.B.O. } \\
\text { SECCIÓN ASIM }\end{array}$ & - & 2 & 3 \\
\hline CUCHILLO DE FILO RETOCADO & 3 & 5 & 1 \\
\hline $\begin{array}{l}\text { CUCHILLO DE FILO NATURAL CON DORSO } \\
\text { FORMATIZADO }\end{array}$ & 1 & 1 & - \\
\hline CORTANTE & 5 & 5 & 2 \\
\hline $\begin{array}{l}\text { MUESCA RETOCADA Y DE LASCADO } \\
\text { SIMPLE }\end{array}$ & 4 & 5 & 3 \\
\hline $\begin{array}{l}\text { DENTICULADO BISEL OBLICUO / ABRUPTO } \\
\text { SECCIÓN ASIM }\end{array}$ & 2 & 6 & 4 \\
\hline CUCHILLO DENTICULADO & 2 & 2 & - \\
\hline PERCUTOR DE ARISTA FORMATIZADA & 1 & 4 & - \\
\hline PUNTA ENTRE MUESCAS & 3 & 1 & 1 \\
\hline ARTEFACTO BURILANTE & 11 & 10 & 3 \\
\hline PERFORADOR & 1 & 2 & 2 \\
\hline GUBIA & 1 & 1 & - \\
\hline CINCEL & - & 1 & - \\
\hline ESCOPLO & - & 1 & 1 \\
\hline PUNTA DE PROYECTIL & 3 & 5 & 2 \\
\hline FILO FORMATIZADO PASIVO & 1 & 3 & 1 \\
\hline $\begin{array}{l}\text { ARTEFACTO DE FORMATIZACIÓN } \\
\text { SUMARIA }\end{array}$ & 2 & 3 & 3 \\
\hline ARTEFACTO BIPOLAR & 1 & 1 & - \\
\hline PALA Y/O AZADA & - & - & 1 \\
\hline
\end{tabular}

Nota: Los grupos cronológicos están conformados de la siguiente forma: GC1: QS3. GC2: PP4 -4 a 5(5)-, PCh1.1 y PCh1.3. GC3: CCHM1 y PP9. 
entenderse, en el GC2, la presencia de raspadores de filo perimetral y extendido, así como bilaterales, además de otros subgrupos, en PP4 y en PCh1.6, a diferencia de los sitios sincrónicos PCh1.1 y PCh1.1, en los que sí se encuentran otras clases de raspadores. En definitiva, parecería que la idea de un empobrecimiento tipológico no caracterizaría adecuadamente el caso de Antofagasta de la Sierra ${ }^{11}$, pese a la existencia de ciertos casos que apuntan a lo contrario. Al respecto, pueden mencionarse a los bifaces, ya que en el GC3 desaparecen los bifaces en sentido estricto y los bifaces parciales están representados por un único ejemplar. Esto sería la respuesta tipológica a la desaparición del adelgazamiento bifacial y al hecho de que la reducción bifacial dejó de implicar bifaces parciales como formas-base secundarias. Así, estaría en todo de acuerdo con las evidencias tecnológicas suministradas en el punto siguiente (8.4.1.1. Evidencias de cambio en la inversión de trabajo: Clases técnicas en artefactos formatizados). Es más, suministrarían indirectamente evidencia de que el biface parcial posiblemente sea producto de reclamación.

Otro caso es el de las puntas de proyectil, que se limitan en el GC3 a sólo dos subgrupos, habiendo, inclusive, una diferenciación temporal entre los mismos, ya que, en base a información de CChM1 (Escola 2000), los diseños pedunculados, si bien se registran a lo largo de toda la secuencia estratigráfica, son exclusivos del lapso 2100-1700 AP, mientras que los diseños apedunculados aparecen sólo en el lapso 1700-1500 AP. En realidad, más que un empobrecimiento, esto refleja un proceso de estandarización de la morfología de las puntas de proyectil a lo largo del tiempo (ver Capítulo 11). Cabe destacar que ambos casos no serían el resultado de una disminución lisa y llana de los subgrupos tipológicos per se, sino consecuencia de la disminución de la movilidad residencial y la consolidación de labores productivas, con la consiguiente disminución de los riesgos de corto plazo, que afectarían procesos en curso de índole tecnológica y tipológica (ver Capítulo 13).

Sin embargo, hay otro tipo de evidencia que si está en consonancia con la perspectiva de una simplificación de los conjuntos de artefactos formatizados que componen las muestras analizadas, que se relacionan con una serie de cambios progresivos en la cantidad de partes componentes por pieza, con el transcurso del tiempo. Para su abordaje, se parte de la noción de complejidad, que implica, justamente, el número de partes por instrumento (en base a Oswalt 1976). Siguiendo los requerimientos del estudio en curso, se ha modificado la acepción original del término en dos sentidos. Por un lado, se amplía su uso a todo el instrumental y no sólo al extractivo y, por el otro lado, la combinación de partes no implica materiales de distinta índole.

\footnotetext{
${ }^{11}$ Si habría evidencias, en cambio, de lo que Escola (2000) ha señalado como una suerte de "degeneración tecnológica” en función de la consolidación de estrategias expeditivas a partir del 2100 AP. Así también, en el punto 8.5. Evidencias de cambio en la inversión de trabajo, en este Capítulo, se exponen una serie de resultados que indican una reducción considerable en cuanto a opciones tecnológicas e inversión de trabajo.
} 
Con el objeto de cuantificar su composición, cada instrumento se ha analizado en función de la identificación de transformaciones (aplicadas exclusivamente a bifaces), combinaciones, superposiciones y reciclajes a partir de la identificación de secuencias tipológicas y secuencias de formatización (ver Capítulo 4).

Es importante realizar algunas especificaciones sobre la forma de cuantificación. Así, el caso más sencillo, un filo simple, contaría con una complejidad de 1. Se destaca que a las puntas de proyectil y bifaces se las considera como una unidad, es decir, como piezas simples, pese a que de hecho poseen varían partes que varían según el caso (formas, pentagonales, triangulares, etc.); esto se hace así a los fines comparativos. Asimismo, un artefacto doble o compuesto por dos filos o puntas, o una pieza trasformada o reciclada en un filo, presentaría una complejidad de 2. Por otro lado, un instrumento compuesto por tres filos y/o puntas o una pieza transformada en un filo y posteriormente reciclada, la complejidad sería 4 , y así sucesivamente, cubriendo múltiples posibilidades. Finalmente, no se han incluido en el análisis fragmentos no diferenciados de artefactos formatizados.

A partir de la Tabla 8.19. es posible observar una disminución en el número de partes del instrumental con el paso del tiempo, ya que en los GC 1 y 2 se cuenta con un máximo de 7 partes, estando representadas todas las categorías entre 1 y 7 , más allá de la importancia relativa de cada una, mientras que el GC3 registra, por su parte, como máximo, sólo 4 partes. Esto estaría señalando una restricción sustantiva en la cantidad de partes formatizadas por pieza, a partir del 2100 AP aproximadamente.

Ahora bien, al considerar la frecuencia de casos de piezas simples versus las categorías restantes (2 a 7 para el GC1 y el GC2 y 2 a 4 para el GC3) surge que en el GC1 el nivel 1 de complejidad cuenta con un $44,21 \%$ y que la suma de partes combinadas involucra un 55,79\%. Ya en el GC2, la tendencia se invierte, ya la categoría 1 implica el 54,86\% de los casos y la sumatoria de las categorías 2 a 7 el 45,13\%. Finalmente, en el GC3 dicha tendencia se profundiza, al presentar un 87,27\% de piezas simples y sólo un 12,73\% de artefactos con dos o más de dos partes. A partir de estos datos claramente se vislumbra un proceso de simplificación en cuanto a número de partes en los artefactos formatizados utilizados entre los 5500 y los 1500 años AP, que se radicaliza ca.2100 AP. 
Tabla 8.19. Complejidad del instrumental por grupo cronológico

\begin{tabular}{|c|c|c|c|}
\hline COMPLEJIDAD & GC1 & GC2 & GC3 \\
\hline $\mathbf{1}$ & 42 & 175 & 144 \\
\hline $\mathbf{3}$ & 13 & 98 & 5 \\
\hline $\mathbf{4}$ & 19 & 24 & 2 \\
\hline $\mathbf{5}$ & 15 & 13 & - \\
\hline $\mathbf{6}$ & 2 & 4 & - \\
\hline $\mathbf{7}$ & 3 & 4 & - \\
\hline
\end{tabular}

Nota: Nota: Los grupos cronológicos están conformados de la siguiente forma: GC1: QS3. GC2: PP4 -4 a 5(5)-, PCh1.1 y PCh1.3. GC3: CCHM1 y PP9.

Los datos de CChM1 en cuanto a artefactos combinados y reciclajes, insertos en el GC3, provienen de Escola (2005)

A modo de corolario, puede plantearse que las diferentes evidencias suministradas distan de reflejar un proceso simple y lineal definido por un "empobrecimiento tipológico". Si bien parte de éstas dan cuenta de una simplificación, en función de la complejidad instrumental que se ve disminuida, desde la representación de los grupos y subgrupos tipológicos la idea de continuidad se manifiesta en toda su dimensión.

\subsection{EVIDENCIAS DE CAMBIO EN LA INVERSIÓN DE TRABAJO}

\subsubsection{VARIACIONES EN INVERSIÓN DE TRABAJO EN LA MANUFACTURA DE ARTEFACTOS LÍTICOS TALLADOS (5500-1500 AP)}

8.4.1.1. Evidencias de cambio en la inversión de trabajo: Clases técnicas en artefactos formatizados

Se recuerda que la noción de clase técnica distingue justamente grados de trabajo invertido en la producción de artefactos líticos tallados (por un tratamiento pormenorizado de las implicancias del término ver punto 4.3.4. Clase técnica en el Capítulo 4), por lo que su aplicación con el objeto de abordar cambios en la inversión de tiempo y energía en la confección de artefactos formatizados es 
pertinente. Cabe destacar que en la estimación de la inversión de trabajo no se tienen en cuenta los costos de obtención de la materia prima (en función de la distancia, por ejemplo), así como los costos de extracción de la forma-base. Un caso paradigmático de esto último lo constituirían las raederas de módulo grandísimo, dado que por su tamaño implicarían un gran esfuerzo de obtención (cf.Escola 2000). De esta forma, se consideran aquí sólo los costos de formatización, a lo que se suma la destreza técnica.

La clasificación de los artefactos formatizados en clases técnicas (por una descripción de las categorías empleadas ver punto 4.4.Características de las clases técnicas en el Capítulo 4) se basó en la consideración de las siguientes muestras (Tabla 8.20): el total de artefactos formatizados recuperados en QS3, PCh1.1, PCh1.3 y PP9 (Sector I.E3 y Sector III.E2 -niveles 4 a 6-), los instrumentos obtenidos en las excavaciones de PP4 durante las campañas correspondientes a los años 1996 y 1999 y la “...muestra no probabilística ... objeto de un análisis tecnológico profundo” empleada por Escola (2000: 118) en su Tesis Doctoral. Se destaca que se emplearon exclusivamente materiales líticos procedentes de excavación.

Tabla 8.20. Clases técnicas en artefactos formatizados por sitio y grupo cronológico

\begin{tabular}{|c|c|c|c|c|c|c|c|c|c|c|}
\hline \multirow[t]{2}{*}{ SITIO } & \multicolumn{10}{|c|}{ CLASE TÉCNICA } \\
\hline & $\begin{array}{c}\text { adela } \\
\text { bif }\end{array}$ & $\begin{array}{c}\text { Red } \\
\text { bif }\end{array}$ & $\begin{array}{l}\text { Adelg/red } \\
\text { bif }\end{array}$ & $\begin{array}{l}\text { Adelg } \\
\text { unif }\end{array}$ & $\begin{array}{l}\text { Red } \\
\text { unif }\end{array}$ & $\begin{array}{c}\text { Trab } \\
\text { no inv } \\
\text { bif }\end{array}$ & $\begin{array}{c}\text { Trab } \\
\text { no inv } \\
\text { unif }\end{array}$ & $\begin{array}{c}\text { Trab } \\
\text { no inv } \\
\text { alter }\end{array}$ & $\begin{array}{c}\text { Trab } \\
\text { bip }\end{array}$ & No dif \\
\hline QS3 & 32 & 13 & 8 & 0 & 2 & 42 & 107 & 12 & 5 & 16 \\
\hline $\begin{array}{c}\text { PP4 } \\
-5(6)-\end{array}$ & 1 & 1 & 2 & 0 & 0 & 0 & 9 & 0 & 0 & 6 \\
\hline GC1 & 33 & 14 & 10 & $\mathbf{0}$ & 2 & 42 & 116 & 12 & 5 & 22 \\
\hline $\begin{array}{c}\text { PP4 } \\
-4 / 5(5)-\end{array}$ & 24 & 8 & 19 & 0 & 0 & 18 & 178 & 2 & 1 & 52 \\
\hline PCh1.3 & 10 & 22 & 12 & 0 & 1 & 29 & 112 & 7 & 1 & 20 \\
\hline PCh1.1 & 32 & 9 & 16 & 1 & 1 & 35 & 145 & 4 & 7 & 31 \\
\hline GC2 & 66 & 39 & 47 & 1 & 2 & 82 & 435 & 13 & 9 & 103 \\
\hline CChM1 & 0 & 22 & 0 & 0 & 0 & 7 & 107 & 0 & 0 & 61 \\
\hline PP9 & 0 & 3 & 0 & 0 & 0 & 7 & 31 & 0 & 0 & 2 \\
\hline GC3 & 0 & 25 & 0 & 0 & 0 & 14 & 138 & 0 & 0 & 63 \\
\hline
\end{tabular}


Trab no inv unif: trabajo no invasivo unifacial. Trab no inv alter: Trabajo no invasivo alternante. Trab bip: Trabajo bipolar. No dif: No diferenciada.

$\mathrm{Al}$ analizar las frecuencias de artefactos formatizados en los sitios arqueológicos considerados (Figura 9.1), es posible advertir la coexistencia de una serie de alternativas tecnológicas con distinto grado de inversión de trabajo en la formatización de artefactos, así como una fluctuación en las frecuencias de las mismas a lo largo del tiempo. Es importante tener en cuenta que para la estimación de los porcentajes no se incluyó la categoría “No diferenciada” (Tabla 8.1).

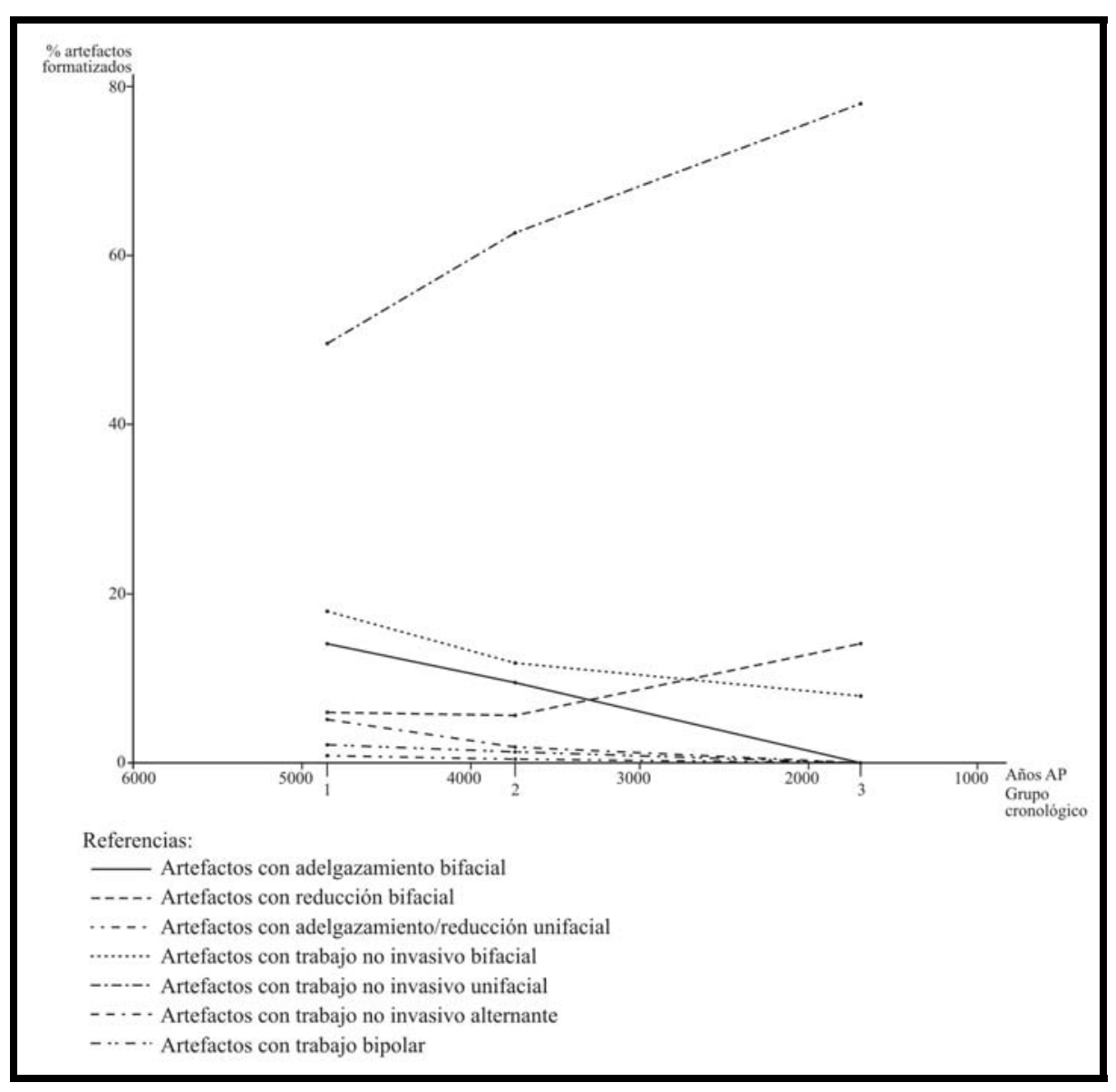

Figura 8.1. Tendencias temporales de clases técnicas en artefactos formatizados

De esta forma, se registra que en los artefactos formatizados confeccionados por adelgazamiento bifacial hay una tendencia a un marcado decrecimiento que involucra la desaparición de esta clase técnica hacia los 2000 años AP, ya que se pasa de un 14,10\% a un 0\% de representación en los conjuntos. Estas tendencias son corroboradas al analizar los porcentajes de las lascas de adelgazamiento bifacial en muestras de desechos de talla (ver punto siguiente 9.1.2. Evidencias de cambio en la inversión de trabajo. Otras líneas de evidencia: Índices diversos). 
En el caso de aquellos instrumentos producidos por reducción bifacial, por su parte, se observa que permanecen relativamente constantes al pasar del GC1 al GC2 -5,98\% y 5,62\%, respectivamente-, para posteriormente aumentar considerablemente en el GC3 -14,12\%-.

En concordancia con el adelgazamiento bifacial, literalmente desaparecen el adelgazamiento y la reducción unifacial en los artefactos formatizados hacia los 3500 años AP. Se hace notar que la representatividad de los mismos es muy baja, ya que en el GC1 es del 0,85\% y en el GC2 es del 0,43\%. Dado lo mínimo de las muestras, en la Figura 8.1 ambas categorías se tomaron en conjunto.

Ahora bien, de la correlación de estas clases técnicas que involucran el tratamiento de la o las caras, surge que el adelgazamiento bifacial prevalece sobre la reducción bifacial hasta los 3500 años AP, para desaparecer hacia el 2000 AP, invirtiéndose dramáticamente la relación. Si a esto se suma la ausencia del adelgazamiento y de la reducción unifacial, es claro que la reducción bifacial no sólo es la única que continúa, sino que, además, ve incrementado notoriamente su papel, el cual está orientado a la confección de las puntas de proyectil con limbo triangular de tipo isósceles, pedúnculo diferenciado y aletas entrantes, típicas de los contextos agro-pastoriles plenos (Escola 2000).

En la Tabla 8.20 se ha definido una categoría, no incluida en la Figura 8.1, de “Adelgazamiento/reducción bifacial”, que refiere a piezas en las que no es posible establecer con precisión a cuál de tales clases técnicas pertenecen. Nótese que dicha categoría está presente en los GC 1 y 2 exclusivamente, como es esperable, dado que posteriormente sólo se cuenta con reducción bifacial.

En lo que respecta a los artefactos que presentan formatización exclusiva de los bordes se pueden establecer ciertas tendencias relevantes. Así, en el trabajo no invasivo bifacial se registra una disminución en la frecuencia de esta clase técnica a lo largo del tiempo, siendo mucho más importante del GC1 al GC2 que del GC2 al GC3 -17,95\% a 11,82\% y 11,82 a 7,91\%, respectivamente-. Un punto que debe ser tenido en cuenta para entender cabalmente el cambio de esta clase técnica en el tiempo es considerar el papel emergente de las palas y/o azadas en el GC3, sin correlato previo en el ámbito local. Se destaca que tales artefactos son confeccionados únicamente mediante trabajo no invasivo bifacial. Al respecto, en la muestra no probabilística de CChM1 definida por Escola (2000), aquí empleada, no se incluyó esta clase de instrumentos, por lo que las mismas no están incorporadas a los conteos por clase técnica. Desafortunadamente, la muestra de CChM1 presenta un alto grado de fragmentación, del 99,34\% -N: 151- (ibid.) y no se ha estimado un número mínimo de piezas (Escola 
com pers.). Pese a que no se puede cuantificar, su aparición implicaría un incremento importante en la frecuencia del trabajo no invasivo bifacial con posterioridad al 2000 AP.

Al considerar el trabajo no invasivo unifacial, se evidencia un destacado incremento tanto al pasar de GC1 al GC2 como del GC2 al GC3 -del 49,57\% al 62,68\% y del 62,68\% al 77,97\%, respectivamente. Es claro que esta clase técnica tuvo un rol preponderante a lo largo de toda la secuencia ocupacional, dadas sus frecuencias ampliamente mayoritarias en relación a las clases restantes. Así, al comparar la diferencia entre el porcentaje de esta clase técnica con la que le sigue en importancia por su frecuencia (ver Tabla 8.19), para cada grupo cronológico, se observa que es verdaderamente notable, y que aumenta con el tiempo -31,62\% en el GC1, 50,86\% en el GC2 y $64,41 \%$ en el GC3-.

El trabajo no invasivo alternante, por su parte, presenta frecuencias mínimas en los GC1 y 2, y nula en el GC3.

Finalmente, el trabajo bipolar reviste la misma situación que el caso anterior. Cabe hacer la salvedad que la técnica bipolar continúa en el GC3, pero ya no en el marco de la manufactura de artefactos formatizados, sino con un objetivo completamente distinto como es la extracción de lascas a partir de núcleos bipolares (Escola 2000).

A partir de la comparación de los instrumentos por adelgazamiento y reducción, por un lado, con aquellos confeccionados por trabajo no invasivo y trabajo bipolar, por el otro, surge que el trabajo no invasivo en sus formas unifacial y bifacial es predominante sobre las categorías restantes, tanto en el GC1 -49,57\% y 17,95\%, respectivamente- como en el GC 2 -62,68\% y 11,82\%, respectivamente-. En cambio, en el GC3 hay un predominio del trabajo no invasivo unifacial -77,97\%-, que en este caso está acompañado por la reducción bifacial -14,12\%-.

Más aún, el trabajo no invasivo unifacial, como se vio previamente, ve acrecentada su importancia relativa con el paso del tiempo, ante la disminución de las frecuencias de artefactos formatizados confeccionados por adelgazamiento y reducción -con excepción de la reducción bifaciale, inclusive del trabajo no invasivo bifacial, es decir, se habría potenciado a expensas de estos últimos. En este sentido, es destacable que para el 2000 AP prácticamente todo el repertorio de artefactos formatizados se confeccionaba de esta manera, quedando exceptuadas las puntas de proyectil y las palas y/o azadas. Por otra parte, desaparecen al finalizar el GC2 una serie de alternativas tecnológicas que implican tanto destacada como escasa inversión de trabajo -adelgazamiento y reducción unifacial 
versus trabajo no invasivo alternante y trabajo bipolar-. De hecho, en los GC 1 y 2 se contaban con la posibilidad de confeccionar instrumentos de ocho formas distintas, mientras que en el GC3 este número se restringió a tan sólo tres.

En función de esto podría postularse la ocurrencia de un proceso de "empobrecimiento tecnológico" 12 , que se contrapone a la ausencia del "empobrecimiento tipológico" tratado previamente en el punto 8.4. Aproximación diacrónica a los artefactos formatizados desde una perspectiva morfológico-funcional. Diversos trabajos previos en Antofagasta de la Sierra ya habían hecho referencia a esta situación, pero básicamente en relación a una reducción en el esfuerzo de manufactura. Por ejemplo, Pintar (1996a), al abordar a QS3 y PCh1.1, entre otros sitios, manifiesta lo antedicho, así como Escola (2000), a la vez que ésta última autora señala que el adelgazamiento bifacial estaría ausente en CChM1.

Se plantea que las variaciones expuestas en las frecuencias artefactuales, así como el desuso de buena parte de las mismas, pueden ser entendidas como el resultado de procesos de toma de decisiones, donde las elecciones de los grupos humanos que ocuparon Antofagasta de la Sierra entre el 5500 y el 1500 AP implicaron, en la cuenta larga, una tendencia a invertir un menor esfuerzo en la manufactura de artefactos formatizados tallados con el paso del tiempo. En efecto, se produjo la desaparición del adelgazamiento bifacial, del adelgazamiento y la reducción unifacial y se mantuvo la reducción bifacial pero sólo vinculada a la confección de puntas de proyectil. Desaparecieron, inclusive, alternativas de baja inversión de trabajo como el trabajo no invasivo alternante y el trabajo bipolar (en función de la manufactura de artefactos). Simultáneamente, se registra un virtual reemplazo de dichas clases técnicas por el trabajo no invasivo bifacial y unifacial, siendo preponderante este último. De esta forma, se optó por estrategias tecnológicas con bajos costos de producción en cuanto a requerimientos de tiempo, energía y destreza técnica (cf.Pintar 1996a, Escola 2000). Se plantea que esto tuvo como correlato importantes cambios en el conocimiento tecnológico local a lo largo del tiempo, en lo que respecta al saber (recetas para la acción y tecno-ciencia), a los requerimientos de destreza técnica y a la aplicación de sistemas de enseñanza concretos (lo cual es desarrollado en los Capítulos 10 y 13).

8.4.1.2. Evidencias de cambio en la inversión de trabajo. Otras líneas de evidencia: Utilización de índices diversos

La tendencia señalada en el punto anterior es corroborada al analizar los porcentajes de las lascas de adelgazamiento bifacial en muestras de desechos de talla y al realizar conteos de artefactos

\footnotetext{
${ }^{12}$ Se considera que este término es más apropiado que el de "degeneración tecnológica”, puesto que este último conlleva la idea de algo negativo y descalifica un proceso que por ciertas causas tuvo una direccionalidad determinada.
} 
con adelgazamiento bifacial, artefactos bifaciales en general, totales de artefactos tallados o retocados y núcleos presentes, resultantes de aplicar los índices propuestos por Parry y Kelly (1987), Aschero (1975) y Ericson (1984) (Tabla 8.21).

Tabla 8.21. Indicadores de adelgazamiento y trabajo bifacial

\begin{tabular}{|l|c|c|c|}
\hline \multicolumn{1}{|c|}{ INDICADORES } & GC1 & GC2 & GC3 \\
\hline $\begin{array}{l}\text { Razón biface-núcleos } \\
\text { (Parry y Kelly 1987) }\end{array}$ & 5,50 & 2,44 & 0 \\
\hline $\begin{array}{l}\text { Indice de bifacialidad } \\
\text { (sensu Ericson 1984) }\end{array}$ & 0,64 & 0,22 & 0 \\
\hline $\begin{array}{l}\text { Indice de bifacialidad } \\
\text { (sensu Aschero 1975) }\end{array}$ & 0,42 & 0,34 & 0,22 \\
\hline
\end{tabular}

El primero de estos índices ha sido reiteradamente asociado a diferencias en los niveles de sedentarismo (Parry y Kelly 1987, Hayden et al. 1996, Andrefsky 1998, Odell 1998), o con variaciones en el riesgo (Torrence 1989) en momentos de cambios en la organización de la subsistencia (Abbott et al. 1996). Más allá de cuáles sean los mecanismos causales, las variaciones en el tiempo de la razón biface/núcleo de lasca se vinculan con cambios tecnológicos que implican modificaciones en la inversión de trabajo, en función de la preponderancia de una u otra categoría (Cowan 1999).

Al comparar la razón biface/núcleo de lasca entre los grupos cronológicos considerados se registra justamente lo que señalan las evidencias obtenidas en cuanto a clases técnicas, ya que se observa una notoria disminución del índice con el paso del tiempo, siendo de 0 en el GC3 (Tabla 8.21). Esto resulta así debido a que el GC1 cuenta con 33 bifaces y 6 núcleos de lasca; el GC2 con 66 bifaces y 27 núcleos de lasca y el GC3 con 0 bifaces y 18 núcleos de lasca. Se destaca que en los conteos se han considerado sólo los bifaces confeccionados por adelgazamiento bifacial, pudiendo ser bifaces en sí mismos, transformados o reciclados. En cuanto a las muestras empleadas, se utilizó el total de materiales recuperados en excavación en QS3, PCh1.3 y PCh1.1, los provenientes de las campañas 1996 y 1999 de PP4, la muestra no probabilística de CChM1 definida por Escola (2000) y los artefactos procedentes de las Estructuras 3 (Sector I) y 2 (Sector III) -niveles 4 a 6- de PP9.

Cabe realizar un comentario acerca de la presencia de bifaces en el registro arqueológico local. En los GC1 y 2, los bifaces han sido confeccionados tanto por adelgazamiento bifacial -bifaces en sentido estricto-, como por reducción bifacial -bifaces parciales-. En el GC3, en cambio, el único biface documentado habría sido confeccionado por reducción bifacial. A éste se suma la reducción 
bifacial implementada en la confección de las puntas de proyectil exclusivamente, pero que, se destaca, no tienen bifaces parciales como formas-base secundaria, sino sencillamente lascas (Escola 2000; ver discusión en Aschero y Hocsman 2004).

En relación a la aplicación de esta razón biface-núcleos de lasca, los resultados no deben ser tomados literalmente. Un trabajo relativamente reciente de Bamforth y Becker (2000), en base a experiencias de remontaje de desechos de talla del sitio Paleoindio Allen, ha demostrado que dicha razón no necesariamente documenta cambios tecnológicos. Específicamente, observan que el valor de la razón biface/núcleos se invierte al considerar la razón en base a secuencias remontadas de lascas, lo que significaría que se desbastaron muchos más núcleos en el sitio Allen de los que efectivamente fueron descartados, estando esta categoría subrepresentada en la estrategia tecnológica total. Esta situación se relacionaría con el hecho de que los bifaces y los núcleos poseen trayectorias de vida diferentes. Mas allá de estos aspectos a tener en cuenta, que llevan a considerar a esta razón con recaudos, la disminución en el número de bifaces confeccionados por adelgazamiento bifacial, evidenciado por el porcentaje decreciente de tales artefactos en función del resto del instrumental (Tabla 8.20), es un hecho indudable.

Otra forma de medir el cambio tecnológico ha sido comparar la frecuencia de las lascas de adelgazamiento bifacial en relación a los tipos de lasca restantes (Parry y Kelly 1987, Andrefsky 1998). Para Bamforth y Becker (2000), su utilización conforma una visión más ajustada que en el caso anterior porque tienen trayectorias de vida más acotadas, aunque reconocen que no siempre sus variaciones reflejan cambios tecnológicos. Para considerar los tipos de lasca -“origen de las extracciones” sensu Aschero 1983- se instrumenta el Indice de bifacialidad de Ericson (1984), que consiste en el cociente entre el total de lascas de adelgazamiento bifacial y el total de desechos de talla.

Se destaca que los conteos se realizaron en función del Número Mínimo de Desechos (Aschero et al. 1993-94). De esta forma, las muestras se conformaron de la siguiente manera: en el caso del GC1 se emplearon datos sólo del sitio QS3, provenientes de distintas fuentes (Tabla 8.22) -no se incluyó al nivel 1 por no contarse con la información respectiva-. En el GC2, por su parte, se empleó información de desechos de talla de las campañas: a) Septiembre de 2002 de PCh1.3 (la muestra consiste de 71 lascas de adelgazamiento bifacial y de 760 desechos de talla en total), b) 1999 de PP4 (365 lascas de adelgazamiento bifacial y 1186 desechos totales, y c) Enero/Febrero de 1991 de PCh1.1 (40 lascas de adelgazamiento bifacial y 323 desechos de talla en total). A este último sitio debe sumarse el análisis tecnológico de desechos de talla realizado por Pintar (1996a: 231-232), con 281 lascas de adelgazamiento bifacial sobre 1179 desechos de talla. Finalmente, el GC3 está formado por 133 desechos de talla correspondientes a PP9 y 1074 lascas a CChM1 (Escola 2000: 194), sin presencia de lascas de adelgazamiento bifacial en ambos casos. 
Tabla 8.22. Cantidad de lascas de adelgazamiento bifacial y total de desechos de talla por nivel. QS3-2b2 a 2b5-

\begin{tabular}{|c|c|c|c|}
\hline Nivel & $\begin{array}{c}\text { Lascas de } \\
\text { adelgazamiento } \\
\text { bifacial }\end{array}$ & $\begin{array}{c}\text { Total de } \\
\text { desechos de talla }\end{array}$ & Fuente \\
\hline $2 \mathrm{~b} 2$ & 79 & 316 & Manzi 1999 \\
\hline $2 \mathrm{~b} 3$ & 284 & 838 & Pintar 1996a \\
\hline $2 \mathrm{~b} 4$ & 2097 & 3198 & $\begin{array}{c}\text { Aschero } \text { et al. } \\
1993-94\end{array}$ \\
\hline $2 \mathrm{~b} 5$ & 1346 & 1556 & Manzi 1999 \\
\hline Total & 3806 & 5908 & \\
\hline
\end{tabular}

La tendencia así generada revela que el índice se hace cada vez menor, en función de la disminución progresiva de la frecuencia de lascas de adelgazamiento bifacial entre los 5500 y los 1500 años AP, siendo 0 en el último grupo cronológico (Tabla 8.21).

Al respecto, Escola (2000) sostiene que la bifacialidad presente en CChM1 no está basada en procedimientos de adelgazamiento bifacial, debiéndose reconocer una importante diferencia técnica entre la manufactura de un artefacto por adelgazamiento bifacial o simplemente por retoque bifacial. Esto es extensible al caso de PP9. Es decir, la bifacialidad existe, pero solamente como trabajo bifacial marginal o parcialmente extendido. Esto se comprueba aplicando el Indice de bifacialidad de Aschero (1975), que se funda en el cociente entre el total de piezas bifaciales (incluidas las marginales) y el total de artefactos tallados o retocados.

Los resultados son claros, el Indice de bifacialidad en el GC3 es de 0,22, aumentando los valores a medida que se retrocede en el tiempo (Tabla 8.21). La información utilizada parte del reconocimiento de filos, puntas y piezas de morfología global bifaciales dentro del set de artefactos formatizados que compone cada grupo cronológico (cabe aclarar que no se han tabulado los instrumentos no diferenciados). Así, el GC1 (QS3 y PP4 -5(6) campaña 1999-) posee 99 instrumentos bifaciales de un total de 234 filos, puntas y piezas de morfología global, el GC2 (PP4 -4 a 5(5) campaña 1999-, PCh1.1 y PCh1.3) 234 de 694 y el GC3 (CChM1 -Escola 2000- y PP9 I.E3 y III.E2 niveles 4 a 6-) 39 de 177.

Ahora bien, si al conteo de piezas bifaciales de este último sitio se le suman las palas y/o azadas con trabajo bifacial por retalla y talla marginal de CChM1 (Escola 2000), el Índice de bifacialidad se vería incrementado notablemente, más allá de que la mayor parte de las piezas 
corresponde a fragmentos. Su ocurrencia denota el papel emergente del trabajo bifacial marginal en el GC3, por la aparición de un instrumento con características particulares de manufactura.

La aplicación de las distintas razones aquí expuestas, más allá de las frecuencias de las distintas clases de artefactos empleados en la comparación y de las consideraciones y críticas vertidas en relación a su utilización, muestra una tendencia que es ineludible, la desaparición del adelgazamiento bifacial en contextos agro-pastoriles hacia los 2000 años AP. Sin embargo, la bifacialidad persiste, pero solamente como trabajo marginal o parcialmente extendido, e inclusive se potencia, con la aparición de nuevas clases de instrumentos.

\subsubsection{INVERSIÓN DE TRABAJO Y COMPLEJIDAD EN ARTEFACTOS FORMATIZADOS}

Interesa abordar aquí el cambio en el tiempo de la inversión de trabajo en artefactos formatizados, a nivel de pieza. Al respecto, se ha postulado que a medida que se incrementa el esfuerzo y el tiempo invertido en la producción de instrumentos, aumenta también la vida útil de los mismos, por ejemplo, a través del mantenimiento y del reciclaje (Shott 1989a, Bousman 1993, Andrefsky 1998). Asimismo, a medida que se eleva la inversión de trabajo sería esperable la ampliación de la secuencia total de formatizaciones (Bousman 1993). Se destaca que esto podría implicar, entre otros aspectos, un mayor número de partes. Por esta razón, sería posible establecer un vinculo entre inversión de trabajo y complejidad (ver las modificaciones realizadas al término en el punto 8.4. Aproximación diacrónica a los artefactos formatizados desde una perspectiva morfológicofuncional). Una expectativa resultante de esto sería que los artefactos con mayor inversión de trabajo deberían presentar la complejidad más alta.

Dado que la comparación tiene su fundamento a nivel de pieza, se plantea diferenciar entre puntas de proyectil, bifaces y "resto del instrumental", siendo los dos primeros instrumentos los de mayor inversión de trabajo en los conjuntos. Cabe destacar con respecto a la última categoría que, pese a que tiene la desventaja de englobar un número significativo de grupos tipológicos, los mismos se definen mayoritariamente por una baja inversión de trabajo. Así, dentro de cada una de estas clases artefactuales se analizan transformaciones (aplicadas exclusivamente a bifaces), combinaciones, superposiciones y reciclajes a partir de la identificación de secuencias tipológicas y secuencias de formatización (ver Capítulo 4). Por especificaciones en cuanto al tratamiento de los conteos de partes ver punto 8.4. Aproximación diacrónica a los artefactos formatizados desde una perspectiva morfológico-funcional). Es conveniente realizar dos comentarios: por un lado, que en el caso de las puntas de proyectil que provienen de bifaces transformados, no se las incluye dentro de estos últimos con el objetivo de establecer si presentan un comportamiento distinto a los bifaces y al resto del 
instrumental y, en segundo lugar, que en los bifaces transformados se analiza en definitiva en qué consiste la transformación, por ejemplo, si se confeccionó un filo simple, o si se combinaron diferentes filos, y si hubo reciclaje.

Del análisis de la información recuperada surgen ciertas tendencias reveladoras. Así, en la Tabla 8.23 puede apreciarse que en las categorías bifaces y resto del instrumental tuvo lugar una disminución progresiva en la complejidad, con el paso del tiempo (posteriormente se tratará el caso de las puntas de proyectil que presenta ciertas particularidades). Esto es interesante, ya que, de acuerdo a lo comentado previamente, los bifaces son artefactos con fuerte inversión de trabajo en su confección, por lo que deberían presentar una complejidad elevada; sin embargo, al comparar los GC1 y 2, los bifaces registran una caída de la misma de casi 30\% -tomando en conjunto la complejidad de 2 a 7, se pasa de 68,97\% en el GC1 a 40,91\% en el GC2-, mientras que en el "resto del instrumental" la disminución es de sólo un 8\%, aproximadamente -55,56\% en el GC1 a 47,14\% en el GC2-. Es decir, que los artefactos con mayor inversión de trabajo -léase bifaces- no sólo disminuyeron en su número de partes, sino que lo hicieron más drásticamente que el "resto del instrumental”. Aparentemente, entonces, la toma de decisiones llevó a que el esfuerzo de manufactura en los bifaces, bajo la forma de transformaciones y reciclaje, se reduzca significativamente hacia los 3600 años AP; es decir, se incidió principalmente sobre los artefactos confeccionados con gran inversión de tiempo y energía, en un contexto de reducción global de la complejidad. Cabe destacar que en el GC3 los bifaces prácticamente desaparecen, por lo que no puede realizarse comentario alguno al respecto (aunque de por sí este hecho es significativo); en tanto que en el "resto del instrumental” la complejidad se hace insignificante, puesto que los artefactos simples cuentan con una representación del 91,78\%.

Las puntas de proyectil, por su parte, presentan un panorama no muy claro en este sentido. En los tres grupos cronológicos hay un predominio del nivel 1 de complejidad -78,25\% en el GC1, 58,46\% en el GC2 y 100\% en el GC3-, en contra de lo esperable. Esto implica que la incidencia del reciclaje es muy baja. Para entender esto, es conveniente analizar si hay alguna tendencia con respecto al reciclado de las piezas y en cuanto al estado de las puntas de proyectil sin reutilización. Por ejemplo, en QS3, en el GC1, con respecto a estas últimas, se presentan en número de 18, de las cuales 9 son fragmentos de pedúnculo y de limbo, relativamente pequeños, y las 9 restantes se presentan enteras o con fracturas de poca relevancia. Ya que los casos de reciclaje (N: 5) se dan exclusivamente en piezas enteras o con fracturas mínimas, con evidencias de mantenimiento extensivo o de fracturas por impacto, podrían señalar una direccionalidad en la selección de los artefactos a reciclar, lo que descartaría los fragmentos de pedúnculo y limbo mencionados, así como a las piezas completas restantes. 
Tabla 8.23. Complejidad en puntas de proyectil, bifaces y resto del instrumental, por grupo cronológico

\begin{tabular}{|c|c|c|c|c|}
\hline INSTRUMENTO & COMPLEJIDAD & GC1 & GC2 & GC3 \\
\hline \multirow[t]{7}{*}{ Punta de proyectil } & 1 & 18 & 38 & 23 \\
\hline & 2 & 2 & 18 & - \\
\hline & 3 & 1 & 7 & - \\
\hline & 4 & 1 & 2 & - \\
\hline & 5 & - & - & - \\
\hline & 6 & 1 & - & - \\
\hline & 7 & - & - & - \\
\hline \multirow[t]{7}{*}{ Biface } & 1 & 8 & 26 & 1 \\
\hline & 2 & 4 & 7 & - \\
\hline & 3 & 8 & 4 & - \\
\hline & 4 & 5 & 4 & - \\
\hline & 5 & 1 & - & - \\
\hline & 6 & 1 & 3 & - \\
\hline & 7 & 1 & - & - \\
\hline \multirow{7}{*}{$\begin{array}{l}\text { Resto del } \\
\text { instrumental }\end{array}$} & 1 & 20 & 120 & 134 \\
\hline & 2 & 7 & 78 & 9 \\
\hline & 3 & 7 & 14 & 3 \\
\hline & 4 & 9 & 9 & - \\
\hline & 5 & 1 & 4 & - \\
\hline & 6 & 1 & 1 & - \\
\hline & 7 & - & 1 & - \\
\hline
\end{tabular}

Nota: El GC1 está constituido sólo por QS3, el GC2 por PP4 -4 a 5(5), PCh1.1 y PCh1.3 y el GC3 por CChM1 y PP9. En el GC3 los datos de CChM1 provienen de Escola (2000, 2005).

Más aún, las puntas de proyectil que se presentan en el registro arqueológico como tales no presentan mayor complejidad sencillamente porque no había razón para extender su vida útil, más allá del mantenimiento extensivo visible en la mayor parte de las mismas, ya que el diseño se mantenía funcional, pudiendo ser, inclusive, parte del equipamiento del sitio. Esta serie de razonamientos pueden extrapolarse perfectamente al GC2.

A modo de corolario, en base a lo desarrollado en los puntos 8.4. Aproximación diacrónica a los artefactos formatizados desde una perspectiva morfológico-funcional y 8.5.1.1. Evidencias de cambio en la inversión de trabajo: Clases técnicas en artefactos formatizados, se pudo comprobar que 
en el lapso abordado habría habido tanto una disminución en la complejidad instrumental como una tendencia a una reducción en inversión de tiempo y energía en la manufactura de artefactos líticos tallados. Desde la perspectiva de la vinculación entre esfuerzo de manufactura y complejidad esto se vería corroborado, con el adicional de evidencias que señalan que la inversión de trabajo diferencial per se no habría influenciado la disminución en la complejidad.

\subsubsection{CAMBIOS EN LA INVERSIÓN DE TRABAJO EN LA PORCIÓN MERIDIONAL DE LOS ANDES CENTRO-SUR}

Si bien no se cuenta, hasta el momento, con información específica acerca de las variaciones de las clases técnicas en sitios arqueológicos de la Puna Septentrional y su borde, así como del borde de Puna en el Desierto del Norte de Chile, ubicados temporalmente entre los 5000 y los 1500 años AP, es factible emplear información édita e inédita de modo de analizar, preliminarmente, si la tendencia a invertir un menor esfuerzo en la manufactura de artefactos formatizados, establecida para Antofagasta de la Sierra, se limitaba al ámbito local o bien tenía carácter regional.

En general, los trabajos considerados señalan que los conjuntos de artefactos formatizados, de distintas cronologías, están formados por piezas con distinto grado de inversión de trabajo, diferenciando, por un lado, artefactos formatizados de baja inversión de tiempo y energía, manufacturados por trabajo unifacial marginal y, por el otro, piezas con mayor inversión de trabajo, bifaciales, generalmente puntas de proyectil y preformas de las mismas (por ejemplo, Núñez 1992, 1994; Lavallée et al. 1997; García 1998; Yacobaccio et al. 1999; Muscio 2004).

Más allá de esto, las muestras están compuestas mayoritariamente por instrumentos confeccionados con bajos costos de producción, como lo atestiguan las ocupaciones del sitio Tomayoc, datadas entre 3500 y 3200 años AP (Lavallée et al. 1997), localizado en la Sierra del Aguilar, o del Alero Unquillar, fechadas hacia los 3500 años AP (Yacobaccio et al. 2000), situado en Susques, en la Puna Norte argentina. Así, en el primero de los sitios, interesan particularmente las Fases II -3480-3250 AP- y III -3000-1530 AP-, aunque sólo se cuenta con información de la primera

-N: 41- (Lavallée et al. 1997). En ésta, los artefactos formatizados con inversión de trabajo mínima constituyen el 92,68\%, mientras que los instrumentos con mayor inversión de trabajo sólo el 7,32\%. Con respecto al segundo de los sitios, al considerar los instrumentos de las Capas 1 y 2 -N: 13- (los datos proceden de Yacobaccio et al. (2000: Tabla 3), el 92,31\% está formado por artefactos con baja inversión de tiempo y energía en su confección, en tanto que el 7,69\% restante por instrumentos con mayor inversión en la manufactura. Se destaca aquí la coincidencia con la secuencia de Antofagasta de la Sierra. 
Al igual que en esta última, además, la información disponible permitiría sostener una tendencia a invertir menor tiempo y energía en la producción de artefactos tallados con el paso del tiempo, a nivel regional. En este sentido pueden señalarse las conclusiones alcanzadas por Carrasco (2004) en cuanto a una disminución en la inversión de trabajo al analizar una serie de sitios adscribibles al Arcaico Tardío, Formativo Temprano, Formativo Tardío, Intermedio Tardío y Tardío de la localidad de Caspana en el ambiente desértico del norte de Chile, o las afirmaciones coincidentes de Rees y De Souza (2004) al abordar el Período Formativo en la Subregión del Río Salado, a una escala espacial más grande en relación con el primero.

Esta tendencia surge, también, de la comparación de los sitios Tulán 52 y Puripica 1 (Núñez 1981), por un lado, y Tulán 54 (Núñez 1994), por el otro, localizados en las Quebradas de Tulán y Puripica, en el desierto del Norte de Chile. Antes de pasar al caso concreto, es pertinente destacar que la adscripción a clases técnicas planteada es preliminar, ya que está basada sólo en las descripciones tipológicas de las categorías de artefactos formatizados realizadas por L. Núñez y equipo y no sobre los artefactos en sí. No obstante, se considera viable su uso si le lo toma como una aproximación gruesa, como es este caso.

Así, los dos primeros sitios, datados entre los 5000 y 4000 años AP, muestran estrechas coincidencias en la representación de las piezas formatizadas por adelgazamiento/reducción bifacial y unifacial en relación a aquellas confeccionadas por trabajo no invasivo bifacial y unifacial, siendo de 34\% y 66\%, respectivamente, en Tulán 52 (datos tomados de Núñez 1981), y de 33,80\% y 66,20\%, respectivamente, en Puripica 1 (en base a datos de Núñez et al. 1999). Estas diferencias de porcentaje entre dichas categorías generales se profundizan al incluir al sitio Tulán 54, fechado entre los 3200 y 2600 años AP, ya que pasan a un 7,82\% y a un 90,42\%, respectivamente (datos de Núñez 1994), señalando la misma tendencia general observada en Antofagasta de la Sierra de preponderancia relativa del trabajo no invasivo con el paso del tiempo.

Ahora bien, de acuerdo a observaciones preliminares de materiales líticos de los sitios Tulán 52 y $54^{13}$, surgen dos aspectos de interés claramente disímiles a lo ocurrido en Antofagasta de la Sierra, relacionados con las frecuencias de aparición del adelgazamiento y de la reducción bifacial. En primer lugar, la importancia relativa de la reducción bifacial sobre el adelgazamiento bifacial en Tulán 52, situación inversa a la de los GC 1 y 2 y, en segundo lugar, la presencia de adelgazamiento bifacial en Tulán 54 en proporciones significativas, cuando en el GC3 prácticamente había desaparecido.

Este último punto es importante, ya que implica que el adelgazamiento bifacial estaba plenamente vigente en un contexto agro-pastoril inicial datado hacia los $3000 \mathrm{AP}$, lo cual se ve

\footnotetext{
${ }^{13}$ Lo cual fue posible sólo gracias al total acceso brindado por L. Núñez a las colecciones de ambos sitios y a la
} colaboración de P. De Souza. 
reforzado por la presencia de esta clase técnica en contextos agro-pastoriles tempranos de la Puna Norte argentina. Ejemplo de esto son los artefactos recuperados en Cueva de Cristóbal, con

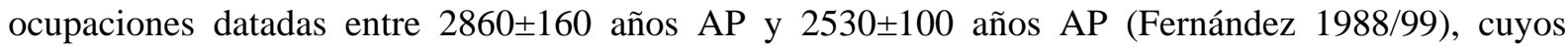
materiales incluyen artefactos formatizados confeccionados de esta forma (al menos 10 piezas de acuerdo a descripciones y fotografías) y lascas de adelgazamiento bifacial (53,96\% del total de desechos -N: 63-). También pueden mencionarse las lascas de adelgazamiento bifacial, con una representación del 11,2\% (sobre cuarcita) -N: 391-, de las capas 5 y 6 del sitio Inca Cueva alero 1, fechada la primera en 2900£70 AP (García y Carrion 1992, García 1998).

Esto significaría que, por lo menos en las áreas consideradas, la desaparición de esta clase técnica se produjo en el seno de las sociedades productoras puneñas y no durante la transición de cazadores-recolectores a grupos agropecuarios, entre los 3000 y 2500 años AP aproximadamente.

Al respecto, se toma como límite más tardío esta fecha ya que las evidencias de adelgazamiento bifacial tienden a desaparecer para estos momentos, de acuerdo a información recuperada en sitios datados entre 2500 y 2000 años AP de la Puna argentina y su borde, tales como: Las Cuevas, Cerro el Dique y Potrero Grande (Raffino 1977), en la Quebrada del Toro, o Campo Colorado (Tarragó 1996), en el Alto Valle Calchaquí, todos situados en el borde oriental de la Puna salteña; Cochinoca 39, en Susques, en la Puna jujeña (Fernández Distel 1998); y Estancia Grande, en la Quebrada de Humahuaca, en el borde oriental de la Puna Jujeña (Palma y Olivera 1992/93).

Entonces, para el 2500 AP, continuaría sólo la reducción bifacial, empleada específicamente en la confección de las puntas de proyectil de limbo triangular con pedúnculo diferenciado y aletas entrantes (Escola 1987, 1991). Si a esto se suma la desaparición de la reducción unifacial, ampliamente extendida en sitios de la Puna argentina con anterioridad a los 3000 AP y cuyo artefacto arquetípico serían las llamadas puntas Saladillo (Fernández 1996), resulta en una mayor importancia relativa del trabajo no invasivo en los conjuntos con el paso del tiempo.

Sin lugar a dudas, para validar las tendencias aquí señaladas se requiere no sólo de una recopilación de mayores casos, sino también de un análisis pormenorizado de las muestras en base a una caracterización por clases técnicas. En este marco, se podría sugerir, como hipótesis a investigar, que la disminución en la inversión de trabajo en los artefactos tallados fue un proceso relativamente ubicuo en el altiplano de la porción meridional de los Andes Centro-Sur, más allá de las particularidades regionales. 


\section{CAPÍTULO 9}

\section{TIPOS Y ESPECÍMENES MORFOLÓGICOS}

\subsection{DESCRIPCIÓN DE TIPOS MORFOLÓGICOS Y ESPECÍMENES MORFOLÓGICOS}

En esta sección se describen los tipos y especímenes morfológicos presentes en Antofagasta de la Sierra entre el 5500 y el 1500 AP. Se recuerda que los primeros se caracterizan por la recurrencia de ciertos atributos morfológicos en una serie de piezas, mientras que en los segundos, en cambio, tal recurrencia no existe, ya que aparecen en un sólo sitio como un único ejemplar (ver punto 4.3.8. Tipo en el Capítulo 4).

Ahora bien, la caracterización de un diseño dado como tipo morfológico (en adelante, TM) o espécimen morfológico (en adelante, EM) puede establecerse tanto en formas específicas de filos o puntas (por ejemplo, raspadores, cuchillos de filo retocado, etc.) como de piezas de morfología global (puntas de proyectil, bifaces, palas, etc.). La definición de tales atributos particulares se basa en la identificación de una regularidad y recurrencia en variantes morfológicas específicas, de índole técnica y/o funcional, o bien de características que particularizan un diseño, haciéndolo distinguible del resto del conjunto instrumental.

De esta forma, se han definido como TM o EM piezas de morfología parcial como los cortantes de filo retocado microdenticulados convergentes sin ápice activo y las raederas de módulo grandísimo, y piezas de morfología global, básicamente diseños de puntas de proyectil, aunque también se cuenta con palas y/o azadas y raspadores de filo perimetral.

En las puntas de proyectil, en particular, para la designación de los TM y EM se debieron emplear no sólo diseños básicos, sino también mantenidos y transformados (por una definición de y diferenciación entre estos conceptos ver punto 4.3.8. Tipo en el Capítulo 4), ya que las muestras se vieron sometidas a importantes procesos de extensión de su vida útil. Siguiendo a Flenniken y Raymond (1986), el mantenimiento de los limbos, entre otros factores, puede producir cambios morfológicos severos que llevan a que se generen formas diferentes a las originales. Por ello, cobra relevancia la morfología de los pedúnculos, ya que no se ven por lo general afectados por la 
reactivación de los filos. De esta forma, a partir de los pedúnculos es posible definir tipos o especímenes morfológicos (diseños básicos), más allá de que se trate de diseños transformados.

La definición de los distintos TM y EM se instrumentó sobre la base de: a) una “caracterización tipológica”, que implicaba, por ejemplo, en las puntas de proyectil, definir si se trataba de piezas pedunculadas o apedunculadas y la descripción de la forma general del contorno y de la morfología del limbo, las aletas y el pedúnculo; b) las “dimensiones” de las piezas, involucrando la estimación del rango, la media y la desviación standard en cuanto a largo, ancho y espesor máximos (para todo el instrumental) y a la longitud, ancho de la raíz, espesor de la raíz y ancho de la base del pedúnculo (para puntas de proyectil exclusivamente) -se destaca que para la medición de cada una de estas variables se tomaron sólo piezas enteras o con fracturas mínimas en cuanto al atributo medido-; y c) “observaciones”, en las que se desarrollaron todo tipo de comentarios para una mejor clasificación e identificación de las piezas.

Para el armado de cada una de las categorías propuestas se emplearon tanto instrumentos procedentes de excavación como recolectados en superficie, en forma sistemática o asistemática, a lo largo de las investigaciones en el área. Esto no sólo permitió aumentar las muestras sino que permitió incluir, además, artefactos formatizados de interés que de otra forma no hubiesen podido ser tenidos en cuenta. La mayor parte de los TM y EM se elaboró en función de piezas procedentes de los sitios que son la base de esta investigación, a saber QS3, PP4 (campañas 1996, mayo de 1998 y 1999), PCh1.3, PCh1.1, PP9 y CChM1. Asimismo, se consideraron instrumentos de PCh1.6, Cueva Salamanca 1 CS1-, Laguna Colorada 2.1 (?) -LC 2.1-, PP1 y sector comprendido entre Piedra Horadada 2 y El Sembrado.

Cabe destacar, finalmente, con respecto a las puntas de proyectil vinculadas a ocupaciones entre el 5500 y el 3400 AP, que se pudo adscribir a un TM o EM, el 83,07\% (N: 189) de las mismas. El 16,93\% restante corresponde a piezas que no pueden ser vinculadas a diseños específicos, más allá del hecho de poder establecer si se trataba de artefactos pedunculados o apedunculados. Al discriminar dentro de este último (N: 32), resulta que el 75\% son fragmentos de puntas de proyectil en forma de ápices, partes de limbos o de pedúnculos, el 12,5\% a piezas enteras con mantenimiento extremo, el 9,38\% a piezas recicladas y el 3,12\% restante a una preforma de punta de proyectil pedunculada. 


\subsubsection{CARACTERIZACIÓN DE TIPOS MORFOLÓGICOS}

\begin{tabular}{|c|c|}
\hline $\begin{array}{l}\text { Tipo morfológico Quebrada Seca B.2 (QS B) } \\
\text { Caracterización tipológica: } \\
\text { Punta de proyectil con pedúnculo destacado, aletas entrantes } \\
\text { rectas u obtusas. La presencia de hombros o aleta y hombro } \\
\text { es indicadora de transformación. } \\
\text { Limbo lanceolado o triangular de bordes convexos o rectos } \\
\text { (en casos con mantenimiento). Limbo largo o mediano (corto } \\
\text { por mantenimiento). } \\
\text { Bordes del pedúnculo paralelos rectos, con regularización } \\
\text { alterna. } \\
\text { Forma de la base del pedúnculo concavilínea atenuada. Casos } \\
\text { aislados de bases escotadas en } V \text {. }\end{array}$ & \\
\hline 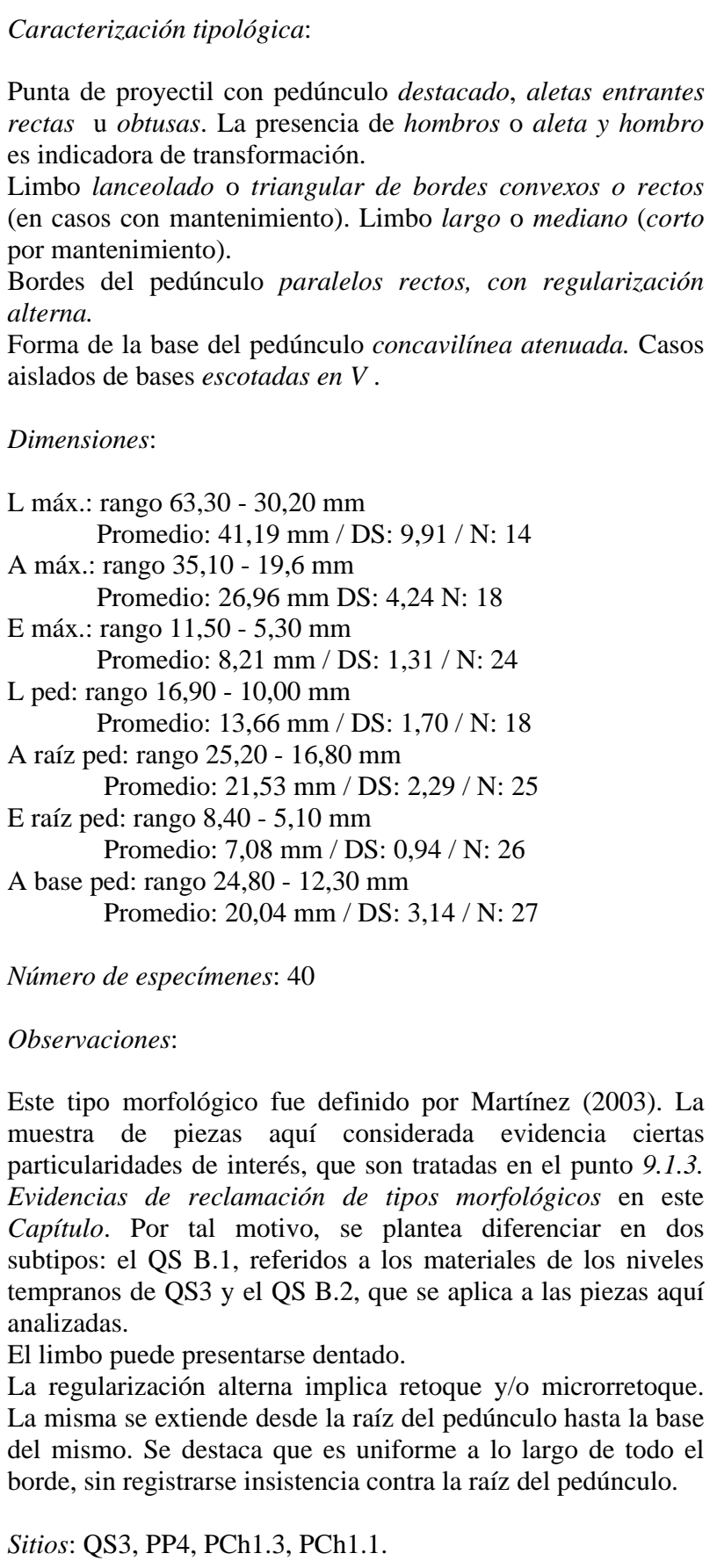 & (4) \\
\hline
\end{tabular}




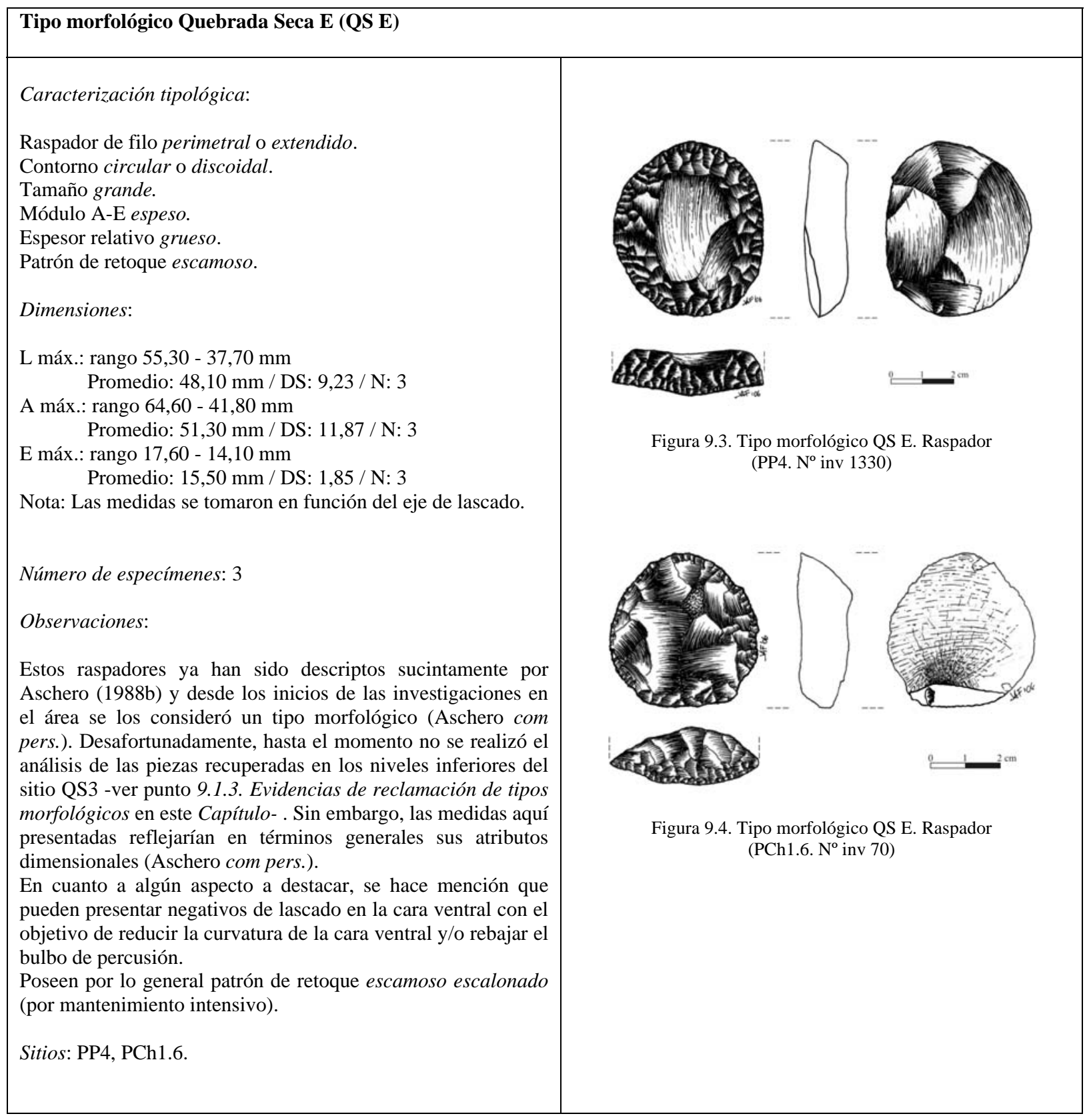




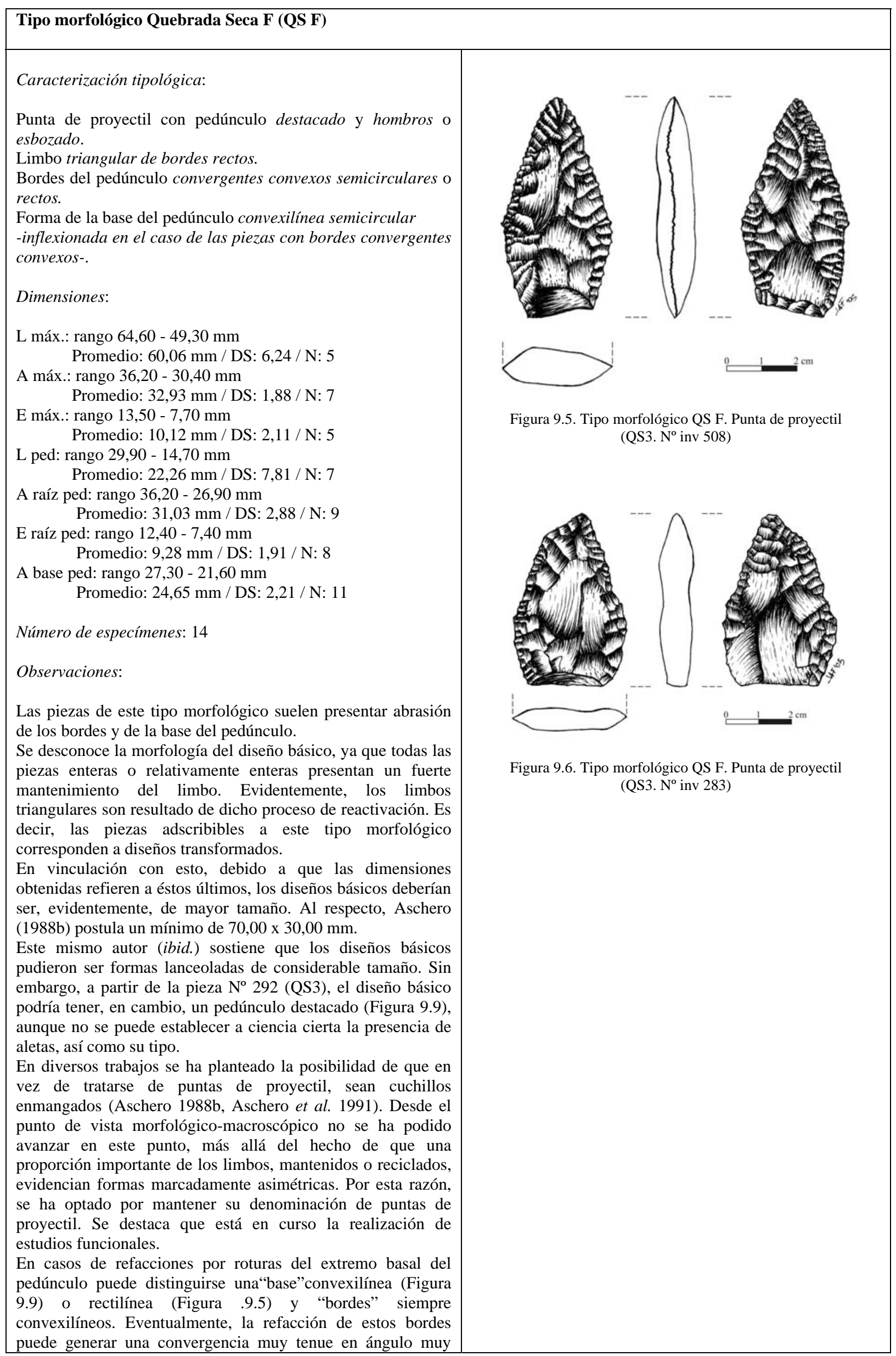


obtuso que no permite diferenciar una” base”(Figura .9.11)

En base a la ocurrencia de diferencias en la morfología del pedúnculo es factible discriminar dos subtipos morfológicos, que se detallan a continuación.

Sitios: QS3, PCh1.3

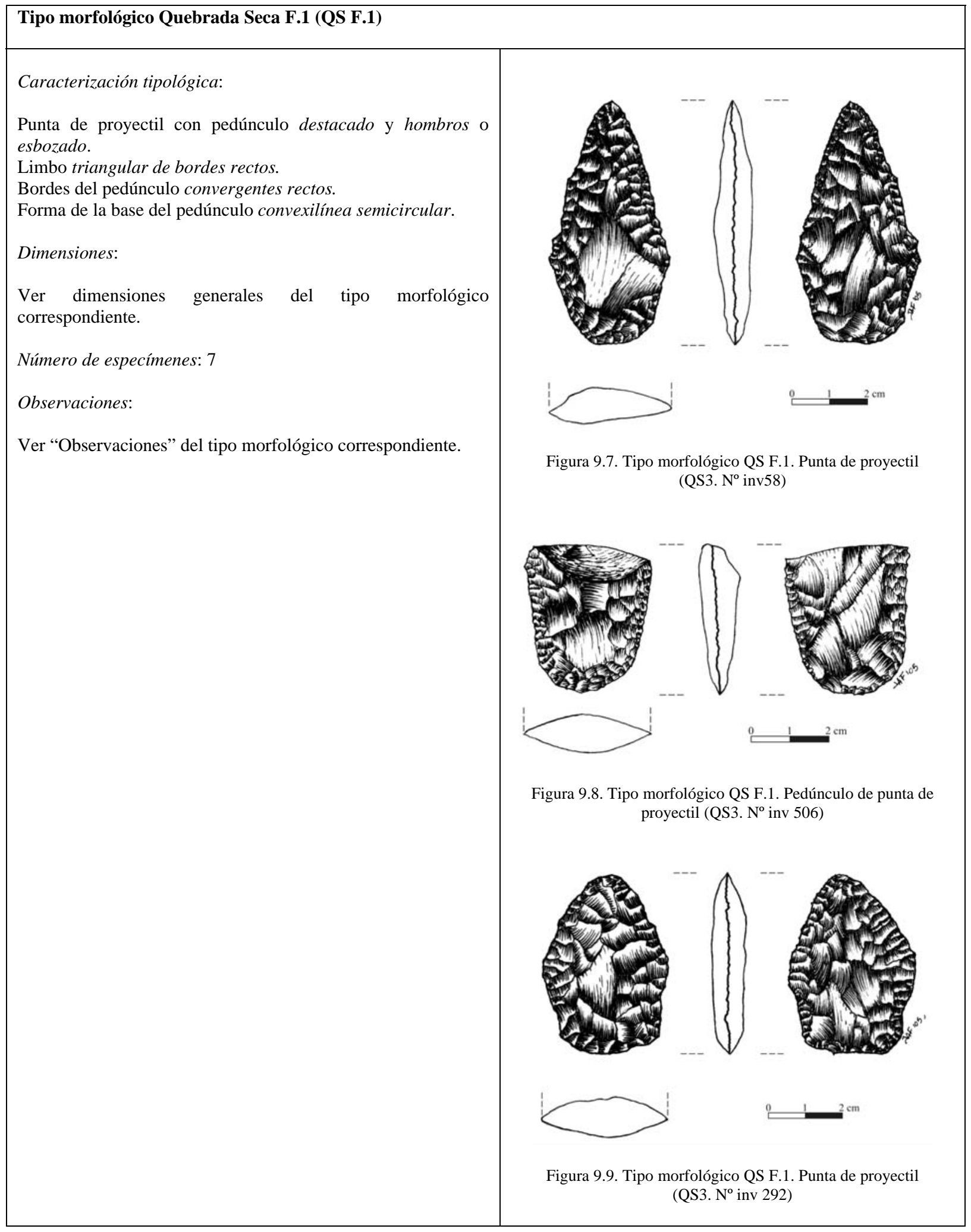




\begin{tabular}{|c|c|}
\hline $\begin{array}{l}\text { Subtipo morfológico Quebrada Seca F.2 (QS F.2) } \\
\text { Caracterización tipológica: } \\
\text { Punta de proyectil con pedúnculo destacado y hombros o } \\
\text { esbozado. } \\
\text { Limbo triangular de bordes rectos. } \\
\text { Bordes del pedúnculo convergentes convexos semicirculares. } \\
\text { Forma de la base del pedúnculo convexilínea semicircular } \\
\text { inflexionada. }\end{array}$ & \\
\hline $\begin{array}{l}\text { Caracterización tipológica: } \\
\text { Punta de proyectil con pedúnculo destacado y hombros o } \\
\text { esbozado. } \\
\text { Limbo triangular de bordes rectos. } \\
\text { Bordes del pedúnculo convergentes convexos semicirculares. } \\
\text { Forma de la base del pedúnculo convexilínea semicircular } \\
\text { inflexionada. } \\
\text { Dimensiones: } \\
\text { Ver dimensiones generales del tipo morfológico } \\
\text { correspondiente. } \\
\text { Número de especímenes: } 7 \\
\text { Observaciones: } \\
\text { Ver “Observaciones” del tipo morfológico correspondiente. }\end{array}$ & Figura 9.11. Tipo morfológico QS F.2. Punta de proyectil \\
\hline
\end{tabular}




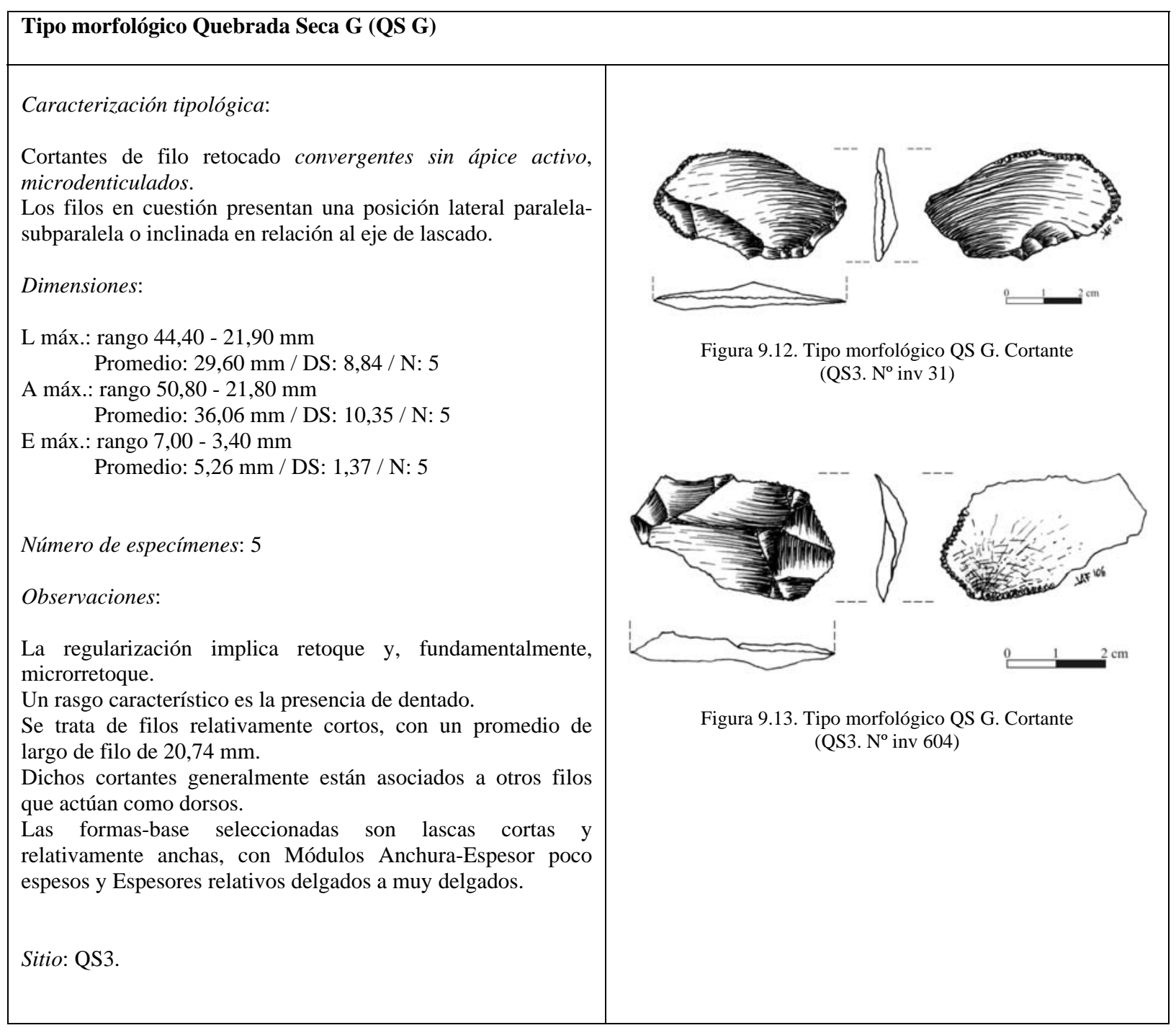




\begin{tabular}{|c|c|}
\hline Tipo morfológico Peñas Chicas A (PCh A) & \\
\hline 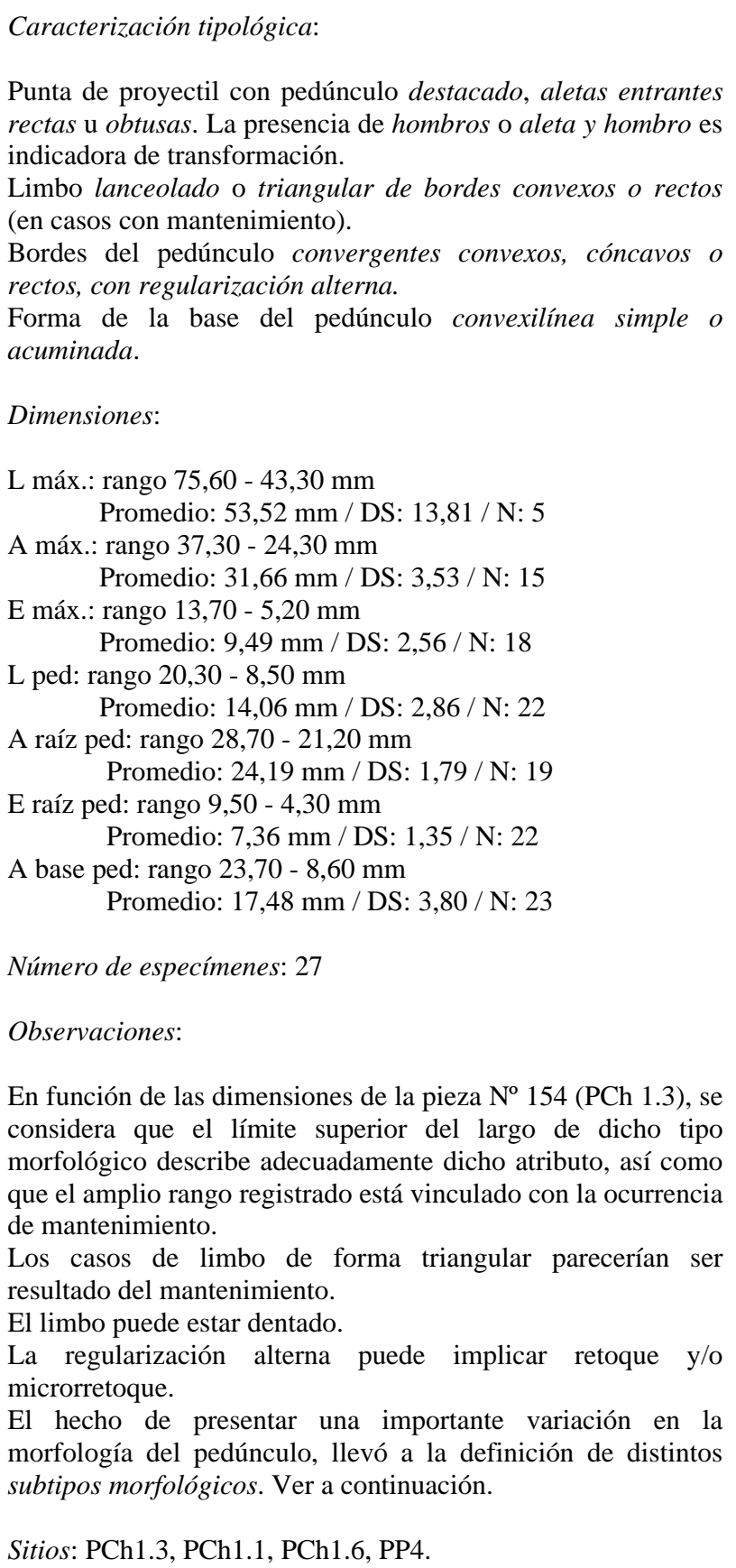 & Figura 9.14. Tipo morfológico PCh A. Punta de proyectil \\
\hline
\end{tabular}




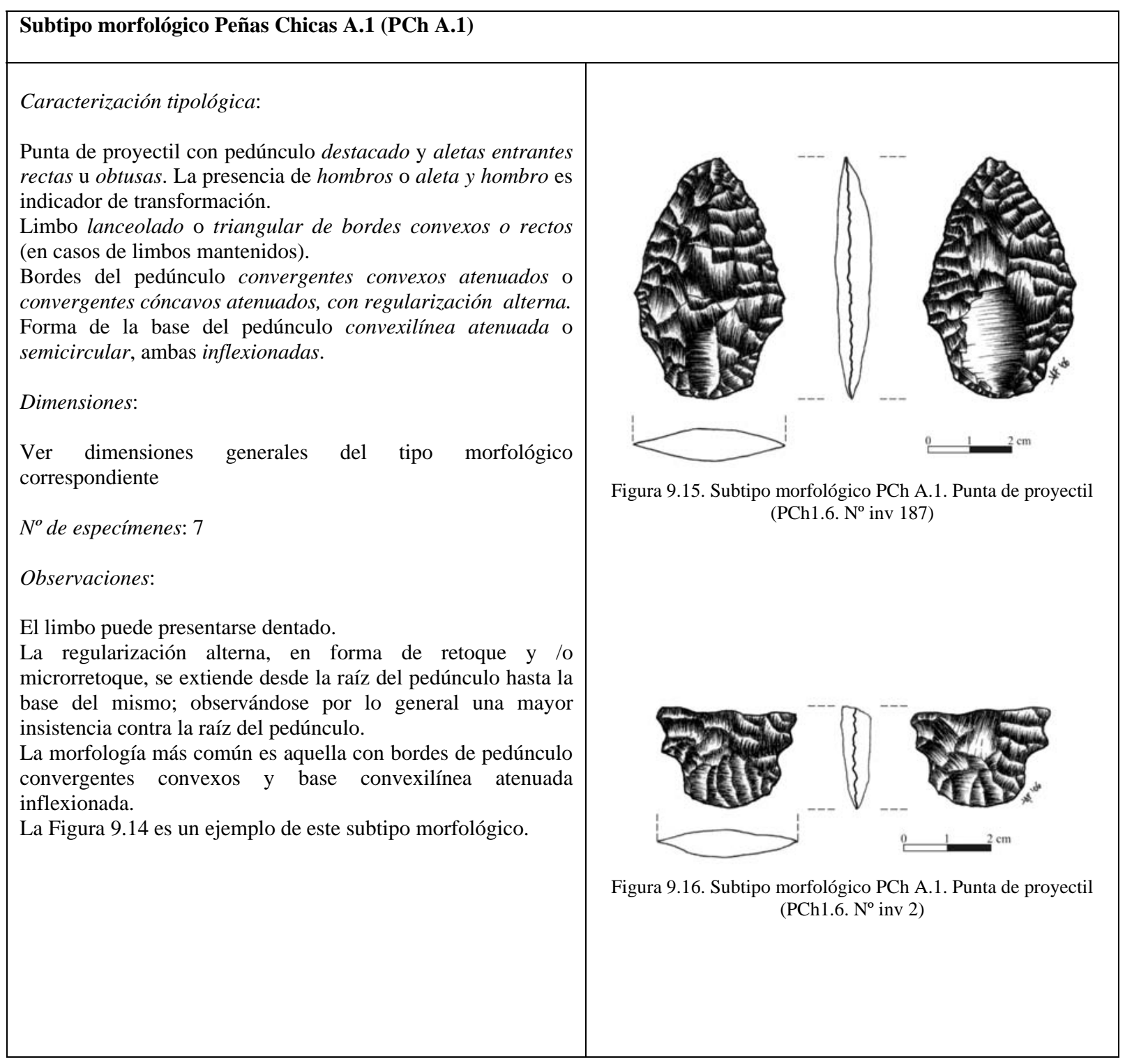




\begin{tabular}{|c|c|}
\hline \multicolumn{2}{|l|}{ Subtipo morfológico Peñas Chicas A.2 (PCh A.2) } \\
\hline 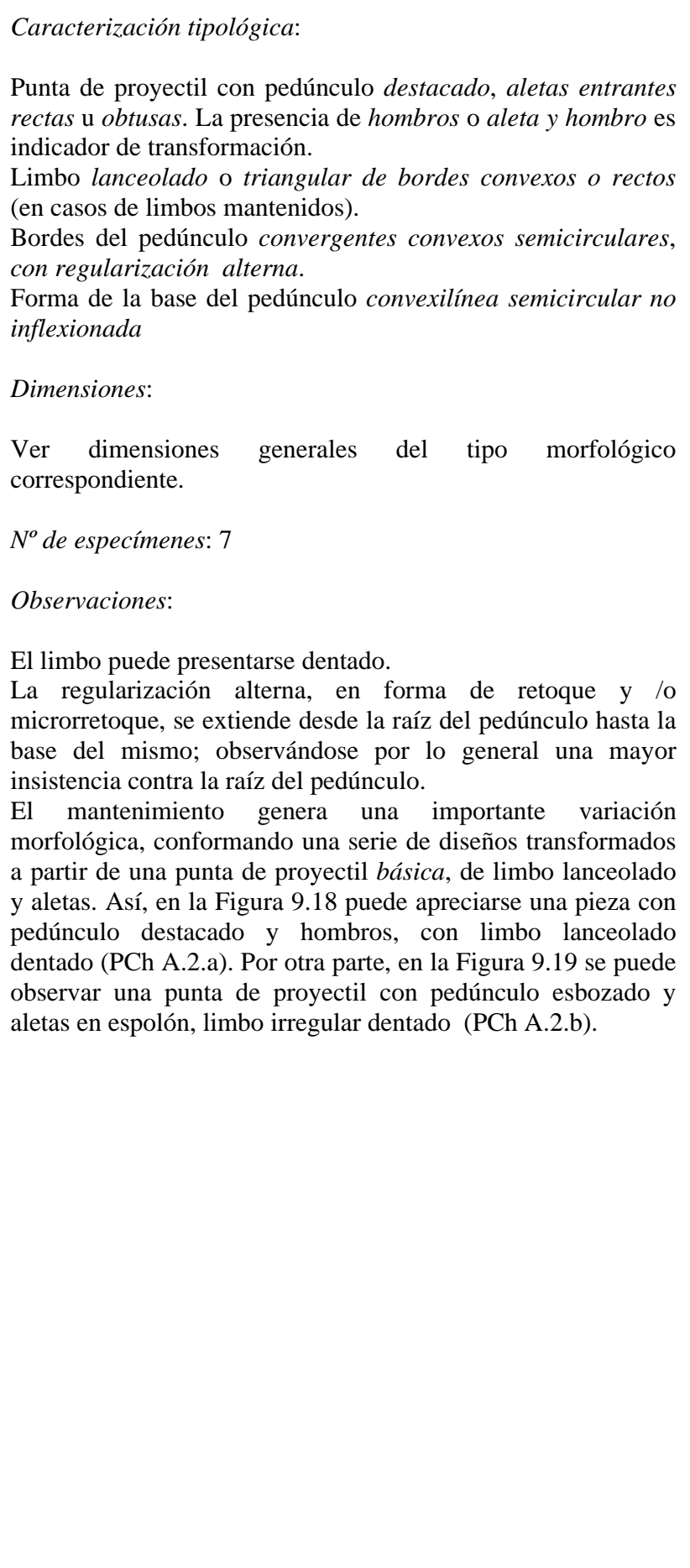 & Figura 9.18. Subtipo morfológico PCh A.2.a. Punta de proyectil \\
\hline
\end{tabular}




\section{Subtipo morfológico Peñas Chicas A.3 (PCh A.3)}

Caracterización tipológica:

Punta de proyectil con pedúnculo destacado, aletas entrantes rectas u obtusas. La presencia de hombros o aleta y hombro es indicador de transformación.

Limbo lanceolado o triangular de bordes convexos o rectos (en casos de limbos mantenidos).

Bordes del pedúnculo convergentes rectos, con regularización alterna.

Forma de la base del pedúnculo convexilínea semicircular, limitada por dos pequeñas escotaduras en sus extremos.

Dimensiones:

Ver dimensiones generales del tipo morfológico correspondiente.

$N^{o}$ de especímenes: 3

Observaciones:

El limbo puede presentarse dentado.

La regularización alterna, en forma de retoque y/o microrretoque, se extiende desde la raíz del pedúnculo hasta la base del mismo. En este caso no se registra una mayor insistencia contra la raíz del pedúnculo.

La Figura 9.21 es un ejemplo de un diseño transformado. Pese a la fractura longitudinal, es posible apreciar un limbo triangular y un hombro (PCh A.3.a).

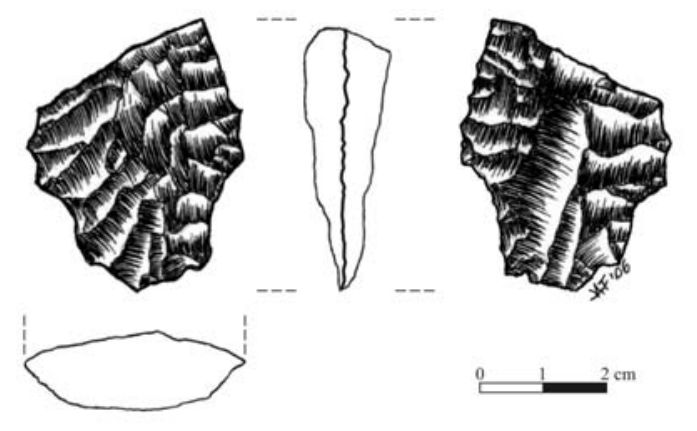

Figura 9.20. Subtipo morfológico PCh A.3. Punta de proyectil (PCh1.3. $\mathrm{N}^{\circ}$ inv 89)

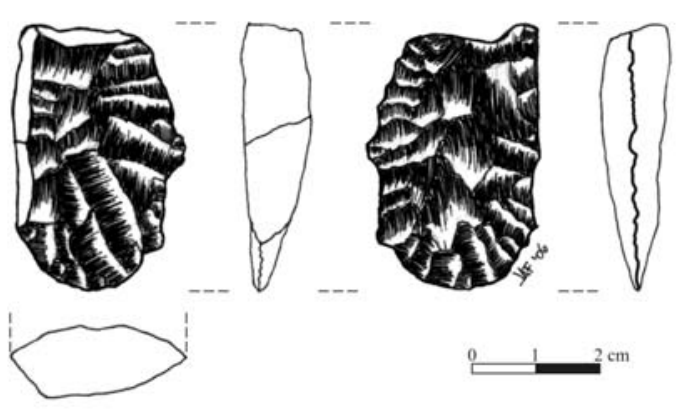

Figura 9.21. Subtipo morfológico PCh A.3.a. Punta de proyectil (PCh1.3. No inv 59) 
Subtipo morfológico Peñas Chicas A.4 (PCh A.4)

Caracterización tipológica:

Punta de proyectil con pedúnculo destacado, aletas entrantes rectas u obtusas._La presencia de hombros o aleta y hombro es indicador de transformación.

Limbo lanceolado o triangular de bordes convexos o rectos (en casos de limbos mantenidos).

Bordes del pedúnculo convergentes cóncavos atenuados, con regularización alterna.

Forma de la base del pedúnculo acuminada puntiforme.

Dimensiones:

Ver dimensiones generales del tipo morfológico correspondiente.

$N^{\circ}$ de especímenes: 3

Observaciones:

El limbo puede presentarse dentado.

La regularización alterna en el pedúnculo se extiende desde la raíz del mismo hasta su base; generalmente se observa una mayor insistencia contra la raíz del pedúnculo. Dicho trabajo alterno se realiza por medio de retoque y/o microrretoque.

Con respecto a la base del pedúnculo, la acuminadura se define a partir de dos filos convexos atenuados o bien de uno cóncavo y otro convexo, pero siempre atenuados.

La Figura 9.23 muestra un caso de diseño transformado (PCh A.4.a), definido por un limbo irregular y la presencia de hombros.

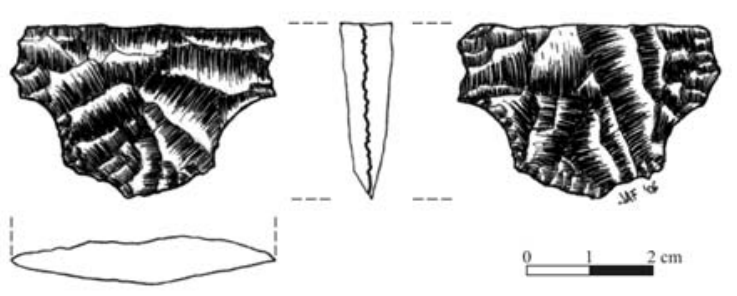

Figura 9.22. Subtipo morfológico PCh A.4. Punta de proyectil (PCh1.3. $\mathrm{N}^{\circ}$ inv 25)

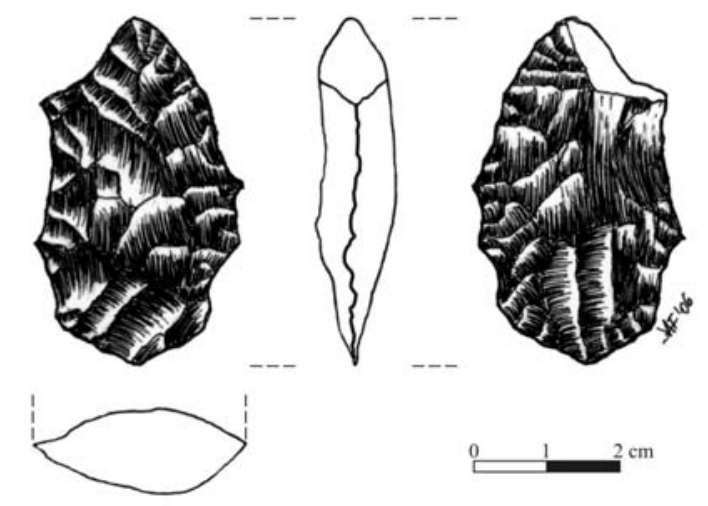

Figura 9.23. Subtipo morfológico PCh A.4.a. Punta de proyectil (PCh1.3. $\mathrm{N}^{\circ}$ inv 19) 


\begin{tabular}{|c|c|}
\hline \multicolumn{2}{|l|}{ Subtipo morfológico Peñas Chicas A.5 (PCh A.5) } \\
\hline $\begin{array}{l}\text { Caracterización tipológica: } \\
\text { Punta de proyectil con pedúnculo destacado, aletas entrantes } \\
\text { rectas u obtusas. La presencia de hombros o aleta y hombro, } \\
\text { así como de pedúnculo esbozado, es indicador de } \\
\text { transformación. } \\
\text { Limbo lanceolado o triangular de bordes convexos o rectos (en } \\
\text { casos de limbos mantenidos). } \\
\text { Bordes del pedúnculo convergentes rectos, con regularización } \\
\text { alterna. } \\
\text { Forma de la base del pedúnculo convexilínea atenuada. } \\
\text { Dimensiones: } \\
\text { Ver dimensiones generales del tipo morfológico } \\
\text { correspondiente. } \\
N^{\circ} \text { de especímenes: } 3 \\
\text { Observaciones: } \\
\text { La regularización alterna en el pedúnculo, como retoque y /o } \\
\text { microrretoque, se extiende desde la raíz del mismo hasta su } \\
\text { base, no observándose una mayor insistencia contra la raíz del } \\
\text { pedúnculo. } \\
\text { Las Figuras puestas como ejemplo de este subgrupo } \\
\text { morfológico son, en realidad, diseños transformados. La } \\
\text { primera (Figura 9.24) presenta un pedúnculo esbozado y un } \\
\text { limbo irregular (PCh A.5.a), mientras que la segunda (Figura } \\
\begin{array}{l}\text { 9.25) es un caso de pieza con pedúnculo destacado y hombros } \\
\text { (PCh A.5.b) que, además, ha sufrido reciclaje en el limbo. }\end{array}\end{array}$ & Figura 9.25. Subtipo morfológico PCh A.5.b. Punta de proyectil \\
\hline
\end{tabular}




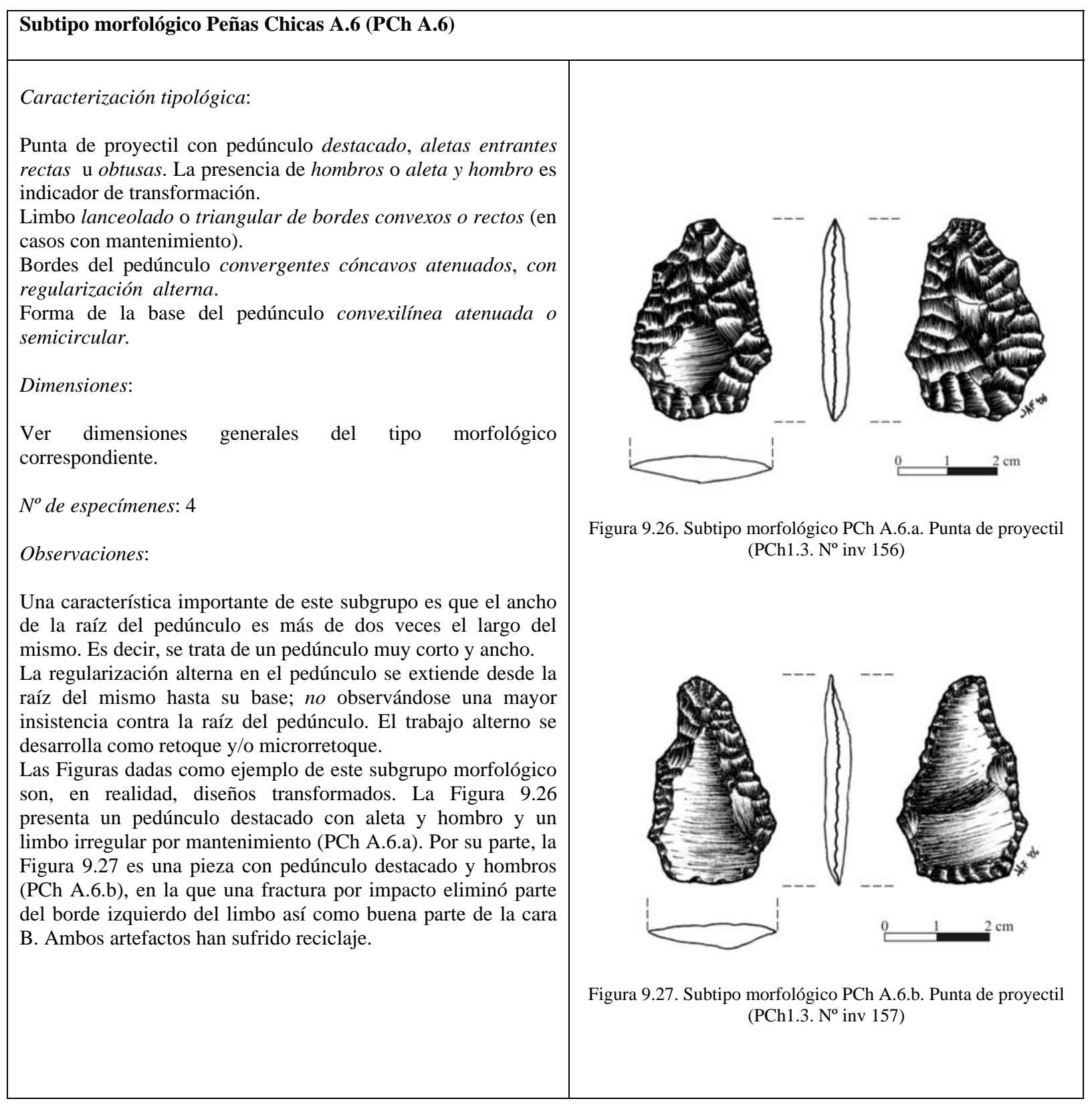




\begin{tabular}{|c|c|}
\hline Tipo morfológico Peñas Chicas B (PCh B) & \\
\hline 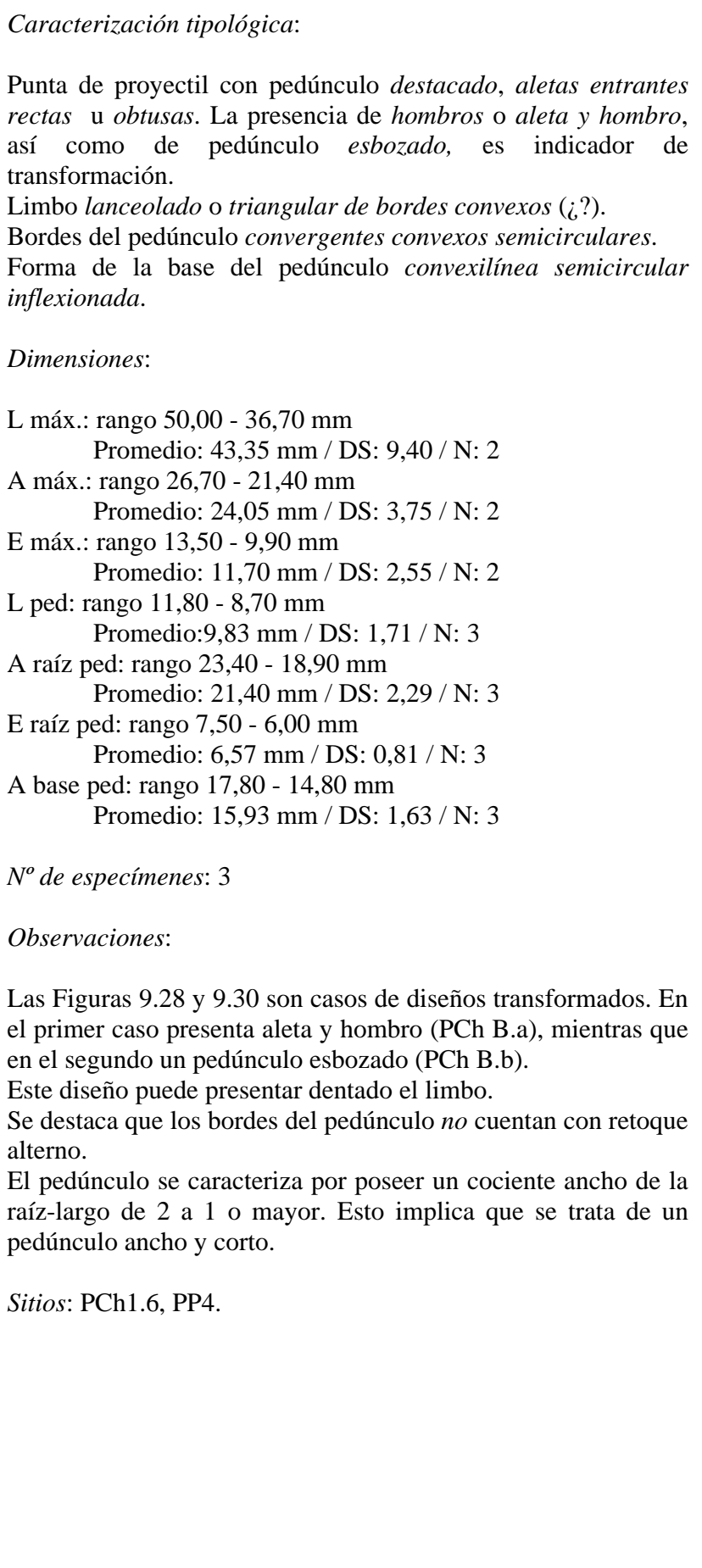 & Figura 9.30. Tipo morfológico PCh B.b. Punta de proyectil \\
\hline
\end{tabular}




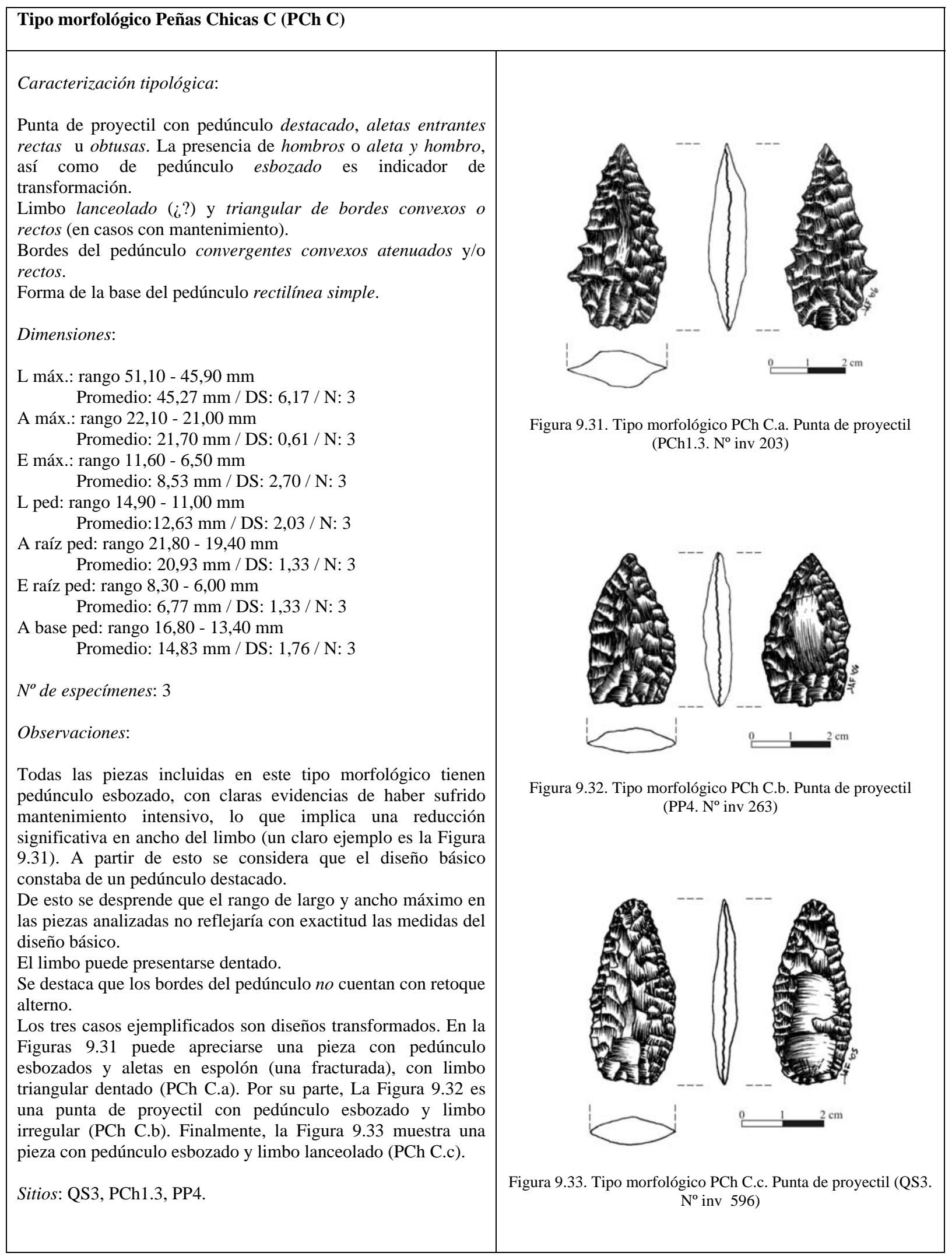




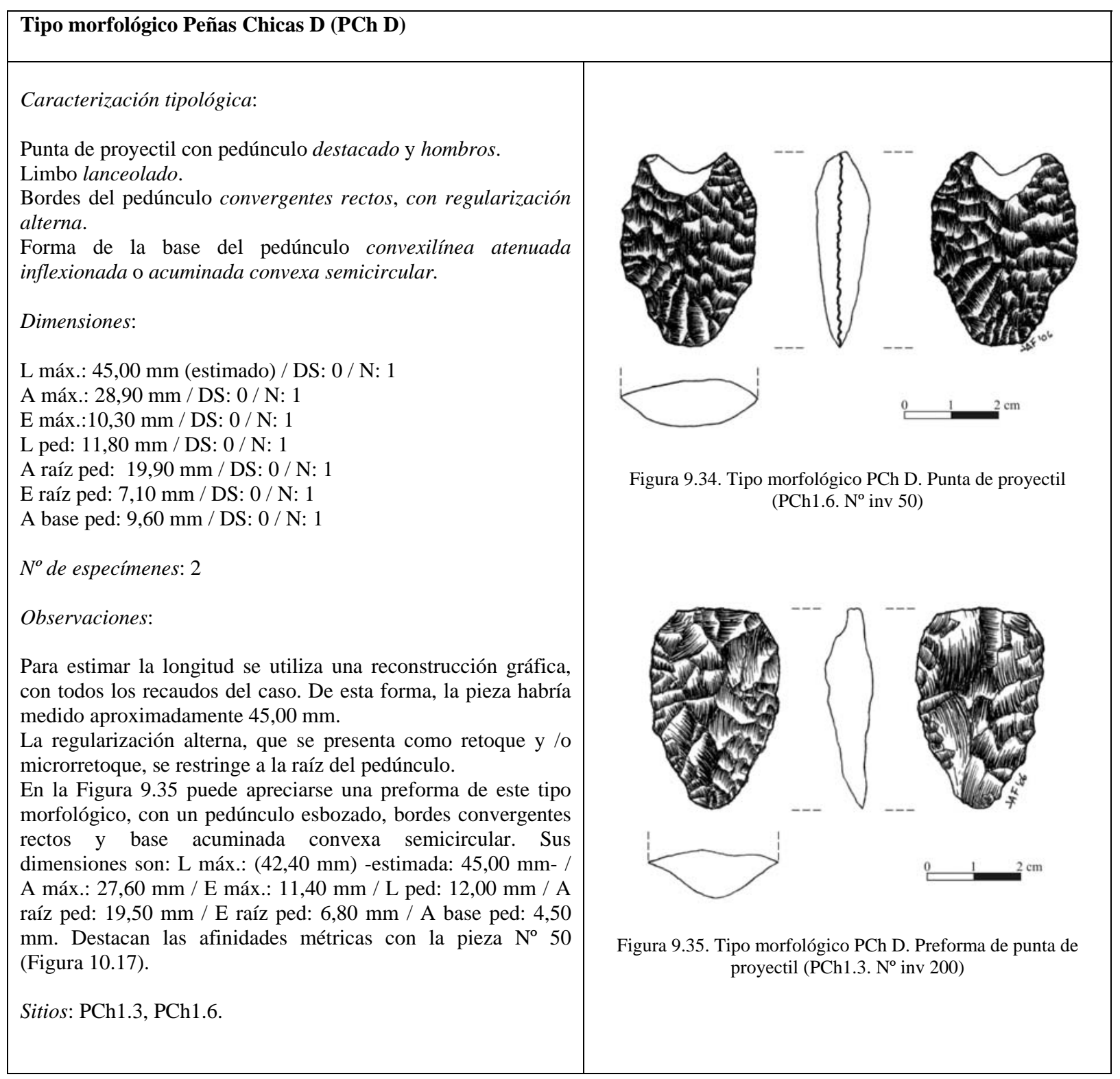




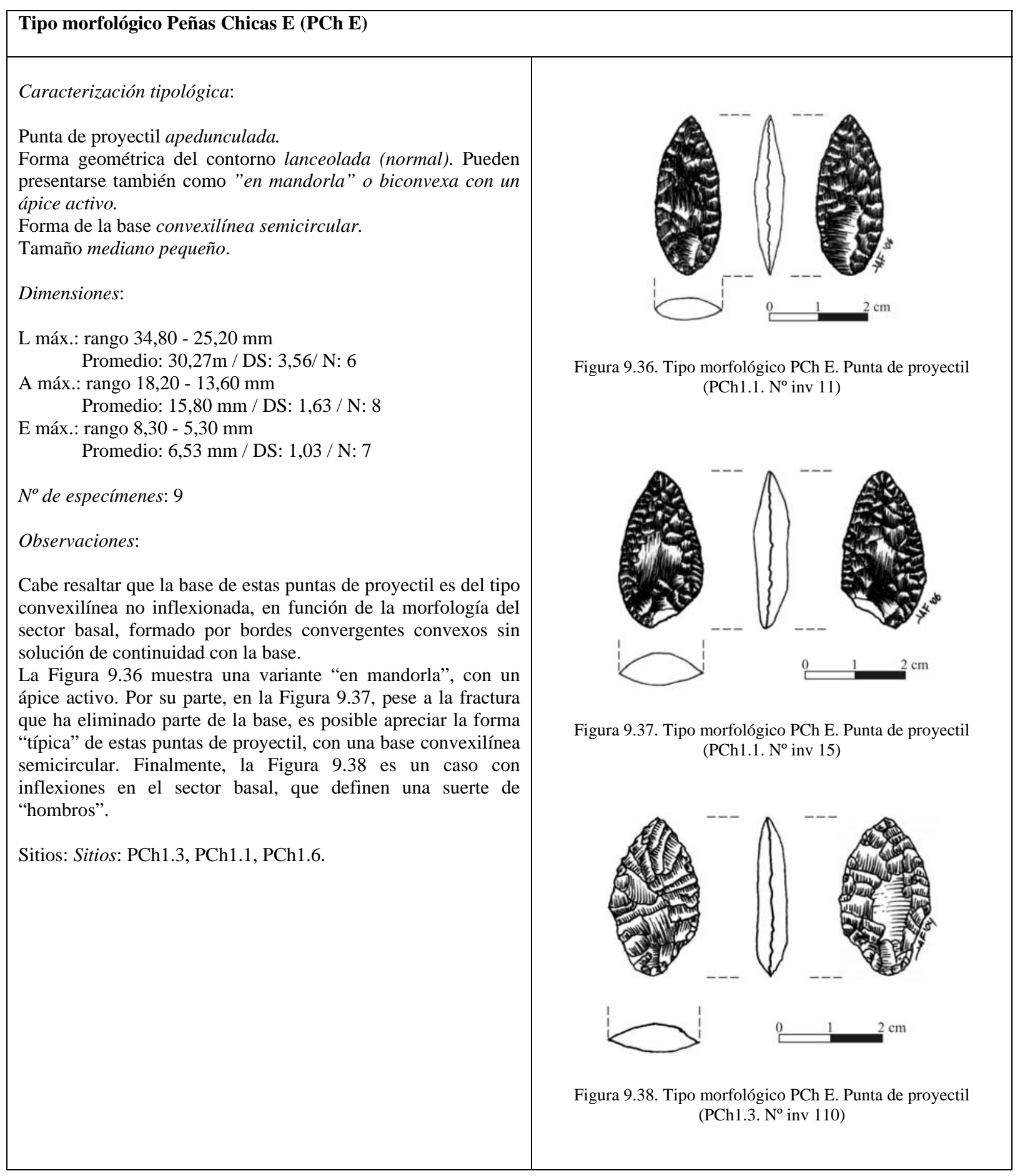




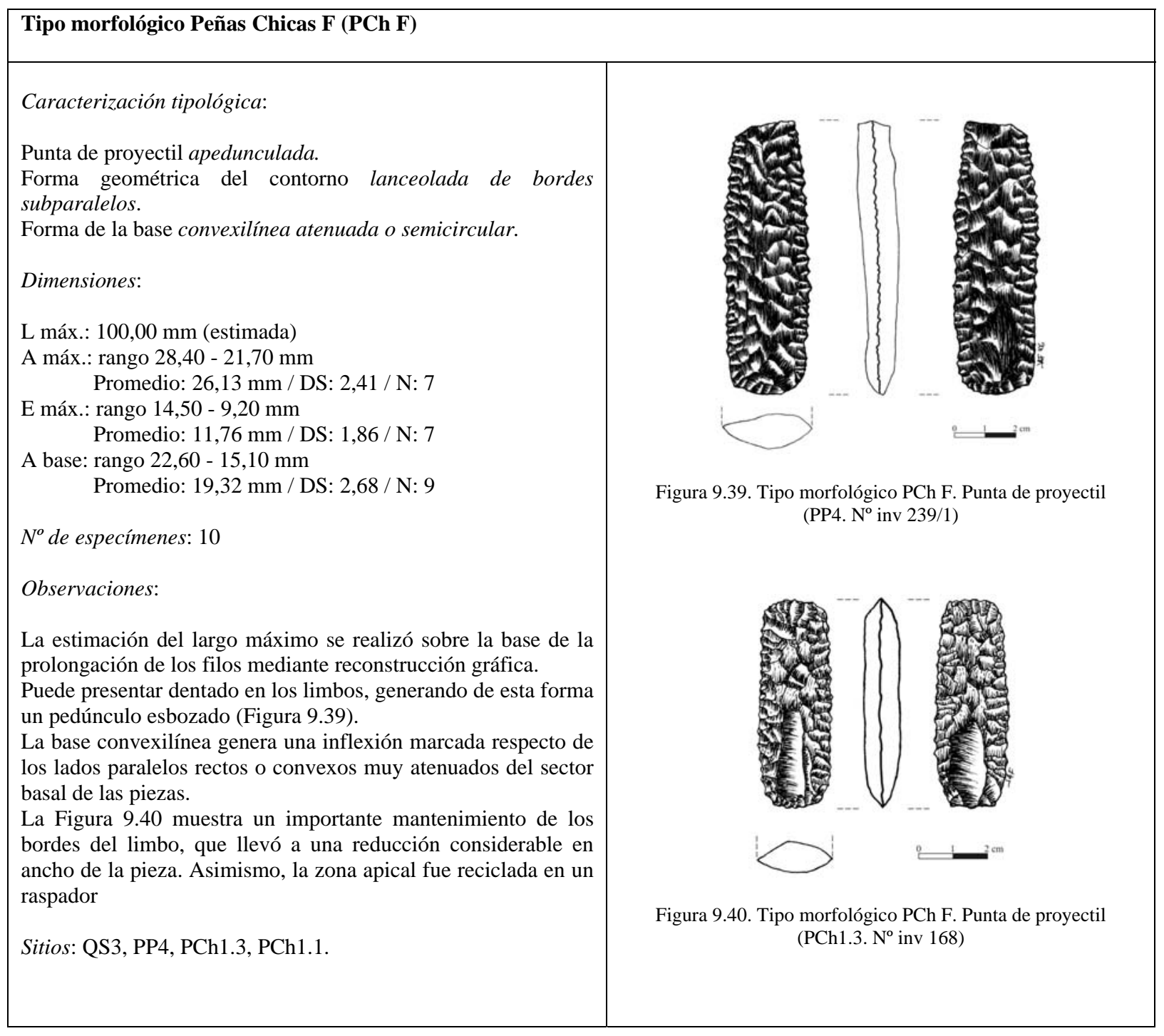




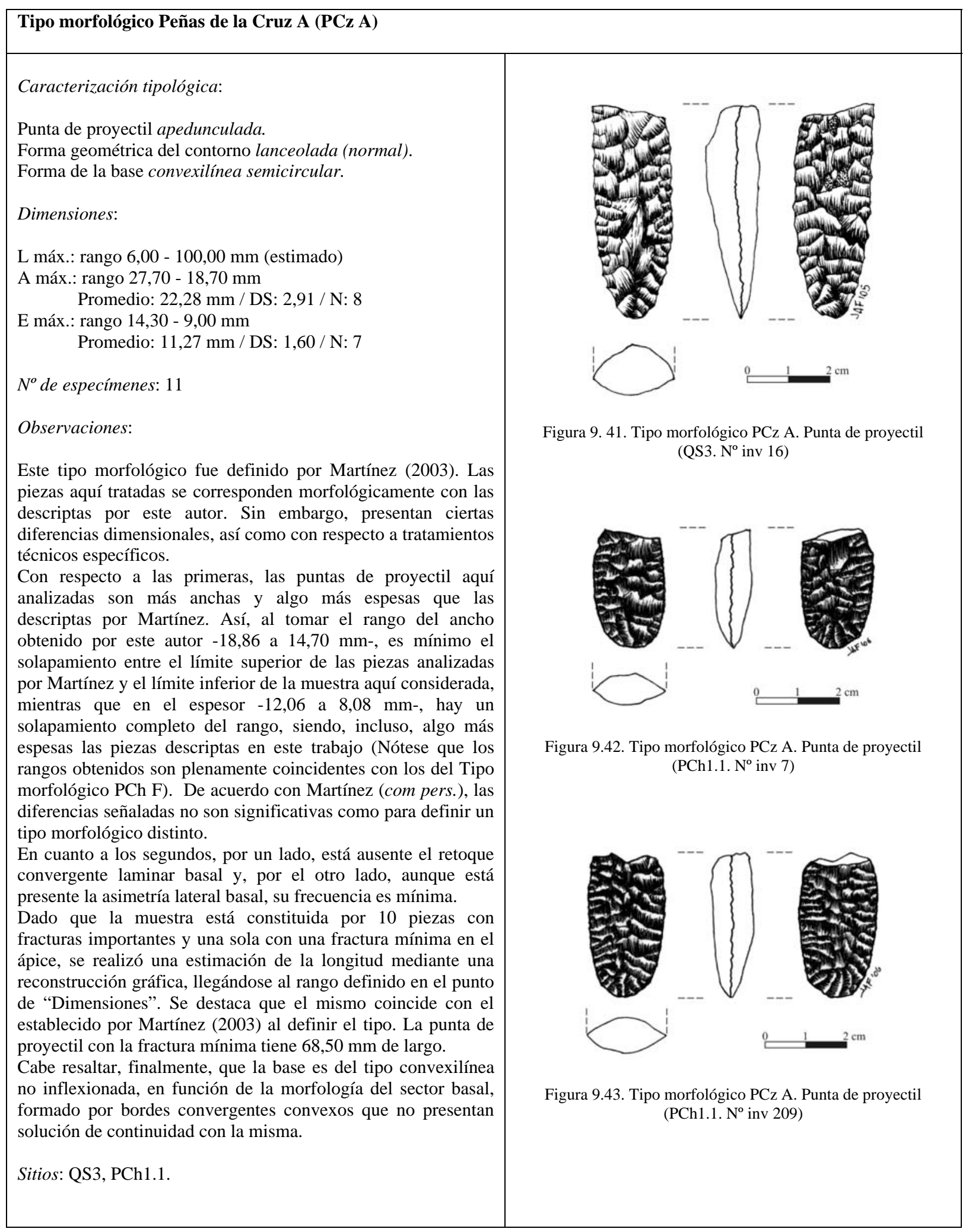




\begin{tabular}{|c|c|}
\hline \multicolumn{2}{|l|}{ Tipo morfológico Peñas Chicas G (PCh G) } \\
\hline 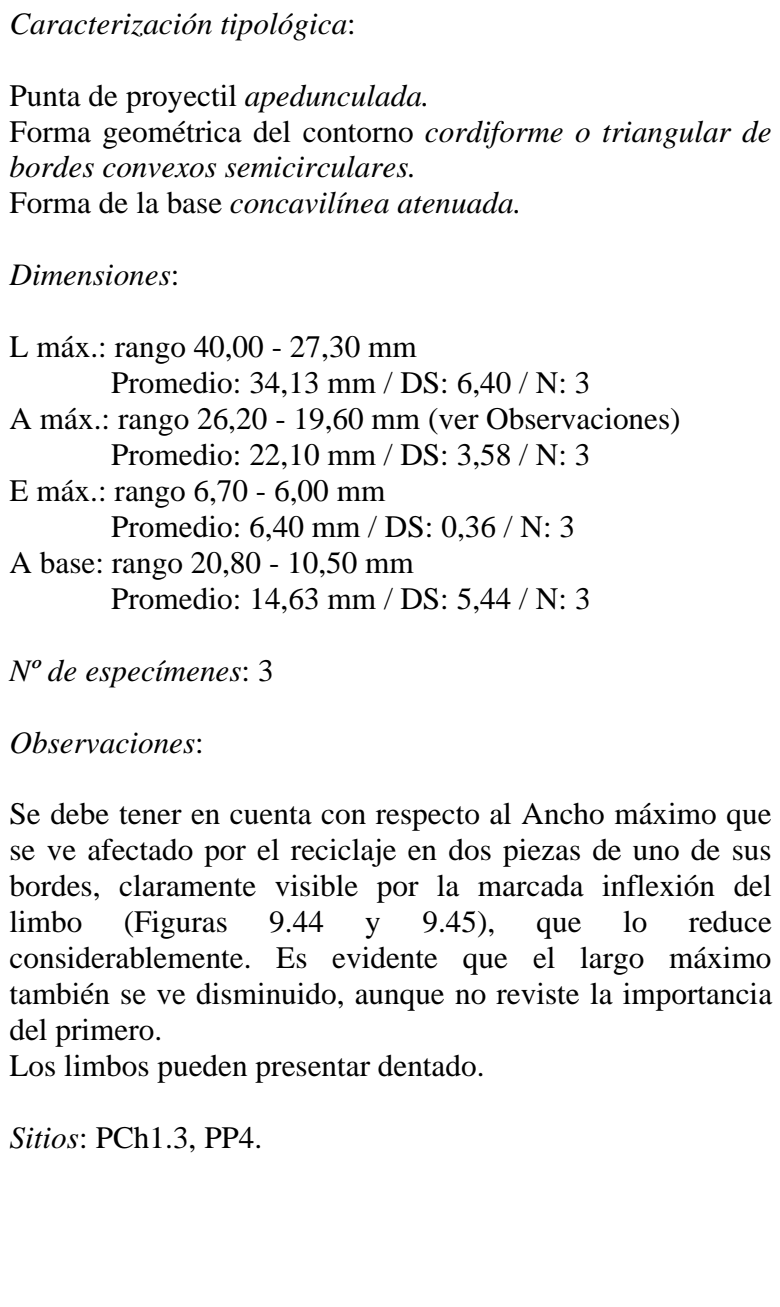 & $\begin{array}{l}\text { Figura 9.45. Tipo morfológico PCh G. Punta de proyectil } \\
\text { (PCh1.3. } \mathrm{N}^{\circ} \text { inv 167) } \\
\text { Figura 9.46. Tipo morfológico PCh G. Punta de proyectil } \\
\text { (PP4. } \mathrm{N}^{\circ} \text { inv 243/28) }\end{array}$ \\
\hline
\end{tabular}




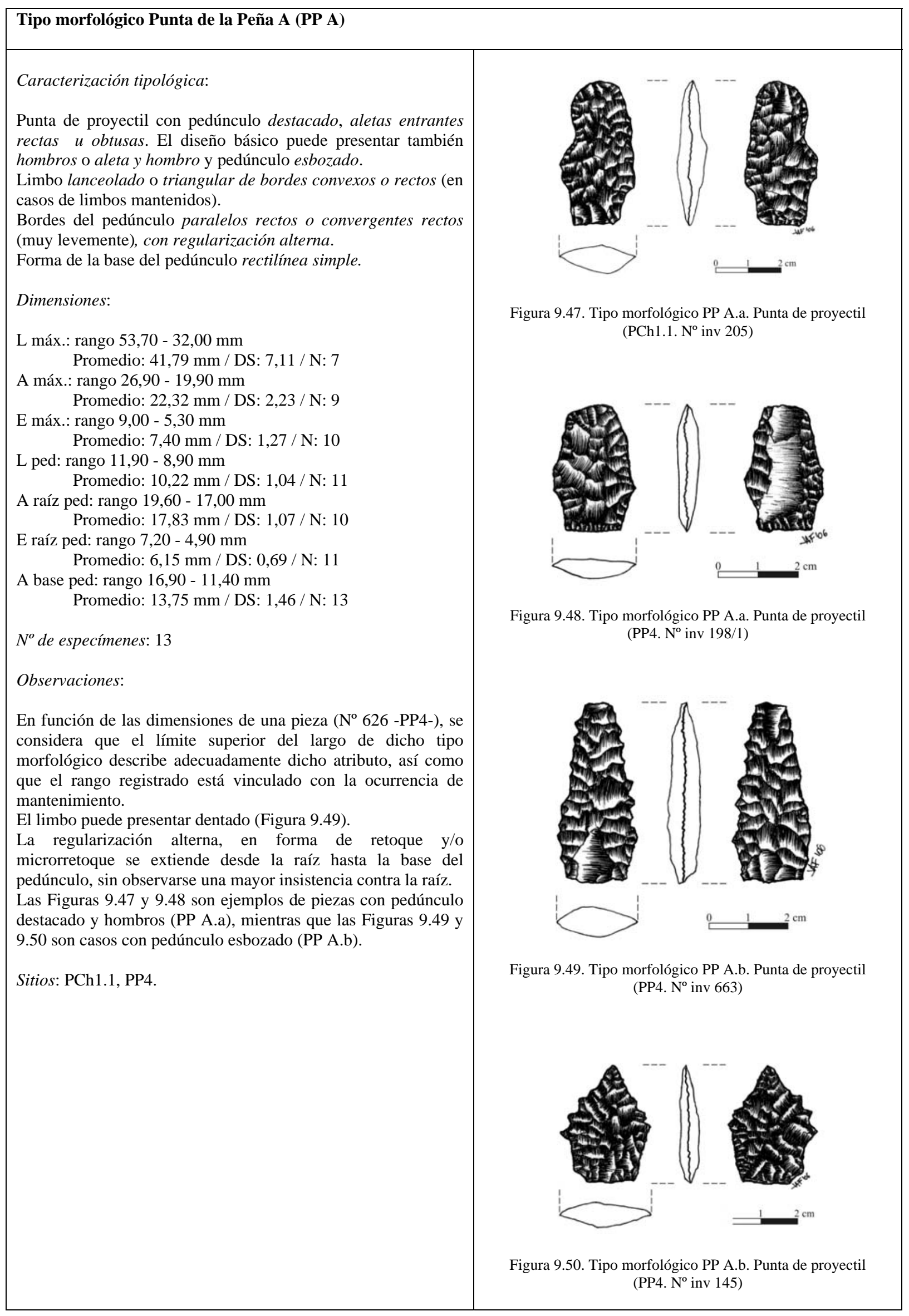




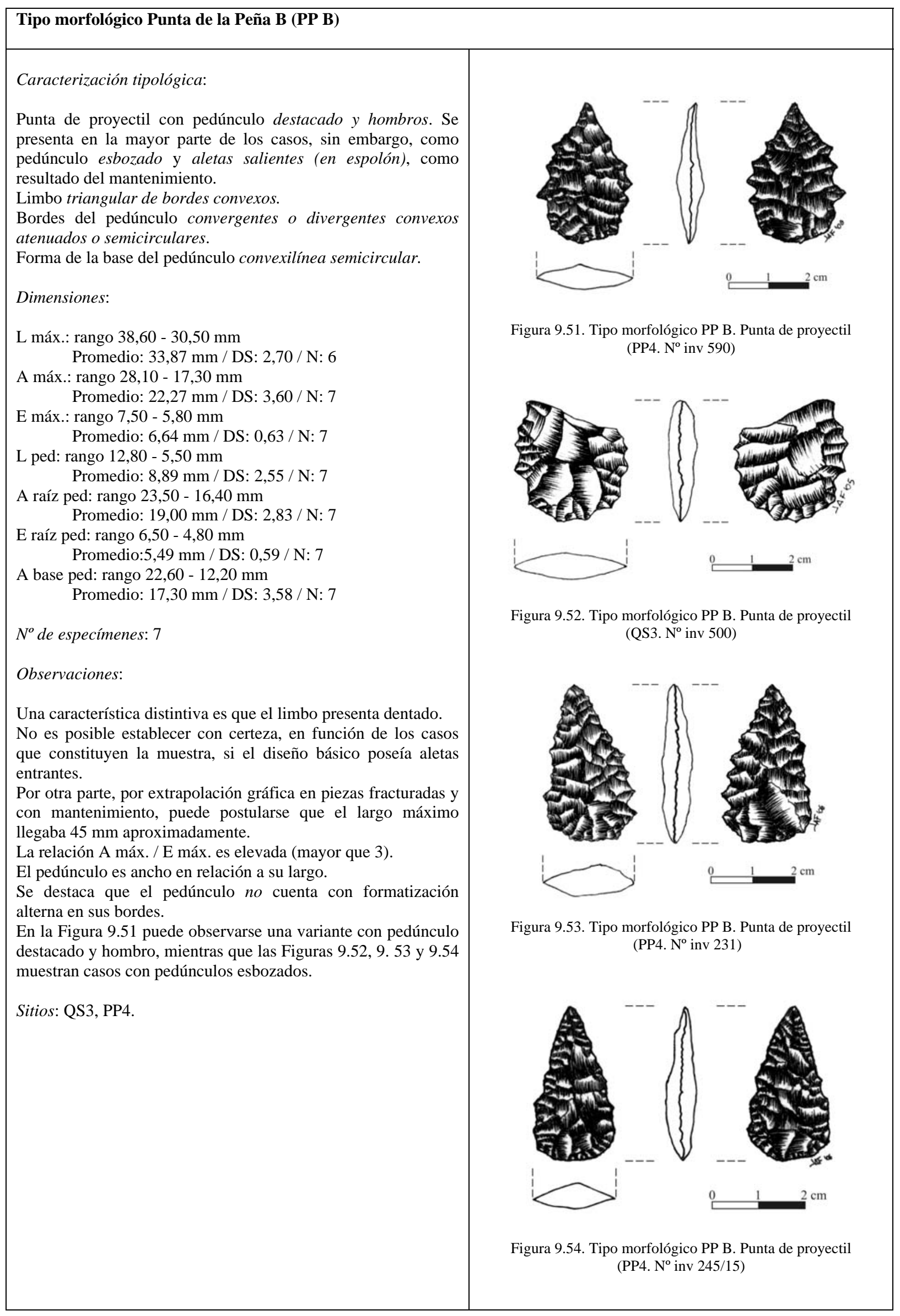




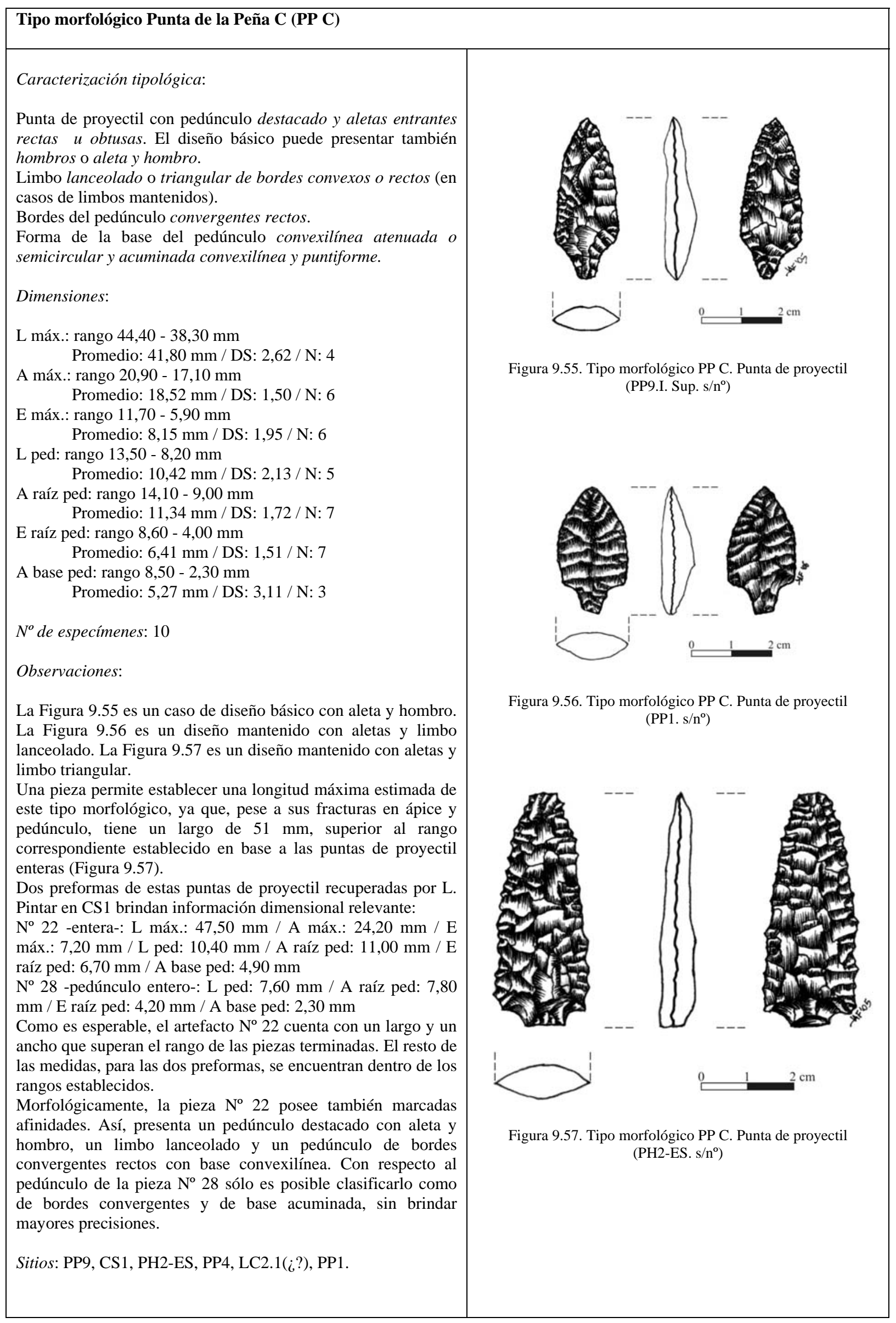




\begin{tabular}{|c|c|}
\hline \multicolumn{2}{|l|}{ Tipo morfológico Casa Chávez Montículos A (CChM A) } \\
\hline $\begin{array}{l}\text { Caracterización tipológica: } \\
\text { Punta de proyectil con pedúnculo diferenciado y aletas } \\
\text { entrantes agudas. } \\
\text { Limbo triangular de lados rectos, corto o alargado, de tipo } \\
\text { isósceles. } \\
\text { Bordes del pedúnculo convergentes o paralelos rectos. } \\
\text { Forma de la base del pedúnculo acuminada puntiforme o } \\
\text { convexilínea atenuada o semicircular. } \\
\text { Dimensiones (en base a datos de CChM1 de Escola -1987-): } \\
\text { L máx.: rango 28,00 - } 17,00 \mathrm{~mm} \\
\text { A máx.: rango 17,50 - 11,00 mm } \\
\text { E máx. (Promedio): 3,73 mm } \\
\text { L ped (Promedio): 3,33 mm } \\
\text { A raíz ped (Promedio): } 3,81 \mathrm{~mm} \\
\text { E ped (Promedio): 1,91 mm } \\
\text { A base ped (Promedio): } 2,56 \mathrm{~mm} \\
\text { Observaciones: } \\
\text { Por una descripción detallada de las puntas de proyectil de este } \\
\text { tipo ver Escola (1987, } 1991,2000 \text { ). } \\
\text { Las dimensiones generales del tipo se obtuvieron realizando un } \\
\text { promedio de los valores obtenidos por Escola (1987) en los } \\
\text { subgrupos A.1.I, A.1.II y A.1.III, correspondientes a una } \\
\text { muestra de piezas de CChM1. } \\
\text { Se adopta la discriminación en subgrupos tipológicos de Escola } \\
\text { (1991, 2000) como subtipos morfológicos. } \\
\text { Sitio: CChM1. }\end{array}$ & $\begin{array}{l}\text { Figura 9.58. Subtipo morfológico CChM A.1.I-A.1.II. Punta de } \\
\text { proyectil (CChM1) -modificado de Escola 1987: 22 y 28; } \\
\text { Láminas 2 y 3- } \\
\text { Figura 9.59. Subtipo morfológico CChM A.1.III. Punta de } \\
\text { proyectil (CChM1) -modificado de Escola 1987: 32; Lámina 4- }\end{array}$ \\
\hline
\end{tabular}




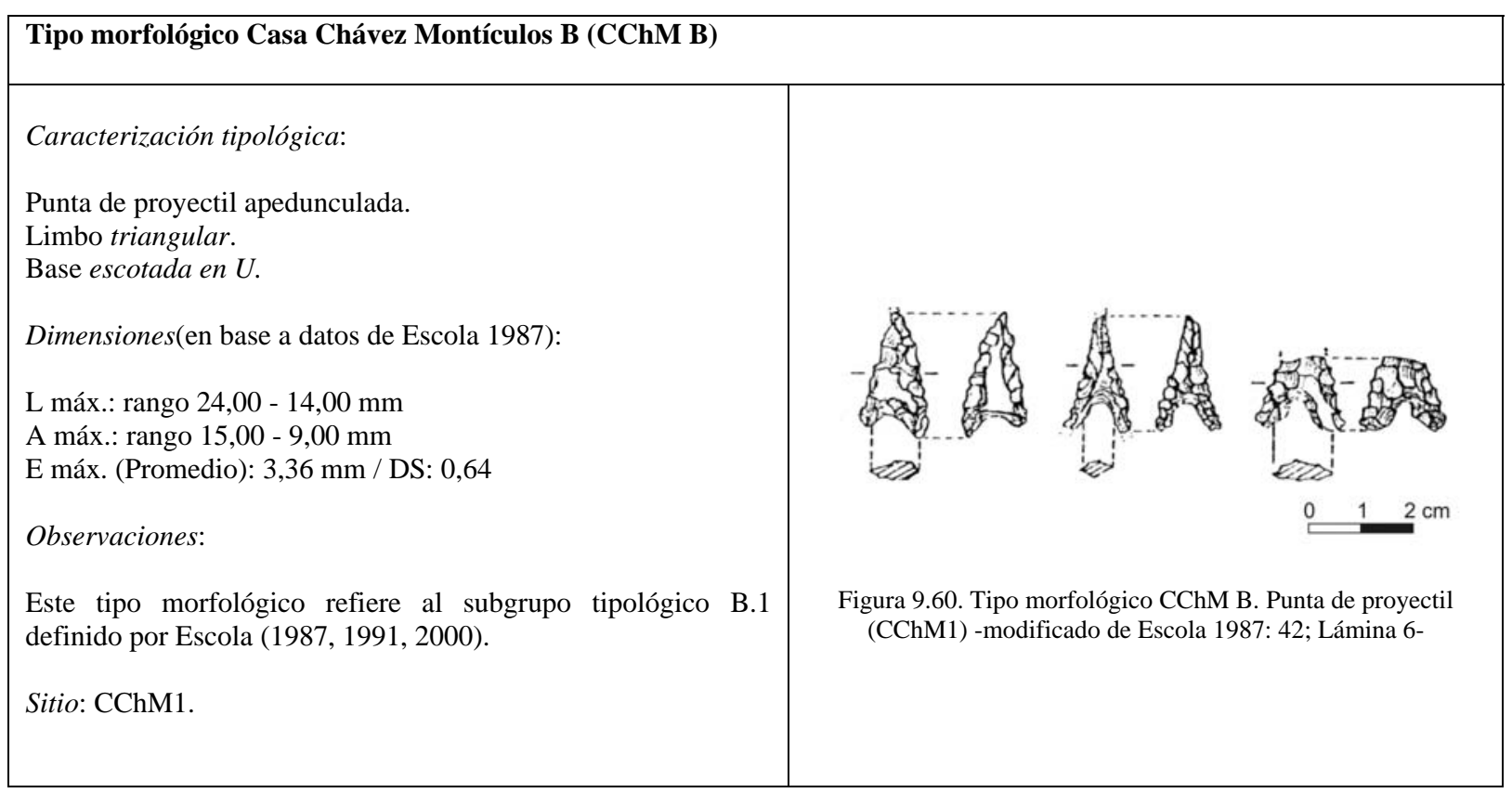




\begin{tabular}{|c|c|}
\hline \multicolumn{2}{|l|}{ Tipo morfológico Casa Chávez Montículos C (CChM C) } \\
\hline $\begin{array}{l}\text { Caracterización tipológica: } \\
\text { Raedera de módulo grandísimo. } \\
\text { Instrumento regularizado por lascados de retalla y retoque } \\
\text { marginal, de tipo unifacial directo. } \\
\text { Características litométricas módulo grandísimo. } \\
\text { Observaciones: } \\
\text { Por una descripción detallada de este tipo morfológico ver } \\
\text { Escola (2000). } \\
\text { Esta autora (ibid.) denomina a estos artefactos formatizados } \\
\text { "grandes lascas con retoque". Aquí se plantea su incorporación, } \\
\text { bajo la denominación de "raederas de módulo grandísimo", } \\
\text { como un subgrupo dentro del grupo tipológico de las raederas } \\
\text { (ver punto 4.5.9. del Capítulo 4). } \\
\text { La presencia en el registro arqueológico de este tipo } \\
\text { morfológico se puede reconocer, además, por la ocurrencia de } \\
\text { desechos de reactivación de tales instrumentos, que son } \\
\text { morfológicamente característicos (ver punto } 12.5 \text {. } \\
\text { Identificación de desechos de talla de mantenimiento de } \\
\text { raederas de módulo grandísimo, en el Capítulo 12). } \\
\text { Sitio: CChM1. }\end{array}$ & $\begin{array}{l}\text { Figura 9.61. Tipo morfológico CChM C. Raedera de módulo } \\
\text { grandísimo (CChM1) -Cortesía P. Escola- }\end{array}$ \\
\hline
\end{tabular}




\begin{tabular}{|c|c|}
\hline \multicolumn{2}{|l|}{ Tipo morfológico Casa Chávez Montículos D (CChM D) } \\
\hline $\begin{array}{l}\text { Caracterización tipológica: } \\
\text { Pala y/o azada. } \\
\text { Instrumento formatizado por lascados de retalla y retoque } \\
\text { bifacial marginal. } \\
\text { Forma-base laja. } \\
\text { Observaciones: } \\
\text { Por una descripción detallada de este tipo morfológico ver } \\
\text { Pérez (2003). } \\
\text { Esta autora (Pérez 2004) incorporó como un nuevo grupo } \\
\text { tipológico a estas palas y/o azadas líticas manufacturadas por } \\
\text { lascado, ya que la lista tipológica definida por Aschero (1983) } \\
\text { refería sólo a azadas-palas manufacturadas por picado-abrasión- } \\
\text { pulido. } \\
\text { Sitio: CChM1. }\end{array}$ & $\begin{array}{l}\text { Figura 9.62. Tipo morfológico CCHM D. Pala y/o azada } \\
\text { (CChM1) -modificado de Escola 2000: 141; Figura 34- }\end{array}$ \\
\hline
\end{tabular}




\subsubsection{CARACTERIZACIÓN DE ESPECÍMENES MORFOLÓGICOS}

\begin{tabular}{l}
\hline Espécimen morfológico Peñas Chicas 1 (PCh 1) \\
Caracterización tipológica: \\
Punta de proyectil con pedúnculo esbozado y aletas \\
salientes (en espolón). \\
Limbo triangular corto (¿mantenimiento?). \\
Bordes del pedúnculo convergentes convexos atenuados. \\
Forma de la base del pedúnculo convexa atenuada \\
inflexionada. \\
Dimensiones: \\
L máx.: (49,20) mm / DS: 0 / N: 1 \\
A máx.: 44,30 mm / DS: 0 / N: 1 \\
E máx.: 12,70 mm / DS: 0 / N: 1 \\
L ped: 21,50 mm / DS: 0 / N: 1 \\
A raíz ped: 36,10 mm / DS: 0 / $\mathrm{N}: 1$ \\
E raíz ped: 11,90 mm / DS: 0 / N: 1 \\
A base ped: $15,90 \mathrm{~mm} / \mathrm{DS}: 0$ / N: 1 \\
Observaciones: \\
Presenta dentado en los bordes del pedúnculo. La pieza en \\
cuestión se trataría de un diseño mantenido (PCh 1.a). \\
Sitio: PCh.1.3. \\
(PCh1.3. No inv. 82)
\end{tabular}


Espécimen morfológico Peñas Chicas 2 (PCh 2)

Caracterización tipológica:

Punta de proyectil con pedúnculo destacado y hombros.

Limbo triangular con bordes rectos.

Bordes del pedúnculo convergentes rectos.

Forma de la base del pedúnculo rectilínea simple.

Dimensiones:

L máx.: $(32,30)$ mm / DS: 0 / N: 1

A máx.: $(27,30) \mathrm{mm} / \mathrm{DS}: 0$ / N: 1

E máx.: 10,60 mm / DS: 0 / N: 1

L ped: 13,40 mm / DS: 0 / N: 1

A raíz ped: 22,80 mm / DS: 0 / N: 1

E raíz ped: 8,60 mm / DS: 0 / N: 1

A base ped: 13,00 mm / DS: 0 / N: 1

Observaciones:

La pieza presenta un fuerte mantenimiento de sus limbos, muy posiblemente se trate de un diseño transformado (definido como PCh 2.a) de una punta de proyectil con pedúnculo destacado y aletas. El mantenimiento generó un limbo triangular, observable a pesar de la fractura que afectó la mayor parte del mismo.

Presenta dentado.

Sitio: PCh.1.3. 
Espécimen morfológico Peñas Chicas 3 (PCh 3) (¿?)

Caracterización tipológica:

Punta de proyectil con pedúnculo destacado y aleta entrante obtusa.

Limbo no diferenciado por fractura.

Borde del pedúnculo convergente convexo semicircular.

Forma de la base del pedúnculo convexa semicircular no inflexionada.

Dimensiones:

L: -

A: -

E: -

L ped: 10,90 mm / DS: 0 / N: 1

A raíz ped: $(17,50) \mathrm{mm} / \mathrm{DS}: 0 / \mathrm{N}: 1$

E raíz ped: $(5,40) \mathrm{mm} / \mathrm{DS}: 0 / \mathrm{N}: 1$

A base ped: $(9,00) \mathrm{mm} / \mathrm{DS}: 0 / \mathrm{N}: 1$

Observaciones:

Se trata de un fragmento limbo-pedúnculo de punta de proyectil que presenta, a su vez el reciclaje del borde derecho del pedúnculo en un cortante de filo retocado. Esto hace que dicho espécimen morfológico tenga carácter de provisional. Sin embargo, sus características morfológicas no tienen correlato con el resto de los diseños de puntas de proyectil de los sitios considerados y son lo suficientemente particulares como para considerarlo como tal. Se destaca que presenta ciertas afinidades en cuanto al pedúnculo con un diseño recuperado por L. Núñez en Tu-54 (Figura 9.65), lo que no significa que este último sea el reflejo de la pieza en cuestión.

Sitio: PCh.1.3.
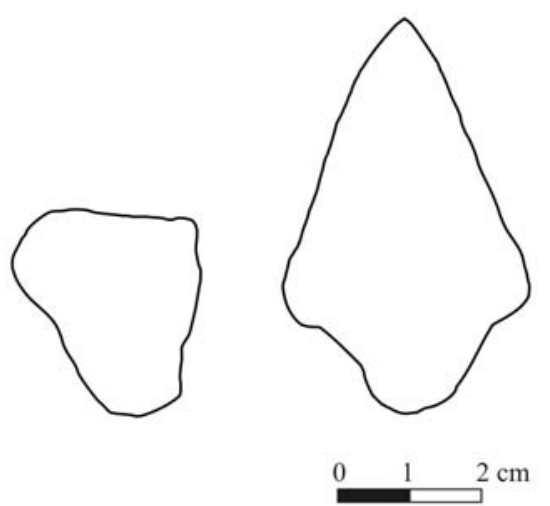

Figura 9.65. Espécimen morfológico PCh 3.

Izq: Pedúnculo de punta de proyectil (PCh1.3. $\mathrm{N}^{\circ}$ inv. 98). Der: Punta de proyectil Tu-54 (Cortesía L. Núñez) 
Espécimen morfológico Peñas Chicas 4 (PCh 4)

Caracterización tipológica:

Punta de proyectil con pedúnculo esbozado (¿).

Limbo triangular largo (mantenimiento).

Bordes del pedúnculo convergentes convexos semicirculares.

Forma de la base del pedúnculo acuminada puntiforme.

Dimensiones:

L máx.: 60,50 mm / DS: 0 / N: 1

A máx.: 22,70 mm / DS: 0 / N: 1

E máx: 7,30 mm / DS: 0 / N: 1

L ped: 19,60 mm / DS: 0 / N: 1

A raíz ped: 21,70 mm / DS: 0 / N: 1

E raíz ped: 7,00 mm / DS: 0 / N: 1

A base ped: 7,10 mm / DS: 0 / N: 1

Observaciones:

La pieza que sirve de marco para definir este espécimen morfológico se trata en realidad de un diseño transformado (PCh 4.a) que muestra claras evidencias de una mantenimiento intensivo del limbo, que llevó a la conformación de un pedúnculo esbozado. Por ende, se desconoce la morfología del limbo original, así como si la pieza tenía aletas u hombros.

En su borde derecho (cara A; izquierda en Figura 9.66) se observa un pequeño hombro, que es tan mínimo que no llega a definir un pedúnculo destacado. Asimismo, en el borde izquierdo presenta una inflexión del borde entre el limbo y el pedúnculo. Esto estaría señalando que dicha punta de proyectil originalmente poseía aletas u hombros.

El pedúnculo se conforma, en definitiva, como la porción remanente que, por sus atributos particulares, permite definir a esta pieza como un espécimen morfológico.

Esta pieza presenta ciertas similitudes, en relación a la morfología del pedúnculo, con el subtipo morfológico QS F.2; sin embargo, el pedúnculo de esta punta de proyectil es más alargado y mucho más delgado. Además, no cuenta con abrasión en los bordes ni en la base.

Sitio: PCh.1.3.

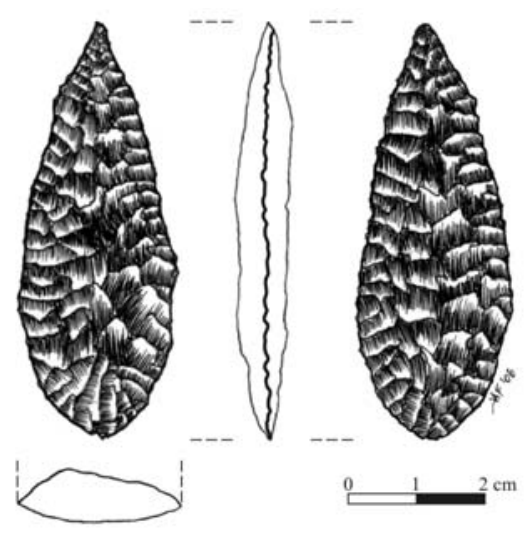

Figura 9.66. Espécimen morfológico PCh 4.a. Punta de proyectil (PCh1.3. $\mathrm{N}^{\mathrm{o}}$ inv. 204) 
Espécimen morfológico Peñas Chicas 5 (PCh 5)

Caracterización tipológica:

Punta de proyectil con pedúnculo destacado y hombro.

Limbo triangular corto (por mantenimiento)

Bordes del pedúnculo convergentes rectos.

Forma de la base del pedúnculo convexilínea semicircular.

Dimensiones:

L máx.: 33,40 mm / DS: 0 / N: 1

A máx.: $(18,60) \mathrm{mm} / \mathrm{DS}: 0$ / N: 1

E máx: 7,00 mm / DS: 0 / N: 1

L ped: $15,50 \mathrm{~mm} / \mathrm{DS}: 0$ / N: 1

A raíz ped: 17,50 mm / DS: 0 / N: 1

E raíz ped: $6,60 \mathrm{~mm} / \mathrm{DS}: 0 / \mathrm{N}: 1$

A base ped: 14,70 mm / DS: 0 / N: 1

Observaciones:

Sobre esta punta de proyectil se confeccionó una muesca de lascado simple, reciclándola. La misma se armó sobre el limbo triangular corto producto del mantenimiento; mas precisamente, en el borde derecho, afectando también la raíz del pedúnculo, anulando, por ende, la posibilidad de establecer la eventual presencia de una aleta u hombro.

Sin embargo, en el borde izquierdo es posible observar un hombro que define a la pieza como con pedúnculo destacado. De esta forma, la combinación de bordes convergentes rectos con una base convexilínea, llevan a a un particularidad que habilita a definir este espécimen morfológico

Se destaca que el pedúnculo no presenta formatización alterna.

Sitio: PCh.1.3. 
Espécimen morfológico Casa Chávez Montículos 1 (CChM 1)

Caracterización tipológica:

Punta de proyectil con pedúnculo destacado y hombros. Forma general del contorno romboidal (¿por mantenimiento?)

Limbo triangular corto (¿por mantenimiento?)

Bordes del pedúnculo convergentes rectos.

Forma de la base del pedúnculo acuminada puntiforme.

Dimensiones:

L máx.: rango 27,00 - 23,00 mm

A máx.: 17,00 - 11,50 mm

E máx (promedio): 6,40 mm

Nota: datos tomados de Escola (1991). Se destaca que no refieren exclusivamente a la pieza en cuestión.

Observaciones:

Este espécimen morfológico se corresponde con el subgrupo tipológico A.1.V definido por Escola (1991, 2000). Esta autora clasifica al pedúnculo como diferenciado, sin embargo, al considerar el ancho de la raíz en función de la suma de la amplitud de las aletas, resulta en un pedúnculo destacado.

Sitio: CChM1.

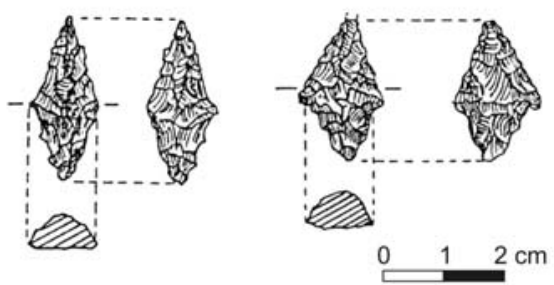

Figura 9.68. Ejemplos del espécimen morfológico CChM 1. Punta de proyectil (modificado de Escola 1991: Lámina 2) 


\subsubsection{EVIDENCIAS DE RECLAMACIÓN DE TIPOS MORFOLÓGICOS}

Diversos autores han manifestado las similitudes tipológicas de las piezas adscribibles al tipo morfológico QSB de los sitios QS3 y PP4 (por ejemplo, Pintar 1996a, Toselli 1998). Más recientemente, Martínez (2003), realizó un análisis comparativo de las variables dimensionales tomando series de piezas de ambos sitios, obteniendo como resultado marcadas semejanzas.

Dado que en QS3 el TM QSB aparece con un rango temporal que abarca desde 9800 a 7700 años AP aproximadamente, se postuló que las puntas de proyectil de este tipo recuperadas en PP4 y, por ende, los niveles arqueológicos que las contenían, deberían tener esta cronología (Pintar 1996a, Toselli 1998). Posteriormente, ya con un número importante fechados que indican ocupaciones ca.3800 años AP, Martínez (2003) señala que este tipo morfológico se presentaría diacrónicamente en PP4 respecto de QS3, con una discontinuidad temporal de uso de unos 4000 años.

Como se vio en el Capítulo 5, la estratigrafía de PP4 involucra un componente inicial sobre el piso de roca aún no claramente definido en su conformación, con una datación de 8900 años AP aproximadamente (Aschero et al. 2005). Asimismo, con respecto a los niveles posteriores mencionados, Aschero (2005a) plantea la posibilidad, en base a ciertas evidencias estratigráficas, de una excavación que habría preparado un área de habitación bajo nivel del terreno (ca.3800 AP), afectando dicha ocupación inicial. Por esta razón, no sería improbable que se haya producido una intensa reclamación de artefactos líticos tallados en el sitio, lo que explicaría la presencia del TM QSB en los niveles de fines del Holoceno Medio.

Lo expresado es razonable en vista de que las evidencias de reclamación de instrumentos en la microrregión son abundantes y cubren todo el lapso abordado. Así, en los niveles que competen de QS3 se recuperaron dos puntas de proyectil apedunculadas de base cóncava ( $\mathrm{N}^{\mathrm{o}} 19$-2b2- y No 111 2b5-) asimilables tipológica y tecnológicamente al TM QS C (Figura 9.69), fechado hacia el 7500 AP (Martínez 2003). Esto estaría corroborado, además, por la presencia de una leve pátina en una de ellas ( $\mathrm{N}^{\circ}$ 19), sólo visible empleando microscopio (Cattaneo com pers.). Por otra parte, Escola (2000) ha señalado la reclamación en contextos agro-pastoriles de puntas de proyectil que por sus diseños provendrían de sitios con cronología anterior al 3500 AP. 


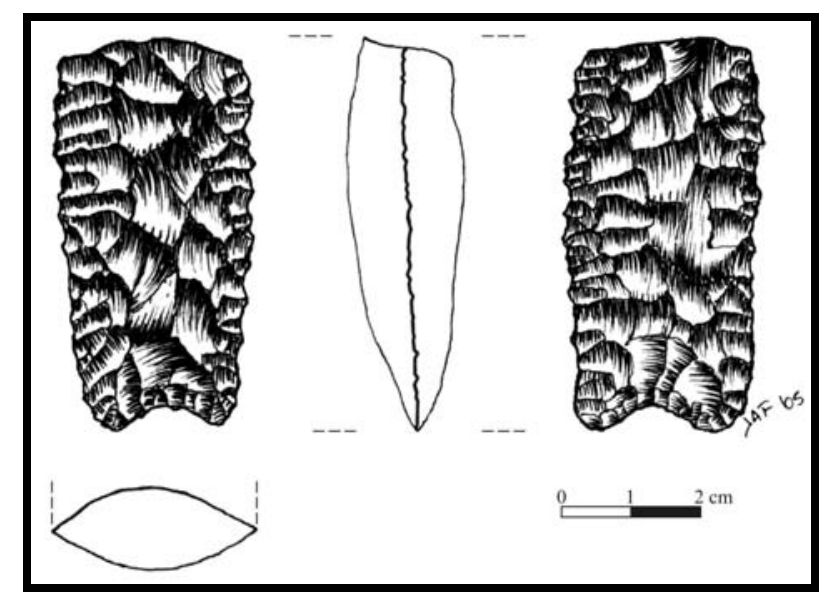

Figura 9.69. Punta de proyectil TM QS C (QS3. No inv 19)

Sin embargo, al evaluar la presencia en PP4 de pátinas o ventifacción diferencial en las piezas clasificadas como TM QSB se registró un único caso, que consiste en una punta de proyectil con regularización alterna que posee pátina sobre una cara y sobre la otra no ( $\left.\mathrm{N}^{\circ} 71\right)$. Interesa esta última, ya que los lascados de retalla y retoque, que eliminaron la formatización original -y que son evidencia de la reclamación-, afectaron el retoque alterno de la pieza original, cortando parcialmente sus bocas en uno de sus bordes y, rearmando, al mismo tiempo, la regularización alterna, por microrretoque en el otro borde. Otro caso se presenta en una pieza adscribible a un TM PPA ( $\left.N^{\circ} 245 / 14\right)$. En ésta, se partió de un artefacto formatizado no diferenciado (con lascados extendidos) como forma-base, trabajándose sobre una cara y quedando la otra cara remanente con pátina. Lo interesante es que se armó una regularización alterna, afectando la cara con pátina sólo en la porción correspondiente al pedúnculo. Pese a tratarse de sólo dos ejemplares, revelan un aspecto muy interesante, puesto que denotan que la regularización alterna se implementó ca.3800 AP, de la misma forma que las piezas con cronología 9800-7700 años AP (amén de otros diseños en pleno funcionamiento en esa época con ciertas variantes en cuanto al retoque/microrretoque alterno).

Esto implicaría, entre otras cosas, que más que la reclamación de un artefacto concreto (se destaca que, de un conteo de 21 piezas enteras o con fracturas no relevantes del TM QS B, sólo una presentaba pátina), se pudo haber producido la reutilización del diseño pero en términos de su incorporación como esquema conceptual (Inizan et al. 1999) a los existentes hacia fines del Holoceno medio; es decir, formando parte nuevamente del bagaje tipológico en una suerte de reclamación aunque con otro sentido al expresado por Schiffer (1987). Así también podría interpretarse el hallazgo de una punta de proyectil de este tipo morfológico en el nivel 2b4 de QS3 ( ${ }^{\circ}$ 638), con una cronología ca.5200 AP, además de las 3 piezas recuperadas en la capa 5(6) de PP4, sin evidencia de pátina, fechada hacia los 4500 años AP aproximadamente. 
Ahora bien, esta idea se ve robustecida por la ocurrencia de una serie de diferencias tipológicas y tecnológicas entre las piezas recuperadas en PP4 y las de los niveles del Holoceno temprano y medio de QS3. Como ya fue mencionado, Martínez (2003) encuentra que hay una estrecha correspondencia dimensional entre las piezas de ambos sitios, concluyendo que se trata del mismo tipo morfológico. Esta similitud en las mediciones se ve corroborada por los resultados logrados en esta investigación, que, además, partió de una ampliación de la muestra de PP4 (ver Tipo morfológico Quebrada Seca B en punto 9.1.1. Descripción de tipos morfológicos). Sin embargo, hay que poner en consideración un aspecto fundamental, el tamaño de las piezas descriptas por Martínez en el trabajo citado refiere al diseño básico, mientras que las dimensiones de las puntas de proyectil de PP4 son el resultado de procesos intensivos de mantenimiento, resultando en diseños mantenidos y transformados. Esto adquiere real significado al mencionar que el largo máximo en la muestra de QS3 es de 39,02 mm (Martínez op cit.), mientras que en PP4 el 52,38\% (N: 21) supera esa cifra, incluso con reactivación de los limbos. Un dato complementario que refuerza lo antedicho está dado por una preforma recuperada en excavación, cuyo largo es de 60,20 mm.

Pero hay otros dos aspectos que deben ser tenidos en cuenta. Por un lado, el diseño básico de las puntas de proyectil QS B de QS3 cuenta con un limbo triangular corto de lados rectos, mientras que las de PP4 poseen limbo lanceolado o triangular de lados convexos o rectos, largo o mediano. Por el otro lado, las primeras están confeccionadas sin mediar adelgazamiento bifacial, mientras que las segundas, por lo menos gran parte, sí. Esto es importante, ya que esta técnica se hace ubicua microrregionalmente recién a partir del 7500 AP, con la confección de las puntas de proyectil QSC y D (Martínez 1999, 2003), lo que permite establecer diferencias temporales en la aplicación de la misma.

La reclamación de un objeto, generalmente, implica tomar un objeto y usarlo sin más o bien modificarlo total o parcialmente para luego utilizarlo. En este caso se plantea que más que la ocurrencia de dichas posibilidades, en función de la puesta en práctica de salvage o scavenging (Schiffer 1987), tuvo lugar, en cambio, la reclamación de un diseño, a nivel de esquema conceptual, mediante la observación y replicación. Esta última no fue exacta, visto el desarrollo de ciertas variantes respecto del original, así como conllevó la implementación de esquemas operativos diferentes.

Por ello, se plantea discriminar en dos subtipos al TM QS B: el subtipo morfológico QS B.1 que comprende las puntas de proyectil con las características descriptas por Martínez (2003) recuperadas en los niveles tempranos de QS3 y el subtipo morfológico QS B.2, que involucra las piezas parte de esta investigación. 
Otro caso de reclamación similar pueden ser los raspadores de filo perimetral o extendido, con ubicación cronológica compatible en QS3 con el TM QSB, recuperados en PP4 y en PCh1.6.

\subsection{DISTRIBUCIÓN Y DIMENSIÓN TEMPORAL DE TIPOS MORFOLÓGICOS Y ESPECÍMENES MORFOLÓGICOS}

Los tipos y especímenes morfológicos tienen, en función de sus contextos de recuperación, una definición temporal más o menos acotada, según el caso. Se destaca, por un lado, que con esta asignación temporal no es la intención definir "tipos culturales” (Aschero 1975), sino, simplemente, vislumbrar diseños temporalmente sensibles y, por el otro lado, que tales adscripciones no tienen el carácter de definitivas, ya que, si bien ciertos tipos morfológicos provienen de contextos con relativa cantidad de fechados radiocarbónicos, en otros se requiere una mayor correlación cronológica (por ejemplo, el TM PP C). Es necesario, además, ampliar las muestras de sitios a nivel microrregional, para el lapso abordado. Cabe resaltar, en relación con esto último, el carácter provisional de los especímenes morfológicos.

Es importante denotar, también, que la designación de tipos y especímenes morfológicos tiene un alcance estrictamente microrregional. De esta forma, un tipo morfológico dado puede no serlo en otras áreas, sean cercanas o lejanas. En relación con esto, la vinculación de ciertos tipos o especímenes recuperados localmente con sitios de otras áreas de la Puna argentina y del desierto del norte de Chile tiene un fin meramente comparativo, con el objeto de analizar la circulación de información sobre diseños relativamente contemporáneos en distintas áreas de la porción meridional de los Andes Centro-Sur.

En la Tabla 9.1 se desarrolla la distribución temporal de las diferentes alternativas de tipos y especímenes morfológicos, por grupo cronológico. De su análisis resultan una serie de tendencias de interés. Destaca, en primer lugar, la diversidad de diseños en el GC2, ya que este grupo cronológico cuenta con el 75\% del total de tipos y especímenes morfológicos identificados (N: 25), mientras que en los GC 1 y 3 es mucho menor -28\% y 20\% respectivamente-. En el GC2 lo expresado se da tanto en los tipos morfológicos como en los especímenes morfológicos, ya que de 19 tipos en total, está representado el 73,68\% y de 6 especímenes morfológicos, el 83,33\%.

En segundo lugar, se puede apreciar que de los 7 tipos morfológicos presentes en el GC1, 6 también lo están en el GC2, siendo exclusivo del GC1 el TM QS G, que corresponde a los cortantes de filo retocado microdenticulados convergentes sin ápice activo. Al comparar el GC2 con el GC3, por su 
Tabla 9.1. Tipos y especímenes morfológicos por grupo tipológico

\begin{tabular}{|c|c|c|c|}
\hline $\begin{array}{l}\text { TIPO MORFOL / } \\
\text { ESPEC MORFOL }\end{array}$ & GC1 & GC2 & GC3 \\
\hline TM QS B.2 & 6 & 34 & - \\
\hline TM QS E & - & 3 & - \\
\hline TM QS F & 13 & 1 & - \\
\hline TM QS G & 5 & - & - \\
\hline TM PCh A & - & 28 & - \\
\hline TM PCh B & - & 3 & - \\
\hline TM PCh C & 1 & 2 & - \\
\hline TM PCh D & - & 2 & - \\
\hline TM PCh E & - & 9 & - \\
\hline TM PCh F & 2 & 8 & - \\
\hline TM PCh G & - & 3 & - \\
\hline TM PPA & - & 14 & - \\
\hline TM PP B & 1 & 6 & - \\
\hline TM PP C & - & 9 & - \\
\hline TM PCz A & 2 & 9 & - \\
\hline TM CChM A & - & - & 27 \\
\hline TM CChM B & - & - & 3 \\
\hline TM CChM C & - & - & 8 \\
\hline TM CChM D & - & - & 65 \\
\hline EM PCh 1 & - & 1 & - \\
\hline EM PCh 2 & - & 1 & - \\
\hline EM PCh 3 & - & 1 & - \\
\hline EM PCh 4 & - & 1 & - \\
\hline EM PCh 5 & - & 1 & - \\
\hline EM CChM 1 & - & - & 1 \\
\hline
\end{tabular}

Nota: La información sobre CCHM1 en el Gc3 proviene de Escola (2000) y Escola et al. (2005) 
parte, no se observa coincidencia alguna en cuanto a tipos y especímenes morfológicos ${ }^{1}$. Esto no sólo implica que el GC3 se diferencia claramente del GC2, con sus cuatro tipos morfológicos y el espécimen morfológico específicos, sino que este último grupo cronológico, a su vez, tiene en su haber tipos y especímenes que le son propios, a saber: TM QS E, PCh A, PCh B, PCh D, PCh E, PCh G, PP A y PP C y EM PCh 1, PCh 2, PCh 3, PCh 4 y PCh 5.

En tercer lugar, la mayor parte de los tipos y especímenes morfológicos en los tres grupos cronológicos son puntas de proyectil (N: 15) -6 de 7 en el GC1, 18 de 29 en el GC2 y 3 de 5 en el GC3-. Situación que tendría sentido en los GC1 y 2 donde la caza jugó indudablemente un papel fundamental en la subsistencia, pero no en el GC3, por tratarse de contextos agro-pastoriles plenos. Sin embargo, diversos trabajos han señalado, que la caza siguió siendo una actividad importante a nivel local (Olivera 1997, 1998; Escola 2002).

Diversos trabajos han señalado que la coexistencia de múltiples diseños de puntas de proyectil responde, entre otros aspectos, a la implementación de diferentes sistemas de armas y de distintas técnicas de caza (Aschero y Martínez 2001, Martínez 2003, Ratto 2003). Es indudable que parte de la variabilidad registrada en los diseños básicos, en los GC1 y 2, responde a ésto; sin embargo, la cantidad de diseños involucrados, en particular en referencia al GC2, excede toda posibilidad de variante de práctica cinegética, mas allá de una virtual especialización en la caza de un recurso concreto como son los camélidos, que pudo haber implicado una diversificación en las formas de obtener tales presas ( $c f$. Hayden 1981).

En este marco, un elemento a tener en cuenta es la implementación en el lapso abordado de una vasta red de obtención de recursos y de circulación de información, ya tratada en el Capítulo 6 (punto 6.2.4. Redes de interacción a larga distancia). La misma puede sostenerse a partir de la presencia de diseños específicos en otras áreas, ya sea a nivel regional o macrorregional, en forma relativamente sincrónica al GC2.

Así, dentro de los tipos morfológicos puede mencionarse, por ejemplo, a las puntas de proyectil lanceoladas de tamaño pequeño (denominadas, para el caso de Antofagasta de la Sierra, TM PCh E), recuperadas en diversos sitios de la Puna Norte argentina y su borde, como Tomayoc, con fechado radiocarbónico de 4250 años AP (Lavallée et al. 1997); Inca Cueva 7, con cronología de 4030 y 4080 años AP (Aguerre et al. 1973, Aschero y Yacobaccio 1998/99); Guayatayoc -3995 AP(Fernández 1968, 1988-89); Cueva El Portillo -3830 AP- (Fernández 1997); Alero Unquillar, datado hacia los 3500 (Yacobaccio et al. 2000); Potrero de Caballo Muerto -turba suprayacente: 3410 y 3590 AP; cronología estimada: 4000 AP (Fernández 1988-89, 1996a); Inca Cueva 1, ubicado por dataciones

\footnotetext{
${ }^{1}$ Aunque esto no significa que no haya vinculaciones entre ambos, ya que, como se verá más adelante, hay claras relaciones genéticas entre el TM PP C del GC2 y el TM CCHM A del GC3.
} 
absolutas ca.2900 AP (García 1998) y Cueva de Cristóbal -2860 AP- (Fernández 1988-89). Por su parte, en el desierto del norte de Chile, aparecen, por ejemplo, en Tulán 52 (Núñez 1992), datado hacia los 4300 años AP; en Puripica 1, con fechados entre 4800 y 4300 AP (Núñez et al. 1999) y en Confluencia 2, ca.3900 AP (Jackson 1993-94).

En suma, este diseño se ubica temporalmente, al conjugar datos de la Puna argentina y su borde y de la circumpuna chilena, entre los 4800 y los 2900 años AP. En Antofagasta de la Sierra, por su parte, el lapso se restringe a los 3700-3400 años AP, a partir de la información de PCh1.1 y PCh1.3 -a los que se podría sumar CS1 (Pintar 2004a)-. Cabe destacar que dicho intervalo se ampliaría si se tomaran en cuenta las puntas de proyectil de este tipo registradas en el talud de CC1A, ya que las mismas estarían asociadas a una serie de fechados en el interior de la cueva que van del 3400 al 2800 años AP aproximadamente (Olivera et al. 2003).

Otro caso podría ser el de las puntas de proyectil lanceoladas (normales), denominadas localmente TM PCz A. Morfologías afines están presentes, por ejemplo, en Potrero de Caballo Muerto, denominadas como tipo La Matadería por Fernández (1996a), con la cronología señalada, así como en múltiples sitios superficiales de la Puna jujeña (Fernández 1971, Fernández Distel 1978), carentes de datación radiocarbónica. Se encuentran, también, entre muchos otros sitios del norte de Chile, en Tulán 52 y Puripica 1 (Núñez 1992, Núñez et al. 1999).

Las puntas triangulares, definidas a nivel microrregional como PCh G, son, a su vez, otro ejemplo, registrándose, siempre en bajas proporciones, en Inca Cueva 7 (Aguerre et al. 1973), en Alero Unquillar (Yacobaccio et al. 2000) y en Guayatayoc (Fernández 1968), entre otros. Asimismo, se encuentran, ya con frecuencias importantes, en Chiu-Chiu Cementerio y Chiu-Chiu 200, en la cuenca del Río Loa (Jackson y Benavente 1994).

Por su parte, también se han recuperado recurrentemente en distintos sitios de la Puna de Jujuy, así como en la Quebrada de Tulán, las puntas de proyectil con pedúnculo destacado, aletas entrantes y limbo lanceolado o triangular identificadas aquí como TM PP C (ver Capítulo 11).

En lo que respecta a los especímenes morfológicos, se puede mencionar al EM PCh2, de morfología comparable al tipo “Aguas Calientes” de Fernández (1996a) y al EM PCh3, que pese a tratarse de un fragmento de pedúnculo, a partir de la porción remanente es posible observar las afinidades con una pieza procedente del sitio Tulán $54^{2}$.

\footnotetext{
${ }^{2}$ Se desea agradecer a L. Núñez por hacer posible el acceso a las colecciones de Tulán 54.
} 
Se considera, entonces, que la interacción habría tenido como correlato la incorporación al acervo tipológico microrregional de una serie de puntas de proyectil de diversa índole. En primera instancia, las evidencias disponibles permitirían postular que esto se desarrolló en el marco de mecanismos de circulación de información (junto con el ingreso de distinto tipo de recursos bióticos), ya que los diseños en cuestión se presentan en la microrregión, en su mayor parte, sobre rocas locales. Los casos de materias primas no locales, minoritarios por cierto, están constituidos por obsidianas que provienen de la Puna catamarqueña.

Sin embargo, excluyendo inclusive a los diseños señalados, el número de tipos y especímenes morfológicos de puntas de proyectil continúa, de todas formas, siendo muy importante en el GC2, con 12 diseños distintos; cantidad que se potencia al considerar la diferenciación del TM PCh A en 6 subtipos morfológicos, ya que aumenta a 18 clases. Sumando las puntas de proyectil con diseño “extralocal”, se contaría con 24 morfologías distintas. Se considera que esta diversidad dentro de las puntas de proyectil podría vincularse con la ocurrencia de una importante cuota de variación estilística a nivel microrregional ${ }^{3}$.

En el caso concreto de las puntas de proyectil aquí consideradas, interesa particularmente la morfología del pedúnculo, ya que las variaciones isocrésticas, es decir, las opciones y alternativas equivalentes que intervienen en la manufactura y/o uso de los objetos (Sacket 1990), se registrarían principalmente en este último. Por ejemplo, dentro del TM Ph A, se presentan marcadas variaciones en la forma tanto de los bordes como de la base de los pedúnculos, sin que haya diferencias aparentes en el tipo de enmangue con el astil o intermediario (Martínez com pers.). Esto no implica que el resto de la pieza no sea relevante para el establecimiento de variantes estilísticas; de hecho, han sido tenidas en cuenta las distintas partes que componen tales instrumentos -por ejemplo, su morfología general- (cf. Whittaker 1987, Rick 1996). No obstante, como la mayor parte de las piezas ha sufrido mantenimiento con mayor o menor grado de intensidad, la posibilidad de una aproximación desde tales aspectos se ve reducida e incluso anulada, según el caso. Justamente, es el área de enmangue la que generalmente se mantiene intacta, debido a que no registra trasformaciones producto del mantenimiento. Un punto a evaluar en el futuro, a partir de la comparación con otras áreas, es si la presencia de la regularización alterna en los diseños pedunculados de la microrregión constituye un rasgo estilístico exclusivo, ya que de 13 tipos y subtipos morfológicos de puntas de proyectil pedunculadas en el GC2, 9 poseen retoque/microrretoque alterno.

\footnotetext{
${ }^{3}$ Se destaca que Rick (1996), al analizar las puntas de proyectil de las cuevas de Pachamachay y Panaulaca, en la puna peruana, sostiene que la multiplicidad de formas de las mismas (con un máximo de 12 a partir de la Figura 2), no puede explicarse a partir de la variabilidad funcional, asignándole, en cambio, un papel importante a la expresión estilística. Se destaca que en este caso se duplica el número de diseños con el que contaba este autor.
} 
Previamente, en los Capítulos 6 y 8 se desarrollaron una serie de evidencias, que abarcan desde arte rupestre hasta la utilización diferencial de materias primas locales, que señalan la implementación de ámbitos de control territorial entre los 3800 y los 3400 años AP. Ante este hecho, sería esperable que la variación estilística en las puntas de proyectil, a nivel espacial, refleje justamente la presencia de territorios. Sin embargo, no es posible establecer, en base a la muestra de sitios considerados, adscribibles al GC2, si efectivamente existió alguna vinculación entre diseños específicos y sectores particulares de la microrregión. Al respecto, se han comenzando a implementar prospecciones en distintas quebradas con este objetivo, pero todavía no se cuenta con resultados concretos. De hecho, los sitios que participan del GC2, a saber: PP4, PCh1.1, PCh1.3 y PCh1.6, se encuentran a menos de 500 m de distancia entre sí, en las localidades próximas de Punta de la Peña y Peñas Chicas, conformando un patrón de distribución de bases residenciales dispersas pero cercanas.

Teniendo esto presente, la conjunción de tal variedad de diseños de puntas de proyectil parecería responder a la puesta en marcha de procesos de diferenciación social, ya sea de individuos o grupos de individuos, aunque, destaca, no implica necesariamente desigualdades y jerarquías ${ }^{4}$, Aschero (2005b) postula que la circunscripción espacial entre los 5000 y los 3500 años AP a nivel local pudo haber incrementado la competencia entre actores sociales de distintos linajes o ancestrías y que el arte rupestre actuó como una suerte de regulador de las condiciones sociales, promoviendo las acciones cooperativas. Tal vez, las puntas de proyectil, así como otro tipo de tecnofacturas aquí no tenidas en cuenta ${ }^{5}$, tuvieron un papel opuesto, propugnando la competencia y la diferencia ( $c f$. Hayden 1998). En este marco, la variación formal en las puntas de proyectil comunicaría información social relevante (Wobst 1977, Wiessner 1983), manteniendo más que minimizando los límites sociales ${ }^{6}$.

\subsection{ANÁLISIS DE LA RECURRENCIA DE TIPOS Y ESPECÍMENES MORFOLÓGICOS}

En este punto se aborda la recurrencia de tipos morfológicos en Antofagasta de la Sierra, es decir, la presencia de tipos morfológicos standard y recurrentes escasos, en función del análisis de las frecuencias de los tipos en los sitios considerados para cada uno de los grupos cronológicos definidos (Tabla 9.2). Pero, previamente, es pertinente recordar qué se entiende por estos términos. De esta

\footnotetext{
${ }^{4}$ No siendo esto, tampoco, contradictorio con el hecho de una especialización en la caza de camélidos vista desde las tecnologías extractivas.

${ }^{5}$ Siguiendo a Wiessner (1983), el contenido estilístico de un ítem estaría correlacionado con la inversión de tiempo y trabajo en la manufactura y con la extensión de la vida útil del mismo (ver, también, Wobst 1977). Así, las puntas de proyectil cumplen tales expectativas. Sin embargo, otro tipo de instrumento, los bifaces como artefactos en sí mismos, que poseen tales características, no parecerían mostrar expresión estilística alguna, denotando una homogeneidad morfológica discernible pese a lo fragmentado de la muestra. Esto puede estar vinculado, en realidad, al hecho de que una mayor modificación intensiva no es equivalente a la capacidad de contener estilo (Sackett 1985, Rick 1996), y a que cualquier artefacto, en realidad, puede denotar estilo.

${ }^{6}$ Sin considerar a los tipos y especímenes morfológicos definidos como "marcadores" culturales.
} 
Tabla 9.2. Recurrencia de tipos y especímenes morfológicos por sitio arqueológico

\begin{tabular}{|c|c|c|c|c|c|c|c|c|c|}
\hline \multirow{2}{*}{ TM / E M } & \multicolumn{2}{|c|}{ GC1 } & \multicolumn{5}{|c|}{ GC2 } & \multicolumn{2}{|c|}{ GC3 } \\
\hline & QS3 & $\begin{array}{r}\text { PP4 } \\
-5(6)-\end{array}$ & $\begin{array}{c}\text { PP4 } \\
-4 \text { a (5)- }\end{array}$ & PCh1.3 & PCh1.1 & PCh1.6 & $\begin{array}{l}\text { Otros } \\
\text { sitios }\end{array}$ & CChM1 & PP9 \\
\hline TM QS B.2 & 1 & 5 & 32 & 1 & 1 & - & - & - & - \\
\hline TM QS E & - & - & 2 & - & - & - & - & - & - \\
\hline TM QS F & 13 & - & - & 1 & - & - & - & - & - \\
\hline TM QS G & 5 & - & - & - & - & - & - & - & - \\
\hline TM PCh A & - & - & 2 & 21 & 2 & 3 & - & - & - \\
\hline TM PCh B & - & - & 1 & - & - & 2 & - & - & - \\
\hline TM PCh C & 1 & - & 1 & 1 & - & - & - & - & - \\
\hline TM PCh D & - & - & - & 1 & - & 1 & - & - & - \\
\hline TM PCh E & - & - & - & 1 & 7 & 1 & - & - & - \\
\hline TM PCh F & 2 & - & 2 & 4 & 2 & - & - & - & - \\
\hline TM PCh G & - & - & 1 & 2 & - & - & - & - & - \\
\hline TM PPA & - & - & 13 & - & 1 & - & - & - & - \\
\hline TM PP B & 1 & - & 6 & - & - & - & - & - & - \\
\hline TM PP C & - & - & 1 & - & - & - & $9 *$ & - & - \\
\hline TM PCz A & 2 & - & - & - & 9 & - & - & - & - \\
\hline TM CChM A & - & - & - & - & - & - & - & 25 & 2 \\
\hline TM CChM B & - & - & - & - & - & - & - & 3 & - \\
\hline TM CChM C & - & - & - & - & - & - & - & 8 & $* *$ \\
\hline TM CChM D & - & - & - & - & - & - & - & 62 & 3 \\
\hline EM PCh 1 & - & - & - & 1 & - & - & - & - & - \\
\hline EM PCh 2 & - & - & - & 1 & - & - & - & - & - \\
\hline EM PCh 3 & - & - & - & 1 & - & - & - & - & - \\
\hline EM PCh 4 & - & - & - & 1 & - & - & - & - & - \\
\hline EM PCh 5 & - & - & - & 1 & - & - & - & - & - \\
\hline EM CChM 1 & - & - & - & - & - & - & - & 1 & - \\
\hline
\end{tabular}

Referencias: TM: Tipo morfológico. EM: Espécimen morfológico.

Nota: Para el sitio PP4 se consideraron las campañas de 1996, mayo de 1998 y 1999.

* CS1: 2 piezas; PP9: 2 piezas; PP1: 1 pieza; PH2-ES: 1 pieza; LC 2.1(¿?): 3 piezas.

** Presencia de desechos de talla de mantenimiento de raederas de módulo grandísismo 
forma, los primeros se caracterizan por poseer siempre la frecuencia más alta, comparativamente con los restantes tipos, en los distintos sitios considerados, mientras que lo segundos se presentan también en distintos sitios pero con frecuencias bajas, o bien en un solo sitio con más de una pieza pero siempre con porcentajes bajos (ver punto 4.3.8. Tipo en el Capítulo 4).

Tendiendo esto presente, en el GC1 no hay casos de tipos morfológicos standard, siendo muy importantes, en cambio, los recurrentes escasos. Así, se pueden definir como tales los TM QS F, QS G, PCh F y PCz A. El primero cuenta con presencia tanto en QS3 como en la capa 5(6) de PP4, mientras que los restantes en el primer sitio mencionado, con muestras constituidas, por ende, por dos o más de dos piezas. Esto muy posiblemente sea resultado de la bajísima tasa de recuperación de materiales de la capa 5(6), a lo que se suma la falta de sitios arqueológicos sincrónicos, transformándose QS3 en prácticamente el único sitio a considerar.

Por su parte, en el GC2, tampoco se registran tipos morfológicos standard. Todos los casos, con excepción del TM QS F, que consta de una sola pieza, son tipos morfológicos recurrentes escasos que se registran en distintos sitios contemporáneamente. Los TM QS E, PCh B, PCh C, PCh D, PCh G y PP A están presentes en dos sitios; los TM QS B.2, PCh E y PCh F en tres sitios; el TM PCh A en cuatro sitios y el TM PP C en 6 sitios. Con respecto al TM QS F, habría que evaluar si la única pieza recuperada representa un espécimen morfológico o es el resultado de las muestras consideradas.

Un aspecto muy interesante, en el GC2, es que tales tipos morfológicos recurrentes escasos presentan diseños de puntas de proyectil que son mayoritarios diferencialmente en cada uno de los sitios considerados. Así, en PCh1.3 hay una predominancia de piezas del TM PCh A, en PP4 de los TM QS B.2, PP A y PP B y en PCh1.1 de los TM PCh E y PCz A, es decir, diseños pedunculados en los dos primeros sitios y apedunculados en el último. Pese a que esto se aleja de la definición aquí propugnada de tipo morfológico recurrente escaso, basada en la baja representación de un tipo determinado en todos los sitios; justamente el hecho de que no sean mayoritarios en el conjunto de sitios, los descalifica como tipos morfológicos standard. De esta forma, se plantea ampliar la noción de tipo morfológico recurrente escaso, incluyendo situaciones en las que se combinan una alta y una baja frecuencia para un mismo tipo en distintos sitios.

Tal diferenciación es notable teniendo en cuenta que se trata de tres sitios que no diferirían funcionalmente y que se encuentran tan cercanos entre si (ver punto anterior). Una posibilidad es que esto sea producto de la producción distintiva de ciertos diseños por parte de individuos o grupos de individuos (¿vinculados por lazos de familia extensa?), lo cual estaría de acuerdo con el proceso de diferenciación señalado en el punto anterior, pero ya no desde una perspectiva diacrónica, sino sincrónica (es interesante, de hecho, que la diferenciación en el GC2 se refleje tanto sincrónica como 
diacrónicamente). En este sentido, Aschero (2005b) señala que hay suficientes indicadores en la Puna argentina como para sugerir que había particulares preferencias hacia los adornos personales y en la “decoración” de objetos de uso cotidiano, y que tal insistencia en la decoración de objetos muebles y atuendos puede ser vista como respuesta diacrítica a la competencia entre grupos. Es decir, como expresiones estilísticas y no de “jerarquías”que ligaban a su poseedor con su grupo o linaje. Esto no quita que procesos intensos de interacción entre grupos vecinos inmediatos lleven al intercambio de puntas de proyectil -y también de tecnofacturas en general-, resultando en el patrón observado (ver, por ejemplo, Wiessner 1983).

En relación con PCh1.1, la importancia cuantitativa de los diseños apedunculados lanceolados de puntas de proyectil llevó a considerar a los mismos como característicos de las ocupaciones cazadoras-recolectoras de fines del Holoceno medio de Antofagasta de la Sierra (Aschero com pers.) (Figura 9.70). Sin embargo, las evidencias presentadas en este trabajo sobre PCh1.3 y de PP4 señalan el destacado papel del componente pedunculado; pero no solamente eso, en el mismo PCh1.1 se recuperaron una serie de piezas que son relevantes para sostener que este sitio no era excepción.

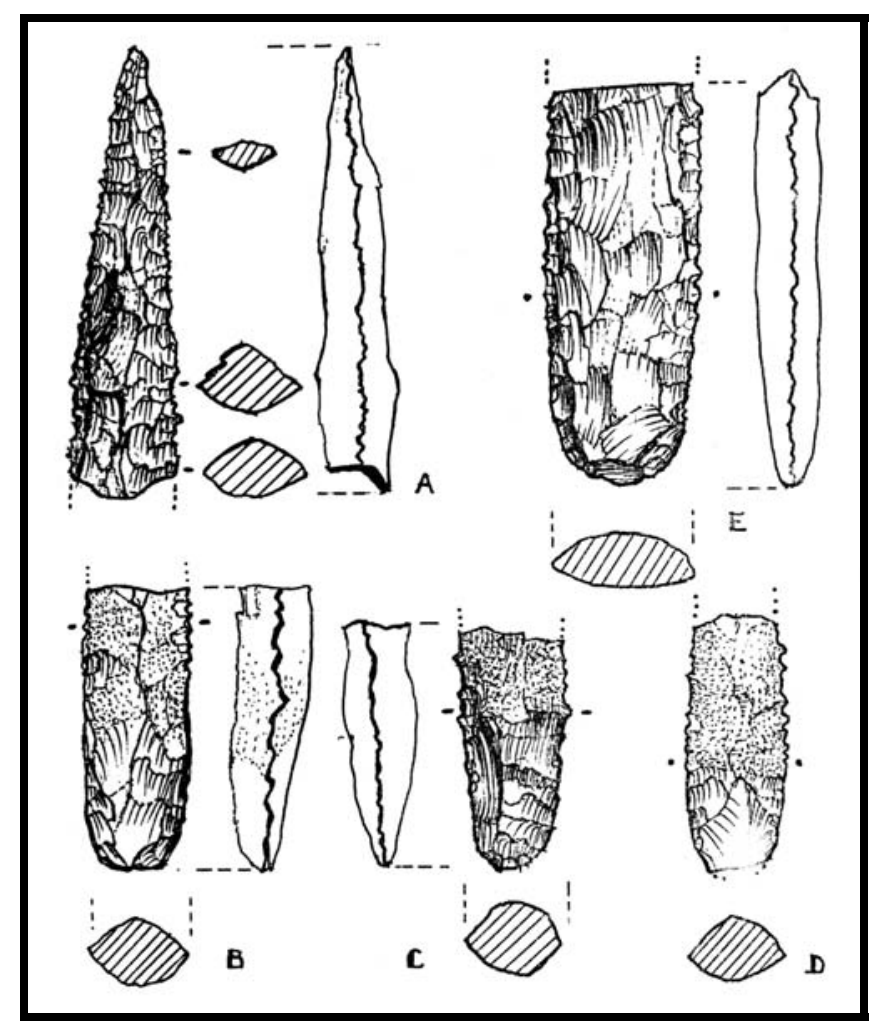

Figura 9.70. Puntas de proyectil lanceoladas apedunculadas. PCh1.1 - excavación (cortesía C. Aschero) 
Así, por ejemplo, se identificó una preforma de punta de proyectil adscribible al TM PCh A, pese a poseer una fractura en el limbo y otra que afectó parte de la base del pedúnculo ( $\mathrm{N}^{\circ}$ inv. 58) (Figura 9.71).

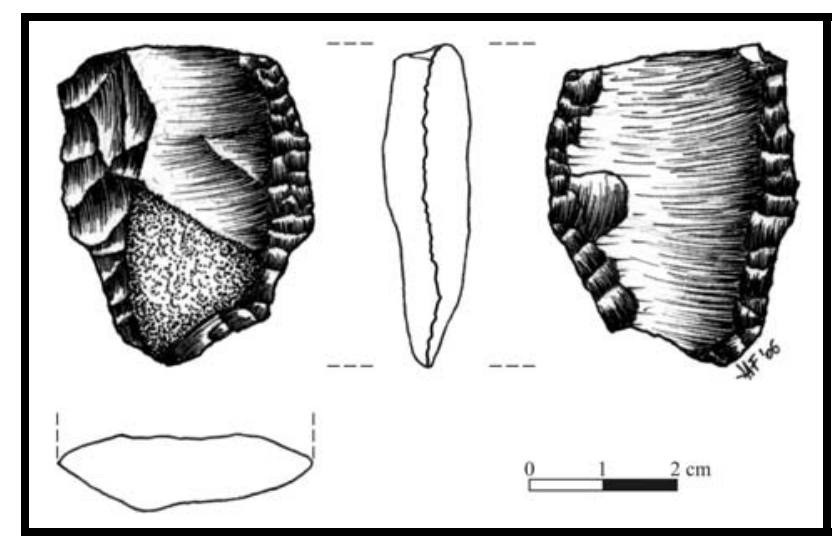

Figura 9.71. Preforma de punta de proyectil TM PCh A. (PCh1.1. $\mathrm{N}^{\mathrm{o}}$ inv 58)

Por otro lado, una serie de fragmentos de limbos también brindan información sobre presencia de piezas pedunculadas en PCh1.1. En la Figura 9.72 se pueden observar que son perfectamente comparables con los recuperados en la excavación del cercano alero Peñas Chicas 1.3.

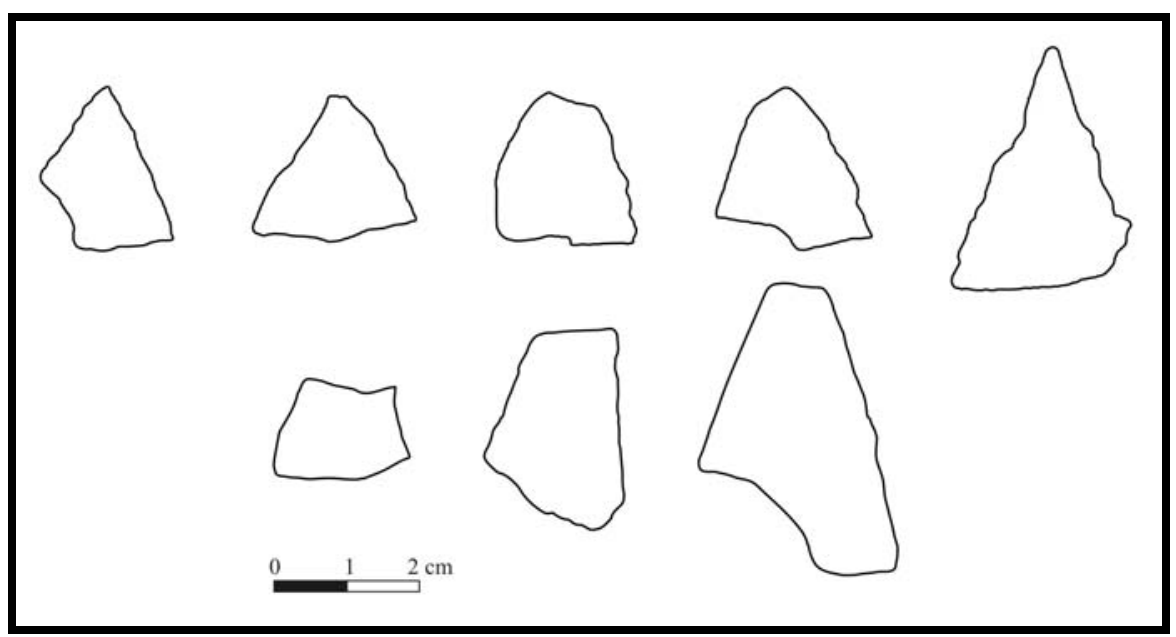

Figura 9.72. Fragmentos de limbos de puntas de proyectil pedunculadas. Arriba: PCh1.3. Abajo: PCh1.1.

Un aspecto de sumo interés se desprende a partir del abordaje de las frecuencias relativas de fragmentos de pedúnculos y limbos, ya que es posible establecer un vínculo entre ambos sitios. Así, PCh1.1 posee, excluyendo a la preforma arriba mencionada, 3 fragmentos de limbo que corresponderían al TM PCh A y 1 solo pedúnculo de este tipo morfológico, mientras que PCh1.3 
cuenta con 6 piezas enteras, 11 fragmentos limbo-pedúnculo, 4 pedúnculos y 5 fragmentos de limbo del TM PCh A. Si se acepta que la alta frecuencia de fragmentos basales de puntas de proyectil en un sitio evidencia tareas de recambio de puntas fracturadas por piezas completas y que el alto porcentaje de fragmentos de limbo (apicales y mesiales) implica faenamiento de presas, infiriendo que tales fragmentos ingresaron al sitio dentro de las presas allí trozadas y/o consumidas (Martínez 2006), PCh1.1 se vincularía al segundo caso en función de la importancia de los fragmentos mesiales de limbo -75\%-, mientras que en PCh1.3 tendría lugar tanto el recambio de puntas de proyectil -57,69\%como el faenamiento de presas -19,23\%-. Pero esto no implica sólo eso, sino también que se podría estar en presencia de un caso arqueológico de distribución de las presas obtenidas en el marco de actividades de caza colectiva -evidenciadas en la microrregión desde ca.7500 AP (Aschero y Martínez 2001)-, integradas por individuos o grupos de individuos de PCh1.1 y PCh1.3. Otra posibilidad es que haya habido una redistribución de carne por parte de cazadores de PCh1.3 que alcanzó a PCh1.1. Por cierto, sea lo que fuere lo acaecido, este hecho de "compartir“ las piezas cazadas (cf. Kelly 1995, Barnard 2001) aparece en estrecha relación con lo que se plantea como expresiones estilísticas de grupos inmediatos, por lo que constituye otro elemento como para postular la ausencia de jerarquías. Por cierto, la situación de colaboración señalada no es contraria a la ocurrencia de procesos de competencia y diferenciación, siendo clave y necesaria, por ejemplo, la actividad comunitaria en las prácticas de caza colectiva vigentes (Aschero y Martínez 2001). De hecho, la competencia puede darse sólo en ciertos aspectos. Así, al mismo tiempo que hay reciprocidad simétrica o asimétrica en ciertas actividades, puede presentarse una situación de competencia en otras.

Finalmente, en cuanto al GC3, los TM CChM A y B, que refieren a puntas de proyectil con pedúnculo y sin pedúnculo, respectivamente, son considerados tipos morfológicos standard, pese al bajo número de las primeras y a la ausencia de las segundas en PP9, que responde a cuestiones contextuales. Esto se plantea así en función de lo expresado por Escola (2000) acerca de la ubicuidad y preponderancia de estos diseños en sitios agro-pastoriles locales fechados entre los 2100 y los 1500 años AP.

En referencia a los TM CChM C (raederas de módulo grandísismo) y CChM D (palas y/o azadas), se los define como tipos morfológicos recurrentes escasos, en función del bajo número de las primeras -se destaca que es posible evaluar su presencia, aunque no su representatividad en los conjuntos de instrumentos, a partir de los desechos de talla resultantes del mantenimiento de las mismas (ver Capítulo 12)- y de la importancia de la fragmentación en las segundas. Dado que se trata de artefactos vinculados con actividades productivas (ver Apéndice III), constituirían tipos morfológicos standard en áreas de campos de cultivo y no en bases residenciales como las consideradas. 


\section{CAPÍTULO 10}

\section{VARIABILIDAD EN BIFACES}

\subsection{APROXIMACIÓN A LA VARIABILIDAD EN BIFACES}

En este Capítulo se aborda la variabilidad de los bifaces recuperados en excavación en los sitios QS3, PCh1.3, PCh1.1 y PP4, desde la combinación y complementación de dos puntos de vista: uno, que parte de la variabilidad morfológico-funcional y dimensional y otro, basado en la evaluación del papel cumplido por los bifaces en los sitios considerados, sea como artefactos de larga vida útil, como subproductos del proceso de manufactura de instrumentos diversos o como núcleos (ver en el Capítulo 1 el punto 1.1.2.1. El problema de los bifaces por una profundización sobre estas categorías). Para ello, se parte de la distinción entre bifaces como tales, transformados y reciclados, por un lado, y entre bifaces en sí mismos y en proceso de manufactura, por el otro.

Cabe destacar que se discute, asimismo, la atribución a aprendices de parte de los bifaces recuperados. Esto es importante, ya que su accionar pudo haber influenciado la variabilidad morfológica existente. De esta forma, se pretende, a partir del análisis de variables morfológicas en bifaces, evaluar el papel que pudieron haber tenido las habilidades motoras y las capacidades cognitivas diferenciales en la conformación de este registro particular.

\subsubsection{CATEGORÍAS DE ABORDAJE DE LOS BIFACES}

Es importante introducir nuevamente aquí la noción de biface transformado y su diferencia con el reciclaje, ya tratada en el punto 4.6.4. Consideraciones acerca del reciclaje y del mantenimiento del Capítulo 4. Para un entendimiento cabal de este concepto, es necesario retomar la definición de reciclaje, de modo de diferenciarlo. Siguiendo a Schiffer (1987), se reserva la ocurrencia de reciclaje sólo a aquellos casos donde hay un cambio de forma y de función en el artefacto formatizado, perdiendo su identidad original. Justamente, una excepción son los bifaces, puesto que la modificación de la arista sinuosa que los define, en otras morfologías, es un aspecto que es parte de la naturaleza misma del biface (Kelly 1988, Hayden et al. 1996). De hecho, en la concepción de transformado, se presenta una situación de premeditación que conlleva un cambio de forma pero que, se destaca, no implica un cambio de función anterior, puesto que desde un comienzo estaba destinado a ser otras 
cosas. Por esto, se emplea el calificativo de biface transformado cuando hay una modificación de la sinuosidad de la arista, generalmente en arista regular, sin mediar reciclaje.

A partir de esto, el reciclaje en los bifaces se presentaría, por ejemplo, en aquellos casos donde la pieza en cuestión se ve afectada por una fractura, conformándose nuevos filos y/o puntas a partir de la ocurrencia de dicha fractura, distinguibles desde un punto de vista morfológico-macroscópico a partir de la utilización de la fractura para la confección de partes activas o pasivas y/o de la ubicación de los filos y puntas en relación a las superficies fracturadas. También, en piezas enteras con evidencias de no poder continuar en proceso de manufactura por presentar defectos de diversa índole.

En cuanto a los bifaces como tales, son piezas que no se han visto transformadas y que tampoco han sido recicladas. Es decir, que han sido descartadas conservando su identidad original.

En el segundo caso, se clasifica como bifaces en sí mismos a aquellas piezas en las que la arista sinuosa pudo ser utilizada como filo activo, habiéndose finalizado la formatización. Se caracterizarían por poseer ángulos agudos, una arista sinuosa regular y una amplitud del sinusoide (offset sensu Callahan 1979) estrecha, además de una sección transversal biconvexa simétrica regular (ver, por ejemplo, Hayden et al. 1996). Un punto importante para caratularlos de esta forma es tener la certeza de que no se trata de preformas de algún tipo de instrumento en particular. Los bifaces en proceso de manufactura, por su parte, son aquellos artefactos que presentan evidencias de continuar en una instancia de producción, como una arista sinuosa irregular con una sinuosidad moderada a amplia, sección transversal biconvexa asimétrica irregular, etc.

Las vinculaciones entre los conceptos previamente explicitados y entre éstos y la propuesta de Kelly (1988) para los bifaces pueden apreciarse en la Figura 10.1. Un punto que es conveniente notar, con respecto a los bifaces transformados, es que en los mismos, dado que generalmente la regularización final implica una modificación intensiva, ésta puede imposibilitar diferenciar morfológicamente si previamente pasó por una etapa como biface en sí mismo o si directamente derivó de un biface en proceso de manufactura. 
Biface como artefacto de larga vida útil

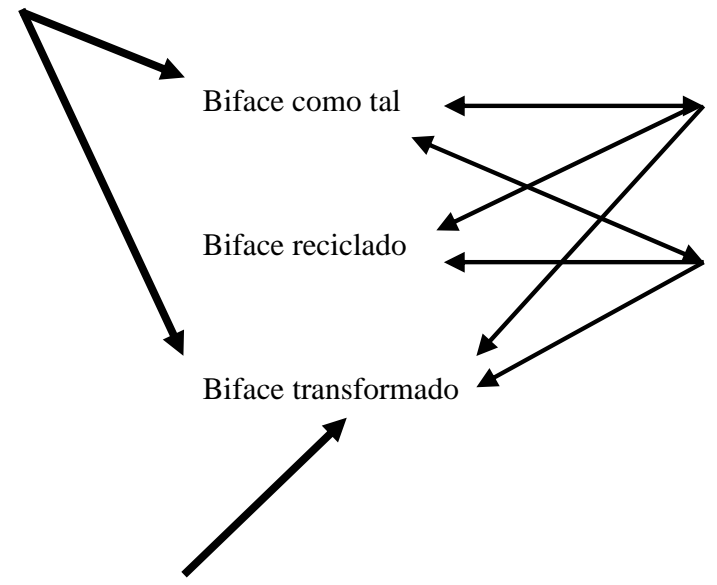

Biface en si mismo

Biface en proceso de manufactura
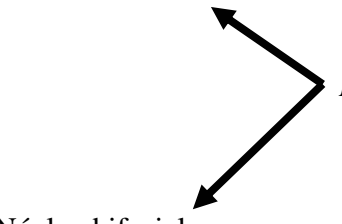

Biface como núcleo

Núcleo bifacial

Biface como subproducto de la manufactura de instrumentos

Figura 10.1. Diferentes papeles de los bifaces

\subsubsection{PRODUCCIÓN LÍTICA Y APRENDICES}

Está ampliamente reconocido que la talla lítica es una actividad tecnológica que requiere de una importante cuota de práctica antes de que puedan lograrse consistentemente resultados satisfactorios. De esta forma, es esperable la presencia en el registro arqueológico de talladores con habilidad variable. Por otro lado, hay cierto consenso en que la práctica de la talla comienza temprano en el ciclo de vida, es decir, durante la niñez y la adolescencia (Pigeot 1990, Grimm 2000). Así, se relaciona, por lo general, con niños a artefactos pobremente elaborados y toscos, por el hecho de ser talladores novatos.

Adquirir las destrezas necesarias para tallar la piedra es un proceso complejo, que demanda la interacción de diferentes tipos de conocimiento que van desde patrones teóricos hasta la habilidad práctica en la ejecución de acciones motoras (Finlay 1997). Al respecto, de acuerdo a Stout (2002), la adquisición de destreza en la talla es un proceso de aprendizaje de cómo actuar para resolver un problema más que de adquirir alguna fórmula motora rígida.

La falta de control sobre principios técnicos básicos se ve reflejada en la concepción y en la ejecución del proceso de talla. Las estrategias de reducción llevadas a cabo por inexpertos están generalmente incompleta o inadecuadamente conceptualizadas, observándose, además, discrepancias entre el concepto y el producto terminado (Karlin et al. 1993). Asimismo, los talladores inexpertos son más proclives a cometer errores en forma frecuente y consistente; estando relacionados, por ejemplo, 
con la limitada apreciación de los novicios de la fuerza necesaria para desprender lascas, lo que lleva a la producción de terminaciones en charnela o quebradas. Al considerar los bulbos de percusión, tienden a estar más marcados en el trabajo de quienes se inician, por la aplicación de fuerza excesiva (Finlay 1997, Grimm 2000). A su vez, los talladores con experiencia son capaces de “leer” la materia prima, anticipar y corregir errores, debido a un entendimiento técnico y habilidades motoras superiores.

Lo importante es que estas destrezas diferenciales se ven reflejadas en atributos particulares en el registro material, que pueden ser abordadas desde aproximaciones morfológico-macroscópicas. En este caso, la identificación de aprendices se realiza a partir de una clase de artefacto formatizado particular, los bifaces. Se parte de la base de que las características morfológicas de los bifaces permiten realizar inferencias sobre destreza técnica. Por ejemplo, a menor espesor y mayor regularidad de la arista sinuosa, mayor destreza técnica.

\subsubsection{CARACTERÍSTICAS DEL ADELGAZAMIENTO BIFACIAL}

Para confeccionar bifaces se requiere de la utilización de una técnica en particular, que es la técnica del adelgazamiento bifacial por percusión blanda, aunque también se puede utilizar percusión dura e incluso presión (Callahan 1979).

En el adelgazamiento bifacial se trabajan las caras de un artefacto por medio de lascados que afectan proporcionalmente más las caras que los bordes. Es manifiesta la intencionalidad de rebajar el espesor del artefacto y generar una sección determinada, generalmente biconvexa. Así, se espera que las piezas con adelgazamiento presenten, como ya fuera planteado en el Capítulo 4: a) lascados que se extiendan desde el borde hasta un poco más allá del centro del artefacto, b) que estos contacten o se superpongan con negativos provenientes del margen opuesto.

Cualquiera sea la técnica de talla, el tallador debe: 1) poseer una buena coordinación manoojo, incluyendo la destreza de golpear un artefacto con un percutor con un golpe incidente seco, 2) contar con un fuerte poder y gran precisión de asimiento y 3) controlar una serie de variables: profundidad de la plataforma, ángulo del golpe, ángulo exterior de la plataforma y fuerza del golpe (ver, por ejemplo, Pelegrin 1993).

La percusión blanda (madera, asta o una roca no muy dura) es particularmente útil en adelgazar y dar forma a un biface porque es la forma más fácil de remover lascas largas relativamente planas y delgadas con bulbos de percusión delgados (afectando, por ende, mínimamente el ancho). 
Esto es así porque cuando el percutor blando golpea el biface, se comprime delicadamente y la fuerza se difunde y transmite más lentamente y en forma pareja (Whittaker 1994).

En la percusión dura, el golpe debe caer con un ángulo agudo (menor a 90) en la plataforma (Figura 10.2). Además, el peso del percutor de piedra es a menudo suficiente para proveer la fuerza del golpe, con muy poco esfuerzo muscular en adición. Un percutor blando es diferente, ya que requiere de un golpe de considerable fuerza para extraer una lasca. Esto significa que se requiere de más práctica para controlar los golpes. Además, el golpe contacta la plataforma en un ángulo diferente, mayor que $90^{\circ}$ (ibid.).

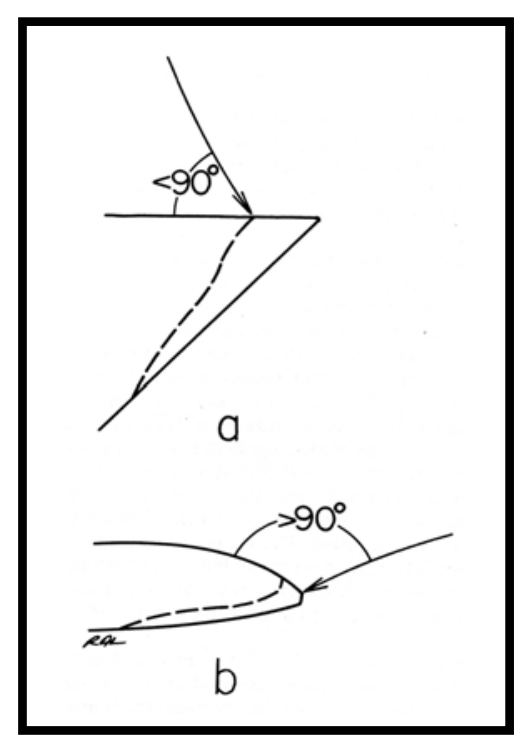

Figura 10.2. a) Percusión dura; b) Percusión blanda (modificado de Whittaker 1994: 188)

Por otro lado, la plataforma de los bifaces es diferente al comparar con los núcleos de lascas, ya que no se trata de una superficie sino de un borde (ibid.).

La posición de la plataforma, a su vez, es un aspecto que debe ser tenido en cuenta, ya que el adelgazamiento requiere de una plataforma centrada con el plano de simetría longitudinal (llamado plano de equilibrio bifacial) -simétrico en relación a las dos caras del biface- (Inizan et al. 1999) (Figura 10.3A). Con ésta es más fácil generar una lasca larga y gruesa -removiendo, por ende, más material- que sobrepase el centro de la cara y corte cualquier arista central (Figura 10.4). Esto produce una sección transversal más aplanada, razón por la cual es éste el mejor tipo de plataforma para adelgazar una pieza. 


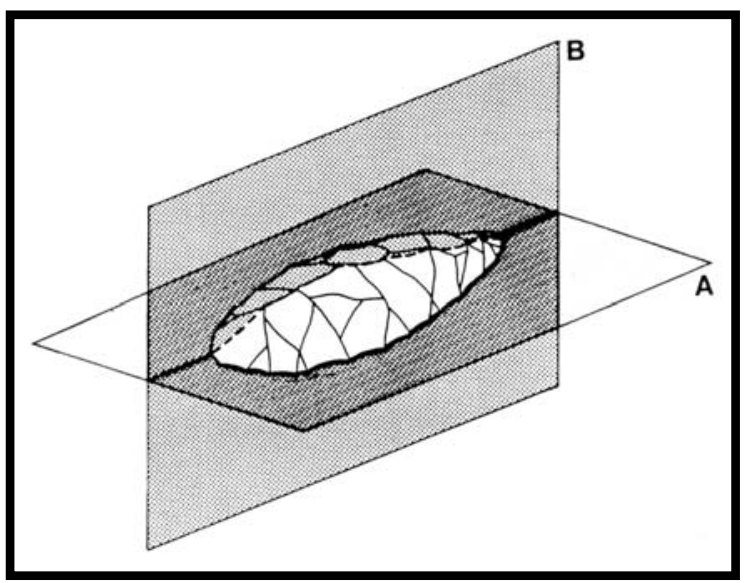

Figura 10.3. A) Plano de equilibrio bifacial; B) Plano de equilibrio bilateral (tomado de Inizan et al. 1999: 44)

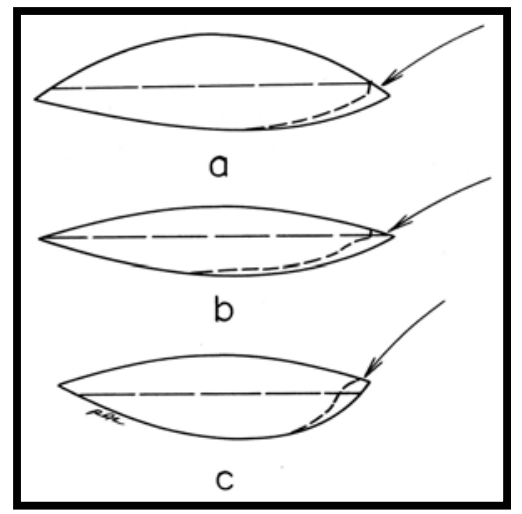

Figura 10.4. Posiciones de la plataforma: a) debajo del plano de simetría; b) cercana al plano de simetría; c) por encima del plano de simetría (tomada de Whittaker 1994: 197)

La confección de bifaces conlleva destrezas operativas sofisticadas. Por un lado, la habilidad de visualizar las relaciones geométricas como la simetría vista en planta (Figura 10.3B) y en sección transversal y, por el otro, de crear un borde derecho y regular (Toth y Schick 1998). De acuerdo a Pelegrin (1993), esto tiene importantes consecuencias en cuanto al "saber-cómo” ideacional y motor. En cuanto al primero, porque implica concebir una forma integral independiente de la morfología de la materia prima, lo que se logra por series de extracciones que están predeterminadas por su naturaleza interdependiente. La remoción de cada lasca reduce el ancho de un lado a la vez que cambia la línea de la arista y la desplaza al punto del golpe. A esto responde por qué cada lascado tiene que ser planeado para obtener un biface regular.

Con respecto al segundo, debe haber una modulación apropiada de los movimientos del golpe. El adelgazamiento bifacial requiere, por lo que se trató previamente, de un gesto técnico muy específico, que implica entrenarse en una forma distinta a la talla o percusión ordinaria, ya que: a) se debe golpear el borde más que la superficie; b) es necesario golpear en un ángulo extremadamente 
obtuso, aproximadamente paralelo a la fractura de la lasca deseada y c) el golpe describe un arco, con la mayor parte de la fuerza dirigida hacia el borde y con una pequeña porción de la misma trabajando en forma descendente para comenzar el negativo de lascado. Como se vio previamente, a partir de la elección de ángulos exteriores de plataforma elevados esta técnica permite producir lascas más largas y extensas sin incrementar el espesor, lo que implica, empero, un marcado incremento en la dificultad de la tarea (Dibble y Pelcin 1995), que tiene como correlato, a su vez, la necesidad de mayores destrezas perceptivas y motoras (Stout 2002).

\subsection{VARIABILIDAD MORFOLÓGICA EN BIFACES E INSTRUMENTOS SOBRE BIFACES}

\subsubsection{CARACTERÍSTICAS DE LOS BIFACES DEL SITIO QS3}

La muestra de bifaces del sitio QS3 proviene de todas las campañas realizadas hasta el momento y está constituida por 33 piezas, de las cuales 9 se han conservado como tales (Tabla 10.1), mientras que otras 7 han sido recicladas (Tabla 10.2). Se destaca que otros 17 bifaces fueron transformados mediante la regularización de sus bordes, conformando una variedad de filos (Tablas 10.3 y 10.3 -continuación-).

Así, los bifaces como tales constan de 3 piezas enteras y 6 fragmentadas, de las cuales 4 son meso-apicales y 2 meso-basales. Por su parte, los bifaces reciclados son fragmentos meso-basales -N: 5- y meso-apicales -N: 2- (Tabla 10.2). En cuanto a los transformados, 10 son artefactos compuestos y/o dobles y 7 puntas de proyectil (Tablas 10.3 y 10.3 -continuación-). En relación con estas últimas, se han considerado sólo aquellas piezas con adelgazamiento bifacial inequívoco, por lo que seguramente la muestra está subrepresentada. Por otra parte, se destaca que no se han incluido en el conteo 2 piezas apedunculadas de base cóncava ( $\mathrm{N}^{\circ} 19$-2b2- y No 111 -2b5-), por considerárselas reclamadas (sensu Schiffer 1987) de ocupaciones previas, por sus semejanzas tipológicas con el tipo QSC recuperado en este sitio en niveles más antiguos, fechados hacia el 7500 AP (Martínez 2003). Esto estaría corroborado, además, por la presencia de una leve pátina en una de ellas ( $\left.\mathrm{N}^{\mathrm{o}} 19\right)$, sólo visible empleando microscopio (Cattaneo com pers.).

La muestra de bifaces en sí mismos consta de 5 piezas mientras que los bifaces en proceso de manufactura son 11. Ambas categorías se incluyen dentro de los bifaces como tales (Tabla 10.1) y de los reciclados (Tabla 10.2). 
Tabla 10.1. Bifaces como tales. QS3

\begin{tabular}{|c|c|c|c|c|c|c|c|c|c|c|c|}
\hline $\mathbf{N}^{0}$ PIEZA & $\begin{array}{l}\text { SUBGRUPO } \\
\text { TIPOLÓGICO }\end{array}$ & $\begin{array}{c}\text { MAT } \\
\text { PRIMA }\end{array}$ & $\mathbf{L}$ & $\mathbf{A}$ & $\mathbf{E}$ & $\mathbf{A} / \mathbf{E}$ & $\begin{array}{l}\text { ANG } \\
\text { FILO }\end{array}$ & $\begin{array}{l}\text { AMPLITUD } \\
\text { SINUSOIDE }\end{array}$ & $\begin{array}{l}\text { SECCION } \\
\text { TRANSV }\end{array}$ & $\begin{array}{l}\text { FORMA GEOM } \\
\text { CONTORNO }\end{array}$ & CAUSA ABANDONO \\
\hline 290 & Biface parcial /2 & Vc1 & 64,60 & 37,30 & 23,70 & 1,57 & $69^{\circ}$ & Moderado & Plano-convexa & Irregular & $\begin{array}{l}\text { Muy grueso defectuoso para } \\
\text { seguir adelgazando }\end{array}$ \\
\hline 28 & $\begin{array}{l}\text { Fragmento meso- } \\
\text { basal de biface en } \\
\text { sentido estricto } / 1 \\
\end{array}$ & Vc1 & $(39,40)$ & $(44,20)$ & $(16,80)$ & $(2,63)$ & $56^{\circ}$ & Estrecho & $\begin{array}{l}\text { Biconvexa } \\
\text { asimétrica regular }\end{array}$ & Lanceolada & $\begin{array}{l}\text { Defecto de la materia prima + } \\
\text { fractura }\end{array}$ \\
\hline 302 & Biface parcial /2 & Vc5 & 63,10 & 58,90 & 27,80 & 2,12 & $69^{\circ}$ & Amplio & $\begin{array}{l}\text { Biconvexa } \\
\text { asimétrica irregular }\end{array}$ & Irregular & $\begin{array}{l}\text { Muy grueso defectuoso para } \\
\text { seguir adelgazando }\end{array}$ \\
\hline 518 & $\begin{array}{l}\text { Fragmento meso- } \\
\text { basal de biface en } \\
\text { sentido estricto } / 1 \\
\end{array}$ & Vc1 & $(39,30)$ & 37,10 & 12,10 & 3,07 & $57^{\circ}$ & Estrecho & $\begin{array}{l}\text { Biconvexa } \\
\text { asimétrica regular }\end{array}$ & Lanceolada & $\begin{array}{l}\text { Fractura + Defecto de la materia } \\
\text { prima }\end{array}$ \\
\hline 40 & $\begin{array}{l}\text { Fragmento meso- } \\
\text { apical de biface en } \\
\text { sentido estricto } / 1\end{array}$ & Vc2 & $(42,20)$ & $(35,30)$ & 8,20 & $(4,30)$ & $49,5^{\circ}$ & Estrecho & $\begin{array}{l}\text { Biconvexa } \\
\text { asimétrica regular }\end{array}$ & Lanceolada & Fractura \\
\hline 36 & $\begin{array}{l}\text { Fragmento meso- } \\
\text { apical de biface en } \\
\text { sentido estricto } / 2\end{array}$ & Vc2 & $(62,40)$ & 46,40 & 12,00 & 3,87 & $57,5^{\circ}$ & Moderado & $\begin{array}{l}\text { Biconvexa } \\
\text { asimétrica regular }\end{array}$ & Lanceolada & Fractura \\
\hline 316 & Biface parcial /2 & Vc5 & 89,50 & 50,10 & 31,40 & 1,60 & $71^{\circ}$ & Amplio & $\begin{array}{l}\text { Biconvexa } \\
\text { asimétrica irregular }\end{array}$ & Irregular & $\begin{array}{l}\text { Muy grueso defectuoso para } \\
\text { seguir adelgazando }\end{array}$ \\
\hline 632 & $\begin{array}{l}\text { Fragmento meso- } \\
\text { apical de biface en } \\
\text { sentido estricto } / 2 \\
\end{array}$ & Vc1 & $(56,10)$ & 36,70 & 13,80 & 2,66 & $66^{\circ}$ & Moderado & $\begin{array}{l}\text { Biconvexa } \\
\text { asimétrica regular }\end{array}$ & Lanceolada & $\begin{array}{l}\text { Fractura + defecto de la materia } \\
\text { prima }\end{array}$ \\
\hline 592 & $\begin{array}{l}\text { Fragmento meso- } \\
\text { apical de biface en } \\
\text { sentido estricto /2 }\end{array}$ & Vc1 & $(40,00)$ & $(26,10)$ & $(9,90)$ & $(2,64)$ & $61^{\circ}$ & Moderado & $\begin{array}{l}\text { Biconvexa } \\
\text { asimétrica regular }\end{array}$ & Lanceolada & Fractura \\
\hline
\end{tabular}

Referencias: 1) Artefacto en si mismo; 2) Pieza en proceso de manufactura / E Medidas de L, A y E en mm / (...): medida afectada por fractura / Ang filo: promedio de los ángulos de los distintos filos que componen la pieza / Amplitud del sinusoide (offset): en base a Callahan (1979) / Causa de abandono: categorías en base a Nami (1993-94) 
Tabla 10.2. Bifaces reciclados. QS3

\begin{tabular}{|c|c|c|c|c|c|c|c|c|c|c|c|}
\hline $\mathbf{N}^{0}$ PIEZA & SUBGRUPO TIPOLÓGICO & $\begin{array}{l}\text { MAT } \\
\text { PRIM }\end{array}$ & $\mathbf{L}$ & $\mathbf{A}$ & $\mathbf{E}$ & $\bar{A} / \mathbf{E}$ & $\begin{array}{l}\text { ANG } \\
\text { FILO } \\
\text { Bf }\end{array}$ & $\begin{array}{l}\text { AMPLITUD } \\
\text { SINUSOIDE }\end{array}$ & $\begin{array}{l}\text { SECCION } \\
\text { TRANSV }\end{array}$ & $\begin{array}{l}\text { FORMA } \\
\text { GEOM } \\
\text { CONTORNO }\end{array}$ & $\begin{array}{c}\text { CAUSA } \\
\text { ABANDONO } \\
\text { Bf }\end{array}$ \\
\hline 20 & $\begin{array}{l}\text { Raclette de filo corto lateral + filo bifacial de } \\
\text { arista sinuosa -parte pasiva- sobre fragmento } \\
\text { meso-basal de biface en sentido estricto } \\
\text { reciclado } / 2\end{array}$ & Vc1 & $(67,30)$ & $(35,00)$ & $(12,00)$ & $(2,92)$ & $55^{\circ}$ & Estrecho & $\begin{array}{l}\text { Biconvexa } \\
\text { asimétrica } \\
\text { regular }\end{array}$ & Lanceolada & Fractura perversa \\
\hline 49 & $\begin{array}{l}\text { Punta burilante lateral + cortante de filo } \\
\text { retocado corto lateral sobre fragmento meso- } \\
\text { apical de biface en sentido estricto reciclado } \\
/ 2\end{array}$ & Vc1 & $(49,60)$ & $(31,40)$ & $(10,20)$ & $(3,08)$ & $70^{\circ}$ & $\begin{array}{l}\text { Amplio/ } \\
\text { moderado }\end{array}$ & $\begin{array}{l}\text { Biconvexa } \\
\text { asimétrica } \\
\text { regular }\end{array}$ & No diferenciada & Fractura \\
\hline 551 & $\begin{array}{l}\text { Raspador de filo corto frontal + cortante de } \\
\text { filo retocado corto lateral sobre fragmento } \\
\text { meso-basal de biface en sentido estricto } \\
\text { reciclado } / 2\end{array}$ & Vc1 & $(38,00)$ & $(32,50)$ & 12,40 & $(2,62)$ & $57^{\circ}$ & $\begin{array}{l}\text { Moderado/ } \\
\text { estrecho }\end{array}$ & $\begin{array}{l}\text { Biconvexa } \\
\text { asimétrica } \\
\text { regular }\end{array}$ & No diferenciada & Fractura \\
\hline 509 & $\begin{array}{l}\text { Raspador de filo restringido angular + } \\
\text { cortante de filo retocado corto lateral + } \\
\text { cortante de filo retocado corto angular + filo } \\
\text { bifacial de arista sinuosa -parte pasiva- sobre } \\
\text { fragmento meso-basal de biface en sentido } \\
\text { estricto reciclado /1 }\end{array}$ & Vc1 & $(60,00)$ & $(46,20)$ & $(11,70)$ & $(3,95)$ & $54^{\circ}$ & Estrecho & $\begin{array}{l}\text { Biconvexa } \\
\text { asimétrica } \\
\text { regular }\end{array}$ & Lanceolada & Fractura perversa \\
\hline 585 & $\begin{array}{l}\text { Muesca retocada lateral + muesca burilante } \\
\text { frontal sobre fragmento meso-basal de biface } \\
\text { parcial reciclado / } 2\end{array}$ & Vc1 & $(31,80)$ & 38,60 & 18,20 & 2,12 & $62^{\circ}$ & Amplio & $\begin{array}{l}\text { Biconvexa } \\
\text { asimétrica } \\
\text { irregular }\end{array}$ & No diferenciada & $\begin{array}{l}\text { Fractura + Cambio de } \\
\text { textura + Muy grueso } \\
\text { defectuoso para seguir } \\
\text { adelgazando + borde } \\
\text { excesivamente grueso }\end{array}$ \\
\hline 545 & $\begin{array}{l}\text { Cortante de filo retocado corto frontal + buril } \\
\text { sobre fragmento meso-basal de biface en } \\
\text { sentido estricto reciclado / } 2\end{array}$ & Vc2 & $(55,40)$ & $(33,00)$ & $(10.00)$ & $(3,30)$ & $45^{\circ}$ & Estrecho & $\begin{array}{l}\text { No } \\
\text { diferenciada }\end{array}$ & No diferenciada & Fractura \\
\hline 514 & $\begin{array}{l}\text { Cuchillo de filo retocado lateral sobre } \\
\text { fragmento meso-apical de biface en sentido } \\
\text { estricto reciclado } / 1\end{array}$ & Vc1 & $(60,00)$ & $(46,40)$ & $(9,00)$ & $(5,16)$ & $42^{\circ}$ & Estrecho & $\begin{array}{l}\text { Biconvexa } \\
\text { asimétrica } \\
\text { irregular }\end{array}$ & Lanceolada & Fractura perversa \\
\hline
\end{tabular}

R eferencias: 1) Artefacto en si mismo; 2) Pieza en proceso de manufactura / Medidas de L, A y E en mm / (...): medida afectada por fractura / Ang filo Bf: promedio de los ángulos de los filos remanentes del biface / Amplitud del sinusoide (offset): en base a Callahan (1979) / Causa de abandono del biface: categorías en base a Nami (1993-94) 
Producción lítica, variabilidad y cambio en Antofagasta de la Sierra -ca.5500-1500 AP-, Salomón Hocsman

Tabla 10.3. Bifaces transformados. QS3

\begin{tabular}{|c|c|c|c|c|c|c|c|c|c|}
\hline $\mathbf{N}^{\circ}$ PIEZA & SUBGRUPO TIPOLÓGICO & $\begin{array}{l}\text { MAT } \\
\text { PRIM }\end{array}$ & $\mathbf{L}$ & $\mathbf{A}$ & $\mathbf{E}$ & $\mathbf{A} / \mathbf{E}$ & $\begin{array}{l}\text { ANG } \\
\text { FILO }\end{array}$ & $\begin{array}{l}\text { SECCION } \\
\text { TRANSV }\end{array}$ & $\begin{array}{l}\text { FORMA GEOM } \\
\text { CONTORNO }\end{array}$ \\
\hline 502 & $\begin{array}{l}\text { Cuchillo de filo retocado lateral + filo bifacial de arista sinuosa (bf)-parte } \\
\text { pasiva- / Biface parcial }\end{array}$ & Vc1 & $(74,40)$ & 36,20 & 11,80 & 3,07 & $45^{\circ} / 58^{\circ}$ & $\begin{array}{l}\text { Biconvexa } \\
\text { asimétrica regular }\end{array}$ & Lanceolada \\
\hline 500 & $\begin{array}{l}\text { Punta de proyectil con pedúnculo destacado y hombros, con limbo no } \\
\text { diferenciado }\end{array}$ & ObC & $(31,30)$ & 28,10 & 6,00 & 4,68 & $41^{\circ} / 39^{\mathrm{a}}$ & $\begin{array}{l}\text { Biconvexa } \\
\text { asimétrica irregular }\end{array}$ & Pentagonal \\
\hline 16 & Fragmento limbo-basal de punta de proyectil apedunculada & Vc4 & $(52,70)$ & 20,00 & 14,30 & 1,40 & $81^{\circ} / 77^{\circ}$ & $\begin{array}{l}\text { Plano-convexa } \\
\text { regular }\end{array}$ & Lanceolada \\
\hline 292 & $\begin{array}{l}\text { Punta de proyectil con pedúnculo destacado y hombros, con limbo } \\
\text { triangular corto }\end{array}$ & Vc1 & 49,30 & 34,10 & 10,20 & 3,34 & $52^{\circ} / 52^{\circ}$ & $\begin{array}{l}\text { Biconvexa } \\
\text { asimétrica regular }\end{array}$ & Pentagonal \\
\hline 508 & Punta de proyectil con pedúnculo esbozado y limbo triangular corto & Vc5 & $(64,20)$ & 31,80 & 13,50 & 2,36 & $59^{\circ} / 73^{\circ}$ & $\begin{array}{l}\text { Biconvexa } \\
\text { asimétrica regular }\end{array}$ & No diferenciada \\
\hline 515 & Punta de proyectil apedunculada & Vc1 & $(88,00)$ & 28,00 & 14,50 & 1,93 & $69^{\circ} / 74^{\circ}$ & $\begin{array}{l}\text { Biconvexa } \\
\text { asimétrica regular }\end{array}$ & Lanceolada \\
\hline 506 & $\begin{array}{l}\text { Fragmento de punta de proyectil con pedúnculo esbozado y limbo no } \\
\text { diferenciado }\end{array}$ & Vc2 & $(37,00)$ & $(34,30)$ & $(9,00)$ & $(3,81)$ & $50^{\circ} / 51^{\circ}$ & $\begin{array}{l}\text { Biconvexa } \\
\text { asimétrica regular }\end{array}$ & No diferenciada \\
\hline 59 & $\begin{array}{l}\text { Raedera de filo largo lateral + perforador no diferenciado + filo bifacial } \\
\text { de arista sinuosa -parte pasiva- + filo bifacial de arista sinuosa (bf) / } \\
\text { Biface en sentido estricto }\end{array}$ & Vc1 & 69,40 & 24,90 & 10,20 & 2,44 & $\begin{array}{l}59^{\circ} /-^{\circ} / \\
64^{\circ} / 64^{\circ}\end{array}$ & $\begin{array}{l}\text { Biconvexa } \\
\text { asimétrica regular }\end{array}$ & Lanceolada \\
\hline 530 & $\begin{array}{l}\text { Punta burilante angular + punta burilante de retoque alternante angular + } \\
\text { punta entre muescas lateral + filo formatizado pasivo }+(2) \text { filos } \\
\text { bifaciales de arista sinuosa (bf) / Biface en sentido estricto }\end{array}$ & Vc1 & 74,40 & 39,30 & 19,30 & 2,04 & $\begin{array}{l}-/-/-/ 95^{\circ} / \\
62^{\circ} / 64^{\circ}\end{array}$ & $\begin{array}{l}\text { Biconvexa } \\
\text { asimétrica irregular }\end{array}$ & Irregular \\
\hline
\end{tabular}

Referencias: Medidas de L, A y E en mm / (...): medida afectada por fractura / bf: biface. Implica un filo del biface original que no fue transformado / Ang filo: en el caso de artefactos

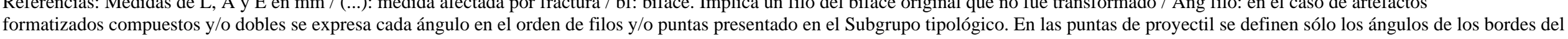
limbo (izquierdo y derecho respectivamente) 
Tabla 10.3 (continuación). Bifaces transformados. QS3

\begin{tabular}{|c|c|c|c|c|c|c|c|c|c|}
\hline $\mathbf{N}^{\circ}$ PIEZA & SUBGRUPO TIPOLÓGICO & $\begin{array}{l}\text { MAT } \\
\text { PRIM }\end{array}$ & $\mathbf{L}$ & A & $\mathbf{E}$ & $\mathbf{A} / \mathbf{E}$ & $\begin{array}{l}\text { ANG } \\
\text { FILO }\end{array}$ & $\begin{array}{l}\text { SECCION } \\
\text { TRANSV }\end{array}$ & $\begin{array}{l}\text { FORMA GEOM } \\
\text { CONTORNO }\end{array}$ \\
\hline 525 & $\begin{array}{l}\text { (2) Cuchillos denticulados convergentes en ápice activo / Biface en } \\
\text { sentido estricto }\end{array}$ & Vc2 & $(72,00)$ & 32,90 & 11,20 & 2,94 & $52^{\circ} / 51^{\circ}$ & $\begin{array}{l}\text { Biconvexa } \\
\text { asimétrica regular }\end{array}$ & Lanceolada \\
\hline 637 & $\begin{array}{l}\text { Cuchillo de filo retocado lateral + filo formatizado pasivo + cortante de } \\
\text { filo retocado corto lateral + (2) filos bifaciales de arista sinuosa (bf) / } \\
\text { Biface en sentido estricto }\end{array}$ & Vc1 & 71,20 & 34,00 & 10,50 & 3,24 & $\begin{array}{l}51^{\circ} / 58^{\circ} / 55 \\
\% / 50^{\circ} / 61^{\circ}\end{array}$ & $\begin{array}{l}\text { Biconvexa } \\
\text { asimétrica regular }\end{array}$ & Lanceolada \\
\hline 142 & $\begin{array}{l}\text { (2) Cortantes convergentes en ápice romo frontal + raclette de filo largo } \\
\text { lateral + raedera de filo largo lateral + raspador de filo restringido frontal } \\
\text { / Biface en sentido estricto }\end{array}$ & $\mathrm{ObC}$ & 48,00 & 32,00 & 12,90 & 2,48 & $\begin{array}{l}58^{\circ} / 58^{\circ} / 74 \\
\% / 62^{\circ} / 60^{\circ}\end{array}$ & $\begin{array}{l}\text { Biconvexa } \\
\text { asimétrica regular }\end{array}$ & Pentagonal \\
\hline 106 & $\begin{array}{l}\text { (2) Cuchillos de filo retocado laterales + punta burilante angular + } \\
\text { raspador de filo restringido angular + (2) filos formatizados pasivos / } \\
\text { Biface en sentido estricto }\end{array}$ & Vc2 & 70,40 & 31,80 & 11,30 & 2,81 & $\begin{array}{l}46^{\circ} / 53^{\circ} /- \\
/ 85^{\circ} / 67^{\circ} / \\
44^{\circ}\end{array}$ & $\begin{array}{l}\text { Biconvexa } \\
\text { asimétrica regular }\end{array}$ & Lanceolada \\
\hline 593 & $\begin{array}{l}\text { (2) Cortantes de filo retocado cortos angulares + filo formatizado pasivo } \\
\text { + filo bifacial de arista sinuosa -parte pasiva- (2) filos bifaciales de arista } \\
\text { sinuosa (bf) / Biface en sentido estricto }\end{array}$ & Vc4 & 60,60 & 32,40 & 10,00 & 3,24 & $\begin{array}{l}55^{\circ} / 55^{\circ} / 87 \\
\% / 43^{\circ} / 39^{\circ} / \\
49^{\circ}\end{array}$ & $\begin{array}{l}\text { Biconvexa } \\
\text { asimétrica regular }\end{array}$ & Lanceolada \\
\hline 56 & $\begin{array}{l}\text { Punta burilante de retoque alternante angular sobre fragmento de raedera } \\
\text { no diferenciado reciclado sobre fragmento no diferenciado de biface }\end{array}$ & Vc1 & $(37,10)$ & $(46,50)$ & $(17,80)$ & $(2,61)$ & $-/ 60^{\circ} / 56^{\circ}$ & No diferenciada & No diferenciada \\
\hline 596 & $\begin{array}{l}\text { Muesca burilante de retoque alternante axial sobre punta de proyectil con } \\
\text { pedúnculo esbozado y limbo triangular mediano reciclada }\end{array}$ & Vc2 & 45,90 & 22,00 & 7,50 & 2,93 & $67^{\circ} / 64^{\circ}$ & $\begin{array}{l}\text { Biconvexa } \\
\text { asimétrica regular }\end{array}$ & Lanceolada \\
\hline $1610 / 1$ & $\begin{array}{l}\text { Punta burilante angular + }(2) \text { raederas de filo largo lateral + (2) cortantes } \\
\text { de filo retocado corto frontal / Biface en sentido estricto }\end{array}$ & Vc1 & 64,80 & $(30,10)$ & 9,90 & $(3,04)$ & $\begin{array}{l}-/ 71^{\circ} / 51^{\circ} \\
/ 54^{\circ} / 55^{\circ}\end{array}$ & Plano-convexa & Lanceolada \\
\hline
\end{tabular}

Referencias: Medidas de L, A y E en mm / (...): medida afectada por fractura / bf: biface. Implica un filo del biface original que no fue transformado / Ang filo: en el caso de artefactos

formatizados compuestos y/o dobles se expresa cada ángulo en el orden de filos y/o puntas presentado en el Subgrupo tipológico. En las puntas de proyectil se definen sólo los ángulos de los bordes

del limbo (izquierdo y derecho respectivamente) 
Los bifaces en la muestra analizada han seguido diferentes trayectorias de producción, lo que explica, en parte, la variabilidad morfológica imperante. Así, se presentan como: 1) artefactos en sí mismos (Figura 10.5: Arriba izquierda); 2) artefactos en proceso de manufactura hacia diferentes fines (Figura 10.5: Abajo izquierda y derecha); 3) formas-base de artefactos compuestos y/o dobles con configuraciones de filos y/o puntas diversos y de puntas de proyectil pedunculadas y apedunculadas (Figura 10.6) y, en algunos casos, complementariamente a las categorías 1 o 2, 4) piezas recicladas (Figura 10.5: Arriba derecha).

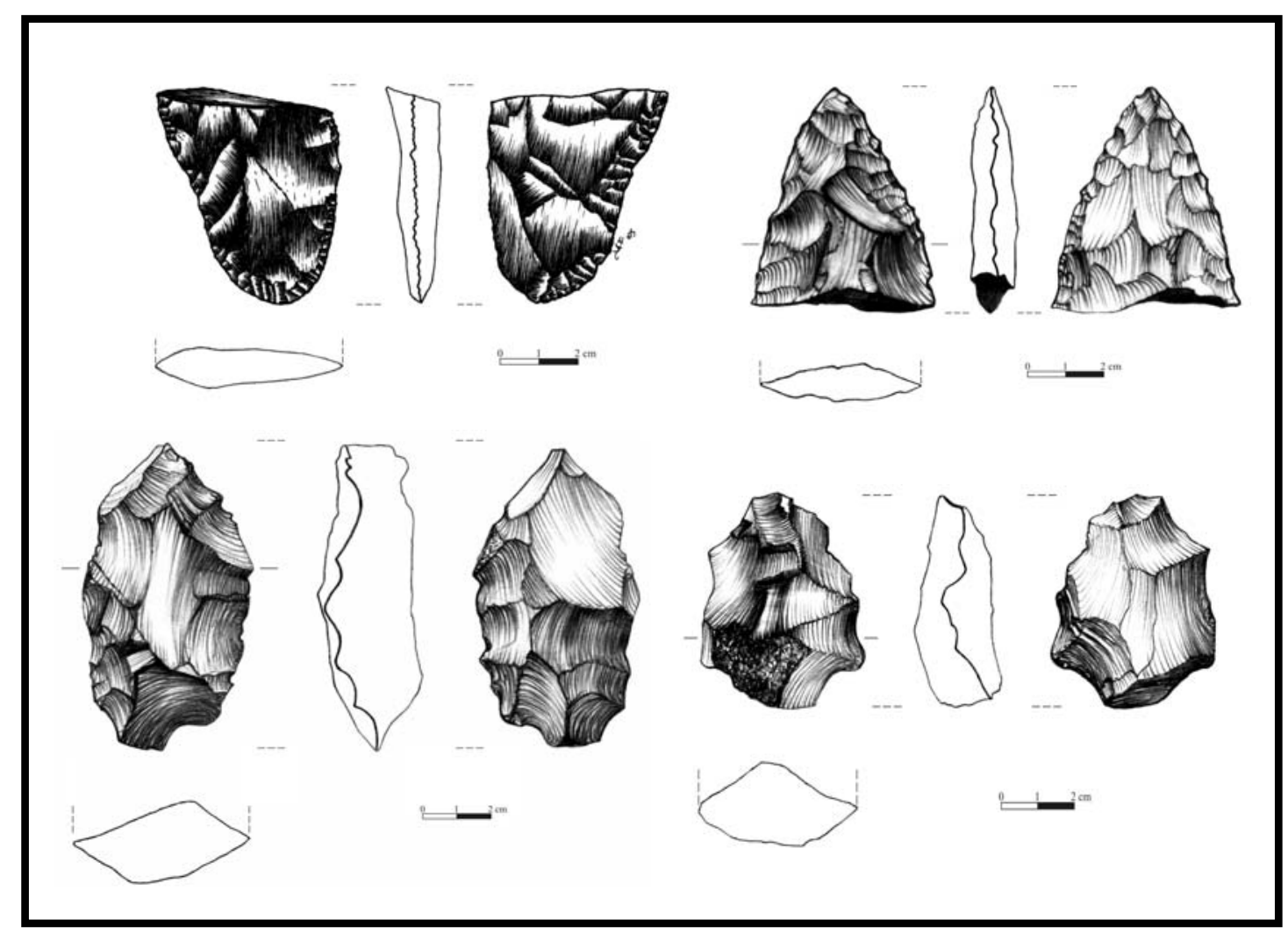

Figura 10.5. Bifaces como tales y reciclados de QS3. Arriba izquierda: No 509. Arriba derecha: $\mathrm{N}^{\circ}$ 514. Abajo izquierda: $\mathrm{N}^{\circ}$ 316. Abajo derecha: $\mathrm{N}^{\circ} 302$ 


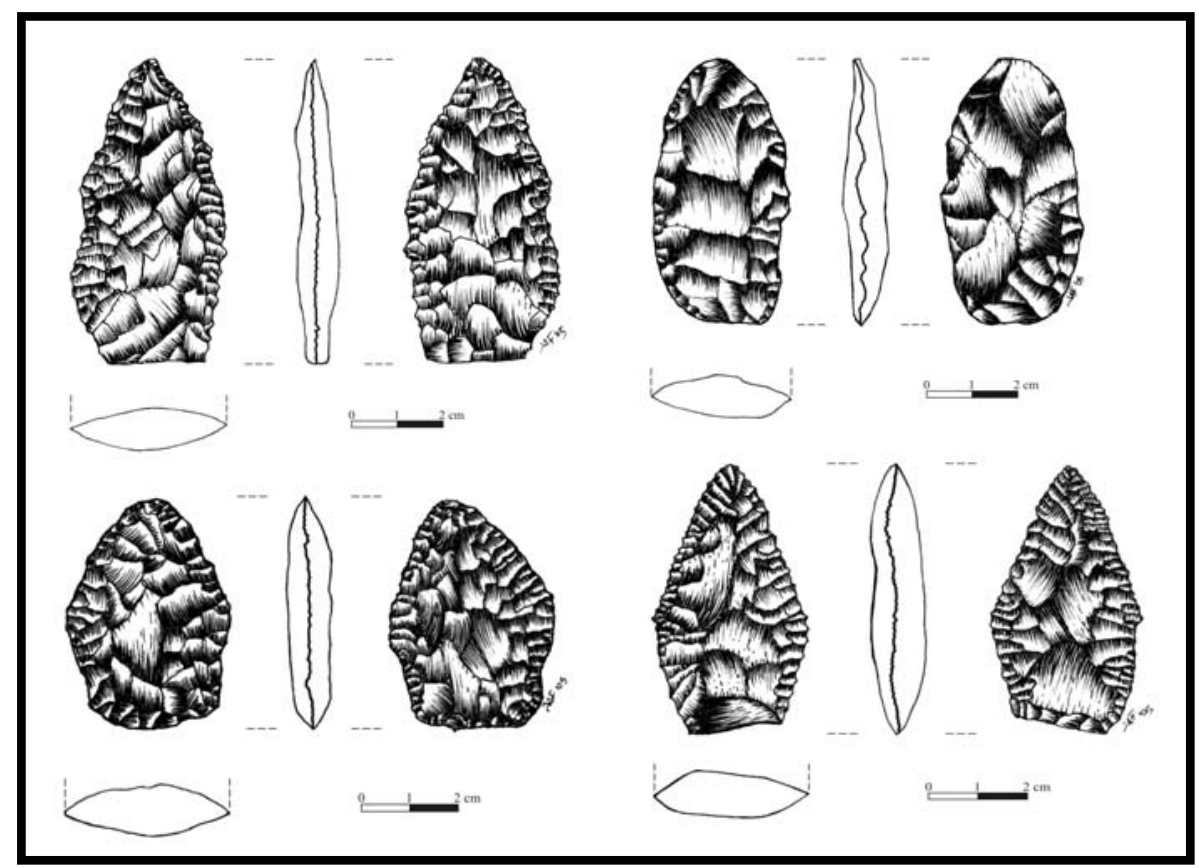

Figura 10.6. Bifaces transformados en QS3. Arriba izquierda: No 525. Arriba derecha: № 593. Abajo izquierda: $\mathrm{N}^{\circ}$ 292. Abajo derecha: $\mathrm{N}^{\circ} 508$

Es importante notar que de la comparación de los tamaños de los bifaces como tales, transformados y reciclados, resultan estrechas vinculaciones entre los mismos. En primer lugar, resalta la homogeneidad relativa de tamaños, discernible a partir de lo abigarrado de la distribución en largo y ancho (Figura 10.7) y más aún, al considerar el ancho y el espesor (Figura 10.8). Destaca la baja variabilidad del espesor en los bifaces transformados. En segundo lugar, la mayoría de los fragmentos de bifaces como tales y bifaces reciclados, que involucran piezas en proceso de manufactura, como es esperable, se encuentran hacia la derecha del gráfico (Figura 10.7), por presentar anchos mayores que los bifaces transformados, tanto enteros como fracturados. A su vez, al considerar el largo, si a modo hipotético se incrementa en un tercio el largo de los bifaces y bifaces fracturados reciclados -medida indudablemente conservadora para buena parte de las piezas consideradas-, el resultado es una plena coincidencia con los tamaños de las piezas transformadas enteras. Finalmente, al tratar con los espesores máximos (no afectados por fractura), se registra una disminución progresiva del espesor entre los bifaces en proceso de manufactura (x: 19,90 -N: 7-), los transformados (x: 11,54 -N: 15-) y los bifaces en sí mismos (x: 10,15 -N: 2-). Se destaca la afinidad de espesores entre los bifaces transformados y los bifaces en sí mismos. 


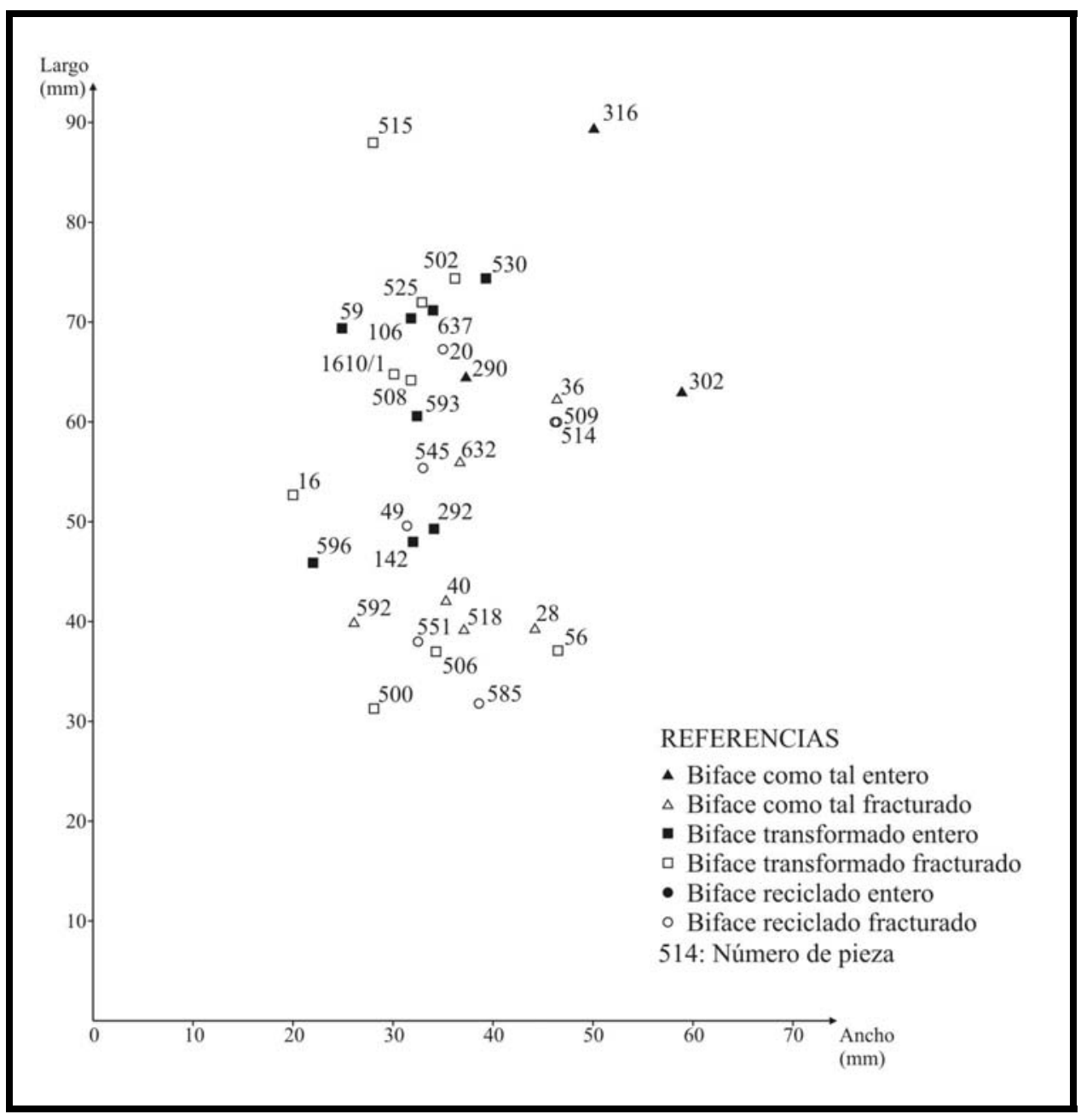

Figura 10.7. Distribución de tamaños (L-A) en bifaces como tales, transformados y reciclados de QS3 


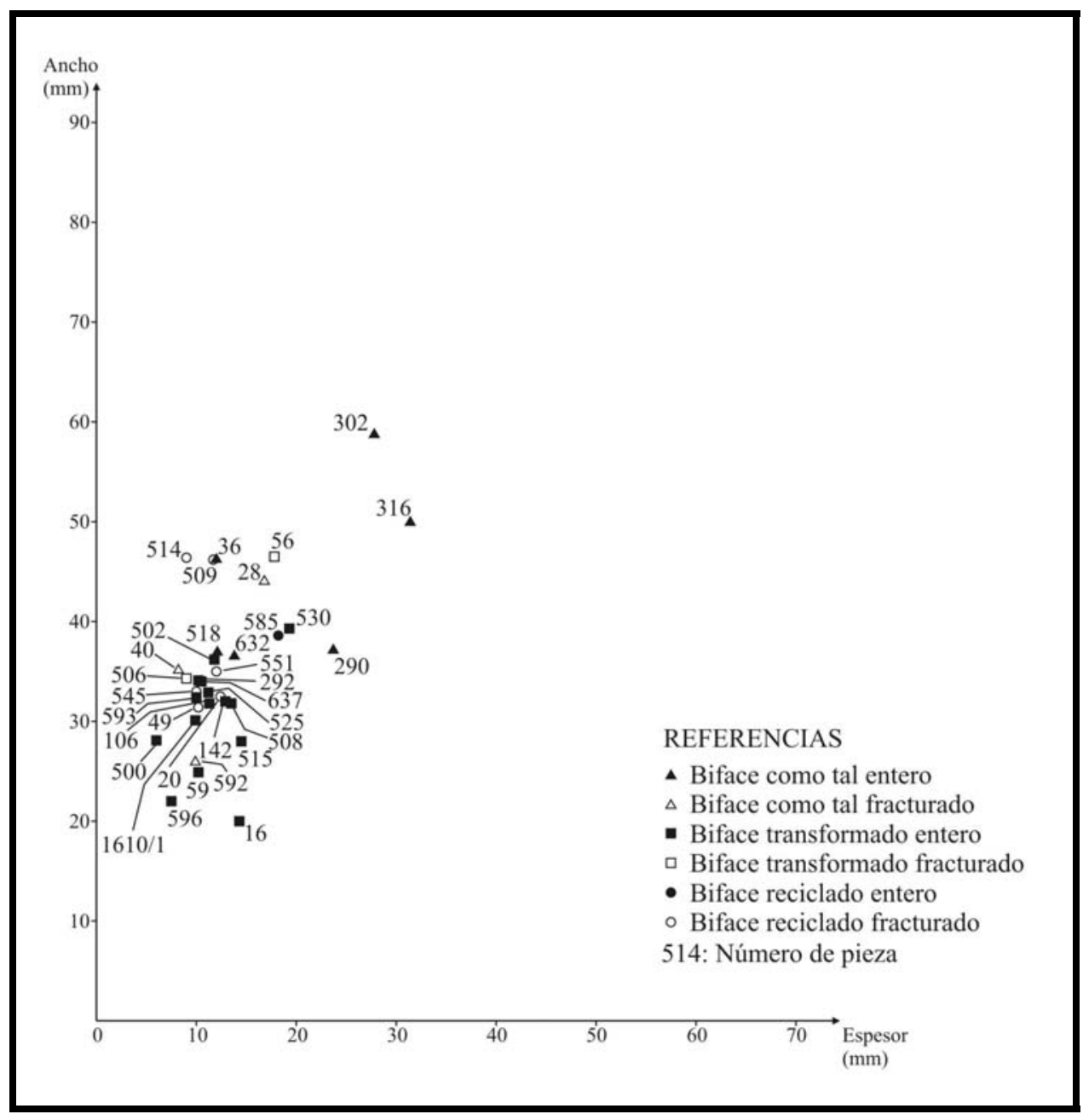

Figura 10.8. Distribución de tamaños (A-E) en bifaces como tales, transformados y reciclados de QS3

Más allá de las tendencias señaladas, que permiten correlacionar en general bifaces en proceso de producción con aquellos terminados, es notoria la variabilidad morfológica interna. La sinuosidad de la arista y los ángulos de los filos son claros ejemplos de ello (Tablas 10.1, 10.2, 10.3 y 10.3 continuación-).

Si bien es posible establecer vinculaciones estrechas entre las piezas en proceso de manufactura y aquellas finiquitadas, ciertas evidencias provenientes ya no de los bifaces en sí sino de lascas de adelgazamiento bifacial dan cuenta de piezas de considerable tamaño, que no tienen correlato en la muestra de bifaces recuperados en el sitio, dando cuenta de variaciones en tamaño que escapan a la tendencia general. En la Figura 10.9 se presentan dos casos. Se trata de sendas lascas de adelgazamiento bifacial de tamaño "muy grande” siguiendo la terminología de Aschero (1983) sobre Vc2. Debido a que presentan en cara dorsal negativos de lascados que proceden del borde opuesto del biface original, el largo de la lasca es representativo de la mitad del ancho del biface al momento de extraer dichas lascas, por lo que es posible realizar una estimación del tamaño del biface original. De esta forma, la lasca de la izquierda en la Figura 10.9 procedería de un biface de $91 \mathrm{~mm}$ de ancho 
aproximadamente y la de la derecha de un biface con una anchura de cerca de $120 \mathrm{~mm}$. Evidentemente, se trataría de bifaces que requerirían de una cuota importantísima de destreza técnica para su confección. Lamentablemente, no es posible realizar inferencia alguna sobre el largo de estas piezas ausentes aunque, evidentemente, se trataría de piezas muy grandes.

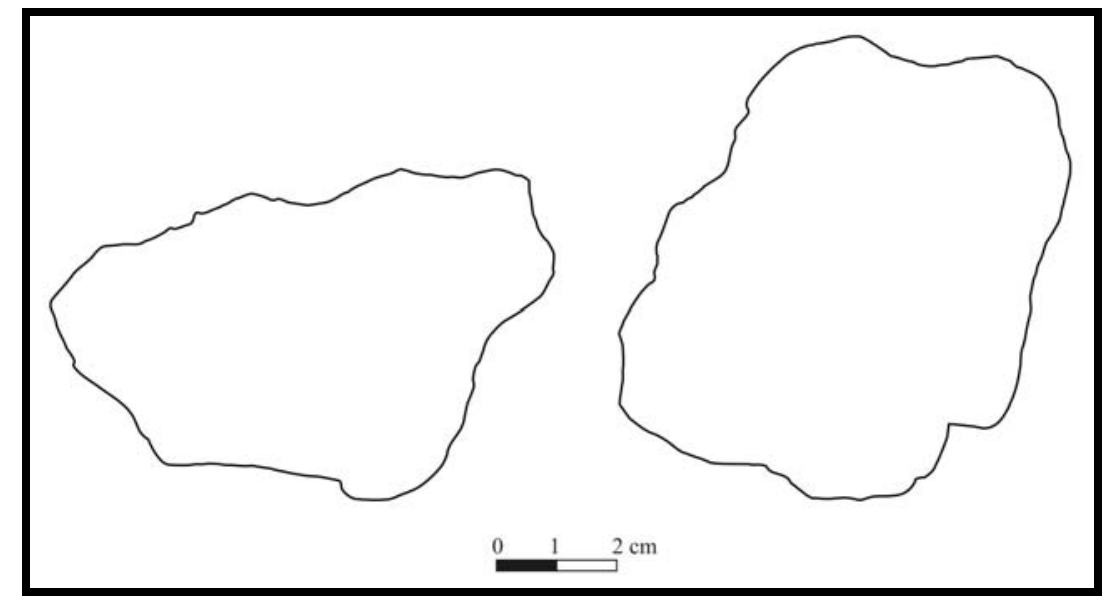

10.9. Lascas de adelgazamiento bifacial de tamaño "muy grande” procedentes de QS3

Asimismo, destacan 3 piezas ( $\mathrm{N}^{\circ}$ 290, 302 y 316), que son claramente diferentes del resto. En la Figura 10.7 puede apreciarse la lejanía relativa de los bifaces № 316 y 302 y en la Figura 10.8, la posición discrepante de las piezas Nº 302, 316 y 290. Básicamente, son mucho más anchas y espesas. Además, se presentan enteras y poseen una forma del contorno irregular, sección transversal planoconvexa o bien biconvexa marcadamente asimétrica e irregular, arista sinuosa irregular con sinuosidad moderada a amplia, ángulos de filo importantes y razones ancho/espesor relativamente pequeñas (Tabla 10.1). Esto contrasta con el resto del conjunto de bifaces como tales y reciclados, que tienen morfologías mayoritariamente lanceoladas, secciones transversales biconvexas levemente asimétricas y regulares, ángulos de filos menores y sinuosidad moderada a estrecha. Destacan, por otra parte, las coincidencias de este último grupo con los bifaces transformados, particularmente en cuanto a razones A/E, sección transversal y morfología del contorno.

En suma, dentro de la muestra hay piezas muy delgadas con lascados profundos y chatos y otras muy voluminosas y marcadamente irregulares, con lascados que no llegan al centro de la cara. Por ejemplo, la pieza № 414 (Figura 10.5), de tipo foliácea (sensu Aschero y Hocsman 2004), y la pieza No 316 (Figura 10.5), respectivamente. De acuerdo a lo señalado previamente, se plantea que esto podría estar denotando la presencia de talladores con habilidades motoras y capacidades cognitivas variadas. 


\subsubsection{CARACTERÍSTICAS DE LOS BIFACES DEL SITIO PCh1.3}

El conjunto de bifaces analizados aquí de PCh1.3 proviene de las dos temporadas de excavaciones realizadas en el alero bajo roca. Específicamente, está compuesto por 20 piezas, que se discriminan de la siguiente forma: 9 bifaces como tales (Tabla 10.4), 5 bifaces reciclados (Tabla 10.5) y 6 bifaces transformados. Los primeros constan de 2 piezas enteras y 7 fracturadas, de las cuales 6 son fragmentos meso-basales y uno sólo es meso-apical. Los segundos, en cambio, involucran una pieza entera, 2 fragmentos meso-basales, 1 fragmento meso-apical y 1 fragmento apical. Los terceros, por último, se presentan como 3 artefactos compuestos y como 3 puntas de proyectil. Al igual que en el caso anterior, se han considerado sólo aquellas puntas de proyectil con adelgazamiento bifacial indudable.

Tanto en los bifaces como tales y en los reciclados hay un predominio absoluto de artefactos en proceso de manufactura (12 sobre 14). Están ausentes las piezas que morfológicamente pueden clasificarse como bifaces en sí mismos, aunque en dos piezas no puede diferenciarse su status.

De acuerdo a lo expuesto, entonces, los bifaces en PCh1.3 han seguido diferentes trayectorias, presentándose como 1) artefactos en proceso de manufactura; 2) formas-base de artefactos compuestos y de puntas de proyectil y 3) piezas recicladas.

Por otra parte, de la comparación de los tamaños de los bifaces como tales, transformados y reciclados, pueden señalarse una serie de tendencias de interés. Así, al considerar los bifaces como tales, que, se remarca, son en su totalidad piezas en proceso de manufactura, se observa que se encuentran mayoritariamente hacia la derecha de la Figura 10.10, por poseer anchos mayores, en relación a los bifaces transformados. Desde la relación ancho-espesor, también, es posible confirmar lo señalado, ya que los bifaces como tales se encuentran hacia arriba y hacia la derecha en la Figura 10.11 .

Sin embargo, una serie de piezas escapan a la vinculación señalada, denotando la ocurrencia de distintas trayectorias de producción. Por un lado, puede apreciarse en la Figura 10.10 que los artefactos $\mathrm{N}^{\mathrm{0}} 115,116$ y 60 presentan anchos mucho menores en relación a los bifaces restantes, así como una marcada homogeneidad en los espesores. Lo mismo se registra al tener en cuenta el ancho y el espesor, ya que se observa que se distribuyen muy próximos entre sí en la porción inferior de la Figura 10.11. Se considera que tales bifaces se vinculan con la producción de puntas de proyectil apedunculadas lanceoladas, de pequeño tamaño (TM PCh E), dadas las similitudes métricas de los bifaces citados con las puntas de proyectil del tipo señalado recuperadas en distintos contextos de la microrregión. Por otro lado, la pieza $\mathrm{N}^{\circ} 96$, un fragmento meso-basal de biface que fue reciclado, 
presenta un ancho que se aleja considerablemente de la anchura que define al resto del conjunto. Esto implicaría que el biface en cuestión formó parte de una trayectoria de producción distinta, tendiente a la confección de una pieza de mayor tamaño.

Finalmente, al igual que en el caso de QS3, hay dos bifaces ( $\mathrm{N}^{\circ} 107$ y 26) que son notoriamente distintos al resto. Los mismos se presentan enteros, con forma geométrica del contorno irregular, sección biconvexa asimétrica irregular marcada, una arista sinuosa irregular con una sinuosidad amplia, ángulos de filos importantes y variables y razones ancho/espesor pequeñas (Tabla 10.4). Tanto en la Figura 10.10 como en la Figura 10.11 ambas piezas se encuentran en la porción superior hacia la derecha, evidenciando un comportamiento diferente. 
Tabla 10.4. Bifaces como tales. PCh1.3

\begin{tabular}{|c|c|c|c|c|c|c|c|c|c|c|c|}
\hline $\begin{array}{c}\mathbf{N}^{\mathbf{0}} \\
\text { PIEZA }\end{array}$ & $\begin{array}{l}\text { SUBGRUPO } \\
\text { TIPOLÓGICO }\end{array}$ & $\begin{array}{c}\text { MAT } \\
\text { PRIMA }\end{array}$ & $\mathbf{L}$ & $\mathbf{A}$ & $\mathbf{E}$ & $\mathbf{A} / \mathbf{E}$ & $\begin{array}{l}\text { ANG } \\
\text { FILO }\end{array}$ & $\begin{array}{l}\text { AMPLITUD } \\
\text { SINUSOIDE }\end{array}$ & $\begin{array}{l}\text { SECCION } \\
\text { TRANSV }\end{array}$ & $\begin{array}{c}\text { FORMA GEOM } \\
\text { CONTORNO }\end{array}$ & CAUSA ABANDONO \\
\hline 90 & $\begin{array}{l}\text { Fragmento meso- } \\
\text { basal de biface } \\
\text { parcial /2 }\end{array}$ & Vc1 & $(31,00)$ & $(41,70)$ & $(14,20)$ & $(2,94)$ & $67^{\circ}$ & Estrecho & Plano-convexa & No diferenciada & Fractura \\
\hline 87 & $\begin{array}{l}\text { Fragmento meso- } \\
\text { apical de biface en } \\
\text { sentido estricto / } 2\end{array}$ & Vc1 & $(45,70)$ & $(36,20)$ & $(14,50)$ & $(2,50)$ & $54^{\circ}$ & Estrecho & $\begin{array}{l}\text { Biconvexa } \\
\text { asimétrica irregular }\end{array}$ & Lanceolada & Fractura \\
\hline $135 / 1$ & $\begin{array}{l}\text { Fragmento basal de } \\
\text { biface en sentido } \\
\text { estricto } / 2\end{array}$ & Vc1 & $(29,30)$ & $(42,60)$ & $(18,20)$ & $(2,34)$ & $67^{\circ}$ & Moderado & $\begin{array}{l}\text { Biconvexa } \\
\text { asimétrica irregular }\end{array}$ & Lanceolada & Charnela \\
\hline 67 & $\begin{array}{l}\text { Fragmento basal de } \\
\text { biface no } \\
\text { diferenciado /3 }\end{array}$ & ObC & $(21,90)$ & $(32,10)$ & $(7,40)$ & - & $61^{\circ}$ & Moderado & $\begin{array}{l}\text { Biconvexa } \\
\text { asimétrica irregular }\end{array}$ & No diferenciada & Fractura perversa + Fractura \\
\hline 107 & Biface parcial /2 & Vc7 & 74,60 & 41,10 & 27,70 & 1,48 & $72^{\circ}$ & Amplio & $\begin{array}{l}\text { Biconvexa } \\
\text { asimétrica irregular }\end{array}$ & Lanceolada & $\begin{array}{l}\text { Muy grueso defectuoso para } \\
\text { seguir adelgazando + borde } \\
\text { excesivamente grueso }\end{array}$ \\
\hline 116 & $\begin{array}{l}\text { Fragmento de } \\
\text { basal de biface no } \\
\text { diferenciado } / 3\end{array}$ & Vc1 & $(15,60)$ & $(19,70)$ & $(5,20)$ & $(3,79)$ & $44^{\circ}$ & Estrecho & $\begin{array}{l}\text { Biconvexa } \\
\text { asimétrica regular }\end{array}$ & No diferenciada & Fractura \\
\hline 115 & $\begin{array}{l}\text { Fragmento meso- } \\
\text { basal de biface en } \\
\text { sentido estricto / } 2\end{array}$ & $\mathrm{ObC}$ & $(26,70)$ & 21,50 & 7,80 & 2,76 & $60^{\circ}$ & Estrecha & $\begin{array}{l}\text { Biconvexa simétrica } \\
\text { regular }\end{array}$ & Lanceolada & Fractura \\
\hline 26 & Biface parcial /2 & Vc1 & 47,60 & 46,50 & 29,60 & 1,57 & $70^{\circ}$ & Amplio & $\begin{array}{l}\text { Biconvexa } \\
\text { asimétrica irregular }\end{array}$ & Irregular & $\begin{array}{l}\text { Muy grueso defectuoso para } \\
\text { seguir adelgazando + borde } \\
\text { excesivamente grueso }\end{array}$ \\
\hline 35 & $\begin{array}{l}\text { Fragmento meso- } \\
\text { basal de biface /2 }\end{array}$ & Vc1 & $(34,60)$ & $(36,60)$ & $(12,00)$ & $(3,05)$ & $68,33^{\circ}$ & $\begin{array}{l}\text { Amplio/ } \\
\text { moderado }\end{array}$ & $\begin{array}{l}\text { Biconvexa } \\
\text { asimétrica irregular }\end{array}$ & Lanceolada & Fractura perversa \\
\hline
\end{tabular}

Referencias: 1) Artefacto en si mismo; 2) Pieza en proceso de manufactura; 3) No diferenciada / E Medidas de L, A y E en mm / (...): medida afectada por fractura / Ang filo: promedio de los ingulos de los distintos filos que componen la pieza / Amplitud del sinusoide (offset): en base a Callahan (1979) / Causa de abandono: categorías en base a Nami (1993-94) 
Tabla 10.5. Bifaces reciclados. PCh1.3

\begin{tabular}{|c|c|c|c|c|c|c|c|c|c|c|c|}
\hline $\mathbf{N}^{\circ}$ PIEZA & SUBGRUPO TIPOLÓGICO & $\begin{array}{l}\text { MAT } \\
\text { PRIM }\end{array}$ & $\mathbf{L}$ & $\mathbf{A}$ & $\mathbf{E}$ & $\mathbf{A} / \mathbf{E}$ & $\begin{array}{l}\text { ANG } \\
\text { FILO } \\
\text { Bf }\end{array}$ & $\begin{array}{l}\text { AMPLITUD } \\
\text { SINUSOIDE }\end{array}$ & $\begin{array}{l}\text { SECCION } \\
\text { TRANSV }\end{array}$ & $\begin{array}{l}\text { FORMA } \\
\text { GEOM } \\
\text { CONTORNO }\end{array}$ & $\begin{array}{c}\text { CAUSA } \\
\text { ABANDONO } \\
\text { Bf }\end{array}$ \\
\hline 60 & $\begin{array}{l}\text { Raspador de filo restringido frontal sobre } \\
\text { biface parcial reciclado } / 2\end{array}$ & Vc1 & 44,80 & 19,00 & 7,70 & 2,47 & $53,5^{\circ}$ & Estrecho & $\begin{array}{l}\text { Biconvexa } \\
\text { asimétrica } \\
\text { irregular }\end{array}$ & Lanceolada & $\begin{array}{l}\text { Angostamiento } \\
\text { excesivo + borde } \\
\text { excesivamente grueso }\end{array}$ \\
\hline 132 & $\begin{array}{l}\text { Punta burilante angular + raspador de filo } \\
\text { restringido frontal + mueca retocada lateral } \\
\text { sobre fragmento meso-basal de biface parcial } \\
\text { reciclado / } 2\end{array}$ & Vc1 & $(53,10)$ & 31,00 & 10,90 & 2,84 & $66^{\circ}$ & $\begin{array}{l}\text { Moderado/ } \\
\text { estrecho }\end{array}$ & $\begin{array}{l}\text { Plano- } \\
\text { convexa }\end{array}$ & Lanceolada & Charnela \\
\hline 105 & $\begin{array}{l}\text { Punta burilante de retoque alternante axial } \\
\text { sobre fragmento meso-apical de biface parcial } \\
\text { reciclado / } 2\end{array}$ & Vc1 & $(43,50)$ & $(33,70)$ & $(10,60)$ & $(3,18)$ & $55,5^{\circ}$ & Estrecho & $\begin{array}{l}\text { Biconvexa } \\
\text { asimétrica } \\
\text { irregular }\end{array}$ & Lanceolada & $\begin{array}{l}\text { Defecto de la materia } \\
\text { prima + fractura }\end{array}$ \\
\hline 96 & $\begin{array}{l}\text { Punta burilante de retoque alternante angular } \\
+ \text { filo formatizado pasivo sobre fragmento } \\
\text { meso-basal de biface parcial reciclado / } 2\end{array}$ & Vc1 & $(32,90)$ & $(56,70)$ & $(14,20)$ & $(3,99)$ & $66,5^{\circ}$ & Estrecho & $\begin{array}{l}\text { Biconvexa } \\
\text { asimétrica } \\
\text { irregular }\end{array}$ & No diferenciada & Charnela \\
\hline 30 & $\begin{array}{l}\text { Punta burilante de filo largo frontal sobre } \\
\text { fragmento apical de biface en sentido estricto } \\
\text { reciclado /2 }\end{array}$ & Vc2 & $(25,60)$ & $(23,40)$ & $(6,50)$ & $(3,60)$ & $37,5^{\circ}$ & Estrecho & $\begin{array}{l}\text { Biconvexa } \\
\text { asimétrica } \\
\text { irregular }\end{array}$ & No diferenciada & Fractura \\
\hline
\end{tabular}

ias: 1) Artefacto en si mismo; 2) Pieza en proceso de manufactura / Medidas de L, A y E en mm / (...): medida afectada por fractura / Ang filo Bf: promedio de los ángulos de los filos tes del biface / Amplitud del sinusoide (offset): en base a Callahan (1979) / Causa de abandono del biface: categorías en base a Nami (1993-94) 
Producción lítica, variabilidad y cambio en Antofagasta de la Sierra -ca.5500-1500 AP-, Salomón Hocsman

Tabla 10.6. Bifaces transformados. PCh1.3

\begin{tabular}{|c|c|c|c|c|c|c|c|c|c|}
\hline $\mathbf{N}^{\circ}$ PIEZA & SUBGRUPO TIPOLÓGICO & $\begin{array}{l}\text { MAT } \\
\text { PRIM }\end{array}$ & $\mathbf{L}$ & $\mathbf{A}$ & $\mathbf{E}$ & $\mathbf{A} / \mathbf{E}$ & $\begin{array}{l}\text { ANG } \\
\text { FILO }\end{array}$ & $\begin{array}{l}\text { SECCION } \\
\text { TRANSV }\end{array}$ & $\begin{array}{l}\text { FORMA GEOM } \\
\text { CONTORNO }\end{array}$ \\
\hline 104 & $\begin{array}{l}\text { Raedera de filo largo lateral + perforador de sección simétrica + filo } \\
\text { formatizado pasivo / Biface en sentido estricto }\end{array}$ & Vc1 & 43,70 & 32,80 & 8,20 & 4,00 & $64^{\circ} /-/ 78^{\circ}$ & $\begin{array}{l}\text { Biconvexa } \\
\text { asimétrica regular }\end{array}$ & Triangular \\
\hline 52 & $\begin{array}{l}\text { (2) Cuchillos de filo retocado largos laterales + filo no diferenciado de } \\
\text { artefacto formatizado / Biface en sentido estricto }\end{array}$ & Vc1 & $(36,80)$ & $(32,20)$ & $(11,90)$ & $(2,71)$ & $\begin{array}{c}83^{\circ} / 55^{\circ} / \\
64^{\circ}\end{array}$ & $\begin{array}{l}\text { Biconvexa } \\
\text { asimétrica irregular }\end{array}$ & No diferenciada \\
\hline 68 & $\begin{array}{l}\text { (2) Raederas de filo largo lateral + filo bifacial de arista sinuosa (bf) / } \\
\text { Biface en sentido estricto }\end{array}$ & Vc1 & $(33,30)$ & $(22,60)$ & $(9,00)$ & $(2,51)$ & $\begin{array}{c}53^{\circ} / 54^{\circ} / \\
60^{\circ}\end{array}$ & Plano-convexa & Lanceolada \\
\hline 59 & $\begin{array}{l}\text { Buril + punta burilante angular sobre punta de proyectil con pedúnculo } \\
\text { esbozado y espolón reciclada }\end{array}$ & Vc1 & $(43,00)$ & $(26,40)$ & $(12,90)$ & $(2,05)$ & $-/ 81^{\circ}$ & $\begin{array}{l}\text { Biconvexa } \\
\text { simétrica regular }\end{array}$ & Pentagonal \\
\hline 25 & $\begin{array}{l}\text { Punta de proyectil con pedúnculo destacado y aletas, con limbo no } \\
\text { diferenciado }\end{array}$ & ObB & $(28,30)$ & $(40,90)$ & $(8,20)$ & $(4,99)$ & $36^{\circ} / 38^{\circ}$ & $\begin{array}{l}\text { Biconvexa } \\
\text { simétrica regular }\end{array}$ & Pentagonal \\
\hline $92 / 1$ & Fragmento meso-basal de punta de proyectil apedunculada & Vc2 & $(18,40)$ & $(26,80)$ & $(5,90)$ & $(4,54)$ & $46^{\circ} / 68^{\circ}$ & $\begin{array}{l}\text { Biconvexa } \\
\text { asimétrica regular }\end{array}$ & Lanceolada \\
\hline
\end{tabular}

Referencias: Medidas de L, A y E en mm / (...): medida afectada por fractura / bf: biface. Implica un filo del biface original que no fue transformado / Ang filo: en el caso de artefactos

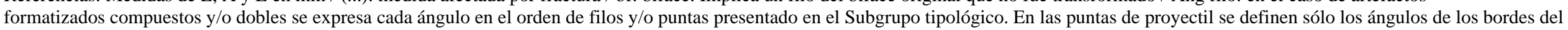
limbo (izquierdo y derecho respectivamente) 


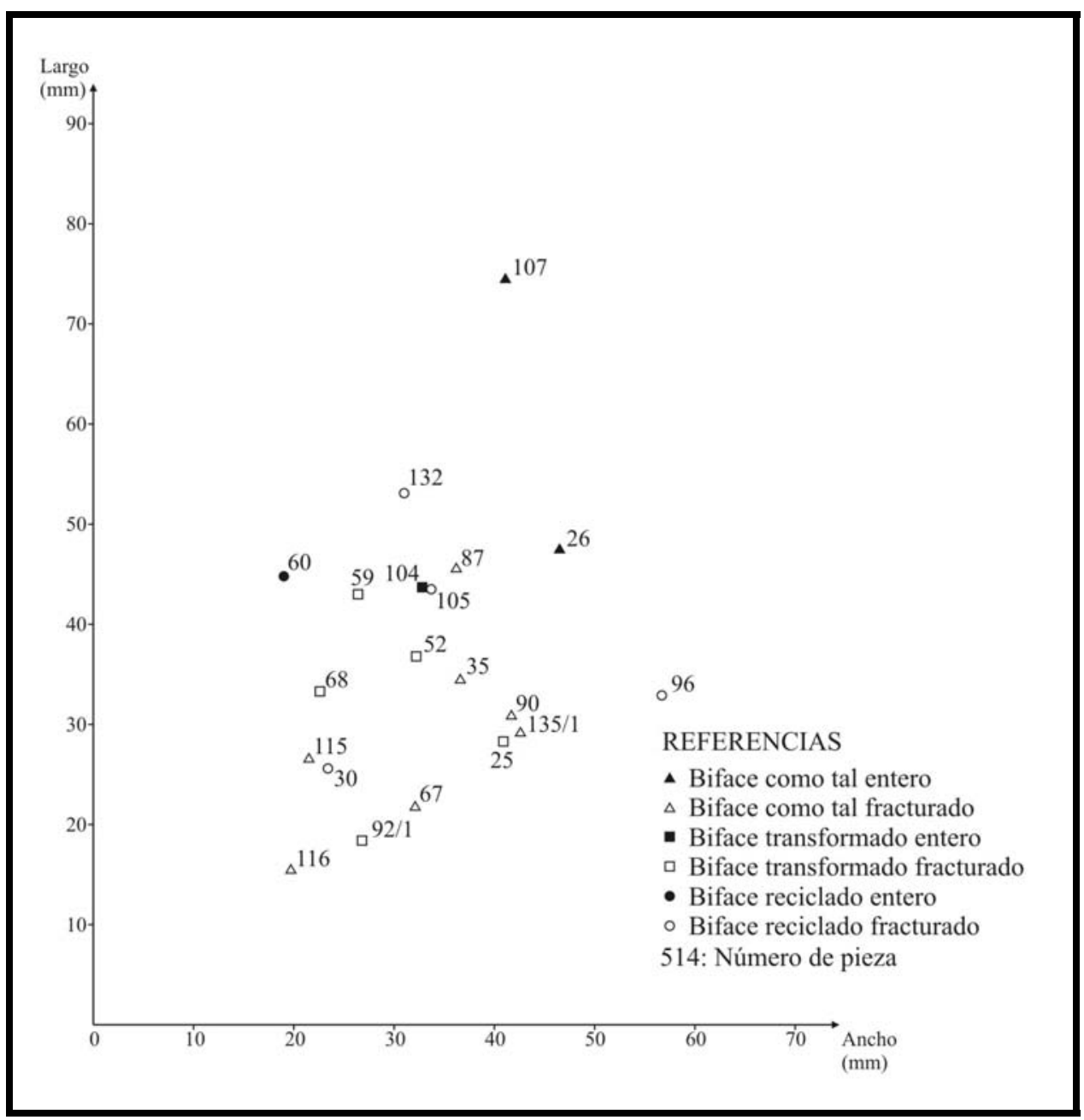

Figura 10.10. Distribución de tamaños (L-A) en bifaces como tales, transformados y reciclados de PCh1.3 


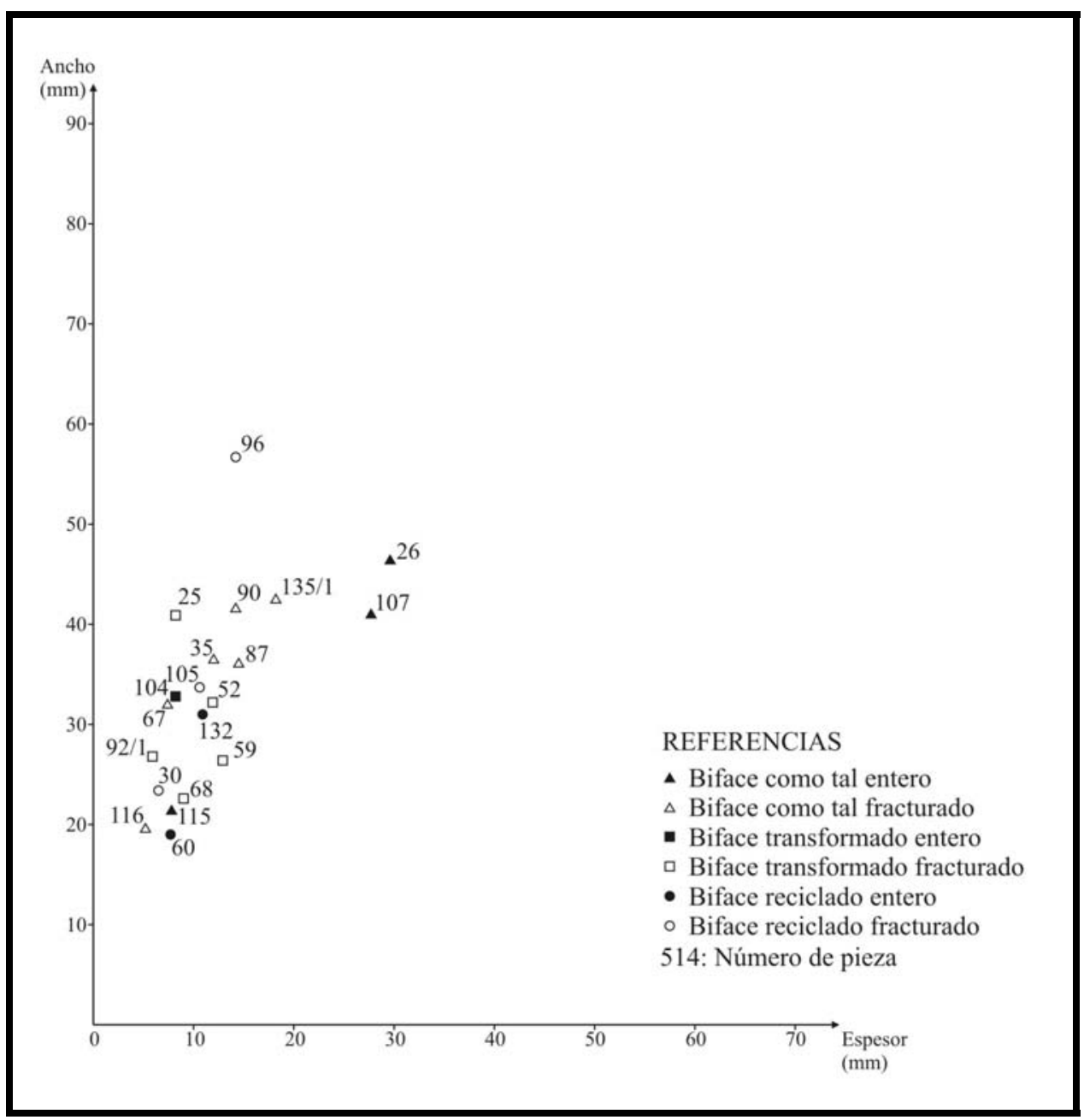

Figura 10.11. Distribución de tamaños (A-E) en bifaces como tales, transformados y reciclados de PCh1.3 


\subsubsection{CARACTERÍSTICAS DE LOS BIFACES DEL SITIO PCh1.1}

PCh1.1 cuenta con 33 bifaces recuperados en las distintas campañas que involucraron excavación en el alero, de los cuales 14 son bifaces como tales (Tablas 10.7 y 10.7 -continuación-), 4 han sido reciclados (Tabla 10.8) y 15 han sido transformados (Tablas 10.9 y 10.9 -continuación-). Con respecto a los bifaces como tales, 5 están enteros y los restantes, fracturados. Estos últimos incluyen 4 fragmentos meso-apicales, 2 fragmentos basales, 1 fragmento meso-basal, 1 fragmento apical y una pieza con una fractura de pequeña envergadura que afecta sólo el largo. Pasando ya a los bifaces reciclados, son 4 piezas, todas fracturadas. Finalmente, dentro de los bifaces fracturados, sobresale el papel de los bifaces como formas-base secundarias de puntas de proyectil apedunculadas, en número de 10. Las 5 piezas restantes son artefactos compuestos de diversa índole.

Por otro lado, se vislumbra un predominio de piezas en proceso de manufactura (14 de un total de 18 artefactos) al considerar en conjunto los bifaces como tales y los reciclados. Sólo 3 piezas pueden ser caratuladas como bifaces en sí mismos, mientras que otra es no diferenciada.

En base a lo expuesto, es evidente la multiplicidad de papeles que cumplieron los bifaces en PCh1.1, a saber: 1) como artefactos en sí mismos; 2) como piezas en proceso de manufactura a diferentes fines, 3) como formas-base secundarias de artefactos compuestos y, básicamente, de puntas de proyectil apedunculadas lanceoladas, de diverso tamaño y 4) como artefactos reciclados. Destaca un caso de biface enmangado. Es así que la pieza $\mathrm{N}^{\circ} 81$ se trata de un biface transformado que presenta en su sector basal bordes convergentes rectos y una base convexilínea no inflexionada, con morfología de la arista sinuosa regular y amplitud del sinusoide estrecho. La porción enmangada queda delimitada claramente debido a la inflexión generada por los filos activos, a ambos lados del biface.

La mayor parte de los bifaces como tales y reciclados tienen morfologías lanceoladas, secciones transversales biconvexas levemente asimétricas y regulares, ángulos de filos de baa gradación y sinuosidad moderada a estrecha. Destacan, por otra parte, las coincidencias de este grupo con los bifaces transformados, particularmente en cuanto a razones $\mathrm{A} / \mathrm{E}$, sección transversal y morfología del contorno. Con respecto a esto último, es evidente la orientación a la confección de puntas de proyectil lanceoladas, de diverso tamaño (PCh E, PCh F y PCz A), pudiéndose vislumbrar que la muestra de bifaces responde, en buena parte, a esa variabilidad. Un ejemplo de ello es la pieza $\mathrm{N}^{\mathrm{o}} 34$ (Figura 10.12), que puede relacionarse con puntas de proyectil de pequeño tamaño ubicuas hacia el 3600 AP en la microrregión. 
Tabla 10.7. Bifaces como tales. PCh1.1

\begin{tabular}{|c|c|c|c|c|c|c|c|c|c|c|c|}
\hline $\begin{array}{c}\mathbf{N}^{\circ} \\
\text { PIEZA }\end{array}$ & $\begin{array}{l}\text { SUBGRUPO } \\
\text { TIPOLÓGICO }\end{array}$ & $\begin{array}{c}\text { MAT } \\
\text { PRIMA }\end{array}$ & $\mathbf{L}$ & $\mathbf{A}$ & $\mathbf{E}$ & $\mathbf{A} / \mathbf{E}$ & $\begin{array}{l}\text { ANG } \\
\text { FILO }\end{array}$ & $\begin{array}{l}\text { AMPLITUD } \\
\text { SINUSOIDE }\end{array}$ & $\begin{array}{l}\text { SECCION } \\
\text { TRANSV }\end{array}$ & $\begin{array}{l}\text { FORMA GEOM } \\
\text { CONTORNO }\end{array}$ & CAUSA ABANDONO \\
\hline 19 & $\begin{array}{l}\text { Biface en sentido } \\
\text { estricto /1 }\end{array}$ & Vc1 & 60,50 & 21,00 & 10,40 & 2,02 & $60^{\circ}$ & $\begin{array}{l}\text { Moderado/ } \\
\text { estrecho }\end{array}$ & $\begin{array}{l}\text { Biconvexa } \\
\text { asimétrica irregular }\end{array}$ & Lanceolada & - \\
\hline 51 & $\begin{array}{l}\text { Fragmento meso- } \\
\text { basal de biface en } \\
\text { sentido estricto / } 2\end{array}$ & Vc1 & $(31,00)$ & 28,60 & 9,90 & 2,89 & $68,33^{\circ}$ & Estrecho & $\begin{array}{l}\text { Biconvexa } \\
\text { asimétrica irregular }\end{array}$ & Lanceolada & Fractura \\
\hline 30 & $\begin{array}{l}\text { Biface en sentido } \\
\text { estricto fracturado } \\
/ 2\end{array}$ & Vc1 & $(55,50)$ & 46,00 & 18,50 & 2,49 & $79,5^{\circ}$ & Moderado & $\begin{array}{l}\text { Biconvexa } \\
\text { asimétrica irregular }\end{array}$ & Irregular & $\begin{array}{l}\text { Muy grueso defectuoso para } \\
\text { seguir adelgazando + borde } \\
\text { excesivamente grueso + } \\
\text { charnela }\end{array}$ \\
\hline 13 & Biface parcial /2 & Vc1 & 57,90 & 47,80 & 23,90 & 2,00 & $72^{\circ}$ & $\begin{array}{l}\text { Amplio/ } \\
\text { moderado/ } \\
\text { estrecho }\end{array}$ & $\begin{array}{l}\text { Biconvexa } \\
\text { asimétrica irregular }\end{array}$ & Irregular & $\begin{array}{l}\text { Muy grueso defectuoso para } \\
\text { seguir adelgazando + defecto de } \\
\text { la materia prima + cambio de } \\
\text { textura }\end{array}$ \\
\hline 68 & $\begin{array}{l}\text { Biface en sentido } \\
\text { estricto } / 2\end{array}$ & Vc1 & $(65,50)$ & 29,10 & 16,70 & 1,74 & $63,5^{\circ}$ & Moderado & $\begin{array}{l}\text { Biconvexa } \\
\text { asimétrica irregular }\end{array}$ & Lanceolada & $\begin{array}{l}\text { Fractura }+ \text { muy grueso } \\
\text { defectuoso para seguir } \\
\text { adelgazando }\end{array}$ \\
\hline 79 & $\begin{array}{l}\text { Fragmento basal de } \\
\text { biface no } \\
\text { diferenciado /3 }\end{array}$ & Vc1 & $(15,20)$ & $(24,70)$ & $(8,40)$ & $(2,94)$ & $59,33^{\circ}$ & Estrecho & $\begin{array}{l}\text { Biconvexa } \\
\text { asimétrica irregular }\end{array}$ & No diferenciada & $\begin{array}{l}\text { Fractura + defecto de materia } \\
\text { prima }\end{array}$ \\
\hline 34 & $\begin{array}{l}\text { Biface en sentido } \\
\text { estricto } / 2\end{array}$ & ObA & 26,20 & 16,50 & 6,90 & 2,39 & $68,5^{\circ}$ & Estrecha & $\begin{array}{l}\text { Biconvexa } \\
\text { asimétrica irregular }\end{array}$ & Lanceolada & - \\
\hline 9 & $\begin{array}{l}\text { Biface en sentido } \\
\text { estricto } / 2\end{array}$ & Vc1 & 77,10 & 28,70 & 20,00 & 1,44 & $73^{\circ}$ & $\begin{array}{l}\text { Amplio/ } \\
\text { moderado }\end{array}$ & $\begin{array}{l}\text { Biconvexa } \\
\text { asimétrica irregular }\end{array}$ & Irregular & $\begin{array}{l}\text { Charnela + muy grueso } \\
\text { defectuoso para seguir } \\
\text { adelgazando + borde } \\
\text { excesivamente grueso }\end{array}$ \\
\hline $39 / 3$ & $\begin{array}{l}\text { Fragmento meso- } \\
\text { apical de biface en } \\
\text { sentido estricto / } 2\end{array}$ & Vc1 & $(47,40)$ & $(24,40)$ & $(11,30)$ & $(2,16)$ & $64,5^{\circ}$ & $\begin{array}{l}\text { Moderado/ } \\
\text { estrecho }\end{array}$ & $\begin{array}{l}\text { Biconvexa simétrica } \\
\text { regular }\end{array}$ & Lanceolada & Fractura perversa \\
\hline 19 & $\begin{array}{l}\text { Fragmento basal de } \\
\text { biface en sentido } \\
\text { estricto } / 2\end{array}$ & Vc1 & $(26,60)$ & $(25,30)$ & $(7,20)$ & $(3,51)$ & $48^{\circ}$ & Estrecho & $\begin{array}{l}\text { Biconvexa } \\
\text { asimétrica irregular }\end{array}$ & No diferenciada & Golpe fallido \\
\hline
\end{tabular}

Referencias: 1) Artefacto en si mismo; 2) Pieza en proceso de manufactura; 3) No diferenciada / E Medidas de L, A y E en mm / (...): medida afectada por fractura / Ang filo: promedio de los

íngulos de los distintos filos que componen la pieza / Amplitud del sinusoide (offset): en base a Callahan (1979) / Causa de abandono: categorías modificadas de Nami (1993-94) 
Tabla 10.7 (continuación). Bifaces como tales. PCh1.1

\begin{tabular}{|c|c|c|c|c|c|c|c|c|c|c|c|}
\hline $\begin{array}{c}\mathbf{N}^{\circ} \\
\text { PIEZA }\end{array}$ & $\begin{array}{l}\text { SUBGRUPO } \\
\text { TIPOLÓGICO }\end{array}$ & $\begin{array}{c}\text { MAT } \\
\text { PRIMA }\end{array}$ & $\mathbf{L}$ & $\mathbf{A}$ & $\mathbf{E}$ & $\mathbf{A} / \mathbf{E}$ & $\begin{array}{l}\text { ANG } \\
\text { FILO }\end{array}$ & $\begin{array}{l}\text { AMPLITUD } \\
\text { SINUSOIDE }\end{array}$ & $\begin{array}{l}\text { SECCION } \\
\text { TRANSV }\end{array}$ & $\begin{array}{l}\text { FORMA GEOM } \\
\text { CONTORNO }\end{array}$ & CAUSA ABANDONO \\
\hline 12 & $\begin{array}{l}\text { Fragmento meso- } \\
\text { apical de biface en } \\
\text { sentido estricto /1 }\end{array}$ & Vc1 & $(66,50)$ & $(34,00)$ & $(11,60)$ & $(2,93)$ & $64,5^{\circ}$ & Estrecho & $\begin{array}{l}\text { Biconvexa } \\
\text { asimétrica regular }\end{array}$ & Lanceolada & Fractura perversa \\
\hline 3 & $\begin{array}{l}\text { Fragmento meso- } \\
\text { apical de biface en } \\
\text { sentido estricto / } 2\end{array}$ & Vc1 & $(59,90)$ & $(39,10)$ & $(13,60)$ & $(2,88)$ & $57^{\circ}$ & Moderado & $\begin{array}{l}\text { Biconvexa } \\
\text { asimétrica irregular }\end{array}$ & Lanceolada & $\begin{array}{l}\text { Fractura perversa }+ \text { defecto de } \\
\text { materia prima }\end{array}$ \\
\hline 4 & $\begin{array}{l}\text { Fragmento meso- } \\
\text { apical de biface en } \\
\text { sentido estricto } / 1\end{array}$ & Vc3 & $(56,60)$ & 27,50 & $(12,50)$ & $(2,20)$ & $62^{\circ}$ & Estrecho & $\begin{array}{l}\text { Biconvexa } \\
\text { asimétrica irregular }\end{array}$ & Lanceolada & Fractura \\
\hline $59 / 2$ & $\begin{array}{l}\text { Fragmento apical } \\
\text { de biface parcial /2 }\end{array}$ & ObC & $(26,20)$ & $(19,00)$ & $(8,00)$ & $(2,38)$ & $80^{\circ}$ & Estrecho & $\begin{array}{l}\text { Biconvexa } \\
\text { asimétrica irregular }\end{array}$ & No diferenciada & Fractura perversa \\
\hline
\end{tabular}

Referencias: 1) Artefacto en si mismo; 2) Pieza en proceso de manufactura; 3) No diferenciada / E Medidas de L, A y E en mm / (...): medida afectada por fractura / Ang filo: promedio de los ingulos de los distintos filos que componen la pieza / Amplitud del sinusoide (offset): en base a Callahan (1979) / Causa de abandono: categorías modificadas de Nami (1993-94) 
Tabla 10.8. Bifaces reciclados. PCh1.1

\begin{tabular}{|c|c|c|c|c|c|c|c|c|c|c|c|}
\hline $\mathbf{N}^{\circ}$ PIEZA & SUBGRUPO TIPOLÓGICO & $\begin{array}{l}\text { MAT } \\
\text { PRIM }\end{array}$ & $\mathbf{L}$ & $\mathbf{A}$ & $\mathbf{E}$ & $\mathbf{A} / \mathbf{E}$ & $\begin{array}{l}\text { ANG } \\
\text { FILO } \\
\text { Bf }\end{array}$ & $\begin{array}{l}\text { AMPLITUD } \\
\text { SINUSOIDE }\end{array}$ & $\begin{array}{l}\text { SECCION } \\
\text { TRANSV }\end{array}$ & $\begin{array}{l}\text { FORMA } \\
\text { GEOM } \\
\text { CONTORNO }\end{array}$ & $\begin{array}{l}\text { CAUSA } \\
\text { ABANDONO } \\
\text { Bf }\end{array}$ \\
\hline 42 & $\begin{array}{l}\text { Cuchillo de filo retocado lateral + filo bifacial } \\
\text { de arista sinuosa (bf) -parte pasiva- sobre } \\
\text { biface parcial reciclado } / 2\end{array}$ & Vc1 & $(46,80)$ & $(29,30)$ & $(10,60)$ & - & - & Estrecho & $\begin{array}{l}\text { Biconvexa } \\
\text { asimétrica } \\
\text { regular }\end{array}$ & No diferenciada & Fracturas \\
\hline 14 & $\begin{array}{l}\text { Punta burilante angular en filo retocado + (2) } \\
\text { filos formatizados pasivos sobre fragmento } \\
\text { meso-apical de biface en sentido estricto } \\
\text { reciclado / } 2\end{array}$ & Vc1 & $(37,70)$ & $(41,70)$ & $(21,50)$ & $(1,94)$ & $62^{\circ}$ & Moderado & $\begin{array}{l}\text { Biconvexa } \\
\text { asimétrica } \\
\text { irregular }\end{array}$ & Lanceolada & Charnela \\
\hline 29 & $\begin{array}{l}\text { Percutor de arista formatizada fronto-lateral } \\
\text { sobre fragmento meso-basal de biface en } \\
\text { sentido estricto reciclado } / 2\end{array}$ & Vc1 & $(43,50)$ & $(33,70)$ & $(10,60)$ & $(3,18)$ & $73^{\circ}$ & Estrecho & $\begin{array}{l}\text { Biconvexa } \\
\text { asimétrica } \\
\text { irregular }\end{array}$ & Lanceolada & Charnela \\
\hline $39 / 1$ & Buril sobre biface parcial reciclado /2 & ObA & $(25,30)$ & $(14,70)$ & 7,40 & $(1,99)$ & $66,5^{\circ}$ & Moderado & $\begin{array}{l}\text { Biconvexa } \\
\text { asimétrica } \\
\text { irregular }\end{array}$ & Irregular & Charnela \\
\hline
\end{tabular}

ias: 1) Artefacto en si mismo; 2) Pieza en proceso de manufactura / Medidas de L, A y E en mm / (...): medida afectada por fractura / Ang filo Bf: promedio de los ángulos de los filos tes del biface / Amplitud del sinusoide (offset): en base a Callahan (1979) / Causa de abandono del biface: categorías en base a Nami (1993-94) 
Tabla 10.9. Bifaces transformados. PCh1.1

\begin{tabular}{|c|c|c|c|c|c|c|c|c|c|}
\hline $\mathbf{N}^{\circ}$ PIEZA & SUBGRUPO TIPOLÓGICO & $\begin{array}{l}\text { MAT } \\
\text { PRIM }\end{array}$ & $\mathbf{L}$ & A & $\mathbf{E}$ & $\mathbf{A} / \mathbf{E}$ & $\begin{array}{l}\text { ANG } \\
\text { FILO }\end{array}$ & $\begin{array}{l}\text { SECCION } \\
\text { TRANSV }\end{array}$ & $\begin{array}{l}\text { FORMA GEOM } \\
\text { CONTORNO }\end{array}$ \\
\hline 24 & $\begin{array}{l}\text { Punta burilante angular + cortante de filo retocado restringido frontal + } \\
\text { filo formatizado pasivo + cuchillo de filo retocado lateral + buril / Biface } \\
\text { en sentido estricto }\end{array}$ & Vc1 & 58,00 & 30,30 & 13,00 & 2,33 & $\begin{array}{c}-/ 47^{\circ} / \\
73^{\circ} / 53^{\circ}\end{array}$ & $\begin{array}{l}\text { Biconvexa } \\
\text { asimétrica regular }\end{array}$ & Lanceolada \\
\hline 41 & $\begin{array}{l}\text { Raedera de filo largo lateral + filo bifacial de arista sinuosa (bf) / Biface } \\
\text { en sentido estricto }\end{array}$ & Vc1 & $(50,70)$ & $(34,20)$ & $(11,10)$ & $(3,08)$ & $57^{\circ} / 66^{\circ}$ & Plano-convexa & Lanceolada \\
\hline 47 & $\begin{array}{l}\text { Fragmento basal de cuchillo de filo retocado no diferenciado + filo } \\
\text { bifacial de arista sinuosa (bf) / Biface en sentido estricto }\end{array}$ & Vc1 & $(19,50)$ & $(22,10)$ & $(9,00)$ & $(2,46)$ & $55^{\circ} / 66^{\circ}$ & $\begin{array}{l}\text { Biconvexa } \\
\text { asimétrica regular }\end{array}$ & Lanceolada \\
\hline 81 & $\begin{array}{l}\text { Raspador de filo corto lateral + punta burilante axial + raedera no } \\
\text { diferenciada + filo formatizado pasivo + filo no diferenciado de artefacto } \\
\text { formatizado + (3) filos bifaciales de arista sinuosa (bf) / Biface en } \\
\text { sentido estricto }\end{array}$ & Vc5 & 64,40 & 25,70 & 10,50 & 2,45 & $\begin{array}{l}62^{\circ} /-/ 64^{\circ} \% \\
93^{\circ} / 71^{\circ} \% \\
52^{\circ} / 48^{\circ} / \\
58^{\circ}\end{array}$ & $\begin{array}{l}\text { Biconvexa } \\
\text { asimétrica irregular }\end{array}$ & Lanceolada \\
\hline 34 & $\begin{array}{l}\text { Cuchillo de filo retocado lateral + denticulado bisel oblicuo/abrupto } \\
\text { sección asimétrica largo lateral / Biface en sentido estricto }\end{array}$ & Vc4 & 60,30 & 33,00 & 9,80 & 3,37 & $52^{\circ} / 50^{\circ}$ & $\begin{array}{l}\text { Biconvexa } \\
\text { simétrica regular }\end{array}$ & Lanceolada \\
\hline 2 & Fragmento limbo-basal de punta de proyectil apedunculada & Vc1 & $(21,10)$ & 14,20 & $(7,00)$ & $(2,03)$ & $63^{\circ} / 75^{\circ}$ & $\begin{array}{l}\text { Biconvexa } \\
\text { asimétrica regular }\end{array}$ & Lanceolada \\
\hline 32 & Punta de proyectil apedunculada & ObC & 34,80 & 16,60 & 7,20 & 2,31 & $81^{\circ} / 70^{\circ}$ & $\begin{array}{l}\text { Biconvexa } \\
\text { asimétrica regular }\end{array}$ & Lanceolada \\
\hline 7 & $\begin{array}{l}\text { Buril sobre fragmento limbo-basal de punta de proyectil apedunculada } \\
\text { reciclada }\end{array}$ & ObC & $(28,60)$ & 17,40 & 8,30 & 2,10 & $76^{\circ} / 72^{\circ}$ & $\begin{array}{l}\text { Biconvexa } \\
\text { simétrica regular }\end{array}$ & Lanceolada \\
\hline 26 & $\begin{array}{l}\text { Cuchillo de filo retocado lateral sobre fragmento limbo-basal de punta de } \\
\text { proyectil apedunculada reciclada }\end{array}$ & Vc1 & $(48,80)$ & 28,40 & 12,00 & 2,37 & $53^{\circ} / 60^{\circ}$ & $\begin{array}{l}\text { Biconvexa } \\
\text { simétrica regular }\end{array}$ & Lanceolada \\
\hline $\mathrm{s} / \mathrm{n}^{0}$ & $\begin{array}{l}\text { Punta burilante angular sobre fragmento limbo-basal de punta de } \\
\text { proyectil apedunculada reciclada }\end{array}$ & Vc1 & $(64,60)$ & 24,80 & 9,20 & 2,70 & $-/ 66^{\circ} / 67^{\circ}$ & $\begin{array}{l}\text { Biconvexa } \\
\text { asimétrica regular }\end{array}$ & Lanceolada \\
\hline $\mathrm{s} / \mathrm{n}^{\mathrm{o}}$ & Fragmento limbo-basal de punta de proyectil apedunculada & Vc1 & $(46,20)$ & 24,70 & 11,60 & 2,13 & $69^{\circ} / 63^{\circ}$ & $\begin{array}{l}\text { Biconvexa } \\
\text { simétrica regular }\end{array}$ & Lanceolada \\
\hline
\end{tabular}

Referencias: Medidas de L, A y E en mm / (...): medida afectada por fractura / bf: biface. Implica un filo del biface original que no fue transformado / Ang filo: en el caso de artefactos

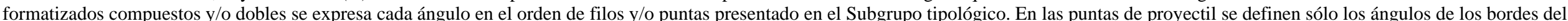
limbo (izquierdo y derecho respectivamente) 
Producción lítica, variabilidad y cambio en Antofagasta de la Sierra -ca.5500-1500 AP-, Salomón Hocsman

Tabla 10.9 (continuación). Bifaces transformados. PCh1.1

\begin{tabular}{|c|c|c|c|c|c|c|c|c|c|}
\hline $\mathbf{N}^{\circ}$ PIEZA & SUBGRUPO TIPOLÓGICO & $\begin{array}{l}\text { MAT } \\
\text { PRIM }\end{array}$ & $\mathbf{L}$ & $\mathbf{A}$ & $\mathbf{E}$ & $\mathbf{A} / \mathbf{E}$ & $\begin{array}{l}\text { ANG } \\
\text { FILO }\end{array}$ & $\begin{array}{l}\text { SECCION } \\
\text { TRANSV }\end{array}$ & $\begin{array}{l}\text { FORMA GEOM } \\
\text { CONTORNO }\end{array}$ \\
\hline 82 & Fragmento limbo-basal de punta de proyectil apedunculada & Vc1 & $(50,50)$ & 25,60 & $(11,80)$ & $(2,13)$ & $(2,17)$ & $\begin{array}{l}\text { Biconvexa } \\
\text { asimétrica irregular }\end{array}$ & Lanceolada \\
\hline 45 & $\begin{array}{l}\text { Muesca de lascado simple lateral + filo formatizado pasivo sobre } \\
\text { fragmento limbo-basal de punta de proyectil apedunculada reciclada }\end{array}$ & Vc2 & $(50,40)$ & $(25,70)$ & $(11,30)$ & $(2,27)$ & $\begin{array}{c}-/ 84^{\circ} / \\
59^{\circ} / 59^{\circ}\end{array}$ & $\begin{array}{l}\text { Biconvexa } \\
\text { simétrica regular }\end{array}$ & Lanceolada \\
\hline 21 & $\begin{array}{l}\text { Buril sobre fragmento limbo-basal de punta de proyectil apedunculada } \\
\text { reciclada }\end{array}$ & Vc4 & $(45,50)$ & 23,40 & 11,20 & 2,09 & $-/ 74^{\circ} / 56^{\circ}$ & $\begin{array}{l}\text { Biconvexa } \\
\text { asimétrica regular }\end{array}$ & Lanceolada \\
\hline $\mathrm{s} / \mathrm{n}^{\mathrm{o}}$ & $\begin{array}{l}\text { Buril + filo bifacial de arista sinuosa-parte pasiva- sobre fragmento } \\
\text { mesial de punta de proyectil apedunculada reciclada }\end{array}$ & Vc1 & $(65,90)$ & $(24,00)$ & 11,50 & $(2,09)$ & $60^{\circ} / 63^{\circ}$ & $\begin{array}{l}\text { Biconvexa } \\
\text { asimétrica regular }\end{array}$ & Lanceolada \\
\hline
\end{tabular}

Referencias: Medidas de L, A y E en mm / (...): medida afectada por fractura / bf: biface. Implica un filo del biface original que no fue transformado / Ang filo: en el caso de artefactos

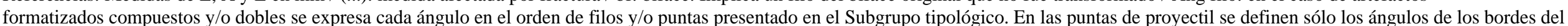
limbo (izquierdo y derecho respectivamente) 


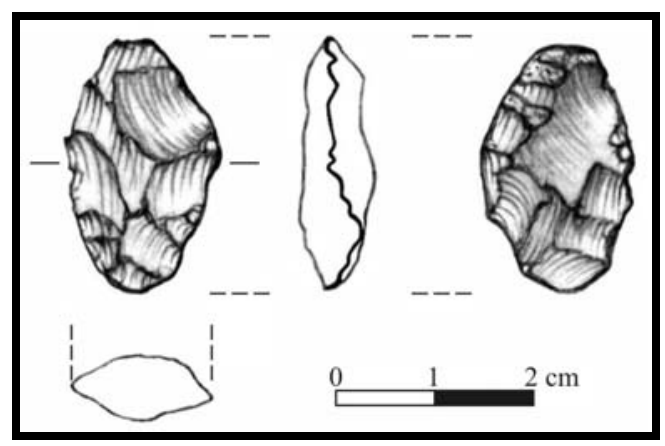

Figura 10.12. Biface en proceso de manufactura (PCh1.1. $N^{\circ}$ inv. 34)

A lo dicho se deben sumar una serie de piezas ( $\mathrm{N}^{\circ} 30,13$ y 9 ) que se alejan de las características arriba señaladas, por lo que no pueden ser vinculadas a producto final alguno. Las mismas se definen por una forma del contorno irregular, sección transversal biconvexa marcadamente asimétrica e irregular, arista sinuosa irregular con sinuosidad moderada a amplia, ángulos de filo importantes y razones ancho/espesor relativamente pequeñas. En las Figuras 10.13 y 10.14 puede apreciarse que las piezas en cuestión tienden a un mayor tamaño en cuanto al ancho y al espesor, situándose en una posición "periférica” en la distribución de puntos, hacia arriba y hacia la derecha, en ambas figuras.

Volviendo a la generalidad de las piezas, en la Figura 10.13 se observan dos nubes de puntos que dan cuenta de trayectorias de producción distintas. Por un lado, la que se encuentra en la porción inferior, a la izquierda, relacionada con la confección de puntas de proyectil lanceoladas de pequeño tamaño. En esta distribución interesan las puntas de proyectil $N^{o} 32$, 7 y 2 y los bifaces $N^{\circ} 34$, 39/1 y 51. Las restantes piezas que se encuentran en la nube citada no guardarían relación con la trayectoria citada, ya que en 3 casos son fragmentos basales de bifaces como tales ( $\mathrm{N}^{\circ} 19$ y 79 ) y transformados $\left(\mathrm{N}^{\circ} 47\right)$ que se relacionarían con la otra trayectoria en ciernes. Con respecto a esta última, que se encuentra en la porción superior y hacia la derecha del gráfico, estaría definida, en realidad, por un amplia gama de productos finales, que va de artefactos compuestos diversos a dos diseños de puntas de proyectil lanceoladas. Dicha nube de puntos se ve relativamente desdibujada, no pudiéndose establecer relaciones claras entre piezas en proceso de manufactura y finiquitadas. Esto puede responder, en buena parte, a que la mayor parte de las actividades de producción de bifaces se realizaron en el taller superficial inmediato al alero (Aschero com pers.), lo cual requiere, para ser comprobado, un abordaje sistemático de dicho taller, que se realizará en el futuro.

Ahora bien, al considerar la variabilidad en ancho y en espesor, cabe destacar que se ha graficado, por un lado, a los bifaces como tales y a los reciclados (Figura 10.14) y, por el otro lado, a los bifaces transformados (Figura 10.15). Esto responde al hecho de que la distribución total se presenta excesivamente abigarrada. Teniendo esto presente, destaca la variación en ancho y en 


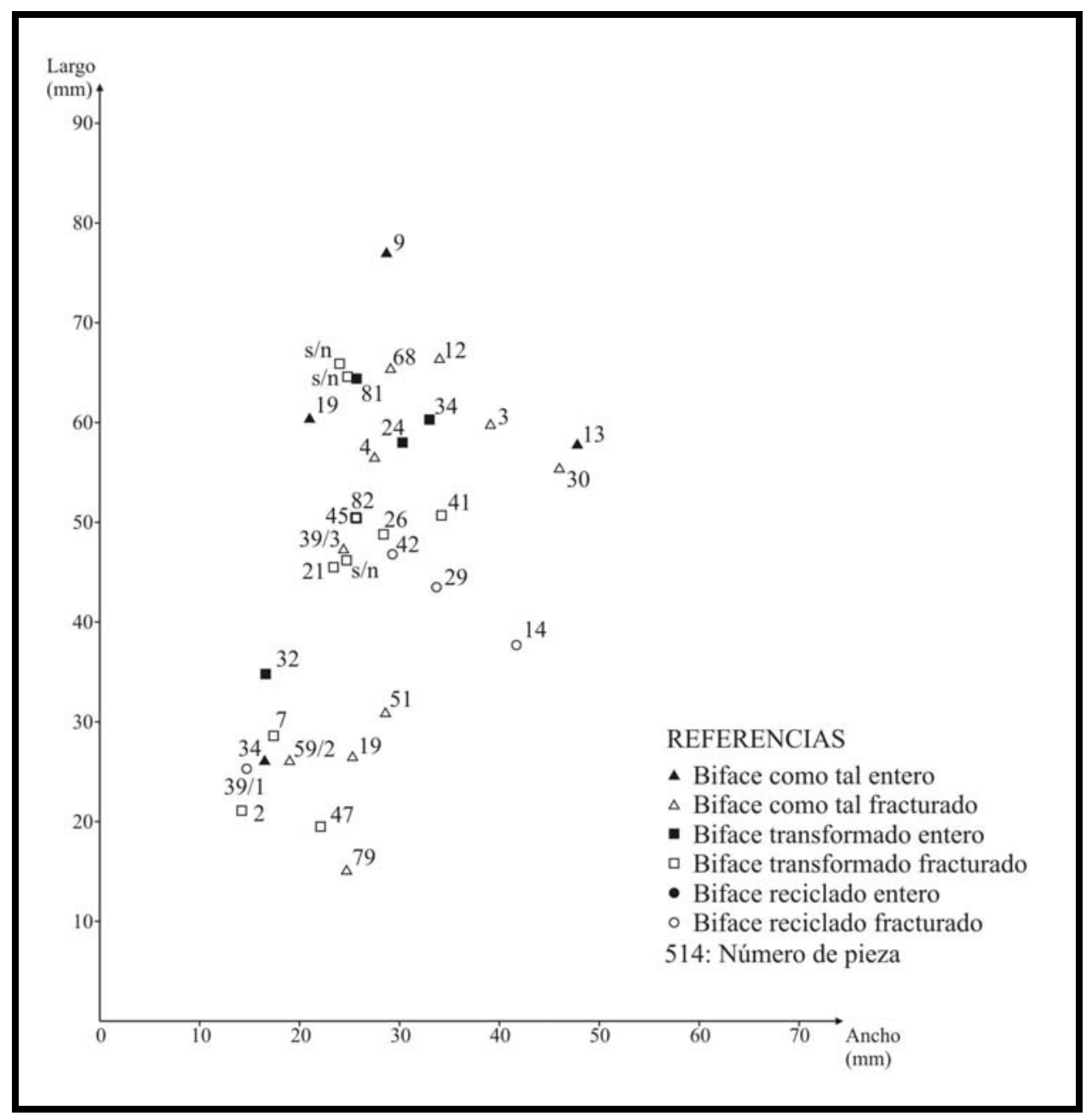

Figura 10.13. Distribución de tamaños (L-A) en bifaces como tales, transformados y reciclados de PCh1.1 


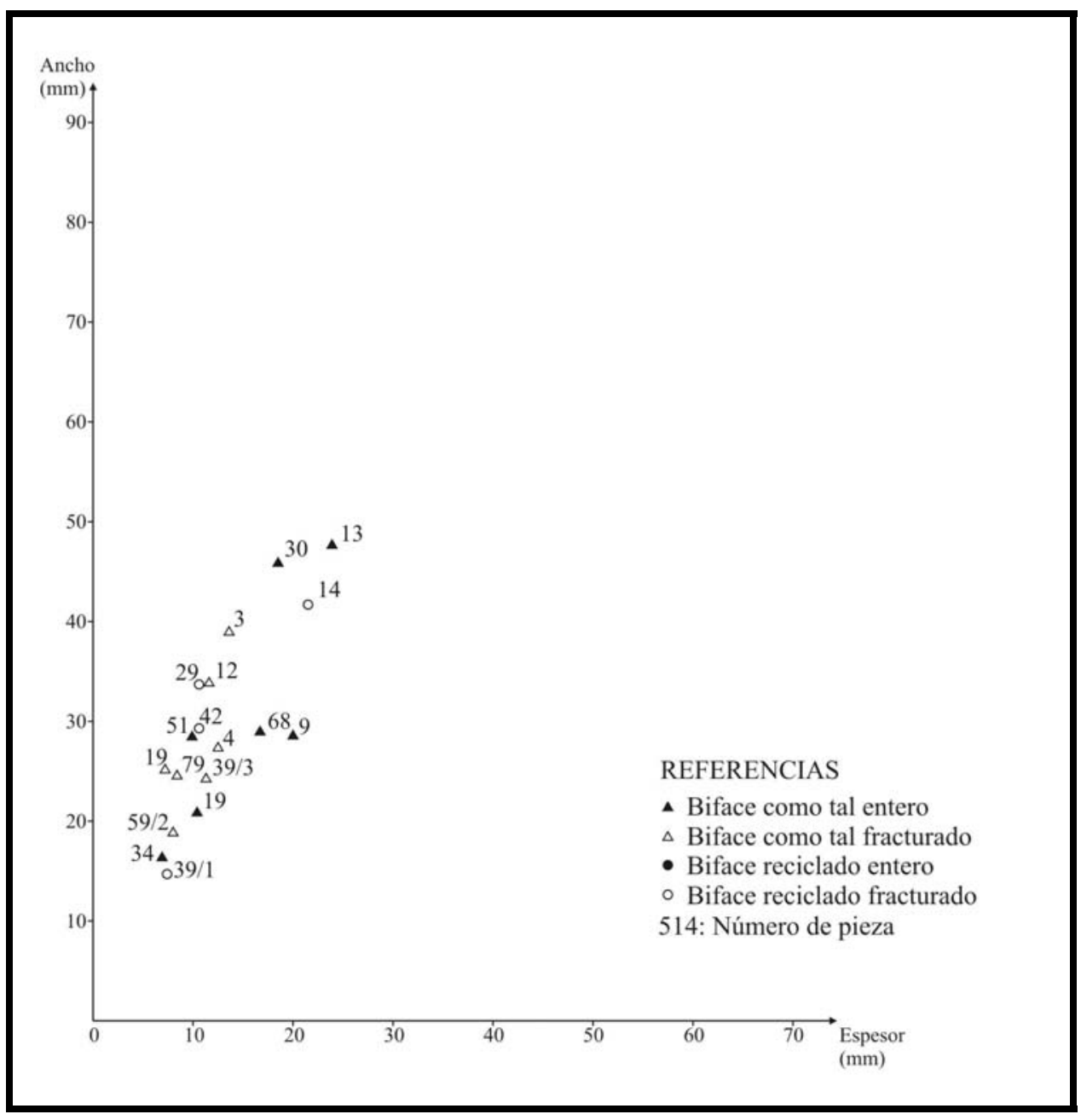

Figura 10.14. Distribución de tamaños (A-E) en bifaces como tales y reciclados de PCh1.1 


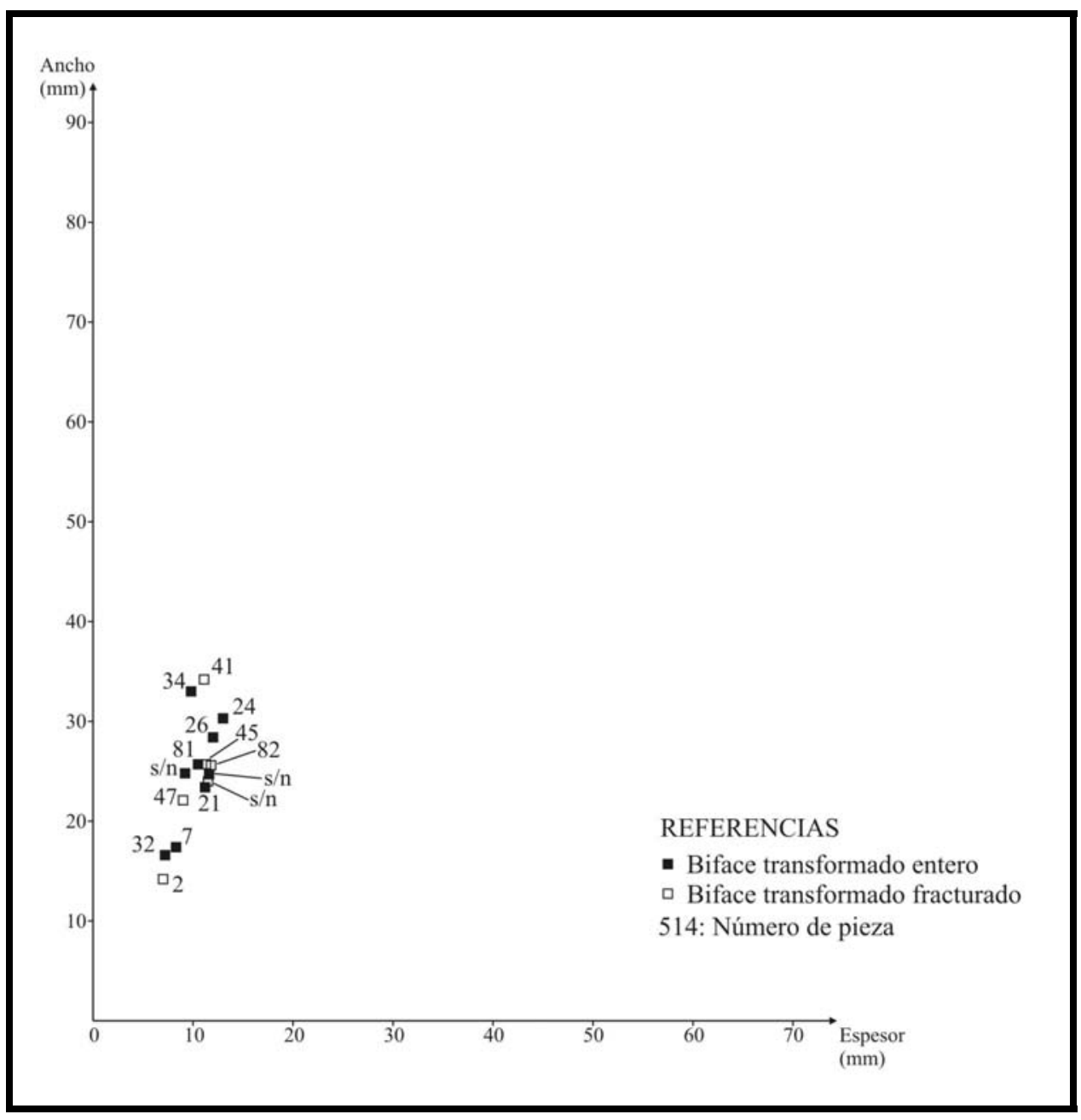

Figura 10.15. Distribución de tamaños (A-E) en bifaces transformados de PCh1.1 
espesor de los bifaces como tales y reciclados (Figura 10.14) en relación a los bifaces transformados, que se encuentran más acotados, principalmente en cuanto al espesor (Figura 10.15). Nótese la variación de los bifaces como tales enteros. Por otro lado, se registra nuevamente en la Figura 10.15 la diferenciación entre las puntas de proyectil lanceoladas de pequeño tamaño -porción inferior hacia la izquierda- versus las piezas compuestas y lanceoladas de mayor tamaño -porción superior hacia la derecha-.

\subsubsection{CARACTERÍSTICAS DE LOS BIFACES DEL SITIO PP4}

La muestra de bifaces de PP4 considerada en este punto proviene del sector del alero excavado durante la campaña del año 1999. La misma consta de 10 piezas, que se distribuyen de la siguiente forma: 5 bifaces como tales, todos fracturados -2 fragmentos meso-basales, 2 fragmentos mesoapicales y 1 fragmento no diferenciado- (Tabla 10.10), 1 biface reciclado (Tabla 10.11) y 4 bifaces transformados, específicamente en puntas de proyectil (Tabla 10.12).

Por otra parte, cuenta tanto con piezas en proceso de manufactura -N: 4- como con artefactos en si mismos -N: 2- (Tablas 10.10 y 10.11).

Dimensionalmente pueden establecerse ciertas correspondencias entre los bifaces como tales y reciclados y los bifaces transformados. Así, por ejemplo, los primeros tienden a ubicarse a la derecha en la Figura 10.16. Asimismo, destaca la similitud en cuanto a los espesores, visible en la Figura 10.17. Es relevante notar, a partir de esta última figura, que los bifaces en sí mismos ( $\mathrm{N}^{\mathrm{o}} 1374$ y 1344), dentro de los bifaces como tales, si bien tienen espesor similar que los bifaces transformados, son más anchos que estos últimos.

Destaca, finalmente, la anchura de la pieza $\mathrm{N}^{\circ}$ 1342, que la discrimina claramente del resto. Posiblemente esté señalando un biface de mayores dimensiones. 
Tabla 10.10. Bifaces como tales. PP4

\begin{tabular}{|c|c|c|c|c|c|c|c|c|c|c|c|}
\hline $\begin{array}{c}\mathbf{N}^{\circ} \\
\text { PIEZA }\end{array}$ & $\begin{array}{l}\text { SUBGRUPO } \\
\text { TIPOLÓGICO }\end{array}$ & $\begin{array}{c}\text { MAT } \\
\text { PRIMA }\end{array}$ & $\mathbf{L}$ & $\mathbf{A}$ & $\mathbf{E}$ & $\mathbf{A} / \mathbf{E}$ & $\begin{array}{l}\text { ANG } \\
\text { FILO }\end{array}$ & $\begin{array}{l}\text { AMPLITUD } \\
\text { SINUSOIDE }\end{array}$ & $\begin{array}{l}\text { SECCION } \\
\text { TRANSV }\end{array}$ & $\begin{array}{l}\text { FORMA GEOM } \\
\text { CONTORNO }\end{array}$ & CAUSA ABANDONO \\
\hline 1342 & $\begin{array}{l}\text { Fragmento no } \\
\text { diferenciado de } \\
\text { biface parcial } / 2\end{array}$ & Vc1 & $(22,60)$ & $(58,90)$ & $(14,60)$ & $(4,06)$ & $64^{\circ}$ & Moderado & No diferenciada & No diferenciada & Charnela \\
\hline 1352 & $\begin{array}{l}\text { Fragmento meso- } \\
\text { apical de biface } \\
\text { parcial /2 }\end{array}$ & Vc1 & $(45,60)$ & $(39,60)$ & $(9,70)$ & $(4,08)$ & $51^{\circ}$ & Estrecho & $\begin{array}{l}\text { Biconvexa } \\
\text { asimétrica irregular }\end{array}$ & No diferenciada & Charnela \\
\hline 1351 & $\begin{array}{l}\text { Fragmento meso- } \\
\text { basal de biface en } \\
\text { sentido estricto / } 2\end{array}$ & Vc2 & $(41,50)$ & $(32,70)$ & $(8,70)$ & $(3,76)$ & $47^{\circ}$ & Estrecho & No diferenciada & Lanceolada & Fractura perversa + fracturas \\
\hline 1374 & $\begin{array}{l}\text { Fragmento meso- } \\
\text { basal de biface en } \\
\text { sentido estricto /1 }\end{array}$ & Vc2 & $(45,20)$ & $(35,30)$ & $(9,60)$ & $(3,68)$ & $42,67^{\circ}$ & Estrecho & $\begin{array}{l}\text { Biconvexa } \\
\text { asimétrica irregular }\end{array}$ & Oval & Fractura perversa \\
\hline 1344 & $\begin{array}{l}\text { Fragmento meso- } \\
\text { apical de biface en } \\
\text { sentido estricto /1 }\end{array}$ & Vc3 & $(44,50)$ & $(36,20)$ & $(11,90)$ & $(3,04)$ & $48,5^{\circ}$ & Estrecho & $\begin{array}{l}\text { Biconvexa } \\
\text { asimétrica irregular }\end{array}$ & Lanceolada & $\begin{array}{l}\text { Charnela + defecto de materia } \\
\text { prima }\end{array}$ \\
\hline
\end{tabular}

Referencias: 1) Artefacto en si mismo; 2) Pieza en proceso de manufactura; 3) Biface no diferenciado / E Medidas de L, A y E en mm / (...): medida afectada por fractura / Ang filo: promedio de los íngulos de los distintos filos que componen la pieza / Amplitud del sinusoide (offset): en base a Callahan (1979) / Causa de abandono: categorías en base a Nami (1993-94)

Tabla 10.11. Bifaces reciclados. PP4

\begin{tabular}{|c|c|c|c|c|c|c|c|c|c|c|c|}
\hline $\mathbf{N}^{0}$ PIEZA & SUBGRUPO TIPOLÓGICO & $\begin{array}{l}\text { MAT } \\
\text { PRIM }\end{array}$ & $\mathbf{L}$ & A & $\mathbf{E}$ & $\mathbf{A} / \mathbf{E}$ & $\begin{array}{l}\text { ANG } \\
\text { FILO } \\
\text { Bf }\end{array}$ & $\begin{array}{l}\text { AMPLITUD } \\
\text { SINUSOIDE }\end{array}$ & $\begin{array}{l}\text { SECCION } \\
\text { TRANSV }\end{array}$ & $\begin{array}{c}\text { FORMA } \\
\text { GEOM } \\
\text { CONTORNO }\end{array}$ & $\begin{array}{c}\text { CAUSA } \\
\text { ABANDONO } \\
\text { Bf }\end{array}$ \\
\hline 1341 & $\begin{array}{l}\text { Raspador de filo restringido frontal sobre } \\
\text { biface parcial reciclado } / 2\end{array}$ & Ob1 & $(26,70)$ & $(22,50)$ & 6,00 & $(3,75)$ & $53,5^{\circ}$ & Estrecho & $\begin{array}{l}\text { Biconvexa } \\
\text { simétrica } \\
\text { regular }\end{array}$ & No diferenciado & Charnela \\
\hline
\end{tabular}

ias: 1) Artefacto en si mismo; 2) Pieza en proceso de manufactura; 3) Biface no diferenciado / Medidas de L, A y E en mm / (...): medida afectada por fractura / Ang filo Bf: promedio de los ángulos os remanentes del biface / Amplitud del sinusoide (offset): en base a Callahan (1979) / Causa de abandono del biface: categorías en base a Nami (1993-94) 
Tabla 10.12. Bifaces transformados. PP4

\begin{tabular}{|c|c|c|c|c|c|c|c|c|c|}
\hline $\mathbf{N}^{\circ}$ PIEZA & SUBGRUPO TIPOLÓGICO & $\begin{array}{l}\text { MAT } \\
\text { PRIM }\end{array}$ & $\mathbf{L}$ & $\mathbf{A}$ & $\mathbf{E}$ & $\mathbf{A} / \mathbf{E}$ & $\begin{array}{l}\text { ANG } \\
\text { FILO }\end{array}$ & $\begin{array}{l}\text { SECCION } \\
\text { TRANSV }\end{array}$ & $\begin{array}{l}\text { FORMA GEOM } \\
\text { CONTORNO }\end{array}$ \\
\hline 1343 & $\begin{array}{l}\text { Punta de proyectil con pedúnculo destacado y aletas, con limbo } \\
\text { triangular }\end{array}$ & Vc7 & 53,80 & 35,10 & 11,50 & 3,05 & $45^{\circ} / 43^{\circ}$ & $\begin{array}{l}\text { Biconvexa } \\
\text { asimétrica regular }\end{array}$ & Pentagonal \\
\hline 1372 & Punta de proyectil con pedúnculo esbozado y limbo lanceolado & ObC & $(37,80)$ & 24,30 & 9,50 & 2,56 & $54^{\circ} / 62^{\circ}$ & $\begin{array}{l}\text { Biconvexa } \\
\text { asimétrica regular }\end{array}$ & Pentagonal \\
\hline 1339 & $\begin{array}{l}\text { Raedera de filo largo lateral sobre punta de proyectil apedunculada } \\
\text { reciclada }\end{array}$ & Vc1 & $(49,40)$ & 25,40 & 11,40 & 2,23 & $81^{\circ} /-/ 57^{\circ}$ & $\begin{array}{l}\text { Biconvexa } \\
\text { asimétrica irregular }\end{array}$ & Lanceolada \\
\hline 979/9 & $\begin{array}{l}\text { Cincel sobre punta de proyectil con pedúnculo destacado y hombro, } \\
\text { limbo no diferenciado }\end{array}$ & Vc2 & $(30,00)$ & 22,20 & 5,90 & 3,76 & $56^{\circ} / 53^{\circ}$ & $\begin{array}{l}\text { Biconvexa } \\
\text { asimétrica irregular }\end{array}$ & Lanceolada \\
\hline
\end{tabular}

Referencias: Medidas de L, A y E en mm / (...): medida afectada por fractura / bf: biface. Implica un filo del biface original que no fue transformado / Ang filo: en el caso de artefactos

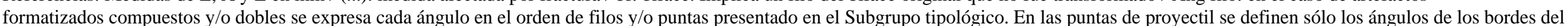
limbo (izquierdo y derecho respectivamente) 


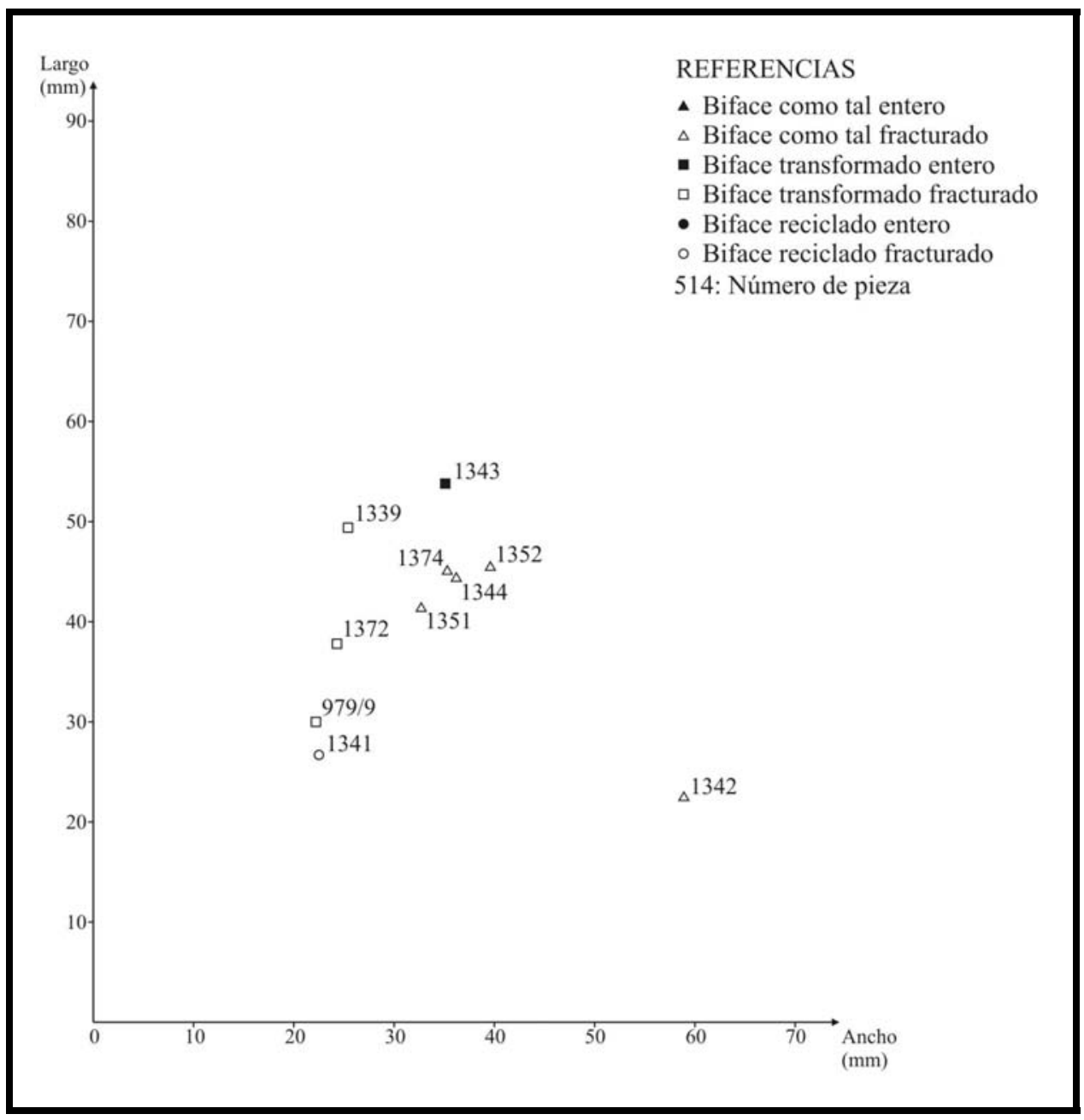

Figura 10.16. Distribución de tamaños (L-A) en bifaces como tales, transformados y reciclados de PP4 


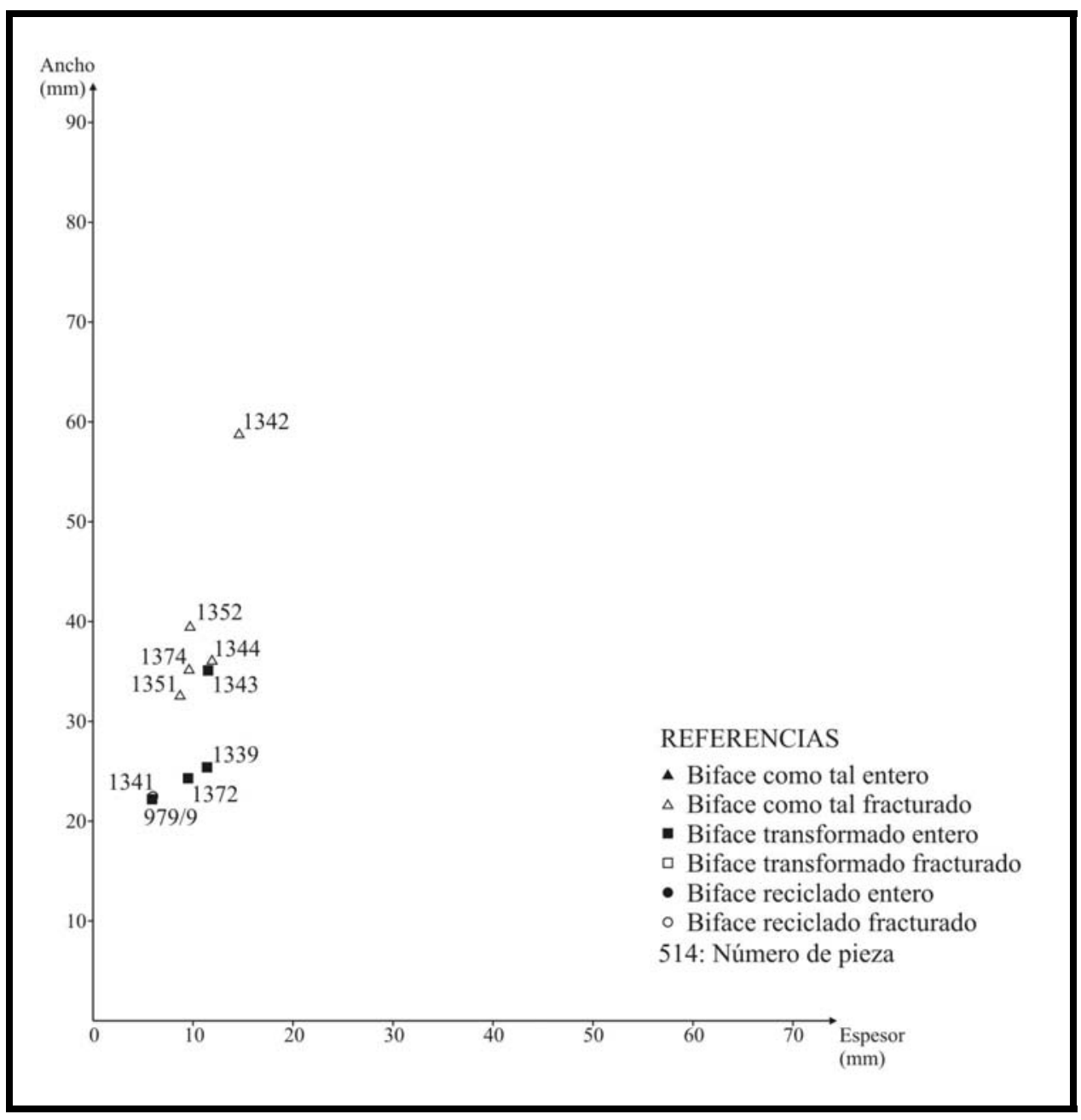

Figura 10.17. Distribución de tamaños (A-E) en bifaces como tales, transformados y reciclados de PP4

\subsection{BIFACES COMO NÚCLEOS}

De la lectura del punto anterior (10.2. Variabilidad morfológica en bifaces e instrumentos sobre bifaces) se desprende que no se ha clasificado a un sólo biface de los sitios considerados como núcleo bifacial, uno de los papeles de este tipo de artefactos (Kelly 1988, Hayden et al. 1996, Wyckoff 1996, Bamforth 2003).

Sin embargo, un conjunto de piezas presentan una serie de atributos esperables en núcleos bifaciales (ver, por ejemplo, Bamforth 2003, Aschero y Hocsman 2004): marcada amplitud del sinusoide, ausencia de plano de simetría longitudinal, irregularidad de las caras, presencia de corteza y/o de remanentes de las caras (caras de lascado) de la forma-base original. Se trata de piezas voluminosas, en las que no hay búsqueda de rebaje del espesor ni de secciones específicas. 
De hecho, una pieza ( $N^{\circ} 316$ ) fue definida previamente como núcleo bifacial (Aschero et al. 1993-94). El que suscribe, inclusive, en un principio clasificó como tal a este artefacto, sumando dos piezas más en este sitio ( $\mathrm{N}^{\circ} 302$ y 290). Misma situación se presenta en PCh1.3 y en PCh1.1, con las piezas $\mathrm{N}^{\circ} 107$ y 26 y No 30, 13 y 9, respectivamente. Cabe mencionar que no se han registrado piezas de este tipo en PP4, en la porción del sitio considerada.

Se destaca, empero, que dichas características morfológicas generales son recurrentes también en presencia de aprendices, como se vio previamente (ver punto 10.1.2.Producción lítica y aprendices), por lo que hay un problema de equifinalidad. Al respecto, hay una serie de evidencias contextuales que indican que no se trataría de núcleos bifaciales. Para abordar este punto se toma como caso de estudio información del sitio QS3, la cual es perfectamente extrapolable a los sitios PCh1.3 y PCh1.1.

Así, en primer lugar, los núcleos bifaciales han sido recurrentemente asociados a áreas con escasez de materia prima y con rocas de mala calidad, así como con elevada movilidad residencial (Parry y Kelly 1987, Kuhn 1994).

En el caso de Antofagasta de la Sierra, las materias primas líticas son abundantes, variadas y de buena calidad (ver Capítulo 7). De hecho, los bifaces están confeccionados principalmente con rocas que se encuentran en fuentes inmediatas, es decir, a no más de un kilómetro y medio de distancia de QS3 (QSZAC, Pampa Este o Pampa Norte), con una representación del 66, 67\% (Vc1 -N: 19- y Vc5 -N: 3-). Les siguen en orden de importancia dos rocas disponibles en fuentes mediatas, localizadas a distancias menores a 20 kilómetros del sitio considerado (Peñas de la Cruz ZAC y Sector Norte de Los Negros), con el 27,27\% (Vc2 -N: 7- y Vc4 -N: 2). El 6,06\% restante fue elaborado sobre $\mathrm{ObC}$, con fuente hasta el momento no determinada.

Por otra parte, QS3 es considerado una base residencial que habría funcionado en el momento abordado en un contexto de movilidad residencial reducida (ver Capítulo 6).

En segundo lugar, al ser el núcleo bifacial uno de los núcleos más comunes en el "equipo personal” (personal gear) de individuos móviles (Kuhn 1994; Rasic y Andrefsky 2001), se debería demostrar que los núcleos bifaciales en consideración satisfacen las demandas del equipo personal, a saber: a) transporte en anticipación a usos futuros, b) extensión de la vida útil del artefacto (mantenimiento y reciclado) y c) producción mediante una manufactura en estadios implicando diferentes tiempos y lugares (Binford 1979). En este caso puntual, no se cumplen los aspectos a y b, puesto que, al ser las rocas ubicuas, no habría ventajas de contar con artefactos en antelación a su uso eventual; no presentan evidencias de mantenimiento de la plataforma de percusión y no han sido 
reciclados. Con respecto al c, no hay evidencias que sugieran que la manufactura de estas piezas se realizó involucrando diferentes sitios y una diacronía.

En tercer lugar, siguiendo a Bamforth (2003), la presencia de núcleos bifaciales tendría como contrapartida que los núcleos no bifaciales, así como las lascas extraídas de los mismos, sean raros o estén ausentes. Al respecto, los niveles $2 \mathrm{~b} 1$ a $2 \mathrm{~b} 5$ de QS3 se caracterizan por un bajísimo número de núcleos no bifaciales, todos de pequeño tamaño, a saber: dos poliédricos irregulares, un prismático irregular, un bipolar y dos fragmentos no diferenciados. Pero esto no respondería a la ocurrencia sistemática de núcleos bifaciales, sino a las características de los sistemas de producción lítica imperantes, de tipo secuencial, que implicaban que las formas-base eran obtenidas en otros sitios, como las canteras-talleres cercanas, e ingresadas a QS3 para su formatización (Aschero et al. 1991, Aschero et al.1993-1994, Pintar 1996a, Manzi 1999).

Una posibilidad alternativa es contar con núcleos bifaciales confeccionados sobre algún tipo de materia prima en particular, coexistiendo con otros tipos de núcleos realizados sobre otras clases de rocas. Sin embargo, en este caso, las materias primas son las mismas para bifaces, núcleos no bifaciales y resto del instrumental, por lo que no podría sostenerse un uso particular en referencia a una materia prima en especial.

En cuarto lugar, y en vinculación con el punto anterior, sería esperable contar con una destacada proporción de lascas de adelgazamiento bifacial como formas-base de artefactos formatizados, ya que, identificar a un objeto como un núcleo depende, en última instancia, de demostrar que las lascas fueron usadas como instrumentos, sobre la base de una selección sistemática (Bamforth 2003).

$\mathrm{Al}$ analizar la proporción de lascas de adelgazamiento bifacial empleadas como formas-base en la confección de instrumentos con trabajo no invasivo, de filos naturales con rastros complementarios y de artefactos con sustancia adherida ${ }^{1}$-en este caso se ha incluido este tipo de registro en función de la posibilidad de una selección de este tipo de lascas específicamente para usar sus filos naturales-, se observa que no hay una búsqueda específica de este tipo de formas-base. Sólo el 20,59\% -N: 14- corresponde a lascas de adelgazamiento bifacial. El 79,41\% restante -N: 54- puede atribuirse a lascas generadas por percusión ordinaria. Este no es el patrón que se esperaría en una situación de utilización de núcleos bifaciales (ver Bamforth 2003).

\footnotetext{
${ }^{1}$ Se aclara que en estos conteos se han incluido sólo aquellas piezas cuya forma forma-base es una lasca, no considerándose puntas de proyectil, bifaces, artefactos bipolares, núcleos o nódulos. En relación con las puntas de proyectil y los bifaces, es improbable que se hayan usado lascas de adelgazamiento bifacial en su manufactura, dados los espesores registrados.
} 
Un punto crucial en relación con esto es que, en realidad, las lascas de adelgazamiento bifacial no fueron producidas a partir de los núcleos bifaciales analizados, ya que estos últimos no presentan, de hecho, adelgazamiento bifacial (para una discusión sobre esto ver el Capítulo 4). Por sus características morfológicas implican la producción de lascas diferentes a las típicas del adelgazamiento bifacial (Whittaker 1994, Andrefsky 1998), por ejemplo, una expansión desde el borde menos frecuente, una menor curvatura y talones más espesos. Dentro de las formas-base lasca confeccionadas por percusión ordinaria, hay un 8,82\% -N: 6- de piezas que cuentan con estos atributos, por lo que podría tratarse de lascas de reducción bifacial. De todas formas, es un porcentaje tan bajo que puede incluso dudarse de su carácter. En suma, podría postularse la selección casual de una minoría de lascas de adelgazamiento bifacial producidas durante la confección de artefactos formatizados bifaciales, más que la utilización sistemática de núcleos bifaciales.

En quinto y último lugar, los tamaños de las lascas empleadas como formas-base deberían coincidir con los tamaños de los negativos de lascado en los bifaces. En este caso, si bien hay cierta yuxtaposición, la tendencia general señala diferencias notorias. Así, las formas-base lascas (enteras -N: 24-) presentan, siguiendo a Aschero (1983), un predominio de lascas grandes -41,67\%-, medianograndes -29,17\%- y muy grandes -12,5\%- sobre las mediano-pequeñas -8,33\%- y pequeñas -8,33\%-, mientras que las extracciones de las 3 piezas bifaciales en cuestión (negativos completos -N: 4-) son de tamaño mediano-pequeño -75\%- y pequeño -25\%-. Obviamente, extracciones previas tendrían un mayor tamaño; aún teniendo en cuenta esto, no hay una búsqueda sistemática de lascas de adelgazamiento bifacial como formas-base.

$\mathrm{Al}$ considerar exclusivamente las lascas de adelgazamiento bifacial enteras empleadas como matrices (N: 7), se registra la misma situación con tamaños mediano-grandes -57,14\%-, grandes 28,57\%- y muy grandes -14,29\%-. Esta es esperable puesto que las lascas generadas en estadios medios y finales de la secuencia de producción de bifaces son pequeñas y delgadas y tienen filos extremadamente agudos y frágiles; son las lascas de los estadios iniciales las potencialmente más útiles (Bamforth 2003). Esto significa que un biface sólo puede servir como núcleo una porción limitada de su vida de uso (Rasic y Andrefsky 2001).

\subsection{BIFACES COMO PRODUCTO DE LA PRÁCTICA DE APRENDICES}

Además de las evidencias contextuales que rechazan la idea de utilización de núcleos bifaciales en la microrregión, una combinación de atributos morfológicos de diversa índole en parte de 
los bifaces sustentan la hipótesis de presencia de aprendices, ya que denotan ausencia de pericia en la talla.

Los bifaces en cuestión (QS3: N 316, 302 y 290; PCh1.3: 107 y 26; № 30, 13 y 9) presentan una sección transversal plano-convexa ( $\left.\mathrm{N}^{\circ} 290\right)$ o biconvexa ( $\mathrm{N}^{\circ} 302,316,107,26,30,13$ у 9) marcadamente asimétrica e irregular, una arista sinuosa irregular con sinuosidad moderada ( $\mathrm{N}^{\circ} 290,13$ y 30) o amplia ( $N^{\circ}$ 302, 316, 26, 107 y 9), ángulos de filo elevados, con espesores importantes en relación al ancho, marcada irregularidad en vista de planta y negativos de lascado espaciados irregularmente que no formatizan cuidadosamente las caras. (Figuras 10.5 -Abajo izquierda y derecha, 10.18, 10.19 y 10.20). Tales características son típicas de bifaces confeccionados por talladores novatos, como se vio previamente.

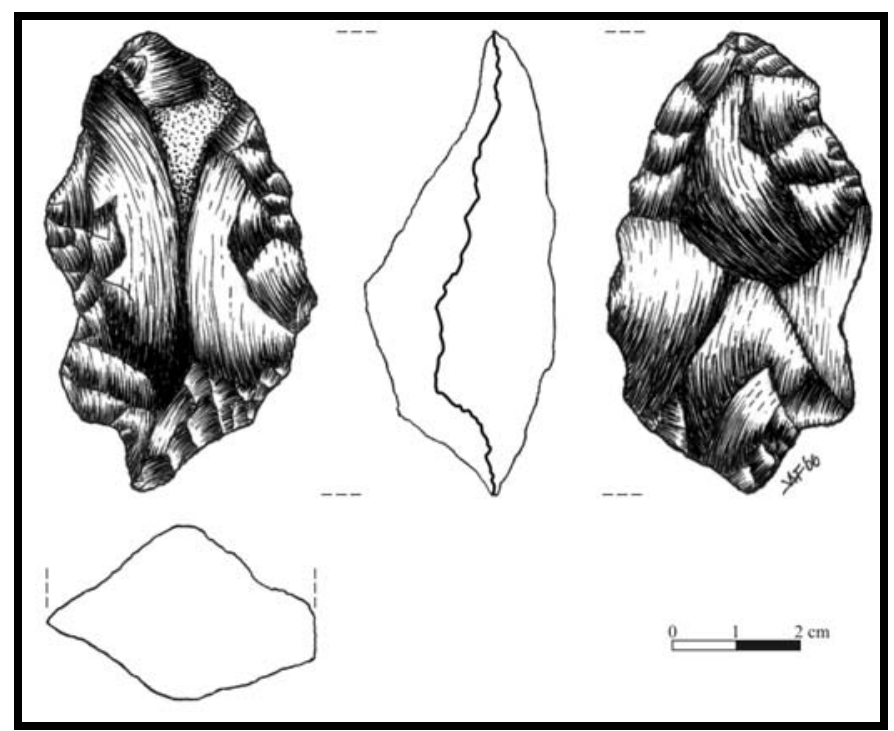

Figura 10.18. Biface producto de aprendiz (PCh1.3. $\mathrm{N}^{\circ}$ inv 107)

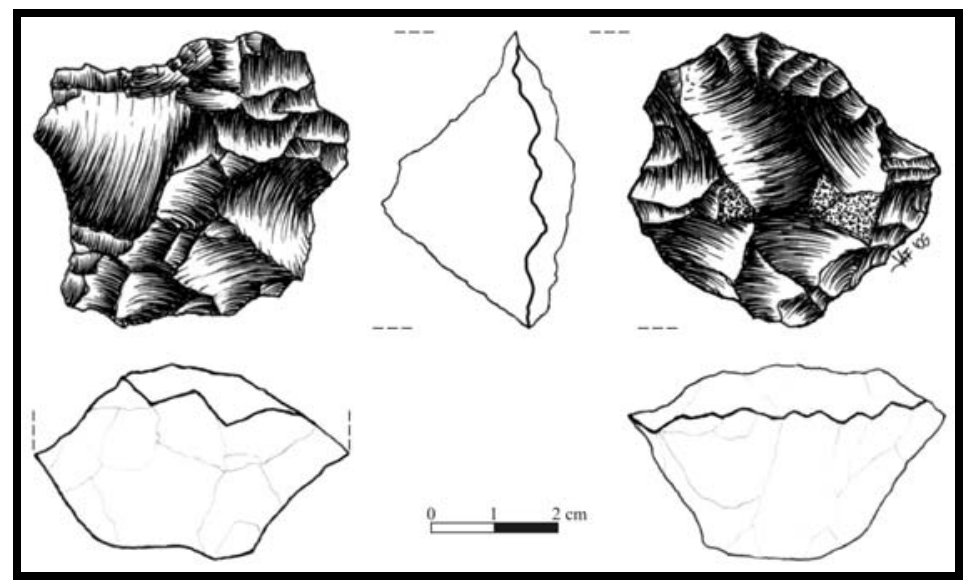

Figura 10.19. Biface producto de aprendiz (PCh1.3. $\mathrm{N}^{\mathrm{o}}$ inv 26) 


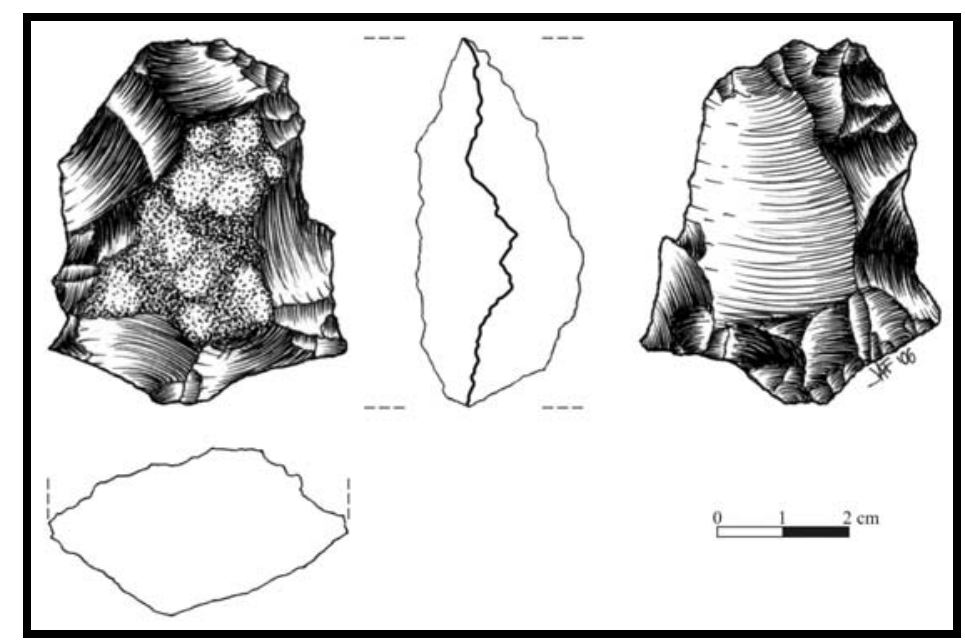

Figura 10.20. Biface producto de aprendiz (PCh1.1 No inv 13)

Junto con esta serie de elementos hay otros que refuerzan la atribución de estos artefactos a talladores inexpertos, a saber: características del borde (presencia de machacado, fracturas y sobreengrosamientos), morfología de las extracciones en las caras del biface (terminaciones en charnela y quebradas abundantes y presencia de negativos de lascado "estallados" -producidos por golpes con fuerza excesiva, en la zona del bulbo de percusión-), no contar con un plano de simetría longitudinal y evidenciar cambios de ángulo (Whittaker 1994, Finlay 199, Grimm 2000, Stout 2002). Así, las piezas No 319 y 9 cuentan con el 100\% de estos elementos -N: 9-, las No 30, 107 y 26 con el 88,89\% -N: 8-, las No 302 y 13 con el 77,78\% -N: 2- y la No 390 con el 55,56\% (Tablas 10.13, 10.14 y 10.15).

El resto de los bifaces -piezas como tales y reciclados-, como es esperable, muestra una muy baja incidencia de estas variables. Así, en QS3 -N: 13-, un 38,46\% no presenta ninguno de estos atributos, un 15,38\% le corresponde a las 2 piezas con un solo atributo, así como al par que tienen dos, mientras que un 7,69\% a cada uno de los bifaces con 3 y 4 elementos (Tabla 10.13). PCh1.3 -N: 12-, por su parte, presenta un 25\% con ningún atributo, un 16,67\% con uno, un $8,33 \%$ con dos, un $41,67 \%$ con 3 y un 8,33\% con 5 atributos (Tabla 10.14). En el caso de PCh1.1 -N: 15-, finalmente, el 33,33\% no cuenta con ningún atributo de los considerados, las piezas con uno y con dos atributos se presentan ambas con un $20 \%$, un $6,67 \%$ le corresponde a la pieza con cuatro atributos y un $13,33 \%$ a aquellas con 5 atributos; el 6,67\% restante corresponde a un caso no diferenciado (Tablas 10.15 y 10.15 continuación-).

Si se incluye, además, información de PP4, se confirma la ausencia de los bifaces adscriptos a aprendices, ya que de 6 piezas (Tabla 10.16), el 33,33\% no presenta ninguno de los atributos señalados 
Tabla 10.13. Bifaces como tales y reciclados de QS3. Atributos vinculados con destreza técnica

\begin{tabular}{|c|c|c|c|c|c|c|c|c|c|}
\hline $\mathrm{N}^{0}$ PIEZA & $\begin{array}{c}\text { BORDE } \\
\text { MACHAC }\end{array}$ & $\begin{array}{l}\text { BORDE } \\
\text { FRACT }\end{array}$ & $\begin{array}{l}\text { BORDE } \\
\text { ENGROS }\end{array}$ & $\begin{array}{l}\text { PROBLEM } \\
\text { BORDE }\end{array}$ & $\begin{array}{c}\text { TERMIN } \\
\text { QUEBRADA }\end{array}$ & $\begin{array}{c}\text { TERMIN } \\
\text { CHARNELA }\end{array}$ & $\begin{array}{l}\text { NEG BULBO } \\
\text { ESTALLADO }\end{array}$ & $\begin{array}{l}\text { PLANO } \\
\text { SIM } \\
\text { LONG }\end{array}$ & $\begin{array}{l}\text { CAMBIOS } \\
\text { ANGULO }\end{array}$ \\
\hline 290 & $\mathrm{Si}$ & No & No & No & $\mathrm{Si}$ & $\mathrm{Si}$ & No & No & $\mathrm{Si}$ \\
\hline 28 & No & No & No & No & No & No & No & $\mathrm{Si}$ & No \\
\hline 20 & $\mathrm{Si}$ & No & No & No & $\mathrm{Si}$ & No & No & $\mathrm{Si}$ & $\mathrm{Si}$ \\
\hline 49 & $\mathrm{Si}$ & No & $\mathrm{Si}$ & No & $\mathrm{Si}$ & Si & No & $\mathrm{Si}$ & No \\
\hline 551 & No & $\mathrm{Si}$ & No & $\mathrm{Si}$ & No & No & No & $\mathrm{Si}$ & Si \\
\hline 302 & $\mathrm{Si}$ & $\mathrm{Si}$ & No & No & $\mathrm{Si}$ & $\mathrm{Si}$ & $\mathrm{Si}$ & No & $\mathrm{Si}$ \\
\hline 518 & No & No & No & No & $\mathrm{Si}$ & $\mathrm{Si}$ & No & $\mathrm{Si}$ & No \\
\hline 40 & No & No & No & No & No & No & No & $\mathrm{Si}$ & No \\
\hline 36 & No & No & No & No & No & No & No & $\mathrm{Si}$ & No \\
\hline 509 & No & No & No & No & No & No & No & $\mathrm{Si}$ & No \\
\hline 316 & $\mathrm{Si}$ & Si & $\mathrm{Si}$ & $\mathrm{Si}$ & Si & $\mathrm{Si}$ & $\mathrm{Si}$ & No & $\mathrm{Si}$ \\
\hline 632 & $\mathrm{Si}$ & No & No & No & No & No & No & $\mathrm{Si}$ & No \\
\hline 592 & No & No & No & No & No & No & No & $\mathrm{Si}$ & No \\
\hline 585 & - & - & - & - & - & - & - & - & - \\
\hline 545 & - & - & - & - & - & - & - & - & - \\
\hline 514 & No & No & No & No & $\mathrm{Si}$ & No & No & $\mathrm{Si}$ & No \\
\hline
\end{tabular}

Nota: en el caso de los bifaces reciclados, aquellas variables que refieren a porciones de filo han sido analizadas exclusivamente en aquellos sectores de los filos remanentes del biface original 
Tabla 10.14. Bifaces como tales y reciclados de PCh1.3. Atributos vinculados con destreza técnica

\begin{tabular}{|c|c|c|c|c|c|c|c|c|c|}
\hline $\mathrm{N}^{\circ}$ PIEZA & $\begin{array}{l}\text { BORDE } \\
\text { MACHAC }\end{array}$ & $\begin{array}{l}\text { BORDE } \\
\text { FRACT }\end{array}$ & $\begin{array}{l}\text { BORDE } \\
\text { ENGROS }\end{array}$ & $\begin{array}{c}\text { PROBLEM } \\
\text { BORDE }\end{array}$ & $\begin{array}{c}\text { TERMIN } \\
\text { QUEBRADA }\end{array}$ & $\begin{array}{c}\text { TERMIN } \\
\text { CHARNELA }\end{array}$ & $\begin{array}{l}\text { NEG BULBO } \\
\text { ESTALLADO }\end{array}$ & $\begin{array}{l}\text { PLANO } \\
\text { SIM } \\
\text { LONG }\end{array}$ & $\begin{array}{l}\text { CAMBIOS } \\
\text { ANGULO }\end{array}$ \\
\hline 90 & No & No & No & No & No & No & No & No & No \\
\hline 87 & No & No & No & No & $\mathrm{Si}$ & $\mathrm{Si}$ & No & $\mathrm{Si}$ & No \\
\hline $135 / 1$ & No & No & No & No & No & $\mathrm{Si}$ & No & No & $\mathrm{Si}$ \\
\hline 67 & No & No & No & $\mathrm{Si}$ & No & $\mathrm{Si}$ & No & No & No \\
\hline 107 & No & $\mathrm{Si}$ & $\mathrm{Si}$ & $\mathrm{Si}$ & $\mathrm{Si}$ & $\mathrm{Si}$ & $\mathrm{Si}$ & No & $\mathrm{Si}$ \\
\hline 116 & No & No & No & No & No & No & No & $\mathrm{Si}$ & No \\
\hline 115 & No & No & No & No & No & No & No & $\mathrm{Si}$ & No \\
\hline 26 & $\mathrm{Si}$ & $\mathrm{Si}$ & $\mathrm{Si}$ & No & $\mathrm{Si}$ & $\mathrm{Si}$ & $\mathrm{Si}$ & No & $\mathrm{Si}$ \\
\hline 35 & No & No & No & No & No & $\mathrm{Si}$ & No & No & $\mathrm{Si}$ \\
\hline 60 & $\mathrm{Si}$ & No & No & No & No & No & No & No & Si \\
\hline 132 & No & No & $\mathrm{Si}$ & No & $\mathrm{Si}$ & $\mathrm{Si}$ & No & No & $\mathrm{Si}$ \\
\hline 105 & No & $\mathrm{Si}$ & Si & No & No & No & No & $\mathrm{Si}$ & $\mathrm{Si}$ \\
\hline 96 & No & No & No & No & No & No & No & No & No \\
\hline 30 & No & No & No & No & No & No & No & $\mathrm{Si}$ & No \\
\hline
\end{tabular}

Nota: en el caso de los bifaces reciclados, aquellas variables que refieren a porciones de filo han sido analizadas exclusivamente en aquellos sectores de los filos remanentes del biface original 
Tabla 10.15. Bifaces como tales y reciclados de PCh1.1. Atributos vinculados con destreza técnica

\begin{tabular}{|c|c|c|c|c|c|c|c|c|c|}
\hline $\mathrm{N}^{0}$ PIEZA & $\begin{array}{c}\text { BORDE } \\
\text { MACHAC }\end{array}$ & $\begin{array}{l}\text { BORDE } \\
\text { FRACT }\end{array}$ & $\begin{array}{l}\text { BORDE } \\
\text { ENGROS }\end{array}$ & $\begin{array}{l}\text { PROBLEM } \\
\text { BORDE }\end{array}$ & $\begin{array}{c}\text { TERMIN } \\
\text { QUEBRADA }\end{array}$ & $\begin{array}{c}\text { TERMIN } \\
\text { CHARNELA }\end{array}$ & $\begin{array}{l}\text { NEG BULBO } \\
\text { ESTALLADO }\end{array}$ & $\begin{array}{l}\text { PLANO } \\
\text { SIM } \\
\text { LONG }\end{array}$ & $\begin{array}{l}\text { CAMBIOS } \\
\text { ANGULO }\end{array}$ \\
\hline 19 & No & No & $\mathrm{Si}$ & $\mathrm{Si}$ & No & $\mathrm{Si}$ & No & No & $\mathrm{Si}$ \\
\hline 51 & No & No & No & $\mathrm{Si}$ & No & No & No & $\mathrm{Si}$ & No \\
\hline 30 & No & $\mathrm{Si}$ & $\mathrm{Si}$ & $\mathrm{Si}$ & $\mathrm{Si}$ & $\mathrm{Si}$ & $\mathrm{Si}$ & No & $\mathrm{Si}$ \\
\hline 13 & No & Si & No & Si & Si & Si & $\mathrm{Si}$ & No & $\mathrm{Si}$ \\
\hline 68 & No & No & No & No & $\mathrm{Si}$ & No & No & $\mathrm{Si}$ & No \\
\hline 79 & - & - & - & - & - & - & - & - & - \\
\hline 34 & No & No & $\mathrm{Si}$ & $\mathrm{Si}$ & No & No & No & $\mathrm{Si}$ & No \\
\hline 9 & $\mathrm{Si}$ & $\mathrm{Si}$ & $\mathrm{Si}$ & $\mathrm{Si}$ & $\mathrm{Si}$ & $\mathrm{Si}$ & $\mathrm{Si}$ & No & $\mathrm{Si}$ \\
\hline $39 / 3$ & No & No & No & No & No & No & No & $\mathrm{Si}$ & No \\
\hline 19 & No & No & No & No & No & No & No & $\mathrm{Si}$ & No \\
\hline
\end{tabular}

Nota: en el caso de los bifaces reciclados, aquellas variables que refieren a porciones de filo han sido analizadas exclusivamente en aquellos sectores de los filos remanentes del biface original 
Tabla 10.15 (continuación). Bifaces como tales y reciclados de PCh1.1. Atributos vinculados con destreza técnica

\begin{tabular}{|c|c|c|c|c|c|c|c|c|c|}
\hline $\mathbf{N}^{\circ}$ PIEZA & $\begin{array}{l}\text { BORDE } \\
\text { MACHAC }\end{array}$ & $\begin{array}{l}\text { BORDE } \\
\text { FRACT }\end{array}$ & $\begin{array}{l}\text { BORDE } \\
\text { ENGROS }\end{array}$ & $\begin{array}{l}\text { PROBLEM } \\
\text { BORDE }\end{array}$ & $\begin{array}{c}\text { TERMIN } \\
\text { QUEBRADA }\end{array}$ & $\begin{array}{c}\text { TERMIN } \\
\text { CHARNELA }\end{array}$ & $\begin{array}{l}\text { NEG BULBO } \\
\text { ESTALLADO }\end{array}$ & $\begin{array}{l}\text { PLANO } \\
\text { SIM } \\
\text { LONG }\end{array}$ & $\begin{array}{l}\text { CAMBIOS } \\
\text { ANGULO }\end{array}$ \\
\hline 12 & No & No & No & No & No & No & No & $\mathrm{Si}$ & No \\
\hline 3 & No & No & No & No & No & No & No & $\mathrm{Si}$ & No \\
\hline 4 & No & No & No & No & Si & $\mathrm{Si}$ & No & No & $\mathrm{Si}$ \\
\hline $59 / 2$ & $\overline{\mathrm{Si}}$ & No & $\overline{\mathrm{Si}}$ & No & $\overline{\mathrm{Si}}$ & $\mathrm{Si}$ & No & No & No \\
\hline 42 & No & No & No & No & No & No & No & $\mathrm{Si}$ & No \\
\hline 14 & No & No & No & No & No & $\mathrm{Si}$ & No & No & No \\
\hline 29 & No & No & No & No & Si & $\mathrm{Si}$ & No & $\mathrm{Si}$ & No \\
\hline $39 / 1$ & No & No & No & No & No & $\mathrm{Si}$ & No & $\mathrm{Si}$ & No \\
\hline
\end{tabular}

Nota: en el caso de los bifaces reciclados, aquellas variables que refieren a porciones de filo han sido analizadas exclusivamente en aquellos sectores de los filos remanentes del biface original 
Tabla 10.16. Bifaces como tales y reciclados de PP4. Atributos vinculados con destreza técnica

\begin{tabular}{|c|c|c|c|c|c|c|c|c|c|}
\hline $\mathrm{N}^{\circ}$ PIEZA & $\begin{array}{c}\text { BORDE } \\
\text { MACHAC }\end{array}$ & $\begin{array}{l}\text { BORDE } \\
\text { FRACT }\end{array}$ & $\begin{array}{l}\text { BORDE } \\
\text { ENGROS }\end{array}$ & $\begin{array}{l}\text { PROBLEM } \\
\text { BORDE }\end{array}$ & $\begin{array}{c}\text { TERMIN } \\
\text { QUEBRADA }\end{array}$ & $\begin{array}{c}\text { TERMIN } \\
\text { CHARNELA }\end{array}$ & $\begin{array}{l}\text { NEG BULBO } \\
\text { ESTALLADO }\end{array}$ & $\begin{array}{c}\text { PLANO } \\
\text { SIM } \\
\text { LONG }\end{array}$ & $\begin{array}{l}\text { CAMBIOS } \\
\text { ANGULO }\end{array}$ \\
\hline 1342 & - & - & - & - & - & - & - & - & - \\
\hline 1352 & No & No & No & No & No & No & No & $\mathrm{Si}$ & No \\
\hline 1351 & No & No & No & No & No & No & No & $\mathrm{Si}$ & No \\
\hline 1374 & No & No & No & $\mathrm{Si}$ & No & No & No & $\mathrm{Si}$ & No \\
\hline 1344 & No & $\mathrm{Si}$ & No & No & No & No & No & $\mathrm{Si}$ & $\mathrm{Si}$ \\
\hline 1341 & - & - & - & - & - & - & - & - & - \\
\hline
\end{tabular}

Nota: en el caso de los bifaces reciclados, aquellas variables que refieren a porciones de filo han sido analizadas exclusivamente en aquellos sectores de los filos remanentes del biface original 
y el 16,67\% le corresponde tanto a piezas con uno y dos atributos. En el 33,33\% restante tales atributos son no diferenciados.

Cabe destacar que las terminaciones quebradas en estos bifaces son de naturaleza distinta a los de los bifaces postulados como de aprendices, ya que son muy poco espesas y transversales al eje de lascado de los negativos. Las mismas están vinculadas a la extracción de lascas largas y delgadas, mediante un golpe muy obtuso (Whittaker 1994). Esto implica que la representación de los atributos en discusión se ve aún más disminuida.

Desde un punto de vista tecnológico, se observan dos procedimientos de talla bifacial. Las piezas $\mathrm{N}^{\circ}$ 290, 316, 107 y 9 han sido formatizadas por lascados alternados en las dos caras, mientras que las $\mathrm{N}^{0} 302,26$ y 30 por extracciones por caras sucesivas. Ambos mecanismos implican gestos técnicos diferentes. En el primero, se extraen consecutivamente lascas sobre una y otra cara en relación a un mismo borde; es decir, se trabajan las dos caras simultáneamente. En el segundo, se extraen series de lascas de una de las caras, para luego invertir la pieza y pasar a extraer series de lascas de la otra cara; es decir, se trabaja con una cara del biface a la vez. Se destaca que la pieza $\mathrm{N}^{0} 13$ no muestra patrón discernible, con series de extracciones completamente irregulares.

El gesto técnico del primer procedimiento implica un grado mayor de pericia motora, ya que el biface se debe girar $180^{\circ}$ luego de cada golpe asestado o serie corta de golpes, debiendo ser colocado cada vez en la posición correcta. Su condición de alternante implica que el biface debe girar sobre sí mismo continuamente. En cambio, es mucho más fácil extraer lascas sobre una cara y una vez finalizada la serie, pasar a la otra, para volver posteriormente a la primera y así sucesivamente. De esta forma, es altamente factible contar con esta modalidad de talla bifacial en presencia de aprendices. En el caso de la pieza $\mathrm{N}^{\circ} 26$, la talla adopta una modalidad particular, ya que se trabajan sectores de la pieza sucesivamente y no la cara completa, sin llegar a ser un trabajo alternante.

Una interpretación alternativa para la pieza $\mathrm{N}^{\circ} 302$ es que podría tratarse de un núcleo discoidal. Sin embargo, no se trataría de un núcleo de este tipo, puesto que no cuenta con los atributos típicos: la talla no es perimetral, la forma es irregular (por lo general su morfología es circular, oblonga o discoidal), las extracciones son espacialmente irregulares y de tamaño variable, predominando tamaños de negativos muy pequeños.

Por otra parte, las destrezas menos desarrolladas se ven reflejadas en la ausencia de habilidad de control de las proporciones de las piezas. Como ya fue señalado, los bifaces de aprendices se discriminan fuertemente por el ancho y el espesor. Esto puede observarse en QS3, particularmente, en los bifaces No 316 y 302 en QS3, en tanto que la Nº 290 es sólo por el espesor (Figuras 10.7 y 10.8); 
también en las piezas No 107 y 26 de PCh1.3 (Figuras 10.10 y 10.11) y las № 13, 30 y 9 de PCh1.1 (Figuras 10.13 y 10.14). Es decir, mientras sus largos son relativamente iguales al resto de las piezas, son más anchos y más espesos. Este adelgazamiento insuficiente es un error común entre talladores principiantes (Stout 2002).

Las dificultades con el adelgazamiento están estrechamente relacionadas con la necesidad de generar extracciones suficientemente invasivas como para adelgazar las piezas. Vinculado con esto, además, está el tema de la regularidad en el espaciado de las mismas. Estos problemas se ven reflejados en las piezas consideradas en el hecho de que se observan remanentes de las formas-base primarias, en forma de corteza ( $\mathrm{N}^{\circ} 290,316,107,30$ y 9), superficies de lascado originales -sean cara A o B- ( $\left.\mathrm{N}^{\circ} 26\right)$ o combinaciones de estas últimas con corteza ( $\mathrm{N}^{\circ} 302$ y 13).

\subsection{NIÑOS Y/O ADOLESCENTES COMO APRENDICES EN LOS SITIOS CONSIDERADOS}

Probar la presencia de niños y/o adolescentes en los sitios considerados no es fácil, pero, al mismo tiempo, es ilógico no reconocer que los niños y las mujeres estaban presentes en el registro arqueológico local, y más aún cuando se piensa en los 10000 años de secuencia relativamente continua de Antofagasta de la Sierra. Al respecto, Pintar (2005) aborda en un provocador trabajo las actividades que las mujeres podrían haber realizado en el área de estudio, entre los 8000 y los 6000 años AP, las cuales pueden extrapolarse perfectamente al momento aquí considerado.

Como los niños pasan la mayor parte del tiempo dentro y en las inmediaciones del campamento residencial, es esperable que sea en las bases residenciales donde se recuperen las evidencias de su presencia (Politis 1999). Al respecto, QS3, para el lapso abordado, ha sido definido como una base residencial ocupada muy posiblemente por unidades sociales reducidas -familia nuclear o individuos aislados- (Aschero et al. 1993-94), por lo que está implícito que niños y/o adolescentes habitaban la cueva y que pudieron descartar diversos tipos de objetos. Esta caracterización puede ser extrapolada perfectamente a PCh1.3, PCh1.1 y PP4.

El hallazgo de un fardo funerario en 2b2 en QS3 constituido por un envoltorio de cuero de camélido atado con un cordel de lana conteniendo restos óseos de un feto humano (Aschero et al. 1991), refuerza justamente esta idea de ocupaciones por parte de grupos familiares. 
De acuerdo a Finlay (1997), la experiencia práctica del aprendizaje de la talla de rocas sería más factible que ocurra en aquellos contextos donde hay gran disponibilidad de materia prima, como, por ejemplo, canteras-talleres. Más allá de que Antofagasta de la Sierra se caracteriza por la cantidad y calidad de las rocas para la talla, por lo que se convierte en un ámbito propicio para encontrar evidencias de aprendices, en QSZAC se observaron algunas concentraciones con piezas bifaciales muy gruesas, con aristas y contornos irregulares, que fueron interpretados en su momento como núcleos para la obtención de lascas (Aschero et al. 1993-94). La misma situación ha sido informada para PPZAC (Toselli 1998, Manzi 1999). Se plantea aquí que tales piezas pueden corresponder, en realidad, a talladores novatos realizando prácticas en las fuentes de aprovisionamiento. Teniendo en cuenta esto, entonces, no es casual que las piezas de QS3, PCh1.3 y PCh1.1 interpretadas como producto de aprendices tengan como formas-base rocas de procedencia inmediata.

Otras evidencias que apuntan a talladores novatos son, por un lado, que los bifaces en cuestión no revisten utilidad alguna, dada la arista sinuosa irregular amplia (un caso - $\mathrm{N}^{\circ}$ 316- no presentaría evidencias de uso, en base a un análisis preliminar mediante microscopía -Cattaneo com pers.-) y, por el otro, que dichos artefactos se descartaron en proceso de manufactura estando enteros y sin mediar, por ejemplo, reciclaje. De hecho, la causa de abandono más importante de los bifaces en cuestión es la imposibilidad de seguir adelgazando dado su grosor (Tablas 10.1, 10.4 y 10.7). En el resto de las piezas se debe básicamente a fracturas.

En vista de que recurrentemente se asocia a los niños con carencia de destreza, un punto importante a considerar es que a lo largo de la vida de un individuo puede haber cambios de habilidad, no sólo durante la niñez. Por ejemplo, una persona puede perder así como adquirir destreza a corto o largo plazo por trauma o fatiga. Las destrezas motoras, asimismo, pueden deteriorarse a través de heridas o de enfermedades degenerativas como artritis (Finlay 1997). Un ejemplo de esto es la apraxia, un desorden motor de alto grado debido a una lesión cerebral en la cual movimientos transitivos como los movimientos de uso de instrumentos están deteriorados (Jacobs et al. 2001). Las personas con apraxia pueden ser completamente incapaces de usar instrumentos por varias razones, porque no pueden recordar la función del artefacto, o debido a que no recuerdan cómo es el gesto técnico. Pueden realizar la acción, pero en una forma aproximada, por ejemplo, porque la postura de la mano que sostiene la pieza es incorrecta (ibid.). Esto indudablemente tiene consecuencias sobre la morfología de los materiales recuperados en el registro arqueológico.

Por otra parte, un artesano puede tener conocimiento pleno de una técnica de talla, pero ser incapaz de transformar una forma-base en el producto deseado. Es posible, inclusive, que un artesano haya practicado un método por muchísimo tiempo -toda su vida- y sin embargo ser incapaz de fabricar un objeto de gran calidad (Bril et al. 2001). 
El punto es que si de hecho hubo un individuo adulto con algún tipo de problema físico que afectó la formatización y el resultado final, debería manifestarse no sólo en la muestra de bifaces, sino también en el resto de los artefactos formatizados. Se destaca que no hay evidencias de ningún tipo en este sentido entre los artefactos con trabajo no invasivo. Por otra parte, la falta innata de destreza en la producción de estos bifaces no parece ser el caso, puesto que las piezas evidencian atributos característicos no sólo de una ausencia marcada de habilidad motora, sino también, y más importante aún, de un escaso "saber-cómo” ideacional. Es decir, implican una falta total de destreza técnica y no serían comparables con los resultados de un tallador mediocre.

Al descartar ambas posibilidades, la perspectiva de que se trate de niños y/o adolescentes se ve potenciada.

En relación con grados de competencia en la talla, Pigeot (1990) distingue tres niveles: muy buenos talladores, talladores menos talentosos y aprendices-debutantes. En tanto que Bodu et al. (1990) incorporan una cuarta categoría, la de "niño”, distinguido por el carácter no utilitario de piezas toscamente talladas, mostrando menor destreza que los novicios. En el caso considerado, en primera instancia, podría plantearse la existencia de un excelente tallador -en sentido genérico-, reflejado en la pieza $\mathrm{N}^{\circ} 514$ de QS3, de tipo foliácea, y, por ende muy chata y ancha, que si bien está fracturada, el tamaño de los negativos en ambas caras induciría a sostener que se trataba de un biface de gran porte. Esto estaría corroborado por la existencia de lascas de adelgazamiento bifacial, utilizadas como formas-base, muy grandes (sensu Aschero 1983) que remiten a artefactos de gran tamaño. Talladores menos talentosos podrían estar reflejados en las piezas que no presentan características notorias, que son la mayoría. Desafortunadamente, no se cuenta aquí con herramientas como para discriminar entre las categorías señaladas de “aprendiz” y “niño”, ya que, amén de no ser funcionales, se trata de piezas que no son compatibles con las manos de niños (¿adolescentes?), dado su tamaño, aunque debe tenerse en cuenta que la relación miniatura-niños no siempre es tan directa (Finlay 1997).

Para finalizar, los bifaces citados podrían caratularse, siguiendo la clasificación de Politis (1999), como de Clase 2, aunque con la salvedad del tamaño y, en función de esto último, de que no se trataría de juguetes. Se los considera, en definitiva, bifaces en proceso de manufactura realizados por niños y/o adolescentes en el marco de prácticas de talla. 


\subsection{A MODO DE COROLARIO}

En este capítulo se han explorado una serie de aspectos vinculados a la variabilidad de los bifaces en los contextos considerados. Desafortunadamente, dada la elevada tasa de fragmentación de la muestra, uno de los principales atributos que hacen a la variación morfológica en bifaces, como es la forma del contorno, de amplio desarrollo a nivel mundial (por ejemplo, Bordes 1961; Roe 2003; McPherron 1995, 2003; Adams 1999) no ha podido ser debidamente abordada. Esto es realizado en función de la obtención de una serie de medidas pertinentes, que requieren de contar con piezas enteras (ver, por ejemplo, Brézillon 1983).

No obstante, es posible realizar, con los recaudos pertinentes, una serie de observaciones de manera de caracterizar en forma general las muestras. Al respecto, se parte de la observación de los bifaces como tales y de los bifaces reciclados sin modificación extensiva por dicho proceso. Así, puede señalarse que no habría variabilidad morfológica a nivel de contorno, siendo las piezas básicamente lanceoladas,. Escapa, empero, a esta perspectiva la pieza $\mathrm{N}^{\circ} 1374$ de PP4, de forma claramente oval.

Ahora bien, dentro de las morfologías lanceoladas, es posible reconocer un grado importante de variación en distintos atributos. De esta forma, varía el grado de redondeamiento de la porción apical. Por otra parte, se registran variaciones en la ubicación del ancho máximo de las piezas respecto del sector basal, aunque siempre en el marco de un patrón lanceolado. Esto incide, a su vez, sobre el "aguzamiento" del sector basal. Finalmente, en cuanto a las bases, si bien son convexas en su totalidad, presentan grado de convexidad variable, cubriendo un rango que va de lo muy atenuado a lo semicircular. Pasando a los bifaces transformados, las morfologías lanceoladas continúan siendo predominantes, coexistiendo, sin embargo, con formas pentagonales y triangulares.

Un aspecto de sumo interés refiere a la posibilidad de utilizar información cuali y cuantitativa de forma de vincular piezas en proceso de manufactura con aquellas terminadas. Al respecto, los gráficos bidimensionales de L-A y A-E han sido muy útiles para establecer relaciones entre bifaces como tales y reciclados y bifaces transformados. Un ejemplo de esto son las dos aglutinaciones de puntos en PCh1.3 y PCh1.1, que señalan trayectorias de producción distintas para puntas de proyectil lanceoladas de pequeño tamaño, por un lado, y para puntas lanceoladas grandes y artefactos compuestos varios, por el otro. Destaca, al respecto, la dimensión temporal en la ocurrencia de dichas trayectorias, siendo la razón clara: las puntas de proyectil del TM PCh E, ubicuas ca.3600 AP necesitaban de bifaces de pequeño tamaño para su confección, situación que no estaba presente con anterioridad -léase QS3-. 
Otro caso es el de los bifaces de gran tamaño que no tiene parangón con el resto de las piezas, así como las lascas de adelgazamiento bifacial de gran tamaño que permiten inferir la existencia de artefactos ausentes. Finalmente, la identificación de ciertos bifaces como producto de aprendices, es decir, que fueron descartados sin ser terminados, dan cuenta de morfologías que no tienen correlato con diseño final alguno.

De acuerdo a lo visto precedentemente, el adelgazamiento bifacial implica una marcada inversión de trabajo en la manufactura, así como importantes requerimientos de experiencia y destreza manual. Si se tiene en cuenta que el grado de dificultad del tipo de técnica a emplear incide sobre la capacidad del aprendiz de llevarla a cabo, es indudable que la practica del adelgazamiento bifacial habría insumido mucho tiempo y esfuerzo.

Las evidencias morfológicas en conjunto son coherentes con los resultados esperables en situaciones de aprendizaje de la técnica del adelgazamiento bifacial por parte de talladores inexpertos. Se considera, entonces, que parte de los bifaces recuperados en los sitios considerados pueden ser atribuidos a aprendices. $\mathrm{Al}$ respecto, es posible que se haya tratado de niños y/o adolescentes.

Por otra parte, la presencia de piezas foliáceas o de gran tamaño identificaría a talladores expertos, que pueden distinguirse por su habilidad de producir piezas elongadas en relación a su ancho y espesor.

Finalmente, destaca la ausencia de bifaces adscribibles a aprendices en el sitio PP4, cuando se trata de una base-residencial, igual que QS3, PCh1.3 y PCh1.1, donde es esperable encontrar piezas de este tipo.

Debido a que se considera improbable que los aprendices realizaran sus prácticas en otros sitios y no en PP4, caben dos posibilidades. Por un lado, que, por el hecho de estar el sitio en una situación de inmediatez respecto del PPZAC, se hayan realizado las actividades de talla directamente en la cantera y, por el otro lado, que los bifaces fueran descartados en otros sectores del alero, no considerados. Con respecto a esto último, se recuerda que, para el análisis en cuestión, se seleccionó la muestra de bifaces correspondiente a la campaña del año 1999, destacando el bajo número de bifaces en la muestra así definida. Por ello, se procedió a revisar las colecciones de bifaces recuperados en el sitio durante las excavaciones de los años 1996 y Mayo de 1998 -N: 51-, con el objeto de verificar la existencia de tales piezas en el sitio, sin resultado positivo. Por tal motivo, dicha ausencia debe ser abordada sistemáticamente en el futuro, siendo, por el momento, una verdadera incógnita. 


\section{CAPÍTULO 11}

\section{VARIABILIDAD TÉCNICO-MORFOLÓGICA Y MORFOLÓGICO- FUNCIONAL EN PUNTAS DE PROYECTIL -GRUPOS CRONOLÓGICOS 2 Y 3-}

\subsection{ANÁLISIS COMPARATIVO DE PUNTAS DE PROYECTIL}

Se plantea en este Capítulo: 1) analizar la variabilidad técnico-morfológica y morfológicofuncional de puntas de proyectil correspondientes a los Grupos cronológicos 2 y 3 y 2) visualizar desde categorías tecnológicas y tipológicas generales la ocurrencia de diferencias y semejanzas en las puntas de proyectil de los sitios PP4, PCh1.3 y PCh1.1, por un lado, y CChM1 y CChM4, por el otro, en búsqueda de relaciones genéticas entre las mismas. Por esta razón, interesa particularmente la comparación entre los dos grupos cronológicos citados, ya que se considera que los antecedentes de las puntas de proyectil que caracterizan a los contextos agro-pastoriles plenos se deben encontrar en el nodo del proceso transicional, que coincide con la cronología del GC2.

La muestra de puntas de proyectil del GC2 consiste en 110 artefactos, entre piezas enteras y fracturadas. Las piezas proceden de los niveles 4 a 5(5) de PP4 -se incluyen las excavaciones de los años 1996, Mayo de 1998 y 1999-, PCh1.1 -todas las campañas de excavación realizadas hasta el momento, más una serie de piezas obtenidas mediante recolecciones superficiales- y PCh1.3 -idem anterior-. Una excepción es el TM PP C, ya que las piezas analizadas han sido recuperadas en distintos sitios de la microrregión, a saber, PP4, CS1, PH2-ES, PP9, PP1 y LC2.1(?). Se destaca que se consideran exclusivamente tipos morfológicos. A continuación se realiza una breve descripción de los TM incluidos (por una caracterización precisa y por el gráfico correspondiente ver el Capítulo 9):

- TM QS B.2. Punta de proyectil con pedúnculo destacado y aletas entrantes, limbo lanceolado o triangular de bordes convexos o rectos. Bordes del pedúnculo paralelos rectos, con regularización alterna.

- TM PCh A. Punta de proyectil con pedúnculo destacado y aletas entrantes, limbo lanceolado o triangular de bordes convexos o rectos. Bordes del pedúnculo convergentes convexos, cóncavos o rectos, con regularización alterna. 
- TM PCh B. Punta de proyectil con pedúnculo destacado y aletas entrantes, limbo lanceolado o triangular de bordes convexos (¿ं). Bordes del pedúnculo convergentes convexos semicirculares.

- TM PCh C. Punta de proyectil con pedúnculo destacado y aletas entrantes, limbo lanceolado (¿?) y triangular de bordes convexos o rectos. Bordes del pedúnculo convergentes convexos atenuados y/o rectos.

- TM PCh D. Punta de proyectil con pedúnculo destacado y hombros, limbo lanceolado. Bordes del pedúnculo convergentes rectos, con regularización alterna.

- TM PCh E. Punta de proyectil apedunculada. Forma geométrica del contorno lanceolada (normal). También "en mandorla" o biconvexa con un ápice activo. Tamaño mediano pequeño.

- TM PCh F. Punta de proyectil apedunculada. Forma geométrica del contorno lanceolada de bordes subparalelos.

- TM PCz A. Punta de proyectil apedunculada. Forma geométrica del contorno lanceolada (normal).

- TM PCh G. Punta de proyectil apedunculada. Forma geométrica del contorno cordiforme o triangular de bordes convexos semicirculares.

- TM PP A. Punta de proyectil con pedúnculo destacado y aletas entrantes, limbo lanceolado o triangular de bordes convexos o rectos. Bordes del pedúnculo paralelos rectos o convergentes rectos, con regularización alterna.

- TM PP B. Punta de proyectil con pedúnculo destacado y hombros. Limbo triangular de bordes convexos. Bordes del pedúnculo convergentes o divergentes convexos atenuados o semicirculares.

- TM PP C. Punta de proyectil con pedúnculo destacado y aletas entrantes. Limbo lanceolado o triangular de bordes convexos o rectos. Bordes del pedúnculo convergentes rectos.

En cuanto al GC3, la muestra consiste en un total de 91 artefactos entre piezas enteras y fracturadas. Los sitios involucrados son CChM1 y CChM4. La información aquí utilizada proviene de las 48 piezas analizadas por Escola en su tesis de licenciatura (Escola 1987) y de las 43 piezas de su Tesis Doctoral (Escola 2000 y fichas de inventario). La comparación se realiza sobre la base de los subgrupos tipológicos diferenciados por Escola (1987, 1991, 2000) (Figura 11.1):

- A.1.I-A.1.II. Punta de proyectil con pedúnculo diferenciado y aletas entrantes. Limbo triangular corto de tipo isósceles.

- A.1.III. Punta de proyectil con pedúnculo diferenciado y aletas entrantes. Limbo triangular alargado de tipo isósceles.

- A.1.V. Punta de proyectil con pedúnculo diferenciado y aletas entrantes. Limbo de módulo geométrico romboidal de tipo equilátero.

- A.2.I. Punta de proyectil con pedúnculo destacado y hombros. Limbo triangular alargado de tipo isósceles. Este subgrupo tipológico es clasificado como destacado y no como diferenciado, tal como 
fue denominado originalmente por Escola (1987), debido a que la suma de la amplitud de los hombros es menor al ancho de la raíz del pedúnculo (Aschero com pers.).

- B.1. Punta de proyectil de limbo triangular apedunculada, con base escotada.

- B.2. Punta de proyectil de limbo triangular apedunculada, con base recta.

- C.1. Punta de proyectil de limbo lanceolado, apedunculada, con base convexa.

- D. Preforma (código agregado por el que suscribe).

- E. Punta de proyectil no diferenciada (código agregado por el que suscribe).

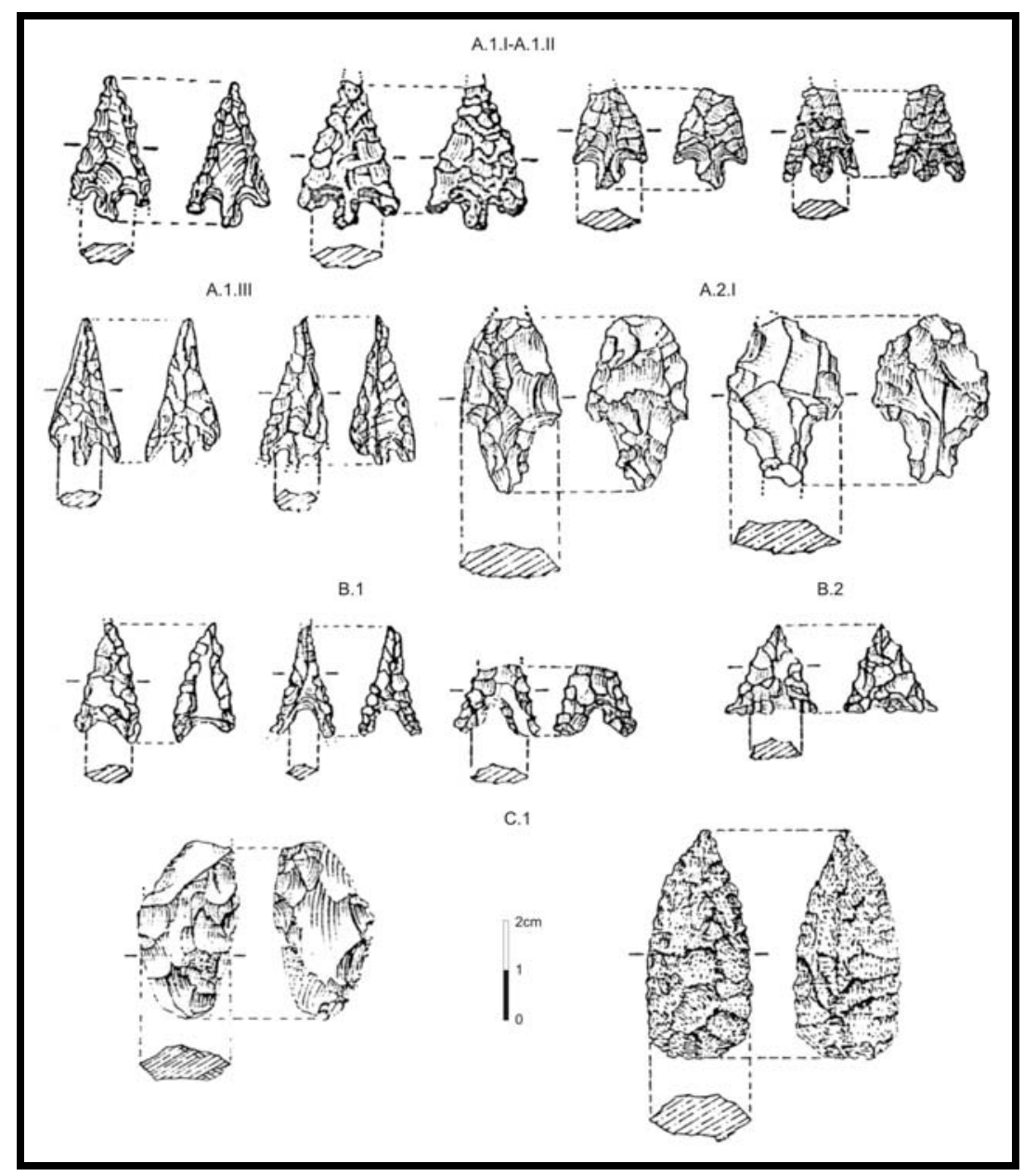

Figura 11.1. Puntas de proyectil del sitio CChM1 (modificado de Escola 1987)

Para el abordaje de las variables tecnológicas y tipológicas se utilizaron en los conteos respectivos básicamente piezas enteras o con fracturas irrelevantes. Se empleó también información de piezas que presentaban fracturas de importancia, pero sólo de aquellos atributos no afectados por las mismas (por ejemplo, en un pedúnculo completo de una punta de proyectil fragmentada, el ancho de la base). 
A continuación se procede al análisis de una serie de características relevantes de las puntas de proyectil de las muestras estudiadas:

\subsubsection{PEDÚNCULOS, LIMBOS Y ALETAS}

Desde una perspectiva muy general, en las puntas de proyectil de los dos grupos cronológicos considerados hay un rasgo homogeneizador en el hecho de que en ambas muestras se registran piezas pedunculadas y apedunculadas. Sin embargo, al abordar las puntas de proyectil pedunculadas, en el GC2 los pedúnculos son destacados (y esbozados en caso de diseños transformados), mientras que en el GC3 los mismos son mayoritariamente diferenciados (la excepción es un sólo caso, el subgrupo A.2.I). En cuanto a los limbos, en el GC2 son lanceolados o triangulares de bordes convexos o rectos, largos y medianos, mientras que en el GC3 son triangulares, con la particularidad de ser limbos de tipo isósceles (Escola 1991), y predominantemente cortos. Las aletas también difieren, siendo aletas entrantes agudas en el GC3, es decir, con ángulos menores a 90², mientras que en el GC2 las aletas de las piezas tienen ángulos iguales o mayores a $90^{\circ}$, siendo entrantes rectas u obtusas.

En lo que respecta a las puntas de proyectil apedunculadas, hay una mayor variabilidad de diseños en el GC2, en forma de diseños lanceolados de distinto tipo y cordiformes o triangulares de bordes convexos, respecto del GC3, donde se restringen a triangulares de bordes rectos.

En ambos momentos hay conformación de bordes de limbos de tipo normal, dentado y festoneado, con la particularidad de que este último, en la muestra del GC3 se limita a las piezas pedunculadas.

Finalmente, a partir de lo expresado es posible advertir la ocurrencia de una mayor estandarización en las formas de los contornos de las piezas en el GC3 respecto del GC2.

\subsubsection{MATERIAS PRIMAS}

Con respecto a las materias primas líticas empleadas en la confección de las puntas de proyectil de uno y otro grupo cronológico, destaca que las muestras consideradas en este Capítulo, que implican un mayor número de piezas que las tenidas en cuenta en el Capítulo 8, replican los resultados alcanzados en el mismo, en el sentido de una direccionalidad en el uso de la obsidiana para la manufactura de tales instrumentos, presentando ambos grupos cronológicos marcadas diferencias en cuanto a la representación de rocas (Figura 11.2). En efecto, al considerar la muestra de piezas de 
CChM1 (Escola 1987), dentro del GC3, la misma se caracteriza por una preponderancia absoluta de la obsidiana procedente de la fuente de Ona (Ob A) (91,5 \% del total de puntas de proyectil), respecto del resto de las materias primas locales (las rocas restantes cuentan con el 8,5\%), tal como ya fue planteado por Escola (1999, 2000). Es pertinente hacer referencia a un trabajo reciente de esta autora (Escola 2004b) en el que se reafirma lo aquí señalado, ya que al analizar 39 puntas de proyectil de CChM1 encuentra que el 97,44\% fue confeccionada con la obsidiana de Ona y el 2,56\% restante con la de Cueros de Purulla. Esto implica una utilización preferencial de lo que aquí se define como ObA (en este caso, formada exclusivamente por obsidiana de Ona) en el GC3 y en mínima proporción de ObB.

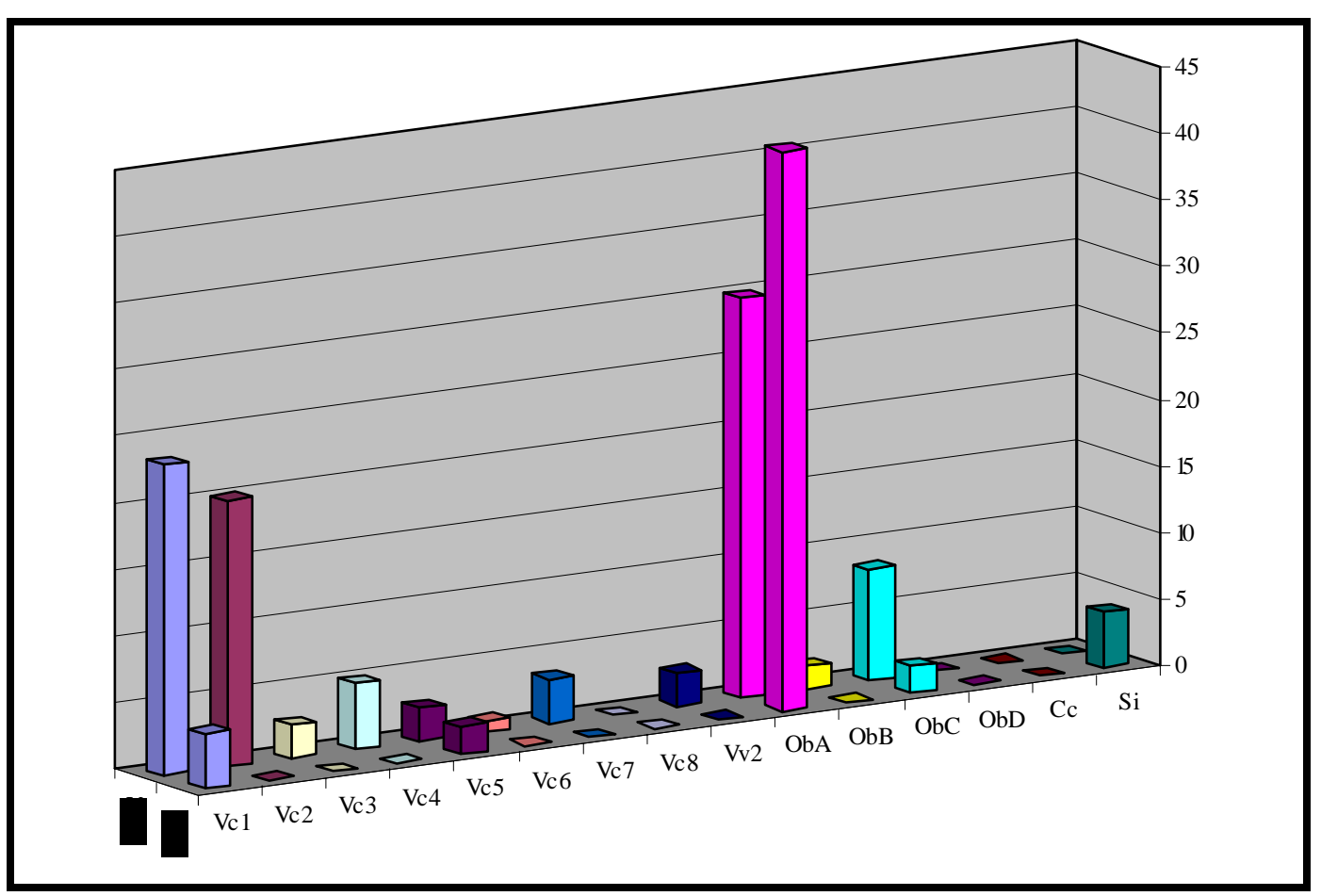

Figura 11.2. Distribución de puntas de proyectil por materia prima. GC2 y GC3

En cuanto al GC2, la Ob A es también dominante, aunque con sólo un 30\% del total de piezas. Esto implica que las rocas restantes están representadas en mayor proporción respecto del caso anterior, dando como resultado una mayor homogeneidad relativa en las proporciones de rocas, independientemente de que se hayan empleado una mayor cantidad de materias primas (en número de once) en la confección de las puntas de proyectil de dicho grupo cronológico.

Es posible sostener, a partir de estos datos, el hecho de una estandarización en el uso de una materia prima lítica particular, léase obsidiana, en CChM1, lo cual puede extrapolarse al resto de los sitios agro-pastoriles plenos de la microrregión. 


\subsubsection{TAMAÑOS}

Al considerar el tamaño de las puntas de proyectil, surge, en primer lugar, que son, en términos generales, significativamente más pequeñas en el GC3 que en el GC2 y, en segundo lugar, que la variación en largo y ancho es mayor en la muestra de este último grupo cronológico, como puede observarse a partir de las áreas de dispersión de los tamaños de uno y otro grupo -las mismas se definieron en función de las piezas terminadas- (Figura 11.3). Esto llevaría a postular que hay una mayor estandarización de tamaños en el GC3. Cabe aclarar que se han considerado sólo piezas enteras o con fracturas mínimas en largo y /o ancho, con excepción de los TM PCh B y PCh D en el GC2 y subgrupo tipológico A.1.V en el GC3, ya que las muestras de estos diseños están constituidos por un único ejemplar.

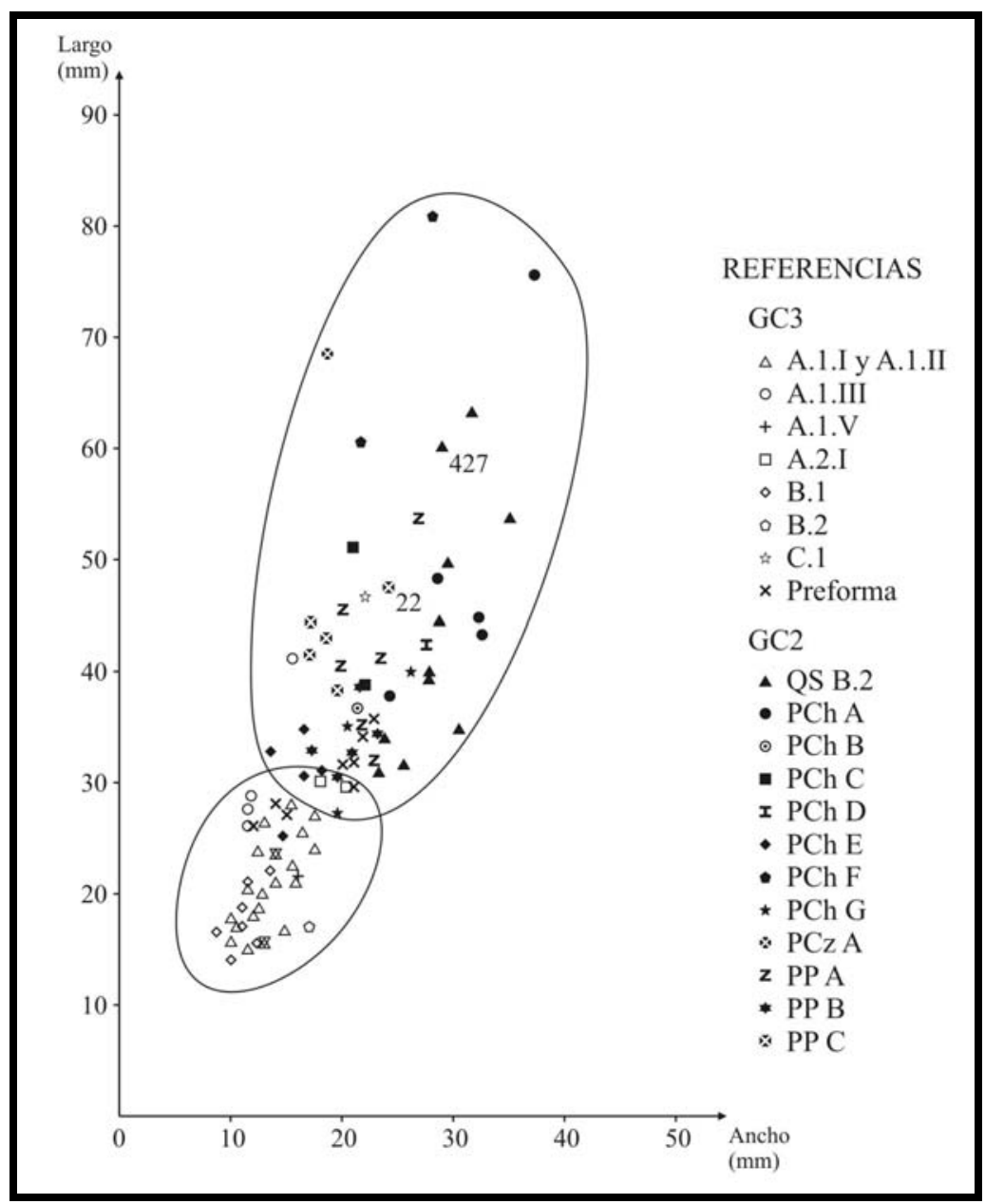

Figura 11.3. Distribución de tamaños de puntas de proyectil. GC2 y GC3

Las variaciones antes mencionadas se relacionarían no sólo con consideraciones de diseño, sino también con la presencia de mantenimiento, el cual puede reducir significativamente las dimensiones de los instrumentos (Schiffer 1987, Nami 1993). Dicha actividad incidió principalmente sobre los subgrupos tipológicos mayoritarios de los GC2 y 3, a saber, QS B.2 y PCh A y A.1.I.-A.1.II, 
respectivamente, aunque con mayor variación en el primero ya que las piezas que lo conforman tienen más volumen de materia prima lo que permite sucesivas reactivaciones.

El resto de los subgrupos de ambos sitios presenta un rango de variación más acotado. Es interesante destacar, para el GC2, los importantes tamaños que pueden alcanzar las piezas apedunculadas lanceoladas (PCh F y PCz A) aún respecto de los artefactos terminados más grandes del TM QS B.2 y el tamaño de la preforma que puede ser asociado a las dimensiones iniciales de tales puntas de proyectil. En lo que respecta al GC3, se destacan los tamaños de las piezas de limbo alargado (A.1.III y A.2.I.), generándose una superposición con el área de dispersión de los materiales del GC2. Esto se registra también en las preformas que, obviamente, tienen mayores dimensiones que las piezas terminadas y, finalmente, la punta de proyectil del subgrupo tipológico C.1., que por su tamaño y otras características tecnológicas y tipológicas correspondería a diseños confeccionados por grupos cazadores-recolectores (Escola 2000).

\subsubsection{MÓDULOS ANCHURA-ESPESOR}

Al analizar la variable módulo anchura-espesor, se observa que las puntas de proyectil de ambos grupos cronológicos (Figura 11.4), factibles de ser medidas en ancho y espesor por ser piezas enteras o por tener fracturas irrelevantes (excepto en el subgrupo tipológico A.1.V de CChM1-4 que comprende una única pieza), tienen mayoritariamente módulos A-E espesos.

Excepciones a esto, en el GC2, son los módulos muy espesos mayoritarios en la piezas apedunculadas lanceoladas (TM PCh E, PCh F y PCz A). La presencia de módulos muy espesos, en baja proporción, en los TM QS B.2 (1 de 21), PCh A (2 de 17), PCh C (1 de 2), PP A (1 de 11) y PP C (3 de 8) se debería a los efectos del mantenimiento, que afecta básicamente el ancho, lo cual repercute en la razón con el espesor. En cuanto al GC3, las excepciones se registran con módulos muy espesos en los subgrupos A.1.I.-A.1.II. (2 piezas de un total de 33), A.1.III. (1 pieza de un total de 4) y preformas (4 de 12). En este último caso sería esperable en función de las expectativas de producción de estos diseños pedunculados. 


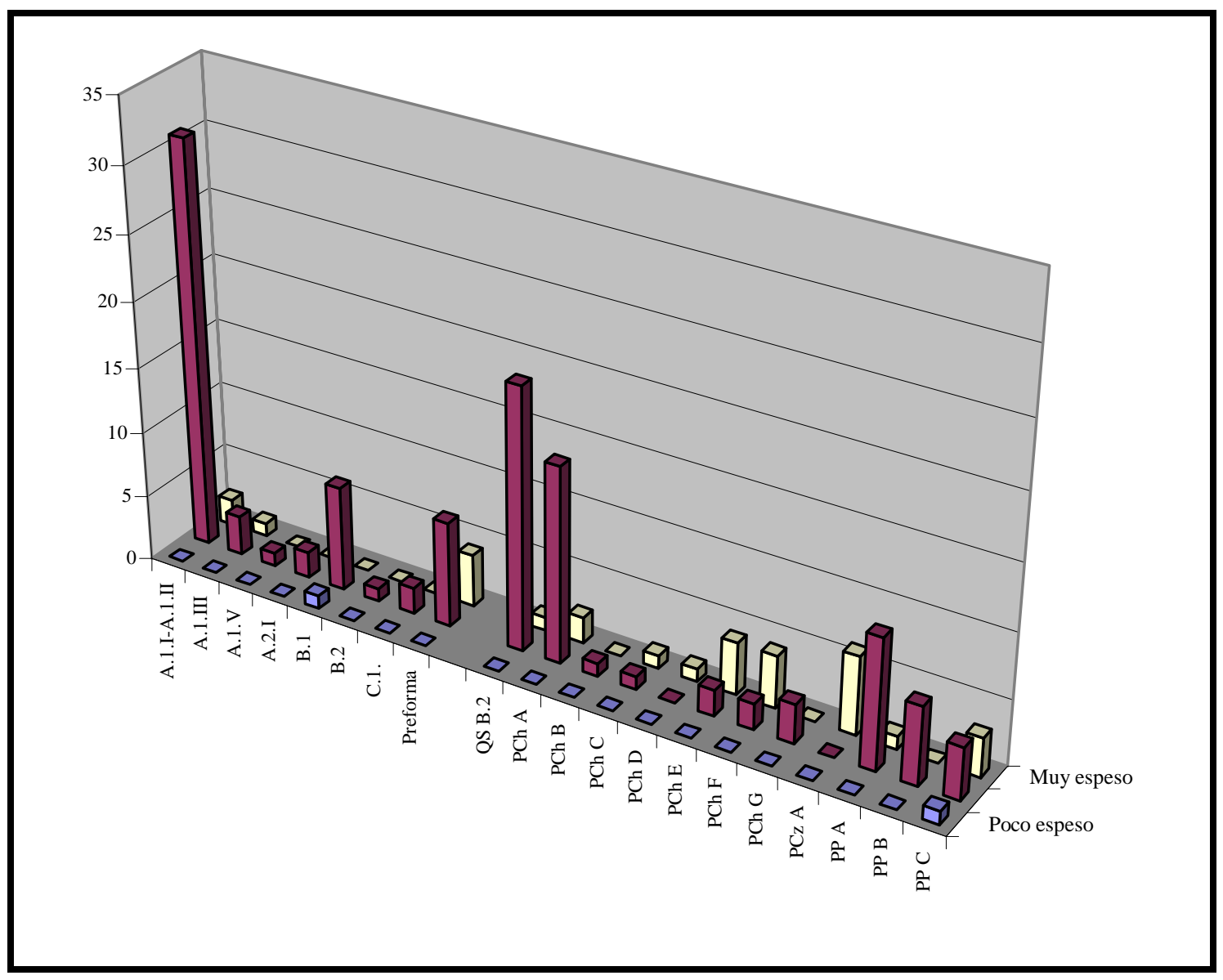

Figura 11.4. Módulos A/E en puntas de proyectil. GC2 y GC3

\subsubsection{ESPESORES RELATIVOS}

Al considerar el espesor relativo, se manifiestan importantes diferencias, en relación al punto anterior (Figura 11.5). Así, en el GC3 predominan los espesores muy delgados a diferencia del GC2, donde lo hacen los delgados y los gruesos. Al profundizar en las particularidades de cada grupo cronológico, en el primero prevalecen los espesores muy delgados en los subgrupos tipológicos A.1.IA.1.II (18 de un total de 21), A.1.III (3 de un total de 4), B.1. (9) y B.2. (1) y los delgados en los subgrupos A.1.V (1) -en este caso no se contaba con el espesor máximo- y A.2.I. (2). Como es esperable, las preformas son en general más espesas, ya que tienden a ser delgadas ( 6 de un total de 11) y gruesas (1 de un total de 11). 


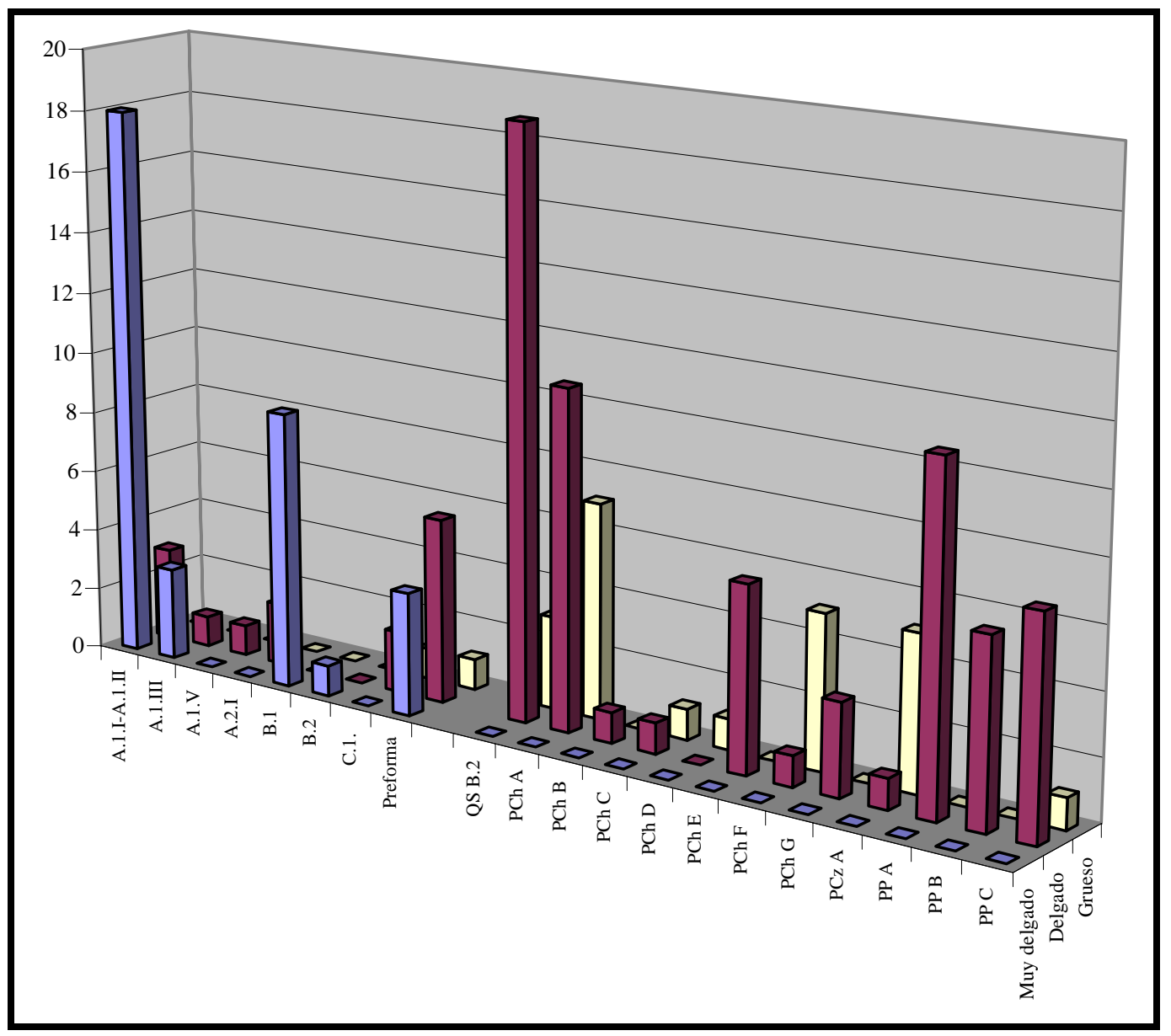

Figura 11.5. Espesores en puntas de proyectil. GC2 y GC3

Ya en el GC2, si bien no hay piezas muy delgadas, se puede marcar una diferencia entre los diseños pedunculados y los apedunculados. Los primeros se caracterizan por espesores delgados; de hecho, de 9 tipos morfológicos, 7 cuentan mayoritariamente con este tipo de espesor, a saber: QS B.2, PCh A, PCh B, PCh G, PP A, PP B y PP C. Los segundos, por su parte, se definen por espesores gruesos, en dos casos de tres; específicamente, en los tipos morfológicos PCh F y PCz A. La excepción es el TM PCh E, con espesores delgados.

\subsubsection{PESOS}

Los pesos de las puntas de proyectil en los sitios considerados también presentan sustanciales divergencias. De esta forma, en el GC2 los pesos son superiores a los $2 g$, mientras que en el GC3, tomando como caso a CChM1, en base a datos obtenidos por Escola (1987), en general son inferiores a este gramaje. Tanto sobresale el bajo peso de las puntas de proyectil en este último sitio, que en el intervalo de 0 a 1,99g, de las 20 piezas que lo componen, 17 pesan menos de un gramo. Dos categorías, sin embargo, presentan un comportamiento diferente. Específicamente, se trata de las 
preformas que, en número de 4 (de un total de 8), van de los 2 a los 6 g, como es esperable, y la pieza del subgrupo tipológico C.1., adscribible a cazadores-recolectores.

Por otra parte, en el GC2, destaca la variabilidad de los pesos en los diseños pedunculados, que va de los 2 a los 18g, aproximadamente. A este intervalo se deben sumar las puntas de proyectil lanceoladas pequeñas del TM PCh E y cordiformes o triangulares del TM PCh G. Una situación diferente presentan las puntas de proyectil apedunculadas lanceoladas de los TM PCh F y PCz A, con pesos mayores, llegando hasta los $40 \mathrm{~g}$ en algunos casos.

\subsubsection{CARACTERÍSTICAS DE LOS PEDÚNCULOS Y SECTORES BASALES EN PIEZAS APEDUNCULADAS}

También hay notorias diferencias al tomar exclusivamente los artefactos pedunculados, por ejemplo, en el tamaño de los pedúnculos, con implicancias en cuanto a los diámetros requeridos para la elección y confección de los astiles o intermediarios (Figura 11.6).

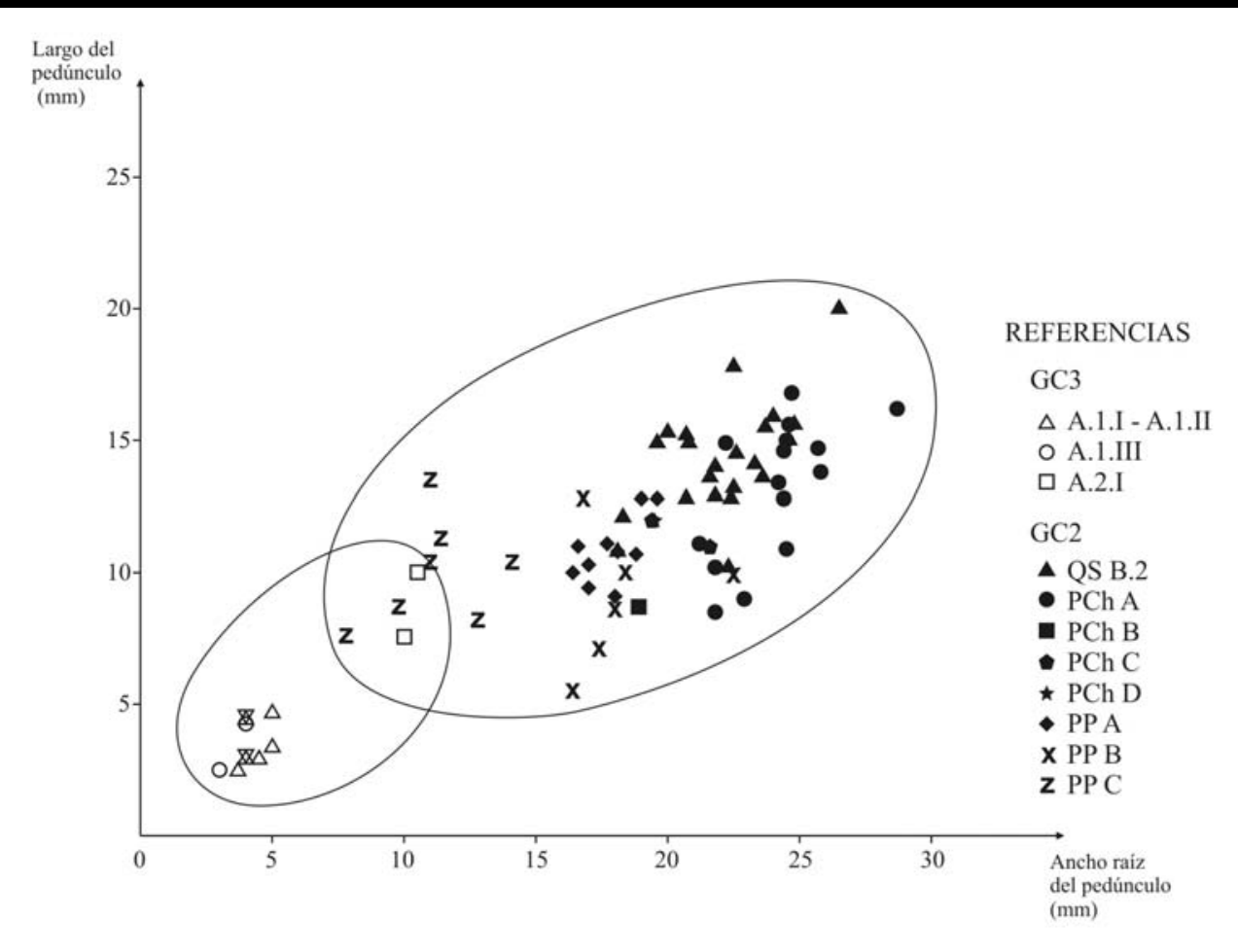

Figura 11.6. Distribución de tamaños de pedúnculos de puntas de proyectil. GC2-GC3 
$\mathrm{Al}$ igual que en el caso de los tamaños generales de las puntas de proyectil, las variaciones en largo y ancho de los pedúnculos son mayores en el GC2 que en el GC3. Es así que los TM QS B.2 y PCh A son los que presentan una distribución mayor. Destacan, también, en la porción inferior del área de dispersión de la Figura 11.6, la homogeneidad relativa de los tamaños de los pedúnculos de los TM PP A, PP B y PP C. Ya en el GC3, es manifiesta la similitud de tamaños de los pedúnculos en los subgrupos tipológicos A.1.I.-A.1.II. y A.1.III., los cuales se discriminan claramente del subgrupo A.2.1., éste último con dimensiones mayores, superponiéndose a las piezas del GC2, específicamente con el TM PP C. Desafortunadamente, no se cuenta con información con respecto al subgrupo A.1.V.

La tendencia señalada es verificada al analizar el ancho de la base de los pedúnculos, variable que tiene la ventaja de no ser afectada, en principio, por las actividades de mantenimiento, conservando las bases sus dimensiones originales. De esta manera, las bases de los pedúnculos en CChM1 (Escola 1987) no superan los 5 mm de ancho (Figura 7.17); a modo de ejemplo, de 10 piezas consideradas en el subgrupo A.1.I.-A.1.II., 6 tienen anchos entre 2 y 2,99mm. Si bien no se cuenta con información métrica sobre el subgrupo A.2.I, de acuerdo a la Lámina 5 cita en Escola (1987: 37), habría una correspondencia estrecha del mismo con el resto de los subgrupos que caracterizan al GC3.

En el GC2, en cambio, las bases de los pedúnculos se caracterizan en general por poseer anchos mucho mayores, que en su mayor parte se encuentran entre los 12 y los 21mm. Los tipos morfológicos que presentan mayor variación son el QS B.2 y el PCh A, con un rango que va de los 11 hasta los $25 \mathrm{~mm}$. Sin embargo, se destaca que hay dos tipos morfológicos del GC2 que cuentan con anchos de bases de pedúnculo que se solapan con las de las piezas del GC3, estos son el TM PCh D y el TM PP C. 


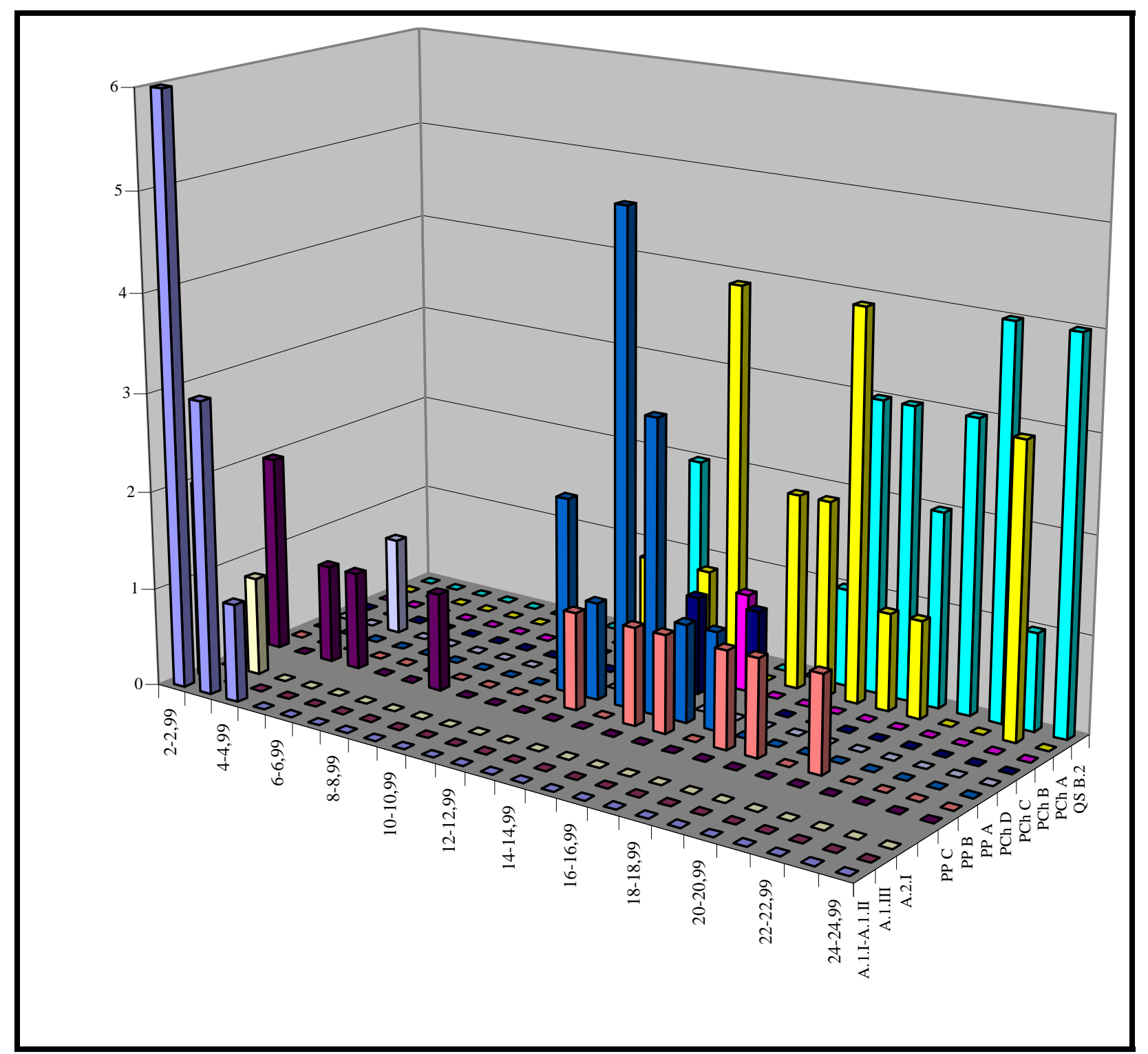

Figura 11.7. Ancho de la base del pedúnculo en puntas de proyectil. GC2-GC3

El tratamiento técnico diferencial de los bordes del pedúnculo también evidencia diferencias sustanciales. Es el caso de los tipos morfológicos QS B.2, PCh A y PP A. en el GC2, donde los bordes de los pedúnculos han sido terminados por medio de retoques/microrretoques alternos, con un ángulo muy abrupto. Esta regularización alterna se relaciona con el enastilado de la pieza, de manera que cumple la función de evitar el corte de la atadura de enmangue (Martínez 1997). El resto de los tipos morfológicos del GC2 y el conjunto de subgrupos tipológicos del GC3 se define por bordes de pedúnculo no embotados, es decir, con bordes activos.

En cuanto a la forma de la base en las piezas pedunculadas, en el GC2 se registran: bases concavilíneas atenuadas y algunos casos de escotadas en $V$ en el TM QS B.2; rectilíneas simples en los TM PCh C y PP A; convexilíneas semicirculares en los TM PCh B y PP B; convexilíneas atenuadas o semicirculares y acuminadas puntiformes (en función de una prolongación mínima de una base convexilínea) en el TM PCh A; convexilíneas atenuadas o acuminadas convexas 
semicirculares en el TM PCh D y convexilíneas atenuadas o semicirculares y acuminadas puntiformes y convexilíneas en el TM PP C. Al considerar al GC3, en base a datos de CChM1 (Escola 1987), las bases son preponderantemente las acuminadas puntiformes y las convexilíneas atenuadas o semicirculares.

En lo que respecta a las puntas de proyectil apedunculadas, en el GC2, las bases son convexilíneas en los distintos diseños lanceolados -convexilíneas semicirculares en los TM PCh E y PCz A y convexilínea atenuada o semicircular en el TM PCh F- y concavilínea atenuada en el TM PCh G. En cambio, en el GC3, son rectilíneas (B.2.), escotadas en U (B.1.) y convexilíneas (C.1.) (Escola 1987, 2000).

De acuerdo a la información recuperada a partir de los pedúnculos, es posible realizar algunas inferencias sobre los sistemas de enmangue, en particular acerca de los diámetros de los astiles o intermediarios y de la forma del sector de enmangue de los mismos. Surge, en primer lugar, la utilización de astiles o intermediarios de diferentes grosores, siendo mucho más delgados en el GC3 que en el GC2. En segundo lugar, es muy probable que los pedúnculos con regularización alterna (exclusivos del GC2) superaran el diámetro de los astiles o intermediarios, mientras que los pedúnculos esbozados y diferenciados con bordes no embotados del GC2 y del GC3, respectivamente, hayan tenido dimensiones menores o iguales al diámetro de éstos. En tercer y último lugar, sobre la forma del sector de enmangue de los astiles o intermediarios, es posible postular, en base a la morfología de la base (Knecht 1997), para el GC2 enchufes con ranura simple, tanto en U como en $V$, más un hoyuelo cónico o cilíndrico -específicamente para el TM PPC- y, para el GC3, enchufes con ranura más un hoyuelo cónico o cilíndrico, para el caso de los subgrupos pedunculados, y ranuras simples, para los apedunculados (Martínez com pers).

\subsubsection{MANTENIMIENTO Y RECICLAJE}

Dejando ya de lado las características puntuales de los pedúnculos, en las muestras bajo análisis se observan claros efectos de actividades de mantenimiento, evidenciadas por patrones de retoque escamoso irregular y modificaciones apreciables en la morfología y dimensiones del limbo. Se afectaron básicamente filos, ápices y aletas, pudiendo, en este último caso, transformarse en hombros.

Al respecto, Escola (2000) señala que la reactivación de algunas de las puntas de proyectil de CChM1-4 se produjo estando las piezas aún enastiladas. Esta situación parece haberse producido en la mayor parte de los tipos morfológicos presentes en el GC2, dadas las evidencias morfológicas (TM QS B.2, PCh A., PCh C, PCh E, PCh F, PCz A, PP A, PP B y PP C), aunque las evidencias positivas de 
mantenimiento en algunos bordes de pedúnculos y en los sectores basales de los diseños lanceolados., llevaría a postular que también se desmantelaron los sistemas de enmangue para el mantenimiento de las piezas.

Indudablemente, el mantenimiento fue muy importante en ambas muestras. Así, Escola (2000) encuentra que de 30 puntas de proyectil en CCHM1-4, 16 casos presentan reactivación (53,5\%). En el GC2 la situación es semejante, de 72 piezas (se descuentan aquí las piezas indiferenciadas, los pedúnculos y fragmentos de limbos, además de las recicladas), 56 presentan mantenimiento. Siguiendo a Flenniken y Raymond (1986), el mantenimiento, entre otros factores, puede producir cambios morfológicos severos que llevan a que se generen formas diferentes a las originales. Por ende, parte de la variabilidad de los diseños presentes en CCHM1-4 podría explicarse a partir de esto (Escola com pers). Lo mismo podría mantenerse para PP4, de acuerdo a lo expresado por Toselli (1998).

Por otro lado, las evidencias de fracturas por impacto en las piezas también son abundantes en ambos grupos cronológicos, lo que implicaría que retornaron al sitio dentro de la presa o en astiles recuperados. En el GC2 debería sumarse a esto el número importante de fragmentos de pedúnculos o incluso pedúnculos enteros fracturados a la altura de la raíz, también factibles de relacionarse con tareas de recambio. Estas fracturas, junto con las consecuencias del mantenimiento sobre el tamaño de las piezas, llevaron a que algunas fueran recicladas, aunque solo en este último grupo cronológico.

\subsubsection{FORMAS-BASE}

La última variable considerada refiere a las formas base empleadas en la confección de las puntas de proyectil, observándose algunos puntos de interés. Aunque en buena parte de las piezas no es posible discernir el tipo de forma base debido al retoque extendido (Figura 11.8), la identificación de lascas como matrices, en base a la observación de remanentes de las caras ventral y/o dorsal que subyacen a los retoques que finalizan las puntas, es proporcionalmente destacable en CChM1-4. Tanto es así que en todos los subgrupos han sido identificadas lascas no diferenciadas, con excepción de C.1. (Escola 1987). Por ejemplo, en el subgrupo A.1.I.-A.1.II. representan el 34,04\% del total de las piezas que lo conforman. Esta tendencia se potencia en la categoría preforma, con el 92,31\%, como es esperable. Al respecto, Escola (2000) señala que las puntas de proyectil en CChM1 eran confeccionadas sobre lascas. Esto es clave, ya que en la confección de dichas puntas de proyectil destaca la ausencia de bifaces en sentido estricto o bifaces parciales como estadios intermedios en la manufactura, con excepción del subgrupo C.1. 


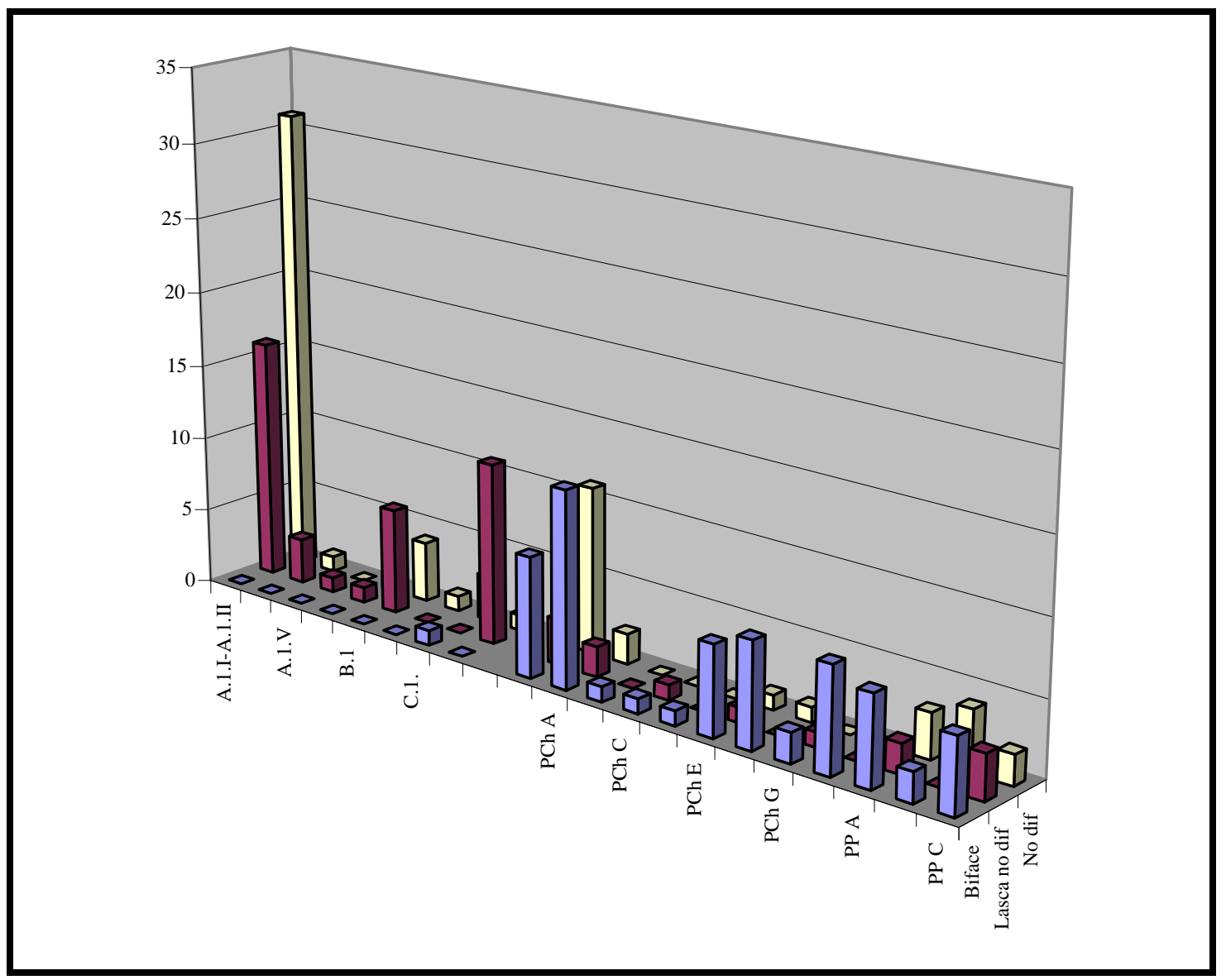

Figura 11.8. Formas-base de puntas de proyectil. GC2 y GC3

En el GC2 la situación es diferente, ya que las evidencias señalan que las formas-base no eran sólo lascas, sino también bifaces. La participación de estos últimos como formas base secundarias bifaciales (sensu Nami 1988) parece haber sido importante, a la luz de los conteos realizados (Figura 11.8). Destaca que los bifaces se emplearon tanto en la confección de diseños pedunculados como apedunculados. Una línea que debe explorarse en el futuro refiere a que, aparentemente, en ciertos tipos morfológicos (como el QS B.2 o el PCh A), las piezas grandes se habrían confeccionado a partir de bifaces y las de menor tamaño a partir de lascas, señalando una tendencia que es observada en contextos totalmente diferentes a éste (Nami 1984, 2000; Flegenheimer 2001).

\subsubsection{A MODO DE COROLARIO}

Del análisis de las características tecnológicas y tipológicas de las puntas de proyectil de los Grupos cronológicos 2 y 3 resultan diferencias significativas entre ambas muestras, como, por ejemplo, en la forma general del contorno, la materia prima utilizada, la forma del limbo, el tamaño, el peso, el ángulo de las aletas, el tipo y tamaño de los pedúnculos, el tratamiento técnico diferencial de 
los bordes del pedúnculo, el ancho y forma de la base del pedúnculo y sectores basales de piezas apedunculadas, y las formas-base empleadas (Tabla 11.1).

Tabla 11.1. Diferencias en las puntas de proyectil de los GC 2 y 3

\begin{tabular}{|c|c|c|}
\hline VARIABLES & GC2 & GC3 \\
\hline Subgrupos tipológicos & $\begin{array}{c}\text { Diversidad de puntas } \\
\text { pedunculadas y apedunculadas }\end{array}$ & $\begin{array}{c}\text { Puntas pedunculadas y } \\
\text { apedunculadas. Preponderancia de } \\
\text { puntas pedunculadas }\end{array}$ \\
\hline Forma del limbo & $\begin{array}{c}\text { Triangulares de bordes convexos y } \\
\text { rectos y lanceolados }\end{array}$ & $\begin{array}{c}\text { Triangulares de bordes rectos de tipo } \\
\text { isósceles. Estandarización de las } \\
\text { formas }\end{array}$ \\
\hline Tamaño & Más grandes & $\begin{array}{c}\text { Más pequeñas. } \\
\text { Estandarización de los tamaños }\end{array}$ \\
\hline Materia prima & Más diversificada & $\begin{array}{c}\text { Estandarización de la materia prima } \\
\text { en base a la obsidiana }\end{array}$ \\
\hline Peso & Mayores & Menores \\
\hline Aletas & Rectas u obtusas & Agudas \\
\hline Tipo pedúnculo & Destacados y esbozados & Diferenciados \\
\hline $\begin{array}{l}\text { Tratam. técn. diferenc. } \\
\text { bordes pedúnculo }\end{array}$ & Regularización alterna & No embotados \\
\hline Tamaño pedúnculos & Mayores & Menores \\
\hline Ancho base pedúnculo & Mayores & Menores \\
\hline $\begin{array}{c}\text { Forma de la base } \\
\text { pedúnculo o sector basal }\end{array}$ & $\begin{array}{c}\text { Puntas pedunculadas: } \\
\text { convexilíneas, rectilíneas y } \\
\text { concavilíneas. Presencia de bases } \\
\text { acuminadas } \\
\text { Puntas apedunculadas: } \\
\text { convexilíneas }\end{array}$ & $\begin{array}{l}\text { Puntas Pedunculadas: acuminadas y } \\
\text { convexilíneas } \\
\text { Puntas Apedunculadas: escotadas. }\end{array}$ \\
\hline Forma base & Lascas y bifaces & Lascas \\
\hline
\end{tabular}

Básicamente, dichas puntas de proyectil tienen en común sólo aquellas características que hacen a consideraciones morfológico-funcionales generales, a saber: secciones transversales biconvexas simétricas o asimétricas, o plano-convexas; secciones longitudinales simétricas; el hecho de presentar un ápice, activo o no; el tener bordes regulares retocados y contar con un área de enmangue. No es casual que estas variables son las que en definitiva definen a dichas piezas como puntas de proyectil (sensu Aschero 1975), tendientes a lograr un efecto de corte y penetración, a partir de un modo de acción por percusión a distancia. Sin embargo, esto no significa que no haya relaciones genéticas aparentes entre las puntas de proyectil de los GC2 y 3, como se verá en el punto siguiente. Al margen de esta situación, ciertos elementos como el tamaño y el peso, entre otros, sugieren la posibilidad que el subgrupo C.1., presente en CChM1-4, sea el producto de la recolección de 
artefactos de un contexto ya arqueológico correspondiente a cazadores-recolectores, siendo las piezas retomadas para su empleo (Escola 2000).

Al tener en vista las diferencias en peso, tamaño y dimensiones de las puntas de proyectil en los GC2 y 3 surge, también, la cuestión de la presencia del sistema arco-flecha en los sitios considerados, en contraposición a la del sistema dardo-propulsor y de la lanza, que se asume en el GC2 ${ }^{1}$. Diversas variables se han tomado para tratar de identificar entre uno y otro. Así, Fenenga (1953) diferencia entre puntas con pesos menores y mayores a $4 \mathrm{~g}$ aproximadamente, y las relaciona con puntas de flecha y dardos de propulsor, respectivamente. También se ha tomado al tamaño como criterio relevante, siendo las piezas pequeñas adscriptas a flechas y las grandes a dardos (para profundizar en el tema, ver Escola 1987; Martínez 1997, 2003; Ratto 2003).

De acuerdo a estos criterios de peso y tamaño, las puntas de proyectil de CChM1-4, exceptuando las pertenecientes al subgrupo C.1., se identificarían como puntas de flecha. Sin embargo, la aplicación de las ecuaciones clasificatorias de Thomas (1978), basadas en un análisis multivariado que considera longitud, ancho, espesor y ancho de la raíz del pedúnculo, por parte de Escola (1987) a muestras de CChM1 dieron resultados positivos para la presencia de propulsor. En suma, la diferenciación no es fácil, y definir la presencia de arco y flecha en el GC2 es aún más difícil todavía.

En un trabajo reciente, Ratto (2003) señala la presencia en sitios de la región de Chaschuil Puna Meridional argentina-, con cronología estimada entre 5000 y 4000 años AP, de diferentes sistemas de armas, a saber, arma de mano, propulsor y lanza arrojadiza. El arco y flecha tendría lugar recién hacia el 2000 AP, siendo la única alternativa extractiva.

Por su parte, De Souza (2004b) aborda las tecnologías de proyectil entre los 6000 y los 1200 años AP en sitios de la región del Loa Superior, en el desierto del norte de Chile. Entre los resultados alcanzados, el autor sostiene que es indiscutible la presencia del dardo de propulsor y la lanza en cronologías previas al 4000 AP, así como de astiles de flecha con posterioridad al 2100 AP, reconociendo un lapso de indefinición entre los 3200 y los 2100 AP, en el que postula el ingreso de la tecnología del arco y flecha.

\footnotetext{
${ }^{1}$ Se destaca que este tema será abordado en el futuro inmediato con la profundidad que merece, con el especialista en sistemas de armas del equipo, Dr. Jorge Martínez.
} 
11.2. LAS PUNTAS DE PROYECTIL CON PEDÚNCUlO DESTACADO, ALETAS Y/U HOMBROS Y LIMBO LANCEOLADO COMO ANTECEDENTE DE LAS PUNTAS CON PEDÚNCULO DIFERENCIADO, ALETAS Y LIMBO TRIANGULAR

De acuerdo a lo visto precedentemente, a simple vista, hay un cambio substancial en los diseños de puntas de proyectil pre 3400 y post 2100 AP. No obstante, en la microrregión se ha encontrado con cierta recurrencia un diseño particular de punta de proyectil, denominado TM PP C (ver punto 9.1.1. Caracterización de tipos morfológicos en el Capítulo 9), que presenta características afines y, al mismo tiempo, diferencias en ciertos aspectos cruciales, con las puntas de proyectil con pedúnculo diferenciado, aletas entrantes agudas y limbo triangular, designadas CChM A, típicas de los contextos agro-pastoriles plenos (Escola 2000).

Específicamente, se definen por presentar un pedúnculo destacado, aletas entrantes rectas $u$ obtusas, hombros o una combinación de ambos y un limbo lanceolado o triangular de bordes convexos (Figura 11.9).

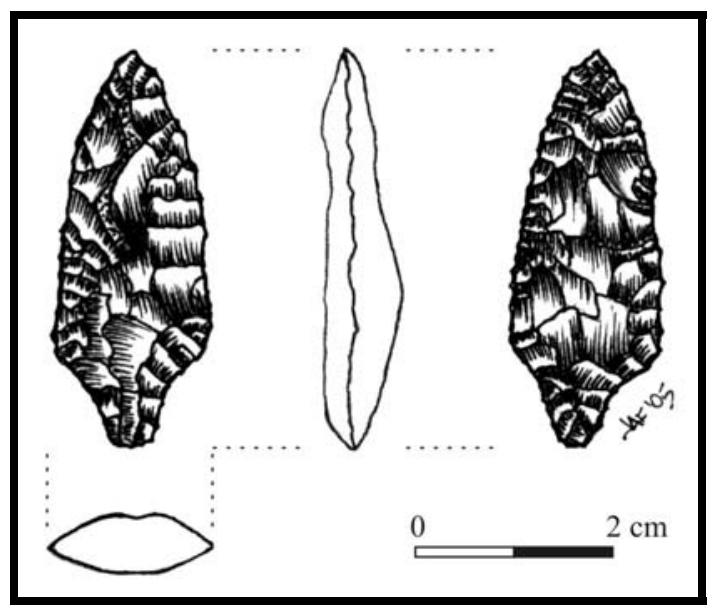

Figura 11.9. Punta de proyectil con pedúnculo destacado, aleta y hombro y limbo triangular de bordes convexos. PP9.I -superficie-

Se destaca que los limbos pueden ser también triangulares de bordes rectos, pero se destaca que cuando esto ocurre hay claras evidencias de mantenimiento. Los bordes del pedúnculo son convergentes rectos y las bases convexilíneas atenuadas o semicirculares y acuminadas convexilíneas y puntiformes. En cuanto a su tamaño, en largo y ancho superan holgadamente a las puntas de proyectil agro-pastoriles, mientras que en espesor tienden a ser delgadas y gruesas y no muy delgadas como estas últimas. Con respecto al pedúnculo, son más largos y anchos (ver descripción del Tipo morfológico Punta de la Peña C y Casa Chávez Montículos A en el punto 9.1.1. Descripción de tipos morfológicos en el Capítulo 9). 
Se destaca que estas puntas de proyectil han sido confeccionadas tanto por adelgazamiento bifacial (Figura 11.10) como por reducción bifacial, lo que representa una variación importante en relación con la forma de confección de los diseños de CChM1 y PP9, ya que estos últimos sólo se presentan manufacturados por reducción bifacial.

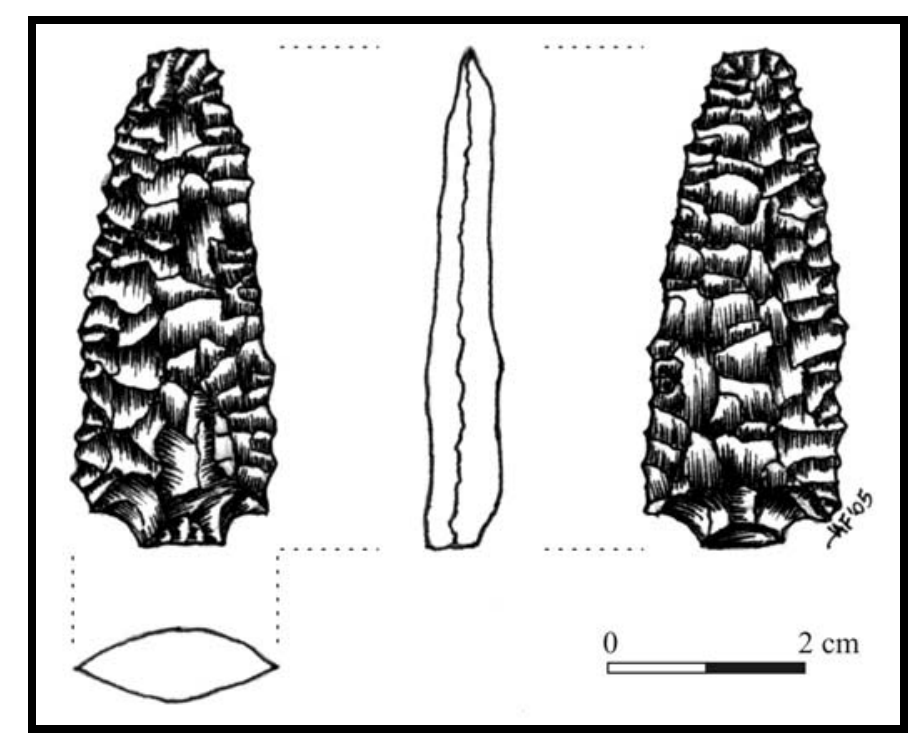

Figura 11.10. Punta de proyectil confeccionada por adelgazamiento bifacial. Recuperada en superficie entre Piedra Horadada 2 y El Sembrado (Punta de la Peña)

Los hallazgos de estas puntas de proyectil en Antofagasta de la Sierra proceden, hasta el momento, en su mayor parte, de superficie. Más precisamente, de la localidad de Punta de la Peña, a saber, sector I de PP9 (Figura 11.9), senda entre Piedra Horadada 2 y El Sembrado (Figura 11.10) y sitio Punta de la Peña 1, y de las adyacencias de Laguna Colorada. Aunque se desconoce el lugar preciso en esta última localidad dado que las piezas fueron recolectadas asistemáticamente por pobladores locales (Figura 11.11), una posibilidad es que se trate del sitio Laguna Colorada 2.1, identificado recientemente por Olivera y equipo (Tchilinguirian y Olivera 2005), que contaría con este diseño entre los materiales visibles en superficie (Olivera com pers.). 

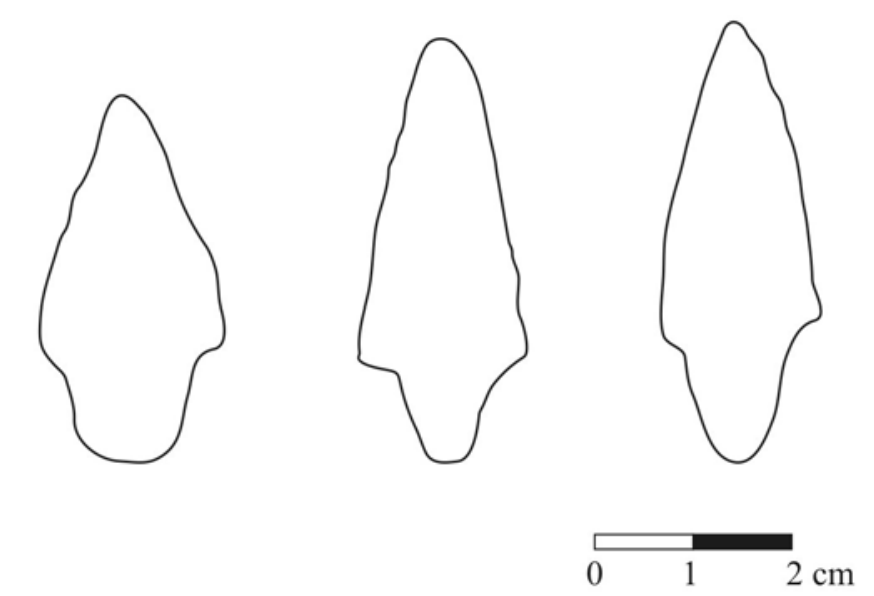

Figura 11.11. Contornos de puntas de proyectil recuperadas por pobladores locales en inmediaciones de la Laguna Colorada (¿LC2.1?). Museo del Hombre de Antofagasta de la Sierra

Afortunadamente, este diseño ha sido recuperado también en estratigrafía, en una serie de sitios arqueológicos de la localidad de Punta de la Peña. Así, PP4 cuenta con un ejemplar correspondiente a la campaña del año 1999, que consta de un pedúnculo completo con un remanente mínimo del limbo ( $\mathrm{N}^{\circ}$ inv 981/1) (Figura 11.12). Se recuerda que la cronología para las ocupaciones de PP4 rondan los 3800 años AP.

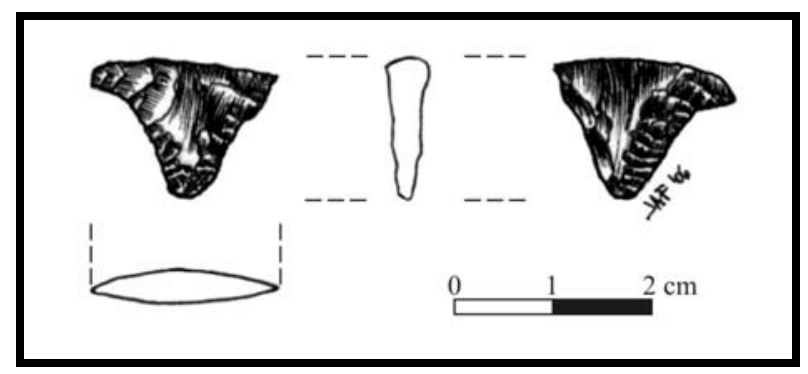

Figura 11.12. Fragmento limbo-pedúnculo de punta de proyectil (PP4. $\mathrm{N}^{\mathrm{o}}$ inv 981/1)

En PP9, por su parte, se recuperó en la estructura 2 del sector III una pieza con evidencias de haber sido reclamada ( $\mathrm{N}^{\circ}$ inv 15) (Figura 11.13). La misma presenta una fuerte ventifacción que cubría toda dicha punta de proyectil y que fue parcialmente removida por la confección de un filo posterior que generó una leve asimetría del limbo, pero conservando el patrón lanceolado. Este último también sufrió los efectos de la erosión eólica, pero en forma mucho más leve. Se destaca que este caso de reclamación ya fue señalado por López Campeny (2001a), aunque se difiere aquí con respecto a que este último filo no presenta ventifacción. Evidentemente, la pieza fue tomada por los ocupantes de esta estructura estando la pieza ya ventifacteada, por lo que se presume una importante antigüedad de la misma, estando el contexto de hallazgo datado post 1100 AP (ibid.). 


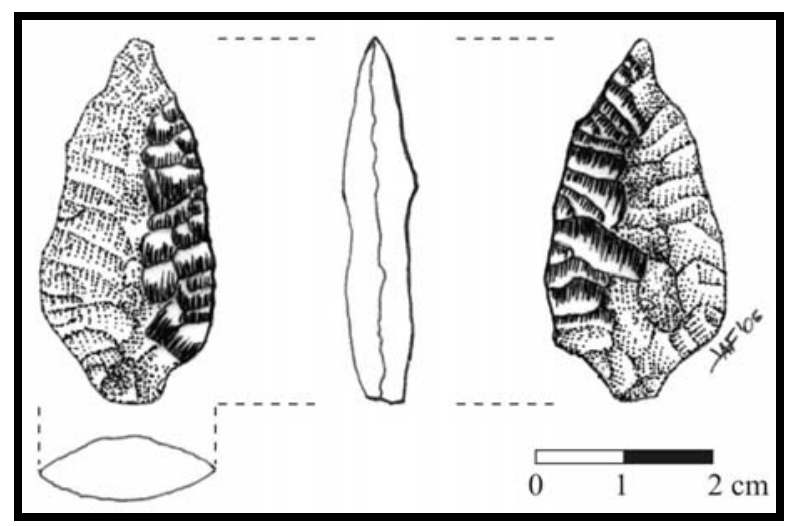

Figura 11.13. Punta de proyectil con evidencias de reclamación (PP9. $\mathrm{N}^{\mathrm{o}}$ inv 15)

En CS1, asimismo, se dispone de dos piezas procedentes de las excavaciones realizadas por la Dra. E. Pintar, a saber: una preforma de punta de proyectil con pedúnculo destacado, hombro y aleta y limbo lanceolado irregular ( $\mathrm{N}^{\mathrm{o}}$ inv 22), y una punta de proyectil con pedúnculo destacado y hombros y limbo no diferenciado por fractura ( $\mathrm{N}^{\mathrm{o}}$ inv 28 ), que responden a las características arriba señaladas. $\mathrm{Si}$ bien las dos piezas fueron recuperadas en el nivel 2, datado hacia los 6500 años AP (Pintar 2004b), es muy posible que, en realidad, se relacionen con el nivel suprayacente, en función de su ubicación y profundidad relativa y de procesos de migración vertical por tratarse de una matriz arenosa (Pintar com pers.). Se destaca que en el nivel 1 se ha remontado una punta de proyectil lanceolada de pequeño tamaño, que localmente se registra entre los 3800 y los 3000 años AP, por lo que esta autora le ha otorgado a dicho nivel una cronología tentativa afín a este lapso temporal (Pintar 2004a).

Finalmente, se considera que las dos piezas del subgrupo tipológico A.2.I definido por Escola (1987) para CChM1 podrían corresponder al tipo morfológico citado. No sólo son notorias las similitudes morfológicas del limbo, aletas y pedúnculo, sino también que se registra una superposición con las piezas del TM PP C en cuanto a tamaño del pedúnculo (Figura 11.6). En caso de presentar mantenimiento del limbo, coincidirían también métricamente con el tamaño general de las piezas, siendo el ancho similar (Figura 11.3). La pregunta que resulta de esto es si es posible que dichas puntas de proyectil estén presentes en CCHM1 como resultado de procesos de reclamación. Lamentablemente, no se cuenta con precisión alguna al respecto (Escola com pers.).

En base a lo expuesto, el lapso 4000-3000 AP sería el más coherente para estas puntas pedunculadas del TM PP C. Esto se vería corroborado por las cronologías disponibles para diseños marcadamente afines de la Puna argentina y del desierto del norte de Chile.

Efectivamente, en la Puna Norte y su borde, tales diseños aparecen en sitios como Cueva de Cristóbal (Fernández 1988-89: 155 y 162, Figura 8: e y g; Figura 10: 1), Inca Cueva Alero 1 (Garcia 
1998: 286; Ilustración № 106: 42 y 43) o Huachichocana III (Fernández Distel 1986: 375; Figura 11: pieza $\mathrm{N}^{\circ}$ 17), con fechados de $2860 \pm 160$ años $A P, 2900 \pm 70$ años AP y $3400 \pm 130$ años AP, respectivamente. Ver, también, las piezas denominadas "El Perchel”, provenientes del sitio de superficie del mismo nombre (Fernández 1971: Láminas XXXIX y XL) y del sitio Espinazo del Diablo (Fernández 1971: Lámina XXIV). Se destaca que no se dispone de cronología para estos dos últimos sitios.

Asimismo, en el Salar de Atacama, se registran en el sitio Tulán 54 con dataciones de $3030 \pm 70$ y 2900 \pm 70 años AP en sus niveles más tempranos (Núñez 1992, 1994) (Figura 11.14²). Por su parte, De Souza (2004b: 74; Figura 11) analiza ejemplares afines a estas piezas procedentes de distintos sitios del "Formativo Temprano” del Loa Superior -3500-2500 AP-.

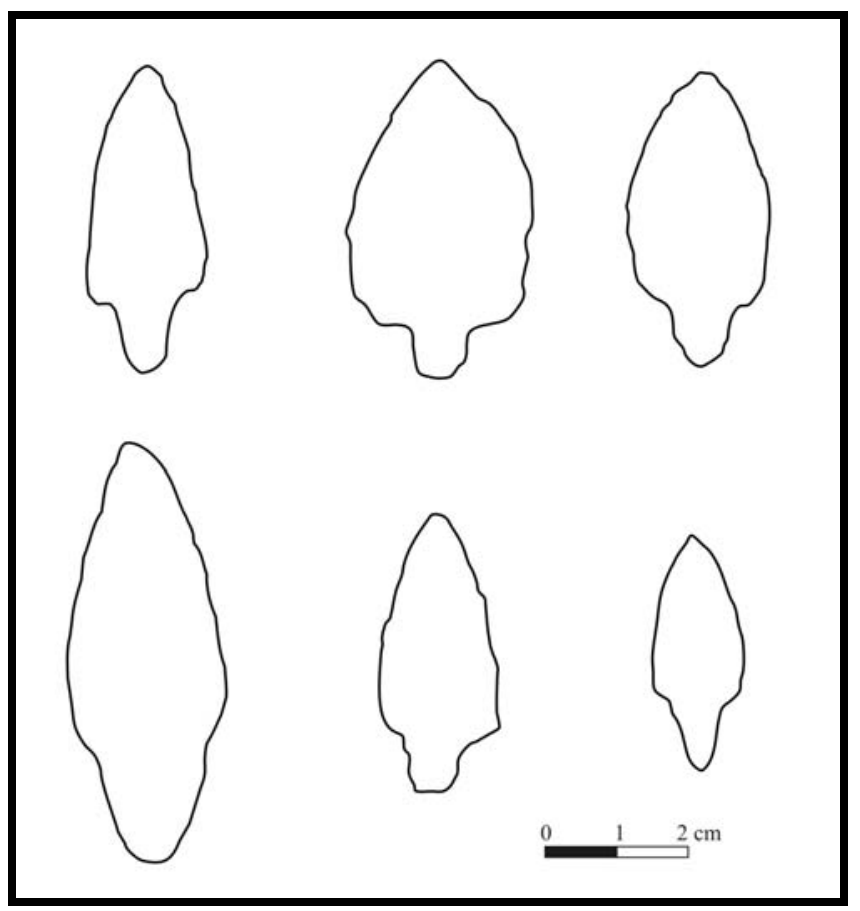

Figura 11.14. Contornos de puntas de proyectil recuperadas en Tulán 54

Se encuentran, también, en la Puna Meridional argentina, en el área de Chaschuil, en sitios de superficie -se hace notar que diseños de este tipo fueron catalogados por Ratto como "diseños no homologables” en la Tabla 10.4; ver, además, las piezas “a” a “e” al inicio de la misma- (Ratto 2003: 238-240), así como en Archibarca (Haber 1999: Figura 8.22 y com pers.). Desafortunadamente, en el primer caso no se cuenta con cronología absoluta y se desconoce si en el segundo se dispone o no de la misma.

\footnotetext{
${ }^{2}$ Se desea agradecer expresamente al Dr. Lautaro Núñez por facilitar la consulta de colecciones de Tulán 54. También a Patricio De Souza por su colaboración en el laboratorio.
} 
Por otra parte, una serie de piezas recuperadas en los sitios de Las Cuevas y Potrero Grande Quebrada del Toro, Prepuna salteña- (Raffino 1977), con cronología de ca.2500 años AP, revisten sumo interés. Se trata de puntas de proyectil con pedúnculo destacado y aletas, descriptas bajo el calificativo de subgrupo tipológico A.2.II por Escola $(1987,1991)$ (Figura 11.15). Cabe destacar que si bien esta autora las definió en los trabajos citados como con pedúnculo diferenciado, en función del ancho de la raíz en relación a la sumatoria de la amplitud de los hombros, resulta que se trata de pedúnculos destacados. Morfológicamente, presentan aletas entrantes rectas u oblicuas, con limbos triangulares de bordes levemente convexos o rectos. No se cuenta con información sobre los pedúnculos debido a la presencia de fracturas (Escola 1987), aunque por las representaciones gráficas podrían mencionarse los bordes paralelos o convergentes rectos.

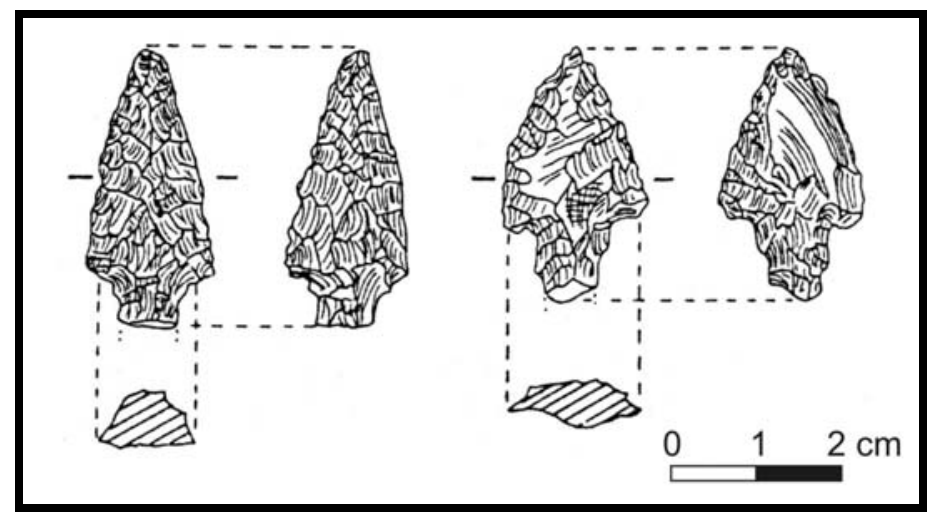

Figura 11.15. Puntas de proyectil del subgrupo tipológico A.2.I. CChM1 (modificado de Escola 1987: 37; Lámina 5)

A partir de lo expuesto son notorias las semejanzas morfológicas con el TM PP C, definido para Antofagasta de la Sierra; sin embargo, se diferencian significativamente al considerar sus dimensiones generales (Tabla 11.2). Nótese que el subgrupo tipológico A.2.II se encuentra dimensionalmente en una posición "intermedia” entre el PP C y el CChM A. Se destaca que la diferencia entre los dos últimos diseños ya fue señalada por Escola (1987).

Tabla 11.2. Comparación dimensional de las puntas de proyectil PP C, A.2.II y CChM A

\begin{tabular}{|c|c|c|c|}
\hline DIMENSIONES & TM PP C & A.2.II & TM CChM A \\
\hline L máx. (rango) & $44,40-38,30 \mathrm{~mm}$ & $33-27 \mathrm{~mm}^{*}$ & $28,00-17,00 \mathrm{~mm}^{* *}$ \\
\hline A máx. (rango) & $20,90-17,10 \mathrm{~mm}$ & $19-14 \mathrm{~mm}^{*}$ & $17,50-11,00 \mathrm{~mm}^{* *}$ \\
\hline $\begin{array}{c}\text { E máx. } \\
\text { (promedio) }\end{array}$ & $8,15 \mathrm{~mm}$ & $6,07 \mathrm{~mm}^{*}$ & $3,73 \mathrm{~mm}^{* *}$ \\
\hline $\begin{array}{c}\text { A raíz ped } \\
\text { (promedio) }\end{array}$ & $11,34 \mathrm{~mm}$ & $7,10 \mathrm{~mm}^{* *}$ & $3,81 \mathrm{~mm}^{* *}$ \\
\hline $\begin{array}{c}\text { E raíz ped } \\
\text { (promedio) }\end{array}$ & $6,41 \mathrm{~mm}$ & $6,60 \mathrm{~mm}^{* * * * *}$ & $1,91 \mathrm{~mm}^{* *}$ \\
\hline
\end{tabular}

Nota: El subgrupo tipológico A.2. II se armó en base a muestras de Las Cuevas y Potrero Grande. * Datos en base a Escola (1991). ** Datos en base a Escola (1987). *** Esta medida refiere al espesor máximo del pedúnculo y no necesariamente a la raíz. 
Ahora bien, se plantea que hay una vinculación genética entre las puntas de proyectil definidas como TM PPC y las TM CChM A, que implicó no sólo cambios de tamaño con el transcurso del tiempo, sino también variaciones morfológicas en los limbos, aletas y pedúnculos. De esta forma, podría enunciarse que los limbos triangulares rectos (de tipo isósceles siguiendo a Escola 1991) se priorizaron por alguna razón en desmedro de los lanceolados y triangulares de lados convexos. Se recuerda que el mantenimiento de los limbos llevaba a formas triangulares, por lo que, si esto fue así, se comenzó a replicar un grupo tipológico complementario que pasó a ser básico. En cuanto a las aletas, si bien no cambiaron su situación de entrantes, pasaron de ser rectas u oblicuas a agudas. Finalmente, con respecto a los pedúnculos, los bordes se mantuvieron convergentes rectos, en cambio, las bases se vieron transformadas, al pasar básicamente de convexilíneas semicirculares a acuminadas puntiformes.

Las evidencias estratigráficas, obtenidas hasta el momento a nivel local, fecharían la aparición de las puntas de proyectil CChM A hacia el 2000 AP (cf.Escola 2000), debiéndose evaluar si el subgrupo tipológico A.2.II está representado microrregionalmente a través del subtipo A.2.I., siguiendo información de CChM1 considerada por Escola (1987). Por su parte, con respecto al TM PP C, en función de la cronología obtenida, su presencia en Antofagasta de la Sierra no significa que se sostenga un origen local de las puntas de proyectil que caracterizaron a las ocupaciones agro-pastoriles posteriores, sino que, simplemente, muestra que esta microrregión formó parte activa del proceso de cambio tipológico macrorregional. Es evidente que para contar con un panorama más claro, es necesario contar con mayor información acerca del lapso 3000-2000 AP, justamente el momento en el que no se cuenta con información sobre sitios residenciales en la microrregión.

Resulta sugerente, en relación a este diseño pedunculado temprano, que otras puntas de proyectil cuentan con ciertas características morfológicas que implican que el esquema conceptual (Inizan et al. 1999) involucrado no surgió de la nada, sino que deriva del seno mismo de los diseños que estaban siendo utilizados contemporáneamente. Puede mencionarse, así, al TM PCh D, definido por un limbo lanceolado y un pedúnculo destacado y hombros, bordes del pedúnculo convergentes rectos, con regularización alterna y base convexilínea atenuada inflexionada o acuminada convexa semicircular (Figura 11.16). 


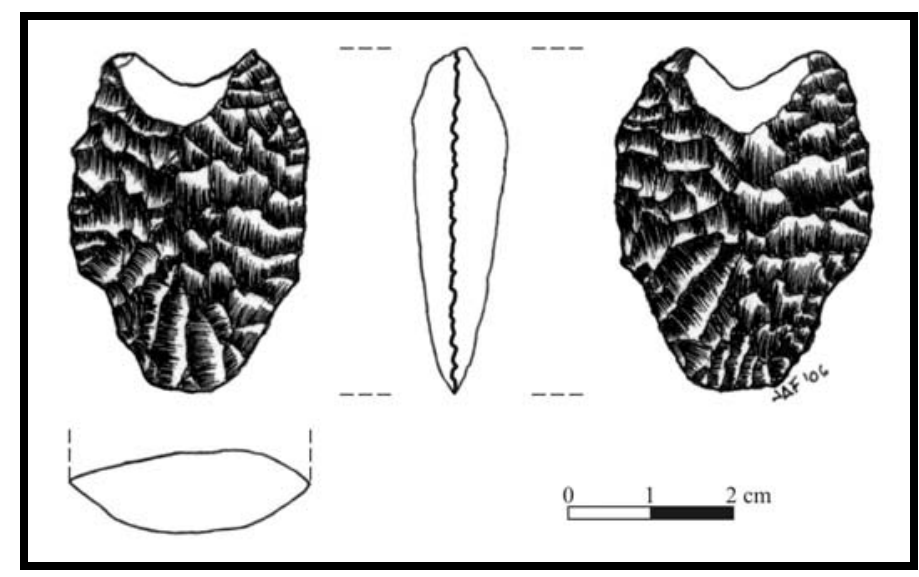

Figura 11.16. Punta de proyectil (PCh1.6. Nº inv 50)

Es interesante notar, también, las afinidades morfológicas y dimensionales de este diseño temprano con las puntas de proyectil lanceoladas de pequeño tamaño presentes en ocupaciones entre los 4000 y los 3000 años AP, aproximadamente. Sería muy importante evaluar las secuencias de producción de tales diseños. Se resalta la práctica de “destacar” el sector de prensión de las piezas, ya sea intencionalmente o como resultado de "errores". En la Figura 11.17 puede apreciarse una punta de proyectil lanceolada apedunculada, recuperada en PCh1.3, que presenta un "esbozo" en su sector basal, como una suerte de antecedente de la confección de pedúnculos del tipo señalado.

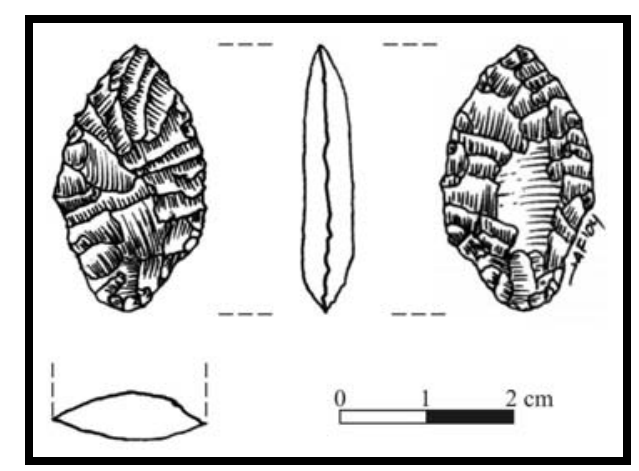

Figura 11.17. Punta de proyectil lanceolada apedunculada (PCh1.3. No inv 110)

Finalmente, desde las materias primas empleadas en la confección del TM PPC se vislumbran una serie de aspectos de interés, que hacen a la vinculación en ciernes. Destaca, por un lado, el papel de las vulcanitas, ya que el 40\% de las piezas está confeccionado sobre Vc1 (N: 3) y Vc6 (N: 1), que, por cierto, es un comportamiento típico de las ocupaciones del GC2, como se ha visto en el Capítulo 8 y en este mismo y, por otro lado, la importancia de la obsidiana como roca empleada en su manufactura, que es un antecedente de lo que ocurriría posteriormente en el GC3. De hecho, el 50\% de estas puntas de proyectil tiene por materia prima a la obsidiana, aunque con una mayor variedad de variantes, como son la ObA (N: 3) y la ObC (N: 2). También se cuenta con una pieza sobre Vv2. 


\section{CAPÍTULO 12}

\section{ANÁLISIS DE INSTRUMENTOS Y DESECHOS DE TALLA A PARTIR DE CASOS ESPECÍFICOS: APROXIMACIONES DESDE LA SEGMENTACIÓN DESCRIPTIVA}

La segmentación descriptiva puede ser sumamente útil para tratar la variabilidad tecnológica y tipológica al nivel del artefacto. Interesa abordar aquí, a partir de la utilización de la misma, la variabilidad en la toma de decisiones de los artesanos, en relación a la elección de partes pasivas y a la vinculación de las mismas con los activas, a las características que tomó el reciclaje y a las formas de tratamiento de los limbos de las puntas de proyectil. Se destaca que estos tres aspectos resultan de propuestas desarrolladas en el Capítulo 4, a saber, diferenciación entre partes activas y pasivas, implicancias de la noción de reciclaje y secuencia de formatización (en este caso, como forma de acercamiento al tratamiento de los limbos). Por otro lado, se plantea la identificación de desechos de talla resultantes del mantenimiento de raederas de módulo grandísimo.

La segmentación se realiza, en los primeros tres casos, sobre la base de la diferenciación de los distintos filos y/o puntas que conforman cada una de las piezas, en artefactos formatizados. En el cuarto y último caso, donde se trata con desechos de talla, se parte de la identificación de atributos específicos a partir de la segmentación en caras ventral y dorsal, y talón.

\subsection{VARIABILIDAD DE FILOS PASIVOS: EL SITIO PCh1.1 COMO CASO DE ESTUDIO}

En el Capítulo 4 se planteó como importante la diferenciación entre partes activas y pasivas (se remite al punto 4.2.1. Segmentación del conjunto y de cada una de las piezas), aquí se retoma esta cuestión, mediante el análisis de la variabilidad morfológica de las partes pasivas de una serie de artefactos formatizados del sitio PCh1.1.

Se parte de la base de que todo artefacto formatizado requiere de un sistema de prehensión adecuado tanto como de filos y/o puntas activos capaces de realizar la tarea para la cual fueron concebidos. En muchos casos, la morfología de la forma-base brinda las condiciones necesarias para 
la prehensión; en otros, en cambio, se requiere de la confección de partes ligadas a la necesidad de asir el artefacto. De hecho, la muestra de instrumentos con filos que presentan regularización de los bordes vinculada con mecanismos de prehensión consta de sólo 16 piezas, tomando el total de piezas recuperadas en las 3 campañas realizadas hasta el momento -N: 160- (Tabla 12.1).

Tabla 12.1. Artefactos formatizados con asociación de filos activos y pasivos formatizados (PCh1.1)

\begin{tabular}{|c|c|c|}
\hline $\begin{array}{l}\text { PIEZA } \\
\mathbf{N}^{\mathbf{0}}\end{array}$ & FILO ACTIVO & FILO PASIVO \\
\hline 35 & Denticulado (1) & Filos formatizados pasivos (2) \\
\hline 30 & Perforador (1) & Filos formatizados pasivos (2) \\
\hline 77 & Buril (1) & Filo formatizado pasivo (1) \\
\hline \multirow[t]{2}{*}{80} & Raspador (1) & Raederas (2) \\
\hline & Cortante de filo retocado (1) & Filo unifacial de arista sinuosa (1) \\
\hline 81 & Punta burilante (1) & Filo formatizado pasivo (1) \\
\hline $\mathrm{s} / \mathrm{n}^{0 *}$ & Buril (1) & Filo bifacial de arista sinuosa (1) \\
\hline 25 & Buril (1) & Filos formatizados pasivos (3) \\
\hline 24 & Cortante de filo retocado (1) & Filo formatizado pasivo (1) \\
\hline 40 & Sierras (2) & Filo formatizado pasivo (1) \\
\hline $\mathrm{s} / \mathrm{n}^{0 * *}$ & $\begin{array}{c}\text { Raspador (1) + Cepillo (1) + } \\
\text { Raedera (1) }\end{array}$ & Filo bifacial de arista sinuosa (1) \\
\hline 22 & $\begin{array}{l}\text { Filo bifacial de arista sinuosa } \\
\text { (1) sobre raedera (1) reciclada }\end{array}$ & Filo formatizado pasivo (1) \\
\hline 23 & Escoplo (1) & Filo formatizado pasivo (2) \\
\hline 60 & Perforador (1) & Filo formatizado pasivo (2) \\
\hline 14 & Punta burilante (1) & Filo formatizado pasivo (2) \\
\hline $8 / 1$ & Raspador (1) & Filo formatizado pasivo (1) \\
\hline 42 & Cuchillo de filo retocado (1) & Filo bifacial de arista sinuosa (1) \\
\hline
\end{tabular}

Un tipo de filo pasivo característico es el dorso, que consiste en un filo abrupto, mayor de $70^{\circ}$, que se opone a un filo (sensiblemente) menor de $70^{\circ}$ (Aschero 1975) (posibilidad a). Sin embargo, otras morfologías pueden caratularse también como pasivas, ser empleadas para la prehensión y no contar con las características señaladas. Así, los filos pasivos pueden implicar: b) un filo con un ángulo mayor a $70^{\circ}$ que no es opuesto al filo activo, c) un filo con un ángulo menor a $70^{\circ}$ que es opuesto al filo activo y d) un filo menor de $70^{\circ}$ que no es opuesto al filo activo. Cabe destacar que estas diferentes posibilidades remiten a "medios de prehensión” digito-unguicular, digital, interdigital y digito-palmar. Si bien no hay reglas fijas, se esperaría, por ejemplo, que los dorsos vinculados a piezas de tamaño considerable conllevarían un medio de prensión digito-palmar. 
Un punto importante a tener en cuenta es que la utilización de cada una de las alternativas mencionadas va a estar relacionada con la manera de lograr una prehensión adecuada, que va a variar según el caso. Específicamente, en la muestra considerada, la categoría b es la de mayor representación, con un 68,75\%, le siguen en orden de importancia las categorías a y d, con el 18,75\% y el 12,5\%, respectivamente. Se hace notar que la categoría c no está presente. En el caso de la a, un ejemplar debió ser utilizado, por lo menos en manos de un adulto, mediante prehensión interdigital, por lo que constituiría una excepción dentro de los dorsos (pieza $\mathrm{N}^{\circ} 35$ ), señalando lo antedicho de ausencia de reglas taxativas.

Los filos pasivos se pueden presentar bajo la forma de filos bifaciales o unifaciales de arista sinuosa, como filos formatizados pasivos, sean unifaciales, bifaciales o alternantes, e incluso, como cualquier otro filo que morfológicamente corresponda a alguno de los grupos tipológicos de la clasificación de Aschero (1975), así como de agregados posteriores (ver Capítulo 4). Como ejemplo del primer caso se presenta una pieza $\left(\mathrm{s} / \mathrm{n}^{\circ}\right)$ que está formada por un raspador, un cepillo y una raedera como filos activos, asociados a un filo bifacial de arista sinuosa que actúa como dorso. En cuanto al segundo caso, se describe la pieza $\mathrm{N}^{\circ} 81$, un biface transformado en el que se combinan una serie de filos; interesan particularmente una punta burilante, como filo activo y un filo formatizado pasivo bifacial categoría b. Con respecto al tercer y último caso, se trae a colación el instrumento $\mathrm{N}^{\circ} 80$. En éste, a un filo activo de raspador de filo frontal se asocian dos filos de raedera, subparalelas, que sirvieron indudablemente para la prehensión. Una de ellas presenta su arista con abrasión, enromada por desgaste.

Ahora bien, para asir la pieza, los dedos y la palma de la mano cambian de posición según sea su morfología, en pos de una correcta realización del gesto técnico. Al mismo tiempo, el artefacto se debe amoldar a los requerimientos de la mano. Un aspecto vinculado a esto es la toma de decisiones del artesano en relación a la selección de la ubicación de las partes pasivas y activas. Evidentemente, la elección de una pieza para confeccionar un filo activo implica un análisis por parte del tallador de la potencialidad de dicha forma-base, pero también de las formas plausibles de tomar al artefacto. Al respecto, se plantean una serie de posibilidades. En una, se decide de antemano la ubicación de filos activos y pasivos, en base a una elección "programada” como respuesta a su necesaria complementariedad. En otra, la elección es “situacional”, en función de los requerimientos surgidos al momento de la utilización de las piezas; aquí, el establecimiento de los filos pasivos se da a posteriori y es función de la posición de los filos activos. Se debe considerar, también, una situación donde un filo es realmente idóneo como filo de prehensión, por lo que la pieza se selecciona por este motivo (se está pensando en bifaces transformados, por ejemplo, donde se regulariza una arista y la otra, sinuosa, se usa como dorso). 
Evidentemente, no es fácil distinguir en el registro arqueológico la presencia de tales situaciones. Es factible, en cambio, tratar con una serie de instrumentos que denotan la variabilidad existente. Así, en un fragmento mesial de punta de proyectil $\left(\mathrm{s} / \mathrm{n}^{\circ}\right)$ se utilizó una fractura transversal para confeccionar un buril (Figura 12.1). Para poder realizar el gesto técnico, dado que el filo izquierdo del limbo continuaba activo, era necesario generar un sector pasivo, por lo que se afectó una porción mínima de dicho filo contra la fractura mencionada mediante un filo bifacial de arista sinuosa embotado. En este caso podría postularse una elección "situacional” del filo pasivo, en vista de la conveniencia de emplear la fractura para conformar el buril.

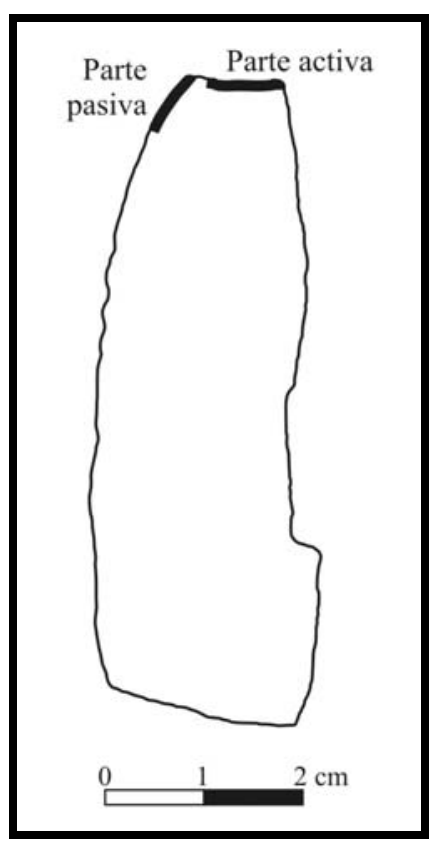

Figura 12.1. Buril más filo bifacial de arista sinuosa sobre fragmento mesial de punta de proyectil reciclada (PCh1.1. $\mathrm{N}^{\mathrm{o}}$ inv. $\mathrm{s} / \mathrm{n}^{\mathrm{o}}$ )

Otra pieza relevante es la $\mathrm{N}^{\circ} 25$, la cual también es un fragmento mesial del limbo de la punta de proyectil lanceolada. En este caso, las dos fracturas transversales resultantes se usaron como plataforma. De esta forma, la parte activa consiste en un buril generado a partir de un lascado que tomó como punto de inicio una de las fracturas (Plataforma A) y que eliminó el borde derecho del limbo. La parte pasiva, por su parte, está formada por tres filos formatizados pasivos unifaciales embotados. Dos de estos filos pasivos se confeccionaron tomando como origen de las extracciones la misma fractura de arranque del buril (Plataforma A), uno en cara A y el otro en cara B, en tanto que el restante se realizó empleando la fractura opuesta (Plataforma B). Uno de los filos pasivos situados en la Plataforma A se superpone al buril, lo que significa que primero se eligió el lugar de emplazamiento del buril y luego se armaron los filos pasivos. 


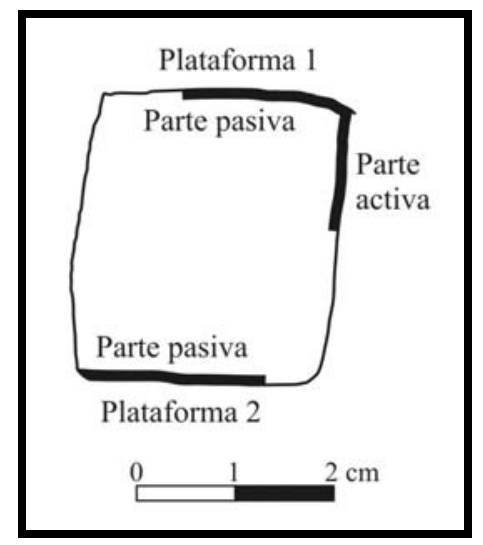

Figura 12.2. Buril más tres filos formatizados pasivos sobre fragmento mesial de punta de proyectil reciclada (PCh1.1. $\mathrm{N}^{\mathrm{o}}$ inv. 25)

Por otra parte, interesan una serie de filos de la pieza $\mathrm{N}^{\circ}$ 81, ya que ejemplificarían la primer opción. Específicamente, estos son un filo de raspador que se superpone a los de dos raederas subparalelas, lo que implica que el diseño general se concibió previamente, viendo necesaria la integración de dos filos pasivos con uno activo como respuesta a la morfología en ciernes.

Con respecto al papel de los dorsos en la elección de una forma-base, se trae a colación la pieza $\mathrm{N}^{\circ} 42$, que consiste en un biface parcial que sufrió una fractura longitudinal, por lo que fue reciclado. La fractura citada se utilizó como plataforma para la confección de un cuchillo de filo retocado (filo activo), en tanto que el filo bifacial de arista sinuosa remanente del biface fue empleado como dorso, para lo cual se machacó la arista, logrando un filo embotado $\left(90^{\circ}\right)$.

Finalmente, la variabilidad existente se vislumbra, además, al considerar las asociaciones de filos activos con filos pasivos. Las mismas se presentan de la siguiente manera: un filo activo vinculado a un filo pasivo -43,75\%- (Figura 12.1), un filo activo con dos filos pasivos -37,50\%-, un filo activo con tres filos pasivos -6,25\%- (Figura 12.2), dos filos activos con un filo pasivo -6,25\%(Figura 12.3) y tres filos activos con uno sólo pasivo -6,25\%-. Esto esta vinculado estrechamente con la forma y tamaño de las formas-base, así como con la posición de los filos activos. Ejemplo de esto último se aprecia en la Figura 12.3, ya que el lugar del filo pasivo se eligió en función de poder emplearlo indistintamente con los dos filos activos. 


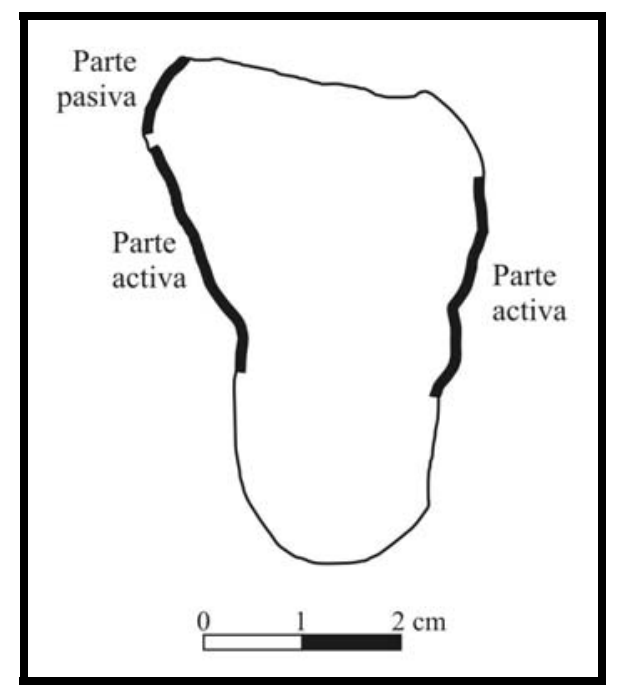

Figura 12.3. Sierras más filo formatizado pasivo (PCh1.1. $\mathrm{N}^{\mathrm{o}}$ inv. 40¹)

\subsection{VARIABILIDAD DE CASOS DE RECICLAJE EN ARTEFACTOS FORMATIZADOS: UN EJEMPLO DESDE PCh1.1}

En este punto interesa, a partir de una serie de artefactos relevantes, explorar la variabilidad implicada en la noción de reciclaje. Para ello, se abordan, por un lado, las diferentes formas en que puede presentarse el reciclado y, por el otro lado, las decisiones de los artesanos con respecto a cómo reciclar los artefactos formatizados.

Para abordar lo expresado se emplea una muestra de artefactos formatizados recuperados en las distintas excavaciones realizadas hasta el momento en el sitio PCh1.1 De esta forma, el set de instrumentos sometidos a reciclaje está conformado por 37 piezas (Tabla 12.2).

\footnotetext{
${ }^{1}$ Este número de inventario corresponde a la campaña de Mayo de 1991.
} 
Tabla 12.2. Casos de reciclaje (PCh1.1)

\begin{tabular}{|c|c|}
\hline $\begin{array}{l}\text { PIEZA } \\
\text { N }^{\circ}\end{array}$ & CARACTERIZACIÓN \\
\hline $89 / 2$ & (1) Raspador sobre (1) Fragmento no diferenciado de artefacto formatizado reciclado \\
\hline 24 & $\begin{array}{c}\{[(1) \text { Cortante + (1) Filo formatizado pasivo sobre (1) Punta burilante reciclada }]+(1) \text { Buril + (1) } \\
\text { Cuchillo de filo retocado }\} \text { sobre (1) Biface }\end{array}$ \\
\hline $92 / 1$ & (1) Buril sobre (1) Fragmento no diferenciado de artefacto formatizado reciclado \\
\hline $98 / 1$ & (1) Punta burilante sobre (1) Fragmento no diferenciado de artefacto formatizado reciclado \\
\hline 11 & $\begin{array}{c}\text { [(1) Punta burilante angular + (1) Percutor de arista formatizada sobre (1) Percutor de arista } \\
\text { formatizada reciclado] + (1) Percutor de arista formatizada }\end{array}$ \\
\hline 22 & [(1) Filo bifacial de arista sinuosa sobre (1) Raedera reciclada] + (1) Filo formatizado pasivo \\
\hline 30 & (1) Perforador sobre (1) Fragmento no diferenciado de artefacto formatizado reciclado \\
\hline 42 & (1) Cuchillo de filo retocado + (1) Filo bifacial de arista sinuosa sobre Biface reciclado \\
\hline 40 & $\begin{array}{l}\text { [(1) Filo bifacial de arista sinuosa sobre (1) Filo no diferenciado de artefacto formatizado } \\
\text { reciclado] + (1) Denticulado }\end{array}$ \\
\hline 49 & (1) Muesca de lascado simple sobre (1) Filo no diferenciado de artefacto formatizado reciclado \\
\hline 67 & (1) Punta burilante sobre (1) Artefacto bipolar reciclado \\
\hline 71 & $\begin{array}{c}\text { [(1) Artefacto bipolar sobre (1) Filo no diferenciado de artefacto formatizado reciclado] + (1) } \\
\text { Muesca retocada }\end{array}$ \\
\hline 72 & (1) Muesca retocada sobre (1) Denticulado reciclado \\
\hline 80 & $\begin{array}{c}\text { [(1) Cortante sobre (1) Raspador reciclado] + (1) Filo unifacial de arista sinuosa sobre (1) Raedera } \\
\text { reciclada }+(1) \text { Cortante }+(1) \text { Raedera }\end{array}$ \\
\hline 25 & (1) Punta burilante sobre (1) Filo bifacial de arista sinuosa reciclado \\
\hline 81 & $\begin{array}{l}\{[(1) \text { Raspador + (1) Punta burilante sobre (1) Raedera reciclada] + [(1) Filo formatizado pasivo } \\
\text { sobre (1) Filo no diferenciado de artefacto formatizado reciclado] sobre (1) Biface transformado }\end{array}$ \\
\hline 60 & (1) Perforador sobre (1) Fragmento no diferenciado de artefacto formatizado reciclado \\
\hline $18 / 2$ & (1) Punta burilante sobre (1) Esbozo de pieza bifacial reciclado \\
\hline 14 & (1) Punta burilante + (2) Filos formatizados pasivos sobre (1) Biface reciclado \\
\hline 29 & (1) Percutor de arista formatizada sobre (1) Biface reciclado \\
\hline $18 / 1$ & (1) Denticulado sobre (1) Filo no diferenciado de artefacto formatizado reciclado \\
\hline 34 & (1) Denticulado sobre (1) Biface transformado reciclado \\
\hline $39 / 1$ & (1) Buril sobre (1) Biface reciclado \\
\hline 205 & (1) Cortante de filo retocado sobre (1) Punta de proyectil reciclada \\
\hline 7 & (1) Buril sobre (1) Punta de proyectil reciclada \\
\hline 26 & (1) Cuchillo de filo retocado sobre (1) Punta de proyectil reciclada \\
\hline $\mathrm{s} / \mathrm{n}^{\mathrm{o}}$ & (1) Punta burilante sobre (1) Punta de proyectil reciclada \\
\hline 1339 & (1) Raedera sobre (1) Punta de proyectil reciclada \\
\hline 45 & Muesca de lascado simple sobre (1) Punta de proyectil reciclada \\
\hline 21 & (1) Buril sobre (1) Punta de proyectil reciclada \\
\hline 210 & (1) Raspador sobre (1) Raspador reciclado sobre (1) Punta de proyectil reciclada \\
\hline 27 & ta de proyectı reciclada \\
\hline
\end{tabular}


Producción lítica, variabilidad y cambio en Antofagasta de la Sierra -ca.5500-1500 AP-, Salomón Hocsman

\begin{tabular}{|c|r|}
\hline $\mathrm{s} / \mathrm{n}^{\circ}$ & (1) Buril + (1) Filo bifacial de arista sinuosa sobre (1) Punta de proyectil reciclada \\
\hline 9 & (1) Artefacto bipolar sobre (1) Punta de proyectil reciclada \\
\hline $39 / 2$ & (1) Denticulado sobre (1) Punta de proyectil reciclada \\
\hline 25 & (1) Buril + (2) Filos formatizados pasivos sobre (1) Punta de proyectil reciclada \\
\hline 8 & (1) Perforador sobre (1) Punta de proyectil reciclada \\
\hline
\end{tabular}

Referencias: ( ): Cantidad de filos o puntas involucrados

Como ya fuera señalado en el Capítulo 4 (punto 4.6.4 Consideraciones acerca del reciclaje y del mantenimiento), siguiendo a Schiffer (1987), el reciclaje implica un cambio de morfología y de función en el artefacto formatizado y una pérdida de su identidad original. Tal vez, el caso arquetípico de lo antedicho sean las puntas de proyectil que ven reciclados sus limbos, no pudiendo continuar con su función de proyectil. En la Figura 12.4 puede apreciarse un cortante de filo retocado corto frontal transversal sobre una punta de proyectil con pedúnculo destacado, aleta y hombro. Por su parte, en la Figura 12.5 la pieza en cuestión cuenta con un raspador de filo corto lateral inclinado que se armó sobre un raspador de filo restringido frontal transversal, al verse este último embotado y con astilladuras múltiples. Este, a su vez, es otro caso de reciclaje sobre punta de proyectil, aunque aquí apenduculada.

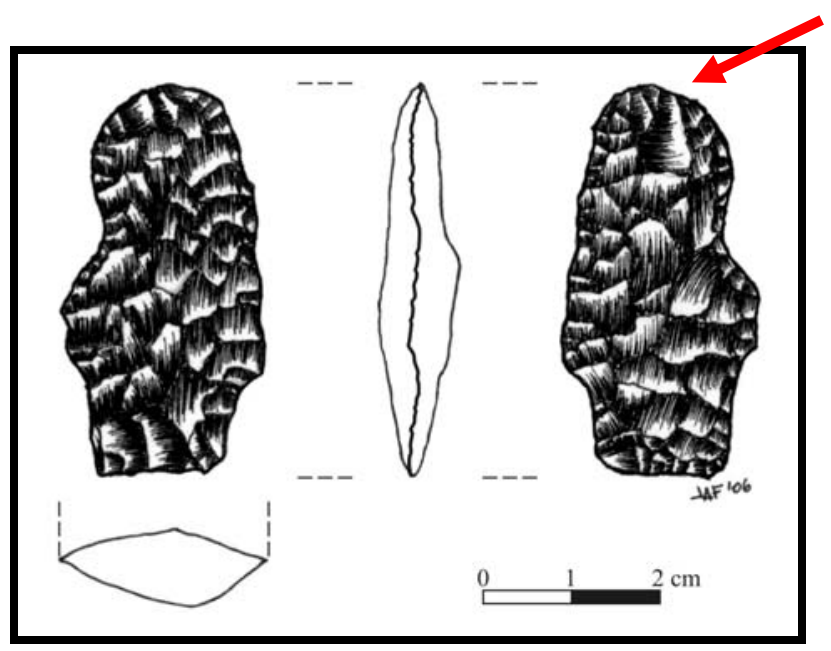

Figura 12.4. Cortante sobre punta de proyectil reciclada (PCh1.1. No inv 205). La flecha de color rojo señala la porción del limbo reciclada 


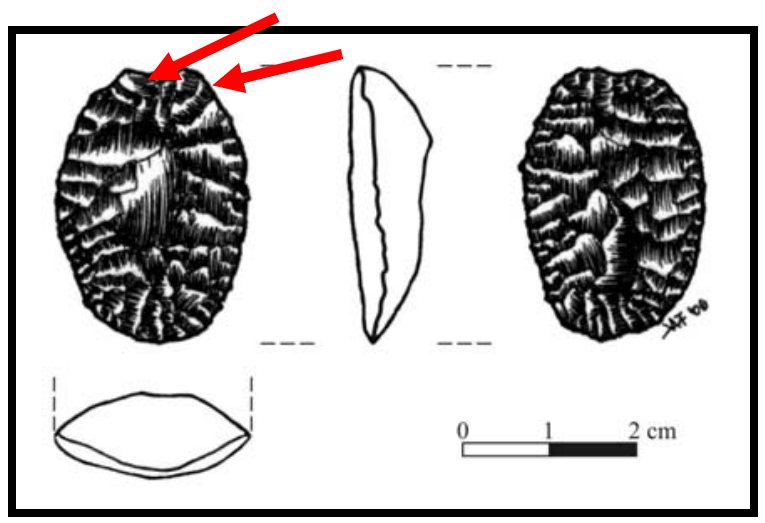

Figura 12.5. Raspador sobre raspador reciclado sobre punta de proyectil reciclada (PCh1.1. No inv 210). Las flechas de color rojo señalan las porciones del limbo recicladas

Por lo general, se considera que el reciclaje conlleva la eliminación del instrumento confeccionado originalmente. Ejemplo de esto es la pieza $\mathrm{N}^{\circ} 72$, en la que una muesca retocada eliminó buena parte del denticulado preexistente. Sin embargo, el hecho de la eliminación no es excluyente. En ciertos casos puede darse una modificación en pos de una reconfiguración del filo. La pieza $\mathrm{N}^{\circ} 42$ se constituye en un ejemplo clarificador. Originalmente se trataba de un biface parcial que sufrió una fractura longitudinal; sobre dicha fractura se armó un cuchillo de filo retocado. Por otra parte, en el otro borde el filo bifacial de arista sinuosa remanente del biface se utiliza como "dorso", dado el ángulo de $73^{\circ}$. Este último presenta su arista machacada con astilladuras y microastilladuras bifaciales. Dicho machacado generó un filo cóncavo que adapta perfectamente al artefacto a la prensión digito-palmar para emplear el cuchillo. Entonces, el filo bifacial de arista sinuosa del biface original se modifica para actuar como dorso. Otro caso es el de la pieza $\mathrm{N}^{\circ} 40^{2}$. En ésta, sobre un filo previo -un filo no diferenciado de artefacto formatizado (unifacial)- se confeccionó uno nuevo, bajo la forma de un filo bifacial de arista sinuosa. Así, sobre el filo unifacial previo se llevaron a cabo una serie de extracciones pero, al mismo tiempo, se realizaron extracciones en la otra cara, usando como plataforma el mismo borde, generando el filo bifacial citado. Por ende, el filo anterior no se eliminó, sino que se utilizó para configurar uno nuevo.

Otro aspecto a tener en cuenta con respecto a la "pérdida de su identidad original”, es que esto es cierto sólo en aquellos casos con filos simples o bien en piezas de morfología global, como ya fuera mencionado. Hay que considerar, sin embargo, aquellos artefactos que consisten en dos o más filos y/o puntas diferentes, es decir, que son compuestos (ver Capítulo 4). En éstos, el reciclaje puede afectar parte de los filos involucrados, por lo que sólo perderían su identidad los sometidos a tal proceso y no toda la pieza. A colación se expone el caso del instrumento $\mathrm{N}^{\mathrm{0}} 22$, que consiste de un filo bifacial de arista sinuosa sobre una raedera reciclada; en tanto que en otro sector de la pieza se confeccionó un

\footnotetext{
${ }^{2}$ Dicho número de inventario corresponde a la campaña de Enero/Febrero de 1991.
} 
filo formatizado pasivo, aunque no es posible establecer con qué filo se vincula, y de la pieza $\mathrm{N}^{\circ} 80$, que presenta un cortante sobre raspador reciclado y un filo unifacial de arista sinuosa sobre una raedera reciclada, más dos filos complementarios, un cortante y una raedera. En tales casos, no toda la pieza se ve reciclada, denotando la importancia de la segmentación en la definición apropiada del reciclaje.

Por otra parte, el reciclaje se presenta básicamente cuando se acaba la vida útil de un objeto, sea por fractura, por embotamiento del filo y/o ante el hecho de no poder seguir manteniéndolo por una reducción extrema de tamaño (cf.Schiffer 1987). En la Figura 12.6 se muestran dos casos de puntas de proyectil recicladas luego de haberse fracturado. La de la izquierda es un fragmento limboapical de punta de proyectil apedunculada lanceolada reciclada en un perforador, mientras que la de la derecha es un fragmento meso-basal de punta de proyectil apedunculada lanceolada sobre el cual se confeccionó una punta burilante angular. La Figura 12.4 también sería un caso de reciclaje por fractura, ya que presenta una en el borde izquierdo del limbo que alteró significativamente su morfología. La Figura 12.5, por su parte, es un ejemplo, por un lado, de reciclaje por embotamiento del filo -es decir, el primer raspador- y, por el otro, por mantenimiento extremo del limbo de la punta de proyectil, evidenciado claramente por la morfología general de la pieza y por el tipo de extracciones en un sector remanente del mismo, que llevó a que sea reciclada.

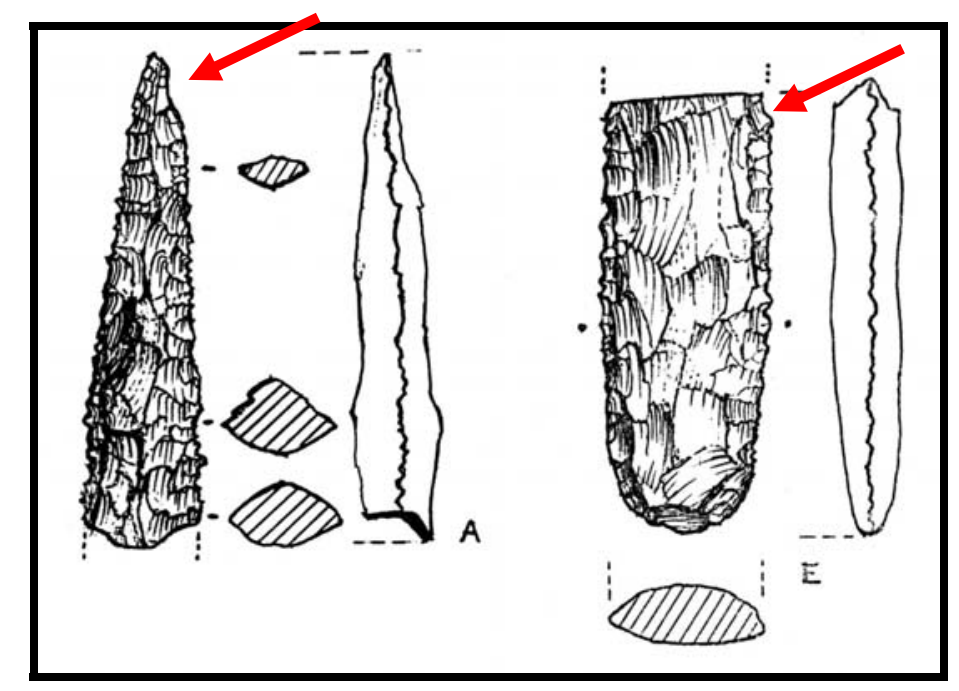

Figura 12.6. Izquierda: Perforador sobre fragmento limbo-apical de punta de proyectil reciclado (PCh1.1. $\mathrm{N}^{\mathrm{o}}$ inv. 27). Derecha: Punta burilante sobre fragmento limbo-basal de punta de proyectil reciclado (PCh1.1. $\mathrm{N}^{\circ}$ inv. s/n $\mathrm{n}^{\circ}$ ) (cortesía C. Aschero). Las flechas rojas respectivas señalan el lugar del reciclaje

Otra posibilidad es que el reciclaje de un filo se produzca por la necesidad de generar un dorso u otro filo relacionado con la prensión, es decir, la confección de un filo pasivo de forma de lograr que la mano se adapte adecuadamente a la pieza. Un ejemplo puede ser la pieza $\mathrm{N}^{\circ} 42$, ya descripta. 
De esto se deriva un aspecto interesante; como consecuencia del reciclaje, la pieza gira, cambia de posición en la mano del artesano para su uso adecuado. La confección de una punta burilante asociada a dos filos formatizados pasivos en la fractura de un fragmento apical de biface $\left(\mathrm{N}^{\circ}\right.$ 14) es un claro ejemplo de ello.

En las puntas de proyectil recicladas sucede algo distinto, ya que debe considerarse la posibilidad del enmangue. Así, además de las piezas № 205 y 210 descriptas, una serie importante de tales instrumentos han visto modificados sus limbos, aunque conservaron sus pedúnculos o sectores basales, por lo que muy posiblemente los nuevos filos se utilizaron enmangados. Entre éstos se encuentran un cuchillo de filo retocado ( $\left.\mathrm{N}^{0} 26\right)$ y una raedera ( $\left.\mathrm{N}^{0} 1339\right)$. Ambos sobre fragmentos limbo-basales de puntas de proyectil apedunculadas, o un perforador sobre una punta de proyectil con pedúnculo destacado y hombros $\left(\mathrm{N}^{\circ} 8\right)$.

Otro aspecto interesante en las puntas de proyectil, y en otros artefactos como los bifaces, refiere a la utilización sistemática de fracturas para la confección de nuevos filos y/o puntas. En la muestra abordada destaca una fractura transversal al eje morfológico en la porción distal de las piezas (en puntas de proyectil apedunculadas lanceoladas), ya que ha sido empleada recurrentemente para el armado de diversos grupos tipológicos; como buriles, puntas burilantes y muescas de lascado simple.

De lo expuesto resulta que el reciclaje involucró tanto piezas enteras (11 casos) como fracturadas (26 casos). Asimismo, en cuanto a las partes de los artefactos sobre las que se produjo dicho proceso, se debe considerar a los filos o puntas (16 casos), a las fracturas de diversa índole (13 casos) y a las piezas completas o fragmentadas (8 casos). Tal variabilidad alerta sobre la diversidad de situaciones en que se presenta el reciclaje, pero no sólo eso, ya que también posibilita un acercamiento al accionar de los artesanos sobre las piezas mismas, en forma de elecciones particulares de morfologías y de gestos manuales de uso de filos o puntas.

\subsection{UTILIDAD DEL ANÁLISIS DE LA SECUENCIA DE FORMATIZACIÓN: EL TRATAMIENTO DE LOS LIMBOS EN PUNTAS DE PROYECTIL DEL TM QS B.2}

Trabajar con la secuencia de formatización (por una definición ver punto 4.6.2. "Secuencia de formatización" en artefactos formatizados en el Capítulo 4) puede ser de suma utilidad para abordar la variabilidad en el comportamiento tecnológico en artefactos puntuales o series de artefactos. Con el fin de avizorar lo expresado, se plantea abordar el tratamiento dado a los limbos de una clase particular de puntas de proyectil, definidas como TM QS B.2 (Figura 12.7). 


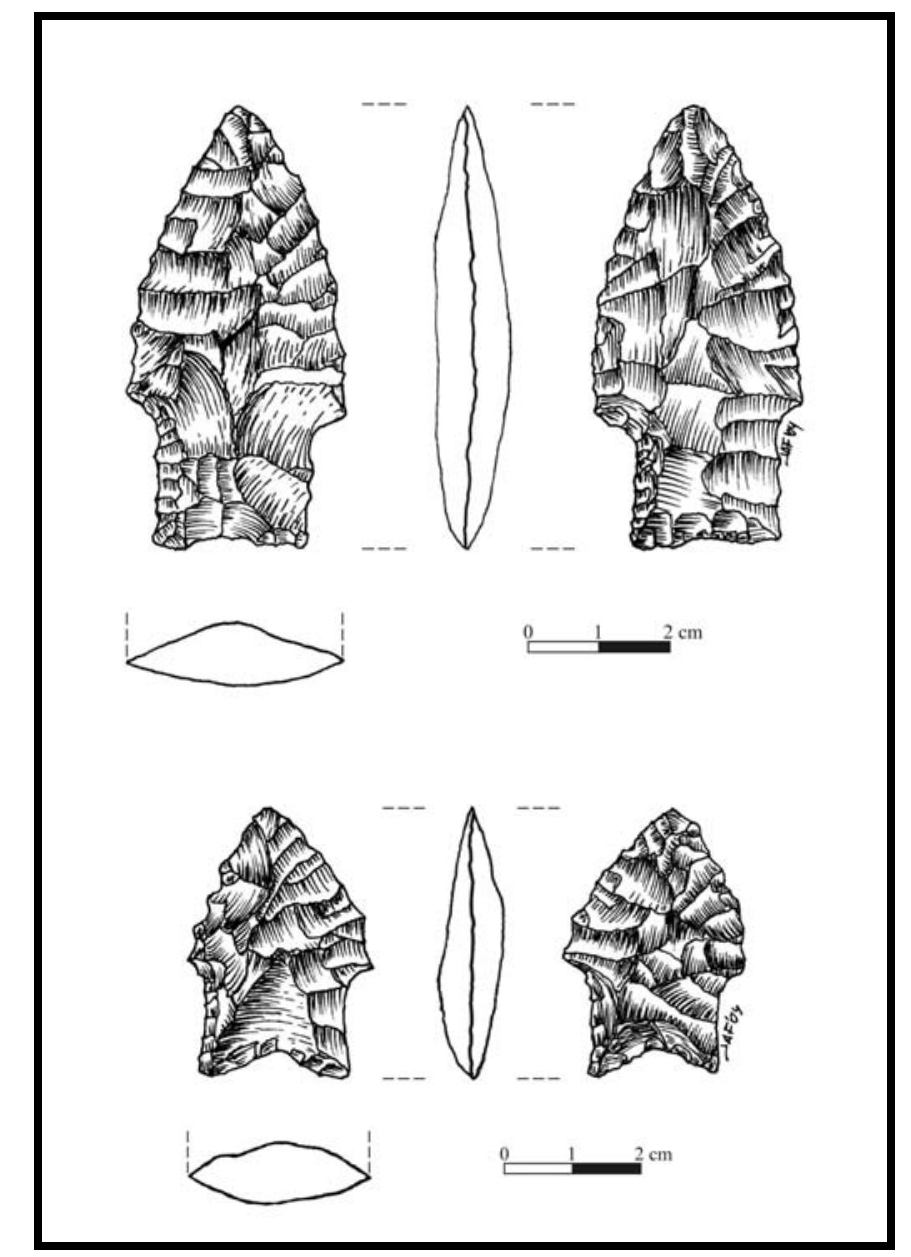

Figura 12.7. Puntas de proyectil TM QS B.2. Arriba: Diseño mantenido ( $\mathrm{N}^{\circ}$ inv. 342). Abajo: Diseño transformado ( $\mathrm{N}^{\circ}$ inv. 542)

Las puntas de proyectil en cuestión provienen de los niveles 4 a 5(5) del sitio arqueológico PP4, con cronología absoluta ca.3800 AP. Las piezas incluidas en el análisis se seleccionaron en función de no contar con reciclaje y de presentarse enteras o con fracturas mínimas. Dado que interesa el tratamiento de los limbos, se han utilizado tanto diseños básicos como mantenidos y transformados. La muestra resultante comprende nueve ejemplares.

A continuación se describen las secuencias de formatización para cada una de las piezas incluidas en el análisis (por la metodología de descripción de las secuencias ver el punto 4.6.2. “Secuencia de formatización” en artefactos formatizados en el Capítulo 4): 
1) $[(\mathrm{A} 31) \mathrm{C} 3+\underline{\mathrm{D} 2} / /(\mathrm{B} 24) \mathrm{C} 3+\mathrm{D} 2]+[(\mathrm{A} 24) \mathrm{C} 3+\mathrm{D} 2 \|(\mathrm{B} 31) \mathrm{C} 3+\underline{\mathrm{D}}]]-\mathrm{N}^{\mathrm{o}}$ inv 342.

Descripción: La pieza en cuestión presenta un cierto grado de mantenimiento, conformando un diseño mantenido. Siguiendo el desarrollo de la secuencia, en el borde izquierdo del limbo los lascados de la cara A se superponen sobre los de la cara $\mathrm{B}$, en forma de retoque marginal, mientras que en el borde derecho, el retoque marginal de la cara B se superpone al de la cara A. Esto implica que el mantenimiento se implementó en forma alterna. Se destaca que al trabajar así se pudo obtener una sección transversal relativamente simétrica; lográndose, además, que las aristas coincidan con el plano de simetría longitudinal.

2) $[(\mathrm{A} 31) \mathrm{C} 3+\underline{\mathrm{D} 2} / /(\mathrm{B} 24) \mathrm{C} 3+\mathrm{D} 2]+[(\mathrm{A} 24) \mathrm{C} 3+\mathrm{D} 2 \backslash \backslash(\mathrm{B} 31) \mathrm{C} 3+\underline{\mathrm{D}}]-\mathrm{N}^{\circ}$ inv 52.

Descripción: El mantenimiento generó un diseño transformado con un limbo triangular mediano. Esta punta de proyectil presenta una situación similar que el caso anterior, por lo que se remite a la descripción de este último.

3) $[(\mathrm{A} 31) \mathrm{C} 3+\mathrm{D} 2 \backslash \backslash(\mathrm{B} 24) \mathrm{C} 3+\underline{\mathrm{D} 2}]+[(\mathrm{A} 24) \mathrm{C} 3+\underline{\mathrm{D} 2} / /(\mathrm{B} 31) \mathrm{C} 3+\mathrm{D} 2]-\mathrm{N}^{\circ}$ inv 542.

Descripción: El mantenimiento en esta pieza modificó notoriamente el limbo, siendo éste triangular corto. Por ende, se trataría de un diseño transformado. En este caso, en el borde izquierdo del limbo el retoque marginal de la cara B se superpone al de la cara A, en tanto que en el borde derecho es a la inversa, implicando mantenimiento alterno. Si bien esto posibilitó obtener una sección transversal simétrica, la arista vista en norma sagital se presenta como un sinusoide, mientras que en norma longitudinal ambos bordes se acercan al plano de simetría longitudinal.

4) $[(\mathrm{A} 3 \mathrm{u} 1) \mathrm{C} 3+\mathrm{D} 2 \backslash \backslash(\mathrm{B} 24 \mathrm{u}) \mathrm{C} 3+\underline{\mathrm{D} 2}]+[(\mathrm{A} 2) \mathrm{C} 3+\underline{\mathrm{D} 2} / /(\mathrm{B} 1) \mathrm{C} 3+\mathrm{D} 2]-\mathrm{N}^{\circ}$ inv 400.

Descripción: El mantenimiento extremo generó un limbo triangular corto, conformando así un diseño transformado. Dado que se trata de un caso similar al anterior, ver la descripción arriba explicitada.

5) $[(\mathrm{A} 31) \mathrm{C} 3+\mathrm{D} 2 \backslash \backslash(\mathrm{B} 24) \mathrm{C} 3+\underline{\mathrm{D} 2}]+[(\mathrm{A} 24) \mathrm{C} 3+\mathrm{D} 2 \backslash(\mathrm{B} 31) \mathrm{C} 3+\underline{\mathrm{D} 2}]-\mathrm{N}^{\circ}$ inv 1343.

Descripción: La pieza en cuestión se trata de un diseño básico. De acuerdo a lo que expresa la secuencia lograda en función del sistema descriptivo propuesto, en ambos bordes del limbo el retoque marginal de la cara B se superpone al de la cara A Esto significa que más allá de que esta punta de proyectil haya sido trabajada bifacialmente, la regularización final se realizó trabajando primero sobre una cara, y luego sobre la otra. Esto parecería estar vinculado a una búsqueda de simetría en sección 
transversal, dada la morfología resultante en dicha sección. Esto tuvo como consecuencia, empero, que las aristas en ambos bordes sean asimétricas respecto del plano de simetría longitudinal, ya que con la última serie de lascados, para cada borde, las aristas se vieron corridas por debajo de dicho plano de simetría.

6) $[($ A3vu1) $\mathrm{C} 3+\underline{\mathrm{D} 3} / /($ B24uv) D2] + [(A24uv) C3 + $\underline{\mathrm{D} 3} / /($ B3vu1) D2] - No inv 59.

Descripción: El limbo de esta punta de proyectil es de tipo triangular corto, en el marco de un diseño transformado. Con respecto a la superposición de las extracciones, la pieza evidencia una retalla profunda en la cara A superpuesta al retoque marginal de la cara B. Se destaca que esto llevó a una sección transversal plano convexa, amén del hecho de que la pieza presentaba de por sí una cara A marcadamente convexa y una cara B relativamente plana.

7) $[(\mathrm{A} 31) \mathrm{C} 3+\underline{\mathrm{D} 2} / /(\mathrm{B} 24) \mathrm{D} 2]+\{[(\mathrm{A} 4 \mathrm{vw}) \mathrm{C} 3+\underline{\mathrm{D} 2} / /(\mathrm{B} 3 \mathrm{wv}) \mathrm{D} 2]+[(\mathrm{A} 24 \mathrm{u}) \mathrm{C} 3+\mathrm{D} 2 \|(\mathrm{B} 3 \mathrm{u} 1)$ D2] $\}-\mathrm{N}^{\mathrm{o}}$ inv. 398.

Descripción: El limbo de esta pieza se encuentra extensamente modificado por el mantenimiento, adoptando una morfología triangular corta irregular. El borde izquierdo del limbo presenta en toda su extensión una superposición mediante retoque marginal de la cara A sobre la B. Por su parte, el borde derecho se diferencia del anterior por una regularización final que puede calificarse como alternante, ya que parte del filo cuenta con una superposición de la cara A y la B y la restante a la inversa. Su ocurrencia se relacionaría con la necesidad de enderezar dicho filo, logrando de esta forma que el mismo coincida con el plano de simetría longitudinal.

8) $\{[(\mathrm{A} 3) \mathrm{C} 3+\mathrm{D} 2 \|(\mathrm{B} 4) \mathrm{C} 3+\underline{\mathrm{D} 2}]+[(\mathrm{A} 1) \mathrm{C} 3+\underline{\mathrm{D} 2} / /(\mathrm{B} 2) \mathrm{C} 3+\mathrm{D} 2]\}+[(\mathrm{A} 24) \mathrm{C} 3+\mathrm{D} 2 \backslash$ (B31) C3 $+\underline{\mathrm{D} 2}]-\mathrm{N}^{\mathrm{o}}$ inv. $247 / 18$

Descripción: La pieza en cuestión se trata de un diseño transformado que presenta un limbo triangular corto irregular. La secuencia de formatización señala que se trata del mismo caso que la punta de proyectil anterior, aunque en bordes de limbo invertidos. Asimismo, al igual que en la pieza señalada, tal regularización alternante parecería tener por objeto lograr una arista coincidente con el plano de simetría longitudinal. 
9) $\{[(\mathrm{A} 3) \mathrm{C} 3+\underline{\mathrm{D} 2} / /(\mathrm{B} 4) \mathrm{C} 3+\mathrm{D} 2]+[(\mathrm{A} 1 \mathrm{X}) \mathrm{C} 3+\underline{\mathrm{D} 2}=\mathrm{C} 3+\underline{\mathrm{D}} 2]\}+\{[(\mathrm{A} 2 \mathrm{w} 4) \mathrm{C} 3+\mathrm{D} 2 \rrbracket(\mathrm{B} 31 \mathrm{w})$ $\mathrm{C} 3+\underline{\mathrm{D} 2}]+[(\mathrm{A} 2 \mathrm{uv}) \mathrm{C} 3+\underline{\mathrm{D} 2} / /(\mathrm{B} 1 \mathrm{vu}) \mathrm{C} 3+\mathrm{D} 2]\}-\mathrm{N}^{0}$ inv. 249/1

Descripción: se trata de un diseño transformado, con un limbo afín a una morfología lanceolada. En su borde izquierdo el limbo presenta en una parte del filo la superposición, a través de una serie de lascados de retoque marginal, de la regularización de la cara A sobre la cara B, mientras que el resto del filo consta de un filo bifacial por extracciones alternadas, que definen una arista sinuosa regular con una amplitud del sinuoside muy estrecho. El borde derecho del limbo, por su parte, cuenta con un tratamiento del filo de tipo alternante, bajo la forma de retoque marginal.

Del análisis de las secuencias de formatización de los limbos de las puntas de proyectil del tipo QS B.2, resulta que el panorama dista de ser homogéneo. De acuerdo con lo registrado, el tratamiento de los limbos implicó una serie de variantes tecnológicas que tienen como correlato la consecución de gestos técnicos específicos. Por ejemplo, girando la pieza de acuerdo a los requerimientos del trabajo bifacial, alterno y alternante. Tales procesos de acción sobre la materia, parafraseando a Lemmonier (1992), parecerían vincularse estrechamente con la búsqueda de una sección transversal biconvexa simétrica, que sería lo esperable por el hecho de tratarse de puntas de proyectil. Esto se logró, por ejemplo, al trabajar en forma alterna una cara de un borde para pasar al borde y cara opuestos (casos 1 y 2) o bien primero una cara y luego la otra (caso 5). Se destaca, empero, que la búsqueda de una sección biconvexa no fue exclusiva, como lo señala el caso 6, ya que a una forma de por sí plano-convexa las series de lascados se instrumentaron de tal forma que no tendieron a enderezar la arista, sino todo lo contrario, ya que acentuaron la asimetría.

Ciertos elementos son realmente interesantes puesto que hacen referencia a la toma de decisiones por parte del o los artesanos a una escala de artefacto, en función de los atributos peculiares de cada pieza. Uno de ellos es que los artesanos tuvieron que sortear el problema de la reducción significativa del tamaño del limbo vía mantenimiento intensivo y continuar, al mismo tiempo, obteniendo una sección transversal biconvexa. Así, siguiendo la información morfológica, las piezas con limbos triangulares cortos presentan una arista sinusoidal en norma sagital (casos 3 y 4), por lo que no siguen el plano de simetría correspondiente. Parecería que a los talladores les resultaba conveniente trabajar en forma alterna, para lograr la simetría; sin embargo, la escasa porción de limbo remanente les impedía insistir lo suficiente como para nivelar la arista, optando por conseguir lo primero. Otros se vinculan a la necesidad de enderezar un arista, aplicando, por ejemplo, series de lascados alternantes (casos 7 a 9). Se hace notar que en estos últimos tres casos, el trabajo alternante se presenta combinado con otros tratamientos del borde, cambiando de filo según la pieza. Esto refleja la variabilidad de gestos técnicos y de acciones llevados a cabo en respuesta a los requerimientos peculiares de cada limbo. 
A modo de corolario, lo señalado permite sostener que la secuencia de formatización es una herramienta útil como forma de aproximación a las decisiones tomadas por los artesanos, así como a la variabilidad de las mismas.

\subsection{IDENTIFICACIÓN DE DESECHOS DE TALLA DE MANTENIMIENTO DE RAEDERAS DE MÓDULO GRANDÍSIMO}

Como se ha visto en el Capítulo 9, las raederas de módulo grandísimo, definidas como grandes lascas con retoque por Escola (2000), son instrumentos relativamente habituales en sitios agro-pastoriles plenos de Antofagasta de la Sierra. Se trata de artefactos formatizados regularizados por retalla y retoque marginal unifacial directo (sobre la cara dorsal de la lasca). Presentan un tamaño considerable, ya que superan los $10 \mathrm{~cm}$ de longitud y los $20 \mathrm{~cm}$ de ancho (tamaño grandísimo siguiendo criterios de Aschero 1975, 1983) (Figura 12.8).

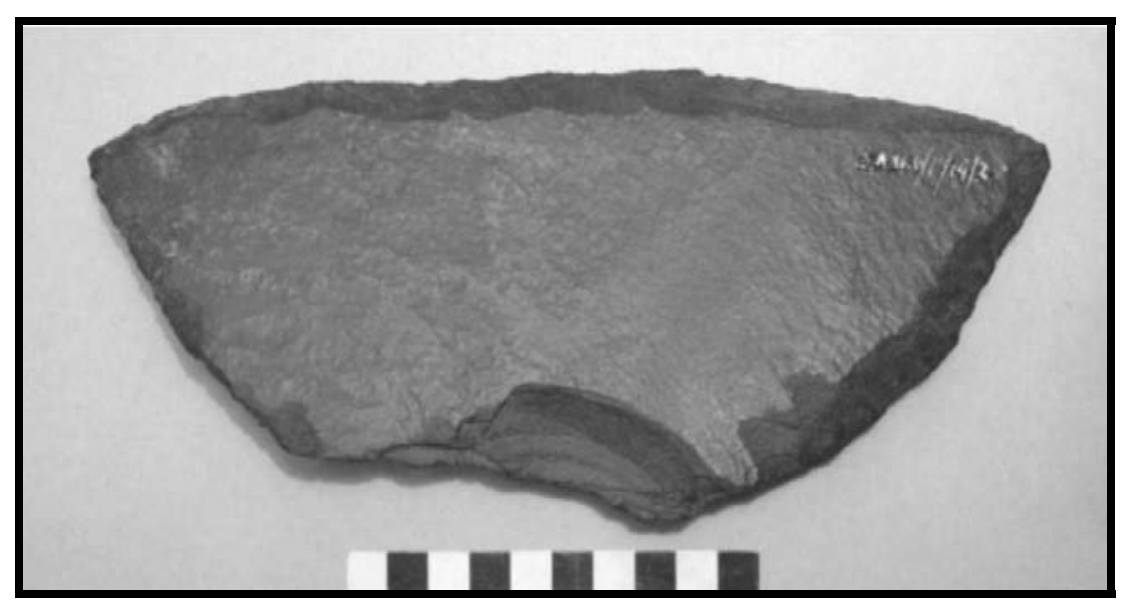

Figura 12.8. Raedera de módulo grandísimo. CChM1 (cortesía P. Escola)

Se plantea aquí que es posible reconocer los desechos de talla producto del mantenimiento de tales raederas, ya que poseen una serie de características morfológicas que los particularizan de los desechos de talla restantes. De esta forma, es posible establecer una vinculación entre un producto concreto y sus subproductos derivados. Se destaca que a partir de esto se pueden obtener evidencias indirectas de la presencia de las raederas de módulo grandísimo a partir de los desechos de reactivación, cuando los artefactos formatizados están ausentes en los contextos, ya que las lascas proceden necesariamente de artefactos que fueron usados y luego mantenidos. 
Tanto en la estructura 2 del Sector III como en la estructura 2 del Sector I de PP9 no se han registrado raederas de módulo grandísimo ${ }^{3}$; sin embargo, en la segunda estructura mencionada se recuperaron desechos de talla que pueden ser vinculados con la reactivación de sus filos.

Tales lascas de reactivación se definen por los siguientes elementos, en función de la segmentación en cara ventral, dorsal y talón y del análisis de las características de los atributos relevantes en cada uno de los mismos, además de variables dimensionales (Figura 12.9):

a) ser relativamente anchas en relación al largo, en una proporción aproximada de 2 a 1 . En general, se trata de piezas de regular tamaño (tamaños lasca pequeña-lasca sensu Aschero 1983), acordes al módulo de las raederas.

b) presentar negativos de lascado con patrón escamoso escalonado en cara dorsal. En la porción distal por lo general conservan un remanente de corteza. Esto se debe a que, como la formatización es unifacial directa, se realiza sobre la cara dorsal de la forma-base, la cual es cortical. Se destaca que la media de la longitud de los negativos de lascado en dichos instrumentos coincide con la de los negativos de lascado de la cara dorsal en las lascas de reactivación. Los casos que presentan una coincidencia en la media pero carecen de este escalonamiento podrían corresponder a lascas de regularización de este instrumento.

c) contar con talones filiformes o puntiformes. En caso de ser lisos, son muy poco espesos y están muy inclinados hacia la cara ventral.

d) presentar cara ventral relativamente inclinada y plana, con un bulbo difuso.

\footnotetext{
${ }^{3}$ Sí se encuentran en forma abundante en superficie, habiéndose recuperado también un ejemplar en estratigrafía en otra área del Sector I (López Campeny com pers.).
} 


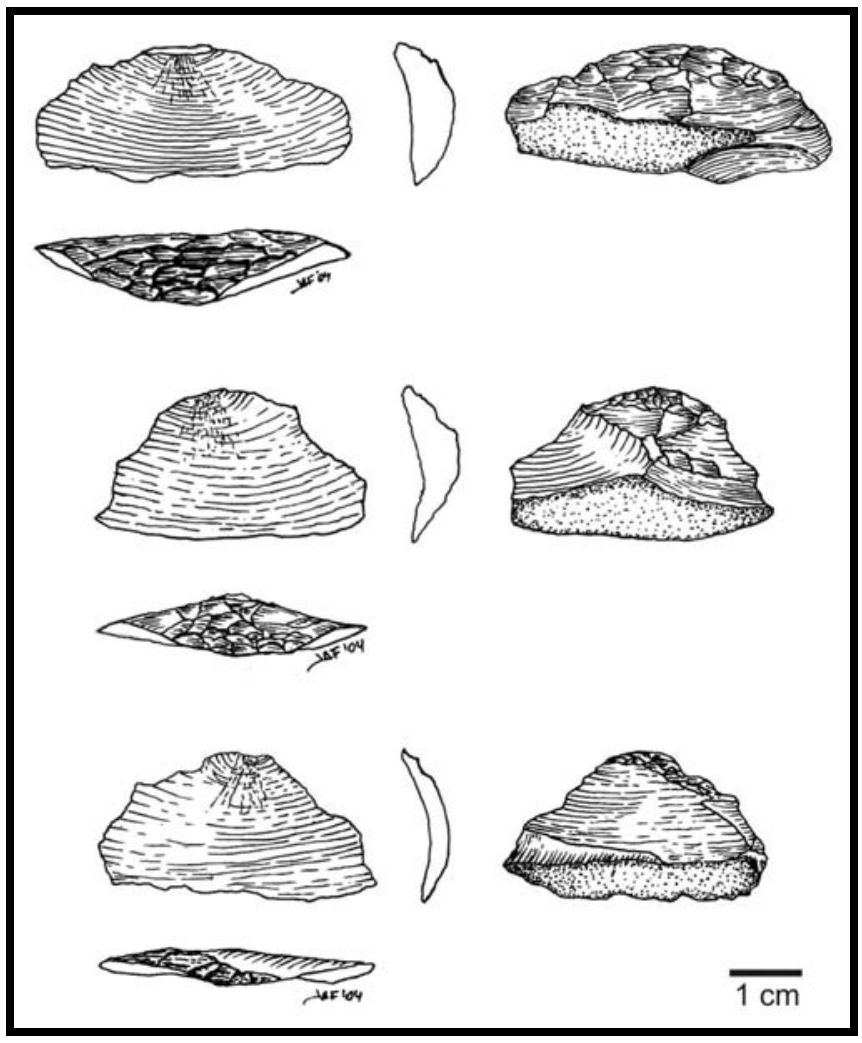

Figura 12.9. Desechos de talla de mantenimiento de raederas de módulo grandísimo. PP9- I- E3

Por sus características morfológicas se trata de lascas de reactivación directa (sensu Aschero 1983).

El hecho de contar con un remanente de corteza en la cara dorsal posibilita, por otra parte, una estimación del espesor deducido de la pieza original -desde el punto de percusión hasta la saliente máxima del borde distal-, siendo estrecha la correspondencia entre tales desechos y los instrumentos en ciernes.

Una manera adicional de relacionar tales subproductos con las raederas de módulo grandísimo en la cuenca de Antofagasta de la Sierra es considerar la materia prima sobre la que se confeccionaron las raederas en cuestión, ya que la manufactura implicaba la utilización de una roca en particular, la Vc4 (Escola 2000). Esta circunstancia, en el caso de las lascas de reactivación de E3, señala que en su interior se regularizaron formas-base y/o se reactivaron piezas terminadas procedentes del fondo de cuenca, ya que se cuenta con 10 lascas con las características descriptas en Vc4, que representan el 90,90\% de las lascas de este tipo.

Se destaca que la presencia de un desecho de talla con la morfología señalada en Vc1, denotaría por un lado, una manufactura local y, por el otro lado, la confección de estas piezas con una materia prima distinta a la registrada hasta ahora -ateniéndose a la circunstancia de tratarse de un caso puntual-. Este punto de manufactura local estaría validado, además, por la ocurrencia de 3 lascas de 
regularización (sin patrón escamoso escalonado) en Vc4, lo que podría significar que las formas-base ingresaron a PP9, desde el fondo de cuenca, sin formatizar. Esto debe ser corroborado mediante la identificación de un mayor número de casos.

Finalmente, ya no desde un punto de vista morfológico-macroscópico, sino funcional (sustancias adheridas), es posible correlacionar a los desechos de talla con los instrumentos citados. Al respecto, se parte de la base que la cara dorsal de los desechos de talla, como remanente del filo original de las raederas, debería contener residuos de uso coincidentes con los registrados en los filos de los instrumentos mismos. Esto pudo ser confirmado, ya que el análisis de microfósiles (fitolitos, almidones y oxalatos) realizado por la Dra. Babot (CONICET, Instituto de Arqueología y Museo) permite postular estrechas vinculaciones entre ambos (ver Apéndice III). 


\section{CAPÍTULO 13}

\section{DISCUSIÓN GENERAL Y CONCLUSIONES}

En este Capítulo se discuten los resultados de la investigación en el marco de los objetivos e hipótesis planteados al comienzo del trabajo. En la primera parte, se evalúan las evidencias generales de la transición, así como las relacionadas con la emergencia de complejidad en Antofagasta de la Sierra, en el lapso abordado. Asimismo, se analizan las vinculaciones entre complejidad y artefactos líticos tallados. En la segunda parte se aborda la variabilidad y el cambio en los artefactos líticos tallados, procurando establecer tendencias generales, en el marco de pautas de subsistencia y movilidad, entre otros factores, en proceso de transformación. En la tercera y última parte se presentan las Conclusiones.

\subsection{LA TRANSICIÓN DE CAZADORES-RECOLECTORES A PASTORES Y AGRICULTORES EN ANTOFAGASTA DE LA SIERRA}

\subsubsection{EVALUACIÓN DE LAS EVIDENCIAS GENERALES DE LA TRANSICIÓN}

Al utilizar la información producida conjuntamente con otras líneas de evidencia en estudio por el equipo de investigación para establecer las características generales del proceso de cambio resulta que el proceso transicional implicó modificaciones substanciales en el modo de vida de los grupos humanos que ocupaban la microrregión. Entre otras (ver Capítulo 6), destacan las evidencias de disminución en la movilidad residencial a una escala microrregional. Esto pudo ser observado, por ejemplo, a través de la consideración de las materias primas empleadas en la confección de artefactos líticos tallados. Así, el análisis de las frecuencias de las diferentes materias primas locales revela un marcado incremento en el uso de las rocas inmediatas al pasar del GC1 al GC2, tanto en artefactos formatizados como en desechos de talla y, como contraparte, una disminución de la importancia relativa de las rocas mediatas. Asimismo, disminuyen los dos tipos de rocas mediatas diferenciados, denominados rocas mediatas lejanas y mediatas cercanas, al pasar de un grupo cronológico a otro, con la particularidad de que las lejanas se reducen a una mínima expresión en el GC2. A partir de esto se postuló una restricción progresiva en la movilidad residencial (y también logística), al haber una cada 
vez menor representación de rocas de más de $2 \mathrm{~km}$ y menos de $25 \mathrm{Km}$ y, al mismo tiempo, un recorte en las distancias involucradas en el aprovisionamiento.

En el GC3, por su parte, se presentan dos situaciones distintas, por un lado, se registra en PP9 un comportamiento similar al del GC2 y, por el otro en CChM1, se observa un predominio de rocas locales mediatas. Esto ha sido relacionado, por ejemplo por Escola (2000) y Escola et al. (2005), con el sistema logístico propio de una estrategia pastoril, enmarcado en el modelo de "sedentarismo dinámico" propuesto por Olivera (1992) para el área. Cabe destacar que se ha sugerido para el lapso 5500-3500 AP una movilidad muy pautada, con retorno a lugares previstos, en el marco de un sistema de asentamiento semi-sedentario o bien de recorridos/circuitos estacionales bien demarcados (Aschero et al. 1993/94, Aschero 1999a), A esto se suma información obtenida recientemente, como, por ejemplo, la concreción de cosechas de Chenopodiaceas, que plantea una situación de estadías prolongadas en un mismo lugar. Para ver en profundidad este tema ver punto 8.2 Utilización de materias primas líticas en el Capítulo 8.

El patrón de asentamiento también sufrió variaciones en el tiempo. De hecho, los GC1 y 2 habrían estado definidos por bases residenciales dispersas a nivel microrregional. Es más, al considerar en conjunto las localidades arqueológicas de Punta de la Peña y Peñas Chicas, resulta que los sitios no sólo se presentaban dispersos sino también muy cercanos entre si. Es el caso de los sitios PCh1.3, PCh1.1, PCh1.6 y PP4, con cronología entre los 4000 y los 3500 años AP aproximadamente. Por otra parte, la mayor parte de las bases residenciales anteriores a los 3000 años AP son cuevas y/o aleros; la excepción a esto sería el sitio PCh1.6, a cielo abierto, aunque se requiere continuar los trabajos de excavación que recién se han comenzado en el sitio, de forma de poder suministrar mayores precisiones. Con respecto al GC3, hay un cambio substancial, ya que se trata de sitios a cielo abierto de mayor tamaño que los sitios precedentes.

La organización interna misma de los sitios sufrió modificaciones. Una de las más destacadas es la recurrencia intersitio de la construcción de estructuras de piedra en aleros bajo roca correspondientes al GC2, como PP4, PCh1.3 y CS1(¿?) (Pintar 2004a). También parecería haber estructuras de piedra en el sitio a cielo abierto PCh1.6, aunque esto necesita confirmación. Se recuerda que Kelly (1992) vincula directamente el aumento de la inversión en arquitectura residencial con una disminución en la movilidad. Ahora bien, una mayor complejidad en la organización de los espacios domésticas se registra en CChM1 y PP9, de acuerdo a lo descripto por Olivera (1992) para el primer sitio, y por López Campeny (2001a) Babot et al. (2004) para el segundo. 
Ahora bien, un elemento importante al analizar la transición de un modo de vida cazadorrecolector a otro agro-pastoril es, obviamente, la subsistencia; específicamente, el abordaje del inicio y consolidación de las prácticas productivas. Se recuerda que en el Capítulo 6 se desarrollaron las evidencias disponibles en este sentido, a nivel local. Cabe, aquí, discutir el proceso de cambio de las estrategias predominantes en el tiempo.

Hay un marcado consenso en que la domesticación de camélidos en la Puna argentina fue un proceso regional, y en el cual Antofagasta de la Sierra no habría sido la excepción (Olivera y Elkin 1994; Elkin 1996a; Olivera 1997, 1998; Yacobaccio 2001b; Reigadas 1994, 2000-2002). Cabe destacar que, si bien no hay evidencias osteométricas seguras de su ocurrencia en Antofagasta de la Sierra, la ambigüedad de los resultados lleva a no descartar la posibilidad de un proceso domesticatorio local (cf. Elkin 1996a, 1996b; Olivera y Elkin 1994; Olivera 1998).

En este marco, de singular importancia, es la instancia de experimentación registrada a nivel local por Reigadas (2000-2002), desde las evidencias de la fibra, involucrando un contexto de control intencional con cronología entre 4700 y 4500 AP. Al respecto, Yacobaccio (2001b) propone para el área una situación de protección con igual cronología, correlacionándola con los niveles 2b3 y $2 \mathrm{~b} 2$ analizados por Pintar (1996a).

De esta forma, podría definirse una estrategia de caza-recolección exclusiva para aquellos contextos anteriores a los 5000 años AP, aproximadamente, y de caza-recolección/domesticación con posterioridad a esa fecha ${ }^{1}$. Utilizando la terminología de Smith (2001) -ver el Capítulo 3-, ca.4500 AP se estaría ante una situación de "economía productiva de bajo nivel, sin domesticados". El punto es dilucidar cuándo se pasó a una "economía productiva de bajo nivel, con domesticados".

Por el momento, no se cuenta con evidencias osteométricas, osteológicas, de fibra o contextuales (por ejemplo, corrales) que remitan a la presencia a nivel microrregional de camélidos domesticados (ver Capítulo 6). Sin embargo, el arte rupestre local esta suministando información relevante. Así, en distintos sitios se observan camélidos de tendencia figurativo-analítica versus camélidos de tendencia figurativa-sintética y geométrica, que se diferencian, además, los primeros de los segundos, por una cierta dinámica del movimiento contra un marcado estatismo, distinguiendo camélidos silvestres y domésticos, respectivamente, de acuerdo a lo sugerido por Aschero (2003, 2005a). Tal diferenciación tendría lugar en la denominada modalidad estilística Río Punilla, fechada relativamente entre los 3500 y los 2500 años AP (Aschero 1999a, 2005a). Esto se vería corroborado, además, por el hecho de contar con un caso de camélido figurativo sintético del tipo señalado con clara

\footnotetext{
${ }^{1}$ No debe dejar de mencionarse la presencia de fibra denominada "tercer grupo" en niveles del Holoceno temprano de QS3 (Reigadas 1994), que corresponde morfológicamente al patrón doméstico actual (llama intermedia). Para una discusión sobre el tema ver Reigadas (2000-2002), Yacobaccio (2001b) y Olivera (1997).
} 
evidencia de carga, en el sitio Peñas Coloradas 1 y con representaciones de camélidos figurativosintéticos en actitudes no dinámicas asociadas a figuras humanas sin armas en Real Grande 3, interpretadas como escenas de pastoreo (Aschero 2005a, com pers.). A partir de lo expresado, podría considerarse, entonces, la ocurrencia de una "economía productiva de bajo nivel, con domesticados", con fecha máxima de 3500 AP; lo cual se destaca, es perfectamente compatible con los datos obtenidos en otras áreas de la Puna argentina (Yacobaccio et al. 1997-98, Yacobaccio et al. 2000; Yacobaccio 2001b).

Dado que puede hablarse de pastoralismo cuando hay un sistema productivo en pleno funcionamiento (Yacobaccio et al. 1997-98, Reigadas 2000-2002), es de suma importancia evaluar la ocurrencia de este último, así como su cronología. Así, estrictamente en base a la información obtenida hasta el momento, la práctica pastoril estaría presente en Antofagasta de la Sierra recién hacia los 2100 AP; sin considerar las evidencias del arte rupestre señaladas. Sin embargo, dada la ausencia de sitios habitacionales entre los 3400 y los 2100 AP, cabe la posibilidad de que los contextos pastoriles se puedan retrotraer, localmente, a fechas tan tempranas como 3500-3000 años AP. Se propone, entonces, una estrategia predominante de caza-recolección/pastoreo para estos momentos. Por su parte, el cambio a una estrategia de pastoreo/caza-recolección tiene bases para ser definida hacia los 2000 años AP.

Ahora bien, diversos autores han sugerido que la ocurrencia de la domesticación animal y la "opción pastoril" son procesos y estrategias "naturales" en la Puna, dadas las características ambientales de la misma, dándole a la agricultura un papel completamente secundario (Yacobaccio et al.1997-98; Olivera 1996; Muscio 2001, 2004). Con respecto a Antofagasta de la Sierra, se ha planteado una situación de complementariedad pastoril-agrícola hacia el $2000 \mathrm{AP}$, aunque con mayor peso de la primera estrategia (Olivera 1992, Olivera y Elkin 1994), a diferencia de otras áreas, como Susques, en la Puna jujeña, donde la agricultura habría estado directamente ausente (Yacobaccio et al. 1997-98). No se pretende discutir aquí la importancia relativa de una estrategia sobre otra a nivel local, sino, simplemente, tratar las evidencias recientemente generadas por Babot (2004a), para el ámbito de Antofagasta de la Sierra, en relación a la presencia de cultígenos y, sobre esta base, establecer que la opción agrícola tuvo un papel destacado en la transición acaecida en la microrregión.

Así, Babot (2004a, 2005), realizó estudios sistemáticos sobre microfósiles en artefactos de molienda que resultaron en el hallazgo de una importante variedad de recursos vegetales comestibles, tanto silvestres como domesticados, en sitios de la microrregión datados entre 4700 y 3400 años AP. Entre los últimos, destacan Chenopodium sp aff. C. quinoa, Oxalis tuberosa "oca", Solanum tuberosum "papa blanca", Ullucus tuberosus "ulluco" y Zea mays "maíz". La información procedente de los fitolitos y almidones señala, en relación a estos cultígenos, que, indudablemente, fueron 
procesados y, seguramente, consumidos; sin embargo, el hecho de que hayan sido consumidos no implica necesariamente que fueran producidos localmente (cf. Gil 1997-98).

De hecho, las evidencias de interacción a largas distancias son abundantes y variadas en el lapso abordado (ver Capítulo 6), incluyendo, entre otros, tecnofacturas varias, recursos vegetales silvestres y domesticados de clara naturaleza no local e información, como arte rupestre y diseños específicos de puntas de proyectil. En este contexto, los cultígenos podrían ser considerados un recurso más a adquirir vía intercambio, reciprocidad, etc. Si esto fuera así, se plantea un escenario de obtención de recursos domesticados por interacción con grupos productores, sean cercanos o lejanos. Ahora bien, esto implica aceptar que grupos productores de cultígenos, a baja escala, estaban presentes en el Noroeste argentino ca.3600 AP, por lo que no hay razón alguna para no considerar como plausible que agricultores tempranos hayan vivido en Antofagasta de la Sierra y, más aún, cuando buena parte de los recursos domesticados son típicos del altiplano andino. Por ello, se plantea provisionalmente una estrategia de caza-recolección/agricultura de pequeña escala para el lapso 40003500 AP. Al mismo tiempo, puede proponerse que la presencia de ciertos cultígenos, como el maíz, se debe, en cambio, a interacción, debido a su carácter mesotérmico. Sin embargo, la existencia a nivel regional de ciertas variedades de maíz resistentes a la altura (ver, por ejemplo, Abiusso y Cámara Hernández 1974), así como el mejoramiento de las condiciones ambientales generales en la microrregión hacia los 3500-3000 AP (Olivera et al. 2002) pueden haber propiciado el cultivo de este recurso a nivel local.

Se destaca que no hay evidencias suficientes como para sustentar la ocurrencia de procesos de domesticación vegetal. Más allá de esto, resulta sugerente que buena parte de los recursos vegetales domesticados sean de tipo microtérmico (quínoa, papa, oca, ulluco), por lo que se están adaptados concretamente a las condiciones ambientales de los desiertos del altura, y que las fechas radiocarbónicas disponibles entre 4000 y 3500 AP están en consonancia con las de cultígenos de otros contextos transicionales de la porción meridional de los Andes Centro-Sur (ver punto 6.2.3. Subsistencia en el Capítulo 6). Por todo esto, se plantea que no es posible hipotetizar la ocurrencia de una "economía productiva de bajo nivel, sin domesticados", siguiendo la ya mencionada terminología de Smith (2001), implicando, por ende, prácticas de manejo y protección de plantas silvestres, pero si de una "economía productiva de bajo nivel, con domesticados" ca.3500 años AP.

La incorporación de cultígenos a la subsistencia, aunque no sea mediante la producción directa, conlleva igualmente cambios en el modo de vida cazador-recolector preexistente (Gil 199798). Sin embargo, considerar al proceso como transicional, desde los restos vegetales, implica sostener que los cazadores-recolectores incorporaron prácticas agrícolas en su estrategia de vida. En este sentido, en el Capítulo 3 se planteó que la transición podía estructurarse de dos formas. Por un lado, a 
partir del inicio de prácticas domesticatorias en el seno de los grupos cazadores-recolectores locales y, por el otro, mediante la incorporación de prácticas agrícolas por contacto con grupos productores. Esta segunda opción es relevante, puesto que la red de interacción que implicaba tecnofacturas, materias primas y circulación de información vigente en ese momento avalaría una situación del tipo señalado. Lo expresado, de hecho, es perfectamente extrapolable a la domesticación animal y al pastoralismo en la microrregión, ya que, de acuerdo con Yacobaccio et al. (1997/98), aunque los dos sucesos se encuentran indudablemente ligados, no tuvieron que darse necesariamente en el mismo lugar.

Desde el punto de vista arqueológico y etnográfico, está claro que los grupos cazadoresrecolectores han mantenido contactos regulares con grupos productores en diversas partes del mundo (Bodley 1999, Lee y Daly 1999). Esta interacción ha sido planteada, por ejemplo, a nivel microrregional, por Cornejo y Sanhueza (2003) y Planella et al. (2005) para el valle del Río Maipo (Chile Central), a partir de indicadores del patrón de asentamiento, la movilidad, la tecnología cerámica y lítica y la arqueobotánica. Por otra parte, Gil (1997-98) considera como muy probable, en el Sur de Mendoza, la adquisición de cultígenos por parte de grupos cazadores-recolectores de grupos agricultores vecinos a nivel regional. En Antofagasta de la Sierra, puntualmente, no parecería haber diferencias en la organización del asentamiento, la movilidad, la ergología o la tecnología que permitan aseverar la coexistencia a nivel microrregional de grupos cazadores-recolectores y agropastoriles, por lo que se considera que la interacción, si es que el proceso se dio de esa forma, implicó una escala regional. Se recuerda que los datos sobre extensión de las redes avalan esta idea.

Pasando al lapso 2100-1500 AP, la información disponible permite aseverar la presencia de un sistema agrícola pleno. Esto estaría atestiguado no sólo por la presencia de cultígenos en forma de micro y macrorrestos en artefactos diversos, sino, principalmente, porque dentro de los conjuntos de artefactos líticos se han recuperado palas y/o azadas y raederas de módulo grandísimo indudablemente vinculadas con actividades de labranza. Se propone, entonces, para las ocupaciones posteriores al 2000 AP una estrategia de agricultura/caza-recolección. Cabe destacar que los recursos vegetales domésticos presentes en este momento son los mismos que los identificados en el lapso 4000-3500 AP.

Ahora bien, el desarrollo de prácticas agrícolas y pastoriles en Antofagasta de la Sierra lleva a la necesidad de conjugar las mismas con la caza-recolección, de forma de establecer cómo se habría dado el cambio en las estrategias predominantes en el área. Así, los contextos con cronología anterior al 5000 AP estarían definidos por una situación de caza-recolección exclusiva. Posteriormente, entre los 4700 y 4500 años AP, se estaría en presencia de caza-recolección más una "economía productiva de bajo nivel, sin domesticados" -con prácticas de manejo y protección de camélidos silvestres y sin poder aseverar experimentación con recursos vegetales-. El lapso 4000-3500 años AP, a su vez, estaría 
definido por la combinación de caza-recolección/“economía productiva de bajo nivel, con domesticados", tanto en lo que respecta a camélidos domesticados como a cultígenos, involucrando, posiblemente, pastoralismo (¿?). Finalmente, el segmento 2100-1500 AP estaría representado por estrategias pastoriles-agrícolas/caza-recolección.

En base al esquema suministrado, al introducir la diferenciación en grupos cronológicos (ver punto 5.4 Grupos cronológicos en el Capítulo 5), el GC1 coincidiría con un contexto de cazarecolección pleno que incluiría prácticas de manejo y protección de recursos silvestres, el GC2 con una estrategia caracterizada por la caza-recolección y donde habría prácticas productivas a baja escala, tanto de recursos animales como de vegetales domesticados y el GC3, por último, con una estrategia productiva agro-pastoril complementada con caza y recolección. Desafortunadamente, con respecto a este último grupo cronológico, por el momento no es posible establecer la "escala" de la práctica agrícola en la microrregión. Sin embargo, las evidencias parecen indicar que la agricultura habría tenido una mayor importancia que la que anteriormente se le había otorgado.

Recientemente, se ha comenzado a generar, a nivel microrregional, información sobre dieta que involucra contextos enmarcados en el lapso abordado. Si bien todavía se trata de datos aislados, los resultados son verdaderamente sugerentes, ya que no sólo muestran que el componente vegetal era una parte significativa en la dieta sino también que su importancia relativa se vio incrementada con el paso del tiempo. Así, se realizaron análisis isotópicos sobre muestras del cabello de un párvulo momificado naturalmente hallado en un fardo funerario (Aschero et al. 2002) en la localidad arqueológica Punta de la Peña (PP11A). El hallazgo proporcionó una datación de ca.3400 años AP (ibid.). Entre los resultados alcanzados por Macko et al. (2001a), destaca el $\delta^{15} \mathrm{~N}$ en el cabello del bebé de 10,3, que indica una dieta omnívora, si se compara con valores de poblaciones humanas actuales. Tales autores estiman que la dieta de la madre también era omnívora, ya que a la temprana edad del párvulo (máximo de 4 meses), el $\delta^{15} \mathrm{~N}$ de ambos puede diferir sólo en un 1 ó $1.5 \%$, resultando un valor de 8.8 a $9.3 \%$ para la madre. Por su parte, el $\delta^{13} \mathrm{C}$ resultó en $-16,1$, derivando el carbono del bebé en un $74 \%$ de plantas $\mathrm{C} 4$ y en un $26 \%$ de plantas $\mathrm{C} 3$. Al respecto, consideran que aunque parte del carbono del bebé derive de carne de camélido proveniente de la dieta de su madre, hay un componente importante extra derivado de plantas $\mathrm{C} 4$, que puede ser maíz u otros cereales $\mathrm{C} 4$ silvestres. Finalmente, debido a que las plantas C4 no dominaban el ecosistema, sugieren que la presencia en la dieta de cultivos $\mathrm{C} 4$, como el maíz, es más probable que la recolección de cereales silvestres. Se recuerda que hay evidencias de maíz en artefactos de molienda como microrrestos con igual cronología (Babot 2004a).

Por otra parte, Macko et al.(2001b) analizaron muestras de cabello y uña humanas procedentes de un contexto funerario recuperado en la estructura habitacional E2 del Sector III del sitio PP9, 
datado hacia los 1500 años AP (López Campeny 2001a). Según los autores citados, los valores de $\delta$ ${ }^{13} \mathrm{C}$ indican, para las muestras de uña y de cabello, una dieta basada exclusivamente en plantas $\mathrm{C} 4$, siendo el porcentaje de las mismas en la dieta del $98 \%$ para la primera y del $95 \%$ para el segundo. Al respecto, sostienen que la elevada proporción de plantas $\mathrm{C} 4$ en la dieta podría estar vinculada al consumo de cultígenos como, por ejemplo, el maíz; en tanto que la abundancia natural de $\delta{ }^{15} \mathrm{~N}$ en las muestras (cabello: 11 y uña: 10,2), indicaría que la dieta de estos individuos tenía un importante componente de origen animal, en el marco de una dieta de de tipo omnívora.

Destaca, por último, que los valores de $\delta{ }^{13} \mathrm{C} \%$ del "bebé de la peña" muestran una menor proporción de plantas C4 (74\%) en la dieta, al comparar con los porcentajes (95\% y 98\%) proporcionados por las muestras de individuos de PP9. Estos porcentajes les permiten a Macko et al. (2001b) notar un incremento en la proporción de los vegetales C4 que están presentes en la dieta humana de estos individuos de Antofagasta de la Sierra, en un lapso de aproximadamente 1.900 años.

Desde éstas y otras líneas de evidencia consideradas (ver Capítulo 6), es posible sostener que el "nudo" del proceso transicional se presenta localmente ca.3500 años AP. Más allá de las convergencias con otras áreas puneñas, por ejemplo, en cuanto a cronología o a la disminución de la movilidad residencial, son significativas las particularidades de la secuencia de Antofagasta de la Sierra. Entre éstas, se pueden mencionar, la importancia de los recursos vegetales comestibles en la subsistencia, la ausencia de conglomerados residenciales a cielo abierto como los de la Quebrada de Tulán o de Puripica, en el desierto del norte de Chile (Núñez 1992, 1994; Núñez et al. 1999) o el hecho de carecer, hasta el momento, de evidencias de utilización de cerámica, que si está presente en otros contextos puneños, como se verá a continuación. Todo esto estaría manifestando una situación de marcada heterogeneidad en la transición de cazadores-recolectores a sociedades agro-pastoriles a nivel macro-areal, la cual ya fue señalada por diferentes autores (por ejemplo, Aschero 1994; Yacobaccio 1994, 1997; Olivera y Elkin 1994; Olivera 1998; Yacobaccio et al. 1997-98).

Con respecto a la presencia de cerámica en contextos arqueológicos de la Puna, diversos sitios con cronología entre 3600 y 2900 años AP cuentan con esta tecnofactura. En la Puna jujeña se encuentran, por ejemplo, Tomayoc, Inca Cueva alero 1 y Cueva de Cristóbal, con fechados entre 3000 y 2800 años AP aproximadamente (García 1995, 1997, 1998; Fernández 1988-89); en la Puna salteña, por su parte, es el caso del sitio Ramadas (Estructura 1), fechado hacia los 3600 años AP (Muscio 2004); finalmente, en la Quebrada de Tulán, en la cuenca del Salar de Atacama (Chile), en los sitios Tulán 54 y Tulán 85, fechados entre 3200 y 2900 AP (Núñez 1992, 1994).

En Antofagasta de la Sierra, en cambio, la cerámica aparece recién con los grupos agropastoriles plenos, ca.2100 AP (Olivera 1992). Aschero et al. (2002) hacen referencia al hallazgo de 
dos fragmentos de un tubo cerámico en el borde externo de la oquedad que contenía el fardo funerario del sitio PP11A, planteando la asociación con el mismo, por lo que estarían datados entre los $3600 \mathrm{y}$ los 3200 años AP. Se destaca que la ubicación cronológica de estos fragmentos cerámicos está en discusión. Por ende, el único vestigio recuperado, hasta el momento, con fecha anterior a la citada sería, en realidad, un antecedente de la cerámica propiamente dicha. El mismo proviene del sitio PCh1.5, datado ca.3800 años AP. Si bien no está establecida fehacientemente la naturaleza de este hallazgo a nivel contextual, posiblemente se trate de una tumba o una ofrenda. Específicamente, es un fragmento de la pared de un recipiente de forma no determinable (Figura 13.1), compuesto por una estructura de haces de Poaceas que puede apreciarse en las múltiples fracturas. Esta "armadura" estaría sostenida entre sí por una cubierta constituida por arcilla, ceniza, microcarbones y fragmentos de tejido (tallo y/o hojas) de Poaceas, presente tanto en la cara externa como en la interna. Su color es pardo-grisáceo, con un acabado de superficie de tipo alisado. Su cocción habría sido por secado al sol. Este fragmento guarda similitudes con un recipiente recuperado en el sitio Inca Cueva 7, en la Puna Jujeña con, cronología ca.4000 AP (Aguerre et al. 1973, Aschero y Yacobaccio 1998-99). Este último se diferencia del primero en el tipo de armadura empleada, ya que se trata de un entramado de varillas curvas y rígidas, y en la cubierta, debido a que reviste sólo la cara externa.

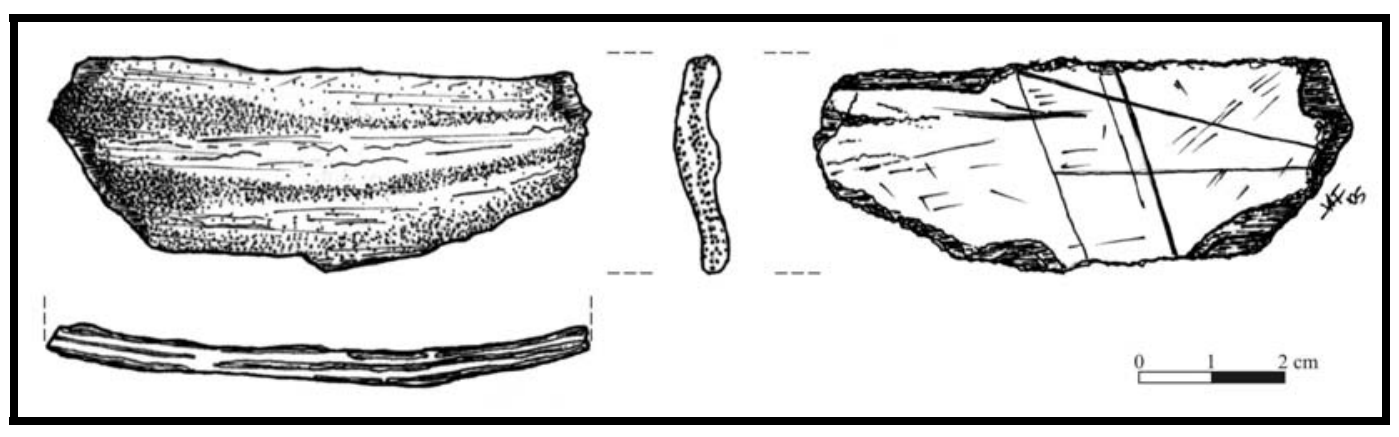

Figura 13.1. Fragmento de artefacto de arcilla secada al sol (PCh1.5, $\mathrm{N}^{\mathrm{o}}$ inv. 33)

\subsubsection{EVIDENCIAS DE COMPLEJIDAD SOCIO-CULTURAL EN ANTOFAGASTA DE LA SIERRA}

En el Capítulo 3 (punto 3.1.4.2. Indicadores arqueológicos de complejidad) se presentaron los indicadores generalmente vinculados con la ocurrencia de complejidad en cazadores-recolectores, a saber: movilidad residencial reducida/sedentarismo, comportamiento territorial, densidad poblacional elevada, desigualdad social, redes de interacción a largas distancias bien constituidas, explotación intensiva de recursos particulares, economías de retorno diferido e importancia de las prácticas rituales. Por su parte, en el Capítulo 6 se abordaron las evidencias disponibles con respecto a los indicadores mencionados para Antofagasta de la Sierra. Ahora bien, en este punto se trata, específicamente, la presencia de complejidad socio-cultural en los cazadores-recolectores que 
ocuparon la microrregión entre los 5500 y los 3000 años AP aproximadamente, desde los indicadores aludidos. Asimismo, simultáneamente, se analiza la relación entre complejidad y artefactos líticos tallados a partir de las características tecnológicas y tipológicas de los conjuntos analizados.

De esta forma, si se tiene en cuenta cada uno de los indicadores considerados en el Capítulo 6 por separado, parecería que las evidencias de complejidad son fragmentarias o ambiguas como para sostener que tal proceso tuvo un desarrollo local en la microrregión. Sin embargo, esta situación se revierte al analizar en conjunto las diferentes líneas de información disponibles, en función de una concepción teórica que considera a la complejidad como un fenómeno producto de múltiples variables definitorias.

Se destaca que la información detallada sobre las distintas líneas de evidencia ha sido desarrollada previamente, por lo que se hace referencia aquí sólo a aquellos aspectos cruciales, profundizándose en ciertos temas relevantes que no fueron tratados previamente.

\subsubsection{Movilidad residencial}

Se registra una disminución progresiva en la movilidad residencial, con, por ejemplo, un predominio absoluto de rocas inmediatas hacia los 3500 AP en instrumentos y desechos de talla. Asimismo, la micromovilidad, orientada a la obtención de recursos básicos para la subsistencia, implica distancias no mayores de $20 \mathrm{Km}$. Interesa recordar aquí lo señalado en el punto 6.2.1. Movilidad residencial reducida (Capítulo 6) en cuanto a que Antofagasta de la Sierra, a fines del Holoceno Medio, contaba con recursos hídricos y vegetales importantes en relación a las condiciones generales imperantes en el resto de la Puna Salada, por lo que pudo haber sido un terreno propicio para la circunscripción social. Tal circunscripción, generada por la competencia social entre territorios con muy baja productividad primaria, habría llevado a una demarcación más estricta de los mismos, como se verá a continuación.

\subsubsection{Territorialidad}

Si bien no hay evidencias de defensa perimetral por la fuerza, destacan una serie de elementos que apuntan claramente en la dirección de una creciente señalización de identidad y de derecho territorial. Al respecto, Aschero (2005b) señala una variabilidad quebrada a quebrada en el arte rupestre local, ca.3500 años AP, formada por diferentes "estilos" de una misma modalidad ("Rïo Punilla"), a modo de elementos idiosincráticos de ciertos sectores del espacio microrregional, que coexisten temporalmente con pautas de diseño y temas compartidos, lo que surge cuando se comparan las series asignadas de sitios ubicados en distintas quebradas, como Cacao 1A, Real Grande 3, Peñas 
Coloradas 1 y del sitio La Torre en el fondo de cuenca. Este autor plantea que, de esta forma, las representaciones rupestres podrían ser marcadores de ciertos espacios y recursos por parte de segmentos sociales específicos (familias, grupos de parentesco o linajes).

Se destaca que esta situación de virtual control de ciertas porciones de la microrregión por parte de grupos específicos tendría un reflejo en la utilización de materias primas empleadas en la confección de artefactos líticos tallados. Es así que entre los 4000 y los 3500 años AP, en coincidencia con la cronología postulada por Aschero, se evidente una drástica restricción en la frecuencia de artefactos manufacturados sobre $\mathrm{Vc} 4$, una roca que se presenta en el fondo de cuenca. Si se tiene en cuenta que los sitios PP4, PCh1.3 y PCh1.1 se encuentran a aproximadamente $16 \mathrm{~km}$ de dicha cantera, y por ende, a una distancia acorde, sobre la base de la información obtenida, con el rango de acción de las actividades diarias de subsistencia, no habría motivo aparente para que no se produzca tal acceso. Por esto, se considera que son pertinentes, en este caso, las diferencias observadas por Aschero en el arte rupestre del sitio La Torre, en el fondo de cuenca y el de Peñas Coloradas 1, en la "Quebrada del Río Las Pitas", donde se encuentran también las 3 bases residenciales aludidas. Es muy posible, entonces, que la restricción en la utilización de dicho recurso lítico se deba a la presencia de ámbitos de control territorial. Cabe realizar una acotación: dicha territorialidad no estaría vinculada a grupos de elite interesados en controlar un recurso determinado (ver punto siguiente), sino, más bien, a grupos familiares que detentan el acceso, por ejemplo, a recursos hídricos, vegetales y fauna de sectores específicos de la microrregión.

Se debería tener en cuenta, también, la diversidad de puntas de proyectil existente entre los 4000 y los 3500 años AP, que alude a una importante cuota de variación estilística a nivel microrregional (ver Capítulo 9), la que, en coordenadas espaciales, podría reflejar la presencia de territorios. Desafortunadamente, la muestra de sitios disponible, correspondientes a una sola quebrada, no permite establecer si hubo alguna vinculación entre diseños específicos y sectores particulares de la microrregión. Se han iniciado prospecciones en otras quebradas, pero por el momento no se cuenta con resultados concretos. Lo que si se puede establecer, en cambio, es un proceso de diferenciación social intra-quebrada, con la cronología en ciernes, lo cual será discutido en el punto siguiente.

Asimismo, ciertos diseños específicos de puntas de proyectil, al aumentar la escala espacial, podrían ser considerados como particulares de Antofagasta de la Sierra (Figura 13.2), abriéndose una interesante perspectiva que debe ser abordada necesariamente a partir de una comparación exhaustiva a nivel regional y macro-regional. De hecho, habría que evaluar si la presencia de la regularización alterna en los diseños pedunculados de la microrregión constituye un rasgo estilístico exclusivo, ya que de 13 tipos y subtipos morfológicos de puntas de proyectil pedunculadas en el GC2, 9 poseen retoque/microrretoque alterno. 


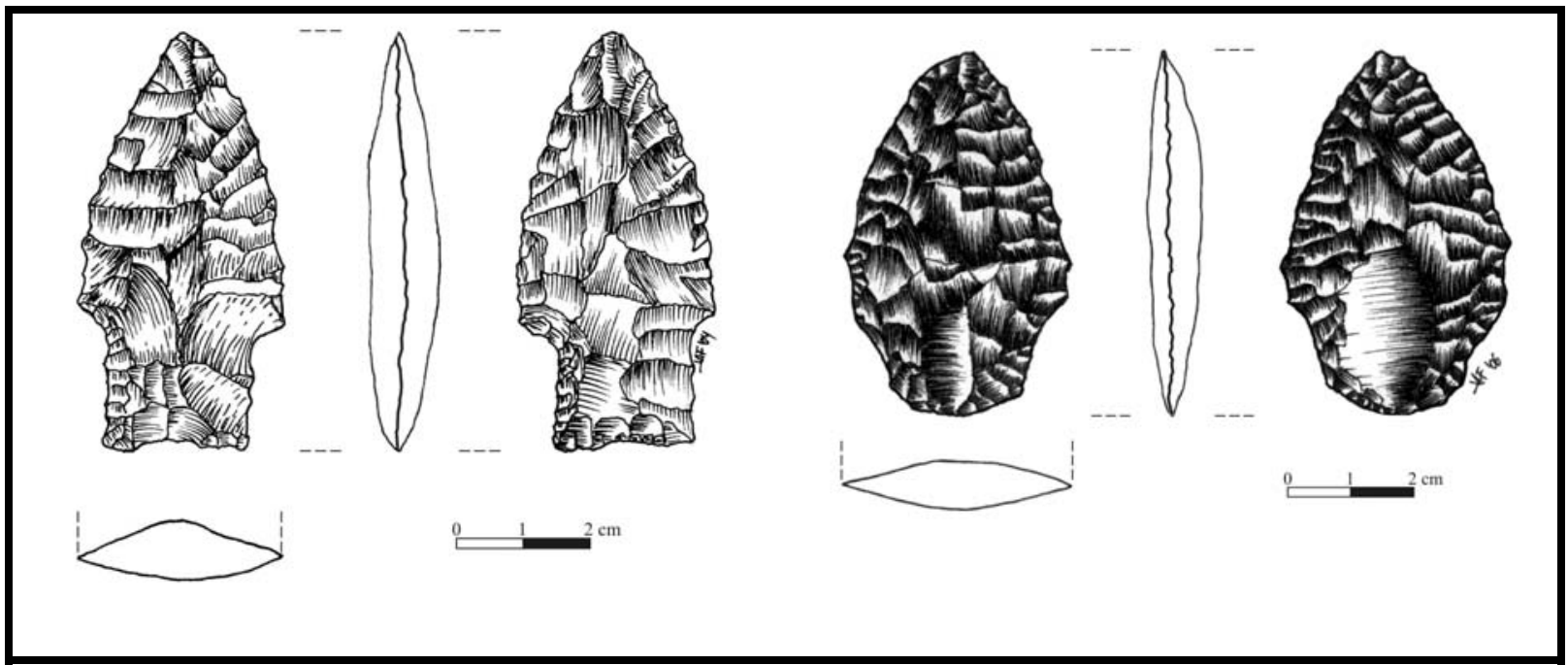

Figura 13.2. Puntas de proyectil con pedúnculo con retoque/microrretoque alterno. Izquierda: TM QS B.2 (PP4. $\mathrm{N}^{\mathrm{o}}$ inv. 342). Derecha: TM PCh A (PCh1.6. $\mathrm{N}^{\mathrm{o}}$ inv. 187)

Finalmente, otro elemento que debe terse en cuenta es la ubicación espacial del arte rupestre y de una serie de inhumaciones y depositaciones intencionales de conjuntos de objetos, definidas como posibles ofrendas por Olivera et al. (2003), coincidente con las zonas con concentración de nutrientes, áreas de vegas o fuentes de agua y espacios aptos para la caza/recolección o el pastoreo; por lo que es probable que esta asociación de los muertos y las ofrendas con sectores particulares del paisaje haya servido para denotar el derecho territorial, funcionando como marca (Aschero 1999b, 2005a, 2005b; Olivera et al. 2003).

\subsubsection{Desigualdad social}

Se destaca la ausencia de indicios claros y definitorios de desigualdad social. En el Capítulo 6 se hizo referencia a la posibilidad de que las diferencias en la composición de los ajuares en sólo dos enterratorios diacrónicos esté correlacionado con el surgimiento de desigualdades sociales en la microrregión. Sin duda, es necesario contar con mayor cúmulo de información, por ejemplo, en cuanto a inhumaciones y sus contenidos.

Sin embargo, desde otras líneas de evidencia, se cuenta con información que sería contraria, en primera instancia, a la presencia de desigualdad social. Oportunamente se señaló que las evidencias de jerarquías aparecían en el arte rupestre con posterioridad al 2000 AP, en base al tamaño y tratamiento de las figuras humanas representadas -por ejemplo, tocados cefálicos, armas, cabezas-trofeo o adornos pectorales- (Podesta 1986/87; Aschero 1998, 1999a). Es más, Aschero (2005b), propone una situación hacia los 3500 años AP de accionar cooperativo entre poblaciones pequeñas que regula el uso de recursos, el acopio de excedentes y el mantenimiento de las interacciones a distancia; planteándola 
como una respuesta distinta al usufructo del trabajo de otros que la desigualdad traería aparejada. En este marco, subraya el papel del sitio Confluencia 1 como parte de una estrategia que refuerza las relaciones cooperativas disminuyendo grados de conflicto causados por la competencia por los recursos, ya que el sitio reúne representaciones de diferentes "estilos" de una misma modalidad ("Río Punilla"). De esta forma, el contexto funcional del sitio propuesto es el de un espacio de coparticipación ritual, mediante el cual se activa la cosmovisión común, de manera de disminuir los posibles conflictos derivados de la competencia entre individuos, grupos o linajes, a partir de la valorización de lo que es común a todos.

De hecho, la puesta en práctica de un accionar cooperativo a nivel local, puede ser considerada, por ejemplo, al tener en cuenta las evidencias de técnicas de caza colectiva (Aschero y Martínez 2001) o la redistribución de presas entre PCh1.1 y PCh1.3, en base al análisis de los fragmentos de puntas de proyectil recuperados en ambos sitios (ver punto 9.3. Análisis de la recurrencia de tipos y especímenes morfológicos en el Capítulo 9).

Cabe destacar que, desde los artefactos líticos tallados no hay evidencia alguna de que haya habido control de la producción de artefactos específicos por parte de grupos (élites) que tienen el control sobre el trabajo de otros (Arnold 1996) -ver punto 8.1.2.8. ¿Evidencias de especialización artefactual y artesanal en artefactos líticos tallados?-.

Por cierto, la virtual ausencia de jerarquías no implica que no haya habido diferencias de status entre los miembros de los grupos abordados, situación habitual entre grupos de cazadoresrecolectores "igualitarios" (Kelly 1995, Barnard 2001). Por ejemplo, ciertos individuos pueden poseer mayor prestigio que otros por ser habilidosos en la caza o en la confección de tecnofacturas, pero, por cierto, no tienen poder. Asimismo, pueden surgir líderes para el desempeño de tareas específicas, como en el caso de las partidas de caza comunales mencionadas. En el caso de los artefactos líticos tallados aquí considerados, es posible que la variación morfológica de los bifaces registrada en el Capítulo 10, relacionada con habilidades motoras y cognitivas diferenciales por parte de individuos con distinto grado de habilidad (muy buenos talladores, mediocres y aprendices), sea también un ejemplo de ello, teniendo un correlato en el prestigio de los artesanos que los manufacturaron (cf.Bodú 1996, Stout 2002).

Más allá de la presencia o no de desigualdades y jerarquías, lo cierto es que entre los 5500 y los 3500 años AP tuvieron lugar procesos de diferenciación social, de acuerdo a las evidencias suministradas por el análisis de los diseños de puntas de proyectil. Es notorio que tales procesos no sólo se presentan en forma diacrónica sino que tienen también una expresión sincrónica (ver Capítulo 9 por información detallada). En el primer caso, se registra un aumento de la variación estilística con 
el correr del tiempo, resultante de la comparación de los tipos y especimenes morfológicos presentes en los GC 1 y 2. En el segundo caso, sitios relativamente sincrónicos, que se sitúan cronológicamente en el GC2, presentan diseños de puntas de proyectil que son mayoritarios diferencialmente en cada uno de los sitios considerados. Así, en PCh1.3 predomina el TM PCh A, en PP4 los TM QS B.2, PP A y PP B y en PCh1.1 los TM PCh E y PCz A (Figura 13.3).Se destaca que los tres sitios son bases residenciales ocupadas por pequeños grupos familiares, poseen el mismo repertorio artefactual y ecofactual y se encuentran muy próximos entre sí, por lo que puede descartarse el hecho de una funcionalidad distinta que explique tal diferenciación.

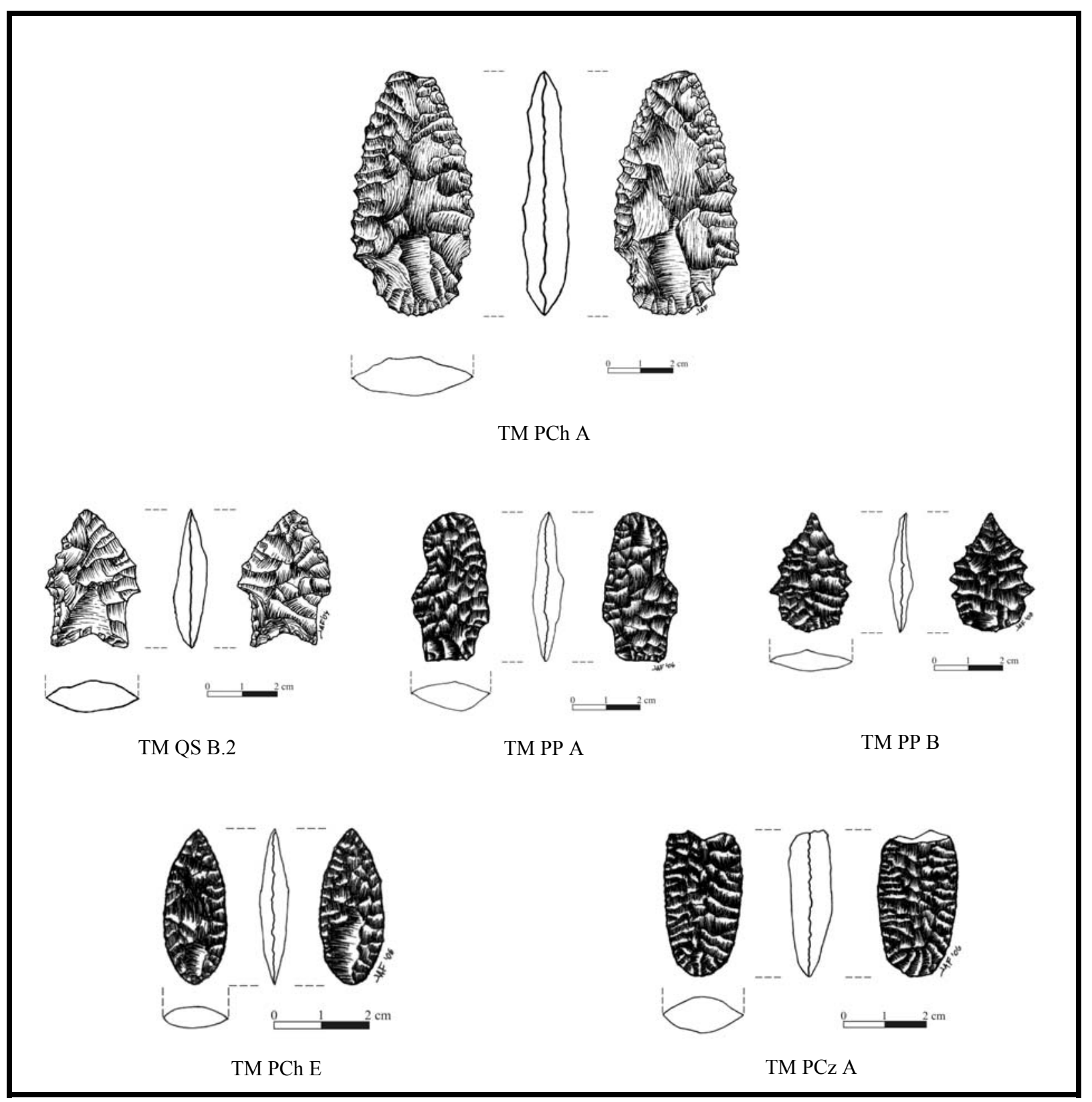

Figura 13.3. Tipos morfológicos predominantes en los sitios PCh1.3 (arriba), PP4 (medio) y PCh1.1 (abajo) 
Es pertinente realizar una serie de acotaciones con respecto a la forma de utilización de los tipos morfológicos. Es evidente que el uso dado a los mismos, que implica una adscripción temporal, los asemeja a los tipos culturales definidos por Aschero (1975); sin embargo, la escala de análisis es diferente a la empleada en la definición de estos últimos, puesto que se parte de una aproximación microrregional, y más aún, al nivel de una quebrada en particular, y no de comparaciones regionales o macrorregionales, como es el punto de partida en la definición de los tipos culturales (ibid.). Por otra parte, el interés no es identificar unidades culturales sino, por el contrario, abordar la variabilidad a nivel de segmentos sociales dentro de un grupo mayor. Es decir, se plantea la existencia de diferencias entre individuos y/o grupos de individuos dentro de un mismo sistema social o sociedad que comparten una adscripción de conjunto. Desde esta perspectiva, dentro de un grupo es factible encontrar diferencias a nivel local, por ejemplo, entre los buenos talladores antes mencionados que pueden diferenciarse a través de diferencias en los diseños producidos.

Esto implica que las tendencias observadas en el Río Las Pitas no reflejan a un grupo buscando diferenciarse de otros de regiones distintas, sino a segmentos poblacionales que forman parte de una unidad mayor y que tratan de individualizarse de cierta forma. Así como Aschero (2005b) plantea que el arte rupestre, justamente en el GC2, tuvo un papel importante minimizando los límites sociales, la utilización de las puntas de proyectil se vincularía, por el contrario, con el hecho de reforzar los mismos y marcar la diferencia, con su variación formal comunicando información social relevante (Wobst 1977, Wiessner 1983).

De acuerdo a Whittaker (1987), es posible, a través de la variación estilística, distinguir grupos sociales a distintos niveles, desde la comunidad, pasando por núcleos familiares y llegando hasta el individuo. El problema es identificar con certeza la clase de grupo social con la que se está tratando. De esta forma, habría que evaluar, por ejemplo, si los subtipos morfológicos diferenciados en el TM PCh1.3 son el resultado de individuos concretos, denotando variación estilística al nivel del individuo. Esta es una interesante perspectiva que será abordada en el futuro

\subsubsection{Interacción a grandes distancias}

Las evidencias de recursos bióticos y abióticos alóctonos entre los 5500 y los 3500-3000 años AP son abundantes en el registro arqueológico local, siendo utilizados como materia prima para la confección de diversas tecnofacturas, para la alimentación -taxones silvestres y domesticados diversos-, y formaron parte, además, de una tecnología de prestigio (ver Capítulo 6 por mayores precisiones). 
Dadas las distancias involucradas en la interacción, la adquisición de los recursos se habría dado a través de una red de circulación regional de recursos, información y conocimientos. De hecho el "área de captación" de los insumos es realmente amplio, incluyendo distintos sectores de la Puna Meridional argentina, zonas de menor altitud del Noroeste Argentino -los Valles y quebradas mesotermales, el área de Yungas y la Llanura chaqueña- y la costa del Océano Pacífico.

A nivel regional, se ha planteado que los recursos alóctonos considerados como bienes de prestigio, recuperados en contextos que indiquen el acceso individual y la posesión de los mismos son importantes a la hora tratar la complejidad en cazadores recolectores -ver, por ejemplo, Yacobaccio 2001a). En el caso de Antofagasta de la Sierra, los bienes suntuarios o de prestigio representan sólo con el 5,66\%, mientras que los recursos de subsistencia cuentan con un 79,20\%, los artefactos vinculados con prácticas de subsistencia con el 11,32\% y los artefactos con funcionalidad indiferenciada, con el 3,77\%. Es decir, no hay un predominio de los elementos suntuarios o de prestigio sobre las materias primas alóctonas, pero no sólo eso, los contextos donde se recuperaron son, básicamente, residenciales; en los cuales es esperable que primen los elementos comestibles y los artefactos vinculados con actividades de subsistencia. En los contextos funerarios y en los conjuntos intencionales de objetos si adquieren un papel significativo los bienes suntuarios o de prestigio -como sería el caso de artefactos sobre valva, calabaza y cordeles de palmera-; sin embargo, no hay evidencias claras de un acceso individual a los mismos.

En cuanto a la naturaleza misma de estos ítems, destaca el hecho de que no involucran una gran inversión de trabajo en su confección -con excepción del sonajero de Cc1A-, estando la inversión de tiempo y energía aplicada, en realidad, a la obtención de dichos recursos, sea para viajar a los lugares de aprovisionamiento o para producir artefactos o disponer de recursos que puedan ser intercambiados, como fuera propuesto por Aschero (2005b). Desde los conjuntos líticos tallados no hay ningún artefacto en particular que permita plantear que su producción estuvo orientada al intercambio, como en el caso de los bifaces y de la tecnología de hojas en Norteamérica y Australia (Sassaman 1994, Barton 1999).

\subsubsection{Densidad poblacional}

A pesar de que no se han identificado, hasta el momento, conglomerados residenciales como los del desierto del norte de Chile (Núñez 1981, 1992), ciertas evidencias parecerían direccionarse a una mayor densidad poblacional, sin implicar necesariamente un incremento poblacional. Así, se plantea que el contexto de movilidad reducida y de circunscripción social, ya aludidos, podría haber llevado a una densidad de población relativamente alta, que puede responder al patrón de distribución de sitios residenciales disperso, propuesto a nivel microrregional. 


\subsubsection{Intensificación en la explotación de recursos de subsistencia}

Debido a que la información relativa a la subsistencia en el lapso considerado ya fue tratada exhaustivamente en el Capítulo 6 y a que en el punto 13.1.1. Evaluación de las evidencias generales de la transición de este Capítulo se evaluó el cambio de las estrategias en el tiempo, se plantea abordar aquí sólo algunos tópicos de interés en relación a la intensificación en la subsistencia.

Así, con respecto a los recursos animales, destaca la explotación intensiva de camélidos silvestres en el lapso 5500-3500 AP (Aschero et al. 1991; Olivera y Elkin 1994; Elkin 1996a, 1996b), la cual habría derivado en una especialización cinegética que involucró, a su vez, una diversificación en los sistemas de armas y en las técnicas de caza. De esta forma, al contar con lanzas de mano arrojadizas y no arrojadizas, dardos de propulsor y arcos y flechas(?) (Martínez com pers.) y ante la amplia gama de alternativas de situaciones de caza al emplear, por ejemplo, distintas topografías y diferente número de cazadores en las partidas de caza -individuales, grupales o comunitarias, las posibilidades de obtención de las presas se veían favorecidas (Aschero y Martínez 2001, Martínez 2003). Podría plantearse, entonces, que la diversificación enunciada pudo llevar a una especialización de los diseños de las puntas de proyectil en un contexto de intensificación. Se destaca que Núñez (1981) señala esta situación de especialización de las puntas de proyectil en relación a la caza de camélidos para los sitios Tulán 52 y Puripica 1.

De acuerdo a lo visto precedentemente, la caza de vicuñas y guanacos estuvo acompañada entre los 4700 y los 3500 años AP por situaciones de experimentación y manejo de camélidos, que podría haber llevado a una situación de pastoralismo inicial.

Con respecto a los recursos vegetales comestibles, tanto silvestres como domesticados, son abundantes las evidencias en este sentido. Si bien no es posible establecer la ocurrencia de procesos de domesticación local, los cultígenos habrían tenido un papel importante en la subsistencia.

$\mathrm{Al}$ respecto, Babot (2004b) ha planteado una intensificación en la práctica de la molienda en el lapso 4700-3500 AP, a nivel local. Así, señala una diversificación de la práctica en base a los grupos artefactuales, a los modos de acción y a las funciones primarias presentes. Asimismo, destaca que, aunque los artefactos se caracterizan por la ausencia de estandarización en su forma, tamaño y materia prima, la mayoría presenta una importante inversión en su manufactura destinada a dotarlas de mayor eficiencia. Un resultado evidente del proceso de formatización, en estos artefactos, es la regularización de las formas o su geometrización, sin embargo, el empleo de manufactura polimodal, esto es, más de una técnica involucrada en la producción de los artefactos, no es frecuente. Por otra parte, una serie de características implican que las actividades de molienda se llevaron a cabo en sesiones prolongadas 
y/o reiteradas, como modificaciones destinadas a mejorar la prensión y facilitar el asimiento prolongado y el empleo de técnicas de mantenimiento y administración del desgaste dirigido a prolongar la vida útil de los artefactos.

Esta serie de datos, indican, para la autora, que los artefactos fueron concebidos para desarrollar eficientemente su tarea, destinados a perdurar en el tiempo y mantenidos con la intención de su utilización periódica y reiterada. El rango de uso y las características de la manufactura indican que los instrumentos integraban los equipamientos permanentes de los sitios, fueron conservados en previsión de un uso futuro, y se reutilizaron recurrentemente, por lo que la molienda se habría convertido en una práctica más frecuente, lo que implicaría que los recursos de molienda se habrían consumido en mayor proporción y con mayor regularidad.

Finalmente, se destaca que el desarrollo de las prácticas productivas, inclusive a la baja escala propuesta, habría tenido incidencia sobre los riesgos de corto plazo, reduciéndolos, en el marco de economías de retorno diferido tanto ganaderas como agrícolas.

\subsubsection{Prácticas rituales}

En la microrregión se registra una incremento en la práctica ritual ca.3500 AP, en base a una serie de hallazgos, "ofrendas" o enterratorios, caracterizados por ser eventos discretos de depositación en abrigos rocosos u oquedades, en asociación con fuentes de agua y vegetación abundante (Olivera et al. 2003) -ver Capítulo 6-. A esto se suma, en igual cronología, un culto a la fertilidad de los camélidos silvestres y domésticos (Aschero 2005b), en el que el sitio Confluencia 1 habría tenido un papel simbólico-ritual.

\subsubsection{8. ¿Evidencias de especialización artefactual y artesanal en artefactos líticos tallados?}

Diversos autores han planteado que, ante situaciones de complejidad, es factible contar con procesos de especialización artefactual y artesanal (Price y Brown 1987, Gero 1989, Johnson 1996, Nassaney 1996, Odell 2001). Por esta razón, interesa abordar aquí la ocurrencia de procesos de estandarización y especialización en los conjuntos de artefactos líticos tallados entre los 5500 y los 3500 años AP.

Con respecto a la especialización artefactual, en el caso abordado, más allá de de la posibilidad de considerar a las puntas de proyectil como un ejemplo de especialización, propuesta en un punto anterior, no hay artefactos dentro de los conjuntos líticos analizados que puedan ser identificados como casos concretos y fehacientes de su presencia. 
Ahora bien, establecer si hubo especialización artesanal es importante, puesto que permite, en un contexto de emergencia de complejidad, evaluar si grupos específicos procuraban posicionarse respecto de otros mediante el control de la organización de la producción de artefactos específicos o bien de ciertos recursos (Nassaney 1996).

En relación a la organización de la producción, de acuerdo a Gero (1989), la especialización artesanal implica que la producción de un item particular es realizada por un grupo restringido de personas que poseen el conocimiento, la destreza técnica y los materiales necesarios para llevar a cabo adecuadamente la tarea, lo que implica un incremento en la precisión y control sobre el material que está siendo trabajado y una reducción en el número de errores de producción así como de variantes producidas. De esta forma, unos pocos artesanos son los responsables del total de ejemplares de una clase de artefacto, dando como resultado situaciones de estandarización.

De hecho, un criterio para postular la presencia de especialización artesanal es contar con estandarización de la producción y estandarización de la forma en artefactos específicos (Johnson 1996). Con respecto a la primera, los únicos artefactos de los conjuntos abordados que podrían implicar una manufactura estandarizada son los bifaces y los instrumentos confeccionados sobre bifaces. Sin embargo, de acuerdo a los resultados alcanzados en el Capítulo 10, en todos los casos los contextos incluían una serie de secuencias de producción dirigidas a distintos fines y no una única secuencia involucrada en la producción de un instrumento en particular. En cuanto a la segunda, destaca no sólo la variabilidad morfológica sino también la dimensional, tanto en los instrumentos en general como en los desechos de talla. Esto pudo apreciarse, inclusive, en los bifaces y puntas de proyectil (Capítulos 10 y 11); artefactos que, por las características de sus trayectorias de producción, podrían eventualmente haber presentado una recurrencia morfológica y métrica. Es decir, la diversidad de formas producidas, más allá del predominio de un patrón lanceolado, difiere de la producción focalizada en un único instrumento que sería lo esperable ante un contexto de especialización.

Se destaca que la estandarización formal y de la producción están presentes, en cambio, con posterioridad a los $2100 \mathrm{AP}$, en instrumentos tales como puntas de proyectil (ver Capítulo 11), raederas de módulo grandísimo y palas y/o azadas (Escola 2000), aunque ya en contextos agropastoriles plenos.

Otro aspecto a tener en cuenta, en relación a la especialización artesanal, es el volumen de producción (Johnson 1996), siendo esperable encontrar importantes volúmenes de desechos de talla y piezas descartadas atribuibles a técnicas específicas. Por lo visto precedentemente, la técnica del adelgazamiento bifacial es la única, a nivel local y en la cronología estipulada, que podría haberse visto implicada en situaciones de estandarización. Al respecto, la información obtenida sobre 
cantidades de desechos de talla correspondientes a lascas de adelgazamiento bifacial en los sitios PCh1.3, PCh1.1, PP4 y niveles 2b2, $2 \mathrm{~b} 3$ y $2 \mathrm{~b} 5$ del sitio QS3 (ver punto 8.4.1.2. Evidencias de cambio en la inversión de trabajo. Otras líneas de evidencia: Utilización de índices diversos en el Capítulo 8) no sustenta una producción especializada. Cabe destacar que la excepción a esto es el nivel 2b4 de QS3, en el cual las lascas de adelgazamiento bifacial son 2097, de un total de 3198 desechos (Aschero et al. 1993/94). Esto, a primera vista, implica un volumen importante de desechos relacionados con una técnica en especial. Sin embargo, pese a que las lascas de adelgazamiento bifacial están agrupadas básicamente en dos concentraciones en el sector del alero (Manzi 1999) y a que as piezas tienen mayoritariamente tamaños microlasca e hipermicrolasca (sensu Aschero 1983), denotando estadios finales de formatización y regularización (Manzi 1999), no hay una separación espacial de las actividades de producción respecto del resto de las tareas cotidianas, como sería esperable en loci especializados (Johnson 1996). Cabe destacar que el resto de los sitios mencionados presenta la misma situación, ya que se trata de bases residenciales donde se realizaron múltiples actividades..

Por otra parte, no hay evidencias en ninguno de los sitios considerados de que se hayan producido más bienes de los necesarios para un consumo local.

En suma, la información disponible hasta el momento no parece sustentar la presencia de especialización artesanal y, menos aún, de control de ciertos individuos o grupos sobre la producción y distribución de artefactos específicos. Así, la tarea artesanal se habría estructurado sobre la base de unidades sociales pequeñas, a nivel familiar o de parentesco, de acuerdo a los loci de producción y consumo. Esto estaría confirmado por el hecho de haberse comprobado la existencia de individuos con distinta pericia técnica. Si bien se ha postulado la presencia de expertos, la mayor parte de los bifaces parece ser el resultado, en base a características morfológicas, de talladores "promedio" (ver Capítulo $10)$.

Con respecto al control sobre recursos líticos concretos, se trae a colación la restricción observada hacia los 3500 años AP en la utilización de la Vc4 procedente de la cantera de Los Negros, en el fondo de cuenca, por parte de los ocupantes de los sitios PCh1.1, PCh1.3 y PP4 situados en el Río Las Pitas. Se plantea que, a la luz de los resultados obtenidos, la misma habría sido producto de la disminución de la movilidad residencial y del incremento de la territorialidad (ver punto 8.1.2.2. Territorialidad), más que del accionar de individuos o grupos que detentan poder, tratando de monopolizar un recurso. Con respecto al resto de las rocas empleadas, no hay indicio alguno, ni siquiera entre las no locales, de acceso diferencial a las mismas. 


\subsubsection{A modo de corolario}

Se destaca que no todas las líneas de evidencia consideradas se desarrollaron u ocurrieron paralelamente, sino que presentan trayectorias temporales disímiles y ritmos diferenciales. Así, por ejemplo, las evidencias de movilidad residencial reducida se remontan a 5500 años AP, aunque con mayor énfasis hacia los 3500 años AP, mientras que la intensificación de la actividad ritual se registra a partir de los $3500 \mathrm{AP}$, pudiendo esto ser resultado de las características propias del proceso local o bien una consecuencia de la información recuperada hasta el momento. Más allá de esto, parecería haber una convergencia de los elementos vinculados con la emergencia de complejidad hacia los 3500 AP, coincidiendo con el "nudo" del proceso transicional.

Como se verá en el punto siguiente (13.2. Tendencias diacrónicas y sincrónicas en la confección de artefactos líticos tallados), las evidencias obtenidas al analizar las características tecnológicas y tipológicas de los artefactos líticos tallados refieren, en general, a un proceso de simplificación de la tecnología lítica. Esto es muy interesante, ya que, en un contexto de emergencia de complejidad visto desde distintas evidencias, no habría un cambio hacia una "mayor" complejidad desde los artefactos líticos. Esto tiene una implicancia importante: en un proceso dado no necesariamente debe haber cambios direccionados hacia un incremento de la complejidad (cf. RowleyConwy 2001).

Es importante señalar, asimismo, que la ausencia de asentamientos residenciales grandes, de especialización ocupacional o de en el caso de estudio, no implica la ausencia de complejidad en cazadores-recolectores, ya que, como se ha sostenido, es de esperar que los elementos utilizados en su definición aparezcan combinados de distinta manera de acuerdo con las particularidades de los procesos locales o regionales, no debiendo estar necesariamente presentes en los distintos casos (Yacobaccio 2001a). Esto adquiere sentido si se considera a la emergencia de complejidad como un proceso gradual, variable según zonas o microrregiones, pero "co-participado en relación a información que circula", tomando palabras de Aschero (1998), respecto de los cambios en el arte rupestre de la Puna argentina y chilena y su borde. Es decir, el proceso debe ser entendido como un mosaico de eventos y dinámicas locales y regionales, a diferentes escalas espaciales y temporales. 


\subsection{TENDENCIAS DIACRÓNICAS Y SINCRÓNICAS EN LA PRODUCCIÓN Y USO DE ARTEFACTOS LÍTICOS TALLADOS}

En base a la recapitulación de la información obtenida previamente (Capítulos 8 al 12), es posible definir tendencias generales en cuanto a las estrategias de producción y uso de los artefactos líticos tallados que formaron parte del proceso transicional. Las mismas reflejan las elecciones de individuos y/o grupos, quienes tuvieron la posibilidad de optar entre una serie de alternativas resultantes del bagaje cultural socialmente transmitido y compartido así como de procesos de interacción, sea por contacto directo o indirecto.

Uno de los cambios tecnológicos más importantes en el lapso 5500-1500 AP está relacionado con la tendencia a invertir menor esfuerzo en la manufactura de artefactos líticos. Esto quedó claramente evidenciado al considerar las variaciones en frecuencia de las clases técnicas en artefactos formatizados. En efecto, se produjo la desaparición del adelgazamiento bifacial y del adelgazamiento y la reducción unifacial y se mantuvo la reducción bifacial. Desaparecieron, inclusive, alternativas de baja inversión de trabajo, como el trabajo no invasivo alternante y el trabajo bipolar. Simultáneamente, se registra un virtual reemplazo de dichas clases técnicas por el trabajo no invasivo bifacial y unifacial, siendo preponderante este último. Se destaca que esto se ve corroborado al considerar la disminución y desaparición de las lascas de adelgazamiento bifacial en las muestras de desechos de talla (ver Capítulo 8).

En suma, se registra una tendencia en el instrumental a un énfasis progresivo en las clases técnicas que implican un tratamiento de los bordes y a un desuso de las que involucran la formatización de las caras. Es así que el trabajo no invasivo unifacial ve acrecentada su importancia relativa con el paso del tiempo, ante la disminución de las frecuencias de artefactos formatizados confeccionados por adelgazamiento y reducción -con excepción de la reducción bifacial- e, inclusive del trabajo no invasivo bifacial, potenciándose a expensas de estos últimos. Para el 2000 AP, prácticamente, todo el repertorio de artefactos formatizados se confeccionaba de esta manera, quedando exceptuadas las puntas de proyectil (reducción bifacial) y las palas y/o azadas (trabajo no invasivo bifacial). De esta forma, el proceso transicional local se podría rotular como de “empobrecimiento tecnológico" en lo que respecta a los artefactos líticos tallados.

A esto se suman otras evidencias que están en consonancia con la perspectiva de una simplificación de los artefactos líticos. Las mismas refieren a la complejidad del instrumental, al reciclaje y a la presencia de piezas con filos y/o puntas distintas -artefactos compuestos- (ver Capítulo 8), variables que aluden a un énfasis en el tratamiento de ciertas piezas, relacionado, por ejemplo, con 
la intención de prolongar la vida útil o de emplear distintas porciones de los filos, invirtiendo, por ende, mayor tiempo y energía en la manufactura por pieza.

En cuanto a la complejidad, es pertinente recordar que está relacionada con la cantidad de partes formatizadas que componen una pieza dada. Al respecto, se observa una disminución en el número de partes del instrumental con el paso del tiempo y, en especial, una restricción sustantiva en las mismas a partir del $2100 \mathrm{AP}$ aproximadamente. Ahora bien, no sólo disminuye el número de filos y/o puntas por pieza en general, sino que las piezas conformadas por una sola parte (simples) ven incrementada su importancia a través del tiempo, hasta llegar a prácticamente un 90\% en el GC3.

Al relacionar inversión de trabajo diferencial con complejidad, se afianza lo dicho precedentemente. De acuerdo a lo señalado en el Capítulo 8, los artefactos con mayor inversión de trabajo deberían presentar la complejidad más alta, en este caso bifaces y puntas de proyectil. Sin embargo, la información obtenida precisa que en los bifaces y en el "resto del instrumental" tuvo lugar una disminución progresiva en la complejidad con el paso del tiempo, cuando los primeros deberían presentar una complejidad elevada -cabe notar que las puntas de proyectil no cuentan con una tendencia discernible-. Pero los bifaces no sólo disminuyeron en cuanto al número de partes, sino que lo hicieron más drásticamente que el "resto del instrumental". De esta forma, la toma de decisiones habría llevado a que el esfuerzo de manufactura en los bifaces, bajo la forma de transformaciones y reciclajes, se reduzca significativamente hacia los 3600 años AP, incidiéndose principalmente sobre los artefactos confeccionados con gran inversión de tiempo y energía, en un contexto de reducción global de la complejidad.

Con respecto al reciclaje, la cantidad de casos en las muestras se mantiene relativamente constante en los GC 1 y 2, para descender notoriamente en frecuencia en el GC3.

Finalmente, en relación a los artefactos compuestos, se registran frecuencias decrecientes con el paso del tiempo, siendo muy importantes en el GC1, con cerca del $41 \%$, y reduciéndose drásticamente en los grupos cronológicos subsiguientes, culminando con 5\% aproximadamente en el GC3.

Otra serie de procesos importantes en la transición de la caza-recolección a la producción agro-pastoril en Antofagasta de la Sierra son las variaciones en la diversidad y en el diseño de los artefactos líticos tallados.

Al respecto, tomando nuevamente en consideración la información de las clases técnicas, se evidencia que no sólo se produjeron cambios substanciales en la forma de producir los artefactos 
formatizados, sino que también disminuyó considerablemente el número de alternativas tecnológicas utilizadas, ya que de 8 clases empleadas en el GC2 se pasó a sólo 3 en el GC3, involucrando una restricción importante en la diversidad tecnológica a través del tiempo.

A su vez, del tratamiento de los grupos y subgrupos tipológicos resulta la recurrencia de los grupos tipológicos en el tiempo. En particular, en los grupos tipológicos relacionados con actividades de consumo/procesamiento que implican un cierto número de "funciones primarias" (sensu Aschero 1975) que se mantienen relativamente constantes, dado su carácter básico, por lo que es esperable que haya una continuidad de los mismos. Es decir, la diversidad tipológica se mantiene en el lapso abordado al tratar los grupos tipológicos vinculados con consumo/procesamiento, lo que se ve corroborado al considerar la cantidad de subgrupos tipológicos por grupo cronológico (ver Capítulo 8). Esto lleva a plantear que los grupos humanos en ciernes disponían del conocimiento de toda una gama de alternativas morfológico-funcionales, seleccionando ciertas variantes del total de diseños posibles en función de los requerimientos concretos de las situaciones que se les presentaban. Este conjunto de opciones formaría parte del saber de dichos grupos, a modo de una "memoria virtual" transmitida intergeneracionalmente.

Esto no significa, empero, que la diversidad no sufrió variaciones. De hecho, la desaparición de buena parte de las clases técnicas en el GC2 tuvo como correlato que se dejaran de fabricar artefactos específicos. Ejemplo de esto son los unifaces, respuesta tipológica a la desaparición del adelgazamiento bifacial, o los artefactos bipolares no diferenciados, vinculados al trabajo bipolar. En realidad, esto no es tan sencillo, ya que debe considerarse simultáneamente el hecho de que los instrumentos hayan dejado de ser útiles, por lo que, al estar vinculados a una clase técnica en particular, la misma deja de ser operativa también. Un caso en este sentido podría ser el de los bifaces, ya que, si bien desaparece el adelgazamiento unifacial, se contaba con la reducción bifacial como alternativa; sin embargo, no se siguieron confeccionando bifaces manufacturados a partir de esta última clase, en forma de bifaces parciales, sino que la reducción bifacial implicó trabajar directamente sobre una lasca, sin pasar por una forma-base secundaria biface parcial; por ejemplo, en el caso de las puntas de proyectil típicas de los contextos agro-pastoriles plenos (Escola 2000).

El grupo tipológico de las puntas de proyectil, por su parte, registra una disminución notable en su diversidad al nivel de los subgrupos tipológicos, al comparar los GC1 y 2 con el GC3. Así, los dos primeros cuentan con diseños pedunculados destacados y esbozados y apedunculados lanceolados diversos así como cordiformes/triangulares, mientras que el último con un solo diseño con pedúnculo diferenciado y un solo diseño apedunculado triangular. Es más, ambos subgrupos presentan una diferenciación temporal, ya que, el diseño pedunculado, si bien se registra a lo largo de la secuencia ocupacional de CChM1, es exclusivo del lapso 2100-1700 AP, mientras que el diseño apedunculado 
aparece sólo en el lapso 1700-1500 AP (Escola 2000). Cabe destacar que la disminución de la diversidad en estos instrumentos se combinó con un proceso de estandarización hacia los 2100 AP.

Un fenómeno contrario, es decir, un aumento de la diversidad, se vio promovido por la emergencia de las prácticas productivas, que involucró la aparición de nuevos grupos tipológicos, como el de las palas y/o azadas, y subgrupos, como las raederas de módulo grandísimo.

En suma, la diversidad morfológica del instrumental, relacionada con actividades de procesamiento/consumo, se mantuvo relativamente constante, mientras que aquella vinculada a labores extractivas -léase puntas de proyectil- se vio drásticamente disminuida; al mismo tiempo, las labores productivas llevaron a un incremento de dicha diversidad.

Ahora bien, al considerar el diseño de los artefactos formatizados, resalta la recurrencia morfológica de los grupos tipológicos en los 4000 años considerados, que estaría señalando una "historia morfológica común", refrendando la idea de continuidad. Destaca, asimismo, la relativa homogeneidad formal de los bifaces en el lapso 5500-3400 años AP, con contornos casi exclusivamente lanceolados.

Por otra parte, ciertos subgrupos tipológicos poseen atributos que los particularizan, como resultado de poseer variantes morfológicas específicas, ya sea de índole técnica y/o funcional; siendo definidos, por esta razón, como tipos o especimenes morfológicos. Ejemplos de ésto son una clase particular de cortante, denominado cortante de filo retocado microdenticulado convergente sin ápice activo (TM QS G), de raspador, clasificado como raspador de filo perimetral o extendido de contorno circular o discoidal (TM QS E), o de raedera, definida como raedera de módulo grandísimo (TM CChM C).

En este marco, las piezas que presentan la variación morfológica más importante son las puntas de proyectil, sobre la base de diferencias en la forma general del contorno, en la morfología del limbo, las aletas y el pedúnculo y en las "dimensiones" de las piezas. Así, se definieron 21 variantes de puntas de proyectil, 15 como tipos morfológicos y 6 como especimenes morfológicos (ver Capítulo 9). Cabe notar que, a partir de los 2100 AP se produce una estandarización a distintos niveles de los diseños de puntas de proyectil, incluyendo la morfología, por lo que se redujo considerablemente la variabilidad

De acuerdo a la correlación de estos artefactos con niveles estratigráficos fechados por datación radiocarbónica, los tipos y especimenes morfológicos pueden ubicarse temporalmente en lapsos relativamente acotados, es decir, que son temporalmente sensibles (ver Capítulo 9). Se destaca 
que esto no significa considerarlos diagnósticos de "fases" cronológicas determinadas o el reemplazo de una "cultura" por otra".

A primera vista, la variación en la clase de cultura material abordada parecería ser episódica, caracterizada por extensos períodos de tiempo en los que no se había producido ningún cambio, sucedidos por cambios rápidos y repentinos ( $c f$. Shott 1997, 2003; Scheinsohn 1999). De esta forma, los grupos cronológicos constituirían los períodos de stasis y los momentos inter-grupo, los de cambio.

Sin embargo, desde distintas líneas de evidencia, es posible sostener que este patrón aparentemente tan claro es producto de distintas circunstancias. Una de ellas refiere a las naturaleza del registro arqueológico local, que involucra, por ejemplo, un vacío de información en cuanto a bases residenciales entre los 3400 y 2100 años AP, lo que lleva a que el aspecto pulsativo del registro no sea real, sino que es producto de las características de la secuencia arqueológica al momento de esta investigación. Asimismo, desde los artefactos líticos tallados, al considerar, entre otros, la variación en el tiempo de la representación de las distintas clases técnicas, de la frecuencia de lascas de adelgazamiento bifacial en los conjuntos, de la complejidad del instrumental o del reciclaje, resulta que el cambio es paulatino y gradual. Esto significa que no debe verse a la secuencia considerada como una sucesión de "fases " discretas, cuyas características estarían dadas por los tipos y cuyos límites se definen por cambios episódicos.

En suma, se considera que el patrón pulsátil resultante de definir temporalmente a los tipos y especimenes morfológicos, básicamente al comparar los GC 2 y 3 , es producto de las características de la secuencia microrregional. El cambio en las puntas de proyectil en la Quebrada Tulán (Chile) es un caso donde se pueden apreciar las bondades de un registro continuo. Así, los sitios de las fases Puripica-Tulán (Arcaico Tardío), Tarajne (Transicional) y Tilocalar (Formativo Temprano) (Núñez et al. 2005) cuentan con puntas lanceoladas, lanceoladas y pedunculadas y pedunculadas, respectivamente (Núñez com pers.), denotando un cambio gradual.

Esto no significa, sin embargo, que no pueda haber cambios repentinos, por ejemplo, por la introducción de artefactos vinculados con nuevas actividades, o por la intensificación de prácticas en curso, como puede ser el caso de las palas y/o azadas en Antofagasta de la Sierra, que se registran recién cuando se consolidan las labores agrícolas y la estrategia predominante es agro-pastoril.

Es pertinente, por otra parte, traer a colación, justamente, las diferencias observadas en las puntas de proyectil de los GC2 y 3. Así, en base a un análisis de las características tecnológicas y tipológicas de las muestras en cuestión se pudo establecer que diferían, por ejemplo, en la forma general del contorno, la materia prima utilizada, la forma del limbo, el tamaño, el peso, el ángulo de 
las aletas, el tipo y tamaño de los pedúnculos, el tratamiento técnico diferencial de los bordes del pedúnculo, el ancho y forma de la base del pedúnculo y sectores basales de piezas apedunculadas, y las formas-base empleadas (ver Capítulo 11).

A partir de esto hay un cambio substancial en los diseños de puntas de proyectil anteriores al 3400 y posteriores al 2100 AP; sin embargo, un diseño específico de punta de proyectil permite vincular a los dos grupos cronológicos, dando cuenta de un proceso paulatino de cambio entre tipos morfológicos. Así, en el Capítulo 11, se planteó una vinculación genética entre las puntas de proyectil definidas como TM PPC y las TM CChM A que, se destaca, no implicó solamente cambios de tamaño con el transcurso del tiempo, sino también variaciones morfológicas en los limbos, aletas y pedúnculos. De esta forma, los limbos pasaron de ser los lanceolados y triangulares de lados convexos a ser triangulares rectos, se priorizaron las aletas entrantes agudas por sobre las rectas u oblicuas y las bases de los pedúnculos se transformaron de convexilíneas semicirculares a acuminadas puntiformes.

La ocurrencia de este cambio en Antofagasta de la Sierra no significa que el origen de las puntas de proyectil que caracterizaban a las ocupaciones agro-pastoriles esté justamente en dicha microrregión, sino que la misma formó parte de un proceso de cambio tipológico a nivel macrorregional. Al respecto, se destaca que las bases de la innovación estaban en el conocimiento de la grupos que ocupaban la Puna entre los 4000 y los 3000 años AP, ya que otras puntas de proyectil en uso en ese momento contaban con características morfológicas que implicaban que el esquema conceptual involucrado no surgió de la nada, sino que derivó de los diseños que estaban siendo utilizados contemporáneamente. Es decir, no se habría generado algo radical y completamente original, sino que se produjo una reconfiguración de elementos para armar un diseño nuevo.

La variabilidad técnico-tipológica de los artefactos líticos tallados se abordó, también, en base al análisis de una serie de aspectos vinculados a la variabilidad de los bifaces presentes en los sitios QS3, PP4, PCh1.3 y PCh1.1. Se planteó, en función de esto, diferenciar, a partir de características técnico-morfológicas y morfológico-funcionales, bifaces como núcleos, como artefactos en sí mismos y como preformas de artefactos diversos

Así, por un lado, se discriminaron en las muestras consideradas, en base a criterios morfológicos, bifaces en sí mismos y en proceso de manufactura, por un lado, y bifaces como tales, transformados y reciclados, por el otro. Los primeros se caracterizan por poseer una amplitud de la arista sinuosa estrecha, razones $\mathrm{A} / \mathrm{E}$ elevadas, ángulos de filo agudos y un plano de simetría longitudinal; pueden presentar, en algunos casos, un filo bifacial de arista sinuosa actuando como filo activo y otro como filo pasivo, con diferencias en la amplitud del sinusoide y en el ángulo del filo 
(mayor). Los segundos en cambio, cuentan amplitud del sinusoide moderada a amplia, razones A/espesor menores que los primeros y ángulos de filo en general superiores a los bifaces en si mismos.

Al mismo tiempo, estas dos clases de bifaces se presentaban como bifaces como tales o como piezas recicladas o transformadas. En cuanto a los bifaces sometidos a reciclaje, por lo general, se trata de artefactos fracturados, aunque hay otros que se presentan enteros, que no pudieron continuar la trayectoria de producción prefijada, por ejemplo, por angostamiento excesivo. Con respecto a las piezas transformadas, los bifaces se modificaron expresamente de manera de obtener una importante variedad de productos, en forma de otras piezas de morfología global, como puntas de proyectil, o filos y/o puntas de morfología parcial, conformando piezas simples, dobles o compuestas de diversa índole.

Por otra parte, se evaluó si parte de los bifaces analizados correspondían a núcleos bifaciales, llegándose a la conclusión, en base a una serie de evidencias morfológicas y contextuales, de que es muy poco probable que los mismos hayan sido núcleos (ver Capítulo 10).

En definitiva, se pudo establecer que los bifaces cumplieron una diversidad de papeles en Antofagasta de la Sierra, como formas-base de una amplia gama de instrumentos, evidenciado por la presencia de piezas en proceso de manufactura y de bifaces, de hecho, transformados, y como artefactos en sí mismos. En este marco, los bifaces habrían funcionado, siguiendo la diferenciación de Kelly (1988) como artefactos de larga vida útil y como subproductos de la manufactura de instrumentos, pero no como núcleos.

Con respecto a estos últimos, una serie de piezas presentan una marcada amplitud del sinusoide, ausencia de plano de simetría longitudinal, irregularidad de las caras, presencia de corteza y/o de remanentes de las caras de la forma-base original, atributos que han sido asociados a núcleos bifaciales (Bamforth 2003, Aschero y Hocsman 2004). Sin embargo, estos elementos, que se encuentran también en bifaces producidos por talladores inexpertos, están acompañados en las mismas piezas por otros que son típicos de carencia de pericia en la talla por adelgazamiento bifacial. Estos son: presencia de machacado, fracturas y sobreengrosamientos en los bordes, terminaciones en charnela y quebradas abundantes y presencia de negativos de lascado "estallados", ausencia de plano de simetría longitudinal y notorios cambios de ángulo (cf. Whittaker 1994, Finlay 199, Grimm 2000, Stout 2002). Se plantea, entonces, que es posible discriminar en base a características morfológicas bifaces producidos por aprendices y que parte de la variabilidad observada en los bifaces responde a esto, siendo muy posible que se haya tratado de niños y/o adolescentes. Por lo tanto, deben ser incluidos dentro de los bifaces en proceso de manufactura. 
Cabe destacar que, en realidad, no sólo se ha comprobado la presencia de individuos partícipes de experiencias de aprendizaje, sino también la existencia de talladores expertos, que pueden distinguirse por su habilidad de producir piezas elongadas en relación a su ancho y espesor. Talladores menos talentosos podrían estar reflejados, también, en las piezas que no presentan características notorias, que son la mayoría.

De relevancia, en relación a los bifaces, además, ha sido la utilización de datos cualicuantitativos para establecer vinculaciones entre piezas en proceso de manufactura y piezas terminadas. Así, en base a la correlación del largo con el ancho y del ancho con el espesor, y de su asociación con variables cualitativas (morfología de la arista, plano de simetría longitudinal, etc.) y cuantitativas (por ejemplo, ángulo de los filos), se pudieron definir tendencias generales en la producción de bifaces, relacionando bifaces en proceso de manufactura con bifaces transformados.

De esta forma, por ejemplo, se evidenció que entre los 4100 y los 3400 años AP, había distintas trayectorias de producción: la primera, relacionada con la manufactura de puntas de proyectil lanceoladas de pequeño tamaño; la segunda, implicada en la confección de puntas lanceoladas grandes y artefactos compuestos varios; la tercera, vinculada con la producción de bifaces por parte de aprendices y, finalmente, una cuarta, formada por piezas muy anchas y poco espesas que, pese a las fracturas transversales al eje longitudinal, es posible establecer que se trata de artefactos de tamaño considerable.

En relación con esto último, fue posible reconocer la existencia de ciertos productos finales ausentes a través de la identificación de productos y subproductos intermedios en el proceso de manufactura. Ejemplo de esto son las lascas de adelgazamiento bifacial de tamaño "muy grande" recuperadas en QS3. Al mismo tiempo, se estableció que ciertas morfologías no tuvieron correlato con diseño final alguno, como es el caso de los bifaces identificados como de aprendices, que fueron descartados enteros sin ser terminados.

Por otra parte, la información analizada y discutida, tomada en conjunto, permite sostener que en el lapso 5500-1500 años AP se produjeron cambios importantes en las recetas para la acción y en la tecno-ciencia. Estos cambios en el saber no implicaron sólo la presencia o ausencia de ciertos diseños, sino también variaciones diacrónicas en las formas de hacer las cosas.

En este sentido pueden plantearse las variaciones en el tiempo de las clases técnicas en artefactos formatizados, que motivaron modificaciones en las recetas para la acción y en la tecnociencia, ya que cada una implicaba secuencias de acciones específicas a lo largo del proceso tecnológico y principios físico-mecánicos diferenciados. De particular relevancia, en este marco, es la 
desaparición del adelgazamiento bifacial, que involucra gestos técnicos muy específicos, completamente distintos a la percusión ordinaria y con consecuencias importantes sobre el "sabercómo" ideacional y motor, por sus requerimientos de destrezas operativas sofisticadas.

En suma, el cambio de las clases técnicas a través del tiempo implicó la elección de alternativas técnicas con tecno-ciencia menos elaborada así como recetas para la acción más simples. Ante ésto, los requerimientos de destreza técnica se vieron aminorados, propiciándose aquellas técnicas con programas (en términos de Morin 1995) menos complejos, que prácticamente no requerían del desarrollo de estrategias ad hoc. Al respecto, ver, por ejemplo, la información obtenida por Escola (1991) en cuanto a la confección de las puntas de proyectil con pedúnculo diferenciado y limbo triangular de CChM1.

Se considera, por otra parte, que la variación temporal en dichas técnicas llevó a cambios drásticos en los sistemas de enseñanza vigentes entre los 5500 y los 3400 años AP.

Dado que el adelgazamiento bifacial implica una marcada inversión de trabajo en la manufactura, así como importantes requerimientos de experiencia y destreza manual, la practica del adelgazamiento bifacial habría insumido mucho tiempo y esfuerzo, requiriendo que la duración de la enseñanza sea prolongada, diferenciándose, en este sentido, de las restantes clases técnicas. Al respecto, se plantea que la transmisión del conocimiento en relación al adelgazamiento bifacial se desarrolló sobre la base de una interacción maestro-alumno muy intensa. Por ende, la desaparición del adelgazamiento bifacial en Antofagasta de la Sierra, hacia los 2100 años AP habría motivado importantes cambios en los sistemas de enseñanza.

Entonces, se sostiene, al entender a las técnicas como tradicionales y, por ende, heredadas del pasado y aprendidas (Lemmonier 1992), que los cambios señalados implicaron que la enseñanza de las recetas para la acción, de generación en generación, se vea alterada. Cabe mencionar que esto pudo haber tenido importantes consecuencias sobre las relaciones sociales de los grupos implicados, más allá de que se haya tratado de grupos familiares, ya que la dependencia tan marcada maestro-aprendiz habría desaparecido. Como el aprendizaje de destrezas esta estructurado, de hecho, en el contexto social (Stout 2002), los cambios en la duración de la instrucción y, posiblemente, en la forma de enseñanza, provista por individuos más experimentados, probablemente estén reflejando cambios en el contexto social.

En general, se plantea que la distribución natural de las rocas empleadas para la talla en un área dada incide sobre las estrategias de producción y uso de las mismas. De hecho, en la microrregión de Antofagasta de la Sierra, la disponibilidad de materias primas líticas está caracterizada por una 
oferta destacada de materias primas líticas de muy buena calidad para la talla (ver Capítulo 7), lo que imprimió una serie de características peculiares a la secuencia arqueológica local (ver Capítulo 8).

En primer lugar, se registra, a lo largo del lapso considerado, una utilización sistemática e intensiva de las rocas locales, lo cual se evidencia en los artefactos formatizados, los desechos de talla y los núcleos; patrón que es característico de casos con buena disponibilidad de materias primas de alta calidad (Andrefsky 1994b). En segundo lugar, como es esperable también en este tipo de contextos (Andrefsky 1994a, 1998), sobre las rocas locales se manufacturaron la gran mayoría de los instrumentos con gran inversión de trabajo así como aquellos con baja inversión de tiempo y energía. Sin embargo, una tendencia que debe ser notada es la confección de las puntas de proyectil sobre una roca no local, la obsidiana, que es creciente en el tiempo. Tal direccionalidad parece ser la conclusión de un proceso de estandarización de la materia prima de las puntas de proyectil, que se iniciaría ca.3600 AP. En tercer lugar, destacan los valores bajos del reciclaje a lo largo del lapso abordado, sugeridos en casos de abundancia del recursos líticos. En cuarto lugar y último lugar, en cuanto a la presencia de artefactos compuestos, en contra de lo esperado, se registra una frecuencia importante al inicio de la secuencia, reduciéndose drásticamente con posterioridad, por lo que se plantea que la ubicuidad de materias primas no estaría afectando la complementariedad de filos y/o puntas.

Por otra parte, no se aprecia, en general, una asociación estrecha entre grupos tipológicos y materias primas específicas, notándose un uso indiscriminado de las rocas en la confección de las diferentes clases de artefactos formatizados. La preponderancia de la Vc1 y la Vc2 en el GC1 y el GC2 y de la Vc4 en el GC3 en la mayor parte de los grupos tipológicos se vincularía sencillamente, a una cuestión de acceso a los recursos y de calidad de las rocas. Sólo tres clases de instrumentos remiten a un tipo de materia prima en particular, coincidiendo todas con el lapso 2100-1500 AP, por ser instrumentos con cierto grado de estandarización y por estar vinculados a actividades extractivas o productivas. Estas son: las puntas de proyectil, confeccionadas sobre obsidiana, ya mencionadas, las palas y/o azadas, sobre Vc8 y las raederas de módulo grandísimo, sobre Vc4.

Por lo tanto, puede concluirse que las estrategias de producción y uso de artefactos líticos tallados se vieron influenciadas por la disponibilidad de una amplia gama de rocas a nivel microrregional.

Ahora bien, se considera que dos factores tuvieron un rol fundamental en la conformación de la estructura de los artefactos líticos tallados en Antofagasta de la Sierra y de los cambios registrados en la misma a través del tiempo, a saber: la disminución de la movilidad residencial y la reducción de los riesgos de subsistencia. 
Como ya fuera planteado, de acuerdo a la información obtenida desde distintas líneas de evidencia, se produjo una disminución progresiva de la movilidad residencial en la microrregión, con una serie de cambios importantes en el tiempo; por ejemplo, la aparición de estructuras de piedra entre los 3800 y 3400 años AP y de bases residenciales permanentes ca.2100 AP.

Con respecto a los riesgos de subsistencia, interesa particularmente evaluar las variaciones en el tiempo de los riesgos de corto plazo. De esta forma, se plantea que los contextos con cazarecolección exclusiva, anteriores al 5000 AP aproximadamente, habrían contado con riesgos de corto plazo severos. Ahora bien, una situación de manejo y protección de camélidos silvestres aunque sin poder confirmar experimentación con recursos vegetales, entre los 4700 y 4500 años AP, es decir, de caza-recolección/"economía productiva de bajo nivel, sin domesticados", podría haber tenido algún efecto sobre los riesgos de corto plazo, de acuerdo a lo manifestado por Yacobaccio (2001a). El lapso 4000-3500 años AP, por su parte, definido por la combinación de caza-recolección/“economía productiva de bajo nivel, con domesticados", implicando tanto camélidos domesticados (¿pastoralismo?) como cultígenos, debería haber implicado una reducción considerable de los riesgos abordados. Por último, la disminución de los riesgos de corto plazo continuaría en el momento 21001500 AP, caracterizado por estrategias pastoriles-agrícolas/caza-recolección.

Cabe destacar que las situaciones de manejo y protección enunciadas dieron origen a economías de retorno diferido, con la posibilidad de generar excedentes -no necesariamente cuantiosos- y disminuir en consecuencia, los riesgos de corto plazo. Incluso en tales contextos de protección, el almacenaje de "carne en pie", por ejemplo, habría implicado un reaseguro (cf.Pintar 1995b, Escola 1996). Esto se habría visto potenciado con la intensificación de las prácticas productivas, que llevaron a la consolidación de economías de retorno diferido a nivel local.

Un aspecto que debe ser considerado, en relación a los riesgos de subsistencia de corto plazo, es el mejoramiento ambiental acaecido en la microrregión entre los 3500 y los 3000 años AP (Olivera et al. 2002, Olivera et al. 2004, Tchilinguirian y Olivera 2005), que debería haber tenido consecuencias positivas sobre la disponibilidad de recursos vegetales y animales, aumentando la densidad de los mismos (ver, por ejemplo, Muscio 2004). Cabe destacar que, para Olivera et al. (2004), las condiciones de mayor humedad favorecieron, en realidad, el proceso de consolidación de las economías productivas y el desarrollo de estrategias de asentamiento con mayor sedentarismo.

Tal disminución progresiva en la movilidad residencial y en los riesgos de corto plazo estuvo acompañada por una serie de cambios, también paulatinos, en la toma de decisiones vinculada a la producción y uso de artefactos líticos por parte de los grupos humanos que ocuparon Antofagasta de la Sierra. 
En efecto, a partir de los artefactos formatizados, como es esperable de acuerdo a las expectativas generadas previamente, se evidencia una disminución progresiva en: 1) la inversión de trabajo en la manufactura, 2) la complejidad del instrumental, 3) los casos de reciclaje, 4), la frecuencia de artefactos compuestos, 5) la representación de instrumentos de larga vida útil y 6) la frecuencia de artefactos mutifuncionales. Como contraparte, hay un bajo grado de estandarización del instrumental a lo largo de la secuencia abordada, presentándose sólo en el lapso 2100-1500 AP, en artefactos estrictamente vinculados a labores extractivas y productivas. Así, también, la diversidad del instrumental se mantiene elevada, reduciéndose significativamente a partir de los 2100 AP, específicamente, en las puntas de proyectil. Siguiendo a Torrence (1989), esto sería consecuencia de la disminución substancial de los riesgos de corto plazo. Desde los desechos de talla y los núcleos los datos son plenamente consonantes, por ejemplo, en cuanto a la disminución progresiva de la frecuencia de lascas de adelgazamiento bifacial en los conjuntos o al bajo grado de estandarización en los desechos de talla y en los núcleos.

Oportunamente se destacó un problema de equifinalidad de los factores aludidos con respecto a sus consecuencias materiales sobre los artefactos líticos tallados. Las evidencias disponibles sugieren que tales factores se desarrollaron simultáneamente, por lo que la posición más económica es plantear que las variaciones en el tiempo de los conjuntos de artefactos líticos fueron el resultado de una serie de factores concurrentes. Al respecto, diversos autores han señalado como importantes, en este sentido, los problemas que tienen las comunidades agro-pastoriles de congeniar el trabajo productivo agrícola y pastoril, así como por los requerimientos de manufactura y procesamiento de nuevas tecnologías -cerámica, artefactos de molienda, etc.-, generando dilemas de inversión temporal (por ejemplo, Escola 1996, 2000, Muscio 2004; Carrasco 2004; Babot 2004a), lo que pudo haber llevado, también, a una menor inversión de tiempo y energía en la producción de artefactos líticos tallados.

\subsection{CONCLUSIONES}

En esta investigación se abordó la variabilidad y el cambio de los artefactos líticos tallados en la transición de la caza-recolección a la producción agro-pastoril en Antofagasta de la Sierra. Para ello, se seleccionó el lapso 5500-1500 AP, ya que tenía la suficiente extensión como para incluir los cambios implicados.

Un punto importante a notar es que la secuencia ocupacional microrregional presenta una vacío de información sobre bases residenciales entre los 3400 y los 2100 años AP, aunque si se registran otros tipos de sitios, como los depósitos intencionales de objetos. Sin embargo, se destaca la 
continuidad del proceso transicional local, ya que hay evidencias desde lo ergológico, lo tecnológico, lo tipológico y desde la utilización de las materias primas líticas como para sostener la idea de una continuidad poblacional, más allá de que grupos valliserranos pudieran haber ocupado este enclave puneño de forma de utilizar nuevos sectores ambientales con el objeto de ampliar la productividad agrícola (Olivera 1992, Olivera y Podestá 1993). En el caso de que esto se haya producido, se plantea que habría implicado una agregación de estos nuevos grupos a los preexistentes, y no un reemplazo, ya que no hay información alguna sobre conflictos intergrupales.

La aproximación metodológica implicó un análisis de tipo macroscópico y morfológicodescriptivo, de tipo técnico-morfológico y morfológico-funcional, siguiendo los parámetros generales propuestos por Aschero $(1975,1983)$. Asimismo, tomando como encuadre general dicha clasificación se desarrollaron, en función del problema de la transición, aunque de perfecta aplicación en otras situaciones, una serie de herramientas instrumentales para el análisis artefactual, como las nociones de clase técnica, secuencia de formatización y secuencia tipológica. Por otra parte, se destaca que se rescató y revalorizó la perspectiva tipológica que comprende la clasificación de Aschero (1975), mediante la identificación de "tipos morfológicos" y "especimenes morfológicos", aunque no con la intención de definir "tipos culturales", sino con el objeto de abordar la variabilidad tipológica a nivel diacrónico y sincrónico. La perspectiva tipológica incluyó, también, la elaboración de definiciones consistentes acerca de diversos grupos y subgrupos tipológicos, por ejemplo, en los bifaces, así como de atributos específicos.

La aproximación a la variabilidad de los artefactos líticos tallados se realizó sobre la base de la utilización de tres niveles diferentes: 1) el de conjunto lítico; 2) el de artefacto y 3) el de atributos morfológicos específicos. Al respecto, se abordó la toma de decisiones de los artesanos y/o usuarios, por ejemplo, en relación a las variaciones en la inversión de trabajo en la confección de artefactos, al cambio morfológico en un determinado tipo de diseño o a las formas particulares de realizar el mantenimiento del limbo de una punta de proyectil.

Dicha perspectiva multiescalar permitió exponer ciertas líneas de evidencias sobre los productos y estrategias de producción que son indicadores útiles del proceso transicional, como, por ejemplo, la inversión de trabajo en la manufactura de artefactos formatizados, la complejidad del instrumental o la presencia de ciertos diseños de puntas de proyectil.

También se exploró la incidencia del grado creciente de sedentarismo, de la intensificación de las prácticas ganaderas y agrícolas y de las variaciones paleoclimáticas en la variabilidad observada en los conjuntos líticos, encontrándose que las características generales de las muestras consideradas remiten a esos factores. Sin embargo, no toda la variabilidad puede ser vinculada a los mismos. Así, al 
abordar los bifaces, se pudo comprobar que parte de la variabilidad observada estaba relacionada con destrezas motoras y cognitivas diferenciales dentro de la sociedad. Por otra parte, al considerar los tipos morfológicos de puntas de proyectil del lapso 4100-3400 AP, se evidencia la puesta en marcha de procesos de diferenciación social que, aunque asociados a la restricción de la movilidad, exceden a la misma.

De esto se desprende que es necesario explorar alternativas a la tecnología vista como los objetos y medios usados por la sociedad para actuar sobre el ambiente físico. El comportamiento tecnológico es mucho más complejo, requiriéndose tratar con la acción humana.

Finalmente, se considera apropiado remarcar lo fructífero de utilizar enfoques tecnológicos y tipológicos de grano muy fino, ya que mediante la aplicación de metodologías adecuadas es posible obtener información relevante que de otra forma sería difícil recuperar. 


\section{BIBLIOGRAFÍA CITADA}

\section{ABIUSSO, N. y J. CÁMARA HERNÁNDEZ}

1974 Los maíces autóctonos de la Quebrada de Humahuaca (Jujuy, Argentina), sus niveles nitrogenados y su composición en aminoácidos. Revista de la Facultad de Agronomía. Tomo L(1-2): 1-25. La Plata.

ABBOTT, A.; R. LEONARD y G. JONES

1996 Explaining the Change from Biface to Flake Technology: A Seleccionist Application. En: Darwinian Archaeologies, H. Maschner (Ed.), pp. 33-42. Plenum Press, New York.

ADAMS, B.

1999 Lower, Middle or Upper Palaeolithic?. A classification analysis of the Bársony House hand axes from the North Carphatian Basin. Lithic Technology 24(1): 7-26.

\section{AGUERRE, A.; A. FERNÁNDEZ DISTEL y C. ASCHERO}

1973 Hallazgo de un sitio acerámico en la Quebrada de Inca Cueva (Provincia de Jujuy). Relaciones de la Sociedad Argentina de Antropología VII: 197-235.

AGUIRRE, G.

2005a Arqueobotánica del sitio Peñas chicas 1.3, Antofagasta de la Sierra (Catamarca- Argentina). Trabajo Final de la Carrera de Arqueología. Facultad de Ciencias Naturales e I.M.L. Universidad Nacional de Tucumán. Inédita.

2005b Arqueobotánica del sitio Peñas Chicas 1.3 (Antofagasta de la Sierra, Catamarca, Argentina). En: Investigaciones Arqueobotánicas en Latinoamérica: Estudios de casos y propuestas metodológicas, B. Marconetto, N. Oliszewski y M.P. Babot. En prensa.

\section{ALDENDERFER, $M$.}

1993 Ritual, Hierarchy, and Change in Foraging Societies. Journal of Anthropological Archaeology 12: $1-40$.

1998 Montane Foragers. Asana and the South-Central Andean Archaic. University of Iowa Press. Iowa. 
2002 Late Preceramic Cultural Complexity in the Lake Titicaca Basin. Paper draft Society for American Archaeology. Inédito.

ALDENDERFER, M. y M. BARRETO

2004 Informe Final: Excavaciones Arqueológicas en Jiskairumoko. Cuenca del Río Ilave. Sub-región de Puno. Región “José Carlos Mariategui”. Presentado al Instituto Nacional de Cultura. Lima, Perú. ms.

ALONSO, R.; J. VIRAMONTE y R. GUTIERREZ

1984 Puna Austral. Bases para el subprovincialismo geológico de la Puna argentina. Actas del Noveno Congreso Geológico Argentino I: 25-42.

AMES, K.

1994 The Northwest Coast: Complex Hunter-Gatherers, Ecology, and Social Evolution. Annual Review of Anthropology 23: 209-29.

ANDREFSKY, W.

1994a Raw-material availability and the organization of technology. American Antiquity 59 (1):21-34.

1994b The Geological occurrence of Lithic Material and Stone Tool Production Strategies. Geoarchaeology. An International Journal 9(5): 375-391.

1998 Lithics. Macroscopic approaches to analysis. Cambridge University Press, Cambridge.

ARAGÓN, E. y N.V. FRANCO

1997 Características de rocas para la talla por percusión y propiedades petrográficas. Anales del Instituto de la Patagonia 25: 187-199.

ARANIBAR, J.; S. MACKO; M. COLANERI; R. ZURITA y C. ASCHERO

2001 La dieta del bebe de la peña. Libro de resúmenes del XIV Congreso Nacional de Arqueología Argentina, pp. 146-147. Rosario, Facultad de Humanidades y Artes, Universidad Nacional de Rosario.

ARNOLD, J.

1996 The Archaeology of Complex Hunter-Gatherers. Journal of Archaeological Method and Theory 3(2): 77-126. 
2000 Revisiting Power, Labor Rights, and Kinship. Archaeology and Social Theory. En: Social Theory in Archaeology, M. Schiffer (Ed.), pp. 14-30. Salt Lake City, The University of Utah Press.

\section{ASCHERO, C.}

1975 Ensayo para una clasificación morfológica de artefactos líticos aplicada a estudios tipológicos comparativos. Informe al CONICET. Buenos Aires. ms.

1983 Ensayo para una clasificación morfológica de artefactos líticos aplicada a estudios tipológicos comparativos. Apéndices $A-C$. Revisión. Cátedra de Ergología y Tecnología (FFyL-UBA). Buenos Aires. ms.

1986 Informe de avance. Proyecto: "Estudio Antropológico Integral de una Región de la Puna Argentina: Antofagasta de la Sierra”. Área Arqueología. Asentamientos Cazadores-recolectores. Instituto Nacional de Antropología. ms.

1987 Códigos para inventarios de muestreos. Instituto de Antropología. ms.

1988a De punta a punta: producción, mantenimiento y diseño en puntas de proyectil precerámicas de la Puna argentina. Actas del IX Congreso Nacional de Arqueología Argentina, pp. 219-229. Buenos Aires.

1988b Arqueología precerámica de Antofagasta de la Sierra. Quebrada Seca: una localidad de asentamiento. Informe al CONICET. Carrera del Investigador Científico. Periodo 1986/87. Buenos Aires. ms.

1994 Reflexiones desde el Arcaico Tardío (6000-3000 AP). Rumitacana. Revista de Antropología 1: 13-17.

1998 Arte y arqueología: una visión desde la Puna argentina. Chungara 28 (1-2): 175-197.

1999a El arte rupestre del desierto puneño y el noroeste argentino. En: Arte Rupestre en los Andes de Capricornio, pp. 97-135. Museo Chileno de Arte Precolombino. Santiago de Chile.

1999b Marcando espacios. Resúmenes de las IV Jornadas de Comunicaciones de la Facultad de Ciencias Naturales e Instituto Miguel Lillo (U.N.T.), pag. 4. San Miguel de Tucumán. 
2003 De cazadores y pastores. El arte rupestre de la modalidad Río Punilla en Antofagasta de la Sierra y la cuestión de la complejidad en la Puna argentina. Trabajo presentado al VI Simposio Internacional de Arte Rupestre. Jujuy.

2004a Los grupos tipológicos de las gubias y los escoplos. Resúmenes del Taller Morfología macroscópica en la clasificación de artefactos líticos: innovaciones y perspectivas (Instituto de Arqueología y Museo, UNT), pág. 12. Ciudad Virtual de Antropología y Arqueología. NAyA. 2004. www.naya.org.ar

2004b Sobre las longitudes relativas en limbos de puntas de proyectil. Resúmenes del Taller Morfología macroscópica en la clasificación de artefactos líticos: innovaciones y perspectivas (Instituto de Arqueología y Museo, UNT), pág. 14. Ciudad Virtual de Antropología y Arqueología. NAyA. 2004. www.naya.org.ar

2004c Artefactos no-compuestos, compuestos y relaciones de complementariedad entre grupos tipológicos. Resúmenes del Taller Morfología macroscópica en la clasificación de artefactos líticos: innovaciones y perspectivas (Instituto de Arqueología y Museo, UNT), pp. 15-17. Ciudad Virtual de Antropología y Arqueología. NAyA. 2004. www.naya.org.ar

2005a Arte Antiguo Andino: Perspectivas y Contrastes. Tesis doctoral en preparación. Facultad de Filosofía y Letras (UBA).

2005b Iconos, huancas y complejidad en la Puna Sur Argentina. En: Taller Procesos Sociales Prehispánicos en los Andes Meridionales, pp.18. Instituto Interdisciplinario Tilcara. Tilcara, Jujuy.

\section{ASCHERO, C.; C. BAIED; S. HOCSMAN y J. MARTÍNEZ}

2005 Informe final. Proyecto The Emergence of Cultural Complexity in the Southern Puna of Argentina. Program in Support of Archaeological Field Research in the Development of Early Civilizations. Curtiss T. Brennan \& Mary G. Brennan Foundation. ms.

\section{ASCHERO, C.; D. ELKIN y E. PINTAR}

1991 Aprovechamiento de recursos faunísticos y producción lítica en el precerámico tardío. Un caso de estudio: Quebrada Seca 3 (Puna Meridional Argentina). Actas XII Congreso Nacional de Arqueología Chilena 2, pp. 101-114. Santiago de Chile. 
ASCHERO, C.; P. ESCOLA; S. HOCSMAN y J. MARTÍNEZ

2002 Recursos líticos en escala microrregional. Antofagasta de la Sierra, 1983-2001. En prensa en Revista Arqueología No 12.

ASCHERO, C.; L. MANZI y G. GÓMEZ

1993-94 Producción lítica y uso del espacio en el nivel 2b4 de Quebrada Seca 3. Relaciones de la Sociedad Argentina de Antropología XIX: 191-214.

\section{ASCHERO, C.; A. MARTEL Y S. MARCOS}

2003 El sitio Curuto 5: nuevos grabados rupestres en Antofagasta de la Sierra. En: Arte Rupestre en Sudamérica. Edicion especial $n^{0}$ 5. CD-Rom Rupestre Digital. V Simposio Internacional de Arte Rupestre, Tarija, Bolivia. Editorial Cultura de los Pueblos Pintores. GIPRI. Colombia.

\section{ASCHERO, C. y M. PODESTÁ}

1986 El arte rupestre en asentamientos precerámicos de la Puna argentina. Runa XVI: 29-57.

\section{ASCHERO, C. y S. HOCSMAN}

2004a Revisando cuestiones tipológicas en torno a la clasificación de artefactos bifaciales. En. Temas de Arqueología. Análisis Lítico. Mariano Ramos, Alejandro Acosta y Daniel Loponte (Comp.), pp. 725. Universidad Nacional de Lujan. Lujan.

\section{ASCHERO, C. y J. MARTÍNEZ}

2001 Técnicas de caza en Antofagasta de la Sierra, Puna Meridional Argentina. Relaciones de la Sociedad Argentina de Antropología XXVI: 215-241.

\section{ASCHERO, C. y H. YACOBACCIO}

1998/1999 20 Años Después: Inca Cueva 7 Reinterpretado. Cuadernos del Instituto Nacional de Antropología y Pensamiento Latinoamericano 18: 7-18.

\section{ASCHERO, C.; R. ZURITA; MG. COLANERI y A. TOSELLI}

1999b El Bebe de la Peña. Actas del XIII Congreso Nacional de Arqueología Argentina, Tomo II, pp. 329-338. Cabildo Histórico de la Ciudad de Córdoba.

\section{BABOT, M.}

1999 Un estudio de artefactos de molienda. Casos del Formativo. Trabajo Final de la Carrera de Arqueología. Facultad de Ciencias Naturales e Instituto Miguel Lillo. Universidad Nacional de Tucumán. Inédito. 
2004a Tecnología y utilización de artefactos de molienda en el Noroeste prehispánico. Tesis Doctoral. Facultad de Ciencias Naturales e Instituto Miguel Lillo. Universidad Nacional de Tucumán. Inédita.

2004b El papel de la molienda en la transición hacia la producción agropastoril: un análisis desde la Puna Meridional argentina. En prensa en Estudios Atacameños 32.

2005 Plant Resource Processing by Argentinean Puna Hunter-Gatherers (ca.7000-3200 A.P.) The Phytolitharien. Bulletin of the Society for Phytolith Research 17(2): 9-10.

2006 Movilidad y artefactos de molienda en Antofagasta de la Sierra, Puna Meridional Argentina (ca.6500-1100 AP). En: Artefactos líticos, movilidad y funcionalidad de sitios: problemas y perspectivas, P. Escola y S. Hocsman (Eds.). John and Erika Hedges Ltd. British Archaeological Reports (BAR) Internacional Series. Oxford. En prensa.

BABOT, M.; C. ASCHERO, S. HOCSMAN, M. HAROS, L. GONZÁLEZ BARONI y S. URQUIZA 2005 Ocupaciones agropastoriles en los Sectores Intermedios de Antofagasta de la Sierra (Catamarca): Un análisis desde Punta de la Peña 9.I. En prensa en Comechingonia. Revista de Arqueología.

\section{BABOT, M.; P. ESCOLA y S. HOCSMAN}

2005 Microfósiles en raederas de módulo grandísimo de contextos agropastoriles del Noroeste argentino: una contribución a su asignación funcional. Libro de Resúmenes del Tercer Encuentro de Investigaciones Fitolíticas del Cono Sur, pp. 60-62. Instituto de Arqueología y Museo. Tafí del Valle (Tucumán).

\section{BAMFORTH, D.}

1986 Technological efficiency and tool curation. American Antiquity 51(1): 38-50.

1992 Quarries in context: a regional perspective on lithic procurement. En: Stone tool procurement, production and distribution in California prehistory, vol. 2, pp.131-156. Institute of Archaeology Series, University of California, Los Angeles.

2003 Rethinking the Role of Bifacial Technology in Paleoindian Adaptations on the Great Plains. En: Multiple Approaches to the Study of Bifacial Technologies, M. Soressi y H. Dibble (Eds.), pp. 209228. University of Pennsylvania, Philadelphia. 
BAMFORTH, D. y M. BECKER

2000 Core/Biface Ratios, Mobility, Refitting, and Artifact Use-Lives: A Paleoindian Example. Plains Anthropologist 45(173): 273-290.

BAMFORTH, D. y P. BLEED

1997 Technology, Flaked Stone Technology, and Risk. En: Rediscovering Darwin: Evolutionary Theory and Archaeological Explanation, Barton, C. y A. Clark (Eds.), pp. 109-139. Archaeological Papers of the American Anthropological Association 7.

\section{BARKER, G. y D. GILBERTSON}

2000 The Archaeology of Drylands. Living at the margin. G. Barker y D. Gilbertson (Eds.). Routledge.

BARNARD, A.

2001 Los pueblos cazadores recolectores. Fundación Navarro Viola, Buenos Aires.

BARTON, H.

1999 Generalised Core Technologies: a view from the Southern Hemisphere. World Archaeological Congress 4. Symposium: The Environment. University of Cape Town.

\section{BATES, R. y J. JACKSON}

1987 Glossary of Geology. Third Edition. American Geological Institute, Virginia.

BECK, C.

1998 Projectile Point Types as Valid Chronological Units. En: Units Issues in Archaeology. Measuring Time, Space, and Material, A. Ramenosfsky y A. Steffen (Eds.), pp. 21-40. The University of Utah Press, Salt Lake City.

BETTINGER, R.

1991 Hunter-Gatherers: Archaeological and Evolutionary Theory. Plenum Press, Nueva York.

BINFORD, L.

1979 Organization and Formation Processes: Looking at Curated Technologies. Journal of Anthropological Research 35: 255-273.

1980 Willow smoke and dogs' tails: hunter-gatherer settlement systems and archaeological site formation. American Antiquity 45: 4-20. 
BLEED, P.

1986 The optimal design of hunting weapons: maintainability or reliability. American Antiquity 51(4): 737-747.

1997 Content as Variability, Result as Selection: Toward a Behavioral Definition of Technology. En: Rediscovering Darwin: Evolutionary Theory and Archeological Explanation, C. M. Barton y G. A. Clark (Eds.), pp. 95-104. Archeological Papers of the American Anthropological Association No 7.

BODLEY, J.

1999 Hunter-gatherers and the colonial encounter. En: The Cambridge Encyclopedia of Hunters and Gatherers, R. Lee y R. Daly (Eds.), pp. 465-472. Cambridge University Press.

BODU, P.

1996 Les chasseurs magdaleniens de Pincevent: quelques aspects de leurs comportements. Lithic Technology 21(1) : 48-66.

BODU, P.; C. KARLIN y S. PLOUX

1990 Who is who?. The Magdalenian flintknappers of Pincevent. En: The Big Puzzle, E. Cziesla, S. Eischoff; N. Arts y D. Winters, pp. 143-163. Holos. Bonn.

BORDES, F.

1961 Typologie du Paléolithique ansien et moyen. Ed. Delmas. Bordeaux.

BORRERO, L.

1993. Artefactos y evolución. Palimpsesto. Revista de Arqueología 3: 15-32.

BOELCKE, O.

1986 Plantas vasculares de la Argentina. Nativas y exóticas. Ed. Hemisferio Sur.

BOUSMAN, C.

1993 Hunter-gatherer adaptations, economic risk and tool design. Lithic Technology 18 (1 y 2): 59-86.

BRADLEY, B. A. y Y. GIRIA

1996 Concepts of the technological analysis of flaked stone: a case study from the High Arctic. Lithic Technology 21(1): 23-47 


\section{BRÉZILLON, M.}

1983 La Dénomination des objets de pierre taillée. IV supplément à « Gallia Préhistoire », Centre National de la Recherche Scientifique. Paris.

BRIL, B.; V. ROUX y G. DIETRICH

2001 Working on stone knapping: Cambay a unique opportunity. Abstracts del Workshop La taille de la pierre: une action spécifique à l'homme?. Francia.

BROWMAN, D.

1987a Agro-pastoral risk management in the Central Andes. Research in Economic Anthropology 8: 171-200.

1987b Introduction: risk management in Andean arid land. En: Arid Land Use Strategies and Risk Management in the Andes. A Regional Anthropological Perspective, D. Browman (Ed.), pp. 1-24. Westview Press, Boulder.

BROWN, AD; H. GRAU; L. MALIZIA y A. GRAU

2001 Argentina. En: Bosques Nublados del Neotrópico. M Kappelle y AD Brown (Eds.), pp. 623-659. INBIO. Costa Rica.

BRUNIARD, E. 1999 El escenario geográfico. En: Nueva Historia de la Nación Argentina. 1. La Argentina Aborigen. Conquista y Colonización, pp. 39-63. Academia Nacional de la Historia. Editorial Planeta.

\section{CALLAHAN, E.}

1979 The Basic of Biface Knapping in the Eastern Fluted Point Tradition. A Manual for Flintknappers and Lithic Analysts. Archaeology of Eastern North America 7 (1): 1-180.

\section{CARR, P.}

1994 The Organization of Technology: Impact and Potential. En: The Organization of North American Prehistoric Chipped Stone Tool Technologies, P. Carr (Ed.), pp. 1-8. International Monographs in Prehistory, Archaeological Series 7. Ann Arbor, Michigan.

\section{CARRASCO, C.}

2004 Uso de tecnologías líticas entre el Arcaico Tardío y el Período Tardío. El modelo de la Localidad de Caspana. Chúngara, Volumen Especial: 29-35. 
CIGLIANO, E.

1962 Industrias precerámicas de la Puna argentina. Ampurias. Revista de Prehistoria, Arqueología y Etnología XXIV: 1-34.

COBEAN, R.; J, VOGT; M. GLASCOCK y T. STOCKER

1991 High precision trace element characterization of major Mesoamerican obsidian sources and further analysis of artifacts from San Lorenzo Tenochtitlán, Mexico. Latin American Antiquity 2: 6991.

COHEN, M.

2005 Entre guano y arena. Ocupaciones recurrentes: Un caso de estudio en el sitio Punta de la Peña 9-III. Antofagasta de la Sierra, Catamarca. Trabajo Final de Carrera. Facultad de Ciencias Naturales e I.M.l. Universidad Nacional de Tucumán. Inédita

\section{CORNEJO, l. y L. SANHUEZA}

2003 Coexistencia de cazadores recolectores y horticultores tempranos en la cordillera andina de Chile Central. Latin American Antiquity 14(4): 389-407.

COTTERELL, B. y J. KAMMINGA

1990 Mechanics of pre-industrial technology. Cambridge University Press. Cambridge.

COWAN, F.

1999 Making sense of flake scatters: lithic technological strategies and mobility. American Antiquity 64(4): 593-607.

CRABTREE, D.

1972 An Introduction to Flintworking. Occasional Papers of the Idaho State University Museum, Number 28, Idaho.

DELFINO, D.

1999 Prospecciones en los '90 : Nuevas evidencias para repensar la arqueología de Laguna Blanca (Dpto. Belén, Catamarca). Revista de Ciencia y Tecnología VI(7): 55-80.

DEMARS, P. y P. LAURENT

1992 Types d'outils lithiques du paleolithique superieur en Europe. Presses du CNRS, Paris.

DERRUAU, M. 
1978 Geomorfología. Editorial Ariel. Barcelona.

DE SOUZA, P.

2004a cazadores recolectores del Arcaico Temprano y Medio en la cuenca superior del río LOA: Sitios, conjuntos líticos y sistemas de asentamiento. Estudios Atacameños 27: 7-43.

2004b Tecnologías de proyectil durante los períodos Arcaico y Formativo en el Loa Superior (Norte de Chile: A partir del análisis de puntas líticas. Chungara. Volumen Especial. Tomo I: 61-76.

DIBBLE, $\mathrm{H}$.

1995 Raw material availability, intensity of reduction, and Middle Paleolithic assemblage variability. En: The Middle Paleolithic Site of Combe-Capelle Bas (France), H. Dibble y M. Lenoir (Eds.), pp. 289-315. University Museum Monograph 91, University of Pennsylvania, Philadelphia.

DIBBLE, H. y A. PELCIN

1995 The effect of hammer mass and velocity on flake mass. Journal of Archaeological Science 22: 429-39.

DOBRES, M.

2000 Technology and Social Agency. Outlining a Practice Framework for Archaeology. Blackwell Publishers.

DOBRES, M. y C. HOFFMAN

1994 Social agency and the dynamics of prehistoric technology. Journal of Archaeological Method and Theory 1: 211-258.

DUNNELL, C.

1986 Methodological Issues in Americanist Artifact Classification. Advances in Archaeological Method and Theory 9: 149-207.

EIROA, J.; LOMBA MAURANDI, J.; MARTINEZ SANCHEZ, C. y PONCE GARCIA, J. 1989 Apuntes de Tipología Prehistórica. Universidad de Murcia. Murcia.

\section{ELLEN, R.}

1994 Modes of subsistence : Hunting and gathering to agriculture and pastoralism. En: Companion Encyclopedia of Anthropology. Humanity, Culture and Social Life, T. Ingold (Ed.), pp. 197-225. Routledge. 
ELKIN, D.

1992 Explotación de recursos en relación al sitio acerámico Quebrada Seca 3, Antofagasta de la Sierra, Puna de Catamarca. Shincal 2: 1-14.

1996a Arqueozoología de Quebrada Seca 3: Indicadores de subsistencia humana temprana en la Puna Meridional Argentina. Tesis Doctoral Inédita, Facultad de Filosofía y Letras, Universidad de Buenos Aires.

1996b El uso del recurso fauna por los primeros habitantes de Antofagasta de la Sierra (Puna de Catamarca). Actas del I Congreso de Investigación Social. Región y Sociedad en Latinoamérica. Su problemática en el NOA, pp. 202-209. Facultad de Filosofía y Letras, Universidad Nacional de Tucumán. San Miguel de Tucumán.

ELKIN, D.; C. MADERO; G. MENGONI; D. OLIVERA y H. YACOBACCIO

1992 Avances en el estudio arqueológico de los camélidos del noroeste argentino. VII Convención Internacional de Especialistas en Camélidos Sudamericanos. San Salvador de Jujuy.

\section{ENDICOTT, K.}

1999 Gender relations in hunter-gatherer societies. En: The Cambridge Encyclopedia of Hunters and Gatherers, R. Lee y R. Daly (Eds.), pp. 411-418. Cambridge University Press.

\section{ERICSON, J.}

1984 Toward the analysis of lithic production systems. En: Prehistoric Quarries and Lithic Production. New Directions in Archaeology, J. Ericson y B. Purdy (Eds.), pp. 1-9. Cambridge University Press.

\section{ESCOLA, P.}

1987 Las Puntas de proyectil del Formativo en Puna y Quebradas de Acceso: un estudio tecnotipológico de cuatro casos de análisis. Tesis de Licenciatura. Facultad de Filosofía y Letras, Universidad de Buenos Aires. Inédita.

1990-92 Explotación y maneo de recursos líticos en un sistema adaptativo Formativo de la Puna argentina. Arqueología Contemporánea 3: 5-19.

1991 Puntas de proyectil en contextos formativos: acercamiento tecno-tipológico a través de cuatro casos de análisis. Actas XI Congreso Nacional de Arqueología Chilena 2: 175-187, Santiago de Chile. 
1996 Riesgo e incertidumbre en economías agro-pastoriles: consideraciones teórico-metodológicas. Arqueología 6: 9-24.

1999 La variable tecnológica en contextos agro-pastoriles. Humanitas XXI, Número Extraordinario: 49-76.

2000 Tecnología Lítica y Sociedades Agro-pastoriles Tempranas. Tesis de Doctorado, Facultad de Filosofía y Letras, Universidad de Buenos Aires. Inédita.

2002 Caza y pastoralismo: un reaseguro para la subsistencia. Relaciones de la Sociedad Argentina de Antropología XXVII: 233-245.

2003 Disponibilidad de recursos líticos y fuentes de aprovisionamiento en un sector de la Puna Meridional. Revista Mundo de Antes 3: 65-84

2004a Forma de la base en puntas de proyectil apedunculadas escotadas. Resúmenes del Taller Morfología macroscópica en la clasificación de artefactos líticos: innovaciones y perspectivas (Instituto de Arqueología y Museo, UNT), pág. 15. Ciudad Virtual de Antropología y Arqueología. NAyA. 2004. www.naya.org.ar

2004b Variabilidad en la explotación y distribución de obsidianas en la Puna Meridional Argentina. Estudios Atacameños 28: 9-24.

2004c Tecnología lítica y sociedades agro-pastoriles tempranas. En: Temas de Arqueología, Análisis Lítico, A. Acosta, D. Loponte y M. Ramos (Comp.), pp. 59-100. Universidad Nacional de Luján.

2005 Informe Análisis Tecno-Tipológico de materiales líticos del sitio Casa Chávez Montículos 1 Catamarca-. Manuscrito

\section{ESCOLA, P.; S. HOCSMAN y S. LÓPEZ CAMPENY}

2005 Artefactos líticos y variabilidad de asentamientos en contextos agro-pastoriles de Antofagasta de la Sierra (Catamarca). En: Artefactos líticos, movilidad y funcionalidad de sitios: problemas y perspectivas. Patricia S. Escola y Salomón Hocsman (Eds.). British Archaeological Reports (BAR) Internacional Series. Oxford. En prensa. 
FENENGA, F.

1953 The Weights of Chipped Stone Points: A Clue to Their Functions. Southwestern Journal of Anthropology 9: 309-323.

FERNÁNDEZ, J.

1967 Elementos divergentes en el material lítico procedente de los horizontes precerámicos del Noroeste Argentino. Anales de la Sociedad Científica Argentina, T. CLXXXIV, Entregas V-VI. Serie I, Ciencias, No 13: 97-127.

1968a Asentamiento humano precerámico con molinos en la cuenca de Guayatayok (Puna de Jujuy). Etnía 8: 21-27.

1968b La industria de Mal paso: Materiales de morfología protolítica en las terrazas del Yacoraite Superior (Puna de Jujuy). Anales de Arqueología y Etnología 23: 43-54.

1968c El Aguilarense. Bases para su ubicación dentro de las culturas precerámicas del Noroeste argentino. Anales de Arqueología y Etnología 23: 55-73.

1971 La Edad de la Piedra en la Puna de Atacama. Una investigación regional y cronológica; una aportación de la ciencia geográfica a la solución del problema vinculado a la temprana instalación humana en Sudamérica. Revista del Instituto de Antropología. Tercera Serie, Volumen I. Facultad de Filosofía y Letras. Universidad Nacional de Tucumán.

1972 Las bifaces protolíticas de la Puna de Chile y Argentina. Antiquitas 15: 11-14.

1988/89 Ocupaciones alfareras (2860(160 años AP) en la cueva de Cristóbal, Puna de Jujuy, Argentina. Relaciones de la Sociedad Argentina de Antropología XVII(2) -Nueva Serie-: 139-178.

1996a Potrero de Caballo Muerto: Aspectos arqueológicos, cronológicos y paleoambientales del Precerámico Tardío en el ecosistema hidrófilo de las vegas puneñas. Actas y Memorias del XI Congreso Nacional de Arqueología Argentina (13 Parte). Revista del Museo de Historia Natural de San Rafael (Mendoza) XXV: (1/4): 23-51.

1996b Munitayoc, nuevo sitio con cerámica temprana (1000 años A.C.) en la Puna Jujeña. Actas y Memorias del XI Congreso Nacional de Arqueología Argentina ( $11^{\circ}$ Parte). Revista del Museo de Historia Natural de San Rafael (Mendoza) XXIII (1/4): 51-62. 
1997 Arqueología de la Cueva de El Portillo, Departamento Humahuaca, provincia de Jujuy. Avances en Arqueología 3: 41-69.

FERNÁNDEZ, J.; H. PANARELLO y A. RAMOS

1992 El análisis de elementos traza y de las relaciones entre isótopos estables del carbono en cerámicas del Temprano (3000 años A.P.) de la Puna jujeña, como indicadores de su manufactura autóctona y funcionalidad probable. Cuadernos de la Facultad de Humanidades y Ciencias Sociales 3: 13-19.

\section{FERNÁNDEZ DISTEL, A.}

1978 Nuevos hallazgos precerámicos en la región de las Salinas Grandes, Puna de Jujuy, Argentina. Revista del Instituto de Antropología VI: 15-62.

1986 Las Cuevas de Huachichocana, su posición dentro del precerámico con agricultura incipiente del Noroeste Argentino. Beiträge zur Allgemeinen und Vergleichenden Archäeologie 8: 353-430.

1998 Arqueología del Formativo en la Puna Jujeña (1800 AC al 650 DC). Colección Mankacén. Buenos Aires.

FINLAY, N.

1997 Kid Knapping: the missing children in lithic analysis. En: Invisible People and processes. Writing Gender and Childhood into European Archaeology, J. Moore y E. Scott (Eds.), pp. 203-212. Leicester University Press, London.

FISHER, A.

1990 On being a pupil flintknapper of 11.000 years ago. En: The Big Puzzle; E. Cziesla, S. Eischoff; N. Arts y D. Winters, pp. 447-464. Holos. Bonn.

\section{FLEGENHEIMER, $\mathrm{N}$}

1991 Bifacialidad y piedra pulida en sitios pampeanos tempranos. Shincal 3: 64-78.

2001 Las puntas “cola de pescado” grandes en las colecciones pampeanas. Libro de Resúmenes del XIV Congreso Nacional de Arqueología Argentina, pág. 185, Rosario.

\section{FLEGENHEIMER, N. ; C. BAYÓN y M. GONZÁLEZ DE BONAVERI}

1995 Técnica simple, comportamientos complejos: la talla bipolar en la arqueología bonaerense. Relaciones de la Sociedad Argentina de Antropología XX: 81-110. 
FLENNIKEN, J. y A. RAYMOND

1986 Morphological projectile point typology: replication, experimentation and technological analysis. American Antiquity 51(3): 603-614.

FRANCO, N. y L. BORRERO

1993 El Stress Temporal y los Artefactos Líticos. La Cuenca Superior del Río Santa Cruz. Actas de las Segundas Jornadas de Arqueología de la Patagonia. Puerto Madryn.

GARCÍA, L.

1995 Las primeras cerámicas en la Puna de Jujuy. Cuadernos de la Facultad de Humanidades y Ciencias Sociales 5: 75-80

1997 El material cerámico de Tomayoc. Bulletin Institute Francaise de Etudes Andines 26(2): 177-193

1998 Arqueología de asentamientos formatives en la Puna Oriental y su borde, Provincia de Jujuy. El cambio hacia una vida crecientemente sedentaria y productiva en Azul Pampa, Departamento de Humahuaca. Tesis Doctoral, Facultad de Filosofía y Letras, UBA. Inédita.

\section{GARCÍA, L. y F. CARRION}

1992 El Formativo en la Puna de Jujuy, Inca Cueva-Alero 1. Cuadernos de la Facultad de Humanidades y Ciencias Sociales 3: 21-33.

\section{GARCÍA, S.; D. ROLANDI y D. OLIVERA}

2000 Puna e Historia. Antofagasta de la Sierra, Catamarca. Asociación de Amigos del Instituto Nacional de Antropología. Buenos Aires.

\section{GARCÍA SALEMI, M.}

1986 Geomorfología de regiones secas: Antofagasta de la Sierra, Provincia de Catamarca. Centro de Estudios Regiones Secas 4(1-2): 5-13.

\section{GERO, J.}

1989 Assessing social information in material objects: how well do lithics measure up?. En: Time Energy and Stone Tools, R. Torrence (Ed.), pp. 92-105. Cambridge University Press. Cambridge.

GIL, A.

1997/1998 Cultígenos prehispánicos en el sur de Mendoza. Discusión en torno al límite meridional de la agricultura andina. Relaciones de la Sociedad Argentina de Antropología XXII-XXIII: 295-318 
1988 Differentiation of obsidian sources in Mesoamerica. En: Archaeometry '88. R. Farquhar, R. Hancock y L. Pavlish (Eds.), pp. 245-251. Archaeometry Laboratory. University of Toronto.

\section{GLASCOCK, M.; G. BRASWELL y R. COBEAN}

1998 A systematic approach to obsidian source characterization. En: Archaeological Obsidian Studies. Method and Theory. M. Shackley (Ed.). Advances in Archaeological and Museum Science Series, Vol. 3: 15-65. Plenum Press. New York.

GONZÁLEZ, A.

1952 Antiguo horizonte precerámico en las Sierras Centrales de la Argentina. Runa V(1-2): 110-133.

\section{GONZÁLEZ, O.}

1992 Geología de la Puna Austral entre los $25^{\circ} 15^{\prime}$ a $26^{\circ} 30^{\prime}$ de Latitud Sur y los 66 $25^{\prime}$ a $68^{\circ} 00^{\prime}$ de Longitud Oeste, provincias de Catamarca y Salta, Argentina. Acta Geológica Lilloana XVII (2): 6388.

GRAMLY, R.

1990 Guide to the Palaeo-Indian Artifacts of North America. Persimmon Press Monographs in Archaeology, Buffalo.

\section{GRIMM, L.}

2000 Apprentice flintknapping. Relating material culture and social practice in the Upper Palaeolithic. En: The transmission of knowledge, Sofaer, J. (Ed.), pp. 53-71.

\section{GURÁIEB, A.}

1999 Análisis de la diversidad en los conjuntos instrumentales líticos de Cerro de los Indios I (Lago Posadas, Santa Cruz). Relaciones de la Sociedad Argentina de Antropología XXIV: 293-306.

\section{HABER, A.}

1999 Una arqueología de los oasis puneños. Domesticidad, interacción e identidad en Antofalla, primer y segundo milenios d.C. Tesis de Doctorado, Facultad de Filosofía y Letras, Universidad de Buenos Aires. Inédita.

HARRIS, D. 
1996 The origin and spread of agriculture and pastoralism in Eurasia : an overview. En: The Origin and Spread of Agriculture and Pastoralism in Eurasia. UCL Press.

HASTORF, C. (Editora)

1999 Early Settlement at Chiripa, Bolivia: Research of The Taraco Archaeological Project. Number 57, Berkeley.

\section{HAYDEN, B.}

1980 Confusion in the bipolar world: Bashed pebbles and splintered pieces. Lithic Technology 9(1):27.

1981 Research and Development in the Stone Age: Technological Transitions among HunterGatherers. Current Anthropology 22(5): 519-538

1989 From chopper to celt: the evolution of resharpening techniques. En: Time, Energy and Stone Tools, R. Torrence (Ed.), pp. 7-16. Cambridge University Press, Cambridge.

1998 Practical and Prestige Technologies: The evolution of material systems. Journal of Archaeological Method and Theory 5(1): 1-55.

HAYDEN, B.; N. FRANCO y J. SPAFFORD

1996 Evaluating Lithic Strategies and Design Criteria. En: Stone Tools. Theoretical Insights into Human Prehistory, G. Odell (Ed.), pp. 9-45. Plenum Press, New York.

HILL, J.; W. TRIERWEILER y R. PREUCEL

1996 The Evolution of Cultural Complexity: A case from the Pajarito Plateau, New Mexico. En: Emergent Complexity. The Evolution of Intermediate Societies, J. Arnold (Ed.), pp. 107-127. Ann Arbor, Archaeological Series 9, International Monographs in Prehistory.

\section{HISCOCK, P.}

1994 Technological responses to risk in Holocene Australia. Journal of World Prehistory 8(3): 267292.

\section{HISCOCK, P. y V. ATTENBROW}

2003 Early Australian implement variation: a reduction model. Journal of Archaeological Science 30: 239-249. 
HOCSMAN, S.

2001 Tecnologías líticas extractivas en bases residenciales de cazadores-recolectores y grupos agropastoriles: una comparación. Presentado para su publicación en Actas del XIV Congreso Nacional de Arqueología Argentina. Simposio Estudios Tecnológicos en Arqueología. Sección A: La Tecnología y las Actividades Extractivas. Rosario. ms.

2002 ¿Cazadores-recolectores complejos en la puna meridional argentina? Entrelazando evidencias del registro arqueológico de la microrregión de Antofagasta de la Sierra (Catamarca). Relaciones de la Sociedad Argentina de Antropología XXVII: 193-214.

\section{HOCSMAN, S. y J. MARTÍNEZ}

2004 "Secuencia de formatización” en artefactos formatizados: definición y aplicaciones. Resúmenes del Taller Morfología macroscópica en la clasificación de artefactos líticos: innovaciones y perspectivas (Instituto de Arqueología y Museo, UNT), pág. 18. Ciudad Virtual de Antropología y Arqueología. NAyA. 2004. www.naya.org.ar

\section{HOCSMAN, S.; J. MARTÍNEZ; M. RODRÍGUEZ y C. ASCHERO}

2004 Obtención de recursos distantes en la porción meridional de los Andes Centro-Sur: una visión desde la Puna argentina. En referato en Before Farming: the archaeology and anthropology of huntergatherers.

INGOLD, T.

1988 Tools, minds and machines: an excursion in the philosophy of technology. Techniques et Culture 12: $151-176$.

1990 Society, Nature and the Concept of Technology. Archaeological Review from Cambridge 9: 517.

1998a Tools, techniques and technology. En: Tools, language and cognition in human evolution, K. Gibson y T. Ingold (Eds.), pp. 337-345. Cambridge University Press. United Kingdom.

1998b Tool-use, sociality and intelligence. En: Tools, language and cognition in human evolution, K. Gibson y T. Ingold (Eds.), pp. 429-445. Cambridge University Press. United Kingdom.

INIZAN, M. L.; M. REDURON-BALLINGER; H. ROCHE y J. TIXIER

1999 Technology and Terminology of Knapped Stone. Préhistoire de la Pierre Taillée Tome 5. Cercle de Recherches et d’Etudes Préhistoriques. Nanterre. 
ISAAC, B.

1990 Economy, Ecology, and Analogy: The ¡Kung San and the Generalized Foraging Model. En: Early Paleoindian Economies of Eastern North America, B. Isaac y K. Tankersley (Eds.), pp. 323335. Research in Economic Anthropology Supplement 5. Greenwich, Conn.: JAI Press.

JACKSON, D.

1993-94 Confluencia 2: Un campamento de cazadores arcaicos del Norte de Chile. Revista Chilena de Antropología 12: 113-122.

\section{JACKSON, D. y A. BENAVENTE}

1994 Secuencia, cambios y adaptación de los cazadores-recolectores de la microcuenca de Chiu-Chiu, provincia del Loa. Chungara 26 (1): 49-64.

1995-1996 Instrumentos líticos del complejo pastoril temprano "Chiuchiu 200”, Norte de Chile. Estudios Atacameños 12:41-52.

JACOBS, S.; N. BENNIS y A. ROBY-BRAMI

2001 Three dimensional kinematic analysis of tooluse by apraxic patients. Abstracts del Workshop La taille de la pierre: une action spécifique à l'homme?. Francia.

JESKE, R.

1992 Energetic efficiency and lithic technology: an Upper Mississippian example. American Antiquity 57(3): 467-481.

\section{JOHNSON, J.}

1996 Lithic Analysis and Questions of Cultural Complexity. The Maya. En: Stone Tools. Theoretical Insights into Human Prehistory, G. Odell (Ed.); pp. 159-179. Plenum Press.

JOCHIM, M.

1991 Archeology as Long-Term Ethnography. American Anthropologist 93: 308-320.

\section{KARLIN, C.; M. JULIEN y D. LAVALLÉE}

1995 Las técnicas de fabricación. En: Telarmachay. Cazadores y pastores prehistóricos de los Andes Tomo I: 239-262. D. Lavallée (dir.). Instituto Francés de Estudios Andinos, Lima (edición original en francés, Paris, 1985). 
KARLIN, C.; S. PLOUX; P. BODU y N. PIGEOT

1993 Some socio-economic aspects of the knapping process among groups of hunter-gatherers in the Paris Basin area. En: The Use of Tools by Human and Non-human Primates, A. Berthelet y J. Chavaillon (Eds.), pp. 319-337. Clarendon Press, Oxford.

KELLY, R.

1988 The Three Sides of a Biface. American Antiquity 53 (4): 717-734.

1992 Mobility/sedentism: concepts, archaeological measures and effects. Annual Review of Anthropology 21: 43-66.

1995 The Foraging Spectrum: Diversity in Hunter-Gatherer Lifeways. Smithsonian Institution Press, Washington D.C.

2000 Elements of a Behavioral Ecological Paradigm for the Study of Prehistoric Hunter-Gatherers. En: Social Theory in Archaeology, M. Schiffer (Ed.), pp. 63-78. The University of Utah Press, Salt Lake City.

\section{KNETCH, H.}

1997 Projectile Points of Bone, Antler and Stone. Experimental Explorations of Manufacture and Use. En: Projectile Technology. H. Knecht (Ed.), pp. 191-212. Plenum Press, New York.

\section{KOLDEHOFF, B.}

1987 The Cahokia Flake Tool Industry: Socioeconomic Implications for Late Prehistory in the Central Mississippi Valley. En: The Organization of Core Technology, J. Johnson. y C. Morrow (Eds.), pp. 151-185. Westview Press, Boulder and London.

\section{KORSTANJE, M. y M. BABOT}

2005 A microfossil characterization from South Andean economic plans. En: Pleaces, people and plants. Using phytoliths in Archaeology and Palaeoecology. Proceedings of the 4th International conference on phytolith research. M. Madella, M. Jones y D. Zurro (Eds.). Oxbow Books, Cambridge. En prensa.

KOSSE, K.

1994 The Evolution of Large, Complex Groups: A Hypothesis. Journal of Anthropological Archaeology 13: 35-50. 


\section{KUHN, S.}

1994 A Formal Approach to the design and Assembly of Mobile Toolkits. American Antiquity 59(3): 426-442.

LANATA, J.

1996 La diversidad artefactual en el norte de Península Mitre, Tierra del Fuego. Arqueología 6: 159198.

LANATA, J. y L. BORRERO

1994 Riesgo y Arqueología. “Arqueología de Cazadores-Recolectores. Límites, Casos y Aperturas”. Arqueología Contemporánea 5 (Edición Especial): 129-143.

\section{LARRAHONA, P.}

2001 Determinaciones petrográficas de muestras de rocas de Antofagasta de la Sierra (Catamarca). ms.

LAVALLÉE, D., M. JULIEN; C. KARLIN, L. GARCÍA, D. POZZI ESCOT y M. FONTUGNE 1997 Entre Desierto y Quebrada: Tomayoc, un alero de la Puna. Avances en Arqueología 3: 9-39.

\section{LAYTON, R.}

2001 Hunter-gatherers, their neighbours and the Nation State. En: Hunter-gatherers: An interdisciplinary perspective, C. Panter-Brick, R. Layton y P. Rowley-Conwy (Eds.), pp. 292-321. Cambridge University Press. Cambridge.

LEAF, G.

1979 Variation in the form of bipolar cores. Plains Anthropologist 23(83): 39-50.

\section{LEE, R. y R. DALY}

1999 Foragers and others. En: The Cambridge Encyclopedia of Hunters and Gatherers, R. Lee y R. Daly (Eds.), pp. 1-19. Cambridge University Press.

LEE, R. e I. DEVORE

1968 Man the Hunter. Aldine, Chicago.

\section{LEMMONIER, P.}

1986 The Study of Material Culture Today Toward an Anthropology of Technical Systems. Journal of Anthropological Archaeology 5: 147-86. 
1992 Elements for an Anthropology of Technology. Anthropological Papers No88. Museum of Anthropology, University of Michigan. Ann Arbor.

\section{LEROI-GOURHAN, A.}

1971 El gesto y la palabra. Ediciones de la Biblioteca de la Universidad Nacional de Venezuela. Venezuela.

1988 El Hombre y la Materia (Evolución y Técnica I). Taurus Comunicación.

\section{LILLEHAMMER, G.}

1989 A Chile is Born. The Child's World in an Archaeological Perspective. Norwegian Archaeological Review 22(2): 89-105.

\section{LÓPEZ CAMPENY, S.}

2001a Actividades domésticas y organización del espacio intrasitio. El sitio Punta de la Peña 9. (Antofagasta de la Sierra, Prov. de Catamarca). Trabajo Final de Carrera. Facultad de Ciencias Naturales e Instituto Miguel Lillo. Universidad Nacional de Tucumán. Inédita.

2001b El hogar, los ancestros y el corral: reocupación y variabilidad en el uso del espacio en unidades domésticas arqueológicas (Sitio Punta de la Peña 9, Antofagasta de la Sierra, Catamarca). Actas del XIV Congreso Nacional de Arqueología Argentina, Universidad Nacional de Rosario. En prensa.

\section{LÓPEZ CAMPENY, S.; E. DEL BEL; S. RODRÍGUEZ CURLETTO y A. ROMANO}

2005 Evidencias de ritualidad en contextos agro-pastoriles: el sitio Piedra Horadada 2 (PH2), Puna Meridional Argentina. Libro de Resúmenes de las VII Jornadas de Comunicaciones, pág. 19. Facultad de Ciencias Naturales e I.M.L., Universidad Nacional de Tucumán.

\section{LÓPEZ CAMPENY, S.; D. OLIVERA; V. FERNÁNDEZ VARELA y J. PEÑA}

2005 Procesos taxonómicos, subsistencia y uso del espacio: análisis de la arqueofauna de un sitio agropastoril de la Puna Meridional Argentina (Punta de la Peña 9, Antofagasta de la Sierra, Catamarca). Intersecciones en Antropología 6: 11-28.

\section{LUEDTKE, B.}

1992 An Archaeologist's Guide to Chert and Flint. Archaeological Research Tools 7. Institute of Archaeology, University of California, Los Angeles. 
LUPO, L.

1998 Estudio sobre la lluvia polínica actual y la evolución del paisaje a través de la vegetación durante el Holoceno en la cuenca del río Yavi. Borde Oriental de la Puna. Noroeste Argentino. Servicio Alemán de Intercambio Académico, pp. 1-58. Bamberg.

\section{MACDONALD, D. y B. HEWLETT}

1999 Reproductive Interests and Forager Mobility. Current Anthropology 40(4): 501-523.

MACKO, S.; J. ARANÍBAR, M.G. COLANERI; R. ZURITA y C. ASCHERO

2001a La dieta del bebe de la peña. En prensa en Actas del XIV Congreso Nacional de Arqueología Argentina.

MACKO, S.; ARANÍBAR, J.; COLANERI M.; LÓPEZ CAMPENY, S. y C. ASCHERO

2001b Punta de la Peña 9: Análisis de isótopos estables de un sitio agropastoril temprano de la Puna Meridional Argentina (Antofagasta de la Sierra, Catamarca). En prensa en Actas del XIV Congreso Nacional de Arqueología Argentina.

MANZI, L.

1999 Análisis de la distribución espacial de conjuntos líticos en el sector de las quebradas de altura e intermedio en la cuenca del río Las Pitas. Antofagasta de la Sierra. Catamarca. Tesis de Doctorado. Facultad de Filosofía y Letras (UBA). Inédita.

\section{MARKGRAF, V.}

1985 Paleoenvironmental history of the last 10,000 years in northwestern Argentina. Zentralhlatt für Geologie und Palantologie. Teil I. Stuttgart.

\section{MARKGRAF, V. y H. D’ANTONI}

1978 Pollen flora of Argentina. Modern spores and pollen types of Pteridophyta, Gymnospermae and Angiospermae. The University of Arizona Press. Tucson.

\section{MARTÍNEZ, J.}

1997 Estrategias y técnicas de caza. Análisis tipológico-tecnológico de proyectiles arqueológicos. Trabajo Final de Carrera. Facultad de Ciencias Naturales e Instituto Miguel Lillo. Universidad Nacional de Tucumán. Inédito.

1999 Puntas de proyectil: diseños y materias primas. En: En los Tres Reinos: Prácticas de Recolección en el Cono Sur de América, C. Aschero, M. Korstanje y P. Vuoto (Eds.), pp. 61-69. Ediciones Magna Publicaciones. 
2003 Ocupaciones humanas tempranas y tecnología de caza en la microrregión de Antofagasta de la Sierra (10000-7000 AP). Tesis Doctoral. Facultad de Ciencias Naturales e Instituto Miguel Lillo (UNT). Inédita.

2005 Tecnología de cazadores en la Puna Meridional argentina: El caso de Peñas de la Cruz 1. Mundo de Antes 4: 25-46.

2006 Rastreando cazadores en la Puna: Proyectiles en movimiento y su registro. En: En: Artefactos líticos, movilidad y funcionalidad de sitios: problemas y perspectivas. Patricia S. Escola y Salomón Hocsman (Eds.). British Archaeological Reports (BAR) Internacional Series. Oxford. En prensa.

\section{MARTÍNEZ, J. y S. HOCSMAN}

2001 Aprovisionamiento de materias primas líticas en Antofagasta de la Sierra (Catamarca) -100003500 AP-. Inédito.

2004 Formas de la base: una variante más. Resúmenes del Taller Morfología macroscópica en la clasificación de artefactos líticos: innovaciones y perspectivas (Instituto de Arqueología y Museo, UNT), pág. 15. Ciudad Virtual de Antropología y Arqueología. NAyA. 2004. www.naya.org.ar

\section{MARTÍNEZ, J.; C. ASCHERO; J. POWELL y M. RODRÍGUEZ}

2004 First evidence of extinct megafauna in the Southern Argentinian Puna. Current Research in the Pleistocene 21: 104-107.

\section{MCPHERRON, S.}

1995 A reexamination of the British biface data. Lithics. The Newsletter of the Lithic Studies Society 16: 47-63.

2003 Technological and Typological Variability in the Bifaces from Tabun Cave, Israel. En: Multiple Approaches to the Study of Bifacial Technologies, M. Soressi y H. Dibble (Eds.), pp. 55-75. University of Pennsylvania, Philadelphia.

MORIN, E.

1995 Introducción al pensamiento complejo. Editorial Gedisa, Barcelona.

\section{MORRISON, K.}

1994 The intensification of production: archaeological approaches. Journal of Archaeological Method and Theory 1(2): 111-147. 
MUSCIO, $\mathrm{H}$.

1998/99 Tendencias en la Variabilidad Ambiental de la Puna Argentina: Implicancias para la Ecología Humana Prehistórica y para los Paisajes Arqueológicos. Cuadernos del Instituto Nacional de Antropología y Pensamiento Latinoamericano 18: 271-296.

2001 Una revisión crítica del Arcaico Surandino. Cátedra de Fundamentos de Prehistoria. Facultad de Filosofía y Letras (UBA).

2004 Dinámica Poblacional y Evolución Durante el Período Agroalfarero Temprano en El Valle de San Antonio de los Cobres, Puna de Salta, Argentina. Tesis Doctoral. Facultad de Filosofía y Letras (UBA). Inédita.

NAMI, $\mathrm{H}$.

1983 La experimentación aplicada a la interpretación de artefactos bifaciales: un modelo de manufactura de las Puntas de proyectil de los niveles inferiores del Alero Cárdenas, provincia de Santa Cruz. Tesis de Licenciatura. Facultad de Filosofía y Letras, UBA. Inédita.

1984 Algunas consideraciones sobre la manufactura de las puntas de proyectil de El Volcán. PREP, Informes de Investigación 1: 85-107.

1986 Experimentos para el estudio de la tecnología bifacial de las ocupaciones tardías en el extremo sur de la Patagonia Meridional. PREP: Informe de Investigación 5, 120 págs.

1988 Arqueología experimental, tecnología, artefactos bifaciales y modelos. Estado actual del conocimiento en Patagonia y Tierra del Fuego. Anales del Instituto de la Patagonia 18: 157-176.

1991 Desechos de talla y teoría de alcance medio: un caso de Península Mitre, Tierra del Fuego. Shincal 3 (Tomo 2): 94-112.

1992 El subsistema tecnológico de la confección de instrumentos líticos y la explotación de los recursos del ambiente: una nueva vía de aproximación. Shincal 2: 33-53.

1993 Puntas de proyectil de la capa 2 del Alero Cárdenas. En: Contribución a la Arqueología del Río Pinturas. Provincia de Santa Cruz. C. Gradin y A. Aguerre (Eds.), pp. 92-99. Búsqueda de Ayllu, Concepción del Uruguay. 
1993-94 Aportes para el conocimiento de técnicas líticas del Pleistoceno Final. Análisis de artefactos bifaciales del Norte de Venezuela (Colección Edmonton, Canadá). Relaciones de la Sociedad Argentina de Antropología XIX: 417-450.

1994 Artefactos bifaciales de los niveles inferiores del Alero Cárdenas. En: Contribución a la Arqueología del Río Pinturas. Provincia de Santa Cruz, Gradin y Aguerre (Directores de la publicación), pp. 134-151. Búsqueda de AYLLU. Concepción del Uruguay.

2000 Tecnología y secuencias de reducción paleoindias de Norte y Sud América: un estudio comparativo y experimental. Tesis de Doctorado, Facultad de Filosofía y Letras, Universidad de Buenos Aires. Inédita.

NASSANEY, M.

1996 The Role of Chipped Stone in the Political Economy of Social Ranking. En: Stone Tools. Theoretical Insights into Human Prehistory, G. Odell (Ed.), pp. 181-223. Plenum Press.

\section{NELSON, M.}

1991 The study of technological organization. Journal of Archaeological Method and Theory 3: 57100.

NELSON, M. y H. LIPPMEIER

1993 Grinding stone design as conditioned by land-use pattern. American Antiquity 58: 286-305.

NICHOLAS, G.

1991 Putting wetlands into perspective. Man in the Northeast 42: 29-38.

1998 Wetlands and Hunter-Gatherers: A Global Perspective. Current Anthropology 39(5): 720731.

NUÑEZ, L.

1981 Asentamientos de cazadores-recolectores tardíos de la Puna de Atacama: hacia el sedentarismo. Chungara 8: 137-168.

1992 Ocupación arcaica en la Puna de Atacama: secuencia, movilidad y cambio. En: Prehistoria Sudamericana. Nuevas Perspectivas, Betty Meggers (Ed.), pp. 283-307. Taraxacum, Washington. 
1994 Emergencia de complejidad y arquitectura jerarquizada en la Puna de Atacama: las evidencias del sitio TULAN-54. En: Taller “De Costa a Selva”, Albeck, M. (Ed.), pp. 85-108. Instituto Interdisciplinario Tilcara.

2000 Fase Tilocalar: Nuevas evidencias formativas en la Puna de Atacama (Norte de Chile). En: Formativo Sudamericano, Una Revaluación, P. Ledergerber Crespo (Ed.), pp. 227-242.

\section{NUÑEZ, L.; I. CARTAGENA, C. CARRASCO y P. DE SOUZA}

2005 Quebrada Tulán: Evidencias de interacción circumpuneña durante el Arcaico Tardío y el Formativo Temprano en la cuenca de Atacama. En: Taller Procesos Sociales Prehispánicos en los Andes Meridionales, pp. 33. Instituto Interdisciplinario Tilcara. Tilcara, Jujuy.

\section{NUÑEZ, L. y M. GROSJEAN}

2003 Biodiversity and Human Impact During the Lasta 11,000 Years in North-Central Chile. Ecological Studies, Vol. 162: 7-17. How Landscapes Change. G. Bradshaw and P. Marquet (Eds.). Springer-Verlag Berlin Heidelberg.

\section{NUÑEZ, L.; M. GROSJEAN e I. CARTAGENA}

1999 Un ecorefugio oportunístico en la Puna de Atacama durante eventos áridos del Holoceno Medio. Estudios Atacameños 17: 125-174.

2001 Human Dimensions of Late Pleistocene/Holocene Arid Events in Southern South America. En: Interhemispheric Climate Linkages, V. Markgraf (Ed.), pp. 105-117. Academic Press.

\section{NUÑEZ, L. y C. SANTORO}

1988 Cazadores de la puna seca y salada del área centro-sur Andina (Norte de Chile). Estudios Atacameños 9: 11-60.

ODELL, G.

1994 Assessing Hunter-gatherer Mobility in the Illinois Valley: Exploring Ambiguous Results. En: The Organization of North American Prehistoric Chipped Stone Tool Technologies, P. Carr (Ed.), pp. 70-86. International Monographs in Prehistory. Archaeological Series 7.

1996 Economizing Behavior and the Concept of “Curation”. En: Stone Tools. Theoretical Insights into Human Prehistory, G. Odell (Ed.), pp. 51-80. Plenum Press, New York. 
1998 Investigating Correlates of Sedentism and Domestication in Prehistoric North America. American Antiquity 63 (4): 553-571.

2001 Stone Tool Research at the End of the Millennium: Classification, Function and Behavior. Journal of Archaeological Research 9(1): 45-100.

OLIVERA, D.

1989 Prospecciones arqueológicas en Antofagasta de la Sierra (Puna Argentina), Provincia de Catamarca: Informe Preliminar. Shincal 1: 7-23.

1992 Tecnología y estrategias de adaptación en el Formativo (Agro-Alfarero Temprano) de la Puna Meridional Argentina. Un caso de estudio: Antofagasta de la Sierra (Pcia. de Catamarca, R.A.). Tesis para optar al grado de Doctor, Facultad de Ciencias Naturales, Universidad de La Plata. Inédita.

1996 El proyecto arqueológico Antofagasta de la Sierra: una experiencia de arqueología regional. Actas del I Congreso de Investigación Social. Región y Sociedad en Latinoamérica. Su problemática en el NOA, pp. 443-455. Facultad de Filosofía y Letras, Universidad Nacional de Tucumán. San Miguel de Tucumán.

1997 La importancia del recurso Camelidae en la Puna de Atacama entre los 10.000 y 500 años A.P. Estudios Atacameños 14: 29-41.

1998 Cazadores y pastores tempranos de la Puna Argentina. En: Past and Present in Andean Prehistory and Early History. Etnologiska Studier 42: 153-180.

2001 Sociedades Agropastoriles Tempranas: el Formativo Inferior del Noroeste Argentino. En: Historia Argentina Prehispánica, E. Berberián y A. Nielsen (Eds.), Tomo I: 83-125. Editorial Brujas, Córdoba.

OLIVERA, D. y M. DE AGUIRRE

1995 Arqueología aplicada a la reactivación de sistemas agrícolas prehispánicos: El aporte interdisciplinario. Hombre y Desierto. Una perspectiva cultural $\mathrm{N}^{\circ}$ 9: 337-349. Actas del XIII Congreso Nacional de Arqueología Chilena Tomo I: Simposios.

OLIVERA, D. y D. ELKIN

1994 De Cazadores y Pastores: El Proceso de Domesticación de Camélidos en la Puna Meridional Argentina. Zooarqueología de Camélidos I: 95-124. 
OLIVERA, D. y M. PODESTÁ

1993 Los recursos del arte: Arte rupestre y sistemas de asentamiento-subsistencia formativos en la Puna Meridional argentina. Arqueología 3: 93-141.

OLIVERA, D.; P. TCHILINGUIRIAN y M. DE AGUIRRE

2002 Cultural and environmental evolution in the meridional sector of the Puna of Atacama during the Holocene. XIV International Congress of Prehistoric and Protohistoric Sciences. Belgium. Edicion B.A.R. En prensa.

OLIVERA, D.; P. TCHILINGUIRIAN y L. GRANA

2004 Paleoambiente y arqueología en la Puna Meridional argentina: Archivos ambientales, escalas de análisis y registro arqueológico. Relaciones de la Sociedad Argentina de Antropología XXIX: 229247.

OLIVERA, D.; A. VIDAL y L. GRANA

2003 El sitio Cueva Cacao 1A: hallazgos, espacio y proceso de complejidad en la Puna Meridional (ca.3000 años AP). Relaciones de la Sociedad Argentina de Antropología XXVIII: 257-270.

OSWALT, W.

1976 An Anthropological Analysis of Food-Getting Technology. Wiley and Sons, New York.

ORQUERA, L. y E. PIANA

1986 Normas para la descripción de objetos arqueológicos de piedra tallada. Contribución Científica 1. Publicación Especial CADIC. Ushuaia.

\section{PALMA, J. y D. OLIVERA}

1992/93 Hacia la contrastación de un modelo arqueológico para el Formativo Regional en Humahuaca: el caso de Estancia Grande. Cuadernos del Instituto Nacional de Antropología y Pensamiento Latinoamericano 14: 237-259.

PANTER-BRICK, C.; R. LAYTON y P. ROWLEY-CONWY

2001 Lines of enquiry. En: Hunter-gatherers: An interdisciplinary perspective, C. Panter-Brick, R. Layton y P. Rowley-Conwy (Eds.), pp. 1-11. Cambridge University Press. Cambridge.

PARRY, W. y R. KELLY

1987 Expedient Core technology and Sedentism. En: The Organization of Core Technology, J. Johnson. y C. Morrow (Eds.), pp. 285-308. Westview Press, Boulder and London. 
PELEGRIN, J.

1990 Prehistoric lithic technology: some aspects of research. Archaeological Review of Cambridge 9(1): 116-125.

1993 A framework for analyzing prehistoric stone tool manufacture and a tentative application to some early industries. En: The Use of Tools by Human and Non-human Primates, A. Berthelet y J. Chavaillon (Eds.), pp. 302-314. Clarendon Press, Oxford.

1995 Technologie lithique: le Chatelperronien de Roc de Combe, Lot, et de La Cote, Dordogne, Paris. C.N.R.S. (Cahiers du Quaternaire; 20).

PÉREZ, S.

2003 Experimentación y análisis de microdesgaste de palas y/o azadas líticas de Antofagasta de la Sierra (Pcia. de Catamarca)”. Tesis de Licenciatura, Facultad de Filosofía y Letras, UBA. ms.

2004 Palas y/o azadas líticas manufacturadas por lascado. Nuevo grupo tipológico (M3.33.00). Resúmenes del Taller Morfología macroscópica en la clasificación de artefactos líticos: innovaciones y perspectivas (Instituto de Arqueología y Museo, UNT), pp. 12-13. Ciudad Virtual de Antropología y Arqueología. NAyA. 2004. www.naya.org.ar

PEREZ DE MICOU, C. y E. ANCIBOR

1994 Manufactura cestera en sitios arqueológicos de Antofagasta de la Sierra, Catamarca. Journal de la Societé des Américanistes 80: 207-216.

PERRY, L. ; D. SANDWEISS ; D. PIPERNO; K. RADEMAKER; M. MALPASS; A. UMIRE y P. DE LA VERA

2006 Early maize agriculture and interzonal interaction in southern Peru. Nature 440/2: 76-79.

PETTIJOHN, F.; P. POTTER y R. SIEVER

1987 Sand and sandstones. Second Edition. Springer-Verlag.

PIGEOT, $\mathrm{N}$.

1990 Technical and social actors. Flintknapping specialists and apprentices at Magdalenian Etiolles. Archaeological Review of Cambridge 9(1): 126-141.

1991 Réflexions sur l'histoire technique de l'homme: de l'évolution cognitive á l'évolution culturelle. Paleo 3: 167-200. 
PINTAR, E.

1990 The Transition from Hunting to herding During the Middle to Late Archaic in the Puna Region of Northwest Argentina. Unpublished Master's Thesis, Department of Anthropology, The University of Tulsa. Tulsa, Oklahoma.

1995a Los conjuntos líticos de los cazadores Holocénicos en la Puna Salada. Arqueología 5: 9-23.

1995b Cazadores y pastores arcaicos en la Puna andina. Relaciones de la Sociedad Argentina de Antropología XX: 129-140.

1996a Prehistoric holocene adaptations to the Salt Puna of Northwestern Argentina. Ph.D. Dissertation, Graduate Faculty of Dedman College, Southern Methodist University. ms.

1996b Movilidad, artefactos y materias primas: la organización tecnológica en la Puna desértica. Actas y Memorias del XI Congreso Nacional de Arqueología Argentina (13º Parte): 17-21. San Rafael.

2004a Cueva Salamanca 1: Ocupaciones altitermales en la Puna Sur. Relaciones de la Sociedad Argentina de Antropología XXIX: 357-366.

2004b Cueva Salamanca 1: Ocupaciones humanas en la Puna Sur en el lapso 7600 a 6200 A.P. presentado para su publicación en Actas del XV Congreso Nacional de Arqueología Argentina. Río Cuarto.

2005 Working Hands: Prehistoric Women of the Salt Puna. Presentado en $70^{\text {th }}$ Annual Meetings of the Society for American Archaeology. Salt Lake City, Utah.

PINTAR, E. y C. ASCHERO

1988 Descripción litológica y áreas de aprovisionamiento de las variedades de basalto de la cuenca superior del Río Las Pitas (Real Grande-Quebrada Seca), Antofagasta de la Sierra, Catamarca. Ms.

PLANELLA, M. ; L. CORNEJO y B. TAGLE

2005 Alero Las Morrenas 1: Evidencias de cultígenos entre cazadores recolectores de finales del Período Arcaico en Chile Central. Chungara 37(1): 59-74.

PLANELLA, M. y B. TAGLE

2004 Inicios de presencia de cultígenos en la zona central de Chile, Períodos Arcaico y Agroalfarero Temprano. Chungara (Volumen Especial): 387-399. 
PODESTÁ, M.

1986-1987 Arte rupestre en asentamientos de cazadores-recolectores y agroalfareros en la Puna Sur argentina: Antofagasta de la Sierra, Catamarca. Relaciones de la Sociedad Argentina de Antropología XVII/1 N.S.: 241-263.

PODESTÁ, M. y L. MANZI

1995 Arte Rupestre e Interacción Interregional en la Puna Argentina. Cuadernos del Instituto Nacional de Antropología y Pensamiento Latinoamericano 16: 367-399.

POLITIS, G.

1999 La actividad infantil en la producción del registro arqueológico de cazadores-recolectores. Revista do Museo de Arqueología e Etnologia 3: 263-283.

PORTA CASANELLAS, J.; M. LÓPEZ-ACEVEDO REGUERÍN y C. ROQUERO DE LABURU 1994 Edafología, para la agricultura y el medio ambiente. Ediciones Mundi-Prensa, Madrid.

PRICE, T. y J. BROWN

1985 Aspects of hunter-gatherer complexity. En: Prehistoric Hunter-gatherers: The Emergence of Cultural Complexity, T. Price y J. Brown (Eds.), pp. 3-20. Orlando, Academic Press.

PRICE, T. y A. GEBAUER

1995 New perspectives on the transition to agriculture. En: Last Hunters First Farmers. New Perspectives on the Prehistoric Transition to Agriculture, T. Price y A. Gebauer (Eds.), pp. 3-19. School of American Research Press. Santa Fe, New Mexico.

\section{PRIMERA CONVENCIÓN NACIONAL DE ANTROPOLOGÍA (PRIMERA PARTE)}

1966 Publicaciones del Instituto de Antropología (Nueva Serie), № 1 XXVI. Facultad de Filosofía y Humanidades. Universidad Nacional de Córdoba, Córdoba.

PRIMERAS JORNADAS DE TECNOLOGÍA Y TIPOLOGÍA LÍTICAS

1980 Centro de Investigaciones Antropológicas. Buenos Aires.

\section{RAFFERTY, J.}

1985 The Archaeological record on Sedentariness: Recognition, Development, and Implications. Advances in Archaeological Method and Theory 8: 113-156. 
RAFFINO, R.

1977 Las aldeas del Formativo Inferior de la quebrada del Toro (Salta, Argentina). Estudios Atacameños 6: 64-108.

RAFFINO, R. y E. CIGLIANO

1973 “La Alumbrera” -Antofagasta de la Sierra- Un modelo de ecología cultural prehispánica. Relaciones de la Sociedad Argentina de Antropología VII (Nueva Serie): 241-258.

\section{RAMENOFSKY, A. y A. STEFFEN}

1998 Units as Tools of Measurement. En: Unit Issues in Archaeology. Measuring Time, Space and Material, Ramenofsky, A. y A. Steffen (Eds.), pp. 3-17. University of Utah Press. Salt Lake City.

RASIC, J. y W. ANDREFSKY

2001 Alaskan Blade Cores as Specialized Components of Mobile Toolkits: Assessing Design Parameters and Toolkit Organization through Debitage Analysis. En: Lithic Debitage. Context, Form, Meaning, W. Andrefsky (Ed.), pp. 61-79. The University of Utah Press. Salt Lake City.

\section{RATHJE, W. y M. SCHIFFER}

1982 Archeology. Harcourt, Brace, Jovanovich.

RATTO, N.

2003 Estrategias de caza y propiedades del registro arqueológico en la Puna de Chaschuil (Departamento de Tinogasta, Catamarca, Argentina). Tesis Doctoral. Facultad de Filosofía y Letras (UBA). Inédita.

\section{RATTO, N. y O. NESTIERO}

1994 Ensayos cuantitativos para la determinación de las propiedades físico mecánicas de las rocas: sus implicancias arqueológicas. Actas del XII Congreso Nacional de Arqueología Argentina, en prensa.

REIGADAS, $\mathrm{M}$.

1994 Incidencia de los factores de variación en las especies de camélidos y tipos domésticos especializados en el NOA. Un paso más allá de la taxonomía en la explicación del proceso de domesticación. Estudios Atacameños 11: 53-72.

2000-2002 Innovación tecnológica como factor de cambio en las estrategias económicas. La domesticación animal. Cuadernos del Instituto Nacional de Antropología y Pensamiento Latinoamericano 19: 573-597. 
RICK, J.

1996 Projectile points, style and social process in the Preceramic of central Peru. En: Stone Tools: Theoretical Insights into Human Prehistory, G. Odell (Ed.), pp. 245-278. Plenum Press, New York.

RODRÍGUEZ, M.

1997 Sistemas de asentamiento y movilidad durante el Arcaico. Análisis de macrovestigios vegetales en sitios arqueológicos de la puna meridional argentina. Estudios Atacameños 14: 43-60.

1999a Arqueobotánica de Quebrada Seca 3 (Puna Meridional Argentina): especies vegetales utilizadas en la confección de artefactos durante el Arcaico. Relaciones de la Sociedad Argentina de Antropología XXIV: 159-185.

1999b Explotación de recursos vegetales durante el Arcaico en la Puna Meridional Argentina. Presentación de un caso: Quebrada Seca 3. Actas del XII Congreso Nacional de Arqueología Argentina III: 345-351. La Plata.

1999c Plant species (Poaceae, Asteraceae, fabaceae and Solanaceae) at an archaeological site in the Southern Argentine Puna. Journal of Ethnobiology 19(2): 228-247.

2003 Cambios en el uso de los recursos vegetales durante los distintos momentos del Holoceno en la Puna Meridional Argentina. Actas del XV Congreso Nacional de Arqueología Chilena. Chungara (Volumen especial): 403-413

\section{RODRÍGUEZ, M. y C. ASCHERO}

2005 Confección de cordeles en la Puna Septentrional y Meridional Argentina. Movilidad e interacciones socioeconómicas. En: Investigaciones Arqueobotánicas en Latinoamérica: Estudios de casos y propuestas metodológicas, B. Marconetto, N. Oliszewski y M.P. Babot. En prensa.

\section{RODRÍGUEZ, M.; C. ASCHERO y RÚGOLO DE AGRASSAR}

2003 El género Deyeuxia (Poaceae, Agrostidae) en sitios arqueológicos de la Puna Meridional Argentina, provincia de Catamarca. Chungara 35(1): 51-72

\section{RODRÍGUEZ, M. y N. DEGINANI}

1994-95 Recursos vegetales utilizados en Quebrada Seca 3 (Puna Meridional Argentina) a comienzos del Arcaico Tardío. Palimpsesto. Revista de Arqueología 4: 122-126. 
RODRÍGUEZ, M. y J. MARTÍNEZ

2001 Especies vegetales alóctonas como recursos arqueológicos en el ámbito puneño. Asociación Paleontológica Argentina. Publicación Especial 8:139-145.

RODRÍGUEZ, M. y Z. RÚGOLO DE AGRASAR

1999 Deyeuxia Eminens (Poaceae, Agrostideae) en un sitio arqueológico de la Puna Meridional Argentina (Provincia de Catamarca). Darwiniana 37(3-4): 229-242.

\section{RODRÍGUEZ, M.; Z. RÚGOLO DE AGRASAR y C. ASCHERO}

2005 El uso de las plantas y el espacio doméstico en la Puna Meridional argentina a comienzos del Holoceno Tardío. Sitio arqueológico Punta de la Peña 4, capa 3. Revista Chungara. En prensa.

ROE, D.

2003 An Overview, with Some Thoughts on the Study of Bifaces. En: Multiple Approaches to the Study of Bifacial Technologies, M. Soressi y H. Dibble (Eds.), pp. 273-285. University of Pennsylvania, Philadelphia.

ROSKAMS, S.

2001 Excavation. Cambridge Manuals in Archaeology. Cambridge University Press.

ROWLEY-CONWY, P.

2001 Time, change and the archaeology of hunter-gatherers: how original is the "Original Affluent Society”. En: Hunter-gatherers: An interdisciplinary perspective, C. Panter-Brick, R. Layton y P. Rowley-Conwy (Eds.), pp. 39-72. Cambridge University Press. Cambridge.

\section{SACKETT, J.}

1985 Style, Ethnicity and Stone Tools. En: Status, Structure and Stratification: Current Archaeological Reconstructions, M. Thompson, M. Marcia y F. Kenan (Eds.), pp. 277-282. Calgary.

1990 Style and ethnicity in archaeology: the case for isochrestism. En: The Uses of Style in Archaeology, M. Conkey y C. Hastorf (Eds.), pp. 32-43. Cambridge University Press. Cambridge.

\section{SARMIENTO, J.; S. BARRERA; S. CAZIANI y E. DERLINDATI}

1998 Región 6. Andes del Sur (Argentina). En: Los Humedales en la Argentina. Clasificación, situación actual, conservación y legislación. P. Canevari, D. Blanco, E. Bucher, G. Castro e I. Davidson. Wetlands International No 46: 170-181. 


\section{SCHÄBITZ, F.; L. LUPO; J.L. KULEMEYER y J.J. KULEMEYER}

2001 Variaciones en la vegetación, el clima y la presencia humana en los últimos 15.000 años en el borde oriental de la Puna, provincias de Jujuy y Salta, Noroeste Argentino. Asociación Paleontológica Argentina. Publicación Especial 8: 155-162. Buenos Aires.

\section{SCHEINSHON, V.}

1999 Tecnología y materias primas óseas: Una perspectiva evolucionista. En: Soplando en el viento ... Actas de las Terceras Jornadas de Arqueología de la Patagonia, pp. 211-220.

\section{SCHIFFER, M.}

1987 Formation Processes of the Archaeological Record. University of New Mexico Press. Albuquerque

1995 Behavioral Archaeology: First Principles. University of Utah Press, Salt Lake City.

\section{SCHIFFER, M. B. y J. M. SKIBO}

1987 Theory and Experiment in the Study of Technological Change. Current Anthropology 28: 595622.

1997 The explanation of artifact variability. American Antiquity 62(1): 27-50.

\section{SHOTT, M.}

1989a On Tool-Class Use Lives and the Formation of Archaeological Assemblages. American Antiquity 54: 9-30.

1989b Bipolar industries: Etnographic Evidence and Archaeological Implications. North American Archaeologist 10(1): 1-24.

1992 On recent trends in the anthropology of foragers: Kalahari revisionism and its archaeological implications. Man (N.S.) 27: 843-871.

1996 Innovation and selection in prehistory. A case study from the American Bottom. En: Stone Tools: Theoretical Insights into Human Prehistory, G. Odell (Ed.), pp. 279-309. Plenum Press, New York.

1999 On Bipolar Reduction and Splintered Pieces. North American Archaeologist 20(3): 217-238. 
2003 Time as Sequence, Type as Ideal: Whole-Object Measurement of Biface Size and Form in Midwestern North America. Multiple Approaches to the Study of Bifacial Technologies, M. Soressi y H. Dibble (Eds.), pp. 251-271. University of Pennylvania, Philadelphia.

SIGAUT, F.

1994 Technology. En: Companion Encyclopedia of Anthropology. Humanity, Culture and Social Life. T. Ingold (Ed.), pp. 420-459. Routledge.

SINCLAIR, A.

2000 Constellations of knowledge. Human agency and material affordance in lithic technology. En: Agency in Archaeology. M-A. Dobres y J. Robb (Eds.), pp. 196-212. Routledge, London and New York.

SMITH, P.

1966 Le Solutréen en France. Bordeaux.

SMITH, B.

2001 Low- Level Food Production. Journal of Archaeological Research 9(1): 1-43.

SMITH, E. y B. WINTERHALDER

1992 Natural selection and decision making: some fundamental principles. En: Evolutionary Ecology and Human Behavior, E. Smith y B. Winterhalder (Eds.), pp. 25-60. Aldine de Gruyter, Nueva York.

\section{SOFAER- DEREVENSKY, J.}

1994 Where are the Children?. Accesing Children in the Past. Archaeological Review from Cambridge 13(2): 7-20.

SORESSI, M. y H. DIBBLE

Multiple Approaches to the Study of Bifacial Technologies. University of Pennsylvania, Philadelphia.

SPETH, J.

1991 Nutrition, reproduction, and forager-farmer interaction: a comment on the "revisionist" debate in hunter-gatherer studies. Michigan Discussion in Anthropology Hunter-Gatherer Studies 10: 41-46.

SPIELMANN, K. y J. EDER

1994 Hunters and farmers: then and now. Annual Review of Anthropology 23: 303-323. 
STOUT, D.

2002 Skill and Cognition in Stone Tool Production. An Ethnographic Case Study from Irian Jaya. Current Anthropology 43(5): 693-722.

TAGLE, M. y M. PLANELLA

2002 La Quínoa en la Zona Central de Chile. Supervivencia de una Tradición Prehispana. Editorial Iku. Santiago de Chile

TARRAGÓ, M.

1996 El Formativo en el Noroeste Argentino y el Alto Valle Calchaquí. Arqueología del Temprano en el Noroeste Argentino. Actas y Memorias del XI Congreso Nacional de Arqueología Argentina (11º Parte). Revista del Museo de Historia Natural de San Rafael (Mendoza) XXIII (1/4): 103-119.

\section{TCHILIGUIRIAN, P. y M. BARANDICA}

1995 Acontecimientos naturales que favorecieron el asentamiento humano en ambientes de la Puna catamarqueña. Hombre y Desierto. Una perspectiva cultural. N 9: 351-352. Actas del XIII Congreso Nacional de Arqueología Chilena Tomo I: Simposios.

\section{TCHILIGUIRIAN, P. y D. OLIVERA}

2000 De aguas y tierras: aportes para la reactivación de campos agrícolas arqueológicos en la Puna Argentina. Relaciones de la Sociedad Argentina de Antropología XXV: 99-118.

2005 Evolución paleoambiental e implicancias geoarqueológicas en Laguna Colorada, Puna Catamarqueña, Argentina. Actas del XVI Congreso Geológico Nacional. Actas IV. La Plata.

\section{TELTSTER, $\mathrm{P}$.}

1991 Generalized Core technology and Tool use: A Mississippian Example. Journal of Field Archaeology 18(3): 363-375.

TERUGGI, M.E.

1980 La clasificación de las rocas igneas. Ediciones Científicas Argentinas Librart, Buenos Aires.

\section{THOMAS, D.}

1978 Arrowheads and atlatl darts: How the stones got the shaft. American Antiquity 43(3): 461472. 
TOMKA, S.

2001 The Effect of processing Requirements on reduction Strategies and Tool Form: A New Perspective. En: Lithic Debitage. Context, Form, Meaning, W. Andrefsky (Ed.), pp. 207-223. The University of Utah Press, Salt Lake City.

TORRENCE, R.

1989 Tools as optimal solutions. En: Time Energy and Stone Tools, R. Torrence (Ed.), pp. 1-6. Cambridge University Press. Cambridge.

1994 Strategies for Moving on in Lithic Studies. En: The Organization of North American Prehistoric Chipped Stone Tool Technologies, P.Carr (ed.), pp. 123-131. International Monographs in Prehistory, Archaeological Series 7. Ann Arbor, Michigan.

2001 Hunter-gatherer technology: macro and microscale approaches. En: Hunter-gatherers: An interdisciplinary perspective, C. Panter-Brick, R. Layton y P. Rowley-Conwy (Eds.), pp. 73-98. Cambridge University Press. Cambridge.

TOSELLI, A.

1998 Selección de materias primas líticas y organización tecnológica en el sitio Punta de la Peña 4 (PP4), Depto. Antofagasta de la Sierra, Prov. de Catamarca. Trabajo Final de Carrera. Facultad de Ciencias Naturales e Instituto Miguel Lillo. Universidad Nacional de Tucumán. Inédita.

1999 Andesita variedad 1, ¿una cuestión de disponibilidad o de calidad?. En: En los Tres Reinos: Prácticas de Recolección en el Cono Sur de América, C. Aschero, M. Korstanje y P. Vuoto (Eds.), pp. 51-60. Ediciones Magna Publicaciones.

\section{TOTH, N. y K. SCHICK}

1998 Early stone industries and inferences regarding language and cognition. En: Tools, language and cognition in human evolution, K. Gibson y T. Ingold (eds.), pp. 346-362. Cambridge University Press. United Kingdom.

\section{TURNER, J.}

1972 Puna. En: Geología Regional Argentina, A. Leanza (Ed.), pp. 91-116. Academia Nacional de Ciencias, Córdoba. 
TURNER, J.C. y V. MENDEZ

1979 Puna. II Simposio de Geología Regional Argentina, I: 13-56. Academia Nacional de Ciencias de Córdoba.

VALERO-GARCÉS, B.; A. DELGADO-HUERTAS; N. RATTO; A. NAVAS y L. EDWARDS 2000 Paleohydrology of Andean saline lakes from sedimentological and isotopic records, Northwestern Argentina. Journal of Paleolimnology 24: 343-359.

VALQUI, M.; S. CAZIANI; O. ROCHA-O. y E. RODRÍGUEZ-R.

2000 Abundance and Distribution of the South American Altiplano Flamingos. Waterbirds 23 (Special Publication 1): 110-113.

VÁZQUEZ, C. y P. ESCOLA

1995 X-Ray fluorescence analysis of obsidian object from Catamarca, Argentina. Journal of Radioanalytical and Nuclear Chemistry 200(5): 373-384.

VIERRA, R.

1982 Typology, Classification and Theory Building. Essays on Archaeological Typology: 162-175. Whallon, R. y Brown, J. (eds). Center for American Archeology Press.

WHITTAKER, J.

1987 Individual Variation as an Approach to Economic Organization: Projectile Point at Grasshopper Pueblo, Arizona. Journal of Field Archaeology 14(4): 465-479.

1994 Flintknapping. Making \& Understanding stone tools. University of Texas Press. Austin.

WIESSNER, P.

1982 Beyond willow smoke and dogs'tails: a comment on Binford's analysis of hunter-gatherer settlement systems. American Antiquity 47: 171-178.

1983 Style and social information in Kalahari San projectile points. American Antiquity 48(2): 253276.

WILLEY, G. y P. PHILLIPS

1958 Method and Theory in American Archaeology. University of Chicago Press. Chicago. 


\section{WINTERHALDER, B.}

2001 The behavioural ecology of hunter-gatherers. En: Hunter-gatherers: An interdisciplinary perspective, C. Panter-Brick, R. Layton y P. Rowley-Conwy (Eds.), pp. 12-38. Cambridge University Press. Cambridge.

WOBST, $\mathrm{H}$.

1977 Stylistic behavior and information exchange. En: For the Director: Research Essays in Honor of James B. Griffin, C. Cleland (Ed.), pp. 317-344. Anthropological Papers of the Museum of Anthropology No61. Ann Arbor.

\section{WOODBURN, J.}

1982 Egalitarian societies. Man (NS) 17: 431-451.

WYCKOFF, D.

1996 The Westfahl and Engle Bifaces: Isolated finds of large bifaces on the Southern Plains. Plains Anthropologist 41(157): 287-296.

\section{WYNN, T.}

1998 Layers of thinking in tool behavior. En: Tools, language and cognition in human evolution, K. Gibson y T. Ingold (eds.), pp. 389-406. Cambridge University Press. United Kingdom.

\section{YACOBACCIO, $\mathrm{H}$.}

1994a Biomasa animal y consumo en el Pleistoceno-Holoceno Surandino. Arqueología 4: 43-63.

1994b Hilos Conductores y Nudos Gordianos: Problemas y Perspectivas en la Arqueología de Cazadores-Recolectores Puneños. Rumitacana. Revista de Antropología 1: 19-21.

1997 Sociedad y Ambiente en el NOA Precolombino. En: C. Reboratti (compil.) De Hombres y Tierras: Una Historia Ambiental del Noroeste Argentino, pp. 26-38. Proyecto Desarrollo Agroforestal en Comunidades rurales del Noroeste Argentino, Salta.

1998 The Evolution of South Andean hunter-gatherers. International Union of Prehistoric and Protohistoric Sciences. Proceedings of the XIII Congress, Volume 5: 389-394. Abaco Edizioni, Forli.

2001a Cazadores complejos y domesticación de camélidos. En: El uso de los camélidos a través del tiempo, G. Mengoni Goñalons, D. Olivera y H. Yacobaccio (Eds.), pp. 261-282. Ediciones del Tridente, Buenos Aires. 
2001b La Domesticación de Camélidos en el Noroeste Argentino. En: Historia Argentina Prehispánica, E. Berberián y A. Nielsen (Eds.), Tomo I: 7-40. Editorial Brujas, Córdoba.

2004 Social dimensions of camelid domestication in the southern Andes. Anthropozoologica 39(1): 237-247.

YACOBACCIO, H.; D. ELKIN y D. OLIVERA

1994 ¿El fin de las sociedades cazadoras? El proceso de domesticación animal en los Andes Centro

Sur. En: Arqueología de Cazadores-Recolectores. Límites, Casos y Aperturas. Arqueología Contemporánea 5 (Edición Especial): 23-32.

YACOBACCIO, H. y A. GURAIEB

1994 Tendencia temporal de contextos arqueológicos: Area del Río Pinturas y zonas vecinas. En: Contribución a la Arqueología del Río Pinturas. Provincia de Santa Cruz, C. Gradín y A. Aguerre (Eds.), pp. 13-28. Búsqueda de Ayllu, Concepción del Uruguay.

YACOBACCIO, H.; M. LAZZARI; A. GURAIEB y G. IBAÑEZ

2000 Los cazadores en el borde oriental de Atacama (Susques, Jujuy). Arqueología 10: 11-38.

YACOBACCIO, H.; C. MADERO; M. MALMIERCA y M. REIGADAS

1997/1998 Caza, domesticación y pastoreo de camélidos en la Puna Argentina. Relaciones de la Sociedad Argentina de Antropología XXIII: 389-421.

YACOBACCIO, H. y M. MORALES

2005 Mid-Holocene environment and human occupation of the Puna (Susques, Argentina). Quaternary International 132: 5-14.

YACOBACCIO, H. y B. VILÁ

2002 Condiciones, Mecanismos y Consecuencias de la Domesticación de los Camélidos. Estudios Sociales del NOA 5(5): 4-27. 


\section{APÉNDICE I}

\section{I.1. INSTRUCTIVO PARA LA DESCRIPCIÓN TÉCNICO-MORFOLÓGICA Y TIPOLÓGICA DE ARTEFACTOS FORMATIZADOS (modificada de Hocsman y Martínez 2003, ms)}

Nota: En las variables que lo requieran, se suministra la fuente de adonde se toman los estados de atributos. En caso de tratarse de la clasificación de Aschero (1983), se señala directamente el Apéndice y el número de página

\section{I.1.1. INVENTARIO}

. Operador/a y fecha:

. Hoja $\mathrm{N}^{\circ}$ (número de hoja)

\section{I.1.2. PROCEDENCIA}

1. Sigla del Sitio (nombre del sitio)

2. Campaña mes/año

3. Area/Sector

(en casos de subdivisiones dentro de sitios estratificados o sectorización de áreas de muestreo superficiales. En el caso de abrigos rocosos, se diferenciará talud, alero y cueva según corresponda y se establecerá si se obtuvo de recolección superficial o de excavación)

4. Cuad/mic (cuadrícula / microsector)

5. Capa/Nivel

6. Extracción No (número de extracción)

7. Bolsa $\mathrm{N}^{\circ}$ (bolsa número)

8. Color talon (color talonario)

9. Pieza $\mathrm{N}^{\circ}$ (número de pieza)

\section{I.1.3. DESCRIPCIÓN SUMARIA}

10. Código de Inventario

11. Descripción 
(especificar la cantidad de filos de cada grupo tipológico entre paréntesis y emplear el signo “+” para separar los diferentes grupos tipológicos presentes. Ej: (2) M30701 + (1) M31603 + (1) M32101. En casos de presencia de reciclaje, se expresará: “.... sobre .... reciclado/a”, y de superposición: “... sobre ...”. En el caso de los pedúnculos o sectores basales los bordes se describen de acuerdo a la "Forma de los bordes” de Aschero 1975, a lo que se suma la diferenciación entre base inflexionada o no inflexionada, según se vislumbre o no un punto de inflexión entre el pedúnculo y la base)

12. Manufactura compuesta

(presencia: 1; ausencia: 0; no pertinente)

13. Sustancia adherida -B: 22-

14. Pieza entera/fracturada

(entera: 1 ; fracturada: 2)

15. Forma geom contorno (forma geométrica del contorno) -Bordes 1961; Brézillon 1983; Aschero 1975, 1983, 2004c-

(aplicado a puntas de proyectil apedunculadas, otras piezas de retoque perimetral que no sean puntas de proyectil y puntas de proyectil de pedúnculo esbozado. No entran aquí las puntas de proyectil con pedúnculo destacado ni diferenciado)

16. Forma geom limbo (forma geométrica del limbo) -Bordes 1961; Brézillon 1983; Aschero 1975, 1983, 2004c-

(idem anterior, con la salvedad de que se incluyen todas las puntas pedunculadas)

17. Sección transv (sección transversal de la pieza) -B: 17-

18. Sección longit (sección longitudinal de la pieza)

A. simétrica biconvexa-birectangular

B. asimétrica biconvexa

C. asimétrica plano-convexa

D. asimétrica cóncavo-convexa

X. no diferenciada

19. Cant filos o puntas mismo grupo tipol (cantidad de filos o puntas del mismo grupo tipológico) -B:3-

20. Presencia filos o puntas compl (presencia de filos o puntas complementarias, correspondientes a otros grupos tipológicos) -B: 3-

21. Serie técnica -B: 5-

22. Mantenimiento

(presencia: 1; ausencia: 0; no pertinente: -)

23. Reciclaje

(presencia: 1; ausencia: 0; no pertinente: -)

24. Causa descarte manuf (causa de descarte durante manufactura en bifaces y puntas de proyectil)
A. Fractura (fr)
B. Apice (ap) 
C. Fisura (fis)

D. Charnela (ch)

E. Defecto de la materia prima (dmp)

F. Abultamiento (abu)

G. Fractura perversa (fr per)

H. Muy grueso defectuoso para seguir adelgazando (mg de)

I. Cambio de textura (c tex)

103. Secuencia tipológica -ver Capítulo 4-

104. Clase técnica -ver Capítulo 4-

\section{I.1.4. DIMENSIONES}

25. L máx (longitud máxima de la pieza, en $\mathrm{mm}$ )

26. A máx (ancho máximo de la pieza, en mm)

27. E máx (espesor máximo de la pieza, en mm)

28. Altura A máx (altura al Ancho máximo, en mm, desde la base) -Martínez 2003-

29. Altura E máx (altura al Espesor máximo, en mm, desde la base) -Martínez 2003-

30. L/A (razón largo máximo / ancho máximo)

31. A/E (razón ancho máximo / espesor máximo)

32. Peso (en gramos)

33- Tamaño -B: 34-

34- Mod L-A -B: 34-

35- Mod A-E -B: 35-

36- Espesor relativo -B: 35-

- En bifaces (Bordes , 1961, Brézillon 1983, Adams 1999) :

105. n (anchura a la mitad de la longitud)

106. c (anchura a 3/4 de la longitud -desde porción apical-)

107. L/a (altura del ensanchamiento : “índice de forma”)

108. n/A (redondeamiento de los lados)

- En puntas de proyectil (pedúnculo / sector basal):

37. Long ped (longitud del pedúnculo, en mm)

38. Ancho raíz ped (ancho de la raíz del pedúnculo, en mm)

39. Espesor raíz ped (espesor de la raíz del pedúnculo, en mm)

40. Ancho base ped (ancho de la base del pedúnculo, en mm)

109. L / A raíz (pedúnculo / sector basal)

110. L / A base (pedúnculo / sector basal)

111. A máximo / E máximo (pedúnculo / sector basal) 


\section{I.1.5. CARACTERÍSTICAS TÉCNICO-MORFOLÓGICAS GENERALES}

41. Mat Prima (materia prima)

42. Color (siguiendo Rock Color Chart)

43. Distribución del color -B: 10-

44. Alteraciones -B: 9-

45. Forma base (caracteres básicos) -B: 6-

46. Forma base (caracteres complementarios) -B: 7-

- Cara ventral:

47. Bulbo percusión (bulbo de percusión)

(presencia: 1 ; ausencia: 0 ; no pertinente: -)

48. Cono percusión (cono de percusión)

(presencia: 1; ausencia: 0; no pertinente: -)

49. Punto percusión (punto de percusión)

(presencia: 1; ausencia: 0; no pertinente: -)

50. Ondas percusión (ondas de percusión)

(presencia: 1; ausencia: 0; no pertinente: -)

51. Estrías percusión (estrías de percusión)

(presencia: 1; ausencia: 0; no pertinente: -)

52. Labio

(presencia: 1; ausencia: 0; no pertinente: -)

53. Lascas adventicias

(presencia: 1; ausencia: 0; no pertinente: -)

54. Restos de cara ventral

(presencia: 1; ausencia: 0; no pertinente: -)

- Cara dorsal:

55. Neg lasc orig (negativo/s de lascado original/es)

(presencia: 1; ausencia: 0; no pertinente: -)

56. Corteza

(presencia: 1; ausencia: 0; no pertinente: -)

- Talón/plataforma de percusión:

57. Estado -B: 22-

58. Ancho (en mm)

59. Espesor (en mm)

60. Angulo medido

61. Angulo estimado

62. Forma sup talón (forma de la superficie del talón) -B: 23- 
63. Reg borde/frente de extracción (regularización del borde/frente de extracción) -B: 24-

\section{I.1.6. OBSERVACIÓN N ${ }^{\circ}$}

(cada observación deberá llevar el número de variable a detallar. Se colocará un asterisco: “*”en el casillero correspondiente a la variable en la que se realiza una observación)

\section{I.1.7. DESCRIPCIÓN SEGMENTAL}

64. Cod y registro parte segment (código y registro de parte segmentada)

(arbitrariamente, para bifaces y puntas de proyectil, el análisis se inicia por la limbo izquierdo de la cara A, siguiendo con el mismo limbo en la cara B. Después, el limbo derecho, con el mismo procedimiento)

1) Ápice en puntas de proyectil y bifaces / filo, punta o superficie activa básica en otros artefactos formatizados

2) Limbo o borde izquierdo (caras A y B) / idem en caso de artefacto "doble”

3) Limbo o borde derecho (caras A y B) / idem en caso de artefacto múltiple

4) Pedúnculo borde izquierdo (caras A y B) / idem en caso de artefacto múltiple

5) Pedúnculo borde derecho (caras A y B) / dorso referido a un filo, punta o superficie activa básica (parte pasiva de prehensión o encastre).

6) Base del pedúnculo o sector basal (caras A y B) / filo, punta o superficie activa complementaria

7) Aleta/hombro izquierda / idem

8) Aleta/hombro derecha / idem

9) Dorso o parte pasiva referida a filo, punta o superficie activa complementaria

10 a 19) Filo, punta o superficie activa complementaria

20 a 29) Código y registro de parte segmentada para casos de reciclaje

65. Grupo tipol (grupo tipológico)

66. Cara (cara ventral B o menos convexa y cara dorsal A o más convexa)

67. Posición fil/pta -ver Capítulo 4-

68. L filo o punta (longitud del filo o punta, en $\mathrm{mm}$ )

69. Prof bisel form (profundidad del bisel formatizado, en $\mathrm{mm}$ )

70. Prof últ lc form (profundidad de los últimos lascados de formatización, en mm)

71. A boca lc form (ancho de la boca de los últimos lascados de formatización, en mm)

72. Sec form (secuencia de formatización, definida para un filo y cara particular) -ver Capítulo 4-

73. Prof lc borde (profundidad de los lascados sobre el borde) -1975: 16-

74. Sit lasc caras (situación de los lascados sobre las caras) -B: 5-

75. Conform borde (conformación del borde) -B: 27- 
(Para el caso de un limbo u otro filo que presente diferencias internas en su filo, las mismas se discriminan de acuerdo a los sectores variables - Ejemplo: A(3): B1 = sector 3 de la cara A: dentado; $\mathrm{A}$ (1.5): A1 = normal - /el punto entre paréntesis indica discontinuidad/)

76. Reg borde (regularidad del borde y la arista activa) -B: 28a-

(Para el caso de un limbo u otro filo que presente diferencias internas en su filo, las mismas se discriminan de acuerdo a los sectores variables - Ejemplo: $\mathrm{A}(3)$ : $\mathrm{A}$ = sector 3 de la cara A: regular; $\mathrm{A}$ (1.5): $\mathrm{C}$ = irregular - /el punto entre paréntesis indica discontinuidad/)

77. Form de la base (forma de la base del limbo o pedúnculo en puntas de proyectil u otras piezas de base formatizada) -B: 4, Martínez y Hocsman 2004, Escola 2004-

78. Tratam téc dif (tratamiento técnico diferencial) -B: 28a-

79. For y dir lasc (forma y dirección de los lascados de formatización) -B: 19-

(en el caso de las variables D5 a F0 se modificó el uso, ya que, de aplicarse exclusivamente a artefactos con lascados bilaterales profundos se pasa aquí a emplear dichas categorías para describir cada borde y cara por separado en caso de piezas con lascados cubrientes en sus caras.

Se introduce, además, la figura de lascado simple de formatización)

80. Term lasc caras (terminación de los lascados sobre las caras)

81. Posic react (posición de la reactivación) -ver Capítulo 4-

82. Prof bisel react (profundidad del bisel reactivado, en $\mathrm{mm}$ )

83. Prof últ lc react (profundidad de los últimos lascados de reactivación, en mm)

84. A boca lc react (ancho de la boca de los últimos lascados de reactivación, en mm)

85. Angulo medido

86. Angulo estim (ángulo estimado)

87. Estado f/a act (estado del filo o ápice activo) -B: 28a-

88. Rastros compl. (rastros complementarios) -B: 21-

89. Posic R C (posición de los rastros complementarios)

90. Sust adherida (sustancia adherida) -B: 22-

91. Posic sust adher (posición sustancia adherida)

92. Ang med ápice (ángulo medido del ápice)

93. Ang estim ápice (ángulo estimado del ápice)

94. Amplitud Aleta (en mm)

95. Angulo aleta

96. Posic fractura (posición de la fractura en relación al eje de orientación de la pieza) -B: 24-

97. Espesor fract (espesor de la fractura, en $\mathrm{mm}$ )

98. Form geom frac (forma geométrica de la fractura) -B: 25-

99. Sección fract (sección de la fractura) -B: 25-

100. Form sup fract (forma de la superficie de fractura) -B: 25-

101. Defectos (defectos observados en filos y/o caras, más la posición de los mismos) 
A. Defecto de la materia prima (cambio de textura, inclusiones o fisuras)

B. Abultamiento

C. Borde excesivamente grueso

- Observaciones

102. Sinuosidad -Callahan 1996-

I.1.8. DIBUJO

- Cara (seleccionar la cara correspondiente: A o B)

- Orientación (de acuerdo a si se toma el eje morfológico, el eje de lascado o el eje de lascado en piezas sin talón pero con posibilidad de orientación por este medio) 


\section{I.2. INSTRUCTIVO PARA LA DESCRIPCIÓN TÉCNICO-MORFOLÓGICA DE DESECHOS DE TALLA}

Nota: En las variables que lo requieran, se suministra la fuente de adonde se toman los estados de atributos. En caso de tratarse de la clasificación de Aschero (1983), se señala directamente el Apéndice y el número de página

. Operador/a y fecha:

. Hoja $\mathrm{N}^{\circ}$ (número de hoja)

1. Sitio (sigla y $\mathrm{N}^{\circ}$ )

2. Fecha de campaña

3. Area / sector

(en casos de subdivisiones dentro de sitios estratificados o sectorización de áreas de muestreo superficiales. En el caso de abrigos rocosos, se diferenciará talud, alero y cueva según corresponda y se establecerá si se obtuvo de recolección superficial o de excavación)

4. Cuadrícula / microsector

5. Capa / Nivel / Extracción

6. Número de bolsa

7. Color de talonario

8. Número de planta

9. Número de pieza

10. Materia prima

11. Cantidad de piezas por estado de fragmentación: ENT -Entera-; FCT -Fracturada con talón-; FST

-Fracturada sin talón- e INDIF -Indiferenciada- (Bellelli 1991)

12. Número total de especimenes

13. Tipo de lasca -modificado de Aschero 1983-

- Lascas externas
A. Primaria
B. Secundaria
C. Con dorso natural

- Lascas internas

D. Angular con reserva de corteza

E. Angular sin reserva de corteza

O. Angular con reserva de corteza no diferenciada (en FCT )

F. Arista simple o doble no convergente

G. Plana sin arista o nervadura

H. Adelgazamiento bifacial 


\section{En cresta}

- Lascas de reactivación de núcleos

J. Flanco de núcleo

K. Tableta de núcleo

- Lascas de reactivación de artefactos formatizados

L. Reactivación directa

M. Reactivación inversa

- Lascas por trabajo bipolar

N. Bipolar

N. No diferenciada

(se incorporan las categorías de "lasca bipolar" y de "lasca angular con reserva de corteza no diferenciada”, aplicada cuando es posible discriminar que se trata de una lasca angular pero no es posible identificar con certeza si tenía corteza o no. Asimismo, las "lascas de adelgazamento bifacial” cobran identidad propia, independizándose de las "lascas angulares”. A su vez, estas últimas son diferenciadas como categorías distintas en base a la presencia o no de reserva de corteza)

- Características de cara dorsal

14. Posición del eje morfológico -modificado de Aschero 1975:-

1) Lasca recta

2) Lasca inclinada

3) Lasca oblicua

4) No diferenciado

15. Número de negativos de lascado en cara dorsal

(en el caso de planillas Excel, en FCT, cuando no sea posible estimar la cantidad de lascados, el número 99 significa "No diferenciado")

16. Porcentaje de corteza en cara dorsal

1) $0 \%$

2) 1 a $50 \%$

3) 51 a $99 \%$

4) $100 \%$

5) No diferenciado (para FCT)

17. Longitud máxima de la pieza, en mm

(presencia de fractura en FCT: “(”: afectada porción proximal; “)”: afectada porción distal; “( )”: afectadas porción proximal y distal)

18. Ancho máximo de la pieza, en mm

(presencia de fractura en FCT: “(”: afectado borde izquierdo; “)”: afectado borde derecho; “( )”: afectados ambos bordes)

19. Espesor máximo de la pieza, en mm 
(presencia de fractura en FCT: “( )”: afectado el espesor)

20. Características litométricas -B: 34-

21. Características litotécnicas -B: 34-

- Características del talón

22. Ancho del talón

(presencia de fractura en el talón: “(”: afectado borde izquierdo; “)”: afectado borde derecho; “( )”: afectados ambos bordes)

23. Espesor del talón

(presencia de fractura en el talón: “( )”: afectado el espesor)

24. Angulo de cara ventral (B)

25. Ángulo de cara dorsal (A)

26. Forma del talón -B: 23-

27. Tratamiento técnico diferencial -B: 24-

28. Porcentaje de corteza en el talón

1) $0 \%$

2) 1 a $50 \%$

3) 51 a $99 \%$

4) $100 \%$

5) No diferenciado (en FCT)

29. Número de negativos de lascado en el talón

(en el caso de planillas Excel, en FCT, cuando no sea posible estimar la cantidad de lascados, el número 99 significa "No diferenciado"; el número 98 se aplica a talones filiformes y puntiformes y el número 97 a los talones corticales y liso naturales)

- Características de la cara ventral

30. Punto de percusión

1) Presente: $\mathrm{Si}$

2) Ausente: No

3) No diferenciado

31. Labio

1) Presente: $\mathrm{Si}$

2) Ausente: No

3) No diferenciado

32. Estrías de percusión

1) Presentes: $\mathrm{Si}$

2) Ausentes: No

3) No diferenciadas

33. Bulbo de percusión 

1) Pronunciado
2) Difuso
3) No demarcado
4) No diferenciado

(en caso de estar ausente y por efecto de presencia de lascas adventicias)

34. Lasca adventicia

1) Presente: $\mathrm{Si}$

2) Ausente: No

3) No diferenciada

35. Ondas de percusión

1) Presentes: $\mathrm{Si}$

2) Ausentes: No

3) No diferenciadas

36. Terminación

1) Aguda o normal

2) Quebrada

3) Charnela

4) Sobrepasada

5) No diferenciada 


\section{I.3. INSTRUCTIVO PARA LA DESCRIPCIÓN TÉCNICO-MORFOLÓGICA DE NÚCLEOS}

Nota: En las variables que lo requieran, se suministra la fuente de adonde se toman los estados de atributos. En caso de tratarse de la clasificación de Aschero (1983), se señala directamente el Apéndice y el número de página

. Operador/a y fecha:

. Hoja $\mathrm{N}^{\circ}$ (número de hoja)

1. Sigla del Sitio (nombre del sitio)

2. Campaña mes / año

3. Area / sector

(en casos de subdivisiones dentro de sitios estratificados o sectorización de áreas de muestreo superficiales. En el caso de abrigos rocosos, se diferenciará talud, alero y cueva según corresponda y se establecerá si se obtuvo de recolección superficial o de excavación)

4. Cuadrícula / microsector

5. Capa / nivel

6. Número de extracción

7. Bolsa número

8. Color talonario

9. Número de pieza

10. Designación morfológica del núcleo -B: 4-

11. Materia prima

12. Forma-base -B: 6-

13. Longitud máxima de la pieza, en mm

(presencia de fractura: “(”: afectada porción distal; “)”: afectada porción proximal; “( )”: afectadas porción proximal y distal)

14. Ancho máximo de la pieza, en mm

(presencia de fractura: “(”: afectado borde izquierdo; “)”: afectado borde derecho; “( )”: afectados ambos bordes)

15. Espesor máximo de la pieza, en mm

(presencia de fractura: “( )”: afectado el espesor)

En cada una de las plataforma presentes se analiza:

16. Código y registro de la parte segmentada

17. Estado de la plataforma de percusión -B: 22-

18. Anchura máxima de la plataforma de percusión, en mm

19. Espesor máximo de la plataforma de percusión, en mm

20. Angulo medido entre la plataforma y los negativos de lascado 
21. Forma de la superficie de la plataforma de percusión -B: 23-

22. Regularización del borde de extracción -B: 24-

23. Regularización del frente de extracción -B: 24- 


\section{APÉNDICE II}

\section{II.1. CONSIDERACIONES SOBRE EL ARMADO DE LAS LISTAS TIPOLÓGICAS}

Las listas tipológicas hacen referencia a la estructura del conjunto instrumental, en función de la clasificación en grupos y/o subgrupos tipológicos. Se debe tener en cuenta que, en este caso, dichas listas se arman en base a criterios distintos a los que usualmente se han aplicado. Hasta el momento, lo habitual era, en piezas compuestas, seleccionar un filo o punta "básico" representativo de la pieza por sus características morfológicas (inversión de trabajo, posición del filo, etc) y/o el último filo o punta interviniente (en el caso de piezas recicladas ${ }^{1}$ ). Esto tenía como consecuencia que el número de filos o puntas en un set instrumental coincidía con la cantidad de artefactos formatizados. Sin embargo, este “número" puede no representar, en realidad, el total de filos o puntas presentes, ofreciendo una visión distorsionada de la variabilidad de grupos y subgrupos tipológicos en funcionamiento en un contexto dado. Por ello, tal como fue explicitado en el Capítulo 4, se parte aquí de la consideración de todas las piezas de morfología parcial (filos y puntas) y de morfología global (puntas de proyectil, bifaces, artefactos bipolares, piezas con filos convergentes, palas y/o azadas, etc) recuperadas en una unidad espacial y/o segmento temporal determinados, de forma de considerar el repertorio total de instrumentos actuantes. De esta forma, se deja de lado a la pieza como unidad de referencia al momento de confección de dichas listas.

Para ello, se ha instrumentado una lista tipológica adecuada para tal fin (Tabla 12.1). El armado de la misma implica disponer en una columna los grupos y subgrupos tipológicos correspondientes en el orden seguido por Aschero (1983). A partir de esto, los conteos se realizan en función de la diferenciación de cinco categorías. Las dos primeras implican filos, puntas o piezas de morfología global que no han sido transformadas (el caso exclusivo de los bifaces), recicladas o con evidencias de reclamación, clasificándolas de acuerdo a si se encuentran enteras o fragmentadas. En el caso de haber sido transformadas, recicladas o reclamadas, se disponen en el casillero correspondiente. Una alternativa es diferenciar a los filos, puntas y piezas reciclados en base a si están enteros o fragmentadas (subdividiendo la columna correspondiente). Se destaca que en esta oportunidad esto último no se ha aplicado. Finalmente, se ha incluido una columna en donde se expresen los totales por grupo y subgrupo tipológico.

\footnotetext{
${ }^{1}$ Dado que el reciclaje se desarrolla en el contexto sistémico (sensu Schiffer 1987), no hay razón como para no contabilizar tanto al filo, punta o piezas de morfología global que se realiza sobre un instrumento dado y a éste último, que es el reciclado.
} 
Tabla II.1. Ejemplo de lista tipológica

\begin{tabular}{|l|c|c|c|c|c|c|}
\hline \multirow{2}{*}{$\begin{array}{l}\text { SUBGRUPO / GRUPO } \\
\text { TIPOLÓGICO }\end{array}$} & \multicolumn{3}{|c|}{ ARTEFACTO FORMATIZADO } & TOTAL \\
\cline { 2 - 6 } & ENT & FRACT & $\begin{array}{c}\text { F-B ST } \\
\text { TRANSF }\end{array}$ & $\begin{array}{c}\text { F-B ST } \\
\text { RECIC }\end{array}$ & $\begin{array}{c}\text { F-B ST } \\
\text { RECLAM }\end{array}$ & \\
\hline Subgrupo tipológico A.1 & & & & & & \\
\hline Subgrupo tipológico A.2 & & & & & & \\
\hline GRUPO TIPOLÓGICO A & & & & & & \\
\hline
\end{tabular}

Referencias: Ent: Entero. Fract: Fracturado. F-B ST Transf.: Forma-base subgrupo tipológico transformada. Forma-base subgrupo tipológico reciclada. Forma-base subgrupo tipológico reclamada. Total ST/GT: Total subgrupo tipológico / grupo tipológico.

Cabe destacar que, tal como se ha organizado la tabla, es posible restringir los conteos a columnas puntuales o bien a series de columnas, de acuerdo a las necesidades de cada caso. Por ejemplo, si no se desea considerar a las piezas reclamadas o a los filos, puntas o piezas recicladas.

Ejemplos de funcionamiento de la lista tipológica empleada:

$1^{\circ}$ ) Instrumento simple: Muesca retocada frontal transversal -PP9 - IE3 - Nivel 1- (Tabla 12.2).

Tabla II.2. Caso de instrumento simple en lista tipológica

\begin{tabular}{|l|c|c|c|c|c|c|}
\hline \multirow{2}{*}{ SUBGRUPO TIPOLÓGICO } & \multicolumn{3}{|c|}{ ARTEFACTO FORMATIZADO } & TOTAL \\
ST/GT \\
\cline { 2 - 7 } & ENT & FRACT & $\begin{array}{c}\text { F-B ST } \\
\text { TRANSF }\end{array}$ & $\begin{array}{c}\text { F-B ST } \\
\text { RECIC }\end{array}$ & $\begin{array}{c}\text { F-B ST } \\
\text { RECLAM }\end{array}$ & \\
\hline Muesca retocada frontal transversal & 1 & & & & & 1 \\
\hline Muesca retocada lateral inclinada & & & & & & \\
\hline Muesca retocada angular & & & & & & \\
\hline MUESCA RETOCADA & & & & & & $\mathbf{1}$ \\
\hline
\end{tabular}

Observaciones: nótese que la pieza se presenta entera, disponiéndose en el casillero correspondiente. 
$2^{\circ}$ ) Artefacto formatizado compuesto: Raclette de filo largo frontal oblicuo más filo con formatización sumaria -PCh1.3 (alero bajo roca) - Nivel 2 - № 23- (Tabla 12.3).

Tabla II.3. Caso de instrumento compuesto en lista tipológica

\begin{tabular}{|l|l|l|l|l|c|c|}
\hline \multirow{2}{*}{$\begin{array}{l}\text { SUBGRUPO / GRUPO } \\
\text { TIPOLÓGICO }\end{array}$} & \multicolumn{3}{|c|}{ ARTEFACTO FORMATIZADO } & TOTAL \\
\cline { 2 - 6 } & ENT & FRACT & $\begin{array}{c}\text { F-B ST } \\
\text { TRANSF }\end{array}$ & $\begin{array}{c}\text { F-B ST } \\
\text { RECIC }\end{array}$ & $\begin{array}{c}\text { F-B ST } \\
\text { RECLAM }\end{array}$ & \\
\hline Raclette de filo fronto-lateral & & & & & & \\
\hline $\begin{array}{l}\text { Raclette de filo largo frontal } \\
\text { transversal }\end{array}$ & & & & & & \\
\hline Raclette de filo largo frontal oblicuo & 1 & & & & & \\
\hline Raclette de filo largo lateral inclinado & & & & & & \\
\hline Raclette de filo corto frontal oblicuo & & & & & & \\
\hline $\begin{array}{l}\text { Raclette de filo restringido frontal } \\
\text { transversal }\end{array}$ & & & & & & \\
\hline Raclette de filo no diferenciado & & & & & & \\
\hline RACLETTE & & & & & & \\
\hline
\end{tabular}

Observaciones: ambos filos se presentan enteros, por lo que se ubican en la columna de "ENT" 
$3^{\circ}$ ) Biface transformado: Raedera de filo largo lateral inclinada sobre biface strictu sensu -PCh1.1 - $7^{\text {a }}$ ext. - No 4- (Tabla 12.4).

Tabla II.4. Caso de biface transformado en lista tipológica

\begin{tabular}{|l|l|l|c|c|c|c|}
\hline \multirow{2}{*}{$\begin{array}{l}\text { SUBGRUPO / GRUPO } \\
\text { TIPOLÓGICO }\end{array}$} & \multicolumn{3}{|c|}{ ARTEFACTO FORMATIZADO } & TOTAL \\
\cline { 2 - 6 } & ENT & FRACT & $\begin{array}{c}\text { F-B ST } \\
\text { TRANSF }\end{array}$ & $\begin{array}{c}\text { F-B ST } \\
\text { RECIC }\end{array}$ & $\begin{array}{c}\text { F-B ST } \\
\text { RECLAM }\end{array}$ & \\
\hline Biface en sentido estricto & & & 1 & & & 1 \\
\hline Biface parcial & & & & & & \\
\hline Biface no diferenciado & & & & & & \\
\hline BIFACE & & & & & & 1 \\
\hline & & & & & & \\
\hline Raedera de filo largo frontal oblicua & & & & & & \\
\hline $\begin{array}{l}\text { Raedera de filo largo lateral } \\
\text { paralelo/subparalelo }\end{array}$ & & & & & & \\
\hline Raedera de filo largo lateral inclinada & & 1 & & & & \\
\hline $\begin{array}{l}\text { Fragmento de raedera no } \\
\text { diferenciado }\end{array}$ & & & & & & 1 \\
\hline RAEDERA & & & & & & \\
\hline
\end{tabular}

Observaciones: la raedera se confecciona sobre un biface sin mediar reciclaje. Puede observarse que la raedera está fracturada, en función de que se encuentra en la columna respectiva. 
$4^{\circ}$ ) Pieza reciclada: Punta burilante angular sobre filo bifacial de arista sinuosa reciclado -PCh1.1 - $3^{\mathrm{a}}$ ext. - No 25- (Tabla 12.5).

Tabla II.5. Caso de biface transformado en lista tipológica

\begin{tabular}{|l|c|c|c|c|c|c|}
\hline \multirow{2}{*}{$\begin{array}{l}\text { SUBGRUPO / GRUPO } \\
\text { TIPOLÓGICO }\end{array}$} & \multicolumn{5}{|c|}{ ARTEFACTO FORMATIZADO } & TOTAL \\
\cline { 2 - 5 } & ENT & FRACT & $\begin{array}{c}\text { F-B ST } \\
\text { TRANSF }\end{array}$ & $\begin{array}{c}\text { F-B ST } \\
\text { RECIC }\end{array}$ & $\begin{array}{c}\text { F-B ST } \\
\text { RECLAM }\end{array}$ & \\
\hline Filo bifacial de arista sinuosa & & & & 1 & & 1 \\
\hline $\begin{array}{l}\text { FILO BIFACIAL DE ARISTA } \\
\text { SINUOSA }\end{array}$ & & & & & & 1 \\
\hline & & & & & & \\
\hline Punta burilante axial & & & & & & \\
\hline Punta burilante angular & 1 & & & & & 1 \\
\hline $\begin{array}{l}\text { Punta burilante de retoque } \\
\text { alternante angular }\end{array}$ & & & & & & \\
\hline $\begin{array}{l}\text { Punta burilante en filo retocado } \\
\text { angular }\end{array}$ & & & & & & 1 \\
\hline PUNTA BURILANTE & & & & & & \\
\hline
\end{tabular}

Observaciones: el filo reciclado se coloca en la columna correspondiente, mientras que el último filo confeccionado, se dispone en la fila que refiere al subgrupo tipológico en cuestión, como "entera". 
$5^{\circ}$ ) Caso de transformación y reciclaje: Muesca retocada lateral inclinada sobre punta de proyectil con pedúnculo destacado y hombros reciclada -QS3 - 2b4 - Nº 638- (Tabla 12.6).

Tabla II.6. Caso de transformación y reciclaje en lista tipológica

\begin{tabular}{|c|c|c|c|c|c|c|}
\hline \multirow{2}{*}{$\begin{array}{l}\text { SUBGRUPO / GRUPO } \\
\text { TIPOLÓGICO }\end{array}$} & \multicolumn{5}{|c|}{ ARTEFACTO FORMATIZADO } & \multirow{2}{*}{$\begin{array}{l}\text { TOTAL } \\
\text { ST/GT }\end{array}$} \\
\hline & ENT & FRACT & $\begin{array}{c}\text { F-B ST } \\
\text { TRANSF }\end{array}$ & $\begin{array}{l}\text { F-B ST } \\
\text { RECIC }\end{array}$ & $\begin{array}{c}\text { F-B ST } \\
\text { RECLAM }\end{array}$ & \\
\hline \multicolumn{7}{|l|}{ Biface en sentido estricto } \\
\hline Biface parcial & & & 1 & & & 1 \\
\hline \multicolumn{7}{|l|}{ Biface no diferenciado } \\
\hline BIFACE & & & & & & 1 \\
\hline \multicolumn{7}{|l|}{ Muesca retocada frontal oblicua } \\
\hline \multicolumn{7}{|l|}{$\begin{array}{l}\text { Muesca retocada lateral paralela- } \\
\text { subparalela }\end{array}$} \\
\hline Muesca retocada lateral inclinada & 1 & & & & & 1 \\
\hline MUESCA RETOCADA & & & & & & 1 \\
\hline $\begin{array}{l}\text { Punta de proyectil con pedúnculo } \\
\text { destacado y aletas, aleta y hombro y } \\
\text { hombros }\end{array}$ & & & & 1 & & 1 \\
\hline \multicolumn{7}{|l|}{$\begin{array}{l}\text { Punta de proyectil con pedúnculo } \\
\text { esbozado }\end{array}$} \\
\hline \multicolumn{7}{|l|}{$\begin{array}{l}\text { Punta de proyectil apedunculada } \\
\text { lanceolada (normal) }\end{array}$} \\
\hline \multicolumn{7}{|l|}{$\begin{array}{l}\text { Punta de proyectil apedunculada } \\
\text { lanceolada } \\
\text { (bordes paralelos-subparalelos) }\end{array}$} \\
\hline \multicolumn{7}{|l|}{$\begin{array}{l}\text { Punta de proyectil apedunculada } \\
\text { triangular }\end{array}$} \\
\hline \multicolumn{7}{|l|}{$\begin{array}{l}\text { Fragmento de ápice/limbo de punta } \\
\text { de proyectil }\end{array}$} \\
\hline \multicolumn{7}{|l|}{$\begin{array}{l}\text { Fragmento de pedúnculo de punta de } \\
\text { proyectil }\end{array}$} \\
\hline PUNTA DE PROYECTIL & & & & & & 1 \\
\hline
\end{tabular}

Observaciones: la pieza se discrimina en: a) un filo de muesca retocada, entero, que se confeccionó sobre la punta de proyectil, mediando reciclaje, b) un subgrupo tipológico dentro de las puntas de proyectil, en el casillero de formas-base recicladas y c) un biface transformado, ya que la punta de proyectil tenía como forma-base secundaria un biface parcial. 
$6^{\circ}$ ) Pieza reclamada: Punta de proyectil apedunculada triangular -QS3 - $2 \mathrm{~b} 5$ - $\mathrm{N}^{\circ}$ 111- (Tabla 12.7).

Tabla II.7. Caso de pieza reclamada en lista tipológica

\begin{tabular}{|l|l|l|l|l|l|c|}
\hline \multirow{2}{*}{$\begin{array}{l}\text { SUBGRUPO / GRUPO } \\
\text { TIPOLÓGICO }\end{array}$} & \multicolumn{3}{|c|}{ ARTEFACTO FORMATIZADO } & $\begin{array}{c}\text { TOTAL } \\
\text { ST }\end{array}$ \\
\cline { 2 - 6 } & ENT & FRACT & $\begin{array}{c}\text { F-B ST } \\
\text { TRANSF }\end{array}$ & $\begin{array}{c}\text { F-B ST } \\
\text { RECIC }\end{array}$ & $\begin{array}{c}\text { F-B ST } \\
\text { RECLAM }\end{array}$ & \\
\hline $\begin{array}{l}\text { Punta de proyectil con pedúnculo } \\
\text { destacado y aletas, aleta y hombro } \\
\text { y hombros }\end{array}$ & & & & & & \\
\hline $\begin{array}{l}\text { Punta de proyectil con pedúnculo } \\
\text { esbozado }\end{array}$ & & & & & & \\
\hline $\begin{array}{l}\text { Punta de proyectil apedunculada } \\
\text { lanceolada (normal) }\end{array}$ & & & & & & \\
\hline $\begin{array}{l}\text { Punta de proyectil apedunculada } \\
\text { lanceolada } \\
\text { (bordes paralelos-subparalelos) }\end{array}$ & & & & & & \\
\hline $\begin{array}{l}\text { Punta de proyectil apedunculada } \\
\text { triangular }\end{array}$ & & & & & & 1 \\
\hline $\begin{array}{l}\text { Fragmento de ápice/limbo de punta } \\
\text { de proyectil }\end{array}$ & & & & & & \\
\hline $\begin{array}{l}\text { Fragmento de pedúnculo de punta } \\
\text { de proyectil }\end{array}$ & & & & & & \\
\hline PUNTA DE PROYECTIL & & & & & & 1 \\
\hline
\end{tabular}

En función de las especificaciones precedentes se han armado las listas tipológicas para cada uno de los sitios considerados (ver punto siguiente). 


\section{II.2. LISTAS TIPOLÓGICAS DE LOS SITIOS CONSIDERADOS EN ESTA INVESTIGACIÓN}

\section{II.2.1. LISTA TIPOLÓGICA DEL SITIO QUEBRADA SECA 3}

\begin{tabular}{|c|c|c|c|c|c|c|}
\hline \multirow{2}{*}{$\begin{array}{l}\text { SUBGRUPO / GRUPO } \\
\text { TIPOLÓGICO }\end{array}$} & \multicolumn{5}{|c|}{ ARTEFACTO FORMATIZADO } & \multirow{2}{*}{$\begin{array}{l}\text { TOTAL } \\
\text { ST }\end{array}$} \\
\hline & ENT & FRACT & $\begin{array}{c}\text { F-B ST } \\
\text { TRANSF }\end{array}$ & $\begin{array}{l}\text { F-B ST } \\
\text { RECIC }\end{array}$ & $\begin{array}{c}\text { F-B ST } \\
\text { RECLAM }\end{array}$ & \\
\hline Uniface & & & 1 & 1 & & 2 \\
\hline UNIFACE & & & & & & 2 \\
\hline Biface en sentido estricto & & 6 & 18 & 6 & & 3 \\
\hline Biface parcial & 3 & & 8 & 2 & & 13 \\
\hline Biface no diferenciado & & & 8 & & & 8 \\
\hline BIFACE & & & & & & 51 \\
\hline Filo bifacial de arista sinuosa & 4 & & & 1 & & 5 \\
\hline $\begin{array}{l}\text { FILO BIFACIAL DE ARISTA } \\
\text { SINUOSA }\end{array}$ & & & & & & 5 \\
\hline $\begin{array}{l}\text { Raspador de filo corto frontal } \\
\text { transversal }\end{array}$ & 1 & & & & & 1 \\
\hline $\begin{array}{l}\text { Raspador de filo corto lateral } \\
\text { paralelo-subparalelo }\end{array}$ & 1 & & & & & 1 \\
\hline $\begin{array}{l}\text { Raspador de filo restringido frontal } \\
\text { transversal }\end{array}$ & 1 & & & & & 1 \\
\hline $\begin{array}{l}\text { Raspador de filo restringido lateral } \\
\text { inclinado }\end{array}$ & 1 & & & & & 1 \\
\hline $\begin{array}{l}\text { Raspador de filo restringido } \\
\text { angular }\end{array}$ & 4 & & & & & 4 \\
\hline RASPADOR & & & & & & 8 \\
\hline $\begin{array}{l}\text { Raclette de filo largo frontal } \\
\text { transversal }\end{array}$ & 1 & 1 & & & & 2 \\
\hline $\begin{array}{l}\text { Raclette de filo largo frontal } \\
\text { oblicuo }\end{array}$ & 1 & & & & & 1 \\
\hline $\begin{array}{l}\text { Raclette de filo largo lateral } \\
\text { paralelo/subparalelo }\end{array}$ & 2 & & & & & 2 \\
\hline $\begin{array}{l}\text { Raclette de filo largo lateral } \\
\text { inclinado }\end{array}$ & 3 & & & & & 3 \\
\hline $\begin{array}{l}\text { Raclette de filo corto frontal } \\
\text { transversal }\end{array}$ & 1 & & & & & 1 \\
\hline $\begin{array}{l}\text { Raclette de filo corto lateral } \\
\text { inclinado }\end{array}$ & 4 & & & & & 4 \\
\hline $\begin{array}{l}\text { Raclette de filo restringido lateral } \\
\text { inclinado }\end{array}$ & 2 & & & 1 & & 3 \\
\hline Raclette de filo restringido angular & 1 & & & & & 1 \\
\hline RACLETTE & & & & & & 17 \\
\hline $\begin{array}{l}\text { Raedera de filo largo frontal } \\
\text { oblicua }\end{array}$ & & & & 1 & & 1 \\
\hline $\begin{array}{l}\text { Raedera de filo largo lateral } \\
\text { paralelo/subparalelo }\end{array}$ & 1 & & & 1 & & 2 \\
\hline $\begin{array}{l}\text { Raedera de filo largo lateral } \\
\text { inclinada }\end{array}$ & 2 & & & & & 2 \\
\hline $\begin{array}{l}\text { Fragmento de raedera no } \\
\text { diferenciado }\end{array}$ & & & & 1 & & 1 \\
\hline RAEDERA & & & & & & 6 \\
\hline & & & & & & \\
\hline
\end{tabular}




\begin{tabular}{|c|c|c|c|c|}
\hline $\begin{array}{l}\text { Cuchillo de filo retocado frontal } \\
\text { transversal }\end{array}$ & 1 & & 1 & 2 \\
\hline $\begin{array}{l}\text { Cuchillo de filo retocado lateral } \\
\text { paralelo-subparalelo }\end{array}$ & 4 & 1 & 2 & 7 \\
\hline $\begin{array}{l}\text { Cuchillo de filo retocado lateral } \\
\text { inclinado }\end{array}$ & 6 & & & 6 \\
\hline $\begin{array}{l}\text { Cuchillos de filo retocado } \\
\text { convergentes en ápice romo }\end{array}$ & 1 & & & 1 \\
\hline $\begin{array}{l}\text { CUCHILLO DE FILO } \\
\text { RETOCADO }\end{array}$ & & & & 16 \\
\hline $\begin{array}{l}\text { Cuchillo de filo natural con dorso } \\
\text { formatizado de filo lateral inclinado } \\
\text { (sin ápice activo) }\end{array}$ & 1 & & & 1 \\
\hline $\begin{array}{l}\text { CUCHILLO DE FILO } \\
\text { NATURAL CON DORSO } \\
\text { FORMATIZADO }\end{array}$ & & & & 1 \\
\hline $\begin{array}{l}\text { Cortante de filo retocado corto } \\
\text { frontal transversal }\end{array}$ & 4 & & & 4 \\
\hline $\begin{array}{l}\text { Cortante de filo retocado corto } \\
\text { frontal oblicuo }\end{array}$ & 4 & & & 4 \\
\hline $\begin{array}{l}\text { Cortante de filo retocado corto } \\
\text { lateral paralelo-subparalelo }\end{array}$ & 1 & & & 1 \\
\hline $\begin{array}{l}\text { Cortante de filo retocado corto } \\
\text { lateral inclinado }\end{array}$ & 7 & & & 7 \\
\hline $\begin{array}{l}\text { Cortante de filo retocado corto } \\
\text { angular }\end{array}$ & 3 & & & 3 \\
\hline $\begin{array}{l}\text { Cortante de filo retocado } \\
\text { restringido lateral inclinado }\end{array}$ & 1 & & & 1 \\
\hline $\begin{array}{l}\text { Cortantes de filos convergentes } \\
\text { retocados sin ápice activo }\end{array}$ & 7 & & & 7 \\
\hline CORTANTE & & & & 27 \\
\hline Muesca retocada frontal oblicua & 1 & & & 1 \\
\hline $\begin{array}{l}\text { Muesca retocada lateral paralela- } \\
\text { subparalela }\end{array}$ & 1 & & & 1 \\
\hline Muesca retocada lateral inclinada & 3 & 2 & & 5 \\
\hline MUESCA RETOCADA & & & & 7 \\
\hline $\begin{array}{l}\text { Muesca de lascado simple frontal } \\
\text { oblicuo }\end{array}$ & 1 & & & 1 \\
\hline Muesca de lascado simple angular & & & 1 & 1 \\
\hline $\begin{array}{l}\text { MUESCA DE LASCADO } \\
\text { SIMPLE }\end{array}$ & & & & 2 \\
\hline $\begin{array}{l}\text { Denticulado bisel oblicuo/abrupto } \\
\text { sección asimétrica de filo largo } \\
\text { frontal transversal }\end{array}$ & 2 & & & 2 \\
\hline $\begin{array}{l}\text { Denticulado bisel oblicuo/abrupto } \\
\text { sección asimétrica de filo largo } \\
\text { lateral paralelo-subparalelo }\end{array}$ & & 1 & & 1 \\
\hline $\begin{array}{l}\text { Denticulado bisel oblicuo/abrupto } \\
\text { sección asimétrica de filo largo } \\
\text { lateral inclinado }\end{array}$ & 1 & & & 1 \\
\hline $\begin{array}{l}\text { Denticulado bisel oblicuo/abrupto } \\
\text { sección asimétrica no diferenciado }\end{array}$ & & 1 & & 1 \\
\hline $\begin{array}{l}\text { DENTICULADO BISEL } \\
\text { OBLICUO / ABRUPTO } \\
\text { SECCIÓN ASIMÉTRICA }\end{array}$ & & & & 5 \\
\hline
\end{tabular}




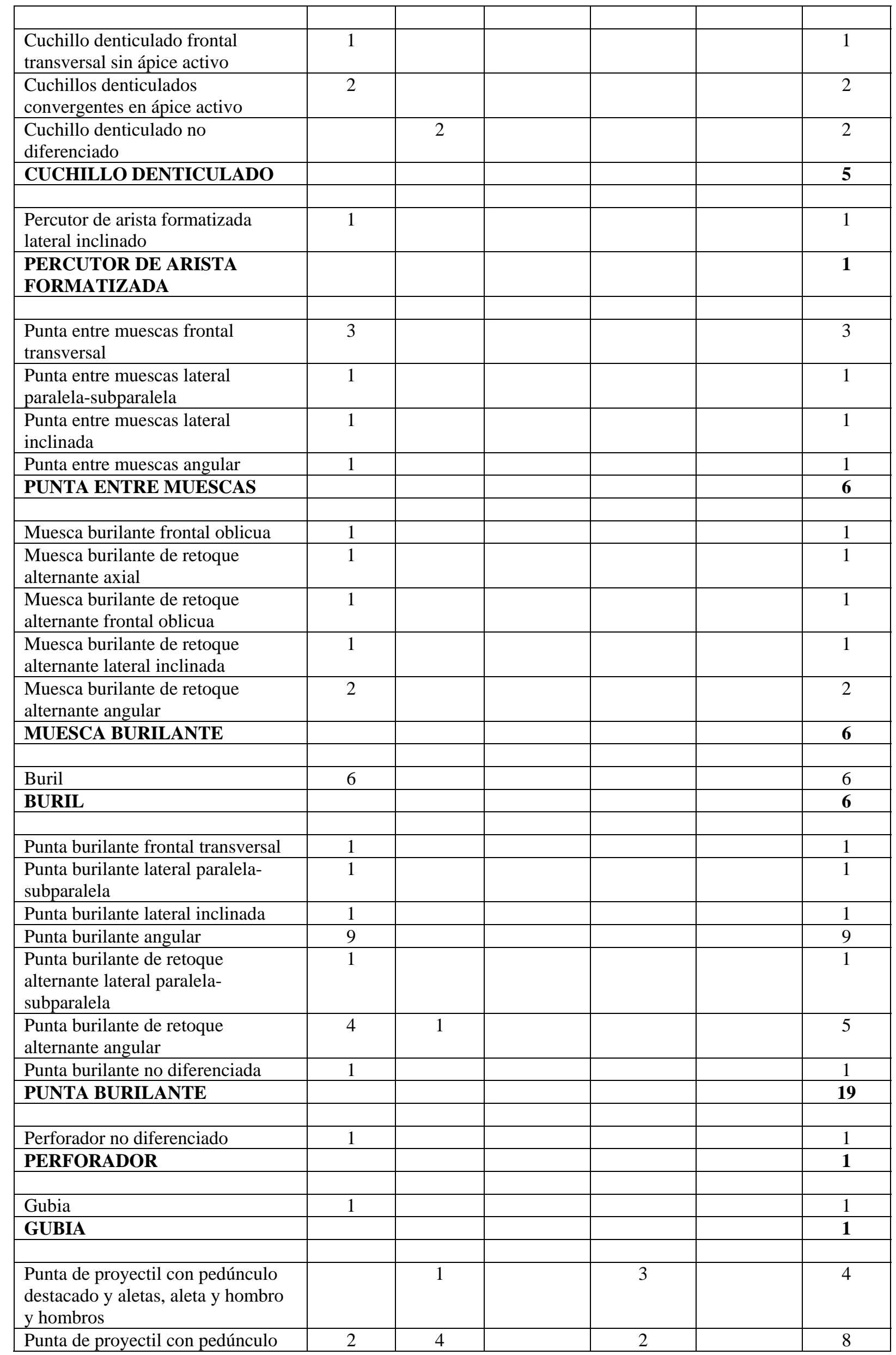




\begin{tabular}{|c|c|c|c|c|c|}
\hline esbozado & & & & & \\
\hline $\begin{array}{l}\text { Punta de proyectil apedunculada } \\
\text { lanceolada (normal) }\end{array}$ & & 2 & & & 2 \\
\hline $\begin{array}{l}\text { Punta de proyectil apedunculada } \\
\text { lanceolada } \\
\text { (bordes paralelos-subparalelos) }\end{array}$ & & & & 1 & 1 \\
\hline $\begin{array}{l}\text { Punta de proyectil apedunculada } \\
\text { triangular }\end{array}$ & & & & 1 & 1 \\
\hline $\begin{array}{l}\text { Fragmento de ápice/limbo de punta } \\
\text { de proyectil }\end{array}$ & & 2 & & & 2 \\
\hline $\begin{array}{l}\text { Fragmento de pedúnculo de punta } \\
\text { de proyectil }\end{array}$ & & 7 & & & 7 \\
\hline PUNTA DE PROYECTIL & & & & & 25 \\
\hline Filo formatizado pasivo unifacial & 8 & & & & 8 \\
\hline $\begin{array}{l}\text { FILO FORMATIZADO } \\
\text { PASIVO }\end{array}$ & & & & & $\begin{array}{l}0 \\
8\end{array}$ \\
\hline $\begin{array}{l}\text { Artefacto con formatización } \\
\text { sumaria }\end{array}$ & 2 & & & & 2 \\
\hline Filo con formatización sumaria & 10 & & 1 & & 11 \\
\hline $\begin{array}{l}\text { ARTEFACTO DE } \\
\text { FORMATIZACIÓN SUMARIA }\end{array}$ & & & & & 13 \\
\hline Artefacto bipolar no diferenciado & 5 & & & & 5 \\
\hline ARTEFACTO BIPOLAR & & & & & 5 \\
\hline $\begin{array}{l}\text { Fragmento no diferenciado de } \\
\text { artefacto formatizado (bifacial) }\end{array}$ & & 1 & & & 1 \\
\hline $\begin{array}{l}\text { Fragmento no diferenciado de } \\
\text { artefacto formatizado (unifacial) }\end{array}$ & & 7 & 1 & & 8 \\
\hline $\begin{array}{l}\text { FRAGMENTO NO } \\
\text { DIFERENCIADO DE } \\
\text { ARTEFACTO FORMATIZADO }\end{array}$ & & & & & 9 \\
\hline $\begin{array}{l}\text { Filo no diferenciado de artefacto } \\
\text { formatizado (unifacial) }\end{array}$ & 1 & 4 & 3 & & 8 \\
\hline $\begin{array}{l}\text { Punta formatizada no diferenciada } \\
\text { (bifacial) }\end{array}$ & 1 & & & & 1 \\
\hline $\begin{array}{l}\text { FILO NO DIFERENCIADO DE } \\
\text { ARTEFACTO FORMATIZADO }\end{array}$ & & & & & 9 \\
\hline
\end{tabular}


II.2.2. LISTA TIPOLÓGICA DEL SITIO PUNTA DE LA PEÑA 4 -5(6)-

\begin{tabular}{|l|c|c|c|c|c|c|}
\hline \multirow{2}{*}{$\begin{array}{l}\text { SUBGRUPO / GRUPO } \\
\text { TIPOLGICO }\end{array}$} & \multicolumn{3}{|c|}{ ARTEFACTO FORMATIZADO } & & TOTAL \\
\cline { 2 - 6 } & & FNTACT & $\begin{array}{c}\text { F-B ST } \\
\text { Transf }\end{array}$ & $\begin{array}{c}\text { F-B ST } \\
\text { RECIC }\end{array}$ & $\begin{array}{c}\text { F-B ST } \\
\text { RECLAM }\end{array}$ & ST \\
\hline $\begin{array}{l}\text { Fragmento de raedera no } \\
\text { diferenciado }\end{array}$ & & & & & & 1 \\
\hline RAEDERA & & & & & & $\mathbf{1}$ \\
\hline $\begin{array}{l}\text { Punta de proyectil con pedúnculo } \\
\text { destacado y aletas, aleta y } \\
\text { hombro y hombros }\end{array}$ & & 1 & & & & 1 \\
\hline PUNTA DE PROYECTIL & & & & & & $\mathbf{1}$ \\
\hline
\end{tabular}


II.2.3. LISTA TIPOLÓGICA DEL SITIO PUNTA DE LA PEÑA 4 -4 a 5(5)-

\begin{tabular}{|c|c|c|c|c|c|c|}
\hline \multirow{2}{*}{$\begin{array}{l}\text { SUBGRUPO / GRUPO } \\
\text { TIPOLÓGICO }\end{array}$} & \multicolumn{5}{|c|}{ ARTEFACTO FORMATIZADO } & \multirow{2}{*}{$\begin{array}{l}\text { TOTAL } \\
\text { ST }\end{array}$} \\
\hline & ENT & FRACT & $\begin{array}{c}\text { F-B ST } \\
\text { TRANSF }\end{array}$ & $\begin{array}{l}\text { F-B ST } \\
\text { RECIC }\end{array}$ & $\begin{array}{c}\text { F-B ST } \\
\text { RECLAM }\end{array}$ & \\
\hline Biface en sentido estricto & & 3 & 7 & 1 & & 11 \\
\hline Biface parcial & & 2 & 1 & & & 3 \\
\hline Biface no diferenciado & & & 3 & & & 3 \\
\hline BIFACE & & & & & & 17 \\
\hline Filo bifacial de arista sinuosa & 2 & & & & & 2 \\
\hline $\begin{array}{l}\text { FILO BIFACIAL DE ARISTA } \\
\text { SINUOSA }\end{array}$ & & & & & & 2 \\
\hline Raspador de filo perimetral & 1 & & & & & 1 \\
\hline Raspador de filo extendido & 2 & & & & & 2 \\
\hline Raspador de filo fronto-bilateral & 1 & & & & & 1 \\
\hline $\begin{array}{l}\text { Raspador de filo largo lateral } \\
\text { inclinado }\end{array}$ & 1 & & & & & 1 \\
\hline $\begin{array}{l}\text { Raspador de filo restringido frontal } \\
\text { transversal }\end{array}$ & 1 & & & & & 1 \\
\hline RASPADOR & & & & & & 6 \\
\hline Raclette de filo fronto-lateral & & & & 1 & & 1 \\
\hline $\begin{array}{l}\text { Raclette de filo largo lateral } \\
\text { paralelo/subparalelo }\end{array}$ & 2 & & & & & 2 \\
\hline $\begin{array}{l}\text { Raclette de filo largo lateral } \\
\text { inclinado }\end{array}$ & 3 & & & & & 3 \\
\hline $\begin{array}{l}\text { Raclette de filo corto lateral } \\
\text { inclinado }\end{array}$ & 1 & & & & & 1 \\
\hline $\begin{array}{l}\text { Raclette de filo corto no } \\
\text { diferenciado }\end{array}$ & 1 & & & & & 1 \\
\hline RACLETTE & & & & & & 8 \\
\hline $\begin{array}{l}\text { Raedera de filo largo frontal } \\
\text { oblicua }\end{array}$ & & 1 & & & & 1 \\
\hline $\begin{array}{l}\text { Raedera de filo largo lateral } \\
\text { inclinada }\end{array}$ & 3 & & & & & 3 \\
\hline $\begin{array}{l}\text { Fragmento de raedera no } \\
\text { diferenciado }\end{array}$ & & 1 & & 1 & & 2 \\
\hline RAEDERA & & & & & & 6 \\
\hline $\begin{array}{l}\text { Cuchillo de filo retocado frontal } \\
\text { oblicuo con ápice activo }\end{array}$ & 1 & & & & & 1 \\
\hline $\begin{array}{l}\text { Cuchillo de filo retocado lateral } \\
\text { inclinado }\end{array}$ & 1 & & & & & 1 \\
\hline $\begin{array}{l}\text { Cuchillos de filo retocado } \\
\text { convergentes en ápice romo }\end{array}$ & & 1 & & & & 1 \\
\hline $\begin{array}{l}\text { Cuchillo de filo retocado no } \\
\text { diferenciado }\end{array}$ & & 2 & & & & 2 \\
\hline $\begin{array}{l}\text { CUCHILLO DE FILO } \\
\text { RETOCADO }\end{array}$ & & & & & & 5 \\
\hline $\begin{array}{l}\text { Cortante de filo retocado corto } \\
\text { frontal frontal transversal }\end{array}$ & 1 & & & & & 1 \\
\hline $\begin{array}{l}\text { Cortante de filo retocado corto } \\
\text { frontal oblicuo }\end{array}$ & 1 & & & & & 1 \\
\hline $\begin{array}{l}\text { Cortante de filo retocado corto } \\
\text { lateral paralelo-subparalelo }\end{array}$ & 1 & 1 & & & & 2 \\
\hline Cortante de filo retocado corto & 1 & 1 & & & & 2 \\
\hline
\end{tabular}




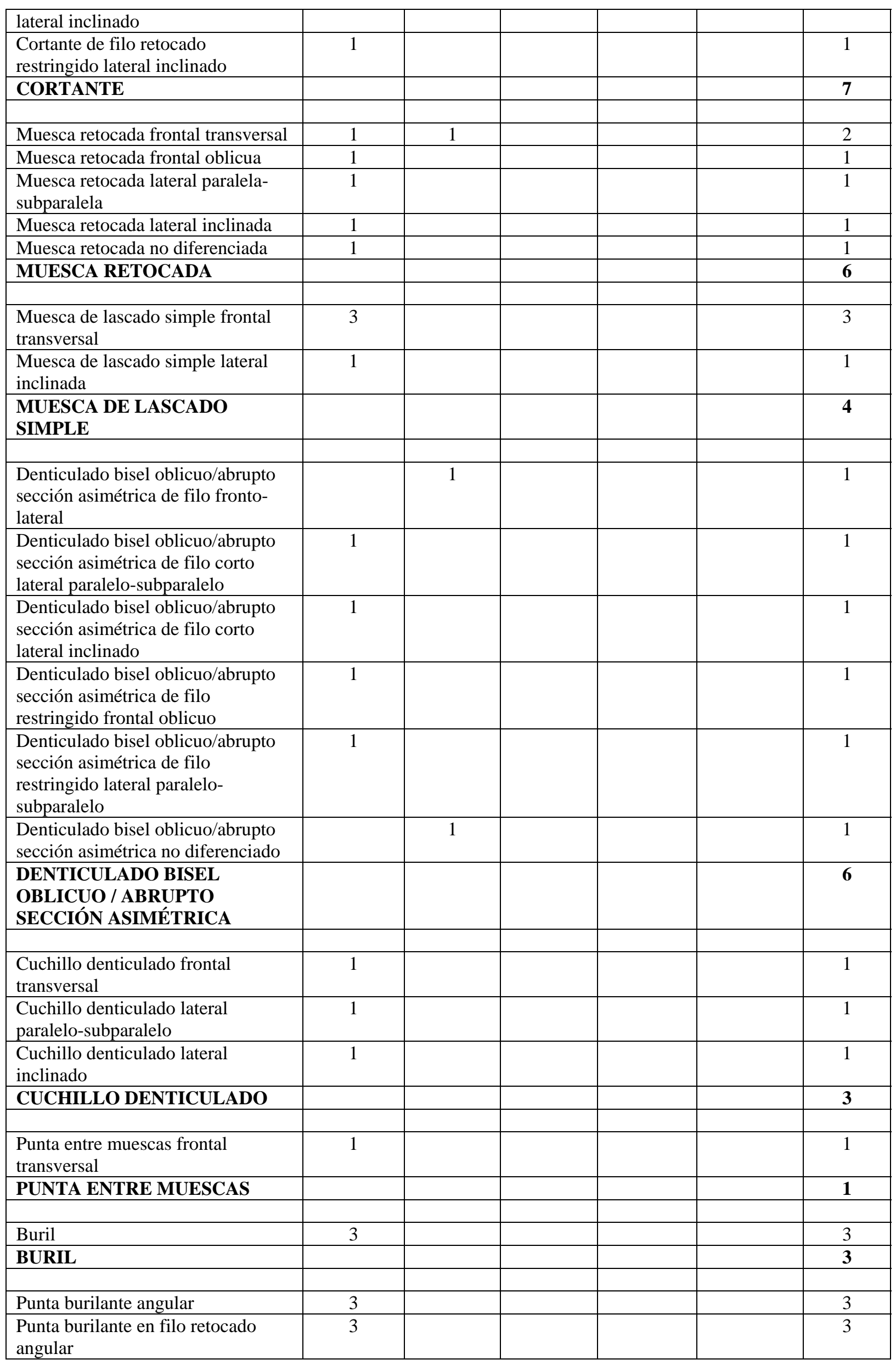




\begin{tabular}{|c|c|c|c|c|}
\hline PUNTA BURILANTE & & & & 6 \\
\hline $\begin{array}{l}\text { Perforador de punta de sección } \\
\text { simétrica, cuerpo/base formatizado }\end{array}$ & & 1 & & 1 \\
\hline PERFORADOR & & & & 1 \\
\hline Gubia & 1 & & & 1 \\
\hline GUBIA & & & & 1 \\
\hline & & & & \\
\hline Cincel & 1 & & & 1 \\
\hline CINCEL & & & & 1 \\
\hline $\begin{array}{l}\text { Punta de proyectil con pedúnculo } \\
\text { destacado y aletas, aleta y hombro y } \\
\text { hombros }\end{array}$ & 1 & 2 & 2 & 5 \\
\hline $\begin{array}{l}\text { Punta de proyectil con pedúnculo } \\
\text { esbozado }\end{array}$ & & 1 & 1 & 2 \\
\hline $\begin{array}{l}\text { Punta de proyectil apedunculada } \\
\text { triangular }\end{array}$ & & & 1 & 1 \\
\hline $\begin{array}{l}\text { Fragmento de ápice/limbo de punta } \\
\text { de proyectil }\end{array}$ & & & 1 & 1 \\
\hline $\begin{array}{l}\text { Fragmento de pedúnculo de punta } \\
\text { de proyectil }\end{array}$ & & 2 & & 2 \\
\hline PUNTA DE PROYECTIL & & & & 11 \\
\hline Filo formatizado pasivo bifacial & 1 & & & 1 \\
\hline Filo formatizado pasivo unifacial & 1 & & & 1 \\
\hline Filo formatizado pasivo alternante & 1 & & & 1 \\
\hline FILO FORMATIZADO PASIVO & & & & 3 \\
\hline & & & & \\
\hline Filo con formatización sumaria & 8 & & & 8 \\
\hline Esbozo de pieza bifacial & 1 & & & 1 \\
\hline $\begin{array}{l}\text { ARTEFACTO DE } \\
\text { FORMATIZACIÓN SUMARIA }\end{array}$ & & & & 9 \\
\hline Artefacto bipolar no diferenciado & & & 1 & 1 \\
\hline ARTEFACTO BIPOLAR & & & & 1 \\
\hline $\begin{array}{l}\text { Fragmento no diferenciado de } \\
\text { artefacto formatizado (bifacial) }\end{array}$ & & 4 & & 4 \\
\hline $\begin{array}{l}\text { Fragmento no diferenciado de } \\
\text { artefacto formatizado (unifacial) }\end{array}$ & & 4 & & 4 \\
\hline $\begin{array}{l}\text { FRAGMENTO NO } \\
\text { DIFERENCIADO DE } \\
\text { ARTEFACTO FORMATIZADO }\end{array}$ & & & & 8 \\
\hline $\begin{array}{l}\text { Filo no diferenciado de artefacto } \\
\text { formatizado (unifacial) }\end{array}$ & & 5 & 1 & 6 \\
\hline $\begin{array}{l}\text { FILO NO DIFERENCIADO DE } \\
\text { ARTEFACTO FORMATIZADO }\end{array}$ & & & & 6 \\
\hline
\end{tabular}




\section{II.2.4. LISTA TIPOLÓGICA DEL SITIO PEÑAS CHICAS 1.3}

\begin{tabular}{|c|c|c|c|c|c|c|}
\hline \multirow{2}{*}{$\begin{array}{l}\text { SUBGRUPO / GRUPO } \\
\text { TIPOLÓGICO }\end{array}$} & \multicolumn{5}{|c|}{ ARTEFACTO FORMATIZADO } & \multirow{2}{*}{$\begin{array}{l}\text { TOTAL } \\
\text { ST }\end{array}$} \\
\hline & ENT & FRACT & $\begin{array}{c}\text { F-B ST } \\
\text { TRANSF }\end{array}$ & $\begin{array}{l}\text { F-B ST } \\
\text { RECIC }\end{array}$ & $\begin{array}{c}\text { F-B ST } \\
\text { RECLAM }\end{array}$ & \\
\hline Uniface & & 1 & & & & 1 \\
\hline UNIFACE & & & & & & 1 \\
\hline Biface en sentido estricto & & 3 & 5 & 2 & & 10 \\
\hline Biface parcial & 2 & 3 & 12 & 4 & & 21 \\
\hline Biface no diferenciado & & 1 & 12 & 1 & & 14 \\
\hline BIFACE & & & & & & 45 \\
\hline Filo bifacial de arista sinuosa & 3 & 4 & & & & 7 \\
\hline $\begin{array}{l}\text { FILO BIFACIAL DE ARISTA } \\
\text { SINUOSA }\end{array}$ & & & & & & 7 \\
\hline Raspador de filo fronto-lateral & 2 & & & & & 2 \\
\hline $\begin{array}{l}\text { Raspador de filo largo lateral } \\
\text { paralelo-subparalelo }\end{array}$ & 1 & & & & & 1 \\
\hline $\begin{array}{l}\text { Raspador de filo restringido frontal } \\
\text { transversal }\end{array}$ & 2 & & & & & 2 \\
\hline $\begin{array}{l}\text { Raspador de filo restringido frontal } \\
\text { oblicuo }\end{array}$ & 2 & & & & & 2 \\
\hline Raspador de filo restringido angular & 1 & & & & & 1 \\
\hline RASPADOR & & & & & & 8 \\
\hline Raclette de filo fronto-lateral & & & & & & \\
\hline $\begin{array}{l}\text { Raclette de filo largo frontal } \\
\text { transversal }\end{array}$ & 1 & & & & & 1 \\
\hline $\begin{array}{l}\text { Raclette de filo largo frontal } \\
\text { oblicuo }\end{array}$ & 2 & & & & & 2 \\
\hline $\begin{array}{l}\text { Raclette de filo largo lateral } \\
\text { inclinado }\end{array}$ & 4 & & & & & 4 \\
\hline $\begin{array}{l}\text { Raclette de filo corto frontal } \\
\text { oblicuo }\end{array}$ & 1 & & & & & 1 \\
\hline $\begin{array}{l}\text { Raclette de filo restringido frontal } \\
\text { transversal }\end{array}$ & 1 & & & & & 1 \\
\hline Raclette de filo no diferenciado & & & & 1 & & 1 \\
\hline RACLETTE & & & & & & 10 \\
\hline $\begin{array}{l}\text { Raedera de filo largo frontal } \\
\text { transversal }\end{array}$ & 1 & & & & & 1 \\
\hline $\begin{array}{l}\text { Raedera de filo largo lateral } \\
\text { paralelo-subparalelo }\end{array}$ & 2 & & & 1 & & 3 \\
\hline $\begin{array}{l}\text { Raedera de filo largo lateral } \\
\text { inclinada }\end{array}$ & & 4 & & & & 4 \\
\hline $\begin{array}{l}\text { Fragmento de raedera no } \\
\text { diferenciado }\end{array}$ & & 1 & & & & 1 \\
\hline RAEDERA & & & & & & 9 \\
\hline $\begin{array}{l}\text { Cuchillo de filo retocado frontal } \\
\text { oblicuo }\end{array}$ & & 1 & & & & 1 \\
\hline $\begin{array}{l}\text { Cuchillo de filo retocado lateral } \\
\text { inclinado }\end{array}$ & 4 & & & 1 & & 5 \\
\hline $\begin{array}{l}\text { Cuchillos de filo retocado } \\
\text { convergentes con ápice activo }\end{array}$ & & 1 & & & & 1 \\
\hline $\begin{array}{l}\text { Cuchillos de filo retocado } \\
\text { convergentes con ápice romo }\end{array}$ & 1 & & & & & 1 \\
\hline Cuchillo de filo retocado no & & 1 & & & & 1 \\
\hline
\end{tabular}




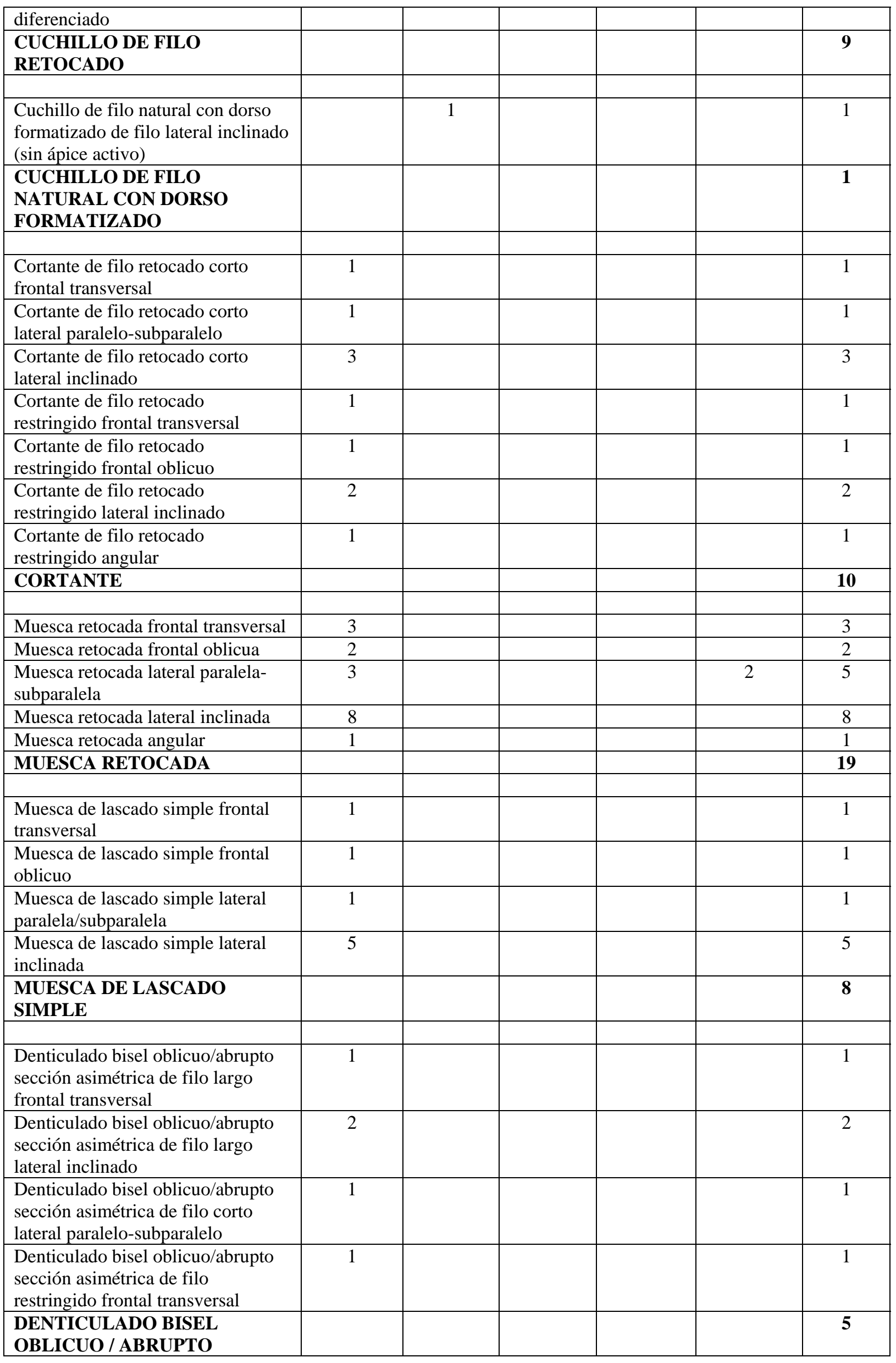




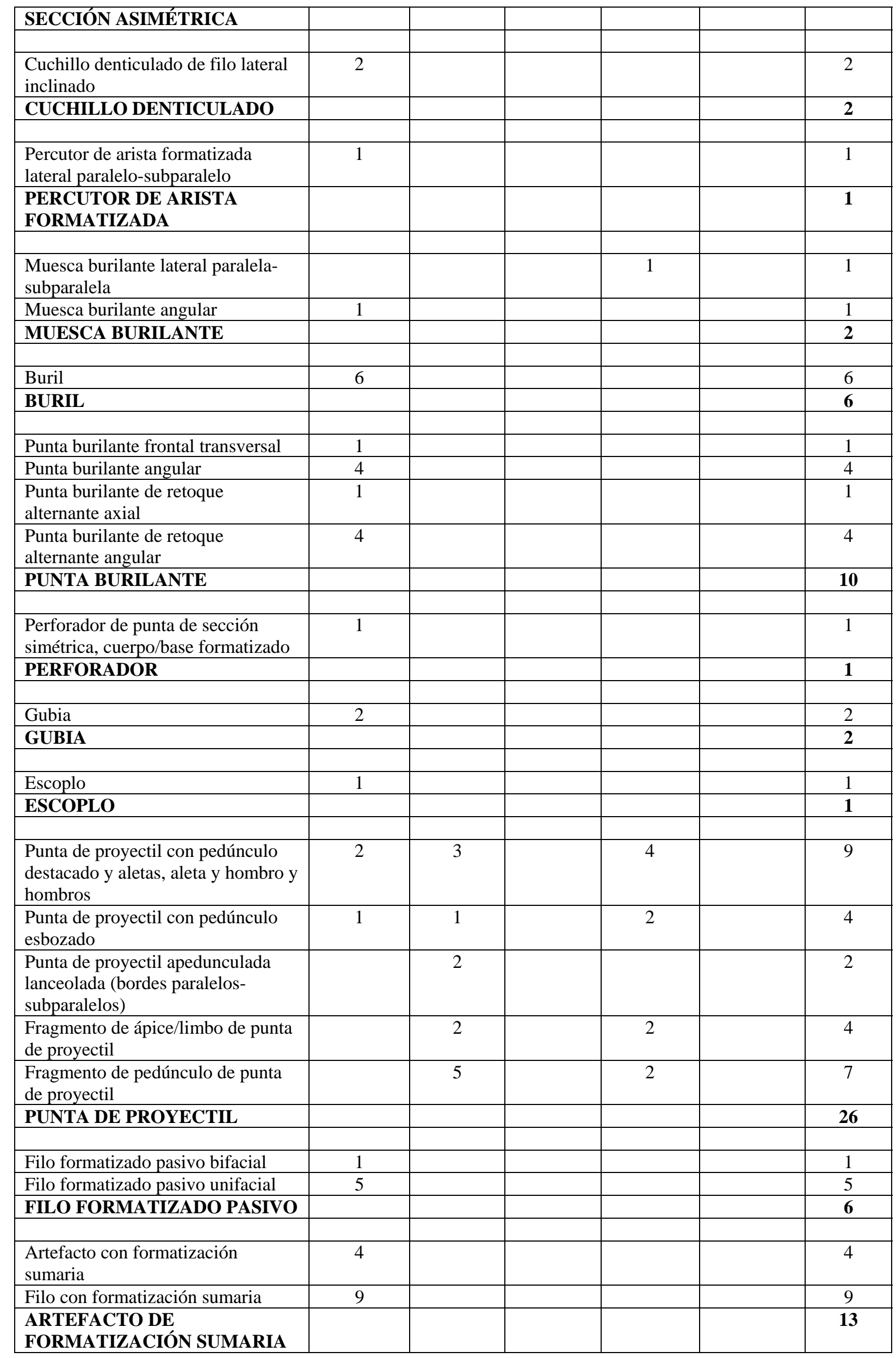




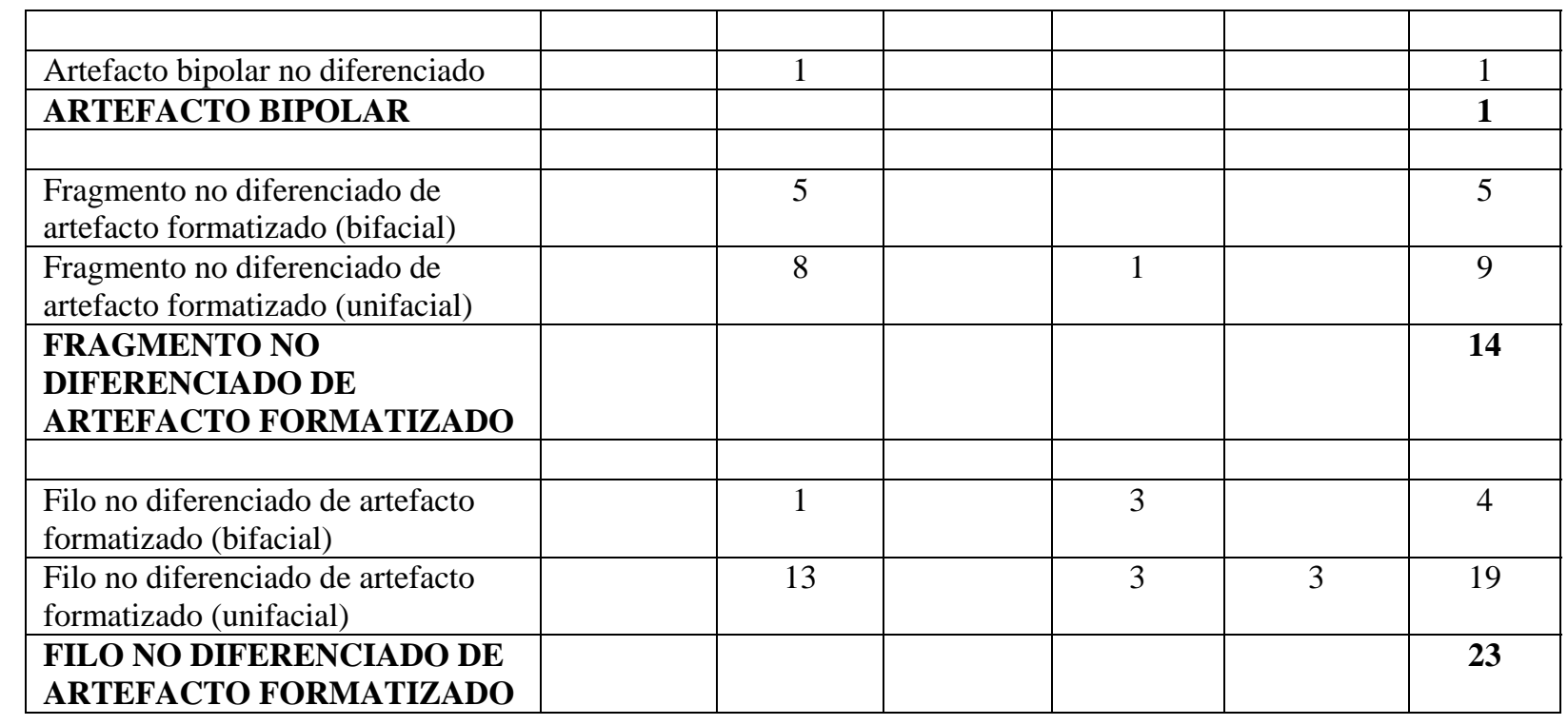

\section{II.2.5. LISTA TIPOLÓGICA DEL SITIO PEÑAS CHICAS 1.1}

\begin{tabular}{|c|c|c|c|c|c|c|}
\hline \multirow{2}{*}{$\begin{array}{l}\text { SUBGRUPO / GRUPO } \\
\text { TIPOLÓGICO }\end{array}$} & \multicolumn{5}{|c|}{ ARTEFACTO FORMATIZADO } & \multirow{2}{*}{$\begin{array}{l}\text { TOTAL } \\
\text { ST }\end{array}$} \\
\hline & ENT & FRACT & $\begin{array}{l}\text { F-B ST } \\
\text { TRANSF }\end{array}$ & $\begin{array}{l}\text { F-B ST } \\
\text { RECIC }\end{array}$ & $\begin{array}{c}\text { F-B ST } \\
\text { RECLAM }\end{array}$ & \\
\hline Uniface & & & 2 & & & 2 \\
\hline UNIFACE & & & & & & 2 \\
\hline Biface en sentido estricto & 3 & 8 & 17 & 3 & & 31 \\
\hline Biface parcial & 1 & 1 & 3 & 2 & & 7 \\
\hline Biface no diferenciado & & 1 & 11 & & & 12 \\
\hline BIFACE & & & & & & 50 \\
\hline & & & & & & \\
\hline Filo bifacial de arista sinuosa & 3 & 2 & & 1 & & 6 \\
\hline $\begin{array}{l}\text { FILO BIFACIAL DE ARISTA } \\
\text { SINUOSA }\end{array}$ & & & & & & 6 \\
\hline & & & & & & \\
\hline $\begin{array}{l}\text { Cepillo de filo corto lateral } \\
\text { inclinado }\end{array}$ & 1 & & & & & 1 \\
\hline CEPILLO & & & & & & 1 \\
\hline $\begin{array}{l}\text { Raspador de filo largo frontal } \\
\text { transversal }\end{array}$ & 2 & & & & & 2 \\
\hline $\begin{array}{l}\text { Raspador de filo corto frontal } \\
\text { transversal }\end{array}$ & 1 & & & & & 1 \\
\hline $\begin{array}{l}\text { Raspador de filo corto lateral } \\
\text { paralelo-subparalelo }\end{array}$ & 1 & & & & & 1 \\
\hline $\begin{array}{l}\text { Raspador de filo restringido frontal } \\
\text { transversal }\end{array}$ & 1 & & & & & 1 \\
\hline $\begin{array}{l}\text { Raspador de filo restringido frontal } \\
\text { oblicuo }\end{array}$ & 1 & & & & & 1 \\
\hline $\begin{array}{l}\text { Raspador de filo restringido lateral } \\
\text { inclinado }\end{array}$ & 1 & 1 & & & & 2 \\
\hline $\begin{array}{l}\text { Raspador de filo restringido } \\
\text { angular }\end{array}$ & 1 & & & & & 1 \\
\hline RASPADOR & & & & & & 9 \\
\hline & & & & & & \\
\hline $\begin{array}{l}\text { Raclette de filo largo frontal } \\
\text { transversal }\end{array}$ & 2 & & & & & 2 \\
\hline
\end{tabular}




\begin{tabular}{|c|c|c|c|c|}
\hline $\begin{array}{l}\text { Raclette de filo largo frontal } \\
\text { oblicuo }\end{array}$ & & 1 & & 1 \\
\hline $\begin{array}{l}\text { Raclette de filo largo lateral } \\
\text { paralelo/subparalelo }\end{array}$ & 1 & & & 1 \\
\hline $\begin{array}{l}\text { Raclette de filo largo lateral } \\
\text { inclinado }\end{array}$ & 6 & 1 & & 7 \\
\hline $\begin{array}{l}\text { Raclette de filo restringido lateral } \\
\text { inclinado }\end{array}$ & 1 & & & 1 \\
\hline $\begin{array}{l}\text { Raclette de filos convergentes en } \\
\text { ápice romo }\end{array}$ & 1 & & & 1 \\
\hline $\begin{array}{l}\text { Fragmento de raclette no } \\
\text { diferenciado }\end{array}$ & 1 & & & 1 \\
\hline RACLETTE & & & & 14 \\
\hline $\begin{array}{l}\text { Raedera de filo largo frontal } \\
\text { oblicua }\end{array}$ & & & 1 & 1 \\
\hline $\begin{array}{l}\text { Raedera de filo largo lateral } \\
\text { paralelo/subparalelo }\end{array}$ & 1 & & & 1 \\
\hline $\begin{array}{l}\text { Raedera de filo largo lateral } \\
\text { inclinada }\end{array}$ & 3 & 1 & 1 & 5 \\
\hline $\begin{array}{l}\text { Fragmento de raedera no } \\
\text { diferenciado }\end{array}$ & & 1 & 1 & 2 \\
\hline RAEDERA & & & & 9 \\
\hline $\begin{array}{l}\text { Fragmento de lámina retocada no } \\
\text { diferenciado }\end{array}$ & & 1 & & 1 \\
\hline LÁMINA RETOCADA & & & & 1 \\
\hline $\begin{array}{l}\text { Artefacto mediano pequeño/muy } \\
\text { pequeño R.B.O. sección asimétrica } \\
\text { de filo largo lateral } \\
\text { paralelo/subparalelo }\end{array}$ & & 1 & & 1 \\
\hline $\begin{array}{l}\text { Artefacto mediano pequeño/muy } \\
\text { pequeño R.B.O. sección asimétrica } \\
\text { de filo corto lateral inclinado }\end{array}$ & 1 & & & 1 \\
\hline $\begin{array}{l}\text { ARTEFACTO MEDIANO } \\
\text { PEQUEÑO/MUY PEQUEÑO } \\
\text { R.B.O. SECCIÓN } \\
\text { ASIMÉTRICA }\end{array}$ & & & & 2 \\
\hline $\begin{array}{l}\text { Cuchillo de filo retocado lateral } \\
\text { paralelo-subparalelo con ápice } \\
\text { activo }\end{array}$ & 1 & & & 1 \\
\hline $\begin{array}{l}\text { Cuchillo de filo retocado lateral } \\
\text { paralelo-subparalelo }\end{array}$ & 4 & & & 4 \\
\hline $\begin{array}{l}\text { Cuchillo de filo retocado lateral } \\
\text { inclinado }\end{array}$ & 1 & 1 & & 2 \\
\hline $\begin{array}{l}\text { Cuchillos de filo retocado } \\
\text { convergentes en ápice activo }\end{array}$ & & 1 & & 1 \\
\hline $\begin{array}{l}\text { Cuchillo de filo retocado no } \\
\text { diferenciado }\end{array}$ & 1 & & & 1 \\
\hline $\begin{array}{l}\text { CUCHILLO DE FILO } \\
\text { RETOCADO }\end{array}$ & & & & 9 \\
\hline & & & & \\
\hline $\begin{array}{l}\text { Cortante de filo retocado corto } \\
\text { frontal oblicuo }\end{array}$ & 1 & & & 1 \\
\hline $\begin{array}{l}\text { Cortante de filo retocado corto } \\
\text { lateral inclinado }\end{array}$ & 3 & & & 3 \\
\hline $\begin{array}{l}\text { Cortante de filo retocado } \\
\text { restringido frontal oblicuo }\end{array}$ & 3 & & & 3 \\
\hline
\end{tabular}




\begin{tabular}{|c|c|c|c|c|}
\hline $\begin{array}{l}\text { Cortante de filo retocado } \\
\text { restringido lateral inclinado }\end{array}$ & 2 & & & 2 \\
\hline $\begin{array}{l}\text { Cortante de filo retocado } \\
\text { restringido angular }\end{array}$ & 2 & & & 2 \\
\hline CORTANTE & & & & 11 \\
\hline Muesca retocada frontal transversal & 2 & & & 2 \\
\hline Muesca retocada frontal oblicua & 3 & & & 3 \\
\hline Muesca retocada lateral inclinada & 6 & & & 6 \\
\hline MUESCA RETOCADA & & & & 11 \\
\hline $\begin{array}{l}\text { Muesca de lascado simple frontal } \\
\text { transversal }\end{array}$ & 2 & & & 2 \\
\hline $\begin{array}{l}\text { Muesca de lascado simple frontal } \\
\text { oblicuo }\end{array}$ & 2 & & & 2 \\
\hline $\begin{array}{l}\text { Muesca de lascado simple lateral } \\
\text { paralela-subparalela }\end{array}$ & 1 & & & 1 \\
\hline $\begin{array}{l}\text { Muesca de lascado simple lateral } \\
\text { inclinada }\end{array}$ & 3 & & & 3 \\
\hline Muesca de lascado simple angular & 1 & & & 1 \\
\hline $\begin{array}{l}\text { MUESCA DE LASCADO } \\
\text { SIMPLE }\end{array}$ & & & & 9 \\
\hline $\begin{array}{l}\text { Denticulado bisel oblicuo/abrupto } \\
\text { sección asimétrica de filo largo } \\
\text { frontal transversal }\end{array}$ & 5 & 1 & & 6 \\
\hline $\begin{array}{l}\text { Denticulado bisel oblicuo/abrupto } \\
\text { sección asimétrica de filo largo } \\
\text { frontal oblicuo }\end{array}$ & 2 & 1 & & 3 \\
\hline $\begin{array}{l}\text { Denticulado bisel oblicuo/abrupto } \\
\text { sección asimétrica de filo largo } \\
\text { lateral paralelo-subparalelo }\end{array}$ & 4 & & & 4 \\
\hline $\begin{array}{l}\text { Denticulado bisel oblicuo/abrupto } \\
\text { sección asimétrica de filo largo } \\
\text { lateral inclinado }\end{array}$ & 6 & 3 & 1 & 10 \\
\hline $\begin{array}{l}\text { Denticulado bisel oblicuo/abrupto } \\
\text { sección asimétrica de filo corto } \\
\text { lateral inclinado }\end{array}$ & 2 & & & 2 \\
\hline $\begin{array}{l}\text { DENTICULADO BISEL } \\
\text { OBLICUO / ABRUPTO } \\
\text { SECCIÓN ASIMÉTRICA }\end{array}$ & & & & 25 \\
\hline $\begin{array}{l}\text { Cuchillo denticulado lateral } \\
\text { paralelo-subparalelo }\end{array}$ & 1 & & & 1 \\
\hline $\begin{array}{l}\text { Cuchillo denticulado lateral } \\
\text { inclinado }\end{array}$ & 1 & & & 1 \\
\hline CUCHILLO DENTICULADO & & & & 2 \\
\hline $\begin{array}{l}\text { Percutor de arista formatizada } \\
\text { extendida }\end{array}$ & & 1 & & 1 \\
\hline $\begin{array}{l}\text { Percutor de arista formatizada } \\
\text { frontal transversal }\end{array}$ & 1 & & & 1 \\
\hline $\begin{array}{l}\text { Percutor de arista formatizada } \\
\text { frontal oblicuo }\end{array}$ & 1 & & & 1 \\
\hline $\begin{array}{l}\text { Percutor de arista formatizada } \\
\text { lateral paralelo-subparalelo }\end{array}$ & & & 1 & 1 \\
\hline $\begin{array}{l}\text { PERCUTOR DE ARISTA } \\
\text { FORMATIZADA }\end{array}$ & & & & 4 \\
\hline Punta entre muescas frontal oblicua & 1 & & & 1 \\
\hline
\end{tabular}




\begin{tabular}{|c|c|c|c|c|}
\hline PUNTA ENTRE MUESCAS & & & & 1 \\
\hline Muesca burilante angular & 1 & & & 1 \\
\hline $\begin{array}{l}\text { Muesca burilante de retoque } \\
\text { alternante lateral inclinada }\end{array}$ & 1 & & & 1 \\
\hline MUESCA BURILANTE & & & & 2 \\
\hline Buril & 9 & & & 9 \\
\hline BURIL & & & & 9 \\
\hline & & & & \\
\hline Punta burilante axial & 1 & & & 1 \\
\hline Punta burilante angular & 8 & & 1 & 9 \\
\hline $\begin{array}{l}\text { Punta burilante de retoque } \\
\text { alternante angular }\end{array}$ & 1 & & & 1 \\
\hline $\begin{array}{l}\text { Punta burilante en filo retocado } \\
\text { angular }\end{array}$ & 4 & & & 4 \\
\hline PUNTA BURILANTE & & & & 15 \\
\hline $\begin{array}{l}\text { Perforador de punta sección } \\
\text { simétrica, cuerpo/base formatizado }\end{array}$ & 2 & & & 2 \\
\hline $\begin{array}{l}\text { Perforador de punta triédrica } \\
\text { sección asimétrica, cuerpo/base } \\
\text { formatizado }\end{array}$ & 1 & & & 1 \\
\hline Perforador no diferenciado & 1 & & & 1 \\
\hline PERFORADOR & & & & 4 \\
\hline Cincel & 1 & & & 1 \\
\hline CINCEL & & & & 1 \\
\hline Escoplo & 1 & & & 1 \\
\hline ESCOPLO & & & & 1 \\
\hline $\begin{array}{l}\text { Preforma de punta de proyectil } \\
\text { pedunculada }\end{array}$ & & 1 & & 1 \\
\hline $\begin{array}{l}\text { Preforma de punta de proyectil } \\
\text { apedunculada }\end{array}$ & & 1 & & 1 \\
\hline $\begin{array}{l}\text { Punta de proyectil con pedúnculo } \\
\text { destacado y aletas, aleta y hombro } \\
\text { y hombros }\end{array}$ & & & 1 & 1 \\
\hline $\begin{array}{l}\text { Punta de proyectil con pedúnculo } \\
\text { esbozado }\end{array}$ & 1 & & & 1 \\
\hline $\begin{array}{l}\text { Punta de proyectil apedunculada } \\
\text { lanceolada (normal) }\end{array}$ & 3 & 5 & 4 & 12 \\
\hline $\begin{array}{l}\text { Punta de proyectil apedunculada } \\
\text { lanceolada (bordes paralelos- } \\
\text { subparalelos) }\end{array}$ & & & 4 & 4 \\
\hline $\begin{array}{l}\text { Punta de proyectil apedunculada } \\
\text { lanceolada no diferenciada }\end{array}$ & & & 1 & 1 \\
\hline $\begin{array}{l}\text { Fragmento de ápice/limbo de punta } \\
\text { de proyectil }\end{array}$ & & 6 & 1 & 7 \\
\hline $\begin{array}{l}\text { Fragmento de pedúnculo de punta } \\
\text { de proyectil }\end{array}$ & & 1 & & 1 \\
\hline PUNTA DE PROYECTIL & & & & 29 \\
\hline & & & & \\
\hline Filo formatizado pasivo bifacial & 2 & & & 2 \\
\hline Filo formatizado pasivo unifacial & 10 & & & 10 \\
\hline $\begin{array}{l}\text { FILO FORMATIZADO } \\
\text { PASIVO }\end{array}$ & & & & 12 \\
\hline Artefacto con formatización & 3 & 1 & & 4 \\
\hline
\end{tabular}




\begin{tabular}{|l|c|c|c|c|c|c|}
\hline sumaria & & & & & \\
\hline Filo con formatización sumaria & 3 & & & & & 3 \\
\hline Esbozo de pieza bifacial & & & & 1 & \\
\hline $\begin{array}{l}\text { ARTEFACTO DE } \\
\text { FORMATIZACIÓN SUMARIA }\end{array}$ & & & & & & $\mathbf{8}$ \\
\hline & & 11 & & 4 & & 15 \\
\hline $\begin{array}{l}\text { Fragmento no diferenciado de } \\
\text { artefacto formatizado (bifacial) }\end{array}$ & & 10 & & & & 10 \\
\hline $\begin{array}{l}\text { Fragmento no diferenciado de } \\
\text { artefacto formatizado (unifacial) }\end{array}$ & & & & & & $\mathbf{2 5}$ \\
\hline $\begin{array}{l}\text { FRAGMENTO NO } \\
\text { DIFERENCIADO DE } \\
\text { ARTEFACTO FORMATIZADO }\end{array}$ & & & & & & \\
\hline & 2 & 4 & & 1 & & 7 \\
\hline Artefacto bipolar no diferenciado & & & & & & \\
\hline ARTEFACTO BIPOLAR & & & 1 & & 3 \\
\hline $\begin{array}{l}\text { Filo no diferenciado de artefacto } \\
\text { formatizado (bifacial) }\end{array}$ & & 6 & & 4 & & 13 \\
\hline $\begin{array}{l}\text { Filo no diferenciado de artefacto } \\
\text { formatizado (unifacial) }\end{array}$ & & & & & & $\mathbf{1 3}$ \\
\hline $\begin{array}{l}\text { FILO NO DIFERENCIADO DE } \\
\text { ARTEFACTO FORMATIZADO }\end{array}$ & & & & & & \\
\hline
\end{tabular}


II.2.6. LISTA TIPOLÓGICA DEL SITIO PUNTA DE LA PEÑA 9 (I.E3 / III.E2: 4 a 6)

\begin{tabular}{|c|c|c|c|c|c|c|}
\hline \multirow{2}{*}{$\begin{array}{l}\text { SUBGRUPO / GRUPO } \\
\text { TIPOLÓGICO }\end{array}$} & \multicolumn{5}{|c|}{ ARTEFACTO FORMATIZADO } & \multirow{2}{*}{$\begin{array}{l}\text { TOTAL } \\
\text { ST }\end{array}$} \\
\hline & ENT & FRACT & $\begin{array}{c}\text { F-B ST } \\
\text { TRANSF }\end{array}$ & $\begin{array}{l}\text { F-B ST } \\
\text { RECIC }\end{array}$ & $\begin{array}{c}\text { F-B ST } \\
\text { RECLAM }\end{array}$ & \\
\hline Filo unifacial de arista sinuosa & 1 & & & & & 1 \\
\hline $\begin{array}{l}\text { FILO UNIFACIAL DE ARISTA } \\
\text { SINUOSA }\end{array}$ & & & & & & 1 \\
\hline Filo bifacial de arista sinuosa & 1 & 1 & & & & 2 \\
\hline $\begin{array}{l}\text { FILO BIFACIAL DE ARISTA } \\
\text { SINUOSA }\end{array}$ & & & & & & 2 \\
\hline Raclette de filo largo lateral inclinado & 1 & 1 & & & & 2 \\
\hline Raclette no diferenciado & & 1 & & & & 1 \\
\hline RACLETTE & & & & & & 3 \\
\hline $\begin{array}{l}\text { Raedera de filo largo frontal } \\
\text { transversal }\end{array}$ & 1 & 2 & & & & 3 \\
\hline Raedera de filo largo frontal oblicua & 1 & & & & & 1 \\
\hline RAEDERA & & & & & & 4 \\
\hline $\begin{array}{l}\text { Artefacto mediano pequeño/muy } \\
\text { pequeño R.B.O. sección asimétrica } \\
\text { de filo largo lateral inclinado }\end{array}$ & 2 & & & & & 2 \\
\hline $\begin{array}{l}\text { ARTEFACTO MEDIANO } \\
\text { PEQUEÑO/MUY PEQUEÑO } \\
\text { R.B.O. SECCIÓN ASIMÉTRICA }\end{array}$ & & & & & & 2 \\
\hline $\begin{array}{l}\text { Cuchillo de filo retocado lateral } \\
\text { inclinado }\end{array}$ & 1 & & & & & 1 \\
\hline $\begin{array}{l}\text { CUCHILLO DE FILO } \\
\text { RETOCADO }\end{array}$ & & & & & & 1 \\
\hline $\begin{array}{l}\text { Cortante de filo retocado restringido } \\
\text { frontal transversal }\end{array}$ & 1 & & & & & 1 \\
\hline CORTANTE & & & & & & 1 \\
\hline Muesca retocada frontal transversal & 2 & & & & & 2 \\
\hline Muesca retocada lateral inclinada & 2 & & & & & 2 \\
\hline Muesca retocada angular & 2 & & & & & 2 \\
\hline MUESCA RETOCADA & & & & & & 6 \\
\hline $\begin{array}{l}\text { Muesca de lascado simple no } \\
\text { diferenciada }\end{array}$ & & & & 1 & & 1 \\
\hline $\begin{array}{l}\text { MUESCA DE LASCADO } \\
\text { SIMPLE }\end{array}$ & & & & & & 1 \\
\hline $\begin{array}{l}\text { Denticulado bisel oblicuo/abrupto } \\
\text { sección asimétrica de filo largo } \\
\text { frontal transversal }\end{array}$ & 1 & & & & & 1 \\
\hline $\begin{array}{l}\text { Denticulado bisel oblicuo/abrupto } \\
\text { sección asimétrica de filo corto } \\
\text { frontal transversal }\end{array}$ & 1 & & & & & 1 \\
\hline $\begin{array}{l}\text { DENTICULADO BISEL } \\
\text { OBLICUO / ABRUPTO } \\
\text { SECCIÓN ASIMÉTRICA }\end{array}$ & & & & & & 2 \\
\hline Punta entre muescas frontal oblicua & 1 & & & & & 1 \\
\hline PUNTA ENTRE MUESCAS & & & & & & 1 \\
\hline
\end{tabular}




\begin{tabular}{|c|c|c|c|c|}
\hline Punta burilante angular & 2 & & & 2 \\
\hline PUNTA BURILANTE & & & & 2 \\
\hline $\begin{array}{l}\text { Perforador de punta de sección } \\
\text { simétrica (cuerpo/base formatizado) }\end{array}$ & & 1 & & 1 \\
\hline PERFORADOR & & & & 1 \\
\hline Escoplo & 1 & & & 1 \\
\hline ESCOPLO & & & & 1 \\
\hline $\begin{array}{l}\text { Punta de proyectil con pedúnculo } \\
\text { diferenciado y aletas, aleta y hombro } \\
\text { u hombros }\end{array}$ & & 2 & & 2 \\
\hline PUNTA DE PROYECTIL & & & & 2 \\
\hline Filo formatizado pasivo bifacial & & & 1 & 1 \\
\hline FILO FORMATIZADO PASIVO & & & & 1 \\
\hline Artefacto con formatización sumaria & 2 & & & 2 \\
\hline Filo con formatización sumaria & 1 & & & 1 \\
\hline $\begin{array}{l}\text { ARTEFACTO DE } \\
\text { FORMATIZACIÓN SUMARIA }\end{array}$ & & & & 3 \\
\hline $\begin{array}{l}\text { Fragmento no diferenciado de } \\
\text { artefacto formatizado (unifacial) }\end{array}$ & & 2 & & 2 \\
\hline $\begin{array}{l}\text { FRAGMENTO NO } \\
\text { DIFERENCIADO DE } \\
\text { ARTEFACTO FORMATIZADO } \\
\end{array}$ & & & & 2 \\
\hline $\begin{array}{l}\text { Filo no diferenciado de artefacto } \\
\text { formatizado (unifacial) }\end{array}$ & & 2 & 1 & 3 \\
\hline Filo formatizado no diferenciado & & 1 & & 1 \\
\hline $\begin{array}{l}\text { FILO NO DIFERENCIADO DE } \\
\text { ARTEFACTO FORMATIZADO }\end{array}$ & & & & 4 \\
\hline Pala y/o azada & & 3 & & 3 \\
\hline PALA Y/O AZADA & & & & 3 \\
\hline
\end{tabular}




\section{II.2.7. LISTA TIPOLÓGICA DEL SITIO CASA CHÁVEZ MONTÍCULOS I}

Datos inéditos suministrados por P. Escola provenientes del Informe Análisis TecnoTipológico de materiales líticos del sitio Casa Chávez Montículos 1 -Catamarca- (Escola 2005). Incluye piezas enteras y fracturadas. En función de las propuestas desarrolladas en el marco de esta Tesis Doctoral se hicieron una serie de modificaciones a la lista tipológica original. Por ejemplo, se incluyó a las "grandes lascas con retoque" como un subgrupo dentro de las raederas bajo el nombre de "Raederas de módulo grandísimo". Asimismo, se invirtió la posición de la extensión relativa del filo y la posición relativa del filo en la definición de los subgrupos tipológicos. Por otra parte, se ha incluido en el listado a la categoría "Pala y/o azada", originalmente no incorporado en el mismo. Los datos respectivos se basan en Escola et al. (2005)

\begin{tabular}{|l|c|}
\hline SUBGRUPO / GRUPO TIPOLÓGICO & TOTAL \\
\hline ST \\
\hline Chopper de filo frontal & 2 \\
\hline & $\mathbf{2}$ \\
\hline Biface parcial & 1 \\
\hline BIFACE & $\mathbf{1}$ \\
\hline & \\
\hline Raspador de filo corto frontal & 1 \\
\hline Raspador de filo restringido frontal & 3 \\
\hline Raspador de filo restringido lateral & 1 \\
\hline Raspador de filo restringido angular & 1 \\
\hline Raspador no diferenciado & 4 \\
\hline RASPADOR & $\mathbf{1 0}$ \\
\hline & \\
\hline Raclette de filo corto frontal & 1 \\
\hline Raclette de filo corto lateral & 3 \\
\hline Raclette de filo restringido lateral & 1 \\
\hline Raclette no diferenciado & 1 \\
\hline RACLETTE & $\mathbf{6}$ \\
\hline & \\
\hline Raedera de filo largo lateral & 4 \\
\hline Raedera de filos convergentes en punta & 1 \\
\hline Raedera de módulo grandísimo & 8 \\
\hline Raedera no diferenciada & 13 \\
\hline RAEDERA & $\mathbf{2 6}$ \\
\hline & $\mathbf{5}$ \\
\hline $\begin{array}{l}\text { Artefacto mediano pequeño/muy pequeño R.B.O. sección } \\
\text { asimétrica de filo frontal }\end{array}$ & 2 \\
\hline $\begin{array}{l}\text { Artefacto mediano pequeño/muy pequeño R.B.O. sección } \\
\text { asimétrica de filo lateral }\end{array}$ & 7 \\
\hline $\begin{array}{l}\text { Artefacto mediano pequeño/muy pequeño R.B.O. sección } \\
\text { asimétrica de filo convergente en ápice romo }\end{array}$ & 2 \\
\hline $\begin{array}{l}\text { Artefacto mediano pequeño/muy pequeño R.B.O. sección } \\
\text { asimétrica de filo no diferenciado }\end{array}$ & 1 \\
\hline $\begin{array}{l}\text { ARTEFACTO MEDIANO PEQUEÑO/MUY } \\
\text { PEQUEÑO R.B.O. SECCIÓN ASIMÉTRICA }\end{array}$ \\
\hline Cuchillo de filo retocado no diferenciado & 2 \\
\hline CUCHILLO DE FILO RETOCADO & 2 \\
\hline Cortante de filo retocado de filo frontal & $\mathbf{2}$ \\
\hline Cortante de filo retocado no diferenciado & \\
\hline CORTANTE DE FILO RETOCADO & \\
\hline Muesca retocada y de lascado simple de filo frontal & \\
\hline
\end{tabular}




\begin{tabular}{|c|c|}
\hline Muesca retocada y de lascado simple de filo lateral & 2 \\
\hline Muesca retocada y de lascado simple no diferenciada & 13 \\
\hline MUESCA RETOCADA Y DE LASCADO SIMPLE & 16 \\
\hline $\begin{array}{l}\text { Denticulado bisel oblicuo/abrupto sección asimétrica de } \\
\text { filo corto frontal }\end{array}$ & 2 \\
\hline $\begin{array}{l}\text { Denticulado bisel oblicuo/abrupto sección asimétrica de } \\
\text { filo corto lateral }\end{array}$ & 2 \\
\hline $\begin{array}{l}\text { Denticulado bisel oblicuo/abrupto sección asimétrica de } \\
\text { filo fronto-lateral }\end{array}$ & 1 \\
\hline $\begin{array}{l}\text { Denticulado bisel oblicuo/abrupto sección asimétrica no } \\
\text { diferenciado }\end{array}$ & 3 \\
\hline $\begin{array}{l}\text { DENTICULADO BISEL OBLICUO / ABRUPTO } \\
\text { SECCIÓN ASIMÉTRICA }\end{array}$ & 8 \\
\hline Punta entre muescas de filo frontal & 2 \\
\hline PUNTA ENTRE MUESCAS & 2 \\
\hline Punta burilante angular & 1 \\
\hline Punta burilante angular en filo retocado & 1 \\
\hline Punta burilante de retoque alternante angular & 1 \\
\hline Artefacto burilante no diferenciado & 2 \\
\hline ARTEFACTO BURILANTE & 5 \\
\hline $\begin{array}{l}\text { Perforador de punta triédrica sección asimétrica } \\
\text { (cuerpo/base no formatizada) }\end{array}$ & 1 \\
\hline Perforador de sección simétrica (cuerpo/base formatizada) & 1 \\
\hline PERFORADOR & 2 \\
\hline Preforma de punta de proyectil pedunculada & 2 \\
\hline Punta de proyectil con pedúnculo diferenciado y aletas & 12 \\
\hline Fragmento basal de punta apedunculada & 1 \\
\hline Fragmento de limbo de punta pedunculada con aletas & 4 \\
\hline Fragmento de pedúnculo & 1 \\
\hline Fragmento no diferenciado de punta de proyectil & 1 \\
\hline PUNTA DE PROYECTIL & 21 \\
\hline Filo/fragmento con diferenciación sumaria & 10 \\
\hline Esbozo de pieza bifacial & 2 \\
\hline Pieza entera no diferenciada & 1 \\
\hline Artefacto de formatización sumaria no diferenciado & 5 \\
\hline ARTEFACTO DE FORMATIZACIÓN SUMARIA & 18 \\
\hline Pala y/o azada & 62 \\
\hline PALA Y/O AZADA & 62 \\
\hline Fragmento no diferenciado de artefacto formatizado & 61 \\
\hline $\begin{array}{l}\text { FRAGMENTO NO DIFERENCIADO DE } \\
\text { ARTEFACTO FORMATIZADO }\end{array}$ & 61 \\
\hline
\end{tabular}




\section{APÉNDICE III}

\section{III.1. FUNCIONALIDAD DE LAS RAEDERAS DE MÓDULO GRANDÍSIMO}

Hasta el momento, los estudios efectuados sobre las raederas de módulo grandísimo se habían centrado en sus características técnico-tipológicas (Escola 2000), desconociéndose su funcionalidad. Con el objetivo de subsanar esta carencia, y de vincular los desechos de talla de reactivación procedentes de estas raederas, la Dra. M. del P. Babot analizó los microfósiles presentes como residuos de uso en dos piezas formatizadas del tipo mencionado ( $\mathrm{N}^{\circ} 14$ y 65 ) recuperadas en el sitio agro-pastoril CChM1. Las mismas se encuentran descriptas en Escola (2000). Asimismo, se consideraron para el análisis desechos de talla vinculados con la reactivación de los filos de dichos instrumentos -lascas de reactivación-, procedentes del recinto de actividades múltiples de tipo doméstico E3- del sitio agro-pastoril PP9.I.

Teniendo en cuenta las características de los artefactos líticos en estudio, se planteó como objetivos:

a) aportar al problema del uso de las raederas de módulo grandísimo a partir de dos fuentes artefactuales diferentes: los propios instrumentos formatizados y sus desechos de reactivación.

b) controlar la correspondencia entre los artefactos formatizados y los desechos de reactivación, a partir de la comparación de los resultados de sus análisis funcionales.

c) obtener información sobre el uso de tales artefactos en muestras procedentes de dos sectores ambientales diferentes dentro del ámbito de Antofagasta de la Sierra, en la Puna Meridional argentina.

La metodología empleada para el análisis de microfósiles corresponde a la descripta en Babot (2004a). Se ubicaron las partes activas de los artefactos, constituidas por los filos formatizados y, dentro de éstos, sectores con residuos visibles macroscópicamente, o bien, irregularidades de la superficie como poros, vesículas, grietas y líneas de fracturas producidas por la talla. Dentro de estos sectores se delimitó una zona acotada que fue cepillada suavemente para eliminar el sedimento superficial y posibles fuentes de contaminación postdescarte. Allí se raspó cuidadosamente con un instrumento punzante para separar las partículas de interés de la matriz rocosa, directamente sobre un portaobjetos previamente limpiado. Se reservó el resto del filo para posteriores análisis de rastros de uso. 
Las muestras se observaron con luz normal y polarizada alternativamente, haciendo barridos completos de una superficie aproximada de $18 \times 18 \mathrm{~mm}$ en un microscopio petrográfico. Las observaciones se efectuaron en barridos consecutivos a 200 y 400X para detectar microfósiles de diferente tamaño. Se controló la presencia de contaminación comparando lo observado en las muestras arqueológicas con lo que se encuentra mayoritariamente en muestras de la superficie actual y la estratigrafía del sitio -principalmente microfósiles atribuibles a especies de Asteraceae y Poaceae que crecen en la zona actualmente-.

Los microfósiles documentados incluyen un número reducido de granos de almidón asignables a tubérculos-raíces y, en un caso, compatibles con granos compuestos de quínoa (Chenopodium quinoa) (Babot 2004a). El registro de silicofitolitos es muy acotado, y se compone mayoritariamente de partículas irregulares no diagnósticas. Esto es compatible con lo esperable en semillas de pseudocereales y tubérculos o raíces (Korstanje y Babot 2005). Otros microfósiles observados incluyen placas perforadas opacas de sílice, característicos de partes aéreas de especies de Asteraceae y granos de polen afín a dicha familia. Un dato a ser confirmado es la posible presencia de polen asignable a Chenopodiaceae (sensu Markgraf y D’Antoni 1978).

Los fitolitos de calcio se presentaron mayoritariamente en forma de arena cristalina o microcristales. Asimismo se recuperaron frústulas de diatomeas en una proporción importante.

Coincidiendo con el único registro posible de quínoa, se han documentado flóculos de coloración rojiza muy abundantes. Los mismos no parecerían corresponder a pigmentos minerales óxidos de hierro u otros- ya que presentan birrefringencia al ser observados con luz polarizada. Aun debe ser investigada su posible vinculación con pigmentaciones orgánicas de las semillas de Pseudocereales.

Los resultados obtenidos sugieren un posible uso de las raederas de módulo grandísimo en actividades vinculadas con la siega o el procesamiento de especies microtérmicas -quínoa y tubérculos o raíces-, al menos en el ámbito de Antofagasta de la Sierra, de donde proceden los ejemplares analizados. Los microfósiles de Asteraceae -polen- procederían de una introducción contemporánea o posterior al uso de los artefactos que no necesariamente se encuentra vinculada con el empleo principal de los mismos. Esto podría ser coherente con el laboreo en zonas de cultivo.

Una segunda etapa de esta investigación aportará información funcional complementaria desde otras dos vías analíticas, el análisis de residuos lipídicos y el análisis de residuos físicomecánicos. 
Los datos de este estudio constituyen un aporte para el establecimiento del uso de una clase artefactual muy difundida en los contextos agropastoriles del NOA y aportan al conocimiento de las prácticas culturales de estos grupos prehispánicos, en cuanto a modalidades de procesamiento de recursos.

La coherencia entre los artefactos formatizados y los desechos de reactivación analizados, en términos de residuos de uso, permiten vincularlos claramente desde lo funcional. 